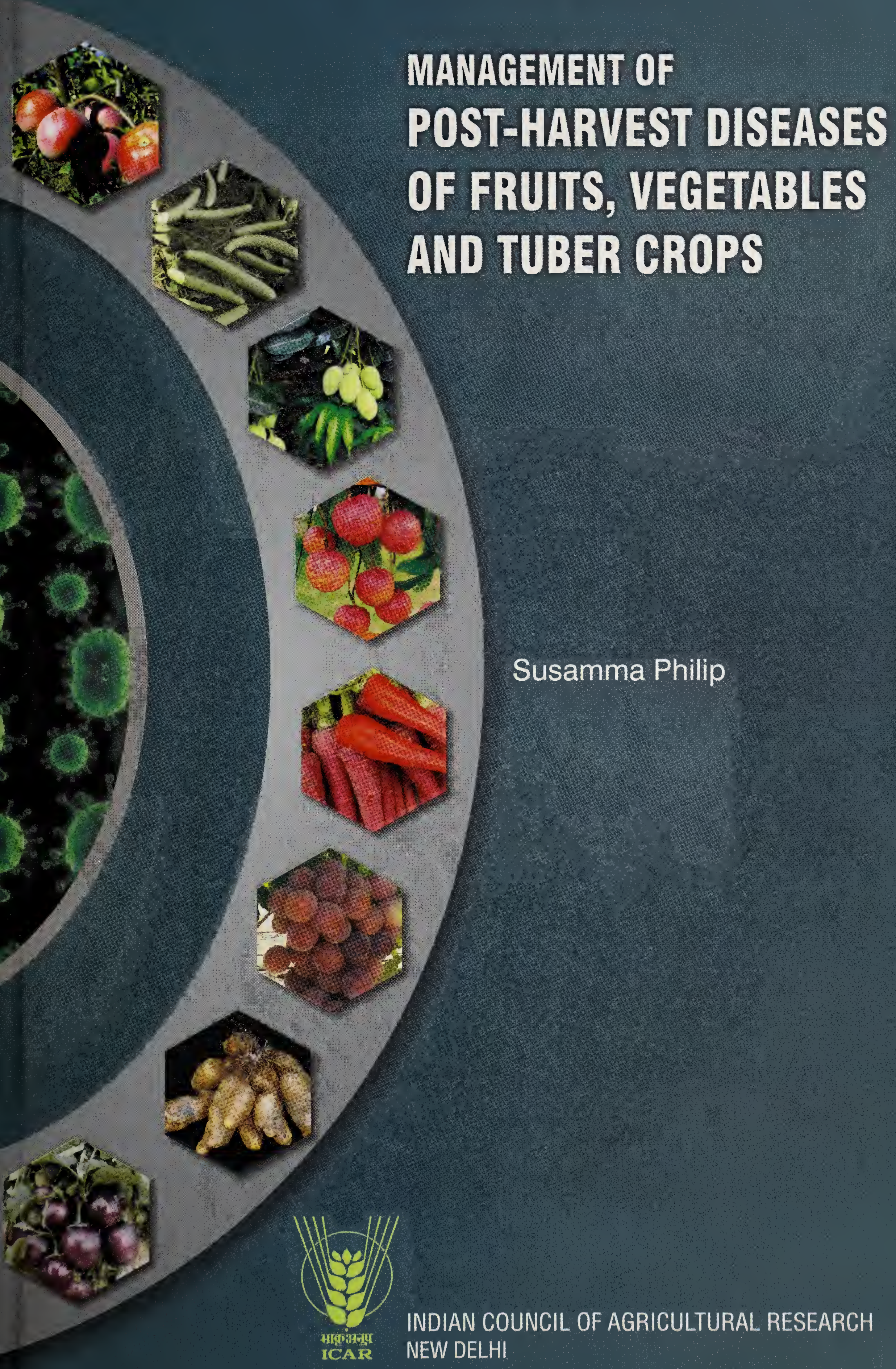





\title{
Management of Post-harvest Diseases of Fruits, Vegetables and Tuber Crops
}

\author{
SUSAMMA PHILIP
}

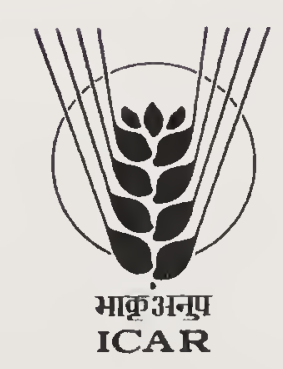

Directorate of Knowledge Management in Agriculture Indian Council of Agricultural Research

Krishi Anusandhan Bhavan I, Pusa, New Delhi 110012 


$$
\text { Project Director : Dr Rameshwar Singh }
$$

Incharge (English Editorial Unit) : Dr Aruna T Kumar

Editing : Shashi A Verma

Chief Production Officer : Dr V K Bharti

Senior Technical Officer (Production) : Punit Bhasin

Cover Design : Narendra Bahadur

(C) 2014, All rights reserved

Indian Council of Agricultural Research, New Delhi

ISBN : 978-81-7164-150-5

Price : $₹ 550.00$

Published by Dr Rameshwar Singh, Project Director, Directorate of Knowledge Management in Agriculture, Indian Council of Agricultural Research, Krishi Anusandhan Bhavan I, Pusa, New Delhi 110 012; Lasertypeset at M/s Print-O-World, 2579, Mandir Lane, Shadipur, New Delhi 110008 and printed at M/s Chandu Press, D-97, Shakarpur, Delhi 110092. 


\section{Foreword}

Quality preservation of fruits and vegetables after harvest, transportation and in storage is of equal important as the cultural and the management aspects of their production. Deterioration in quality of produce after harvest is a serious problem, and results due to physical injuries and biochemical changes consequent to infection by microorganisms.

The publication entitled Management of Post- harvest Diseases of Fruits, Vegetables and Tuber Crops describes in details various aspects of postharvest care of almost all fruits, vegetables and tuber crops, and this has basically been written to be used as a textbook as per the recommendations of the University-level Textbook Writing Scheme of the Education Division of the Indian Council of Agricultural Research.

The publication has description of symptoms and causal organisms of each and every known fungal, bacterial and viral diseases of fruits, vegetables and tuber crops during post-harvest stage. In addition, control measures, physical, chemical and biological methods including use of eco-friendly bio-pesticides, myco-parasites, etc to be adopted in each case are exhaustively given. Further, appropriate practices to minimize losses on post-harvest storage are also highlighted; and the references cited cover available literature in India and abroad up to the year 2010 .

It is hoped that the book will serve as a valuable source of information for students at the graduate/post-graduate level in Plant Pathology and as a reference book for research workers, progressive farmers and business officials associated with import of fruits, vegetables and tuber crops.

Dr Susamma Philip, former Professor and Head, Department of Plant Pathology, Kerala Agricultural University, deserves special appreciations for her earnestness and commitment in bringing out such a valuable publication.

Dr Alice Abraham

Former Professor Kerala Agricultural University 


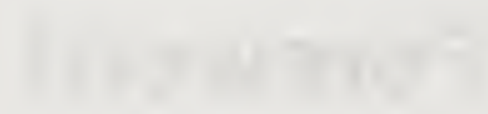




\section{Contents}

Foreword

Page No.

iii

\section{PART-A \\ MANAGEMENT OF POST-HARVEST DISEASES OF FRUIT CROPS}

Chapter 1. APPLE (Malus domestica)

$\begin{array}{ll}\text { Chapter 2. APRICOT (Prunus armeniaca) } & 17\end{array}$

\begin{tabular}{ll} 
Chapter 3. & BANANA (Musa spp.) \\
\hline
\end{tabular}

Chapter 4. CITRUS (Citrus spp.) 32

Chapter 5. EMBLICA/GOOSEBERRY/AONLA 45

(Phyllanthus emblica)

$\begin{array}{ll}\text { Chapter 6. GRAPE (Vitis vinifera) } & 48\end{array}$

Chapter 7. GUAVA (Psidium guajava) 59

Chapter 8. JACKFRUIT (Artocarpus heterophyllus) 67

Chapter 9. LITCHI (Litchi chinensis) 69

$\begin{array}{ll}\text { Chapter 10. MANGO (Mangifera indica) } & 71\end{array}$

Chapter 11. PAPAYA (Carica papaya) 83

Chapter 12. PEACH (Prunus persica) 92

Chapter 13. PEAR (Pyrus communis) 95

Chapter 14. PINEAPPLE (Ananas comosus) 98

Chapter 15. PLUM (Prunus domestica) · 105

Chapter 16. POMEGRANTE (Punica granatum) 106

Chapter 17. SAPOTA (Manilkara zapota) 109

Chapter 18. STRAWBERRY (Fragaria chilensis) 111

PART-B

MANAGEMENT OF POST-HARVEST DISEASES OF VEGETABLE CROPS

Chapter 19. CUCURBITS

[Cucumber (Cucumis sativus); Pumpkin (Cucurbita pepo);

Watermelon (Citrullus lanatus); Muskmelon (Cucumis melo); Chayote/chow-chow(Sechium edule); Bittergourd (Momordica charantia var. charantia); Snakegourd (Trichosanthes anguina); Bottlegourd (Lagenaria siceraria); Ridge-gourd (Luffa acutangula); Sponge-gourd (Luffa aegyptiaca);

Round-gourd (Citrullus vulgaris); Koval (Coccinia cordifolia)] 
Chapter 20. SOLANACEOUS CROPS

[Brinjal (Solanum melongena); Chilli (Capsicum annuum); Potato (Solanum tuberosum);

Tomato (Lycopersicon esculentum)]

Chapter 21. LEGUME CROPS

[Garden-pea (Pisum sativum); Cowpea (Vigna

unguiculata); Common-bean (Phaseolus vulgaris);

Clusterbean (Cyamopsis tetragonoloba);

Winged-bean(Psophocarpus tetragonolobus);

Dolichos-bean (Dolichos lablab);

Sword-bean (Canavalia gladiata)]

Chapter 22. COLE CROPS

[Cabbage (Brassica oleracea con var. capitata Alef. var. capitata); Cauliflower (Brassica oleracea con var. botrytis Alef. var. botrytis); Knol-khol (Brassica oleracea con var. acephala Alef. var. gongylodes)]

Chapter 23. ROOT CROPS

[Beet root (Beta vulgaris); Carrot (Daucus carota var. sativus); Radish (Raphanus sativus)]

Chapter 24. BULB CROPS

[Onion (Allium cepa); Garlic (Allium sativum)]

Chapter 25. MISCELLANEOUS VEGETABLES

[Amarathus (Amarathus sp.); Drumstick (Moringa oleifera); Lady's finger (Abelmoschus esculentus)]

Chapter 26. SPICES AND CONDIMENTS

[Ginger (Zingiber officinale); Turmeric (Curcuma longa)]

PART-C

MANAGEMENT OF POST-HARVEST DISEASES

OF TOPICAL ROOT/ TUBER CROPS

Chapter 27. TROPICAL ROOT/TUBER CROPS

[Tapioca/Cassava (Manihot esculenta); Sweet-potato (Ipomoea batatas); Colocasia (Colocasia esculenta);

Elephant-foot yam (Amorphophallus campanulatus);

Dioscorea (Dioscorea alata)]

Appendix 1

References

Subject Index 


\section{Part - A}

MANAGEMENT OF POST-HARVEST

DISEASES OF FRUIT CROPS 
Digitized by the Internet Archive in 2018 


\section{CHAPTER}

\section{Apple (Malus domestica Borkh.)}

Apple is rich in soluble fibre pectin that helps reduce blood cholesterol levels. Querectin, a flavonoid, present in apple, fights against cancer.

\section{FUNGAL DISEASES}

Apple-scab, c.o. Venturia indequalis (Cke. ${ }^{p}$ Wint:

Anamorph : Spilocaea pomi Fr.

Apple-scab is one of the most destructive diseases of apple. It occurs in all apple-growing areas of the world, and causes heavy losses to apple-growers. In India, the disease had first appeared in 1955 in Jammu and Kashmir, and it had caused epidemic during 1983 (Gupta 1990).

Symptoms : Apple-scab's occurrence on fruits in storage was well documented by Sugiki et al. (1984). Storage scab appears after 45 days in Golden Delicious cultivar in storage (Fig. 1.1).

Dark, almost black, small velvety spots appear on fruits. Later, these spots enlarge and the centre loses its velvety appearance and becomes brown and corky. The loosened cuticle of the fruit appears as whitish band around the dark spot. Scab-infected fruits are also unfit for storage due to pronounced shrinkage and rotting caused by other fungi. Varietal resistance for the disease has been reported; Golden Mira is accepted as a variety resistant to applescab and powdery mildew (Bergamini and Giongo 2002).

Control measures : Post-harvest dip treatment of apple-fruits in Bitertanol $(0.075 \%)$ gave maximum control. Carbendazim $(0.05 \%)$ and Captan $(0.2 \%)$ also protected the crop (Sharma and Kaul 1997). Storage after dipping fruits in a mixture of lime sulphur and copper hydroxide was also reported (Palm et al. 2002).

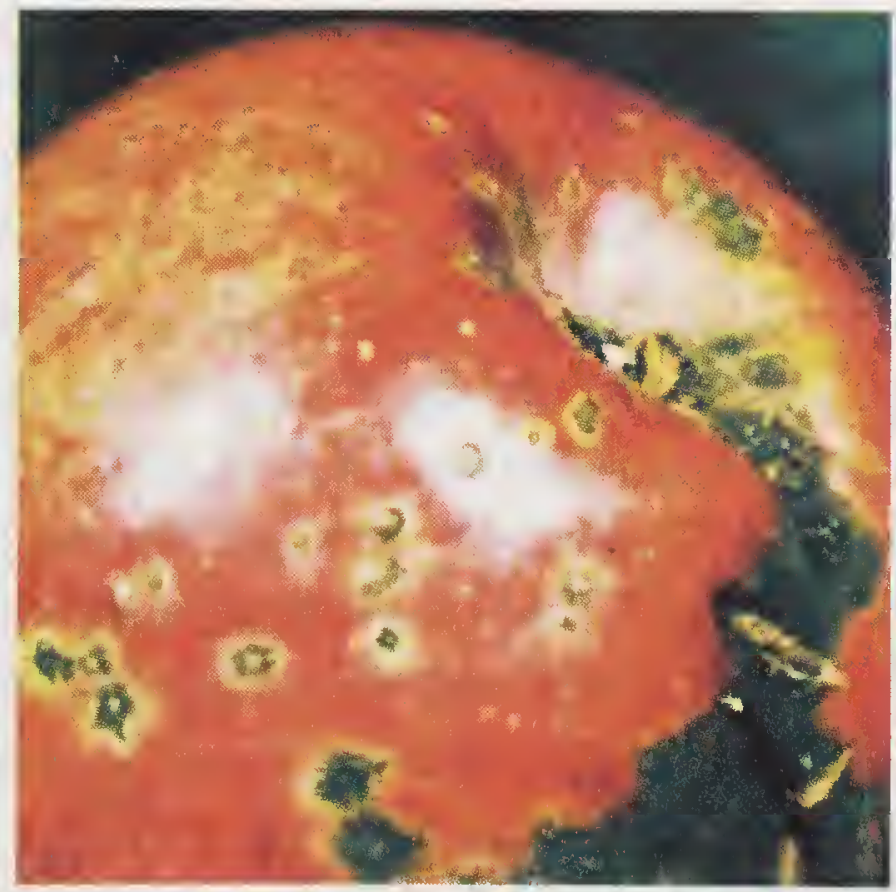

Fig. 1.1. Apple-scab 
Soft-rot/blue-mould, c.o. Penicillium expansum Thom.

\section{P. solitum Westling et al. 1911}

P. crustosum Thom. 1930

Blue-mould is considered as one of the major post-harvest diseases. This disease occurs wherever apples are grown or are shipped. It has been estimated that blue-mould causes $80-90 \%$ of storage decay. The rot is responsible for major damages in storehouses (Agarwala and Sharma 1968; Mandal and Dasgupta 1982). The losses are especially high since they are incurred after harvesting, plucking and storage. In addition to losses, mycotoxins, Patulin and Citrinin, are reported in the infected apple-fruits. High Performance Liquid Chromatography .(HPLC) analysis of Patulin also showed its presence in the nearby non-rotted areas (Singh and Sumbali 2008).

Symptoms : Soft-rot can usually be identified in the early stages by light colour and soft watery texture of the rotted area. A characteristic strong mouldy odour is often emitted. Rot advances rapidly. Rotten areas become blue or green in colour but do not wrinkle. When stored under high humidity, surface becomes studded with characteristic grey-blue cushions of fruiting-bodies.

Red Delicious cultivar is reported as highly susceptible (Singh and Sumbali 2004).

Control measures : Due to the serious nature of the disease, control measures of the disease with a combination of natural compounds, chemicals and antagonists have been attempted.

Pre-harvest spray with Benlate (500ppm) and Topsin M (0.1\%) is effective (Borecka 1977). The disease can be avoided by observing stringent precautions during picking, grading and packing. Diseased and injured fruits are to be culled.

Fruits are to be placed in the cold storage immediately after picking. Jahangir et al.(1993) observed protection of Red Delicious apples from rots (P.expansum) by storing at $0^{\circ} \mathrm{C}$.

Several workers have suggested use of wrappers treated with double boiled linseed oil. Use of skin coatings and wrappers provides protection (Kaul and Munjal 1983). Naik and Joshi (1973) controlled the disease by dipping fruits in Diphenyl amine (1,000 ppm) for five minutes or in Aureofungin (500 ppm) for 20 minutes.

Bavistin (Carbendazim) and Tecto-60 (Thiabendazole) at $250-750 \mathrm{mg} / \mathrm{ml}$ was effective in containing blue-mould infection in harvested fruits under ambient temperature $\left(15-25^{\circ} \mathrm{C}\right)$ and at air-cooled $\left(6-8^{\circ} \mathrm{C}\right)$ conditions. Postharvest dipping of fruits in Benomyl and TBZ (Roy 1975; Northover 1975) as well as in Tecto-60 (Thiabendazole), Rovral (Iprodione) and Bavistin (Chib et al. 1985) was also found effective. Conway (1982) observed treating fruits in $8 \%$ calcium chloride (pressure infiltration), followed by storage, to be effective for three months.

Pre- and post-harvest application of ammonium molybdate controlled 
post-harvest decay due to blue-mould and grey-mould. A significant reduction in severity and incidence of disease was noticed on storage at $1^{\circ} \mathrm{C}$ for three months (Nunes et al. 2001). Spraying of Harpin in the orchard, a few days before harvest was also promising by eliciting hypersensitive response in plants (Guyde et al. 2003).

Biological control is recorded as an effective mean for controlling disease. Certain bacteria and yeasts isolated from phylloplane of leaves and fruits serve as potential antagonists. Control of blue-mould is achieved with antagonistic bacteria (L-22-64), Pseudomonas cepacia, and yeasts, Pichia anomola, Candida sake, C.olephila and Sporobolomyces roseum (Janisiewicz 1987; Janisiewicz et al. 1994; Jijakli et al. 1993; Bagwan and Meshram 2001). Control of fungal-rot in diphenyl amine treated apple-fruit by means of a natural antagonist Candida sake (CPA-1) was also reported (Zanella et al., 2002). Vero et al. (2002) utilized successfully two yeast antagonists, Cryptococcus laurentii (Strain 317) and Candida ciferii (Strain 283), isolated from the fruit surface of apples, in controlling blue-mould infection. Sanhueza and Cattanio (2003) from Brazil also reported effectiveness of antagonistic yeast, $C$. laurentii. Efficacy of yeasts like Saccaromyces sp., Candida sp., Cryptococcus sp. and Rhodotorula sp. was reported from China (He Dan et al. 2003). Selected isolates of Aureobasidium pullulans, Rhodotorula glutinis and Bacillus subtilis were also biocontrol agents in reducing post-harvest pathogens like P. expansum, Botrytis cinerea and Pezicula malicortis (Leibinger et al. 1997).

The yeast Debaromyces hansenii $\left(10^{9} \mathrm{cfu} / \mathrm{ml}\right)$ in combination with sodium bi-carbonate $(1.0 \% \mathrm{w} / \mathrm{v})$ showed minimum spoilage after 42 days of storage under ambient conditions (Singh et al. 2009).

Combination of biocontrol agent (Pseudomonas syringae) and pressure infiltration of fruits with calcium chloride reduced severity of infection by blue-mould (Jainisiewicz et al. 1997). Ting et al. (2001) successfully controlled blue-mould ( $P$. expansum) and grey-mould (Botrytis cinera) in storage by dip treatment with four isolates of $P$. syringae.

\section{Brown-rot, c.o. Monilinia fructigena (Aderh. \& Ruhl.) Honey M. laxa (Aderh. \& Ruhl.) Honey}

The fungus is worldwide in distribution (Byrde and Willetts 1977) and causes serious losses on apple. The disease is reported from India also (Bose 1969; Sharma et al. 2001). Four isolates of Monilinia have been recorded from Uttar Pradesh. Maximum decay is caused by M.laxa (Kaul and Munjal 1980; Sharma and Kaul 1987), when the fruits are stored between 20 and $27^{\circ} \mathrm{C}$, and complete suppression of growth is at $0^{\circ} \mathrm{C}$ (Sharma and Kaul 1988). The pathogen over-winters in rotted infected fruits and in twig cankers.

Symptoms : Small brown spots appear on the maturing fruits. Under storage, first indication of the disease on the fruit is the development of small, circular 
brown spots. In humid conditions, tufts of white growth can be noticed in concentric circles around the point of infection (Snowdon 1990). Even if slightly infected fruit is stored, the disease can spread also to adjacent healthy fruits.

Control measures : The efficacy of hot-water and Carbendazim treatment is reported in controlling brown-rot (Sharma and Kaul 1990). Fruit wrappers impregnated with DCNA (Dichloran) and sodium orthophenyl phenate(SOPP) as well as coating peel with mustard oil protect the crop in storage (Kaul and Munjal 1983).

Phytophthora fruit-rot, c.o. Phytophthora spp.

P. cactorum (Lebert. \& Cohm.) Schroet.

P. syringae, P.cryptogea (Behr and Urban 1986)

In India, $P$. cactorum was found to be associated with fruit-rot as early as 1875, and has been recorded since 1951 (Bose and Mehata 1951; Gupta 1999).

The fungus is soil-borne and becomes active during rainy season. It was reported from Kumaon (Bose 1969). It also causes collar-rot on apple-trees. The fruits hanging low on the branches are likely to be affected severely. Once fruits are infected, they serve as the source of inoculum and can infect other apples during storage.

Symptoms : Infection usually occurs on fruits that fall on the ground or on which water is splashed. Externally, the rot is irregularly outlined. The diseased flesh turns pale to light brown. Vescular bundles and strands becomes dark brown. In the advanced stage, affected portion may become spongy, intensly discoloured and water-soaked. Contamination with infected soil leads to major wastage of apples in storehouses due to rotting by P. syringae (Edney 1978).

Control measures : Spraying trees with Dithane M-45 (0.2\%) in early July, followed by another spray two weeks later is effective in controlling postharvest diseases (Kanwar 1988). But Bharat and Sharma (1994) reported residues of Mancozeb on the stored fruits up to 35 days. Similar observations on residues were available from Pakistan also (Zahida and Masud 2002).

Treating fruits with Captan $(0.2 \%)$ protects them against rotting caused by zoospores or from infected soil (Edney 1978). Infected fruits should not be stored with healthy fruits.

Bitter-rot, c.o. Glomerella cingulata (Ston.) Spauld. \& Schrenk. Colletotrichum fructigenum (Berk.) \& Schrenk.

C. gloeosporioides Penz.

The disease is of worldwide occurrence, and has been reported from several countries including New Zealand (Brook1977), Isreal (Patil and Shohan 1983) and India (Chand et al. 1968).

Symptoms : Faint light-brown discolouration appears beneath the peel. The discolouration increases and extends in a cone-shaped manner. Lesions soon 
become depressed and tiny with raised black dots beneath the cuticle. With increase of lesions, entire fruit becomes rotten. Most of the rotten fruits drop, while some cling as mummies. Epidemiology of the disease has shown that temperature at $25^{\circ} \mathrm{C}$ and relative humidity of $80 \%$ are ideal factors for maximum disease development on fruits. Removal of deadwood and mummies is important.

Disease resistance studies have shown that peel of the resistant varieties (Richard Red) contains higher quantities of total phenols as well as varied fractions of phenolic compounds in comparison to susceptible varieties.

Control measures : Copper fungicides are effective in checking the disease. Trisodium phosphate $(2 \%)$ checks the disease in storage. Suppression of conidial germination and germ-tube elongation by three calcium salts, calcium chloride (CC), calcium propionate(CP) and calcium silicate (CS), has also been observed. Wrappers impregnated with DCNA (Dichloran) and sodium orthophenyl phenate (SOPP) as well as coated with mustard oil provide protection (Kaul and Munjal 1983).

\section{Core-rot, c.o. Alternaria spp.}

This disease is reported from all apple-growing areas of the world, including India and South Africa, where it is considered as a serious postharvest disease (Agarwala and Sharma 1968; Dharam vir and Gaur 1971; Pierson et al. 1971; Prusky and Ben-Aire 1981; Tak et al. 1985; Jahangir et al. 1993).

A. alternata is a ubiquitous mould causing pre- and post-harvest damages to fruits (Torres et al. 1993). The disease is prevalent in refrigerated and stored fruits also.

Symptoms : Infection starts at the injured or other physiologically weakened tissues as brown to black, slightly sunken with clear- cut circular brown lesions on the fruit surface. Tissues beneath the lesions become soft and brown, while skin remains firm and tough. Longitudinal section of the fruit reveals discolouration around the central core (Fig.1.2). Profuse fungal growth is visible when the fruit is cut open and exposed (Philip 2002).

Serdan et al. (2002) in their studies on the core- rot of apples in South Africa observed association of 30 isolates of Alternaria spp., including $A$. arborescens, $A$. infectoria and A.tenuissima. The fungus produces an array of toxic secondary metabolites like

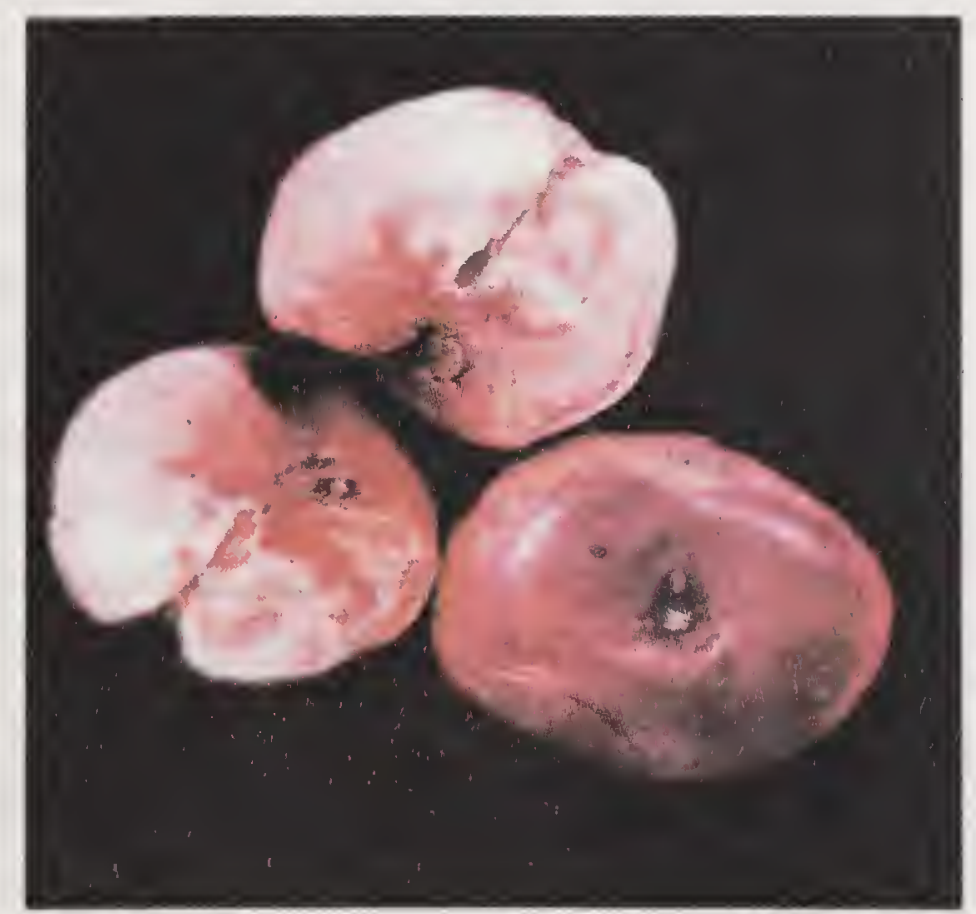

Fig. 1.2. Core-rot in apple 
alternariol $(\mathrm{AOH})$, alternariol monomethyl ether (AME), tenuazonic acid (TeA), altertoxin(ATX-1) etc. Singh and Sumbali (2004 a) in their studies on the post-harvest damage caused by A. alternata observed tenuazonic acid (TeA)-producing strains of A. alternata on the commercially important apple cv Red Delicious.

Control measures : Core-rot of apple is controlled by fungicides (Rovral, $500 \mathrm{ppm}$ ), growth regulators (Maleic hydrazide, $100 \mathrm{ppm}$ ) and hydrogenated groundnut oil (Tak et al. 1985). The disease was successfully managed in Israel by three foliar applications of beta aminobutyric acid (BABA) and potassium phosphite from beginning of the bloom until petal fall (Reuveni et al. 2003).

\section{Whiskers-rot/soft-rot, c.o. Rhizopus arrhizus Fischer \\ R. oryzae Went \& Prinsen Geerligs \\ R. stolonifer (Ehrenb.) Vuill.}

This disease occurs in all apple-growing countries. The pathogens incite a soft-rot (Thakur and Chenulu 1970, 1970 a).

Symptoms : Affected fruits show a russet to verona brown discolouration on the peel that easily peels away from the underlying tissues. Tissues become soft and watery, and fruits are covered with white fungal mycelia and black fruiting bodies. The fungus is visible in seed cavities also. Soft-rot caused by $R$. stolonifer was recorded in cold storage fruits also (Mandal and Dasgupta 1982). Soft-rot development was observed in a wide temperature range from 7 to $40^{\circ} \mathrm{C}$.

Control measures : The fruits are required to be stored below $10^{\circ} \mathrm{C}$; overripe fruits should not be stored. The disease development was found to be slow at $7-8^{\circ} \mathrm{C}$, and was of low intensity, and at temperature between 20 and $40^{\circ} \mathrm{C}$, intensity of infection increased and disease development was fast (Thakur 1972). Thakur and Chenulu (1970) reported protection of fruits by dipping them in 2 aminothiazole plus thiourea (5\%). Thakur et al. (1974) recorded growth regulators like 2, 4-D (100 ppm) and 2, 4, 5-T (100 ppm) to be effective as protectants.

\section{Pink mouldy-rot, c.o. Trichothecium roseum Link. ex Fr.}

This disease has been reported from India (Raina et al. 1971; Sreekantiah et al. 1974; Gracha and Singh 1980; Kaul and Munjal 1981 and Dasgupta and Mandal 1989), and is found associated with scab. The pathogen is usually carried from orchards and gains entry through wounds and bruises that occur during picking and handling of fruits. Fruit decays during transit and storage (Sharma et al. 2001).

Symptoms : Two types of symptoms are observed. In the first type, lightbrown spots of about 4-mm diameter are seen on the surface. Later these spots enlarge and produce characteristic light centre with a brown advancing margin. In the advanced stage of infection, white to pink fungal growth develops on the infected surface.But the fruits remains firm. In the second type of infection, 
chocolate- brown sunken irregular patches develop on the fruit surface. The pulp of the infected fruit may be seen radiating unevenly towards the core and the seed cavities are seen fully covered with pink spore mass. In both, affected fruits become bitter in taste. In China, Chen et al. (2002) reported small black to brown spots on the bagged fruits. They appeared due to poor ventilation in bags.

Control measures : Gupta and Sharma (1978, 1981) reported Bavistin $(0.05 \%)$ and Difolatan $(0.15 \%)$ as pre-harvest spray; both were equally effective against the disease. Similar results were also observed with Thiabendazole (0.1\%) (Blanpied and Purnasiri 1968), Delan (1,000 ppm) and Saprol (1,250 ppm) (Pandey et al. 1980, 1980 a).

\section{Fly- speck and sooty-blotch \\ Fly-speck, c.o. Microthyriella rubi Petr. Zygophiala jamaicensis E.W. Mason Sooty-blotch, c.o. Gloeodes pomigena (Schw.) Colby Phyllachora pomigena Sacc.}

Although fly-speck and sooty-blotch are caused by different fungi, they often appear together, and are difficult to be distinguished separately. Sootyblotch, previously attributed to fungus G. pomigena, is now considered as a disease complex with different mycelial types (Sutton and Sutton 1994; Johnson et al. 1997).

Symptoms : Fly-speck produces characteristic small, round, black spots on the peel of the fruit. The spots have a shining appearance and are of a pinhead size or smaller and usually are numerous in comparison to the sooty-blotch fungus, which produces irregular, dull-black to grey spots. Both fly-speck and sooty -blotch spots are superficial, and do not penetrate deep into the fruit. But they damage fruit appearance. Golden Delicious is more susceptible to infection than Red Delicious group. The spots are prominent on the fruits borne on the inner part of the tree, as they are exposed to contaminated water dripping from upper branches. Philip (2002) observed severe infections in consignments received at Thiruvananthapuram from Bengaluru.

Control measures : The disease can be controlled by spraying Captan $(0.2 \%)$, followed by Benlate $(0.05 \%)$ (Gupta and Dutt 1974) in the field. The spray schedule recommended for scab ( $V$. inaequalis) was helpful in controlling sooty- blotch and fly-speck also (Sharma and Sharma 1990). As the disease is superficial,it can be controlled by dipping fruits in chlorine water (500 ppm) for 5 minutes, followed by brushing and rinsing them with fresh water. This will help in removal of black spots from peel (Hendix 1991). This can be followed by wax-coating.

Influence of application of coconut soap (Biofa cocana RF) applied just before harvest against the sooty-blotch on apple fruits $\mathrm{cv}$. Pinova was evaluated in Switzerland. Coconut soap and 1\% lime sulphur reduced disease development significantly (Fuchs et al. 2002). Post-harvest brushing, rinsing 
or dipping of apples with commercial disinfectants like sodium hypochlorite, hydrogen peroxide, peroxy acetic acid and soap were also practised (Batzer et al. 2002).

Biological control of fly-speck, as effectively as by fungicide, is achieved with Chaetomium globosum formulation containing a carbon source (cellulose suspension) (Davis et al. 1991).

\section{Black mould-rot, c.o. Aspergillus niger Van Tiegh.}

A. versicolor (Vuill.) Tiraboschi

Black rot is one of the most important post-harvest diseases of apples in India.

Symptoms : The rot appears mostly on injured fruits, and is characterized by small water-soaked circular lesions. As the disease advances, rotting continues, and pulp becomes soft and brown. Black masses of conidia and conidiphores at the point of infection become visible.

Control measures : Wrappers impregnated with chemicals and sodium bicarbonate dip treatments are used for controlling storage rots caused by A.niger, Gliocladium roseum and Sclerotium rolfsii. Potassium iodide wraps and sodium bicarbonate dip treatments (Sumbali and Mehrotra 1983) also provided effective control. Use of fixed oils, coconut oil, groundnut oil, mustard oil, castor and cotton-seed oil, protects the crop against post-harvest decay as they are water repellent and stable. Besides, all of them possess antifungal efficacy and act as therapeutants in preventing decay (Sumbali and Mehrotra 1980, 1983). Sulphurdioxide fumigation by using sodium metabisulphate also was effective protectant against storage rots (Kaul and Munjal 1983).

Marssonina-blotch, c.o. Marssonina coronariae (Ell. \& J.J. Davis) Davis syn: M. mali (P. Henn.) S. Ito

This disease is responsible for widespread defoliation in apple in Himachal Pradesh. It was first recorded in 1992, and assumed epiphytotic proportion in 1995 . The disease is favoured by a moderate temperature of $20-22^{\circ} \mathrm{C}$ and high relative humidity,following rains in summers (Sharma 2004).

Symptoms : It appears initially as circular spots of 4-5 $\mathrm{mm}$ on the fruit surface that later become oval, depressed and dark brown with age and black at harvest (Bala et al. 2001; Sharma and Sharma 2006).

\section{Fruit-rot, c.o. Sphaeropsis pyriputrescens Xiao \& J.D. Rogers}

The disease is reported from the USA on Granny Smith and Golden Delicious.

Symptoms : The disease starts at the calyx- end of the fruits. Decayed fruits show no symptoms of wounding but appear brown. Internal decay occurs and decayed pulp appears yellowish brown. Pycnidia of the fungus appear on the surface of the decayed fruits (Xiao et al.2004). 
Control measures : Combination spray of any Dithiocarbamate $(0.2 \%)$ and Carbendazim $(0.1 \%$ ) during summer at 20-25 days interval is reported to be effective in managing the disease (Sonali et al. 2004).

\section{Grey mould-rot/dry-eye rot/Botrytis- rot, \\ c.o. Botryotinia fukeliana (de Bary) Botrytis cinerea Pers.}

Grey mould or dry-eye rot of apple is an important disease, caused by B. cinerea; $12 \%$ incidence of this disease was reported from Shimla markets (Agarwala and Sharma 1968).

Symptoms : The disease is characterized by transulent, watery, light- brown to dark-brown spots. It spreads by contact.

Control measures : Fungicides available are not effective in controlling the disease. However, pre-harvest application of Cyprodinil has been recorded as effective in reducing grey-mould incidence and in reducing lesion diameter in stored apples (Sholberg et al. 2003). Biologically disease can be controlled by spraying conidia of Trichoderma harzianum on the trees during bloom. The spores were shaken in water, filtered and diluted to a concentration of $10^{7}$ spores $/ \mathrm{ml}$. This suspension was added to $0.1 \%$ malt extract with $0.01 \%$ Tween - 80 and was used for spraying on the flowers (Tronsomo and Ystaas 1980).

Sclerotinia fruit-rot, c.o. Sclerotinia sclerotiorum (Lib.) de Bary

Fungus attacks in the field and causes rot in fruits at the calyx-end. Rot in storage due to $S$. fructigena has also been reported. Infection may take place through wounds or eyes on the fruits. The pulp is rendered soft and brown until fruit is mummified.

\section{OTHER DISEASES AND THEIR CAUSAL ORGANISMS}

\begin{tabular}{|c|c|c|}
\hline Disease & Causal organism & Authority \\
\hline Eye-rot & \multicolumn{2}{|l|}{ Nectria galligena Bres } \\
\hline Pestalotia -rot & \multicolumn{2}{|l|}{ Pestalotia hartigi Tub } \\
\hline Stemphylium- rot & \multicolumn{2}{|l|}{ Stemphylium sp. } \\
\hline Fruit- spot & \multicolumn{2}{|l|}{ Phoma mali Schultz \& Sacc. } \\
\hline Brooks fruit- spot & \multicolumn{2}{|c|}{ Mycosphaerella pomi (Pass.) Lindau } \\
\hline \multirow[t]{2}{*}{ Soft- rot } & Khuskia oryzae & $\begin{array}{l}\text { Khanna and Chandra } \\
1975\end{array}$ \\
\hline & Clathridium corticola & Thind et al. 1977 \\
\hline Septonema -rot & Septonema sp. & \\
\hline $\begin{array}{l}\text { Stalk-end rot/ } \\
\text { Bull's eye rot/ }\end{array}$ & \multicolumn{2}{|c|}{ Pezicula malicortis (Jackson) Nannf. } \\
\hline Gloeosporium- rot/ & Gloeosporium malicortis & $\begin{array}{l}\text { Wilkinson, 1954; } \\
\text { Snowdon, } 1990\end{array}$ \\
\hline Bitter- rot & G. album & Jamaluddin et al., 1972 \\
\hline
\end{tabular}




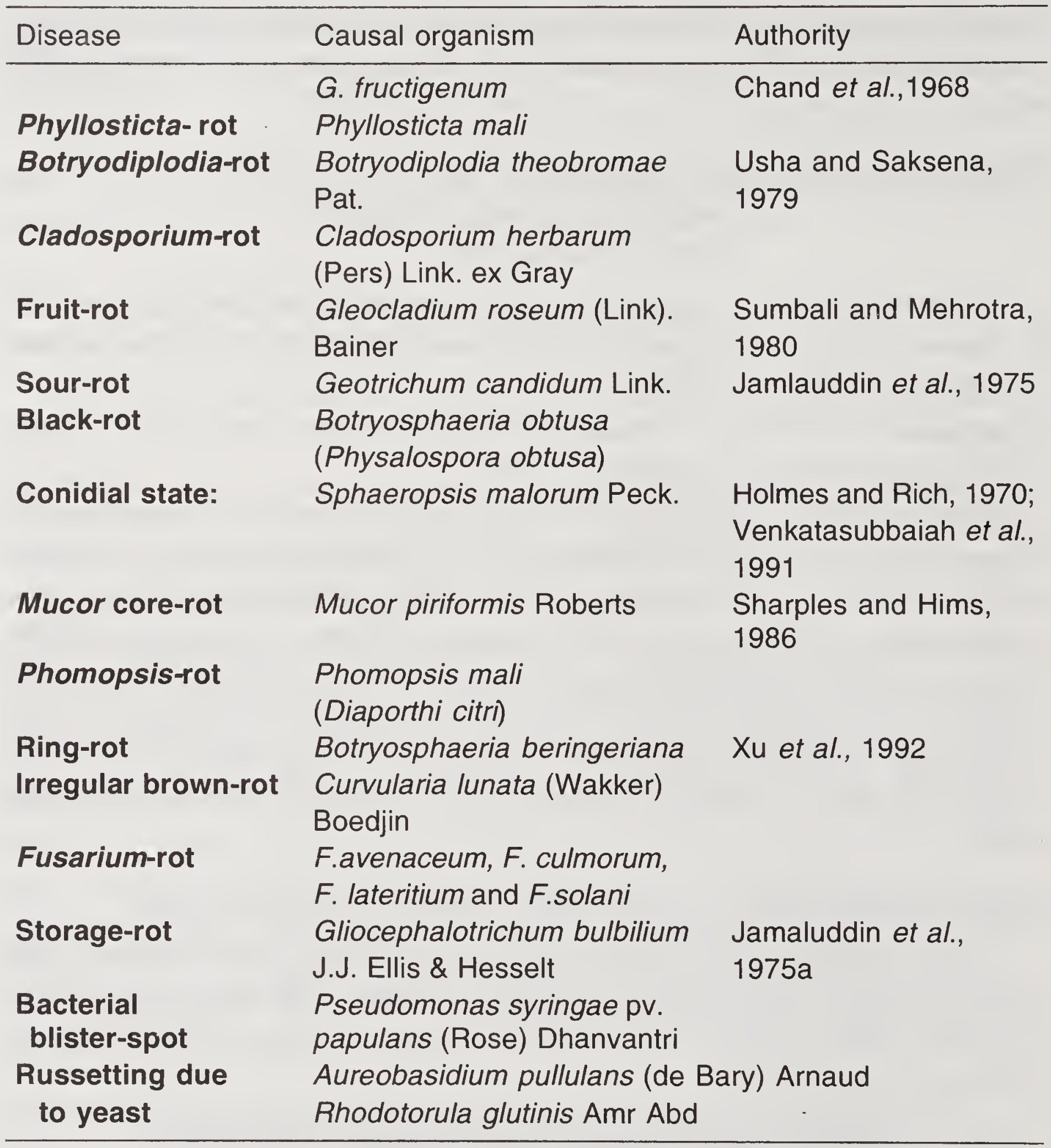

\section{NON-PARASITIC STORAGE DISORDERS}

Apples undergo serious physiological disorders when stored for a longer time. Some of these can be prevented if corrective measures are taken before picking or packing of fruits. Common disorders noticed in storage are as follows.

\section{Apple-scald}

Symptoms : This disorder is characterized by turning of fruit-peel into faint-brown or brown colour (Fig. 1.3); and internal breakdown occurs rapidly; thus skin dies and

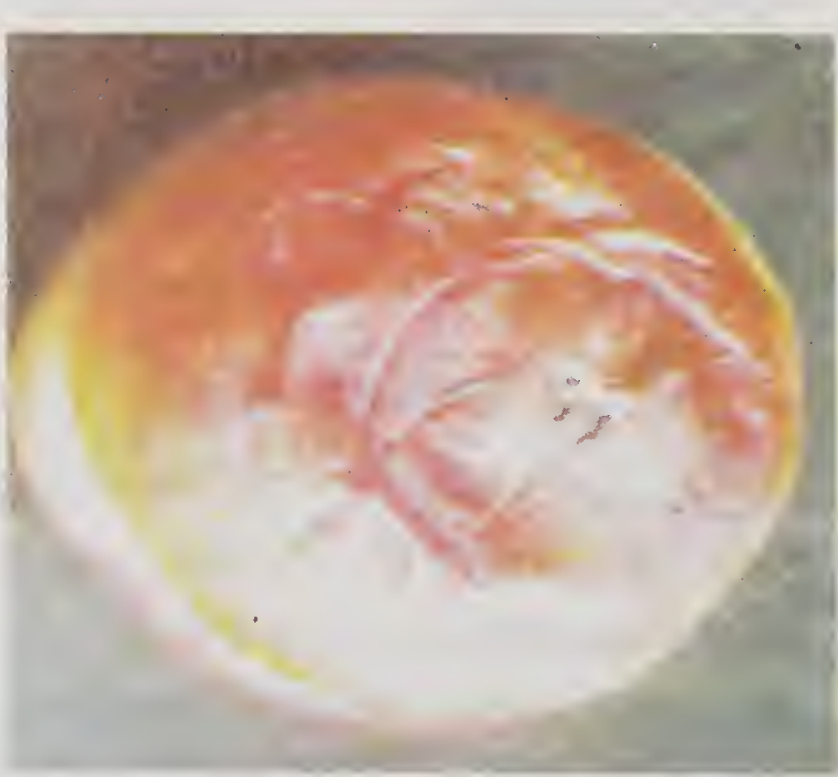

Fig. 1.3. Apple-scald 
readily peels-off from the fruit with a slight pressure. Fruit pulp turns brown and also breaks down.

Control measures : It can be contained by dipping fruits in $2,000 \mathrm{ppm}$ diphenyl amine (DPA) or 2,700 ppm ethoxyquin. Wrapping fruits in paper oiled with $1.5 \mathrm{mg}$ DPA before packing is also effective (Kanwar 1988). It can be controlled by using ultra-low oxygen atmosphere of $1.2 \% \mathrm{O}_{2}+1 \% \mathrm{CO}_{2}$ with no ethylene removal (Coquinot and Richard 1992).

\section{Soft-scald}

It is different from the scald.

Symptoms : This is characterized by discrete brown lesions, which are smooth, slightly sunken, and generally confined to equatorial parts of the apple-fruits. Pulp beneath is also affected; tissues are initially pale-brown, soft, spongy and moist. In advanced stages, lesions may show dark spots (Brooks and Harley 1934). There is sharp demarcation between the healthy and the affected tissues. Pulp of the affected area becomes soft and discoloured.

Control measures: Harvesting crop at optimum maturity is very important. Wax application immediately after harvest proved beneficial in reducing incidence. Calcium chloride treatment has been found beneficial. Application of antioxidants combined with oils is also effective (Wills and Scott 1982). Storing fruits at $2^{\circ} \mathrm{C}\left(36^{\circ} \mathrm{F}\right)$ proved advantageous.

\section{Bitter-pit}

This is one of the most critical disorders of apples,and most of the apple cultivars are susceptible to it. Sometimes, it is discernible in fruits while they are still on the orchards, but usually this develops only after harvest (Perring 1986). Affected fruits show small, deep-coloured spots (Fig. 1.4).

Symptoms : Fruits calyx-end tends to be affected first. Spots colour is green on yellow varieties and deep-red on red varieties. They become sunken and brown and underlying cells also turn brown and dry. In severely affected fruits, spots may appear scattered in the pulp. Sunken pits and coloured tissues taste bitter. The fruits may become mis-shaped due to severe pitting.

Control measures : Bitter- pit is caused by imbalanced water uptake by plants and is induced due to deficiency of calcium in fruits. The incidence of disorder can be reduced through proper cultural practices, regular irrigations and application of balanced

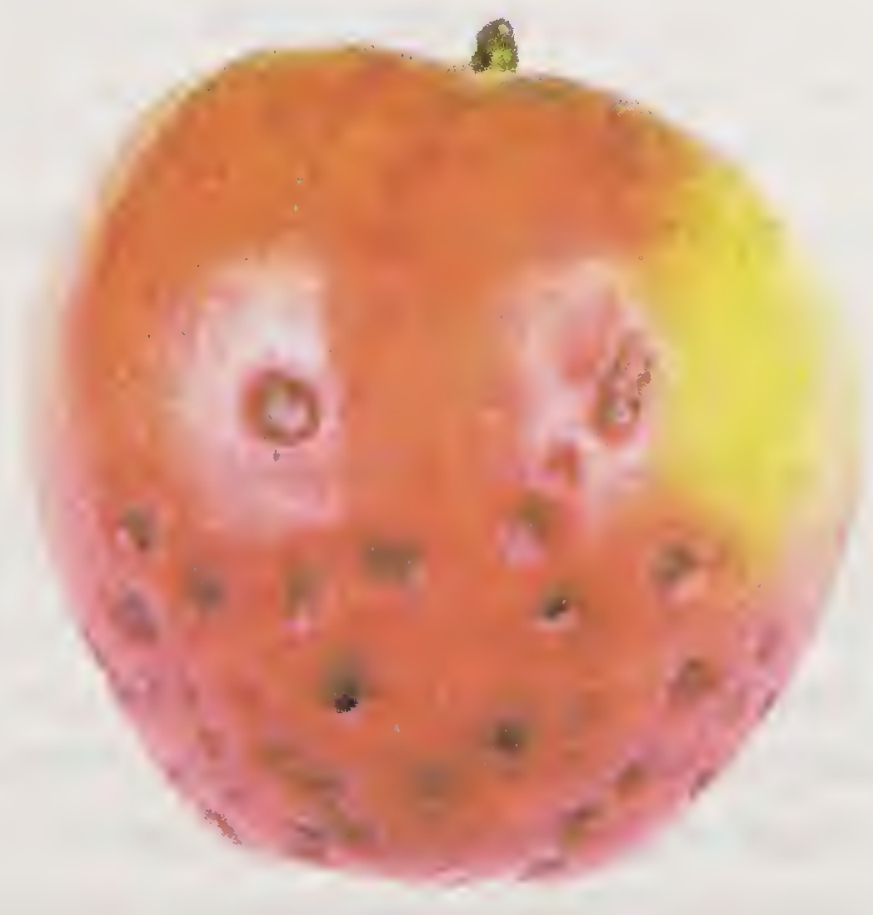

Fig.1.4. Bitter-pit on apple 
fertilizers. Three or four calcium sprays at one or two week intervals before harvest can reduce bitter- pit incidence. Summer pruning and delayed harvesting are also reported effective in reducing disease incidence (Bonn 1980). Bonn (1981) observed reduction in interval of disease development and extended interval of bitter-pit and pulp breakdown by spraying with $0.9 \%$ calcium nitrate and by winter application of gypsum at 4 tonnes/ha in the first year and 2 tonnes/ha in the subsequent year, followed by 10-12 sprayings of calcium nitrate $(0.9 \%)$ duing the season in orchards. Dipping fruits in calcium chloride solution immediately after harvest was also effective (Scott $e t$ al. 1985). Bitter-pit prediction in harvested fruits can be done by dipping fruits in ethephon $(2,000 \mathrm{ppm})$, followed by storage at $20^{\circ} \mathrm{C}$ for 5 days. This will give indication whether the disease would develop in storage on fruits (Ginsburg et al. 1976).

Post-harvest treatment to cv. Golden Delicious dipped in 2\% flaked or anhydrous calcium chloride with or without $1 \%$ lecithin or $0.2 \%$ zinc chloride preceeded by 3-4 orchard sprays of calcium nitrate was reported to reduce bitter-pit incidence under cold storage in boxes for five months (Fochessati 1981).

The incidence and severity of calcium-related bitter-pit was significantly reduced by gypsum use. Coarse gypsum (2-4 tonnes/ha) sprinkled on the surface of the soil and covered with a mulch (black polyethyelene sheet), topped with saw dust, to protect mechanically was reported (Lang et al. 2001). Bitter-pit development and its relation with mineral nutrients and cultivars was also well understood (Kim and Ko 2004)

\section{Water-core}

Symptoms : Water-core symptoms develop before harvest, and can be observed when affected fruits are cut. Any external symptoms are hardly observed but when fruit is cut open, affected one shows watery or glassy appearance of the pulp. Affected fruits have poor keeping-quality. They emit a fermented sweetish odour. Severely affected fruits are heavier than normal ones and hence healthy fruits can be segregated by floating them in a mixture of water and alcohol. The affected fruits can also be detected and segregated by measuring transmittance of light through fruits(Bramlage and Shipway 1967). High temperature at the time of maturity favours development of watercore. The intensity of the disorder increases as fruits overmature.

In Himachal Pradesh, core-rot caused by Alternaria alternata was also found associated with water-core (Gupta and Sharma 2008).

Control measures : This disorder increases as apples overmature. Picking of the fruits at the proper time reduces water-core. Heavy irrigation and manuring with nitrates and potash fertilizers in the orchards are beneficial (Walker 1975). Ensuring proper drainage in the orchard reduces disorder. The fruits should be stored in the ventilated environment at the right maturity. 


\section{Jonathan-spot}

This is common on Jonathan apple. On other varieties, this is known as spys-pot, physiological-spot and senescent-spot.

Symptoms : The disease originates at lenticels. The spots may be dark brown, black or moderately light brown. They appear only after harvest and are likely to be on overmature fruits (Richmond and Dewey 1969).

Control measures : The disorder can be reduced by harvesting apples at the optimum maturity, followed by prompt cooling. Fruits storage in an atmosphere of 2.5-5\% $\mathrm{CO}_{2}$ and $3 \% \mathrm{O}_{2}$ controls the disease (Pathak 1980). The discolouration can be removed by peeling of the skin.

\section{Lenticel spots}

Lenticel spots are centred on the natural openings called lenticels (Richmond and Dewey 1969).

Symptoms : Lenticel spots are slightly depressed, are up to $5 \mathrm{~mm}$ in diameter,and remain fairly superficial, unless invaded by fungi like Alternaria (Brooks and Cooley 1917).

Other disorders include brown heart that is due to excessive concentration of carbon dioxide in the tissues, bruising and other injuries like hail damage, chilling injury, core flesh, senescent breakdown, alcohol formation, black-end etc(Snowdon 1990).

\section{POST-HARVEST DISEASES MANAGEMENT}

Several investigators have reported better control with integrated strategies. Control of apple diseases with a combination of natural compounds, plant resistance and by the use of antagonists is commonly practised (Bosshard et al. 1987; Pathak 1997). The common methods include the following.

\section{Cold storage}

Cold storage of apples is the general practice followed by cultivators and consumers. Keeping fruits in cold storage at $0{ }^{\circ} \mathrm{C}$ immediately after harvesting is recorded as an effective measure (Jahangir et al. 1993).

\section{Use of wrappers, wax-coating and chemicals application}

Dipping of fruits in the fungicide solution before storage is very common. Wax-coating is effective in enhancing shelf-life. Bee wax and cantaleen wax are used for this. Mahajan and Chopra (1992) studied effect of post-harvest application of fungicides and wax-coating on the quality and storage of apples in Punjab; these applications slowed down metabolic rate in apple-fruits. And shelf-life was also prolonged by 30 days or more over control. Fruits treated with calcium chloride $(8 \%)$ at pressure infiltration $\left(10^{3} \mathrm{KPa}\right)$ showed least decay on storage at $0^{\circ} \mathrm{C}$ for three months (Conway 1982; Sams and Conway 1985; Husein et al. 2001). The treatment significantly reduced TSS/acid ratio in apples stored at $0-1{ }^{\circ} \mathrm{C}$. 
Two formulations of phenolic compound, Echinolan, developed in Russia, gave promising results. Both formulations prolonged keeping quality of apples by controlling fungal diseases and other functional disorders during storage. Echinolan $\mathrm{B}_{4}$ at $0.01 \%$ was most effective (Vorob'eva and Vorob' eva 2000).

\section{Controlled atmosphere storage}

Controlled atmosphere is commonly practised for long-duration storage. Carbon dioxide $3 \%$ and oxygen $2 \%$ is the ideal combination. Apple-fruits (cv. Gala) preserved in controlled atmosphere with removal of ethylene remained intact up to eight months; rotting and senescence were also not observed. (Brackmann et al. 2003). Scald incidence was observed to be significantly lower in the CA storage (Erkan et al. 2004).

Alternate control measures include use of UV type C ( $254 \mathrm{~nm})$ irradiation, yeasts, chitosan and harpin. Capdeville et al. (2002) evaluated all these factors for their ability to induce resistance and calculated area under disease progressive curve(AUDPC). UVC proved most effective, followed by harpin, chitosan and yeasts. Fresh fruits were more responsive than controlled atmosphere (CA) stored fruits. Harpin is a bacterial product that induces resistance in plants by eliciting hypersensitive response in them. The use of this may minimize cost of control strategies and reduce risks associated with excessive fungicides use. 


\section{CHAPTER \&}

\section{Apricot (Prunus armeniaca L.)}

It is an important fruit-crop of the cold arid regions of India, and is one of the most delicious temperate fruits with a pleasant flavour. Ripe apricot is an excellent dessert and is used for the table purpose. Orange-coloured fruits are full of beta carotene and vit. $\mathrm{C}$.

\section{FUNGAL DISEASES}

Brown- rot, c.o. Monilinia laxa (Aderh \& Ruhl.) Honey M. fructigena (Aderh \& Ruhl.) Honey

Symptoms and control measures for this are detailed under brown-rot of peaches.

Rhizopus- rot, c.o. Rhizopus spp.

Symptoms and control measures are detailed under Rhizopus-rot of peaches.

Sclerotinia disease caused by Sclerotinia sclerotiorum (Lib.) de Bary has also been reported on apricots (Walker 1975).

\section{BACTERIAL DISEASES}

A bacterial disease caused by Pseudomonas syringae Van Hall was reported by Durgapal (1971). It appeared on the fruits as reddish-purple to dark-brown lesions.

\section{POST-HARVEST MANAGEMENT}

Apricots are soft and delicate and need to be consumed/processed within three days after harvest. They can be stored for $72-80 \mathrm{hr}$ at room temperature. Storage life can be extended by storing at $5^{\circ} \mathrm{C}$ and at $85 \%$ relative humidity. Under controlled atmospheric conditions, fruits can be stored for 10 days at $3^{\circ} \mathrm{C}$. 


\section{CHAPTER}

\section{Banana (Musa spp.)}

Banana and plantain is a dessert fruit or a starch staple to a large population of the world. The fruit is rich in vitamins A, B,C, minerals and energy. Several fungi are reported to cause post-harvest losses in banana.

Cheriyan (1987) recorded maximum reduction in total sugars, total soluble solids and vitamin $\mathrm{C}$ in fruits infected with Colletotrichum gloeosporoides. Under pathogenesis, changes in protein and phenol contents in banana-fruits were also recorded. Protein concentration exhibited gradual fall under pathogenesis by prominent fungi, Botryodiplodia theobromae, Fusarium oxysporum, Helminthosporium speciferum, Curvularia lunata, Aspergillus flavus and Trichothecium roseum. The maximum reduction was observed due to B.theobromae.

Fungal association and changes in carbohydrate and protein contents of fruits have been well understood. Fungal population associated with fruits increases as ripening proceeds. Carbohydrates and proteins increase at the initial stages of ripening but decline after 12 days. Calcium carbide application hastened ripening process in $\mathrm{cv}$. Nendran as carbohydrate and protein contents decreased by eighth or nineth day after treatment. Ripening is correlated with fungal association and reduction in shelf-life of fruits (Bandyopadhyay and Chaudhuri 2007).

Gradual decline in total phenols was reported by Singh et al. (1994). Total phenols, orthodihydric phenol and anthocyanain contents of banana-peels also reduce during rotting, and thus pre-dispose fruits to fungal infection (Khan et al. 2001).

\section{FUNGAL DISEASES}

Anthracnose, c.o. Colletotrichum musae (Berk. \& Curt.) Arx.

Anthracnose and crown-rot are considered as the major post-harvest diseases of banana (Stover 1972; Waredlaw1972; Stover and Simmonds 1987). Anthracnose is also known as black-rot, crown-rot or ripe-rot, depending on the symptoms.

It is one of the most important and widely distributed diseases of ripening 
bananas (Meredith 1961; Bilgrami et al. 1979, 1981). Dastur (1916) first reported its occurrence in India. Lim et al. (2002) reported C. muscae from bananas in Korea. This fungus is also associated with crown-rot.

There are two types of anthracnose infections- latent infection and nonlatent infection. Latent infection occurs in fields on uninjured green fruits. The fungus penetrates into cuticle, and is latent up to five months as subcuticular hyphae. When the fruit approaches maturity, fungus resumes activity and produces typical lesions on the fruit surface, while non-latent infections begin during or after the harvest on the bruised fruit surface and continue to develop without dormant period.

Symptoms : Young latent infections appear as small black-and-circular specks on the flowers, fruit-peels and distal-ends of banana-hands (Fig. 3.1). Soon the lesions increase in size, become sunken and coalesce to form larger spots on the surface of the fruits on which characteristic bright moist salmoncoloured spore masses appear when latency is broken. Severely infected fruits become dark due to blemishes. Infected fruits prematurely ripen and turn black and rotten. Most Cavendish

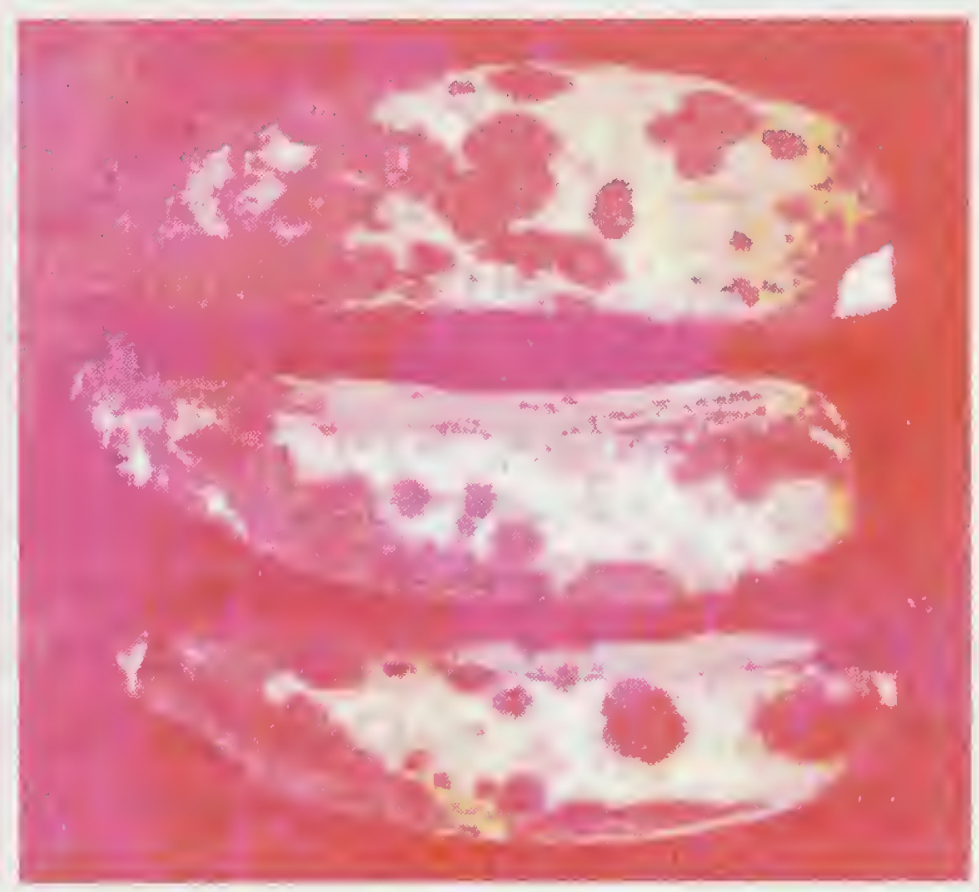

Fig. 3.1. Anthracnose on banana varieties are susceptible to bruising and fruit-rot compared to Gros Michel varieties.

Control measures: Pre-harvest protection. Protection from latent infection can be achieved through fungicidal spraying. Spraying bunches once a month with copper fungicides until fruit is ready for cutting has been found effective. Dithiocarbamates are also found useful in controlling diseases (Chin 1967).

Hot-water treatment. Burden (1968) observed effective control with a slight delay in ripening by dipping banana in water at $55^{\circ} \mathrm{C}$ for two minutes for Colletotrichum musae. But Tandon et al. (1976) observed this to be non-effective.

Use of fungicides and chemicals. The effect of systemic fungicide Benomyl in controlling established latent infection by $C$. musae is well documented. Burden (1968) observed dipping of fruits in Benomyl (100-400 $\mathrm{ppm}$ ) as the most effective treatment. Concentration of $0.1 \%$ offers protection in commercial shipments also. Sridhar and Sohi (1974), Khanna and Chandra (1974), Quimio (1976) and Bolkan et al. (1976) also confirmed the above 
results. The shelf-life of banana cv Robusta enhanced up to 21 days by treatment with Benlate $(500 \mathrm{ppm})$, followed by storage in polyethylene cover of 200 micron thickness(Suharban 1977).

Thiabendazole (TBZ) was also reported to be effective. At 200- $400 \mathrm{ppm}$, almost complete control was obtained (Philips 1970). Rippon et al. (1973) found it effective for commercial shipments. Together with Benomyl, it was effective against non-latent infections also. TBZ is approved in the United States (the permitted residues being $3 \mathrm{ppm}$ in the peel and $0.4 \mathrm{ppm}$ in the pulp). This is being used in Australia, Camaroon, Jamaica, Carribean, Central America and the Windwards Islands where bananas are boxed for shipment. Ram and Vir (1983) tried Bavistin, Benlate, Thiabendazole (2,000 ppm concentration), and observed all of them effective against latent infection by C. musae. Propionic acid and Salycylic acid at (5,000 ppm) were effective, but the latter caused skin discolouration.

Zhu et al. (2004) recorded direct application of crude extract from peels of unheated green banana(UHGB) effective against $C$. musae and also in inducing tolerance before storage.

Cutting off hands from bunches and packing them in cardboard boxes have minimized incidence of anthracnose in bananas to a great extent. Jeger et al. (1995) stated that anthracnose importance as a disease in the international trade is reduced, as fruits are now transported in cartons rather than as whole bunches.

\section{Crown-rot}

Crown-rot is a disease complex; caused by several fungi, sometimes in association with bacteria (Lukezic et al. 1967). Microorganisms predominate differently depending upon the locality and other factors (Meredith 1971). Crown-rot organisms enter after the bunch has been harvested, and usually manifest due to mechanical injuries while harvesting and handling (Fig. 3.2).

Causal organisms include Botryodiplodia theobromae Pat, Cephalosporium sp., Ceratocystis paradoxa (Dade) Moreau. Colletotrichum musae (Burk and Curt.) Arx, Fusarium pallidoroseum (Cooke) Sacc., Acremonium spp. and Verticillium thebromae (Turc.) Mason and Huges.

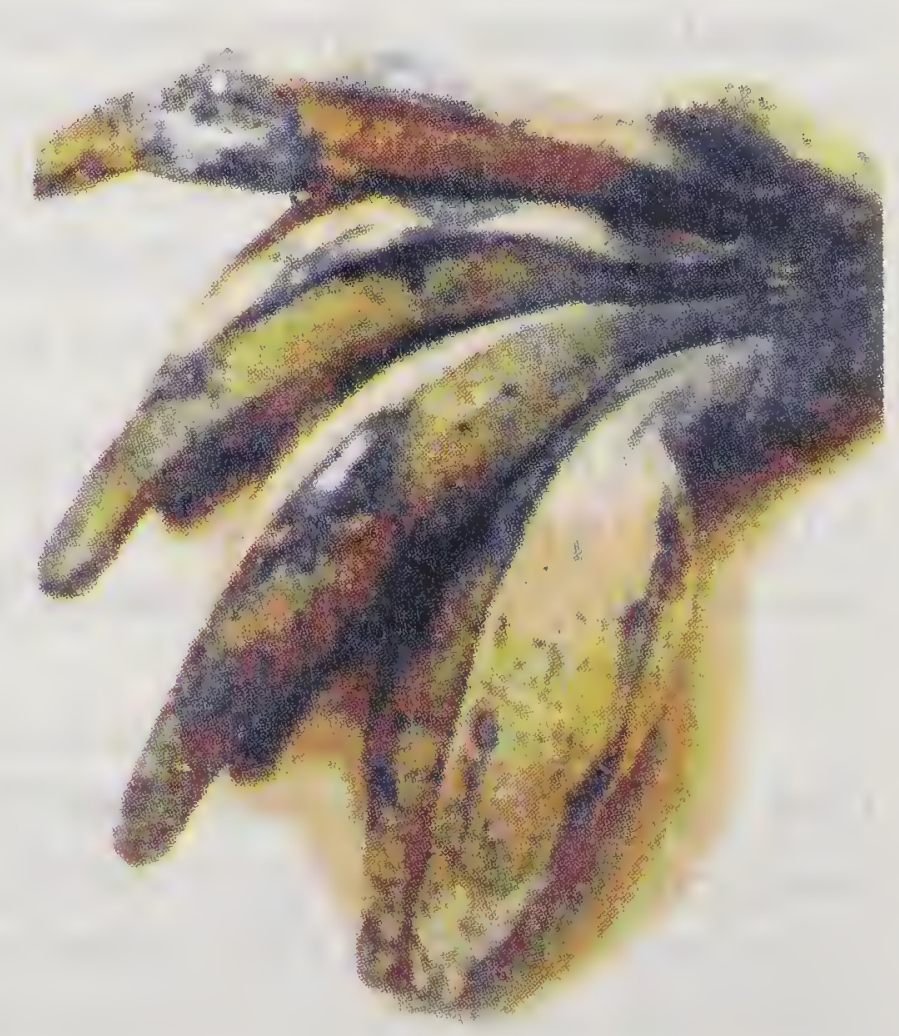

Fig. 3.2. Crown-rot on banana-fruits 
Symptoms: Typical symptoms of major fungi associated with this disease are as follows.

Botryodiplodia theobromae Pat. Being a wound parasite, it readily attacks cushions after they have been dehanded. Infection extends from cushion region to finger-stalks, and from there to fingers, resulting in rotting and dropping of individual fingers. Along with this, a brownish black discolouration is also noticed on the surface of the fruit, and the fruit becomes soft and wrinkled. Light-grey cottony mycelium covers the whole fruit. Later peel gets shriveled and encrusted with pycnidial mass. Maximum damage to fruits occurs at $23-30^{\circ} \mathrm{C}$ and minimum at $7^{\circ} \mathrm{C}$ (Williamson and Tandon 1966; Philip and Nair 1999).

Ceratocystis paradoxa (Dade) Moreau. Infection occurs when main stalk is cut or bananas are dehanded. Infected main stalks decay rapidly; tissues become blackened and soft and give a characteristic sweetish odour. Under humid conditions, fungus forms a cobweb-like mass of dark-coloured mycelia that invade cushion, finger-stalks and fingers. Infected fruits show uneven black discolouration of peel, and pulp is reduced to soft-and-wet consistency of dark-brown colour (Anon. 1971).

Colletotrichum musae (Berk and Curt.) Arx. Infection occurs through small peel injuries on immature banana-fruits and results in the development of lesions; as detailed under anthracnose. In the ripening room, Colletotrichum infection also produces tip-rot when fruits are turning yellow (Anon. 1971).

Control measures : Crown-rot incidence can be reduced with pre-harvest fungicidal applications. In areas where fruit diseases cause serious losses, direct spraying of individual bunches (after 10-20 days of emergence) with fungicides is required. Three to four sprayings with any of the following chemicals can be given: Zineb $(0.2 \%)$ or Maneb $(0.2 \%)$ or CUO $(0.5 \%)$.

In Central America, crown-rot is controlled by dipping (spraying) hands in Maneb $(0.3 \%)$ or Zineb $(0.1 \%)$. Addition of triton as a wetter improved fruit coverage by fungicides. Chlorine presence in the washing tanks supplemented effects of subsequent fungicidal treatments. Application of a paste containing lead arsenate or polyethylene polysulphide (PEPS) to freshly exposed crown tissues prior to placing of fruits in boxes was also effective (Anon. 1971).

Systemic fungicides also offer protection. Bavistin (500 ppm), Benomyl (500 ppm) and Thiabendazole (200-400 ppm) are all equally effective (Griffe and Burden 1974). Cheriyan (1987) could not get any positive results with Bavistin at $300 \mathrm{ppm}$ or $500 \mathrm{ppm}$; with $1,000 \mathrm{ppm}$, shelf-life increased by 14 days, but its residue level on the fruits was above the permissible limit.

Storage at $7^{\circ} \mathrm{C}$ increases shelf-life of bananas up to 10 days without much changes in fruit quality. 
Biological control. Yeast Candida oleophila suspension applied @ $10^{7} \mathrm{cfu} /$ $\mathrm{ml}$ with $2 \% \mathrm{CaCl}_{2}$, followed by storage under modified atmospheric packaging (MAP) in the non-perforated polyethylene bags reduced crown-rot significantly as compared to untreated control (Bastiaanse et al. 2010).

\section{Speckle/ black- spot/ black-tip, c.o. Deightoniella torulosa (Syd.)Ell.}

The fungus causes symptoms on banana leaves and fruits. The disease is characterized by black discolouration just below the flower that progresses along the fruit. The diseased area is bordered by an irregular narrow grey or pale yellow margin. One side of the fruit is affected more than the other. Larger spots may measure up to $4 \mathrm{~mm}$ in diameter with a sunken centre, which may crack as fruit matures (Anon. 1971).

\section{Pitting disease/Johnston-spot, c.o. Magnaporthe grisea (Hebert) Barr Conidial stage : Pyricularia grisea Sacc.}

The disease is prevalent in South America, Central America,Caribbean, the Canary Islands, Australia etc. (Snowdon 1990).

Symptoms : They appear as small reddish spots on the green-fruit peel, which is approaching maturity. Later, these spots develop into typical small, shallow black pits, which may sometimes be so many that bunch appearance is spoiled for marketing. Sometimes no apparent symptoms are noticed on the harvested bunch, but pits may develop during transport and storage. In the ripening room, fungal mycelia develop on the surface of these spots, and as the ripening proceeds, original pits get overgrown by secondary saprophytes (Anon. 1971). Control measures : Pre-harvest spraying with any of dithio-carbamates at $0.2 \%$ concentration when bunch begins to develop gives protection (Anon. 1971).

\section{Cigar-end rot/banana fruit-rot}

The disease is considered a complex one, caused by several fungi, and is associated with Trachysphaera fructigena Tabor \& Bunting in West Africa and with Deightoniella sp. in Jamaica (Meredith 1961a). In Egypt, it was recorded with increased temperature and humidity. Old and badly neglected plantations suffer sometimes to the extent of 100\% (Anon. 1971). Ershad (1972) reported it from Iran. The disease is transmitted by air-borne spores, carried from the debris of banana-plants.

Verticillium theobromae was also reported from most banana- growing areas, including West Indies. In India, the disease was reported to be incited by B. theobromae from Madhya Pradesh (Dhingra et al. 1970), Hyderabad (Srivastava and Tandon 1971) and Kerala (Philip et al. 1980). In Kerala conditions, $B$. theobromae was also found to be associated with $V$. theobromae and Trichothecium roseum.

Symptoms : These appear from the tip of the immature fruits at the pistillateend and spread upwards. The peel becomes folded and shrunken as infection 
spreads slowly along the finger. Ashy conidia and conidiophores cover rotten portions, which become corrugated and impart a burnt ashy cigar appearance with a dark border (Fig. 3.3). Decay may extend up to one-third of the fruit, and the fruit develops a typical dry-rot.

Control measures: Spraying of

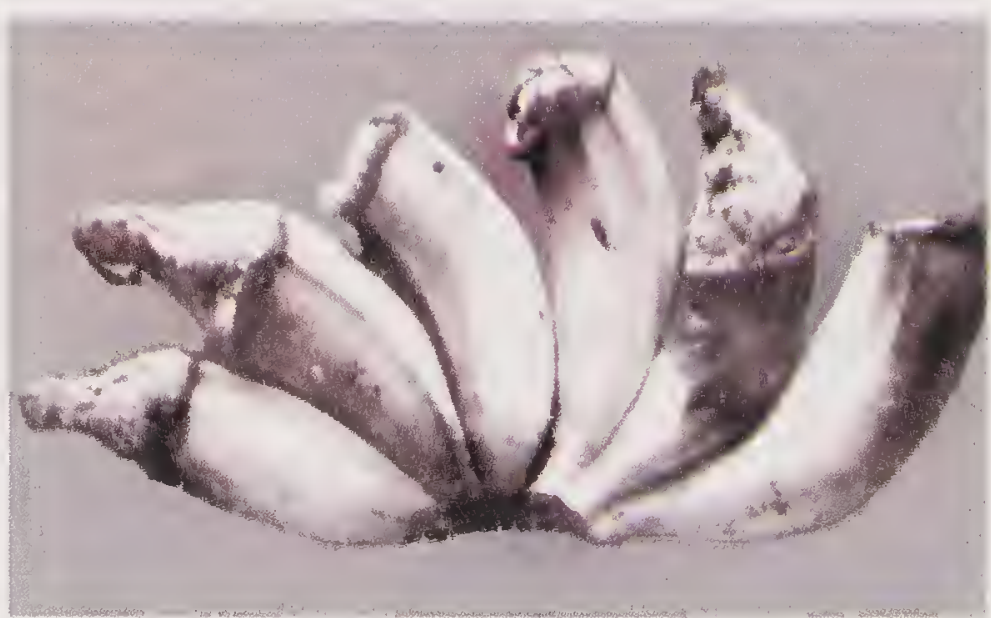

Fig. 3.3. Cigar-end rot on banana bunches at the time of flowering (after all hands open completely) with methyl- 2-benzimi-dazole carbamate (MBC) (0.1\%), Benomyl (500 ppm) and Mancozeb (0.2\%) is effective in reducing cigar- end rot(Dukade 1985).

\section{Squirter disease, c.o. Nigrospora sphaerica (Sacc.) Mason}

This disease caused serious losses to bananas in eastern Australia (Simmonds 1947).

The fungus penetrates through broken stem-ends resulting from mechanical injury, and converts pulp into a dark watery fluid without any symptoms on the peel. The disease is a common cause of wastage when fruits are packed as singles.

Dipping the hands in Thiabendazole solution of $0.04-0.01 \%$ was promising (Anon. 1971).

Freckle/black-spot disease, c.o. Macrophoma musae (Cooke) Berl. \& Vogl.

The disease was reported from Central America (Wardlaw 1972) and from Kerala (Philip and Nair 1999).

Symptoms : The disease is characterized by spotting on the leaves and fruits. The fungus develops numerous minute, greyish brown or dark brown, raised, more or less rounded spots, $1 \mathrm{~mm}$ in size with black dots in the centre. Lesions are present in abundance on the upper surface of the fruits with a narrow water-soaked margin. Minute projecting pycnidia render roughness to fruits. In case of severe infection, affected fruits appear blackish (Wardlaw 1972).

Control measures are not necessary as the symptoms are superficial; on the peel only.

Fusarium tip-rot, c.o. Fusarium spp.

Different Fusarium species are found associated with the disease, and it was reported from Fiji, Brazil, Trinidad, Uganda and Central America (Anon. 1971). 
F. moniliforme and F. roseum were reported from Uttar Pradesh and Delhi (Khanna and Chandra 1974; Dharam Vir 1977); F.solani and F.oxysporum from West Bengal (Chakraborty et al. 1977; Mandal 1981; Das Gupta and Mandal 1989); F.graminearum and F.semitectum from Kalyan and Kerala (Bandopadhyay and Chauduri 2004; Cheriyan and Varghese 2007). And F.dimereum was also reported.

The causal fungus was also identified as Gibberella fujikuroi; the perfect stage of Fusarium sp.

Symptoms : The disease is characterized by tip rotting of the young immature fruits (Fig. 3.4). The infection originates from the base of the decaying perianth and causes blackening and wrinkling of peel, and premature yellowing of fruits. In advanced stage, brown-peel gets covered with rosy powdery fungus growth and inner pulp becomes soft and rotten (rig. 3.5).

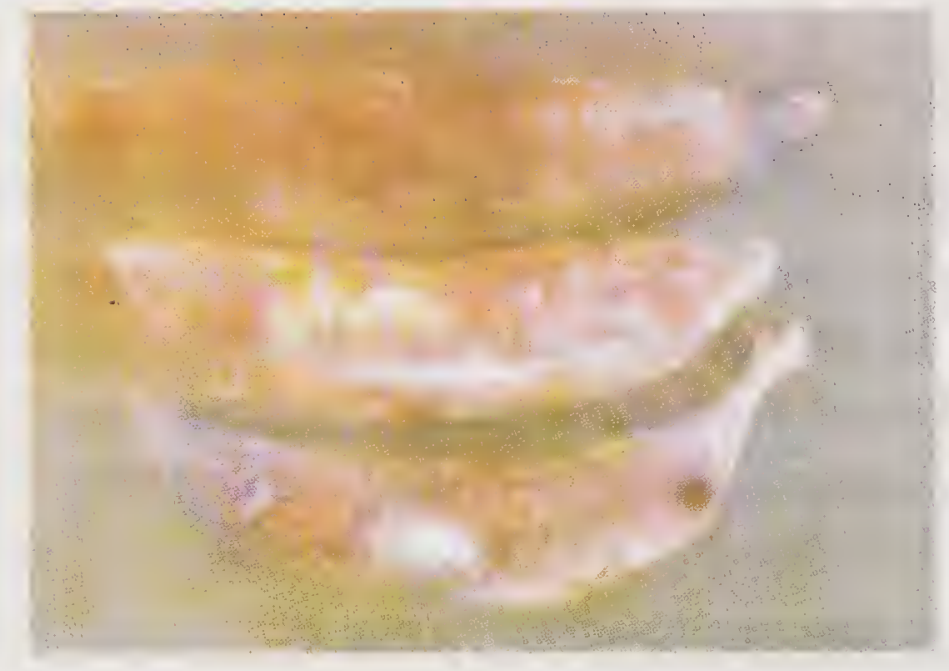

Fig. 3.4. Fusarium-rot on banana-fruits

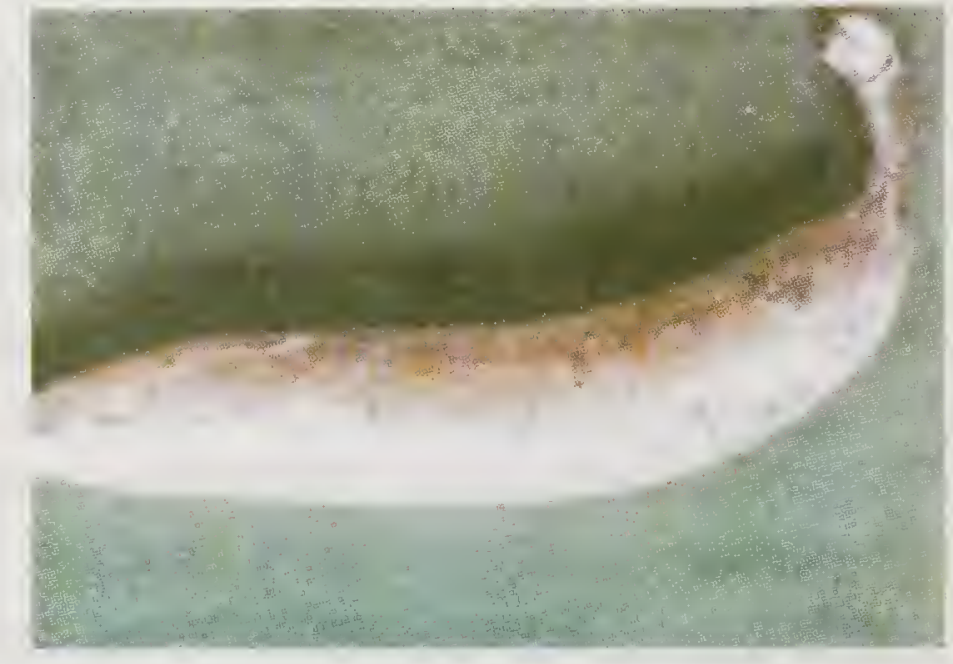

Fig. 3.5. Fusarium-rot at advanced stage

Symptoms due to F.moniliforme are evident on cutting fruits longitudinally. Deep-brown discolouration extending from tip to bottom is noticed; tissues become soft and pulpy (Dharm Vir 1977).

Control measures : Careful handling is essential to avoid wounds and bruises during transport and storage.

Storage of fruits at or below $10^{\circ} \mathrm{C}$ and relative humidity at $25 \%$ is ideal for preventing storage-rots (Cheriyan and Varghese 2007).

Aureofungin has been reported to be effective. Sridhar and Sohi (1974) controlled post-harvest rotting by prophylactic treatment with Aureofungin at $100 \mathrm{ppm}$. Banana-rot caused by Fusarium moniliforme and F. roseum could be controlled with Aureofungin at $200 \mathrm{ppm}$; Cheriyan (1987) could not get any positive results with Aureofungin (50-200 ppm). And the fruits started showing rotting after seven days' storage.

Brown-rot/ Botryodip!odia-rot, c.o. Botryodiplodia theobromae Pat.

It is one of the most important diseases of ripe-bananas, causing extensive damage under stored conditions throughout the year. In Central America, it was reported to cause finger-rot (Goos et al. 1961). In India, the disease was 
recorded from Uttar Pradesh, Delhi, Maharashtra, Andhra Pradesh and West Bengal (Srivastava et al. 1964; Chakrborty and Nandi 1976), and was found associated with crown-rot, tip-rot and finger-rot (Philip and Nair 1999) under Kerala conditions (Fig. 3.6).

Symptoms and control measures detailed under crown-rot are recommended for this also.

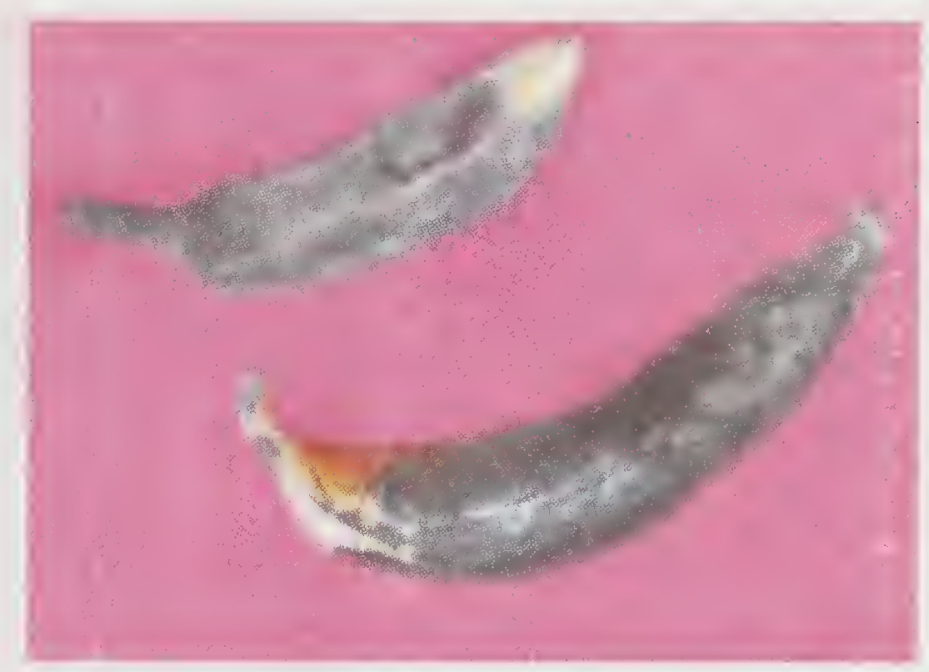

Fig 3.6. Botryodiplodia-rot on the fruit

Rhizopus-rot/soft-rot, c.o. Rhizopus stolonifer (Ehrenb.) Vuill.

$R$. oryzae Went \& Prinsen Geerligs

$R$. arrhizus Fischer

Symptoms : They appear as brown irregular lesions, which gradually increase in size, and within a short span, entire fruit surface gets covered with fungal growth. This results in softening of fruits, and decaying fruits emit a fermented odour (Cheriyan 1987; Philip and Nair 1999).

Mandal and Das Gupta (1983) observed black soft-rot caused by Mucor heimallis, where fruit-surface was covered by fluffy yellowish mycelial growth.

Control measures : Post-harvest management measures as detailed under Fusarium-rot are relevant for this also.

\section{Green mould-rot, ๑.o. Aspergillus flavus Link. ex Fries}

Symptoms : This rot develops as water-soaked lesions on fruits, which later become soft and juicy. In advanced stages, fruit-surface gets covered with olive-green dot-like mycelia with abundant sporulation (Cheriyan 1987).

Control measures : Avoid injuries and bruises on fruits during handling and storage. Fruits decay can be controlled by dipping them in any of the following fungicides/chemicals - Thiophenate methyl, Benlate, Thiabendazole, Bavistin, Propioinic acid, sodium metabisulphite (all at 2,000 ppm). The shelf-life could also be extended by 8 days (Ram and Vir 1984).

\section{Black mould-rot, c.o. Aspergillus niger Van Tiegh.}

The disease is worldwide in occurrence. Wardlaw (1972) considered it as a secondary pathogen associated with rots. Thakur and Chenulu (1970) and Mandal and Das Gupta (1983) reported the disease from West Bengal.

The disease manifests itself as water-soaked circular lesions around the injured tissues. Rotting is gradual and whole surface gets covered with black fungal growth, and ultimately dry-rot symptoms appear. Aspergillus oryzae also caused similar symptoms. In advanced stages, affected fruits become black and shrivelled (Fig. 3.7) (Cheriyan 1987). 


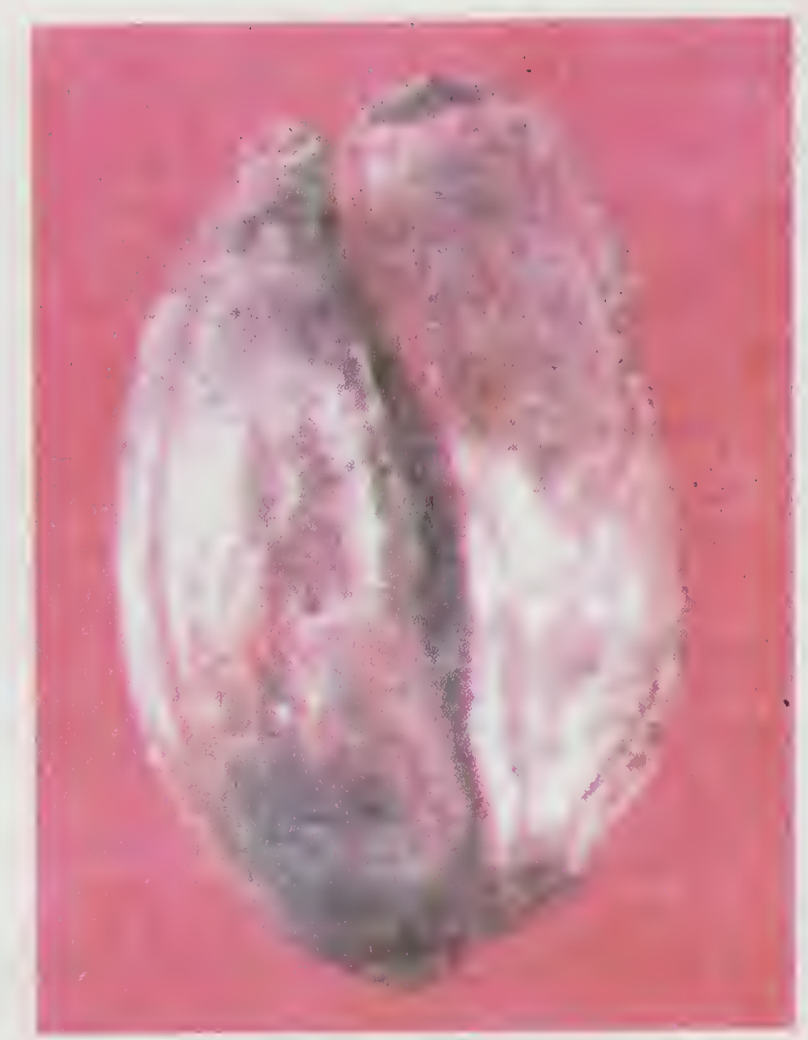

Fig. 3.7. Mixed infection by Botryodiplodia theobromae, Fusarium sp. and Aspergillus niger on banana

Control measures for Green mould -rot(A.flavus) are applicable for this also.

\section{Watery soft-rot /Sclerotinia fruit-rot, c.o. Sclerotinia sclerotiorum (Lib) de Bary}

In 1930, this disease was reported from Palestine, and was considered as one of the most severe fruit-rots. The same was also observed in Bermuda and Costa Rica (Laguna and Salazar 1984).

Infection starts from the perianth region and progresses along the fingers with a brownish water-soaked appearance, which later turns dark-brown. Internal rotting is also noticed. The white inner tissue becomes reddish-black, and finally gets broken down and hollowed out. Black seed-like bodies representing fungal sclerotia are produced in abundance.

Botrytis end-rot, c.o. Botrytis cinerea Pers.

The disease was reported by Singh and Khare (1977) from Uttar Pradesh.

The fungus produces a wet-rot. Infection begins at the fruit-tip or perianth, and spreads causing dark-brown discolouration on the peel, followed by rotting of the pulp. The surface of the decayed fruit is covered by dense, brown mycelia, characterized by sticky, wet, dark-brown epicarp and a reddish-green endocarp due to mycelial growth and fruiting bodies.

\section{Pink mould-rot, c.o. Trichothecium roseum Link. ex Fr.}

The disease was prevalent in Uttar Pradesh, Delhi, Andhra Pradesh, Bihar and Maharashtra (Srivastava and Tandon 1971). It originates mostly from stigma-end, and appears as pale-brown water-soaked lesions that enlarge to form large patches with a pink mouldy overgrowth. 


\section{Helminthosporium fruit-rot,}

c.o. Helminthosporium spiciferum (Bain.) Nicot

The disease was reported from Bhagalpur and caused considerable rotting to banana-fruits (Prasad 1977a). In fruits, gradual loss of ascorbic acid (vit. C) content was also noticed; due to production of ascorbic-acid degenerating enzymes, either by fungus or due to host-pathogen interaction.

\section{Dothiorella-rot, c.o. Botryosphaeria ribis Grossenbe \& Duggar}

Kachawaha et al. (1992) observed 25-30\% loss due to this disease from Sagar (Madhya Pradesh).

Decay begins characteristically from the tip-end of the infected flower part and develops as in the finger-rot. Minute black bodies (pycnidia) are formed on the peel. And a white-to-grey mould growth may also develop (Snowdon 1990).

\section{Phytophthora finger-rot, c.o. Phytophthora nicotianae var. parasitica}

The disease was reported from South Africa.

The rot is firm and black; advancing rapidly from stalk-end or tip-end of fingers. In advanced stage, white- spore growth may be noticed on the lesion surface (Snowdon 1990). The disease is of not much importance.

\section{Banana black-rot, c.o. Thielaviopsis paradoxa Van. Honn}

The disease was reported from Kerala (Cheriyan and Varghese 2007) on Nendran,which is the most important and widely used variety. Black-rot incited by $T$. paradoxa and soft-rot by $F$. semitectum were found very common in several districts of Kerala. Temperature, relative humidity and injuries lead to development and spread of the disease.

Fruits become soft and black. Under in-vitro conditions, intensity of the rotting was found maximum at $35^{\circ} \mathrm{C}$ and at $100 \%$ relative humidity.

Storage of banana-fruits at $10^{\circ} \mathrm{C}$ and below $25 \% \mathrm{RH}$ is effective in reducing spoilage by $T$. paradoxa and $F$. semitectum without affecting fruit quality (Cheriyan and Varghese 2007).

\section{Sooty mould, c.o. Capnodium sp.}

The disease was recorded from the Philippines, South America and Central America (Stover 1975). The mould is associated with the honey-dew secreted by banana-aphid. Occasionally fungus Cladosporium sp. was also found associated with it.

Small, dark-brown flecks appear on the crown, pedicels and fingers of the fruits. These flecks increase in size and merge into blackish brown blotches that may extend up to $1 / 3^{\text {rd }}$ of the fruit (Stover 1975).

The disease can be controlled by dipping in bleaching solution (0.05$0.1 \%)$. 


\section{Fruit-rot, c.o. Penicillium citrinum Thom.}

The disease was reported from West Bengal and Kalyan (Sadhu et al. 1992; Bandyopadhyay and Chauduri 2004).

Diseased fruit's skin becomes soft and shows numerous green pinheadlike structures. On the removal of peel, pulp appears soft, yellow and shrivelled with water-soaked appearance. Fungi population increases with ripening; is significantly higher in fruits where ripening is hastened with calcium carbide.

\section{Curvularia fruit-rot, c.o. Curvularia lunata (Wakker) Boed}

In Delhi, the disease was reported to cause $10 \%$ loss (Ram and Vir 1986). The symptoms appear as water-soaked sunken lesions with irregular margins. In the beginning infection is limited to peel. But in advanced cases, infection occurs in the pulp also. Dipping fruits in propionic acid or salicylic acid or sodium metabisulphite (all at 2,000 ppm) saved banana-fruits from infection.

\section{Fruit-rot, c.o. Chaetosphaeropsis truncata Curzi \& Barbiri}

The disease was reported from Allahabad(Uttar Pradesh). Infection occurs at the stylar-end of the fruits as brownish and water-soaked skin discolourations; spreading around the point of incidence with rotting spreading upwards and covering fruit within 8-10 days. Skin colour turns black. In severe cases, skin shrivels and numerous dark-coloured pycnidia of pathogen appear all-over the fruit surface. Pulp rotting is faster than that of skin (Rai and Bihari Lal 1984).

\section{BACTERIAL DISEASES}

Bacterial disease, c.o. Burkholderia cepacia, was reported from Taiwan. Diseased fingers were recognized by their distorted shape; often narrow at the tip. Pulp appeared gelatinous and yellow.

\section{POST-HARVEST DISEASES MANAGEMENT}

\section{Cultural practices}

Field hygiene is very important. Male bud of the bunch should be removed when all hands open. Leaves which carry diseases like sigatoka should be collected and burnt. They should not be used for packing bunches. Bunches collected during the dry period from January to April (Kerala conditions) could be stored for longer period without fear of microbial spoilage as compared to bunches collected during other periods of the year (Suharban 1977). Bunches should be healthy while they are stored and ripened. Care should be taken as follows.

- Harvesting of the bunches should be at the correct stage of maturity (over-ripening should be avoided).

- Handle the bunches with care to minimize bruising. 
- Storage needs to be carefully done, and rapid cooling is required in the holds.

- In the collecting stations, holds and storage rooms, cleanliness is a must to minimize contamination.

Stover and Simmonds (1987) emphasized need for good hygiene in the plantation and in the packing houses to manage diseases. They also pointed out the importance of transit time in development of a disease. Slow transport at warm temperature leads to pathogens becoming a problem. Introduction of rapid transport to distant markets with adequate facilities for controlling temperature helps reducing incidence of many diseases.

\section{Cool chambers}

A brick-wall evaporative chamber designed for maintaining freshness and for extending shelf-life of plantains was reported from Nigeria (Babarinsa $e t$ al. 2001).

Chamber enclosed by the cavity wall of the burnt-clay bricks is cool. The inside of the cavity is filled with sand, and is kept saturated with water. Water evaporates and cools chamber at $10^{\circ} \mathrm{C}$. This condition delays ripening of banana, maintains freshness and extends shelf-life of plantain-fruits by 9 days and reduces weight loss by $80 \%$. Packaging of these fruits in polyethylene bags $(0.04 \mathrm{~mm}$ thickness) further extends shelf-life by another four days.

\section{Low-temperature storage}

Temperature plays an important role along with humidity in the growth of pathogens and in subsequent spoilage process. Refrigeration system prevents post-harvest spoilage of fruits, and microbial attack to fruits becomes slower below $5^{\circ} \mathrm{C}$. But exposure to higher temperature immediately aftes storage favours microbial invasion and thus rapid spoilage. Refrigeration enhanced storage life of banana-fruits (Bhargava el al. 1965). Tandon (1967) studied effect of low-temperature storage at $10^{\circ} \mathrm{C}$. The fruits remained healthy up to eight days. B.theobromae damaged maximum when fruits were stored at $25-30^{\circ} \mathrm{C}$ and minimum at $7{ }^{\circ} \mathrm{C}$ and below (Williamson and Tandon 1966). Storage at $14.5^{\circ} \mathrm{C}$ with $12 \%$ wax-coating was effrective in enhancing storage life for 25 days (Sadasivam et al. 1971). But Patil and Magar (1975) recorded $13^{\circ} \mathrm{C}$ as the optimum favourable temperature for ripening and storage of banana.

\section{Wax-coating}

It enhances storage of banana in refrigerated conditions, and offers protection against microbial infection. Dwarf Cavendish banana could be stored by coating with $12 \%$ wax-emulsion. Wax application at the cut ends reduced weight loss during refrigeration (Muthuswami et al. 1971; Sadasivamı et al. 1971). But at the ordinary conditions (temperature $28^{\circ} \pm 2^{\circ} \mathrm{C}$ ), wax did not enhance storage life (Anón. 1971; Cheriyan 1987). 


\section{Handling and packing}

Proper packing and handling reduces injuries, moisture loss and recontamination, and maintains desirable storage atmosphere and extends storage life (Scott and Roberts 1967; Pantastico 1975). Storage of banana hands in boxes, cartons with packing materials like paper and hay-cuttings was found effective only up to seven days (Cheriyan 1987).

Packaging has an impact on fruit losses and on the marketing system. Scott et al. (1970), Silvis et al. (1976) and Suharban (1977) reported efficiency of different thickness polythene covers in delaying ripening. They also recommended dehanding of bunches, followed by fungicidal treatment (dipping in Benlate $500 \mathrm{ppm}$ ) and packing in polyethylene bags (200 microns) as the best method for transporting bananas from one place to other.

\section{Vacuum packing}

This is effective for small-scale packing. Vacuum is created in a polythene cover by removing air from inside (Fig. 3.8). Accessory attached to common vacuum cleaner can also be utilized. Vacuum gives oxygen-free atmosphere, and thus eliminates aerobic bacteria and retards oxidation. With the addition of ethylene absorbent (aluminium silicate and potassium permanganate, mixed in equal

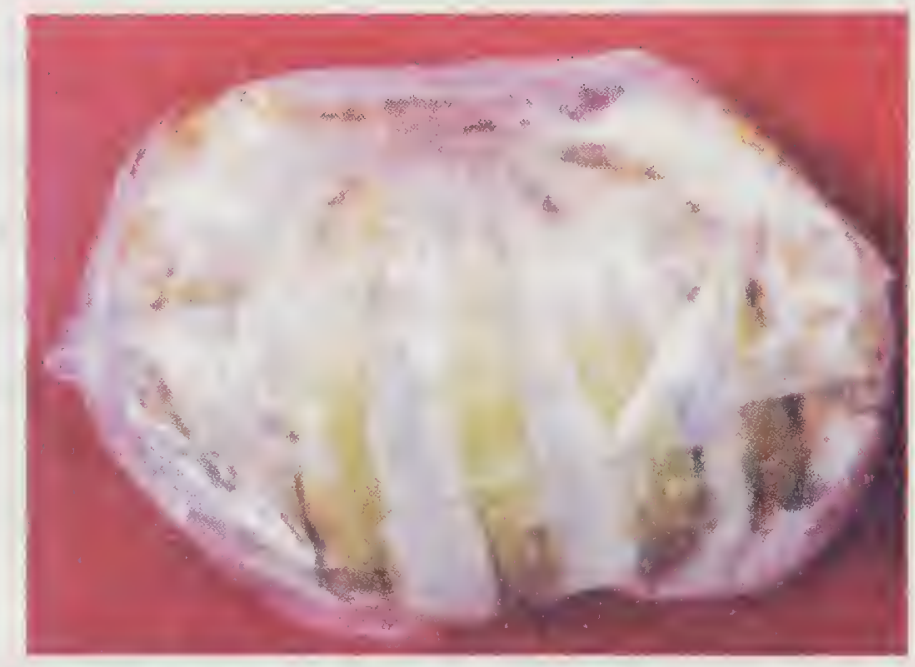

Fig. 3.8. Vacuum packed banana proportion, wrapped in a muslin cloth and kept inside the polythene packet), shelf-life of the fruits increased up to 40 days (Sreenarayanan and Rajeev 1996). But vacuum packing without ethylene absorbents is also effective for maintaining keeping-quality up to 20 days with retention of original fruit colour and taste (Philip and Nair 1999).

\section{Modified and controlled atmosphere (CA storage)}

Modified atmosphere storage is becoming increasingly popular in extending shelf-life of fruits and vegetables. Modified atmosphere with 2-5\% oxygen and 3-8\% carbon dioxide has been shown to extend shelf-life of fruits. Quazi and Freebairn (1970) observed that oxygen negated effects of ethylene and high carbon dioxide concentration delayed climacteric, and low oxygen and high carbon dioxide inhibited ethylene synthesis and thus prolonged storage life. Use of protective coating in addition to modified atmosphere increased shelf-life further (Habibunnisa 1995).

\section{Use of antibiotics and systemic fungicides}

Meredith (1960) reported effectiveness of sodium salicylanilide and Nystatin (Mycostatin) against common diseases of banana. A post inoculation 
dip with Mycostatin at 200-400 ppm controlled wound infection. Anathanarayanan and Seshadri (1965) also recorded effectiveness of Mycostatin as a protectant fungicide, while Tandon et al. (1976) could not get any positive results with Mycostatin (100-400 ppm). Aureofungin is also reported to be effective. Sridhar and Sohi (1974) observed complete control of post-harvest rotting with prophylactic treatment of Aureofungin at $100 \mathrm{ppm}$. 


\section{CHAPTER A}

\section{Citrus (Citrus spp.)}

Citrus-fruits are popular and are extensively grown in tropical and subtropical regions. In India, common citrus fruits are Nagpur mandarin, Kinnow mandarin(Citrus reticulata Blanco), Khasi mandarin, lemon, sweet orange (C.sinensis) and acid lime (C. aurantifolia). India ranks sixth among the citrus-producing countries of the world, and citrus-based fruit industry in India is the third largest after mango and banana. Citrus was grown in 0.45 million ha, and its production was approximately 3.8 million tonnes per annum; with an annual loss of $18-23 \%$ due to post-harvest diseases alone (Naqvi 2001).

Kinnow (Citrus reticulata Blanco) marketing has expanded throughout India and abroad because of its high juice content and attractive fruit colour. Kinnow-fruits contain high levels of vit. C, vit. A, beta carotene (precursor of vit. A), xanthophyll, cryptoxanthin and violaxanthin, which are responsible for orange colour of the rind and juice (Murrata 1997). In general, fruits are stored at a low temperature in January and February to avoid glut in the market. Physiological changes occurring during storage period makes fruits susceptible to fungal infection (Eckert and Ratnayake 1983).

\section{FUNGAL DISEASES}

Penicillium-rots, c.o. Penicillium spp.

Blue mould-rot, $P$. italicum Wehmer

Green mould-rot, $P$. digitatum Sacc.

These are considered as the most important storage rots of citrus, causing considerable damage during transit and storage. In Andhra Pradesh, losses as high as 50\% were reported by Penicillium-rots (Sathyanarayanaswamy and Sreeramulu 1962).

Penicillium- rots are reported from several countries (Bai 1977; Adisa and Fajola 1982; Naqvi 2001; Singh and Thakur 2003). Spores of these fungi are in the atmosphere of the citrus-growing areas, and the initial infection occurs through wounds in the peel. Kaul and Lall (1975) observed entry through stemend region. $P$. digitatum occurs commonly on sweet orange (Citrus sinensis Linn. cv. Sathgudi). P.citrinum (Sadhu et al. 1992) and P. chrysogenum (Verma 
2008) are also reported on citrus-fruits. Fruit decay is determined chiefly by temperature. At $28-30^{\circ} \mathrm{C}$, fruits rot completely within 5-7 days (Philip 2002).

Symptoms : They appear as water-soaked patches. Soon rot advances rapidly and whitish area becomes blue or green due to characteristic mouldy growth (Fig. 4.1). A broad band of white growth is visible on the margin of the lesions. Watery spot size increases under favourable conditions completely covering fruits by fungal growth. On pressing, peel breaks off easily. Endopolygalacturonase, an enzyme, was isolated from grape-fruit ( $C$. paradisi) infected with P.citrinum. This readily degrades pectin and sodium polypectate (NaPP) fractions of fruits (Barmore and Brown 1981). Cell-wall degradation as well as pectin dissolution in mandarin-fruits under pathogenesis by P.digitatum and $P$. italicum was reported from Korea also

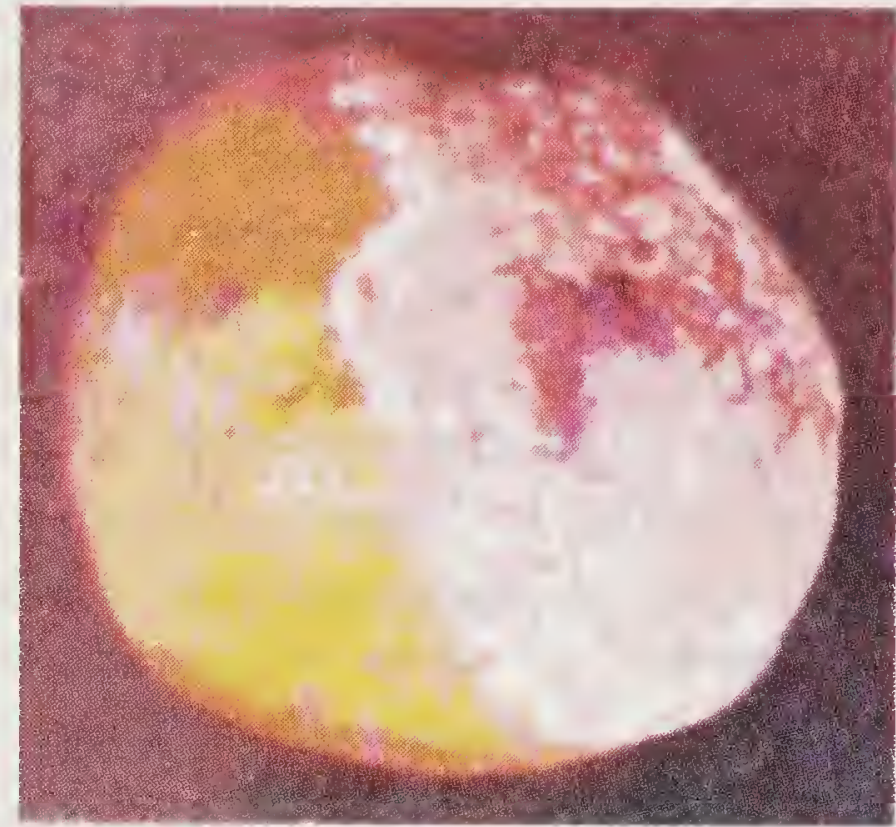

Fig. 4.1. Penicillium-rot on citrus-fruit (Hwang et al. 2002).

Control measures: Use of hot-water. Post-harvest curing of sweet-lime by heat treatment using water at $45^{\circ} \mathrm{C}$ for 5 minutes significantly reduced decay by P.italicum (Mahmoodabadi et al. 2000). Dipping fruits in hot-water at $50^{\circ} \mathrm{C}$ for $2 \mathrm{~min}$. or $60^{\circ} \mathrm{C}$ for 45 seconds was effective in getting acceptable quality of kinnow-fruits with extended storage life up to 90 days (Singh and Thakur 2002). The treatment significantly reduced decay and suppressed green mouldrot, caused by $P$. digitatum.

Use of biphenyl impregnated fruit-wrapper. Fruit wraps or paper sheets impregnated with a heated solution of biphenyl in a mixture of paraffin and mineral oil were placed at the bottom and at the top of the fihre-board cartons. This controlled Penicillium-rot during storage (Eckert 1967).

Use of radiations. Penicillium-rot was delayed up to 90 days of storage in fruits treated with $1.5 \mathrm{Krad}$ gamma radiations. Irradiation benefits in delaying Penicillium-rots during short-term storage.

Use of chemicals. Prior to 1950, borax solution (6-8\%) was used for controlling Penicillium and stem-end rots due to Diplodia and Phomopsis citri. The solution was heated to $43.5^{\circ} \mathrm{C}$, and fruits were dipped for $5 \mathrm{~min}$. In addition to borax, sodium carbonate solution $\left(3-5 \%\right.$ at $\left.38-48^{\circ} \mathrm{C}\right)$ was also used to control P.digitatum in California. Fruit wraps or paper sheets impregnated with heated solution of biphenyl in a mixture of paraffin and mineral oil, placed at the bottom and top of the fibre board cartons (FBC) controlled 
effectively Penicillium-rots (Eckert and Sommer 1967)). Dipping of the fruits in sodium ortho phenyl phenate (SOPP) $2 \%$ is also reported to be effective.

Use of systemic fungicides. Thiabendazole (TBZ) is noted for its effectiveness in controlling blue and green mould rots of citrus (Brown et al. 1967; Harding and Schade 1967; Subramanian et al. 1973,1973 a). TBZ at $0.2 \%$ in wax (Kokkalos 1973) or with flavour seal-wax (Latiff et al. 1975) or in combination with SOPP 1\% (Hall et al. 1978) or dipping of fruits in it, followed by storage in cellophane-lined containers (Farooqui et al. 1978) is effective. Hot-water treatment with TBZ is effective up to 50 days of storage (Morales et al. 1981). Thiophenate methyl $(0.25 \%)$ as a dip is recommended for preventing decay in citrus (Yamada et al. 1992). However, in P. digitatum, thiophenate methyl resistance was reported (Ushiyama 1979; Chander and Thind 1995). Activity of oxidative enzymes was found more in fruits infected by fungicidal resistant strains (Khilare and Gangwane 2002).

Pre-harvest spray of Bavistin (0.3\%), 15 days prior to harvest reduces post- harvest rots due to P.digitatum and $P$. italicum in wax and unwaxed fruits in cold storage (Singh and Thakur 2003).

Pre-inoculation treatments under in-vitro conditions with Thiabendazole, Benomyl and Carbendazim (at $0.05 \%$ ) were effective against green and blue mould-rots (Verma 2008).

Biological control. Use of bark extracts. The antifungal efficacy of the bark extract of Acacia nilotica (5\% aqueous extract) in vivo managed blue mould rot (Penicillium italicum) in mandarin oranges (Tripathy and Dubey 2003).

Use of essential oil. Oil from the epicarp of Citrus sinensis has been recorded as a potential source of natural pesticide, and it exhibited strong fungi toxicity at $0.5 \%$ concentration against P.italicum, A. flavus and A. alternata as a contact toxicant(Shukla et al. 2000). Essential oil of Mentha piperita exhibited maximum efficiency at $1,000 \mathrm{mg} / \mathrm{ml}$. Extracts of Cymbopogon citratus and Cyperus scariousus were also effective (Dhaliwal et al. 2004). Liquid formulations (emulsifiable concentrates) of essential oils of fennel, peppermint and caraway controlled Pencillium-rots as a protective or therapeutic agent (El Tobgy and Mahamoud 2010).

Lac-based formulations inhibited growth of P.italicum during storage. Fruits dipped in a lac-based formulation (stay fresh wax) for 30 seconds, packed in corrugated fibre boxes (CFB- 5 ply) and kept under cool chamber (temperature $5^{\circ} \mathrm{C}$, relative humidity $90-95 \%$ ) showed minimum spoilage and enhanced storage life up to 72 days; fruits showed no shrivelling also (Singh et al. 2008).

Alternaria-rot/core-rot/black-rot, c.o. Alternaria citri Ellis \& N. Pierce

The fungus is widely distributed in all citrus-growing areas (Brown and Mc Cornack 1972; Whiteside 1979; Singh and Thakur 2003). Detection of 
infected fruits is difficult owing to internal rotting that occurs before the appearance of external symptoms.In oranges, grape-fruits and mandarins, infected internal tissues become black due to rotting. Spores gain entry through wounds.

Symptoms : Externally fruits appear healthy and sound. Navel-end showing discolouration was also reported. Apparently sound fruits may show darkened colour. When they are cut open, such fruits may exhibit extensive rotting in the core area, which may be concentrated in the centre or spread length-wise. Presence of olive-brown to black growth is also visible in the hollow space. This type of damage is common in fruits arrived in Thiruvananthapuram markets from Bengaluru and Delhi (Philip 2002).

A.citri infection starts at the stem-end and causes internal black discolouration and maceration of the fruit-core during storage by producing endopolygalacturonase (endo PG). Isshiki et al. (2003) studied fungal colonization and endopolyglacturonase gene expression in interaction of A.citri with citrus-fruits.

The toxigenic behaviour of $A$. alternata isolates has also been reported. The isolates produce tenuazonic acid (TeA) as the major mycotoxin. Alternariol $(\mathrm{AOH})$ and altertoxin ( AT X-1) were also detected (Bamba and Sumbali 2006).

Control measures: Use of fungicides. Karathane (1\%) and Kirti Copper (1\%) as pre-inoculation sprays were effective in checking infection and disease development (Chand et al. 1967).

Biological control. C. sinensis epicarp is a potential source of natural pesticide. The oil contained in it has strong fungitoxicity against $A$. alternata, Aspergillus flavus and P.italicum (Shukla et al. 2000). Acacia nilotica bark (aqueous extract) possessed antifungal activity and inhibited core-rot (Tripathy and Dubey 2003).

Bioagents, Bacillus subtilis, Pseudomonas fluorescens (Pf-1) and yeasts, Debaryomyces hansenii and Sporidiobolus pararoseus all at $10^{9} \mathrm{cfu} / \mathrm{ml}$ were reported to be effective (Sharma et al. 2008).

Anthracnose, c.o. Glomerella cingulata (Ston.) Spauld. \& Schrenk. Condial state: Colletotrichum gloeosporioides (Penz.) Sacc.

This disease has been recorded from all citrus-growing areas. Fruits may be disfigured by 'tearstain' patterns on the peel (Tanaka 1968) or they may show severe rotting with dark, sunken lesions.

Symptoms : They appear as small, brown spots on the rind, which gradually enlarge, depress and coalesce to form large spots, and in the advanced stage of infection, fruits are covered with dark blemishes (Cheriyan 1987).

Control measures : Pre-harvest spraying with Ethephon (250 ppm), 5-7 days before harvest, gives protection against Colletotrichum-rots (Barmore and Brown 1978). 
Washing with water alone reduces anthracnose and stem-end-rot in oranges (Brown 1975). Brown and Barmore (1977) observed promising results against quiescent infections of Colletotrichum by dipping fruits in sodium hypochlorite solution( $2 \%$ ), followed by washing with running tap-water or fumigation with ethylene. Similar results could also be obtained by dipping in bleaching powder (2\% solution), Flit 406 (0.2\%) (Tandon 1961), borax (6-8\%) or thio-urea (4\%) (Srivastava 1968; Mishra and Naik 1984) and boric $\operatorname{acid}(4 \%)$ (Ram and Naidu 1976).

\section{Stem-end-rots, c.o. Botryosphaeria ribis Grossenb. \& Duggar \\ Conidial state : Dothiorella gregaria Sacc. \\ Diaporthe citri Wolf \\ Phomopsis citri Fawcett \\ Physalospora rhodina (Berk. \& Curt.) Cooke}

All the above fungi are widely distributed but their disease symptoms and causal organisms vary depending upon the climate (Brooks 1944). In Japan, Australia and United States, Phomopsis- rot appeared more important (Homma and Yamada 1969; Brown and Albrigo 1972; Singh et al. 1977).

Control measures : Benomyl (500 ppm) is reported to be effective against latent infections of Diplodia and Phomopsis spp. (Gutter and Yanco 1971). Dipping fruits in Benlate $(0.05 \%)$ is effective up to 45 days (Dhuria et al. 1977).

Bark extract of Acacia nilotica was reported effective in inhibiting stemend-rot (Tripathy and Dubey 2003).

\section{Botryodiplodia fruit-rot,}

c.o. Botryodiplodia theobromae Pat./Lasiodiplodia theobromae

$B$. theobromae has been reported as the most important fruit-rot pathogen of Citrus sinensis. It was reported as the predominant disease from Israel and S.W. Nigeria (Zaubermann and Barkai Golan 1975; Adisa and Fajola 1982). And the disease has been reported from India also.

Maximum infection was observed at room temperature $\left(33 \pm 2^{\circ} \mathrm{C}\right)$ under Allahabad conditions (Srivastava and Tandon 1968).

Symptoms : The fungus produces brownish black discolouration on the stemend of the fruit. The lesions later enlarge and cover major portion of the fruitsurface. In advanced stages, greyish mycelia with abundant pycnidial encrustations are noticed on the fruit-surface. The infection usually starts as a circular lesion, which at first is yellow but later turns brown and renders leatheriness to fruit with a strong decaying odour. The fruit rots within 4-6 days. A network of whitish mycelia that later turns dark is observed inside the fruit and also on the surface. Pycnidial encrustations are also noticed abundantly (Adisa and Fajola 1982).

Control measures : The disease could be checked before harvest in the field by the application of copper fungicide $(0.3 \%)$. Benomyl (500 ppm) is effective against latent infections of Diplodia and Phomopsis spp. (Gutter and Yanco 
1971). Dipping of fruits in antibiotics also offers protection. Cheema and Jeyarajan (1971) recorded effectiveness of Aureofungin at $50 \mathrm{ppm}$ against stylar-end-rot of oranges caused by $B$. theobromae.

Low temperature storage at $15^{\circ} \mathrm{C}$ is effective for control of storage-rots (Srivastava and Tandon 1968).

\section{Sour-rot, c.o. Geotrichum candidum Link.}

The disease is especially prevalent after warm-wet seasons, and can cause serious losses.

Symptoms : Water-soaked spots appear on the fruits and the affected tissues become soft. Gradually spots increase in size and result in extensive cracking of the fruit. The lesion surface is covered with slimy off-white spores,and fruittissue beneath the surface breaks down into sour-smelling watery mass (Harding and Savage 1962; Butler et al. 1965; Shankhapal and Hatwalne 1974; Mor et al. 1984; Cheriyan 1987; Naqvi 2001). This fungus survives at 10$35^{\circ} \mathrm{C}$ temperature, and the maximum rotting is observed at $25^{\circ} \mathrm{C}$.

Control measures : The disease is transmitted by fruit-fly Drosophila melanogaster. Fruit- rot of oranges caused by this fungus and others could be controlled successfully with Aureofungin 200 ppm (Shankhapal and Hatwalne 1975).

Latex of Euphorbia hirta (crude extract) is recorded as effective against this fruit-rot. It acts as a repellent( Purnima and Saxena 1990).

The antifungal activity of the bark extract of Acacia nilotica (50\% aqueous extract) is also reported to be effective (Tripathy and Dubey 2003).

\section{Sporotrichum-rot, c.o. Sporotrichum aureum Link.}

Fawcett (1936) reported occurrence of citrus scab due to Sporotrichum citri from Argentina.

Symptoms : Brown-coloured lesions are observed on the fruit surface that later cover fruits in a longitudinal pattern. The fruit becomes soft in advanced stages of infection (Cheriyan 1987).

Control measures : Dipping of fruits in Auroefungin $200 \mathrm{ppm}$ controlled rot up to 49 days under cold storage (Cheriyan 1997).

\section{Aspergillus/black mould-rot, c.o. Aspergillus spp.}

Aspergillus- rot has been reported from most of the citrus-producing areas of the world (Smoot et al. 1971). In India, it was recorded from Uttar Pradesh (Srivastava and Tandon 1969) and Punjab (Garcha and Singh 1980; Singh and Thakur 2003). A. aculatus and A. meleus were reported from Nigeria (Adisa and Fajola 1982).

Symptoms : Aspergillus aculatus lizuka. This fungus produces lightyellow discolouration on the fruit surface. And the rotted area is soft but oozes 
out no watery fluid when pressed. Dark spore masses are noticed inside or on the fruit surface. Whole fruit rots within 8-9 days.

Aspergillus meleus Yukawa. It produces dry-rot. Its infection starts slowly as circular lesions with brownish discolouration, gradually spreading on to the surface of the fruit.

Aspergillus niger Van Tieghm. Water- soaked lesions appear on the fruitsurface. And lesions are soon covered by blackish fungal growth. Internal contents also soften and decay (Philip 2002).

Control measures : Pre-harvest spray of Bavistin (0.3\%), 15 days prior to harvest reduces rot due to $A$. niger in waxed and unwaxed fruits in the cold storage (Singh and Thakur 2003). Systemic fungicides, Thiophenate methyl $(0.25 \%)$ and Borax $6 \%$, were effective against black mould-rot, caused by A.niger (Verma 2008).

\section{Brown-rot/Phytophthora-rot}

Several species of Phytophthora-P. citricola, P. citriphthora, $P$. hibernalis, $P$. nicotianae var. parasitica and P.syringae-are associated with brown-rot.

Symptoms : First, water-soaked spots appear on the peel. Infected fruits give characteristic pungent odour. Under humid conditions (at temperature around $25^{\circ} \mathrm{C}$ and relative humidity above $90 \%$ ), cottony growth of fungus is visible on the peel. Fruits without any apparent symptoms may also produce rotting under storage.

Control measures : The orchards should be kept free of diseases with copper sprays (3: 41/2: 100 Bordeaux mixture). In orchards, where copper damage occurs, spraying with Captan (2g/litre) is recommended (Klotz et al. 1961).

The disease is noticed also on the fallen fruits, lying on the soil. Hence care should be taken to destroy infected fruits. Such fruits should not be used for storage or packing.

\section{Fusarium-rot, c.o. Fusarium spp.}

Several species of Fusarium-F.solani, F. moniliforme, F. oxysporum and F.compactum - are associated with this disease (Cheriyan 1987; Shrivastava et al. 1993). Fusarium-rot is usually considered a minor disease in citrusgrowing areas of South Africa, Israel, Australia (Jofee and Nadelm 1972; Gerlach 1977).

Symptoms : First circular water-soaked lesions appear that later turn lightbrown with fluffy fungal growth over the decayed portions.

Control measures : Dipping fruits in a solution of sodium metabisulphite and salicylic acid (1,000 ppm each) gave complete control of decay (Gaur and Chenulu 1982), and also dipping in Aureofingin (200 ppm) gave good results (Cheriyan, 1987). 
Antifungal activity of bark extract of Acacia nilotica is reported against soft-rots caused by Fusarium moniliforme and Rhizopus stolonifer (Tripathy and Dubey 2003).

\section{Citrus greasy-spot, c.o. Mycosphaerella citri Tilak}

Blemishes caused by the fungus on the rind of the fruit reduce external quality and marketability of the fruit.

One or two copper fungicide applications (0.2\%-0.3\%) before harvesting fruits provide effective control; two sprays gave excellent results (Timmer et al. 2000).

Antifungal activity of bark extract of Acacia nilotica is reported against soft-rots caused by Fusarium moniliforme and Rhizopus stolonifer (Tripathy and Dubey 2003).

Trichoderma-rot, c.o. Trichoderma viride Pers.ex Fr.

Trichoderma-rot is an important cause of losses in South Africa (Pienaar, 1969). It was also recorded from the USSR, USA, China, Israel, India. Snowdon (1990) observed rot on the mandarins and grapefruits in the UK.

Symptoms : Infected peels remain pliable,and become dark- brown eventually. Veins on the inner surface of the peel turn brown. But flesh beneath remains unchanged (Kanaujia 1979). Water-soaked lesions with greenish-white growth are also observed on the peel (Philip 2002).

Control measures : All measures detailed under the Post-harvest management are applicable to this disease.

\section{Fruit-rot/soft-rot, c.o. Aureobasidium pullulans (de Bary) Arnaud}

Panwar and Vyas (1973) reported the disease on Citrus reticulata Blanco. Babu et al. (1982) observed water-soaked areas on the fruit-surface, which increased centrifugally with age. Infected tissues turn soft with a pinkish tinge and spread to adjacent areas. Then infected tissues get separated from healthy tissues.

Post-harvest treatment with any common fungicide, followed by waxcoating is effective in controlling the disease (Naqvi 2001).

OTHER MINOR DISEASES AND THEIR CAUSAL ORGANISMS

\begin{tabular}{lll}
\hline Disease & \multicolumn{1}{c}{ Causal organism } & \multicolumn{1}{c}{ Authority } \\
\hline Fruit-rots & Hendersonula toruloides & Khan, 1954 \\
& $\begin{array}{l}\text { Oospora citri auranti } \\
\text { Rhizoctonia solani }\end{array}$ & Moreau, 1954 \\
& Choanephora trispora & Adisa and Fajola, 1982 \\
& Ceratocystis fimbriata & Singh and Chaudhari, 1974 \\
Soft-rot & Cladosporium & Gaur and Chenulu, 1981 \\
Soft-rot & sphaerospermum & \\
& Sclerotium rolfsii & Malik and Bhargava, 1978
\end{tabular}




\begin{tabular}{|c|c|c|}
\hline Disease & Causal organism & Authority \\
\hline Core-rot & Rhizopus stolonifier & $\begin{array}{l}\text { Garcha and Singh, 1980; } \\
\text { Singh and Thakur, } 2003\end{array}$ \\
\hline Fluffy white-rot & Acremonium cymosum & Dhingra et al., 1980 \\
\hline Dirty core-rot & Absidia corymbifera ? & \\
\hline Polar-rot & Botryosphaeria ribis\} & Mandal and Dasgupta, 1981 \\
\hline Greasy-spot and & Mycosphaerella citri & \\
\hline Rind-blotch & & \\
\hline Black-rot & Pestalotiopsis versicolor & Gaur and Chenulu, 1982 \\
\hline Black encrustation & $\begin{array}{l}\text { Thielaviopsis state of } \\
\text { Ceratocystis paradoxa }\end{array}$ & \\
\hline Grey mould-rot & Botrytis cinerea & \\
\hline Septoria-rot & Septoria spp. & \\
\hline Black-rot & Guignardia citricarpa & \\
\hline Cottony-rot & Sclerotinia minor & \\
\hline
\end{tabular}

\section{BACTERIAL DISEASES}

Citrus canker, c.o. Xanthomonas campestris pv. citri

It originated from Asia and was observed in Florida in 1912. In India, it is endemic and occurs in all citrus-growing areas. Acid lime canker is one of the major diseases in acid-lime cultivation in Vidarbha region of Maharashtra.

Symptoms : Lesions on the fruits are rough and corky. Sometimes several lesions may coalesce and form larger lesions. They appear as rough or corrugated pin-head like rusty spots on the peel. And sometimes, the spots may coalesce and form large irregular patches. Symptoms are noticed on leaves, twigs, petioles, branches, thorns, fruit-stalks and fruits.

Due to infection, reducing and non-reducing sugars and vit. C (ascorbic acid) get reduced, and citric-acid content increases in the juice (Vidhyasekaran and Durairaj 1971).

Control measures: Pre-harvest treatments. The canker is carried from the field and continues under storage. Hence, keeping plantation free of the disease is utmost importance. Spraying trees bearing fruits with streptomycin (500$1,000 \mathrm{ppm}$ ) at 15 days interval proved effective (Rangaswamy et al. 1959 a, b). The disease can also be controlled by spraying on trees streptocycline (100 $\mathrm{ppm})+$ copper oxychloride $(0.1 \%)$ at an interval of 7 or 15 days during winter, summer and monsoon flushes (Kale et al. 1994; Gaur and Sharma 2008).

Foliar spray of streptocycline $(100 \mathrm{ppm})$ along with copper oxide $0.2 \%$ proved effective in controlling citrus canker. Streptocycline $100 \mathrm{ppm}$ along with Carbendazim 0.1\% also proved effective (Gaur and Sharma 2010).

Biological control. Neem-cake solution (neem-cake soaked in water for 7 days) sprayed without filteration is effective in reducing disease incidence and 
increasing general plant vigour (Vaheeduddin et al. 1959). Foliar spray of garlic + green chilli extract also reduced disease incidence (Gaur and Sharma 2010).

Spraying of $0.2 \%$ talc-based P. fluorescens $\left(1 \times 10^{9} \mathrm{cfu} / \mathrm{g}\right)$ was found highly effective(Gaur and Sharma 2010).

\section{POST-HARVEST DISEASES MANAGEMENT}

\section{Pre-harvest treatments}

Orchard sanitation and selection of healthy fruits for storage are utmost important. High inoculum of fungal pathogens and non- scientific methods of harvesting, packing, transporting and inadequate storage are main reasons for encountering losses that can be avoided by following practices.

Protective pre-harvest sprays prevent Penicillium-rot, stem-end-rot (Lasiodiplodia theobromae) and Phomopsis-rot in orange fruits (Brown and Albrigo 1970). Thiophenate methyl was effective when applied to grapefruits(Citrus paradisi), 47 days prior to harvest at $0.5 \mathrm{~g}$ / litre (Timmer 1973): Kuramoto and Yamada (1976) observed DF- 125 effective against Benomyl and Thiophenate methyl resistant and susceptible strains, respectively. Preharvest spray with Bavistin (0.3\%), 15 days before harvest reduced postharvest rot in waxed as well as unwaxed fruits under cold storage ( Singh and Thakur 2003). Three sprays of Carbendazim (0.1\%) at 15 days interval prior to harvest reduced $70 \%$ decay and subsequent treatment on packing reduced decay up to $80 \%$ for three weeks under ambient conditions. And its residue level was below permissible levels (Naqvi 2004).

Pre-harvest spray with Prochloraz (45\% EC 0.10\%) at monthly intervals (4 times) after flowering, followed by Carbendazim (0.15\%) was found effective in reducing post-harvest diseases during storage (Sharma et al. 2010).

\section{Cleanliness in packing houses}

Citrus-packing houses are usually fumigated daily by atomizing with a solution of 1-3\% formaldehyde in the atmosphere. Fruit-conveying and treating equipments are also to be disinfected with quarternary ammonium compounds, hypochlorite, sodium o-phenyl phenate or formaldehyde. This helps in reducing post-harvest rots.

\section{Use of hot-water}

Thiabendazole (TBZ $0.1 \%$ ) with hot-water is effective up to 50 days of storage against common storage rots (Morales et al. 1981).

Hot-water treatment, hot-water rinsing and hot-water brushing are generally practised for controlling fruit-rots( see hot-water treatment under Penicillium-rots). 


\section{Storage under refrigeration}

Most of the citrus varieties are sensitive to chilling and hence cannot be in storgae at low temperature, as fruits are susceptible to physical stress. Under refrigeration $\left(8-10^{\circ} \mathrm{C}\right)$, fruits retain their natural taste up to 30 days, and thereafter on continued storage show brittleness (Cheriyan 1987 ; Philip and Cheriyan 1995).

\section{Wax-coating and polythene packing}

Coating fruits with wax or fungicidal wax (6\%) (Jawanda et al. 1977, 1978; Mann and Randhawa, 1978) or wax emulsions (6\%) with 2,4-D or 2,4,5-T(100 ppm) offer protection (Sohi and Gupta, 1977). Polythene packing along with waxing (Mann and Sandhanwalia 1977) and storage in perforated polythene bags (200 microns) are also effective (Mohan and Sharma 1977; Jawanda et al. 1977, 1978). Wax-coating of fruits prior to harvest or after harvest with fungicides was also reported (Naqvi 2001; Singh and Thakur 2003).

\section{Use of wrappers}

Waxing, followed by storage in DPA wrappers and wrapping in newspapers (Jawanda et al. 1977, 1978) gave protection. Antifungal dips in along with lining materials like newspaper, tissue paper, wax paper, cellophane paper, polythene films (Farooqi et al. 1978) also proved effective. Effect of waxing and of wrapping in low-density polyethylene film (LDPE), followed by package in corrugated fibre boxes (CFB) exhibited low losses through decay for 30 days.Decay could also be minimized by storage at ambient conditions (Sharma et al. 2008).

\section{Use of common chemicals}

Eckert and Sommer (1967) reviewed methods of chemical control. Storage of fruits after cleaning and washing with sodium ortho-phenyl phenate (SOPP) $1 \%$ or calcium or sodium hypochlorite $2 \%$ or fumigation with ammonia (100$150 \mathrm{ppm}$ ) was found effective in reducing post-harvest losses (Mukherjee 1970; Mukherjee and Singh 1977). Fumigation impacted development of storagerots. The packing houses are fumigated daily by atomizing with a solution of $1-3 \%$ formaldehyde into the atmosphere. Fruit conveying belts and treating equipment are also disinfected with quarternary ammonium compounds, hypochlorite sodium ortho-phenyl phenate (SOPP).

Dipping fully mature fruits in 2-4-D (100, 250, 500ppm) or gibberllic acid $(50,100,200 \mathrm{ppm})$ solutions and ethrel $(100,500 \mathrm{ppm})$ also improved fruit appearance and shelf-life. Fruits could be marketed even after 47 days (Saraswathy and Azakiamanavalan 1997).

\section{Non-systemic and systemic fungicides}

Dipping in Dithane M-45 (0.2\%) as well as in Captan or in Difolatan (500 ppm), followed by storage at low temperature (Adisa and Fajola 1982) protected fruits. 
Systemic fungicides show improved distribution and penetration, and thus offer better protection over other groups of fungicides. They suffer less weathering, and consequently control disease better. Bavistin and Benomyl (1,000 ppm each) are also extensively utilized for post-harvest management (Ram and Naidu 1976; Kumbhare and Chaudhari, 1979; Gupta et al. 1980; Gaur and Chenulu 1982). Ethrel and Bavistin combined controlled storage degreening (Reddy and Shanker 1983). Jagannathan and Sampath (1995) observed superiority of Carbendazim (500 ppm) to Benomyl and TBZ. Philip and Cheriyan (1995) observed Aureofungin (200 ppm) to be effective against common fungal rots, and storage life was also enhanced by 49 days with it without any residual toxicity.

In general, TBZ and Benomyl protect fruits against post-harvest infections. But this is to be considered seriously as they pose health hazards to human-beings. Zahida and Masud (2002) monitored fungicides in samples collected from markets of Karachi, Pakistan, and observed residue levels above permissible levels in more than $50 \%$ of samples.

\section{Biological control}

Consumers demand for pesticide-free food and development of pathogenic strains resistant to currently used fungicides necessitate development of alternative technologies for controlling post-harvest damage to fruits and vegetables through bioagents. These include the following.

Use of homeopathic drugs. These drugs of plant origin when applied to harvested fruits of citrus, mango and guava are reported to prevent decay and enhance storage life (Khanna and Chandra 1976).

Use of plant extracts. Babu and Reddy (1986) showed effectiveness of leaf extracts of Eucalyptus globulosa, Punicum granatum, Lawsonia inermis and Datura stramonium in checking fruit-rot of lemons.

Biological control with yeasts. Yeast antagonist Candida oleophila was reported to reduce decay in oranges and grapes (Porat et al. 2002). This is included along with hot-water rinsing, hot-water brushing and sodium carbonate application.

Combination of Pantoea agglomerans (CPA-2) and sodium bicarbonate proved effective against common storage disease (Teixido et al. 2001).

\section{Packing and storage}

Harvested fruits are subjected to a variety of injuries that predispose them to various fungal rots till they reach consumers through a long marketing chain, and thus causes huge losses in value and volume. For reducing these losses, knowledge of packing systems and nature of physical damage caused during post-harvest journey from orchard to ultimate consumer are essential. 
Packing systems and nature of physical damage to Citrus reticulata and C. aurantifolia were studied by Verma and Tikoo (2004). Damage usually occurs due to cuts on the fruit-surface, compression, overfilling and overstacking of bags as well as due to vibration bruises that occur in transit and storage. Injuries predispose fruits to fungal infections, leading to fruit-rots. Infections and cullage losses are direct consequences of rough handling and unhygienic storage. The spectrum of post-harvest pathogens include blue-andgreen mould-rot (P.italicum, $P$. digitatum P. chrysogenum), Aspergillus-rots (Aspergillus flavus, A. fumigatus and A. niger), core-rot (Alternaria alternata, Absidia corymbifera), soft-rot (Fusarium monliliforme, Rhizoctonia stolonifer), stem-end-rot ( $B$. theobromae) and sour-rot ( $G$. candidum). Penicillium spp. inflicted major fruit losses during winter and Aspergillus spp. were dominant during summer and monsoon months.

Packing materials. Packing of injured fruits without apparent symptoms (mechanical or frost) is bound to spread infection to healthy fruits. Singh and Jain (2004) assessed losses in long distance marketing from Punjab to Rajasthan of fruits packed in corrugated fibre boxes (CFB) and wooden boxes. Storage losses were lesser in wooden boxes $(22.9 \%)$ compared to CFB packing (31\%). Alternaria alternata caused maximum spoilage in $\mathrm{CFB}$ packing, followed by $P$. digitatum and P.italicum.

\section{Evaporative cool chamber}

Evaporative cool chamber $2.28 \mathrm{~m} \times 1.82 \mathrm{~m} \times 2.133 \mathrm{~m}(7.5$ feet length $\times 6$ feet width $\times 7$ feet inside height with temperature at 13 to $14^{\circ} \mathrm{C}$, relative humidity at $95-100 \%$ and with drip system for continuous watering and fan for air movement) can store fruits up to 25 days (Anon. 2005).

\section{Vacuum packing}

Vacuum packing has been reported as a feasible technique for storage of sweet oranges. Vacuum packed polyethylene bags in refrigeration retained quality of fruits to a great extent (Dawn et al. 2007).

Procedure for the storage of mandarin oranges has been standardized

This includes pre-harvest sprays, maturity standards, post-harvest treatments (application of Bavistin), degreening process with 5-10 ppm ethylene, followed by chlorine wash, post-harvest fungicidal wax coating (Stafresh $45 \%$ with $1,000 \mathrm{ppm} \mathrm{TBZ}$ ), pre-cooling at $6-7^{\circ} \mathrm{C}$ with $90-95 \% \mathrm{RH}$ and packing in vented polyethylene-lined CFB boxes, wrapping fruits in cryovac and polyethylene-heat shrinkable films, storage for long-term use and refrigerated storage at $6-7^{\circ} \mathrm{C}$ and $90-95 \% \mathrm{RH}$ and use of cool chamber. An evaporative cool chamber for storing fruits $\left(13-14^{\circ} \mathrm{C}\right.$, at $\left.95-100 \% \mathrm{RH}\right)$ up to 25 days is also included as an ideal step (Anon. 2005). 


\section{CHAPTER 5 \\ Emblica/Gooseberry/Aonla (Phyllanthus emblica L.)}

Its fruits contain proteins, fats, carbohydrates, fibres, tannins, and are rich source of iron, calcium, phosphorus and vitamins, especially vitamin C, vitamin $\mathrm{B}_{1}$ and nicotinic acid (Singh et al. 1993). Medicinal properties of the fruits are also very well known.

\section{FUNGAL DISEASES}

Dry surface-rot, c.o. Aspergillus niger Van Tieghm., A. aculeatus lizuka

The disease was reported from Uttar Pradesh (Srivastava et al. 1964), Maharashtra (Rao, 1966), Bihar (Jamaluddin and Tandon 1975), West Bengal (Dasgupta and Mandal, 1989), Sagar (Chopra et al. 1993) and Kerala (Philip 1998), and caused severe losses in fruit yield and quality.

Symptoms : The infection mostly initiates on the injured fruits as soft minute, water-soaked, light-brown spots that turn into an oblongly depressed area of about $1-2 \mathrm{~cm}$ in diameter. In advanced stages, mesocarp gets easily separated from the skin. Under moist conditions, fruit surface is covered with smooth, black or snuffy condiophore heads, depending on the involved organisms. Rot due to A. niger is common and spreads quickly. Maximum diseases development occurs at $28 \pm 1{ }^{\circ} \mathrm{C}$. Aflatoxin production $\left(B_{2}\right.$ and $\left.G_{1}\right)$ was also reported (Nallathambi et al. 2010).

Control measures : Fruit-rot causes severe losses in yield. Hot-water treatment for $10 \mathrm{~min} .\left(50 \pm 1^{\circ} \mathrm{C}\right)$ for three days is effective. Dipping fruits in Carbendazim $(0.1 \%)$ offers protection. Food preservatives like potassium metabisulphite and sodium benzoate are also reported to be effective in preand post-inoculation treatments. Carbendazim + Mancozeb (Sixer at 1,000 ppm) inhibited the rot (Patel et al. 2008).

The extract of Azadirachta indica was also found effective (Yadav et al. 2007).

Fruit-rot, c.o. Colletotrichum gloeosporioides Penz.

A severe pre-and post-harvest fruit-rot was recorded from Andhra Pradesh 
(Wadia et al. 1984). Symptoms appear as isolated brown spots scattered over the fruit-surface, which coalesce to form lesions of $0.3-0.8 \mathrm{~cm}$ in diameter. A dark band demarcates infected region, and lesions turn hard. As the disease advances, pink spore masses appear over lesions. Common forest fruit- tree Calophyllum inophyllum is highly susceptible to this disease. Fruits of $C$. inophyllum, though economically unimportant, serve as a potential reservoir for fruit-rot organism.

\section{Mouldy brown-rot, c.o. Penicillium spp.}

Species of Penicillium - P.islandicum, P. corymbiferum, P.funiculosum, $P$. oxalicum have been reported from various states of India.

Symptoms appear on the intact fruits kept for 6-7 days under the ordinary storage. Colour turns orange, yellow, and finally fruit rots. Skin gets easily slipped off from the internal contents. By the time, scattered fungal growth in the form of pimple-like spots can be noticed allover the fruit-surface (Fig. 5.1). This is followed by complete rotting.

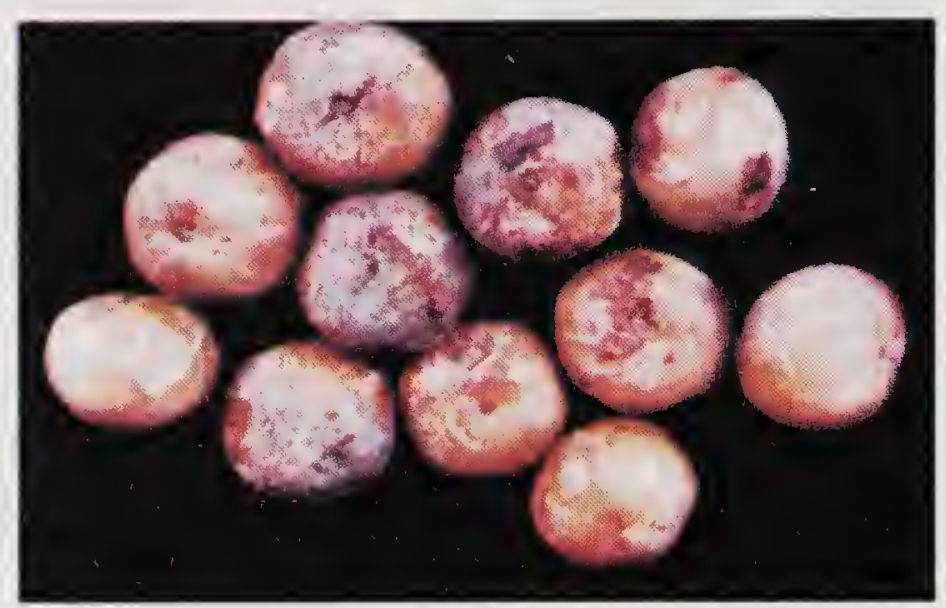

Fig. 5.1. Penicillium-rot on aonla

Fruit-rot disease of E. myriabolam due to P. funiculosum was also reported from the markets of Tirupati (Andhra Pradesh). Symptoms appear as brown necrotic spots ranging in size up to one $\mathrm{cm}$. Mature lesions are depressed, dark-brown and occasionally show concentric zones. In severe cases, lesions coalesce and give fruits a mummified appearance. This fungus also induces rotting in chilli, brinjal, clusterbean, carrot, beetroot, raddish and chayotes (Subrahmanyam and Sarma 1974).

\section{Wrinkled-rot, c.o. Phomopsis phyllanthii Punith.}

This disease was reported from Uttar Pradesh (Bihari Lal et al.1982) and from West Bengal (Dasgupta and Mandal 1989).Rotting starts as discrete water-soaked small areas on any part of the fruit surface. Infected area gradually enlarges and turns depressed and yellowish brown with wrinkled skin. Under humid conditions, mycelial growth is noticed, and rotting becomes fast. Numerous pycnidia can be noticed on the rotten fruits.

\section{Fruit-rot, c.o. Phoma putaminum Speg.}

The disease was reported from several states of India (Jamaluddin, 1975; Pandey et al. 1980). The rot starts as a small pinkish-brown necrotic spot that extends towards both the ends and gives an eye-shaped appearance. In severe cases, lesions coalesce to bigger pustules. Mature lesions are dark brown in colour, and severely infected fruits show wrinkling. Soon underlying tissues get rotten and the fruit becomes soft. 
Brown-rot, c.o. Pestalotiopsis cruenta (Syd.) Steyaert

The disease was reported from Uttar Pradesh (Tandon, and Srivasava 1964). Infection starts as brownish discolouration on the fruits that later develops into characteristic spots. Well-developed spots mummify with a deepbrown centre and an irregular light-brown outer rim. Fluffy fungal aerial growth can be noticed on the infected region with a dry dark-brown discolouration underneath.

Soft-rot, c.o. Syncephalastrum racemosum (Cohn) Yamamoto

The disease was reported from Lucknow. Numerous minute, brown necrotic lesions with white mycelial growth surrounded by water-soaked tissues are noticed on the fruit-surface. The fungus exhibits strong cellulolytic activity (Garg and Ompraksh 2004). 


\section{CHAPTER 6}

\section{Grape (Vitis vinifera L.)}

It is one of the oldest cultivated plants. Its fruit is smooth skinned, juicy, greenish-white to deep-red or purple coloured. It is rich in minerals (potassium, sodium, phosphorus, calcium, magnesium, iron and zinc) and vitamins (vit. $\mathrm{C}$, vit. $\mathrm{B}$, vit. A, folic acid and niacin).

\section{FUNGAL DISEASES}

Grey mould-rot, c.o. Botrytis cinerea Pers.

Among the post-harvest diseases, this is considered to be the most important one. The disease occurs in the entire grape-growing areas of the world, and is considered as the principal cause of spoilage of grapes under storage. The fungus is a nuisance because of its rapid growth rate and ability to spread at cold temperature $\left(0-5^{\circ} \mathrm{C}\right)$ (Harvey and Pentzer 1960).

Grey mould causes both pre-mature and post-harvest decay of tablegrapes. Symptoms are prominent on the berries. The berries are resistant to infection when immature, but become susceptible on maturity. Conidia dispersed on the bunches reside superficially at the berry-pedicel attachment zone and cause bunch-rot during favourable climatic conditions.Nelson (1951) recorded effect of humidity on the infection of table-grapes.

Symptoms : In the early stages, tissues beneath the peel are affected and the pulp gets loosened from the peel. Later fungus advances into inner pulp and converts it into a soft watery mass of decayed tissues contained in a slightly intact brown peel. In the moist environment, pathogen sporulates on the peel and produces typical, powdery, greyish growth. Affected fruits shrivel and turn dark brown. The fungus invades stigma and style and become latent (Mc Cellan and Hewitt 1973; Nair 1985). In a compact bunch, inside fruits may split during growth. Infection of such fruits results in bunch-rot. Even a single infected berry may cause 'nest rot' in transit and storage. Uncontrolled infection from a single berry can spread to an entire packet of grape-berries. Mould incidence on grapes stored at $0^{\circ} \mathrm{C}$ is dependent on the harvest time, and is the highest when fruits are picked after rains.

Studies indicate that polysaccharide- and pectin-degrading enzymes are secreted by the pathogen during pathogenesis. Polysaccharides include high 
molecular weight fractions composed of glucose units. Botrytis-rot also causes sharp reduction in the quantity of aromatic substances responsible for characteristic flavour of grapes. Grape cluster architecture determines susceptibility of berries to infection (Vail and Marois 1991). The cultivars with tight clusters are severely affected by bunch-rot in the field.

Control measures : Klerk (1990) outlined disease-management programme. This includes treatments to be carried out during winter/growing seasons, summer foliage management including fertilizer addition, irrigation and thinning of branches, harvesting procedures and techniques of storage and packing.

Pre-harvest treatments. Pre-harvest infection can be controlled by three applications of Captan $(0.25 \%)$ at monthly intervals before the rainfall (Harvey 1959). Broome et al. (1995) developed a schedule for Botrytis bunch-rot. This includes spraying of Captan $(3.2 \mathrm{~kg} / \mathrm{ha}$ ai) or Vinclozolin (1 kg/ ha ai) at late bloom, cluster thinning in addition to pre-harvest spray plus additional sprays after major rains. The spray schedule reduced post-harvest disease significantly.

The fact that $B$. cinerea spores can establish as latent infection in the flowers, a shift in the schedule of plant-protection operations was made and that led to inclusion of bloom sprays (Nair 1990). Latent infection by $B$. cinerea in grape pedicels and subsequent harvest decay was well established (Holz et al. 1997).

Allan et al. (1998) have recorded the effect of Fenhexamid marketed under the trade name 'Elevate' for application prior to disease establishment as a protectant fungicide with excellent plant compatability. Elevate can be applied three times before harvest. This inhibits germ-tube formation and mycelial growth in susceptible varieties.

Post-harvest management. Sulphur dioxide fumigation. Generally Botrytis-rot is controlled in the storehouses with sulphur-dioxide fumigation. But control is reported with the reduced levels of $\mathrm{SO}_{2} ; 200$ ppm $\mathrm{SO}_{2}$ controlled development and spread of disease when applied three times a week as compared to the standard practice of using 2,500 ppm applied every seven days (Marios et al. 1986). This treatment reduced bleaching of berries.

During initial stages of storage, forced air cooling, followed by 2-6 hours long weekly fumigation is usually practised during cold storage (Luvis et al. 1992). In export package, $\mathrm{SO}_{2}$-generating sheets, which continuously emit gas within the package, are used (Adaskaveg et al. 2002; Palou et al. 2002). In Israel, use of sulphur pills in unventilated containers or introduction of gas through a tube into the containers was also practised as an alternative method (Crisosto and Smilanick 2002).

Effect of radiations. A dose of 200 Krad delays disease development of Botrytis-rot. But irradiated grapes developed severe off-flavours after a few weeks in cold storage (Eckert and Sommer 1967). 
Biological control. Botrytis-rot is controlled with an antagonistic fungus Trichoderma harzianum and a bacteria (Ferreiera 1990). Kohl and Malhoek (2002) recorded Ulocladium atrum as a promising control agent for this disease in grape and strawberry. Yeast strain ID 244 of Candida oleophila has been recorded effective against Botrytis-rot of stored grapes cv. Ruby Seedless (ElNeshawy et al. 2003). Bio-fumigation with Muscador albus, a fungus isolated from the cinnamon-tree in Honduras, producing volatiles (a mixture of low molecular weight compounds) that are biocidal or biostatic to a broad variety of fungi B. cinerea, Geotrichum spp., Monilinia fructicola, Penicillium digitatum and $P$. expansum, has shown promise (Gabler et al. 2006).

\section{Blue mould-rot, c.o. Penicillium expansum (Soto et al. 1973) \\ P. citrinum (Tandon et al. 1975) \\ P. frequentans (Mandal and Dasgupta 1981) \\ P. chrysogenum Thom (Singh and Kainsa 1983) \\ P. canescens (Sharma and Vir 1985 a) \\ $P$. aurantiogriseum (Shrivastava et al. 1993)}

Symptoms : Infection originates from the weak pedicel-end or around any injury as a water-soaked area, which becomes brownish and get covered with a bluish-green growth with a characteristic smell. It progresses slowly during winter. Injuries predispose grape-berries to infection either before or after harvest. The mould spreads through contact and develops soft-rot slowly under refrigeration.

Control measures : Treatment with Difolatan (0.25\%), Benomyl (500ppm) and Carbendazim $(0.1 \%)$ as suspension drips for $1 / 2$ to $1 \mathrm{~min}$. are effective in enhancing shelf-life by checking storage-rot caused by $P$. canescens (Sharma and Vir 1984, 1985). Acetic acid fumigation is effective in controlling decay and berry shatter (Sholberg et al. 1996).

Studies from Italy have shown effects of spraying or immersion in yeast 5A (Pichia gulliermondii) in improving storage as compared to the treatment with yeast 'Aspire'(Candida oleophila). Thiabendazole at $0.1-1.2 \mathrm{~g} / \mathrm{litre}$, followed by treatment with 'Aspire' was promising (Arras et al. 2001).

Black-mould (Snuffy mould), c.o. Aspergillus spp.
A. carbonarius
Gupta, 1956
A. tenuis
A. luchuensis
A. foetidus
Chahal and Malhi, 1969
A. niger Van Tieghem.
Bhargava et al., 1976
A.rugulosus (Thom. \& Raper) | Singh and Kainsa, 1983
A. terrueus Thom.
A. aculeatus
Jarvis \& Traquair, 1984
A.flavus, A.quadrileneatus,
A. nidulans and $A$.variecolor 
It is considered as one of the worst types of rots on grapes. The disease occurs throughout the year but causes considerable damage only during summer months. The disease was reported from Uttar Pradesh, West Bengal and Meghalaya (Bhargava et al. 1976; Dasgupta and Mandal 1989).

Symptoms : They appear as brownish-rot at the stalk-end. Affected fruits fall off from the bunch. Water-soaked areas develop around the infected portion. White mycelial growth is visible at the centre. Later black conidial heads appear profusely on the lesions. The affected tissues become pulpy, shrunken and emit fermented odour. Spores are liberated easily when mature, resulting in soot-like deposits on the adjacent berries.

Control measures : Rotting due to A.niger, A.flavus, A.quadrileneatus, A. nidulans and A.variecolor can be controlled by pre-and and post-harvest dipping in antibiotic Aureofungin 0.05\% (Prasad and Bilgrami, 1975) or by pre-harvest spraying with 2,6-dichloro-4-nitroaniline (DCNA) and Captan at $0.2 \%$ concentration (Subramanian et al. 1973). Grape bunches dipped in Captan suspension $(0.2 \%)$ for 10 minutes (Tandon et al. 1975) and packed with diphenyl (1-2g/3 kg packet) (Singh et al. 1985) were protected. Stable bleaching powder $(6 \%)$ is also used as a protectant.

Application of growth retardant CC (Chlormequat) 2,000 ppm applied at the second rapid growth stage of berry development helps in controlling storage rots associated with A.niger, A.flavus and Penicillium sp. and due to B.cinerea (Ladiniya et al. 1990). Pre-harvest application of growth regulators, $\mathrm{NAA}(100$ or $150 \mathrm{ppm}), \mathrm{GA}_{3}(50 \mathrm{ppm})$ and $\mathrm{CaNO}_{3}(0.75 \%)$, reduced spoilage during storage (Kumar and Gupta 1990).

Post-harvest treatment with Carbendazim $(0.1 \%)$ or Thiabendazole $(0.2 \%)$ checked infection by A.niger and enhanced shelf-life. Acetaldehyde vapours $(0.5 \%)$ were effective in controlling rot caused by black mould, and in improving shelf-life of stored grapes (Avissar and Pesis 1991).

In mixed infections of A.niger and B.theobromae, Bavistin $(0.1 \%)+$ potassium metabisulphite $(5 \%)$ offered better control than either used alone (Mandal and Dasgupta 1983,1984).

Soft-rot, c.o. Rhizopus stolonifer (Ehrenb.) Vuill.

$R$. oryzae Went \& Prinsen Geerligs

Mucor circinelloides Van Tieghem

(Shrivastava et al. 1993)

This is one of the most serious diseases of grapes, and was reported from Uttar Pradesh (Tandon 1968) and West Bengal (Mandal and Dasgupta 1981). Singh and Kainsa (1983) observed decay in packing due to R.oryzae. Rhizopus $\mathrm{sp}$. has been recorded as a serious problem in storage at ambient temperatures (Sawant and Sawant 2001).

Symptoms : Infection appears as soft water-soaked areas, and coarse white mould-strands become visible to naked eye. Smooth, spherical spore-heads 
(sporangia) are at first white and turn black later. Air currents spread spores. Infection occurs before, during and after the harvest. Primary infection usually occurs through injury (Barbetti 1980). In exuded juice, fungus enters through into the intact peel of mature berries. Once established, it spreads to adjacent healthy berries, and often forms 'nests' under warm humid conditions.

Optimum growth temperature lies between 30 and $35^{\circ} \mathrm{C}$ for R.oryzae and 20-25 ${ }^{\circ} \mathrm{C}$ for R.stolonifer (Snowdon 1990).

Control measures : Avissar and Pesis (1991) reported effectiveness of acetaldehyde vapours $(0.5 \%)$ in improving shelf-life of stored grapes.

Biological control. Detached grapes were immersed in aqueous suspension of yeast cells (Kloeckera apiculata and Candida guilliermondii) $\left(5 \times 10^{8} \mathrm{cfu}\right.$ / $\mathrm{ml}$ ), and were taken out and spray inoculated with $10^{3}$ sporangiospores per millilitre of $R$. stolonifer and incubated. Both yeast strains were effective in reducing post-harvest decay of grapes caused by R. stolonifer (McLaughlin et al. 1992). The enhanced effect was noticed when yeast strain was applied with an aqueous suspension of calcium chloride $\left(10^{8} \mathrm{cfu} / \mathrm{ml}\right.$ in $\left.2 \% \mathrm{CaCl}_{2}\right)$.

\section{Brown discolouration, c.o. Alternaria alternata (Fr.) Keissler Stemphylium sp.}

The disease was reported from Andhra Pradesh (Ratnam and Nema 1967)and Maharashtra (Sawant and Sawant 2001). It is incited by other species of Alternaria also.

Symptoms : The disease is characterized by localized tan to dark-brown decayed areas on the stem-end or an any part of the berry. A dry brown-rot was described from Venezuela (Diaz Polanco and Bastida 1971). The fungus penetrates direct into sound grapes. Symptoms were found prominent on Anab-e-Shahi (Philip 2002). Circular brown lesions with dark margin are visible on the peel. In advanced stages, inside pulp becomes soft and decayed. Due to stem-end infection, fruits get easily separated from the cluster.

Control measures: Pre-harvest application of fungicides. Pre-harvest spray of Benomyl (500ppm) two weeks before harvest reduces post-harvest rot in storage.

Post-harvest treatments. Sulphur dioxide fumigation. The disease can be checked in by fumigation with sulphur dioxide (200 ppm) in a humid atmosphere (Couey 1965).

Granules of disodium sulphite are also used for fumigation. They $(1 \mathrm{~g} / \mathrm{kg}$ of fruits) absorb moisture released by fruits and protect them from fungal-rot up to 50 days. But this causes bleaching or browning in fruits Release of $\mathrm{SO}_{2}$ causes browning of fruits due to $\mathrm{SO}_{2}$ toxicity.

Use of antibiotics and weedicides. Dipping bunches in Aureofungin $500 \mathrm{ppm}$ or Panactin $500 \mathrm{ppm}$ or 2, 4-D $500 \mathrm{ppm}$ was effective against 
Alternaria-rot (Sharma and Vir 1985). Acetaldehyde vapours $(0.5 \%)$ are also effective (Avissar and Pesis 1991; Swarta and Holz 1991).

Biological control. Dipping bunches in a spore suspension of Trichoderma, 20 days before the harvest reduced storage-rot and enhanced shelf-life under in-vitro studies (Sawant and Sawant 2001).

\section{Cladosporium-rot (Green ball-rot), c.o. Cladosporium spp.}

Jamaluddin (1977) recorded C.tenuissimum Cooke in storage and transit from Allahabad. This is generally considered a minor disease. But Alternaria spp. and Cladosporium spp. are reported as major fungi associated with postharvest rot of fruits in cold storage in Maharashtra (Sawant and Sawant 2001). $C$. oxysporum and $C$. herbarum were also reported.

Primary infection occurs before harvest. The disease appears on ripe berries as sharply delimited dark spots with a greenish growth of mycelia. The spore balls remain strongly attached to the fruit-surface. The lesions become black, firm, shallow and get localized to one side or at the blossom-end. The fruit becomes flat or wrinkled on the affected side. Affected tissues remain firmly attached to peel (Pathak 1980); the optimum temperature for infection ranges from 21 to $24^{\circ} \mathrm{C}$. Wangikar et al. (1969) recorded shrivelling and browning of berries in the bunch, followed by rotting at the neck. The peel becomes thin, shrivelled and papery.

\section{Curvularia-rot, c.o. Curvularia pallescens Boedijn}

The disease was reported by Jamaluddin and Tandon (1976) in their studies on market diseases of vegetables and fruits from Allahabad, and a loss of $5-7 \%$ was reported.

Symptoms appear as soft areas on the stalk-end or on any place of injury or on the cracked areas on the peel. Gradually lesions develop into distinct light-brown spots, which become finally dark citrine in colour.

\section{Brown-rot (Botryodiplodia-rot), c.o. Botryodiplodia theobromae Pat.}

The disease caused heavy losses in the USA; where it is known as summer bunch-rot (Hewitt 1974). The infection typically occurs at blossoming, and the fungus remains quiescent in the developing fruit and becomes active as berry matures. Sound mature grapes are also directly infected. In India, B.plamarum was reported by Patil and Moniz (1969). Mandal and DasGupta (1981) reported it from West Bengal and Meghalaya during March-April.

Symptoms : As rotting proceeds, pulp turns pinkish, peel cracks and juice leaks out, attracting fruit-flies and houseflies. In advanced stages, berry is covered by greyish black growth of the fungus(Philip 1998).

Control measures : Packing with potassium metabisulphite $5 \%$ as well as dipping in Bavistin $(0.05 \%)$ are very effective. TBZ $(0.25 \%)$ is also moderately effective in reducing infection. In mixed infections of B.theobromae and 
A.niger, Bavistin $(0.1 \%)+$ potassium metabisulphite $(5 \%)$ proved better than either used alone(Mandal and Dasgupta 1983, 1984).

\section{Bitter-rot, c.o. Greenaria fuligena Scribner and Viala}

Luttrell (1946), Luttrell and Murphy (1953) and Critopoulos (1961) reported this disease. Om Prakash et al. (1974) reported it from Muzzaffarpur, Bihar on Anab-e-Shahi.

Symptoms : The fungus attacks ripe and unripe berries just near the peduncle, and the affected berries droop down. The affected berries become light brown to dark fuliginous, with full of dense acervuli, but do not shrivel. On young berries, superficial circular brown spots develop. In severe cases of infection, the lesions coalesce and spread rapidly over the fruit. Rotted fruits get soft and taste bitter. The skin of purple cultivars is bleached to a pink colour. The fungus causes girdling of the canes in the field.

\section{Black-rot, c.o. Guignardia bidwellii (Ell.) Viala \& Ravaz Conidial state : Phyllosticta ampelicida (Engelm.) Aa}

The disease is essentially a field disease, and is of greater significance in Europe and eastern USA (Luttrell 1946). A prolonged wet period causes severe infection. Fruit infection occurs after the fall of calyx, and when the fruit is half to nearly full in size.

Symptoms : The rot appears first on the fruit as light circular spots. Later entire berry becomes discoloured, and soon after, black specks (pycnidia) are formed. The affected berries turn into hard black mummies within a week or ten days and usually remain attached to the stem. Shattering of berries may occur depending upon the variety. The disease does not spread under storage.

\section{Pimple-rot/Phomopsis fruit-rot, c.o. Phomopsis viticola Sacc.}

The disease is responsible for 'dead arm' disease of grape vine. Pycnidia are formed on the infected branches, and during wet weather, spores get disseminated and cause direct infection on intact mature grapes (Hewitt 1974). In India, Gopakrishna et al. (1978) and Lal and Arya (1982) reported this disease.

Symptoms : Infected berries show small, brown spots, which soon get surrounded by distinct dark-brown margin. At the final stage of decay, white mycelial growth and black pinhead-like fruiting bodies develop over the entire surface. The tissues become pulpy and emit fermented odour.

Control measures : Phomopsis fruit-rot is controlled effectively by spraying before harvest with Bavistin, Difolatan, Calyxin (1,000 ppm each) and Dithane M-45 (0.25\%) (Arya 1988).

Leaf extracts of Eucalyptus and Aegle marmelos (50\% water extract), and mustard oil are effective against Phomopsis fruit-rot (Arya 1988). 
Anthracnose (Bird's eye-rot), c.o. Elsinoe ampelina Shear

Conidial state: Sphaceloma ampelinum

Glomerella cingulata (Colletotrichum
loeosporioides Penz.)
Gloeosporium ampelophagum (Pass.) Sacc.

Southworth reported the disease as early as 1891. Daykin and Milholland (1984) reported it as a major problem, caused by $C$. gloeosporioides on the muscadine grapes (Vitis rotundii) from North Carolina. Infection occurs at all stages of fruit development. The fungus remains latent; and the symptoms appear only at the time of ripening.

Symptoms : Immature berries are susceptible to infection. The disease appears first as dark-red spots on the berry (Fig. 6.1). Later these lesions become circular, sunken, ash-grey, and in the late stages spots are surrounded by a dark margin, which gives it the characteristic 'bird's eye-spot' appearance (Fig. 6.2).

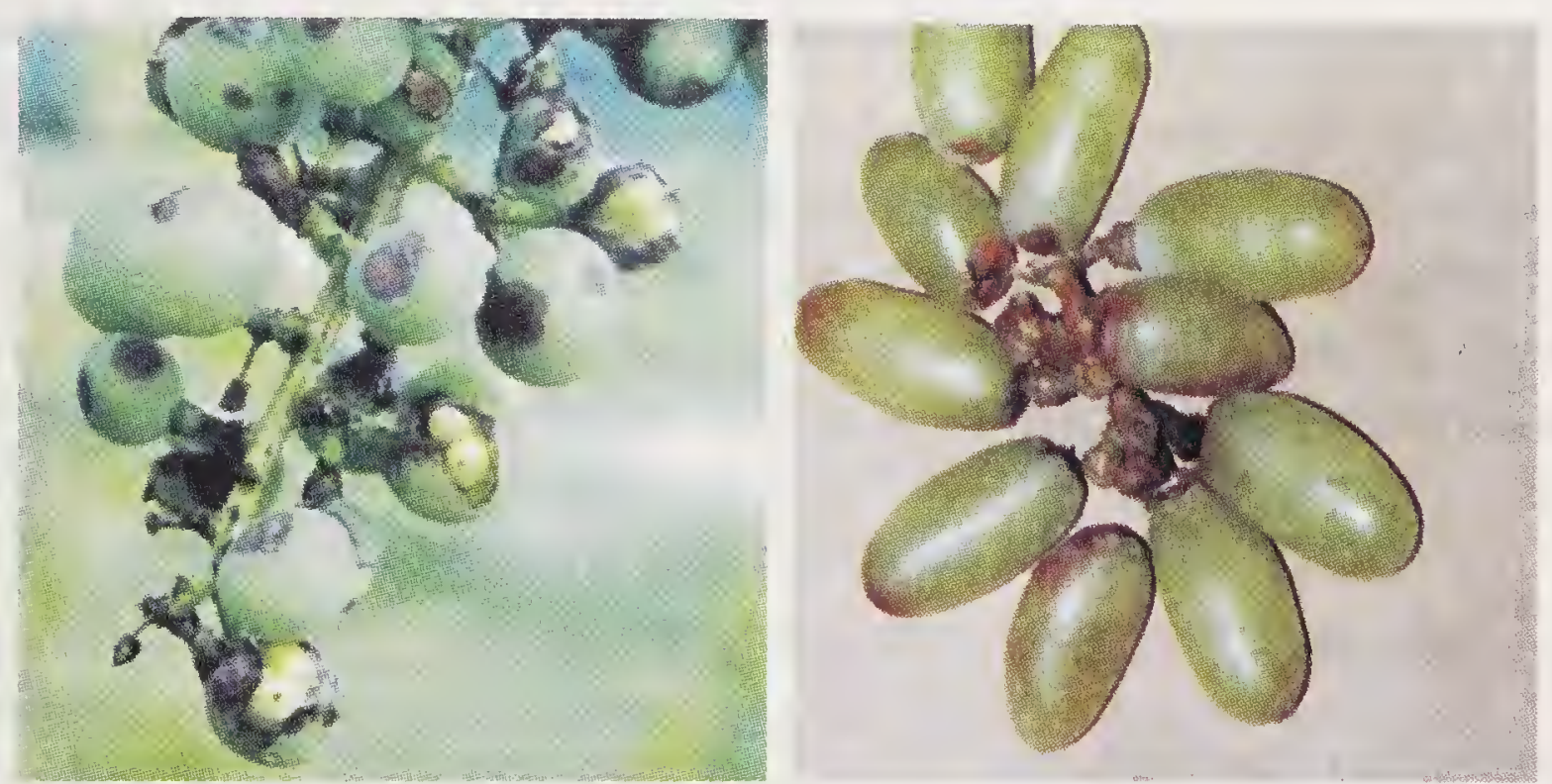

Figs 6.1, 6.2. Anthracnose on grapes

Control measures : Fungicides like Captafol,Carbendazim, Mycobutanil and Ziram (all at $500-1,500 \mathrm{ppm}$ ) are recorded as effective in controlling incidence and intensity of anthracnose (Datar 1994). But Carbendazim use may lead to development of resistance in the pathogen (Chander and Thind 1995). Hence, its use alternately or in a mixture with Thiophenate methyl $(0.25 \%)$ or Benomyl (500 0ppm) is observed to be effective (Deokate et al. 2002).

An unusual bunch-rot of grapes caused by Colletotrichum acutatum was recorded from Australia (Melksham et al. 2002). Salmon-pink discharge of conidia from the infected fruit, and discolouration on grapes and vines were noticed.

\section{Yeast-rotting, c.o. Saccharomyces sp.}

Yeast-rotting is common and damages physically damaged fruits. Singh and Kainsa (1983) observed much decay in packed grapes due to fermentation by yeast Saccharomyces sp. The yeast group, Candida sp., Endomycopsis sp., 
Rhodotorula sp. and an actinomycete Streptomyces sp. were observed on decayed fruits from the baskets.

Sour-rot due to fermentation by acetic-acid bacteria and yeast was also recorded (Bisach et al. 1986). It was also recorded from West Bengal and Meghalaya (Dasgupta and Mandal 1989).

Symptoms : The most important feature of this disease is softening of tissues and fermentation of juice with a strong and sour alcoholic odour and conversion of fruits into a putrefied mass. Fruits become unsuitable for consumption; fruits tightly packed and/or in ill-ventilated containers suffer the most.

Control measures: Packing materials made of bamboo with paper- cuttings as cushioning material are found better in reducing spoilage than wooden boxes with paper-cuttings (Singh and Kainsa 1983).

Melting decay of grapes, c.o. Bacteria and yeasts

Bacillus subtilis (Ehrenberg)

Cryptococcus laurentii (Kuffedath)

Aureobasidium pullulans (de Bary) Arnaud.

The disease was recorded from California on fruits after two weeks of cold storage. Symptoms appear as cracking and as dissolution of epidermal cells, followed by development of sunken, decayed areas. In advanced stages, entire berry gets liquified. Affected berries were randomly distributed but sometimes berry-to-berry spread was also noticed (Morgan and Michailides 2004).

\section{OTHER FUNGI ASSOCIATED WITH ROTTING}

\begin{tabular}{ll}
\hline Fungus & Authority \\
\hline $\begin{array}{l}\text { Cephalosporium rosegriseum } \\
\text { Curvularia lunata }\end{array}$ & Chahal and Malhi, 1969 \\
$\begin{array}{l}\text { Trichoderma lignorum } \\
\text { Macrophomina phaseoli } \\
\text { (Syn: Rhizoctonia bataticola) }\end{array}$ & Ranganathan et al., 1972 \\
$\begin{array}{l}\text { Monilinia fructicola } \\
\text { Pestalotia menezesiana }\end{array}$ & Sholberg et al., 2003 \\
Phoma glomerata & Mishra et al. ,1974 \\
P.macrostoma & Pandotra, 1976 \\
\hline
\end{tabular}

\section{DISEASES MANAGEMENT}

\section{Pre-harvest fungicides application}

Field application of fungicides (non-systemic as well as systemic) and certain chemicals is reported to be effective in reducing infection in the field as well as in storage. Thus Bavistin(0.1\%), Blitox(0.5\%), Dithane-M 45(0.2\%) and potassium sulphate 2\% (Pal et al. 1979), Benomyl(500 ppm), Thiophenate methyl (0.1\%) and Carbendazim (01\%) (Nicoli et al. 1979; Pearson et al. 
1985), Captan 0.2\% (Sall and Hirschfelt 1981), Benlate 500 ppm (Valdebenito, 1973; Kumar and Gupta, 1990) as well as Mycobutanil (Orpin 0.1\%) showed good results. But Nicolli et al. (1979) observed undesirable residues in the fruit and in the vine. Scruno et.al. (1991) observed suitability of dicarboxymide fungicides for field application as well as for post- harvest fumigation during transport and storage.

\section{Post-harvest management}

\section{Improvement in packing and use of quick-release grape guard}

Paper sheets impregnated with $\mathrm{NaHSO}_{3}\left(1.5 \mathrm{~g} / \mathrm{kg}\right.$ of fruits)to release $\mathrm{SO}_{2}$ in holdings are found effective in reducing stem drying, browning and berryrot up to 12 weeks in cold storage (Mansour et al. 1984).

\section{Application of vapours}

Vapour phase $\mathrm{H}_{2} \mathrm{O}_{2}$ produced no changes in the colour of berries (Forney et al. 1991).

\section{Fumigation}

$\mathrm{SO}_{2}$ fumigation (Eckert and Sommer 1967), followed by storage at $0^{\circ} \mathrm{C}$ controlled development and spread of disease for six weeks (Marois et al. 1986). Fumigants included use of sodium metabisulphite $(1.5 \mathrm{~g} / \mathrm{kg})$, which released $\mathrm{SO}_{2}$ in contact with moisture in the packing materials (Kokkalos 1986), and sodium ortho-phenyl phenate (SOPP) $0.2 \%$ or 2-acetyl -3-hydroxy furan was commonly used.

In export package, $\mathrm{SO}_{2}$ generator sheets are used, which continuously emit gas within the packages. But $\mathrm{SO}_{2}$ is not acceptable for organic grapes, because of the issues associated with sulphite residues, $\mathrm{SO}_{2}$ emission, and its negative impact on the grape quality. Hence alternative strategies to control grey mould are required.

\section{Use of benzyl alcohol}

This offered good results in packed grapes during storage in cartons for four weeks (Chambers 1990).

\section{Alternate technologies}

Addition of chlorine (200g) to ammonium bicarbonate and sodium bicarbonate is effective in controlling oxygen and carbon-dioxide levels. Immersing fruits in ethanol, exposure to UV light and ozone are also reported as new technologies in reducing damage in storage of table-grapes (Crisosto and Similanick 2002).

\section{Modifying atmosphere (CA storage)}

Controlled atmosphere (CA) storage as a possible alternative to $\mathrm{SO}_{2}$ treatment for table-grapes has been reported. A concentration of $2 \% \mathrm{O}_{2}$ and 
$10 \% \mathrm{CO}_{2}$ helps prolonging storage life. Chapon (2002) reported high concentrations more effective than low oxygen concentrations. A threshold concentration of around $15 \%$ is optimum. Otherwise it may lead to phytotoxicity or flavour alteration. Crisosto et al. (2002) from Netherlands observed $\mathrm{CO}_{2}$ enriched atmosphere during cold storage to limit losses from Botrytis-rot, but accelerated rachis browning of Red Globe table-grapes. A combination of $10 \mathrm{KPaCO}_{2}+6 \mathrm{KPaO}_{2}$ up to 4 weeks is suggested for early harvested Red Globe grapes. Westerecamp and Blargues (2002) also observed use of modified atmosphere effective in controlling B.cinerea rot of grapes. $\mathrm{CO}_{2}$ - rich atmosphere is considered optimum for decay control of organically grown Thompson Seedless and Red Globe table-grapes during storage at $0^{\circ} \mathrm{C}$ with $\mathrm{CO}_{2}$ at $15 \%$ or more in case of Botrytis-rot. 


\section{CHAPTER 7 \\ Guava (Psidium guajava L.)}

Guava-fruit is an excellent source of vitamin C. It contains niacin, pantothenic acid, thiamine, riboflavin, vitamin $\mathrm{A}$, and is rich in minerals like phosphorus, calcium and iron. It is rich in pectin also, but is low in energy value. Fruits start showing a decline in vitamin content due to fungal infection.

\section{FUNGAL DISEASES}

\section{Anthracnose, c.o. Colletotrichum psidi (Gloeosporium psidi Delacroix) Glomerella cingulata (Stonem.) Spauld. \& Schrenk.}

Guava is attacked by a number of diseases during post-harvest stages, and anthracnose is the most destructive one (Srivastava and Tandon 1969; Liu 1972; Majumdar and Pathak 1997). Anthrancose causes heavy damage during rainy season; estimated losses may vary from 5 to $20 \%$. Adisa (1985) reported this disease from Nigeria. The pathogen remains dormant in the young fruit for about 2-3 months. Studies on guava-fruits cv Allahabad Safeda at different stages of ripening indicated fruits to be the least susceptible at the green stage(Mishra and Kumar 1993). Rotting was observed only in ripe-fruits. In Punjab, anthracnose incidences ranged from traces to 68\% (Singh et al. 2008).

Symptoms : The disease manifests in the form of pinhead-like lesions on the semi-ripe fruits. The lesions gradually become copper-brown, circular and sunken (Fig. 7.1). Acervuli appear in concentric circles, and lesions may coalesce and may cover $4-5 \mathrm{~cm}$ in diameter. Dried pink spore masses are visible within acervuli under moist atmospheric conditions. The pulp under the lesion becomes soft and brown without unpleasant odour. Production of pectinolytic enzymes by the pathogen has been recorded (Midha and Chohan 1967). Two vitamins - para amino benzoic acid (PABA) and choline-were found to inhibit fungus growth in in-vitro

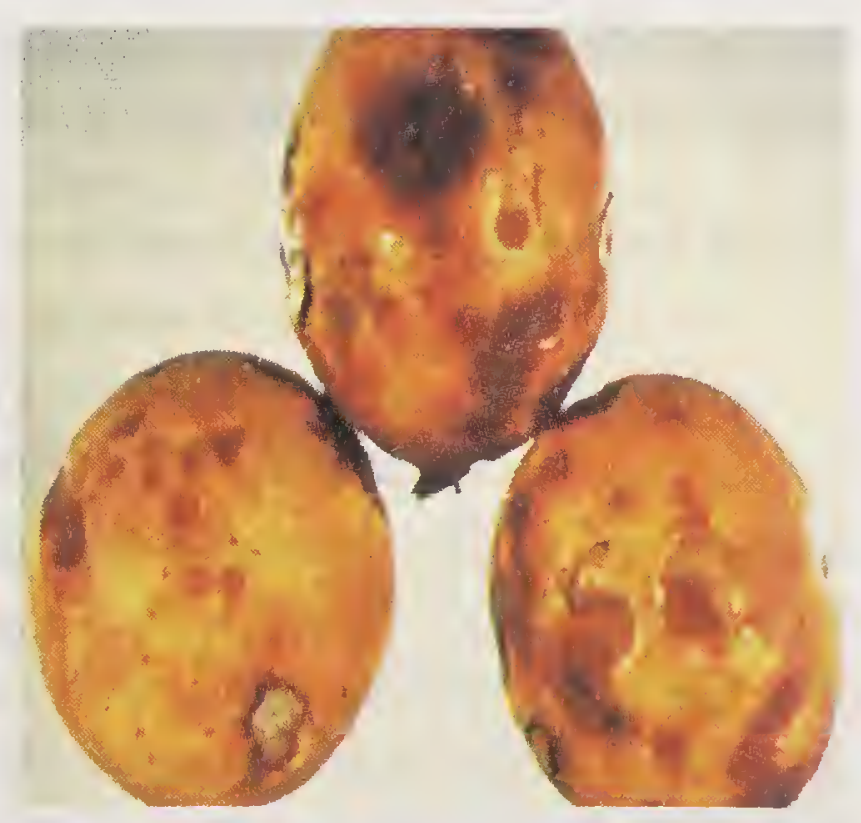

Fig. 7.1. Anthracnose on guava 
studies (Chatrath et al. 1968). Significant increase in fruit-rot was observed with increased spore load (Tandon and Singh 1969).

Control measures : The disease incidence can be reduced by spraying trees with Bordeaux mixture (3:3:50), Copper oxychloride( $0.5 \%)$, Cuprous oxide [1.3-1.8 kg containing 50\% copper in 54.6 litres water (3-4 lb containing $50 \%$ copper in 100 gal water)], Difolatan $(0.2 \%)$ or Dithane-Z 78(0.2\%) (Tandon and Singh 1969; Sohi and Sridhar 1969 Kaushik et al. 1972). Use of copper formulations was reported to cause russetting in Allahabad Safeda fruits. Six monthly spraying with Dithane Z-78 $(0.2 \%)$ or Aureofungin (100 ppm) proved effective.

Several fungicides and chemicals are found to protect fruits against storage rots. Thiram, Kirti copper and Cuman are recorded as good protectants in preinoculation sprays against Colletotrichum-rot (Midha and Chohan 1971). Dipping fruits in Aretan (ethoxy-ethyl mercuric chloride $6 \% \mathrm{Hg}$ ) at $50 \mathrm{ppm}$ is sufficient to check the growth of P.psidii and C.gloeosporioides (Khanna and Chandra 1976) with no symptoms of rotting in pre- and post- inoculation treatments.

Spraying trees before harvest as well as dipping fruits in Bavistin (0.1\%)were promising (Singh et al. 2008).

In packed fruits, fumigation with sodium metabisulphite $(2 \mathrm{~g} / \mathrm{pack})$ and stable bleaching powder satisfactorily controlled anthracnose caused by Glomerella cingulata (Singh and Sharma 1982). Hot Benomyl at $48-50^{\circ} \mathrm{C}$ also proved effective (Wills et al. 1982; Majumdar and Pathak 1997) against anthracnose in pre- and post- inoculation and for post- inoculation treatment against Pestalotia-rots.

An actinomycete isolate (Streptosporangium pseudovulgare@6.2 × 107 cells $/ \mathrm{ml}$ ) of cowdung origin recorded destruction of pathogen in in-vitro conditions (Garg et al. 2004). This actinomycete showed great biocontrol potential against anthrancose. In 'Vrisksha Ayurveda' effects of cowdung paste for healing plant wounds are mentioned.

Fruits stored at $3-10^{\circ} \mathrm{C}$ in polyethylene plastic film bags with pores of 10 - $\mathrm{mm}$ diameter retained physiological and biochemical characteristics and quality up to 18 days of storage (Gutierrez et al. 2002).

\section{Stalk end-rot/Botryodiplodia-rot,}

c.o. Diplodia natalensis Pole-Evans

Botryodiplodia theobromae Pat.

Lasiodiplodia theobromae

Symptoms : The pathogen also causes dry-rot in guava. Symptoms appear initially as light-brown spots, mostly at the stalk-end or at the calyx-end of the fruits. Infection may arise from other parts of the fruits also. Infection spreads quickly and within 3-4 days, entire fruit turns dark brown to black, and ultimately dries up (Fig. 7.2). A number of dried fruits can be seen on an infected tree. Twigs bearing infected fruits exhibit die-back symptoms. The 
disease was recorded from Uttar Pradesh and Kerala (Edward et al. 1964, Srivastava et al. 1964; Srivastava and Tandon 1969 a; Rajagopalan 1971).

The pathogen produces symptoms on the ripe-fruits in storage. Considerable damage occurs during transit and storage. Affected fruits show brownish discolouration, mostly at the stem-end, which gradually proceeds downwards in an irregular wavy manner. In advanced stages, numerous

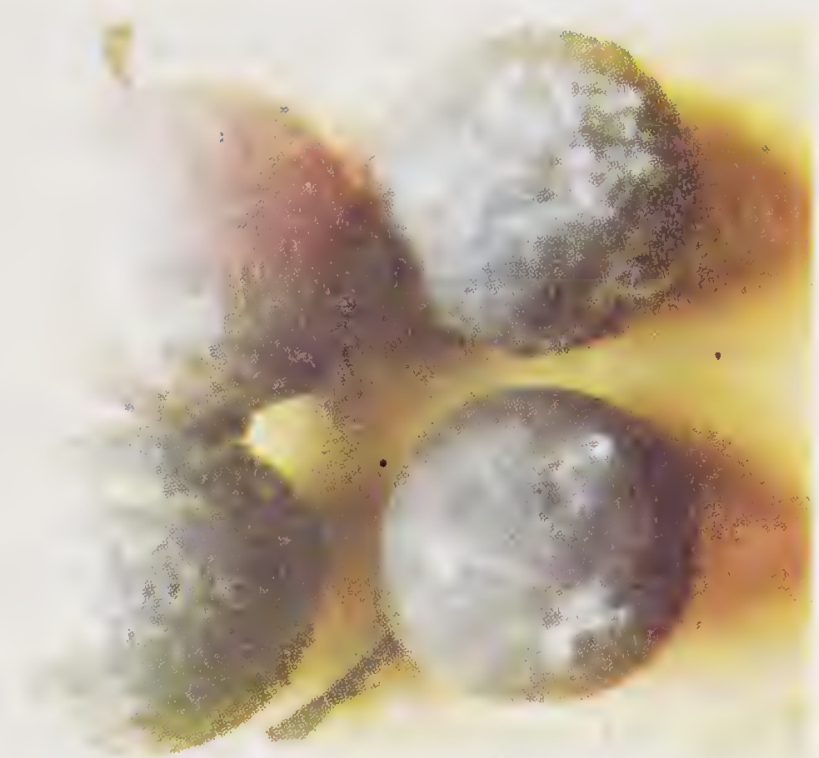

Fig. 7.2. Botryodiplodia-rot on guava pycnidia are produced over the entire fruit-surface. As rotting advances, fruit becomes soft and watery,and its inner pulp becomes discoloured. Rotting spreads through contact. Warm humid weather favours disease. Patel and Pathak (1995) studied the influence of temperature and relative humidity on the disease severity in Rajasthan. Warm humid weather favours it, and low temperature retards its severity by adversely affecting pathogen physiology. The disease was found severe at $30^{\circ} \mathrm{C}$ and $100 \%$ RH. No symptoms occurred at $10^{\circ} \mathrm{C}$ and $30 \% \mathrm{RH}$. Activity of cell-wall degrading enzymes (CWDE) with rots was also studied. Pectic and cellulolytic enzymes (PG, PMG and $\mathrm{Cx}$ ) were active at $30-35^{\circ} \mathrm{C}$. Reduction in vitamin $\mathrm{C}$ (ascorbic acid) in ripe-fruits due to infection was also observed (Srivastava and Tandon 1966; Patel and Pathak 1995).

Control measures : Removal and destruction of infected unripe fruits along with infected stem showing die-back symptoms needs to be carried out. Wounds should be protected with Bordeaux paste. Application of Ziride 3,000 ppm as pre-harvest spray at 15 days interval is effective against dry-rot without any phytotoxicity to flowers and fruits (Rajagopalan1971; Rajagopalan and Wilson 1972, 1972 a).

Careful handling, quick transport and storage of fruits at $10-15^{\circ} \mathrm{C}$ were promising. Imazalil (200 $\mathrm{ppm}$ ) offered protection against rotting incited by L.theobromae (Majumdar and Pathak 1997). Dipping fruits in Tetracycline $(500 \mathrm{ppm})$ controlled effectively the disease, and fruits remained healthy for ten days (Gupta et al. 1973).

\section{Fruit canker/ Pestalotia-rot,}

\section{c.o. Pestalotiopsis psidii (Pat.) Mordue $P$. versicolor (Speg.) Steyaert}

The causal organism was first recorded as Pestalotia psidii from Maharashtra (Patel et al. 1950). Subsequently, it was known as Pestalotiopsis psidii, and has been recorded from all guava-growing tracts of India (Rangaswamy 1978; Mandal 1981; Madhukar and Reddy 1990; Majumdar and Pathak 1997). This fungus is responsible for canker and causes maximum damage to ripe- 
fruits after harvest (Kaushik et al. 1969, 1972). It requires humid atmosphere (25-30 ${ }^{\circ} \mathrm{C}$ and relative humidity $80-100 \%$ ) for maximum development.

Symptoms : Water-soaked lesions of brown colour appear first. These later change into russet-coloured spots. And white fluffy growth along with black pinhead-like acervuli appear after a week (Dhingra and Mehrotra 1980).

Due to this infection, vitamin $\mathrm{C}$ content in fruits reduces considerably. Similar results were also reported with A.niger and P.psidii. This is due to increased respiration under pathogenesis (Srivastava and Tandon1966; Singh and Tandon 1971).

Control measures: Pre-harvest treatments. Rawal and Saxena (1993) suggested sprays of Dithane Z-78(0.2\%) and Thiophenate methyl (Topsin-M $(0.1 \%)$ on the orchard against Pestalotiopsis psidii and C.gloeosporioides under storage.

Avoidance of injury protects fruits from several diseases.

Post-harvest treatments. Low temperature storage. Storage at low temperature and dry atmosphere prevents development of storage rots. Low temperature storage at $8-10^{\circ} \mathrm{C}$ is effective in enhancing storage life.

Use of hot-water. Dipping fruits in water at $50^{\circ} \mathrm{C}$ for $30 \mathrm{~min}$. protected fruits from fungal attack by $P$. versicolor and Rhizoctonia solani (Madhukar and Reddy 1990).

Use of fungicides and antibiotics. Dipping fruits in Aretan (ethoxy-ethyl mercuric chloride $6 \% \mathrm{Hg}$ ) at 1 and $50 \mathrm{ppm}$ is sufficient to check growth of P.psidii and C.gloeosporioides.

Post-harvest wash with Aureofungin (200 ppm) as well as Thiabendazole (2,000/2,500 ppm) keeps fruits free from infection of P.psidii and Phoma psidii (Kaushik et al. 1968, 1972; Bhargava and Singh 1974). Benlate 500 ppm was effective against fruit-rot (Singh and Bhargava 1977), and Benlate $200 \mathrm{ppm}$ with $0.2 \%$ paraffin oil was also promising.

The efficacy of homeopathic drugs like potassium iodine and arsenic oxide against Pestalotia-rot in pre-inoculation trials was also demonstrated (Khanna and Chandra 1977).

\section{Stylar-end rot, c.o. Phomopsis psidii de Camara}

It is a disease of ripe-guavas and causes reduction in fruit yield (Rai 1956; Srivastava and Tandon 1969; Rao and Agarwal 1975). And also reduces nutritional value of fruits.

Symptoms : The disease starts as a circular water-soaked lesion at the stylar end: As the disease advances, small white or light brown pycnidia appear on the infected area, and they aggregate closely.

Control measures : Satisfactory control with Bavistin, Difolatan, Calyxin (1,000 ppm each) and Dithane M-45(1250 ppm) has been reported (Arya, 
1988). Dipping fruits in Aretan (ethoxy-ethyl mercuric chloride 6\% $\mathrm{Hg}$ ) at $50 \mathrm{ppm}$ is sufficient to check growth of $P$. psidii and C. gloeosporiodes. Blitox (0.5\%), Cuman L $0.1 \%$ (Rao and Agarwal 1977) and Cuprasol 50 as well as Planofix (Majumdar and Pathak, 1997) are also effective against Phomopsisand Rhizopus-rots.

Leaf extracts of Eucalyptus and Aegle marmelos (50\% concentration), and mustard oil (1,500 ppm) were effective (Arya 1988).

Phytophthora fruit-rot, c.o. Phytophthora nicotianae (Breda de. Haan) ( $P$. nicotianae var. parasitica Breda de. Haan)

The disease was originally reported by Mitra in 1929. It causes extensive damage during rainy season, and is favoured by high humidity and moderate temperature.

Symptoms : They are of two types. First type is when fungus attacks unripe fruits at the blossom-end, and the infected fruits show small conspicuous, darkbrown circular spots; some of the fruits are shed prematurely. As the fruits ripen, spots extend and cover the fruit-surface. In the second type, infection is noticed on the fully ripened fruits as water-soaked brown patches, when fruit colour is changing from green to light yellow. Infected fruits become softer and emit undesirable odour. They show superficial mycelial growth during humid conditions. Rao (1966) reported occurrence of $P$. nicotianae along with several other fungi, and Singh et al. (1977) recorded it as a new disease problem from Punjab.

Control measures : For Phytophthora fruit-rot control, Kothari (1968) recommended weekly sprays on the orchard with Bordeaux mixture $(2: 2: 50)$ and copper oxychloride (0.2\%). Dipping fruits in Difolatan (500 ppm ) can be safe for controlling Phytophthora fruit-rot. Post-harvest wash with Aureofungin (500 ppm) gave $100 \%$ control for 5 days (Sharma et al. 1978) in non-inoculated treatments against Phytophthora-rots.Bio-assay studies with 12 different fungicides showed inhibition of the pathogen (Roy et al. 2004).

Essential oils (water extract) of Nepeta hindostana and Ocimum canum are reported to have inhibitory effects on $P$. nicotianae (Chauhan et al. 1994).

\section{Fruit-rot, c.o. Macrophoma allahabadensis Kapoor \& Tandon}

The disease was reported from Allahabad (Kapoor and Tandon 1970). In the early stages, diseased fruits show a brownish water-soaked discolouration on the peel; spreading around the infection point. The mycelia colour on the fruit-surface turns from orange-cinnamon to dark-ivy green, and finally becomes black. Numerous dark-coloured pycnidia appear on the fruit-surface.

Fruit sucrose is hydrolyzed completely after infection, and D-glucose and D-fructose are either utilized or reduced in concentration. Considerable changes occur in amino acids, amides and organic acids (Kapoor and Tandon 1971), even changes in ascorbic acid content are noticed. The decline rate is 
fast in the initial stages due to production of certain ascorbic acid-degenerating enzymes, produced by the pathogen or by the host-pathogen interaction (Kapoor 1982).

Cold storage $\left(8-10^{\circ} \mathrm{C}\right)$ and avoidance of fruit injury are also effective measures.

\section{Aspergillus-rot, c.o. Aspergillus spp.}

The following two diseases of this category are important.

\section{Black-rot, c.o. Aspergillus niger Van Tiegh.}

\section{A. awamori Nake Zawa}

The rot was reported by Gupta et al.(1979), Mandal (1981), Adisa (1985) and Madhukar and Reddy (1991).

The disease is characterized by brown spots of $0.1-0.3 \mathrm{~cm}$ diameter randomly distributed over the fruit-surface. Infected areas become watersoaked and the black concentric zones developed later around the point of infection consist of conidial heads. Underneath tissues become soft and decay.

Two-minute dip in Bavistin and Saprol (1,250 ppm each) was effective against $A$. awamori infection (Arya et al. 1981, 1988).

Green mould-rot, c.o. Aspergillus nidulans (Eidam) Wint.

Mandal (1981) reported this disease from West Bengal. It was also reported from Punjab (Garcha and Singh 1980).

Infection is initiated with discolouration anywhere on the surface, but mostly at the injured site. Inner pulp becomes soft with characteristic green sporulating mass and liquid drops cover infected surface.

Gupta et al. (1979) recorded other species of Aspergillus also; A.wentii, A.clavatus and A. flavus. A soft-rot due to A awamori was also reported during monsoon from Allahabad (Bihari Lal et al. 1980).

Control measures under A awamori are effective for this also.

\section{Soft-rot/ Rhizopus-rot, c.o. Rhizopus stolonifer (Ehrenb.) Vuill.}

R. nigricans Ehrenb.

The disease was reported from India (Srivastava and Tandon (1969). Fruitrot due to R.orayzae was reported from Nigeria also (Adisa, 1985).

Symptoms : The lesions on the affected fruits are water-soaked and circular. As the disease advances, affected area gets covered with strands of coarse mycelial growth.

Patel and Pathak (1966) studied relationship of temperature and relative humidity on the development of Rhizopus-rot. Growth retardation was noticed at low temperature.

Control measures : Injuries and bruises need to be avoided. Biocontrol of Rhizopus-rot with a yeast (Saccharomyces cerevisiae) at $250 \mathrm{ppm}$ 
concentration was reported from Allahabad (Dwivedi et al. 2001). No significant variation in nutritional value (vitamin $C$ ) and acidity and in other parameters, $p \mathrm{H}$, shape and size of fruit was observed.

MINOR DISEASES AND THEIR CAUSAL ORGANISMS

\begin{tabular}{|c|c|c|}
\hline Disease & Causal organism & Authority \\
\hline Phoma-rot & Phoma psidii & $\begin{array}{l}\text { Gosh et al., 1965; } \\
\text { Srivastava and } \\
\text { Tandon, 1969; Singh and } \\
\text { Bhargava, } 1977\end{array}$ \\
\hline Fruit-rot & Cylindrocarpon tonkinense & Jamaluddin, 1976 \\
\hline Sour-rot & Geotrichum candidum & $\begin{array}{l}\text { Shankhpal and } \\
\text { Hatwalne, } 1976\end{array}$ \\
\hline Curvularia-rot & Curvularia lunata| & \\
\hline Monilia-rot & Monilia sitophila & Gupta et al., 1979 \\
\hline Black-rot & Ceratocystis paradoxa & Bihari Lal et al., 1980 \\
\hline Yellow mould-rot & Mucor racemosus & Mandal, 1981 \\
\hline $\begin{array}{l}\text { Sunken brown } \\
\text { discolouration }\end{array}$ & $\begin{array}{l}\text { Myxosporium psidium } \\
\text { guajavae sp. nov }\end{array}$ & $\begin{array}{l}\text { Mandal and DasGupta, } \\
1984 a\end{array}$ \\
\hline Soft-rots & Rhizoctonia solani & \\
\hline 1 & Choanephora cucurbitarum & Adisa, 1985 \\
\hline Dry-rot & $\begin{array}{l}\text { Aspergillus fumigatus } \\
\text { Penicillium sp. } \\
\text { P. multicolor }\end{array}$ & \\
\hline 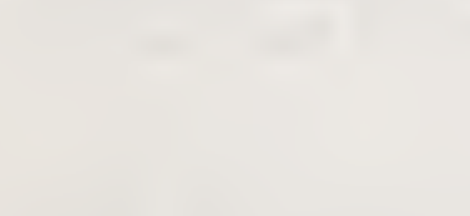 & $\begin{array}{l}\text { Cladosporium sp. } \\
\text { Fusarium equiseti } \\
\text { F. oxysporum }\end{array}$ & Adisa, 1985 \\
\hline & F.solani & Chakarabarti, 1983 \\
\hline Cottony-rot & Fusarium semitectum | & \\
\hline Blue-mould & Penicillium expansum & $\begin{array}{l}\text { Das Gupta and Mandal, } \\
1989\end{array}$ \\
\hline Watery soft-rot & Gliocladium roseum & Rao and Agarwal, 1977 \\
\hline Fruit-rot & Cylindrocarpon tonkinense & Jamaluddin, 1976 \\
\hline \multirow[t]{4}{*}{ Fruits-rots } & 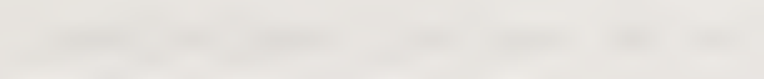 & \\
\hline & $\begin{array}{l}\text { Alternaria alternata } \\
\text { Drechslera hawaiiensis }\end{array}$ & \\
\hline & Sclerotium rolfsii & Madhukar and Reddy, \\
\hline & $\begin{array}{l}\text { Cladosporium cladosporioides } \\
\text { Paecilomyces variotii } \\
\text { Chaetomium globosum }\end{array}$ & 1991 \\
\hline Bacterial rot & Erwinia sp. & Adisa, 1985 \\
\hline
\end{tabular}


Control measures: Pre-harvest application of fungicides. Spraying fungicides on the orchard often offers protection to harvested fruits against storage rot.

Post-harvest management. Guava-fruits suffer mainly due to diseases caused in the unripened stage. Pathogens like C.gloeosporioides, L.theobromae and Pestalotipsis psidii occur in fields as well as in transit and in storage.

Storage at low temperature. Storage of fruits at low temperature $\left(15^{\circ} \mathrm{C}\right)$ with quick transportation helps in minimizing storage problems (Srivastava and Tandon 1969; Patel and Pathak1995).

Hot-water treatment. It protects against storage rots.

Use of fungicides. Several fungicides and chemicals are found to offer protection against storage rots.

Benomyl $(0.3 \%)$ is recorded to be effective against common-rots. But Benomyl $(0.2 \%)$ with paraffin $(0.2 \%)$ is considered better in enhancing storage. Benomyl at $48-50^{\circ} \mathrm{C}$ also proved promising (Wills et al. 1982).

Use of chemicals. Dipping in chemicals other than fungicides also offers protection. Sodium carbonate $(6 \%)$ has been found to be effective in checking rots with lesser intensity of infection. Singh and Chohan (1982) observed Alar 1,000 ppm and calcium nitrate $2 \%$ with promising results.

Use of leaf extracts. Crude leaf extracts of Eucalyptus and Aegle marmelos also protect against rots. Smearing fruits with $5 \%$ mustard oil and castor oil also offers protection (Arya 1988).

Biological control. Yeast (Candida sp.) is reported to have antagonistic activity. Fruits treated with suspension of Candida sp. $\left(10^{9} \mathrm{cfu} / \mathrm{ml}\right)$ for $5 \mathrm{~min}$., followed by packing in high-density polyethylene covers (HDPE) showed no spoilage and offered minimal physiological losses in weight(PLW). This was due to reduced transpiration and respiration of fruits (Abhilasha et al. 2008; Lal et al. 2008).

Packing and storage: Use of wax and polyethylene packings. Fruits treated with $9 \%$ waxol showed increased shelf-life. Fruits chemical attributes were better under polyethylene packings, and organoleptic traits were better under carton packing (Jagadeesh et al. 2001). Similarly fruits kept in polyethylene plastic film bags with pores of $10-\mathrm{mm}$ diameter and stored at $5-10^{\circ} \mathrm{C}$ showed good physiological and biochemical characteristic up to 18 days of storage (Gutierrez et al. 2002). 


\section{CHAPTER $\mathbb{8}$}

\section{Jackfruit (Artocarpus heterophyllus Lam.)}

Jackfruit, known as a poor man's food, is native to Western Ghats. It is hardly recognized as a commercial fruit. Its semi-ripe fruits are used for making chips.

It is a good source of carbohydrates, total soluble solids, vitamins like carotene (Precursor of vit. A), thiamine, minerals like iron, phosphorus and calcium. It is a rich source of pectin also.

\section{FUNGAL DISEASES}

Rhizopus-rot, c.o. Rhizopus artocarpi Racib.

The disease was originally reported from Asom (Chowdhury 1945). Fruitrot caused yield losses to the tune of 60-80\% in Manipur (Pandey et al. 1979). The pathogen attacks male inflorescences and young fruits, and it lives saprophytically on plant debris, manure and compost pits.

Symptoms : They are noticed on the ripe-fruits that have sustained injury, and appear as water-soaked areas. Later the areas are covered with white mycelia and black pinhead-like sporangial heads. Inside tissues become rotten, and in the advanced stage, juice leakage with foul smell results in.

Control measures : Fruits should be taken care of so that they are not damaged at harvest. The disease incidence can be minimized by observing sanitation in orchards and by spraying tender/immature fruits with Bordeaux mixture (2:2:50). Spraying with Dithane M-45 or Iprodione (Rovaral) at 0.2 was reported to be effective (Pandey et al. 1979; Singh and Bhownik 1985; Ahamed 1985). Spraying with Benlate or Bavistin (500 ppm) was also effective.

Phytophthora fruit-rot, c.o. Phytophthora sp.

The disease is observed during the south-west monsoon in Kerala.

Symptoms are noticed on fruits that are in close proximity to soil. Infection starts through a hole or a wounded area in the rind. Under artificial 
conditions, water-soaked lesions occur within 48-78 hours after inoculation. Later they enlarge to form brown patches with sporulating hyphae near the edges.

Fruits touching ground should be kept on raised platforms. And soil around the fruits should be treated with copper-oxy-chloride (COC $0.3-0.5 \%$ ).

Botryodiplodia-rot, c.o. Botryodiplodia theobromae Pat.

This fungus is a wound-pathogen, and its infection symptoms originate at the wounded areas on mature fruits. And fruits rot within 3-4 days; profuse mycelial growth is visible on the fruit-surface. Pycnidial encrustations can be noticed in advanced stages of infection. The juice leaks out with a foul smell.

Proper care should be taken so that the fruits are not damaged at the time of harvest.

\section{Black-rot, c.o. Aspergillus niger Van Tiegm.}

Symptoms of this fungus are noticed on the fully ripened fruits during rainy period of June and July. Infection can be noticed anywhere on the fruit surface, and within 3-4 days area becomes soft and black. Black fungal growth is visible on the fruit rind. Profuse leakage from the fruit with an offensive smell is also noticed.

\section{Brown-rot, c.o. Rhizoctonia solani Kühn}

This disease was recorded during the south- west monsoon period from May to July on cv Mutton Varikka (Singapore Jack) from Vellayani, Thiruvananthapuram (Menon et al. 1979; Philip 2002). The disease is noticed only on jackfruits, which are in close proximity with the soil. The affected area turns slightly brownish and soft with mycelial mat spreading in all directions, particularly under high humidity. Mustard-like sclerotia are also observed in abundance on the surface and the inside area becomes soft and rotten.

Control measures : Fruits in close proximity to soil alone are affected. Hence fruits should not be allowed to touch the soil, instead they should be kept on the raised wooden platforms. 


\section{CHAPTER 9)}

\section{Litchi (Litchi chinensis Sonn.)}

Litchi is a non-climacteric fruit of South East Asian origin. India is the second largest producer of litchi, after China. It is well known for pleasant flavour and attractive colour, and also contains sugars, protein, fat, pectin, vit. $\mathrm{C}$ and organic acids like malic acid, citric acid, levulinic acid, phosphoric acid, glutaric acid, malonic acid, lactic acid, and minerals like calcium, phosphorus and iron (Pandey and Sharma 1998). The fruit is valued for its high antioxidant property.

Shelf-life of litchi at ambient temperature $\left(26 \pm 2^{\circ} \mathrm{C}\right)$ is less than 72 hours. Post-harvest losses of litchi are estimated to be $20-30 \%$, and could reach as high as 50\% (Jiang et al. 2001). Litchi-fruit contains a white translucent aril with a sweet citrus flavour, and is covered by a red leather-like pericarp, which contains anthocyanins. The fruit can be eaten fresh or processed as jelly or wine or used in ice-creams and sorberts (Rivera-Lapez et al. 1999; Hui 2008).

\section{FUNGAL DISEASES}

The fruit-rots are reported from India due to following fungi (Prasad and Bilgrami 1973).

Aspergillus flavus Link. ex Fries;

A.nidulans (Eidam) Wint;

A.niger Van Tieghem.;

A.quadrilineatus Thom. \& Raper;

A.variecolor (Berk. \& Bri.);

Botryodiplodia theobromae Pat.

Colletotrichum gloeosporioides Penz.

Cylindrocarpon tonkinense Bugn.

Pestalotia sp.

Studies on the effect of temperature and humidity on the decay of fruits of 'Shahi' variety showed no infection at $10^{\circ} \mathrm{C}$ and $30 \%$ relative humidity.

Slow pedicel end-rot, c.o. Drechslera sp. Chattopadhyay

(N.C. Mandal and M.K. Dasgupta sp nov) 
Symptoms : Infection starts from the pedicel-end as a brown zone, turning to deep-black with sparse mycelial growth and later turning black in colour. The aril becomes soft, watery, and is covered with mycelial mat. Under high relative humidity, fungal nets are formed within fruits (Mandal and Dasgupta 1984a).

Fruit-rot, c.o. Geotrichum candidum Link. ex Pers.

This disease was recorded from Allahabad (Jamaluddin et al. 1975a).

Symptoms : Infection occurs through cracks or injuries on the fruit. In the early stages, infection starts as a small soft area on the fruit. Soon fruit turns soft and pulpy and nut-like covering becomes loose;and fluid with a disagreeable odour comes out and the brittle nut-like covering gets depressed. White waxy growth of the fungus is observed on the diseased surface.

Control measures are as detailed under tomato in the solanaceous crops.

Fruit-rots due to several fungi are reported from Australia (Scott et al. 1982). This includes Aspergillus-rots caused by A. flavus and A.niger.

Other fungi of minor importance are as follows.

Rhizopus oryzae;

Geotrichum candidum Link.; $\quad$ (Scott et al. 1982)

Botryodiplodia theobromae Pat;

Colletotrichum gloeosporioides Penz

Yeast-rots

\section{POST-HARVEST DISEASES MANAGEMENT}

Sulphur-dioxide fumigation is practised. But $\mathrm{SO}_{2}$ fumigated fruits absorb 30-65\% of the applied $\mathrm{SO}_{2}$.

Dipping fruits in a solution of sodium ortho-phenyl phenate (SOPP, $0.25 \%$ ) or in hot Benomyl $\left(0.05 \%\right.$ at $50^{\circ} \mathrm{C}$ for $\left.2 \mathrm{~min}\right)$, followed by $6 \%$ wax emulsion increases storage life of fruits by four days (Prasad and Bilgrami 1973). Packing of fruits in polyethylene bags after the treatment was reported as effective.

Among the fungicides, Benomyl is known to have a strong-and-broad spectrum of activities, and is effective for controlling litchi fruit decay. But, it is not registered as a post-harvest chemical in many countries. As an alternative, gamma radiation has been reported as an effective treatment. Radiation at $0.5 \mathrm{KGY}$ in combination with low temperature storage $\left(4^{\circ} \mathrm{C}\right)$ offered protection to litchi-fruits and increased shelf-life by 28 days (Hajare et al. 2010). 


\section{CHAPTER ](}

\section{Mango (Mangifera indica L.)}

Mango is considered as one of the choicest fruits of the world because of its attractive colour, delicious taste and excellent nutritional properties. Mangoes, like many other fruits, are highly perishable. In general, fruit losses occur in the orchard as well as during the post-harvest operations of grading, packing, transportation, storage and marketing. Chenulu and Thakur (1968) reported an average loss of $17.7 \%$ due to fungal diseases. Weather conditions prevalent during the period (temperature of $25-30^{\circ} \mathrm{C}$ and relative humidity of $80-90 \%$ ) favoured fungal infection. Infection generally originates at the stemend region. In addition to this, the lenticels on the peel also serve as the site of infection (Sarkar, 1974).

The following diseases were reported from the survey of the fruit markets in different states of India (Raoof and Omprakash 1983; Dasgupta and Mandal 1989; Sharma et al. 1994; Jadeja and Vaishnav 2000).

\section{FUNGAL DISEASES}

Diplodia stem-end-rot, c.o. Diplodia natalensis Pole-Evans

(Botryodiplodia theobromae Pat. Lasiodiplodia theobromae) (Pat.) Griffon \& Maubl.)

In addition to the above mentioned pathogens, Dothiorella ribis and Phomopsis mangiferae are also found responsible for causing stem-end-rot (Sohi et al. 1973).

Stem-end-rot is considered as the most important post-harvest disease of ripe mangoes. Pathak and Srivastava (1967) reported an annual loss of 4-6\% in Indian markets due to this disease alone.

The disease is common in India. It was reported from north India (Chakravorty and Srivastava 1964), Kerala (Cheriyan 1987; Philip 2002) and from Gujarat (Jadeja and Vaishnav 2000). It was also reported from other countries, Sri Lanka (Fernando 1937), Philippines (Alicubuson and Schafer 1958) and Mauritius (Orian 1960). Wagan et al. (2001) also recorded B. theobromae as the predominant fungus from different markets in Pakistan, followed by A.niger, Penicillium spp. etc. Cultural and pathogenic variability has been reported in L.theobromae (Bhatt and Jadeja 2008). 
Symptoms : They initiate as black irregular areas around the pedicel. Soon the affected areas enlarge to form circular black patches that gradually extend downwards (Fig. 10.1). Along with this, isolated circular or irregular patches are seen scattered over the fruit-surface. The whole fruit turns black and rotten within 5-7 days (Fig. 10.2). Under humid conditions, fruit rots rapidly, and greyish black fungal growth covers the fruit. The pulp of the diseased fruit becomes brown and soft. The pathogen incites a soft-rot with the aid of pectinolytic and celluloytic enzymes (Pathak and Srivastava 1969; Pathak and Prasad 1969).

The fungus is a weak parasite that enters through wounds. The dead twigs and bark of mango-trees harbour abundance of pathogen, and with the onset of rains, the atmosphere gets contaminated with fungus spores and subsequent infection occurs through stem-ends or wounds (Pathak and Srivastava 1969).

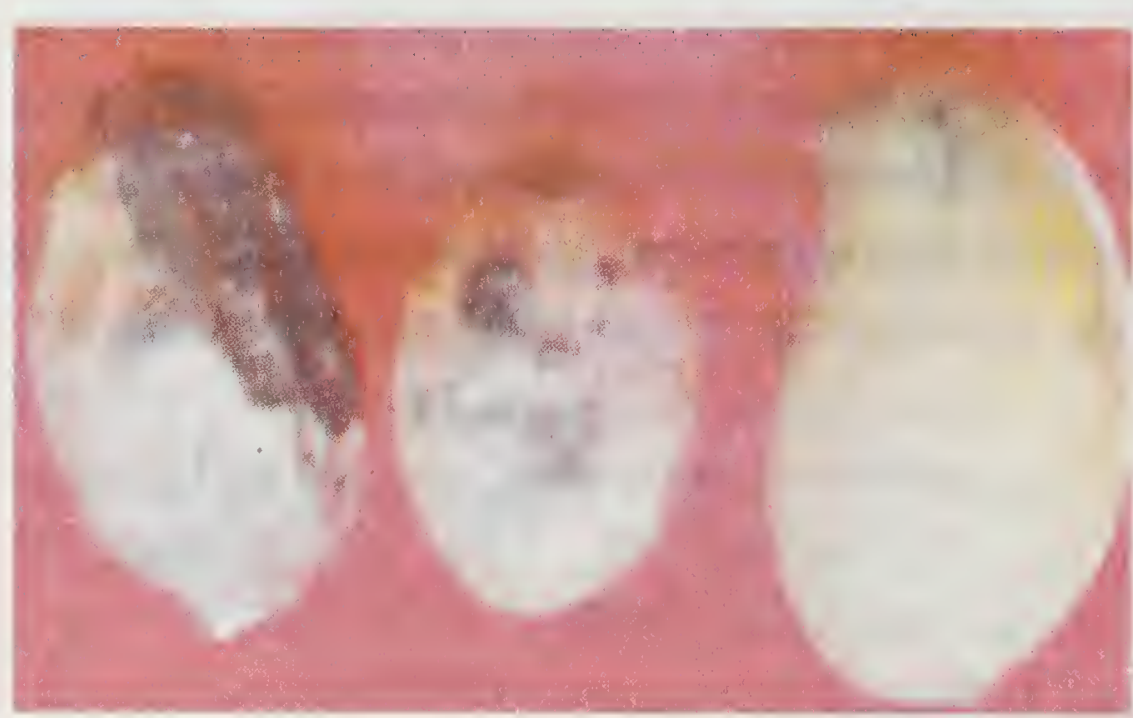

Fig. 10.1. Botryodiplodia-rot on mango-fruits

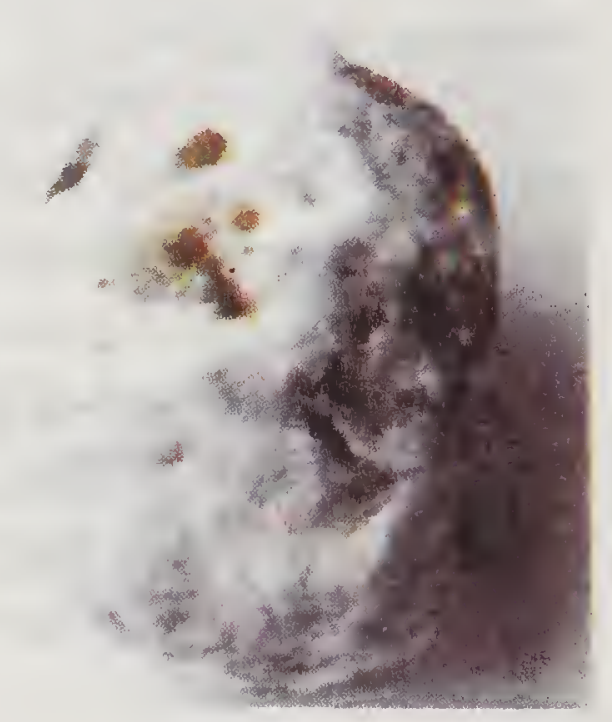

Fig. 10.2. Botryodiplodia-rot (Advaned stage) on the fruit

Control measures : The orchard and the surroundings should be made clean by removing dead branches and also other sources of natural infection. Injuries to fruits should be avoided at all stages of handling. Packing of mango-fruits with dried banana leaves is to be avoided, as they serve as the source of infection (Alicbusan and Schafer 1958).

Dipping of mango-fruits for five minutes in hot water at $50^{\circ} \mathrm{C}+1 \%$ common salt is an effective control measure (Saxena and Rawal 2004).

Chemical control. Pre-and post-harvest treatments with calcium chloride and calcium nitrate (both at 5,000 ppm) were reported in reducing storage rots due to Colletotrichum and Diplodia (Kaiser et al. 2001). Protection of fruits with growth regulators has also been reported.

The disease can be controlled by dipping mango-fruits in Aureofungin $200 \mathrm{ppm}$ or in $6 \%$ borax solution at $43^{\circ} \mathrm{C}$ for three minutes (Dharm Vir et al. 1967; Thomas and Dalal 1968). Dipping in the systemic fungicide Carbendazim $0.1 \%$ for four minutes was found effective (Sharma et al.1994). 
Five minutes dip in benzoic acid (50 ppm) protected against Diplodia stem-end-rot and anthracnose (Nair 1999).

Biocontrol. Trichoderma viride showed inhibition of $B$. theobromae under in-vitro conditons when cultures were placed at equal distance on the potato dextrose agar medium. Under in-vivo conditions also mango-fruits inoculated with T.viride remained free from infection of B. theobromae, Pestalotia, Colletotrichum gloeosporioides, A.niger, A.flavus, R.stolonifer and M.phaseolina, thus indicating their suppression by Trichoderma (Bhuvaneswari and Rao 2001).

Pandey and Pandey (2005) evaluated biocontrol efficiency of Trichoderma harzianum against storage diseases of mango : stem-end-rot, anthracnose and black-rot in dual cultures under in-vitro conditions. T.harzianum, because of its ability to sustain under a wide range of environmental conditions, showed mycoparasitism and parasitized colonies within 5-7 days; mode of action is coiling and penetration.

With bacteria. Post-harvest dip with Bacillus licheniformis (isolates B 250, B 251) has been found effective in controlling anthracnose and stem-end-rot in mango-fruits (Korsten et al. 1993). Ripened mangoes inoculated previously with $0.5 \mathrm{ml}$ suspension of Bacillus isolate $\mathrm{B}_{4}\left(10^{9} \mathrm{cfu} / \mathrm{ml}\right)$ and kept at $28 \pm$ $2^{\circ} \mathrm{C}$ showed no symptoms on inoculation with mycelial cultures of $L$. theobromae (Jadeja and Bhatt 2008).

Non-antibiotic producing yeast in combination with chitosan was also used. Addition of chitosan enhanced efficiency of yeast in controlling postharvest decay (Agnihotri et al. 2008).

Fruit coatings. Krishnaiah et al. (1987) tried food grade fruit coatings (FGFC) approved by the Enviornmental Protection Agencies (EPA) at $0.4 \%$ dilutions; no rotting symptoms were observed up to 15 days by fungi like C.gloeosporioides, L.theobromae, A.alternata etc.

Anthracnose, c.o. Glomerella cingulata (Stonem.) Spauld. \& Schrenk.

Conidial state : Colletotrichum gloeosporioides Penz.

Anthracnose is an important cause for losses in mangoes all-over the world. It was reported from India (Tandon and Singh 1968), and was recorded from the USA also (Mc Millan 1984; Splading and Reader 1986), West Indies (Gordillo and Hermandez 1980), South Africa (Jacobs et al. 1973), Malaysia (Lim and Wai 1986), Philippines (Daquioag and Quimio 1979) and Australia (Fitzel and Peak 1984). It was observed to be responsible for $29.6 \%$ decay of total post-harvest spoilage (Sharma et al. 1994). C.gloeosporioides and Gleosporium mangiferae have been reported to cause heavy post-harvest losses to mango-fruits. 
Symptoms : Ripe-mangoes are infected with anthracnose; symptoms appear as brownish irregular spots on the fruitsurface. The spots become sunken and coalesce to form large dull brownish areas on the peel (Fig. 10.3). The pulp beneath the affected peel becomes discoloured. The pathogen is reported to remain quiescent on the peel in the form of hyphae and appressorium (Daquioag and Quimio 1979) till the fruit matures, and then causes damage during transportation, storage and marketing.

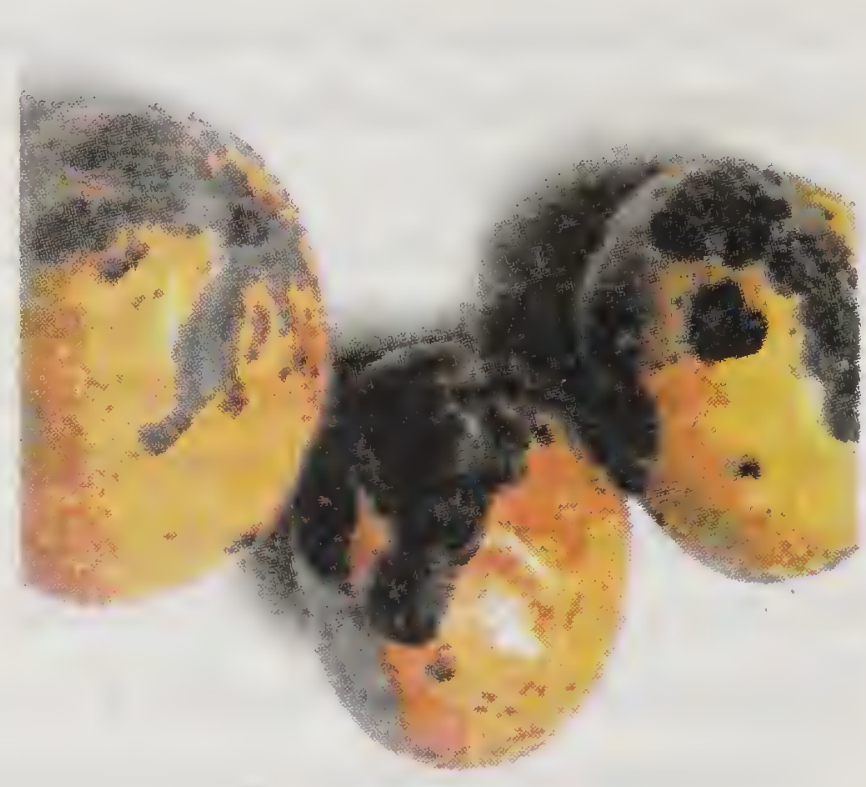

Fig. 10.3. Anthracnose on mangofruits

Symptoms of B.theobromae and C.gloeosporioides are common. But both produce clearly discernible symptoms without mingling (Philip, 2002). Awasthi et al. (2004) from West Bengal studied reaction on 20 cultivars to Diopldia and Colletotrichum fruit-rot and observed several cultivars resistant against both the diseases.

Survey conducted in the mango orchards of Karnataka by Prasanna Kumar et al. (2007) revealed that Neelesham showing maximum anthracnose and Alternaria-rot incidence compared to other varieties.

Control measures : Hot-water treatment of fruits at $53^{\circ} \mathrm{C}$ for 10 minutes or hot-water brushing at $60^{\circ} \mathrm{C}$ for $20-35$ seconds or hot-water dip at $60^{\circ} \mathrm{C}$ for 20-35 seconds reduced anthracnose and stem-end-rot incidence without alterations in physical and chemical characters (Esguerra et al. 2004).

Chemical control. Anthracnose and stem-end-rot can be easily controlled by pre-inoculation dips to mango-fruits in Benlate 1,000 ppm (Pathak and Shekhawat 1976), and with four minutes in Thiabendazole (TBZ) $0.1 \%$ and Carbendazim $0.1 \%$ respectively (Sharma et al. 1994). Mancozeb(0.2\%), Copper oxychloride $(0.5 \%)$ and Prochloraz $(0.1 \%)$ are reported as effective control measures for anthracnose from Australia (Johnson et al. 1989) and copper oxychloride (0.5\%) from South Africa (Lonsdale 1993).

Treating mango-fruits in hot-water $\left(50^{\circ} \mathrm{C}\right)+1 \%$ common salt (sodium chloride) gave maximum control over storage rots. Use of hot-water $\left(50^{\circ} \mathrm{C}\right)$ with half the dose of recommended Methyl thiophenate $(0.05 \%)$ and Carbendazim $(0.05 \%)$ reduced fruit-rots (Kaiser et al. 2001; Saxena and Rawal 2004). This treatment was effective for Botryodiplodia and Aspergillus rots also.

Wax coating. Haden mango-fruits dipped in Benomyl (1g/lit) or Benzalkonium chloride (2g/lit) with clean wax coat (18.5-20.5\% Carnauba wax and acrylic resin) and stored at $13 \pm 1{ }^{\circ} \mathrm{C}$ and $80-90 \%$ relative humidity remained free of infection up to 21 days. Waxing also increased general appearance of fruits (Fonesca et al. 2001, 2004). 
Use of radiations. Lonsdale and Droomer (1994) claimed one-minute exposure to short-wave infrared radiation, followed by 20 seconds dip in Prochloraz $(0.1 \%)$ as an effective control measure for anthracnose and other fruit-rots. Gamma radiations $(0.8$ or $1.0 \mathrm{Krad})$ have also been reported to be effective in increasing shelf-life of mango-fruits (Durigan et al. 2004).

Biological control. Use of plant extracts. These extracts are reported to have fungicidal effect against storage pathogens of mango. Bautista et al. (2002) observed that leaf and stem extracts of Dyospiros ebenaster possess antifungal activity against $C$.gloeosporioides. The solid soluble concentration (SSC) and loss of fruit mass varied with plant extracts. But the extracts did not affect fruit quality.

Antagonistic fungi. Biological control with an antagonistic fungus Fusarium sp. has also been recorded. Mango-fruits inoculated with locally isolated Fusarium sp. remained free of infection from C.gloeosporioides (Bhuvaneswari and Subba Rao 2003). Control with Trichoderma harzianum was also reported under in-vitro studies. Myco-parasitism by coiling and penetration over pathogenic fungus was notice in dual-culture experiments (Pandey and Pandey 2005 a).

Black mould-rot, c.o. Aspergillus niger Van Teighm.; A.aculeatus lizuka

Black mould-rot is common in India (Verma and Kamat 1951; Srivastava 1968; Bhargava and Singh 1975; Pandey et al. 1980; Cheriyan 1987). The disease caused occasional problems in Philippines also (Quimio and Quimio 1974). Patel (1972) observed 16-17\% post-harvest losses due to different species of Aspergillus from Gujarat. Jadeja and Vaishnav(2000) recorded Lasiodiplodia theobromae and A.niger as the important post-harvest pathogens from Gujarat.

Due to the infection, quantity of ascorbic acid in fruits was reduced nearly to half (Gosh et al. 1966).

Symptoms : Greyish or pale-brown spots appear anywhere on the fruitsurface, which becomes soft and sunken with whitish growth and later is covered with a sooty mass of black spores. Stalk-end infection results in premature fruit drop. Injuries on the fruit-surface favour infection.

Control measures : Treating fruits with hot-water at $55^{\circ} \mathrm{C}$ for five minutes (Pathak and Shekhawat 1976) and with hot-water $+1 \%$ sodium chloride gave good control (Saxena and Rawal 2004).

Dipping fruits in Benlate at $1,500 \mathrm{ppm}$ was reported to control rot (Bhargava and Singh1975).

Biocontrol with antagonistic fungi. Trichoderma viride introduced by wound inoculation to mango-fruits inhibited A. niger growth. Control of Aspergillus-rot with a potential antagonist, Fusarium sp., was also reported (Bhuvaneswari and Subba Rao 2001, 2003). 
Yeast isolates used in food processing are potential antagonists. Sharma (2003) observed Saccharomyces cerevisiae Meyer ex Hansen isolate S 4 (@ $10^{8} \mathrm{cfu} / \mathrm{ml}$ ) and four species of Kluyveromyces as highly effective against fruitrot of mango caused by Aspergillus niger. Wounds were made in the mangofruits and were treated with $20 \mathrm{ml}$ of yeast suspension. After drying of wound, each wound was challenged with $20 \mathrm{ml}$ of A. niger $\left(10^{\dagger}\right.$ spores $\left./ \mathrm{ml}\right)$. It is assumed that competition for nutrients played an important role in control of fruit-rot of mango caused by A.niger (Sharma and Nigam 2000; Sharma and Gosh 2000).

\section{Black-blotch, c.o. Aspergillus flavus Link. ex Fries}

The disease was reported by Majumder and Modi (1980).

Symptoms : The disease is charcterized by blackening of peel and softening of tissues of ripe mangoes. Due to infection, three-fold decrease was noticed in total reducing sugars (Majumder and Modi 1980). Cheriyan (1987) recorded water-soaked lesions with greenish-yellow fungal growth. Then fruits became soft and juicy.

\section{Soft-rot, c.o. Rhizopus oryzae Went \& Prinsen Geerligs} $R$. arrhizus Fischer

The disease is widespread in India, and has been recorded from Andhra Pradesh, Punjab, West Bengal and Kerala (Thakur and Chenulu 1970a; Laxminarayana and Reddy 1975; Garcha and Singh 1980; Cheriyan 1987; Philip 2002). Injuries favour Infection. At low temperature $\left(7-8^{\circ} \mathrm{C}\right)$, disease development is of low intensity and is slow, and it is fast between $20^{\circ}$ and $40^{\circ} \mathrm{C}$ (Thakur 1972).

Symptoms : The pathogen incites a type of soft-rot; growth of the fungus is fast. Fruit-peel turns black and in the advanced stages, pulp beneath the peel collapses; profuse leakage is also noticed.

Control measures : Dipping mangoes in $6 \%$ Borax solution at $43^{\circ} \mathrm{C}$ or hotwater $\left(52^{\circ} \mathrm{C}\right)$ was effective (Thomas and Dalal 1968). Thakur and Chenulu (1970) observed protection of mango-fruits against soft-rot by R.arrhizus for 20 days by dipping fruits in 2-aminothiazole +2 -aminopyridin (at $5 \%$ concentration each).

Antagonistic nature of Fusarium sp. against Rhizopus sp. has been reported (Bhuvaneswari and Subba Rao 2003).

\section{Black soft-rot, c.o. Phomopsis mangiferae Ahmad}

Sharma et al. (1994) recorded this disease along with several other pathogens. The fungus produces discrete and discoloured areas all-over the fruit. Infected areas turn dark brown to black on maturity. Occasionally, several spots coalesce to form large patches. The underlying tissues get sloughed off and turn into a soft juicy mass. Black fruiting bodies are clearly visible on these spots (Laxminarayana and Reddy 1975). 


\section{Black-rot, c.o. Alternaria alternata (Fries)}

From West Bengal, brown-rot due to A. tenuissima was also recorded (Mukherjee and Bhattacharya 1969). This disease is of particular significance in Israel, where it is more common than anthracnose (Prusky et al. 1983). The fungus penetrates into the lenticels of immature fruits, and enters into a latent or quiescent stage soon after when the initial stages of infection are complete. After harvest, fruits as they mature lose their resistance and pathogen resumes growth and active lesions are seen on the fruit-surface (Pathak 1997).

The possibility of assessing latent infections as the basis for control of post-harvest disease was tried. The spores could be detected from fruits as well as during the entire period of fruit growth. Based on this, pre- and postharvest treatments can be manipulated (Prusky et al. 1983).

Combination of hot-water spray and hot-water brushing (HWB) for 1520 seconds with Prochloraz $(225 \mu \mathrm{g} / \mathrm{ml})$ was most effective treatment in reducing quiescent infections of $A$. alternata (Prusky et al. 2002).

\section{Storage-rot, c.o. Sclerotium rolfsii Sacc. (Corticium rolfsii Curz.)}

The affected fruits show grey, irregular lesions, scattered all-over the fruitsurface. Fruit-skin becomes soft and discoloured (Dharm Vir and Sharma, 1965; Cheriyan 1987).

Sooty-mould, c.o. Capnodium sp. Meliola sp.

The disease causes dark blemishes on the fruit-surface (Philip 1998) (Fig. 10.4). Insect infestation and deposition of honeydew favours disease.

Bleaching solution $(0.05-0.1 \%)$ is reported to be appropriate for cleaning fruit-rind (Dalvi et al. 2002).

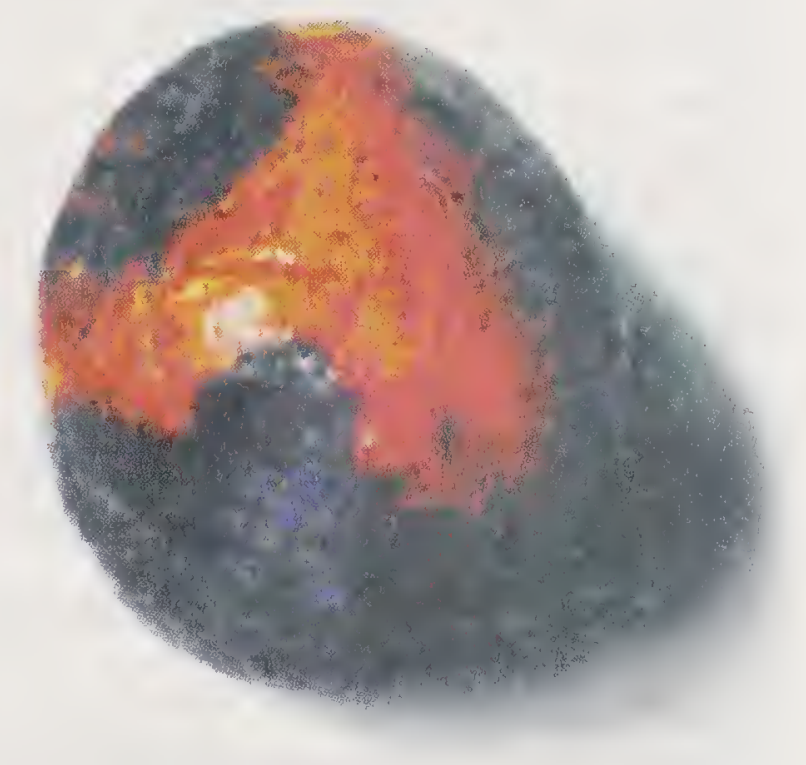

Fig. 10.4. Sooty-mould on mango

\section{BACTERIAL DISEASES}

\section{Bacterial black-spot/mango bacterial canker,}

c.o.Xanthomonas campestris pv mangiferae indicae (Patel, Moniz \& Kulkarni) Dye

Bacterial black-spot was recorded from India (Rao et al. 1977; Bose and Singh 1980), and from hot-humid climatic areas of South Africa (Kotze et al. 1976; Manicom 1986), Australia (Mofett et al. 1979) and Taiwan (Lia 1975).

Symptoms : Small, dark lesions appear on the peel with a sunken centre and raised margin. During the wet weather, bacteria wash down from the tree top 
and can infect sound immature fruits through lenticels and stomata. The disease symptoms appear at fruit ripening. Sinha and Hinda (1988) observed severity of canker in popular mango varieties like Malgoa, Alphonso, Neelum, Rumani and Baneshan in south India.

Control measures : In Lucknow, dipping fruits in streptocycline (200 ppm) was reported to be effective against canker (Mishra and Om Prakash 1992). Disease management by leaf-based liquid pesticides showed promising results. Azadirachta sp., Pongamia sp. and Aegle marmelos based liquid preparations were effective in reducing disease intensity; it was observed to be on a par with streptocycline treatment (Kishun 2008).

\section{Bacterial-rot, c.o. Pseudomonas mangiferae indicae}

(Patel et al.; Bergy et al.)

The disease is noticed in all mango-growing areas.It attacks mango leaves and fruits. Fruit losses are very serious and sometimes whole crop is damaged. In the initial stages, tiny, water-soaked dark-brown spots appear on the leaves, panicles and fruits. The spots gradually increase in size and become slightly raised. At this stage, if it rains, the disease will take an epidemic form. Affected tissues exhibit deep longitudinal cracks and gum exudation. Such fruits drop prematurely and are unfit for consumption. Shekhawat and Patel (1975) observed fruit rotting before harvest as well as during storage.

Control measures : Cultivation of resistant varieties such as Bombay Green is promising. Rao et al.(1977) suggested dipping of fruits in Agrimycin/ streptomycin $(250 \mathrm{ppm})$ or streptocycline $(50 \mathrm{ppm})$ to be effective in reducing

\section{OTHER FRUIT-ROTS AND CAUSAL ORGANISMS}

\begin{tabular}{|c|c|c|}
\hline Disease & Causal organism & Authority \\
\hline Scab & Elisinoe mangiferae & Bitancourt and Jenkins, 1946 \\
\hline Sclerotium fruit-rot & Scelerotium rolfsii & Dharm Vir and Sharma, 1965 \\
\hline \multirow[t]{3}{*}{ Fruit-rots } & Pestalotiopsis versicolor & Anon., 1967 \\
\hline & P.glandicola & Ullasa and Rawal, 1989 \\
\hline & Dothiorella ribis & Sharma et al., 1994 \\
\hline \multicolumn{3}{|c|}{ Corky nasal-end rot Macrophoma mangiferae } \\
\hline Powdery-mildew & \multicolumn{2}{|l|}{ Oidium mangiferae Berthet } \\
\hline Black-spot & Rhizoctonia bataticola & Chhatpur et al., 1972 \\
\hline Dry-rot & Boothiella tetraspora & Tandon and Srivastava,1974 \\
\hline Charcoal-rot/ & \multicolumn{2}{|c|}{ Macrophomina phaseolina Dhawan,1982 } \\
\hline Blue-mould & Penicillium cyclopium & Palejwala and Modi, 1985 \\
\hline Macrophomina-rot/ & Macrophomina sp. & Jadeja and Vaishnav, 2000 \\
\hline Ripe red-rot & \multicolumn{2}{|l|}{ Penicillium purpurogenum } \\
\hline Phyllosticta-rot & \multicolumn{2}{|c|}{ Asexual stage of Guignardia mangiferae } \\
\hline Hendersonia-rot & \multicolumn{2}{|c|}{ Hendersonia cereberrina } \\
\hline Sooty-blotch & \multicolumn{2}{|l|}{ Gloeodes pomigena } \\
\hline Black-spot & Rhizoctonia bataticola & Chhatpur et al. ,1972 \\
\hline
\end{tabular}


intensity of pustules. In Bengaluru, after fruit-set, monthly Bavistin spray (1,000 ppm), followed by Agrimycin (100 ppm) was effective in containing the disease (Anon., 1983a). Dipping of fruits in streptocycline (200 ppm) was found to be effective in Lucknow (Mishra and Om Prakash 1992).

\section{POST-HARVEST DISEASES MANAGEMENT}

\section{Pre-harvest orchard treatments}

To control anthracnose, stem-end-rot and other diseases, pre-harvest treatments, careful harvesting and proper handling are found important (McMillan 1984). Effectiveness of Benomyl application in the field was reduced due to development of resistant strains of Colletotrichum gloeosporioides and Lasiodiplodia theobromae (Spalding 1982).

In the USA, withdrawal of Benomyl from post-harvest use has been reported (Sanchez 1990). In Andhra Pradesh, pre-harvest Carbendazim (0.1\%) application, three times at fortnightly intervals, followed by fruit dip at the harvest stage, resulted in lowering of disease incidence and showed higher decay reduction index (DRI) (Reddy et al. 2004).

Fruits ripened on the trees are not suitable for storage due to their high susceptibility to fungal infection.

Mangoes show a climacteric pattern of respiration; during ripening, pulp becomes soft and juicy with a rich aromatic flavour. Mangoes meant for storage or export should be harvested at the mature green stage, before the start of climacteric changes (Lakshminarayana 1973).

Pathak (1980) has suggested following precautionary measures, especially for controlling Diplodia stem-end-rot, which is the most important post-harvest disease.

- Harvesting should be done on clear days.

- Injuries should be avoided at all stages of handling.

- Care should be taken to prevent snapping off of pedicel.

- Fruits should be covered and transported to ripening houses immediately after harvest.

- It is of added advantage to coat exposed pedicel-end with Chaubattia paint.

Uniform ripening is induced by introducing gas-ethylene into ripening room (Fuchs et al. 1975) or fruits are dipped in ethephon to release ethylene. The process accelerates fruit ripening and improves peel colour.

The following treatments increase shelf-life of the harvested mangoes.

\section{Storage under refrigeration}

Mangoes picked-up green at the proper stage can be preserved under refrigeration for several weeks. Karmarker and Joshi (1942) and Cheema et al. (1950) observed that many varieties when picked fully mature and firm could be stored for $4-7$ weeks at $3.9-9^{\circ} \mathrm{C}$. The recommended storage 
temperatures are within $10-15^{\circ} \mathrm{C}$ for green fruits and $7-8^{\circ} \mathrm{C}$ for ripe-fruits. Most varieties are stored at 5.6-7.2 ${ }^{\circ} \mathrm{C}$ and $85-90 \% \mathrm{RH}$; and for some varieties, $8.9-11^{\circ} \mathrm{C}$ has been more suitable (Srivastava 1967 ). Fruits stored at 7.2-8.8 ${ }^{\circ} \mathrm{C}$, either immediately or after holding for two days, remained in good condition with less than $15 \%$ weight loss and spoilage for 25 days, and those stored after four days holding, could be preserved well for 15 days only (Mann and Singh 1975).

Controlled atmosphere storage at $13^{\circ} \mathrm{C}$ with $5 \% \mathrm{O}_{2}$ and $3.5 \% \mathrm{CO}_{2}$ was effective (Kader 1985).

Storage at $12-13^{\circ} \mathrm{C}$ is generally considered optimum with variations according to the cultivar and the stage of harvest maturity (Medlicott et al. 1990). Low temperature storage is reported to cause chilling injury (Chaplin et al. 1991). Pulp of Haden mangoes stored in Mexico for 37 days $\left(13 \pm 1^{\circ} \mathrm{C}\right.$ and $85-90 \%$ RH) blackened in 22 days of storage. Fruits showed marked loss in weight,were less firm and showed lower concentration of malic acid (Acosta et al. 2001).

\section{Hot-air/hot-water treatment}

Dipping in hot-water at $50^{\circ} \mathrm{C}$ for 15 minutes was effective for Langra and Dasheri (Tandon and Singh 1968). For other varieties, along with this was recommended cold storage $\left(9-10^{\circ} \mathrm{C}\right)$ for 5 weeks. But Chausa fruits could be stored without much change in general appearance and flavour up to 47 days. Pennock and Maldonaldo (1962) and Merino et al. (1985) obtained protection with high humidity hot-air vapour heat. Dipping in hot-water at $46^{\circ} \mathrm{C}$ for $60-120$ minutes or at $48^{\circ} \mathrm{C}$ for 60 minutes (Spalding and Reader, 1986) as well as at $52^{\circ} \mathrm{C}$ for 30 minutes also offered protection (Om Prakash and Pandey 2000). In Pakistan, dipping in hot-water at $55^{\circ} \mathrm{C}$, immediately followed by dipping for 5 minutes in hot-water at $50^{\circ} \mathrm{C}$ was reported to protect fruits from microbial spoilage (Wagan et al. 2001). Hot-water treatment at $52-55^{\circ} \mathrm{C}$ for 5 minutes was recommended for uniform ripening with minimum spoilage (Krishnamoorthy and Rao 2001). Durigan et al.(2004) and Esguerra (2004) reported reduced disease incidence due to hot-water treatment $\left(53^{\circ} \mathrm{C}\right.$ for 10 minutes/ hot-water brushing at $60^{\circ} \mathrm{C}$ for $20-35$ seconds/ hot-water dip at $60^{\circ} \mathrm{C}$ for $20-25$ seconds). Physical and chemical characters of the fruits were not influenced; the treatment was effectve in reducing anthracnose and stemend infections.

\section{Use of radiations}

Lonsdale and Droomer (1994) claimed that one minute exposure to short wave infra-red radiation, followed by 20 seconds dip in Prochloraz $(0.1 \%)$ was effective in controlling anthracnose and soft-rots. Gamma radiations are reported as effective in increasing shelf-life of mango-fruits (Durigan et al. 2004). 


\section{Use of wrappers and plastic-film packing}

Singh (1941) had suggested use of wrappers treated with double-boiled linseed oil as effective. Plastic film wrapping also offered protection. This ensured better storage and limited losses during transportation. The severity of rotting due to stem-end-rots, anthracnose and other rots was significantly reduced due to wrapping in plastic films.Wax-coating was reported to increase shelf-life of mango-fruits up to 14 days (Cheriyan 1987).

Encouraging results were noticed with mangoes stored in heat-shrinkable plastic films at $21^{\circ} \mathrm{C}$ for 14 days (Miller et al. 1983). The fruits were firm in texture and were of good colouration than non-wrapped fruits. Ben-yehoshua (1985) also recorded reduced shrinkage and extended shelf-life with mango-fruits stored in heat shrinkable polyolein films (D-955). Wrapping in plastic films, followed by incubation at $30 \pm 2{ }^{\circ} \mathrm{C}$ and $75-90 \% \mathrm{RH}$, significantly reduced rot severity (Chandra and Pathak 1992). Mango-fruits wrapped individually in polyolein films as well as in low density polyethylene film (LDPE) and stored at $12-17^{\circ} \mathrm{C}$ also showed increased shelf-life up to 30 days with no weight loss (Yamashita et al. 1997).

Individual packing reduces water loss by transpiration and thereby maintain a water saturated atmosphere and a gaseous concentration close to that of air. Reduction in metabolic activity of the storage fungi was also reported. Decay was also lesser with fruits packed with ethysord paper as lining material (Nain et al. 2000).

\section{Chemical protection}

Dipping mangoes in $6 \%$ Borax solution at $43^{\circ} \mathrm{C}$ or hot-water $\left(52^{\circ} \mathrm{C}\right)$ was recorded as effective (Thomas and Dalal 1968).

Dipping in calcium chloride solution is also observed to be effective. Fruits dipped in cold solutions containing up to $8 \%$ calcium chloride and $0.1 \%$ Tween 20 for 2 hours, followed by storage at $15 \pm 2^{\circ} \mathrm{C}$, RH $90 \pm 5 \%$ retarded colour development and textural softening. At 4-6\% concentration, shelf-life was extended up to 9 days under ambient temperature and 14 days under cold storage (Suntharalingam 1996).

\section{Use of antibiotics and fungicides}

Post-harvest treatments with antibiotics and fungicides are commonly practised.

Various fungicides offer protection. The common fungicides include Bavistin (500 ppm), Captan (0.2\%) and TBZ (0.1\%) (Gadre, 1979; Gupta and Srivastava 1979; Srivastava 1984; Cheriyan 1987; Sharma et al. 1994). Philip and Cheriyan (1995) observed Bavistin $500 \mathrm{ppm}$ as the most efficient fungicide in enhancing shelf-life up to 35 days without any residual toxicity.

Dipping mango fruits in Carbendazim(0.1\%), Benomyl (500 ppm) and Thiophenate-methyl $(0.1 \%)$ solution, followed by packing in bamboo baskets, deal wood boxes and ventilated corrugated fibre board boxes (CFB) was 
reported as effective in increasing shelf-life of fruits (Lakshmi et al. 2003). Benomyl-treated fruits showed minimum weight loss and lowest post-harvest spoilage.

Haden mangoes dipped in Benomyl or Benzalkonium chloride ( $2 \mathrm{~g} /$ litre $)$ with or without clean wax could be stored at $13 \pm 1{ }^{\circ} \mathrm{C}$ at $80-90 \% \mathrm{RH}$ for 21 days (Fonesca et al. 2001 2004; Durigan et al. 2004).

\section{Use of fungicide plus wax emulsion}

Dipping fruits in Benomyl (1g/litre) and Benzalkonium chloride (2g/litre) alone or in combination with clean wax-coat (18.5-20.5\% carnauba wax and acrylin resin) improved general appearance, firmness, brightness and delayed fruit-ripening. Physiological losses in weight (PLW) were lower in wax-coated samples and shelf-life was also extended up to 12 days (Raj Kumar et al. 2008). 


\section{CHAPTER \』 \\ Papaya (Carica papaya L.)}

Papaya is a commercial fruit-crop in India. It is rich in sugars and is a good source of vitamins A, C and minerals. Besides, it contains well-known digestive enzyme 'papain'.

Effect of the fungal infection on the content of ascorbic acid (vitamin C) of fruits was studied by a number of workers (Gosh et al. 1966). Prasad and Verma (1976) investigated post infection changes in papaya due to infection by Alternaria tenuis, Chaetomium globosum, Curvularia lunata, Cylindrocarpon tonkinense, Fusarium oxysporum and Helminthosporium speciferum. All pathogens caused significant reduction in ascorbic acid content. Disappearance of ascorbic acid due to pathogenesis was highest with Cylindrocarpon tonkinense, and was lowest with Chaetomium globosum. Alterations in the phenol metabolism were also noticed (Agarwal and Agarwal 1982).

\section{FUNGAL DISEASES}

Anthracnose, c.o. Glomerella cingulata (Stonem.) Spauld. \& Schrenk. Conidial state: Colletotrichum gloeosporioides (Penz.) Sacc.

This is considered an important post-harvest disease in most of the papayagrowing countries-India (Gupta and Pathak 1988; Mohan and Lakshmanan 1989), East Africa, Australia, Taiwan, Hawaii and Singapore (Wallace and Wallace 1948; Tsai 1969; Chau and Alvarez 1983; Dickman and Alvarez 1983; Lim and Tang 1984).

Five species of Colletotrichum: C.capsici, C.circinanas, C.dematium and C.papayae, besides the pathogen C.gloeosporioides have been reported.

Symptoms : They appear only when fruits are fully ripe (Sepiah et al. 1991). The fungus initially establishes on the attached immature fruits by direct cuticular penetration, and symptoms manifest on the fruit surface as chocolate spots or lesions when fruit reaches climacteric phase. In the initial stages, lesions are brown and later enlarge to water-soaked, circular and slightly sunken patches. The lesions may coalesce and scanty white mycelial growth is seen on the margins. Under the humid conditions, centre of the lesion may 
show salmon-coloured pink spore mass. Fruit pulp becomes dark brown and rotten from inside.

Stem-end-rot infection may also be noticed on the harvested fruits. Leaves, petioles and stem may serve as the source of primary infection. Seed-borne nature of Colletotrichum is also established. High relative humidity favours fungus infection, and low or high temperature reduces disease development (Om Gupta and Neema 1979, 1979a).

C.gloeosporioides has also been observed causing infection on unripe papaya fruits (Misra and Om Prakash1986). Very young fruits, 5-10 days old, are also infected; entire fruit-surface is covered with whitish fungal growth. Slightly bigger fruits show symptoms like cigar-end-rot with a burnt tip. White concentric rings are observed over the infected patches, and the colour changes to pink and finally turns black. Infection is also noticed at the stem-end region. This results in weakening of pedicel, followed by premature fruit drop. On the early tender fruits, 93\% infection was recorded (Mishra and Kumar 1987; Mary 1998).

Control measures : Pre-harvest application of fungicides. Control of postharvest stem-end-rots due to C.gloeosporioides and Ascochyta caricae by preharvest spraying of orchards at biweekly intervals using Chlrothalonil (1.7-3.4 $\mathrm{kg}$ ai/ha) or Benomyl (0.56kgai/ha) was recorded (Alvarez et al. 1977).

Post-harvest treatments. Dipping fruits in hot-water at $46-49^{\circ} \mathrm{C}$ for 20 minutes after harvest was recorded to give protection from stem-end-rots and anthracnose (Akamine and Arisumi 1953). Spraying whole fruit with hot-water at $54^{\circ} \mathrm{C}$ for 3 minutes was found effective as compared to immersion treatment. Post-harvest application of Thiabendazole $(0.1 \%)$ reduced disease incidence (Couey et al. 1984). Low pressure storage $\left(15 \mathrm{~mm} \mathrm{Hg}\right.$ and $10^{\circ} \mathrm{C}$ ) was also effective for controlling the disease without damaging fruits (Chau and Alvarez 1983). Dipping harvested fruits in Maneb (0.2\%) solution also offered protection (Raabe and Holtzmann 1964).

Biological control. Plant extracts. Crude leaf and stem extracts of Carica papaya possess antifungal activity and inhibited Colletotrichum fruit-rot completely (Bautista et al. 2002).

With yeast. Dipping fruits in $2 \%$ sodium bicarbonate incorporated wax formulation and coating with biocontrol agent Candida oleophila are commercially accepted as an alternative to chemicals for post-harvest control of anthracnose (Gamagae et al. 2004).

Phytophthora-rot, c.o. Phytophthora palmivora Butler

P. capsici Leonian

P. parasitica Dastur

The disease was reported from Brazil (Trindade and Politronieri 2002). 
It is common in homestead farms of Kerala during south-west monsoon (Philip 2002).

Symptoms : The disease originates as small water-soaked discoloured spots on the mature fruits. The fungus causes a soft watery rot, and under the warm humid conditions, fungus development can be noticed on the fruit surface. On mature fruits, lesions may occur on any part of the fruit. Green fruits are resistant to infection.

Control measures : Spraying trees at weekly or biweekly intervals with Difolatan (0.25) as well as Dithane M-45 (0.2\%) gives control against infection of fruits by P.palmivora (Wang and Chien 1975). Regular application of Mancozeb $(0.2 \%)$ help control storage rots.

Hot-water treatment $\left(49^{\circ} \mathrm{C}\right.$ for 20 minutes) is generally practised for controlling Phytophthora fruit-rot. P. palmivora, $P$. nicotiane var. parasitica as well as $P$. capsici are tolerant to high temperature (Aragaki et al. 1981). Dipping harvested fruits in hot-water maintained at $50^{\circ} \mathrm{C}$ for five minutes protected fruits.

\section{Rhizopus fruit-rot/watery-rot/soft-rot,}

\section{c.o. Rhizopus stolonifer (Ehrenb.) Vuill. R. arrhizus Fischer}

This fungus causes destructive rot in papaya, and losses by this have been reported from Hawaii (Akamine and Arisumi 1953; Hunter et al. 1969) and from different parts of India (Tandon and Mishra 1969; Mishra and Kumar 1987; Vyas et al. 1993).

Symptoms : They appear on the fruit-surface as irregular water-soaked lesions, which gradually enlarge and get covered by white fungal growth (Fig. 11.1). Infection spreads rapidly and the fruit may collapse within 2-3 days with exudation of sap and foul smell. The rot spreads to other fruits also. Fruit-fly puncture increases disease incidence (Hunter and Buddenhagen 1972). Even slightly bruised fruits may suffer. Some yeast may also infect in situ, which results in still faster rate of decay (Das Gupta and Mandal 1989). A fermentative odour may persist.

Ascorbic acid content of fruits reduces to the maximum by $R$. nigricans (Ghosh et al. 1966). Reduction in sugar content was also recorded. Vyas et al. (1993) observed role of cell-degrading enzymes and toxins in pathogenesis.

Control measures : Careful harvesting and handling are essential

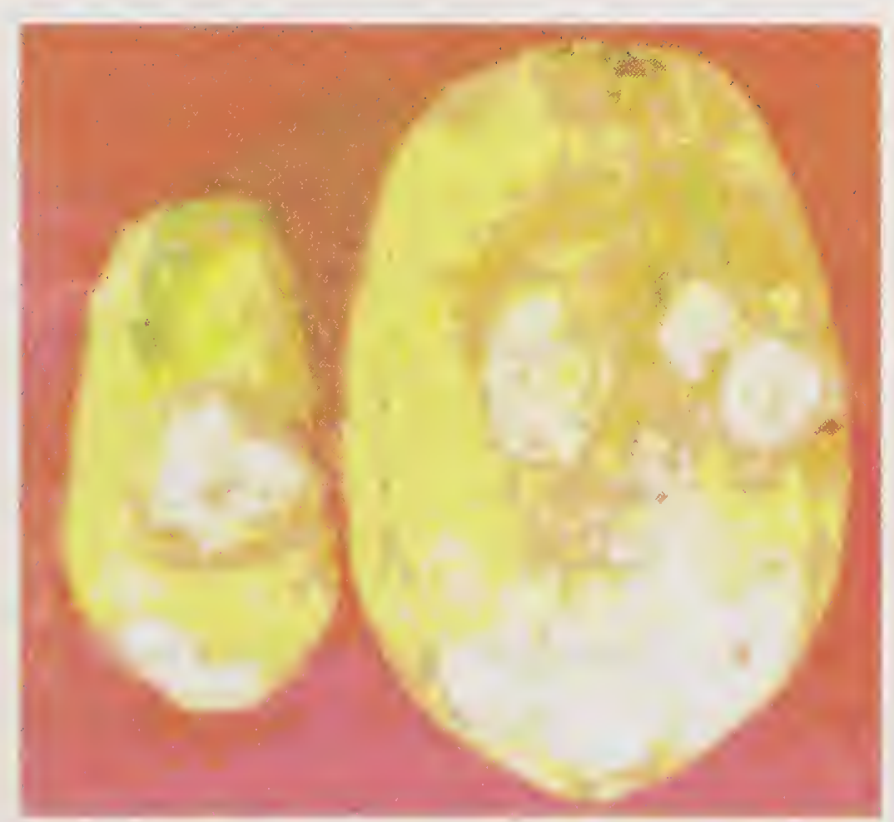

Fig. 11.1. Rhizopus fruit-rot on papaya 
to prevent bruises on the peel. The disease can be checked by low temperature storage. Fruits are generally dipped in hot-water at $49^{\circ} \mathrm{C}$ for 20 minutes (Pathak et al. 1972).

Use of fungicides. Dipping fruits in TBZ (0.1\%) (Arisumi 1956), DCNA (2, 6-dichloro-4 nitroaniline) at 1,000-2,000 ppm and Allisan at 1,000 ppm offered good results (Hunter et al. 1969). Aureofungin $1,000 \mathrm{ppm}$ was also reported to be effective.

Biological control. Pre-treatment with culture filtrate of Bacillus subtilis protected fruits from storage decay due to $R$. nigricans for three days (Podile and Dube 1988). In dual-culture experiements, pathogen failed to produce sporangia, and mycelia were malformed.

\section{Alternaria-rot, c.o. Alternaria alternata (Fr.) Keissler}

\section{A. tenuis Auck}

The disease was reported from Bihar (Prasad and Verma 1980).

Symptoms : The disease is characterized by grey, brown, circular to semicircular patches covered with mycelial growth, and is also recorded on immature fruits. Affected fruits develop typical yellowing at the infection site and show blackening of tissues with greyish mycelia when fruits are cut open. Infection occurs from the fruit centre to periphery, and fruits fail to ripen by remaining hard and are unfit for papain extraction or consumption. Plants bearing infected fruits also show severe infection on leaves.

Control measures : Spraying trees at weekly or bi-weekly intervals with Difolatan $(0.25 \%)$ as well as Dithane M-45 $(0.2 \%)$ gives control against fruitrots in storage.

Dipping fruits in hot-water at $49^{\circ} \mathrm{C}$ for 20 minutes is effective in controlling storage-rots.

\section{Ascochyta-rot, c.o. Ascochyta caricae Pat.}

The disease was reported from India. The pathogen causes fruit- and trunk-rot (Chowdhury (1950). Sirdhana and Jain (1962), Ghosh et al. (1966), Tandon (1967), Srivastava and Tandon (1971) and Gupta and Pathak (1988) recorded fruit-rot.

Symptoms : Infection occurs on half-ripe or mature fruits, which show small circular water-soaked lesions that become sunken and brownish black. As the disease progresses, rot proceeds irregularly. Rotting becomes severe at $30^{\circ} \mathrm{C}$ and $100 \%$ RH.

Control measures : Pre-harvest spraying of fruits with Bordeaux mixture $(2: 2: 50)$ at 21-30 days interval at the time of fruit-set contained disease. And spray with Chlorothalonil at $1.7-3.4 \mathrm{~kg}$ ai/ha was also effective (Alvarez et al. 1977). 
Dipping fruits in hot-water at $48-49^{\circ} \mathrm{C}$ for 20 minutes was found promising (Hunter et al. 1969). And dipping them in 2-aminobutane carbonated solution (1-\% ai) or fumigating them with 2-aminobutane were also effective. Spaying systemic fungicides like Benomyl (500 ppm) and TBZ $(0.05 \%)$ (Bolkan et al. 1976) as well as hot water treatment $\left(50^{\circ} \mathrm{C}\right)$ for five minutes, followed by Benomyl(500 ppm) offered protection to harvested fruits (Brodrick et al. 1972).

\section{Botryodiplodia fruit-rot, c.o. Botryodiplodia theobromae Pat.}

The disease has been reported to be common in India (Siradhana and Jain 1962; Prasad and Varma 1970; Sreevastava and Tandom 1971; Philip 2002). The fungus incites stem-end-rot and fruit-rot. Symptoms of this disease can be confused with those of Ascochyta-rot. Temperature of 25 to $30^{\circ} \mathrm{C}$ with high relative humidity favour development of diseases on papaya (Om Gupta and Neema 1979).

Symptoms : They appear as water-soaked lesions around the injuries. Infection spreads to surrounding areas, and soon affected portion becomes shrivelled and turns dark-brown. Infected fruits get covered with fungal growth completely within 5-7 days,. Numerous pycnidia of the pathogen appear after seven days (Philip 2002). And infection of the fruit-stalk results in fruit drop. Infected fruits showed reduction in ascorbic acid content (Ghosh et al. 1966).

Control measures : Hot-water treatment at $49^{\circ} \mathrm{C}$ for 20 minutes protects against this rot.

\section{Fusarium-rot, c.o. Fusarium spp.}

Raabe (1964) reported post-harvest dry fruit-rot decay due to Fusarium solani. This rot was recorded from Bengal (Chattopadhyay and Mustaffee 1967). Fusarium acuminatum, $F$. equiseti and $F$. oxysporum were recorded from Allahabad markets and orchards (Bihari Lal and Arya 1980). Gupta and Pathak (1988) observed F. equiseti, F. moniliforme, F. oxysporum, F. scripi, $F$. semitectum and $F$. tabacinum along with several other fungi causing rot. $F$. equiseti was also reported by Saxena and Saksena (1984).

Symptoms : Affected fruits show small surface lesions with profuse white hyphae. Bihari Lal and Malaviya (1994) observed severely fruit-rot affected fruits from Allahabad markets. The disease appears as water-soaked, light brown spots, which enlarge and eventually turn black. The whole fruit rots within 10 days. Pulp rotting is faster than rotting of rind; pulp turns black and emits fermented odour.

Control measures : Hot-water treatment $\left(49^{\circ} \mathrm{C}\right.$ for 20 minutes $)$ was reported to be effective. Aureofungin (1,000 ppm) was promising in controlling the disease (Pathak and Sekhawat1976; Prasad and Verma 1980). 


\section{Phomopsis fruit-rot / brown crack-rot,}

\section{c.o. Phomopsis caricae papayae Petrak and Cif.}

The disease was recorded from Madhya Pradesh (Dhingra and Khare 1971; Mishra and Kumar 1987). The fruits were infected while still on the plant. Post-infection changes in sugar content were recorded by Dhingra and Khare (1974).

Symptoms : Infection appears in storage as water-soaked lesions, which gradually increase in size. Spots then depress and turn brown to black. Whole fruit becomes soft and pulpy and cracks at the later stage. In some fruits, rotted portion gets surrounded by raised tissue, white in colour.

Control measures : Borax (2\%), Benlate (500 ppm), Captan (0.2\%), Difolatan $(0.2 \%)$ and Dithane M-45 (0.2\%) applications are effective in containing disease on the detached fruits.

\section{Fruit-rot / hard black pimples, c.o. Macrophomina phaseoli (Maubl.)}

The disease was reported from Punjab (Kapur and Chohan 1968, 1974) and Bihar (Mishra and Kumar 1987). The rot is responsible for 5-20\% losses during summer.

Symptoms : Infection starts as small, water-soaked spots, which appear as circular specks on the fruit surface. The spots gradually enlarge and become sunken. Infected fruits turn brown to black with disintegration of internal contents. Finally, affected tissues harden, and black microsclerotia are clearly visible. Kapur and Chohan (1974 a) observed maximum decay of fruits at $30^{\circ} \mathrm{C}$ with $100 \% \mathrm{RH}$. Rotting at $30^{\circ} \mathrm{C}$ and at relative humidity between 60 and $90 \%$ was also severe. Pricked surface was more conducive to rapid infection and disease development compared to deeply cut or wounded surface. Control measures : Ziram (76\% zinc dimethyl dithiocarbamate), Captan $(50 \%$ $\mathrm{N}$-trichloro methyl thio tetrahydrophthalimide) and Ferbam (76\% ferric dimethyl dithiocarbamate) were found efficient protectants against fruit-rot in in-vitro studies (Kapur and Chohan 1974).

\section{Pink-rot, c.o. Neurospora crassa Shear \& B.O. Dodge}

The disease was reported from Uttar Pradesh. Infected fruits showed softrot on the fruit-surface. And the infected areas were pink, soft and pulpy (Tandon and Srivastava 1974). No specific control measures are available.

\section{Fruit-rot, c.o. Stemphylium lycopersici (Enjoji) Yamamoto}

The disease was observed on cold storage fruits in Hawaii.

Symptoms : Dark-brown sunken lesions appear with distinct reddish-brown margins. The pathogen infects fast wounded fruits, and symptoms appear usually after extended cold storage (7-21 days). Lesion size and disease incidence reduces when storage temperature decreases to $4{ }^{\circ} \mathrm{C}$ (Chau and Alvarez 1983). 
Control measures : Wounded fruits should not be stored. Cold storage of fruits should not be encouraged beyond 21 days. Storage at $4^{\circ} \mathrm{C}$ is considered effective.

\section{Aspergillus- and Penicillium-rots}

Saxena and Sharma (1981) recorded Aspergillus niger and A.flavus while Gupta and Pathak (1988) and Philip (1998) observed A.niger, A.flavus, A.fumigatus, A.nidulans, A.tamarii and A.terreus from infected fruits.

Symptoms : On fully ripened and injured fruits, symptoms of A.niger appear at first as water-soaked spots. These spots enlarge to about $2-3 \mathrm{~cm}$ in diameter within 2 days and their centre turns black due to the presence of profuse conidial heads, surrounded by scanty white fungal growth. The whole fruit decays within 5-7 days with profuse exudation of sap.

Penicillium spp. are also recorded to cause rotting; these include $P$. funiculosum and P.citrinum (Saxena and Sharma 1981), P.islandicum (Gupta and Pathak 1988) and P.implicatum (Albornettn and Sanabria 1994) and Penicillium sp.

Control measures : Fruits should be handled carefully to avoid wounds and bruises. Storage under refrigerated conditions help prolong storage life. Hotwater treatment as detailed under Botryodiplodia-rot is also applicable here.

\section{Corynespora fruit-rot, c.o. Corynespora cassiicola Curt. \& Wei.}

The disease is rarely observed in orchards. The disease was recorded by Mary (1998) from Kerala.

Symptoms : The tip of the fruit becomes dry black and shrunken resembling cigar-end disease of banana. The symptoms originate on immature fruits and are carried on mature fruits during storage (Fig. 11.2). The lesion becomes brown and the surrounding area is yellow in colour. On mature fruits symptoms are noticed anywhere on the fruit surface (Fig. 11.3).

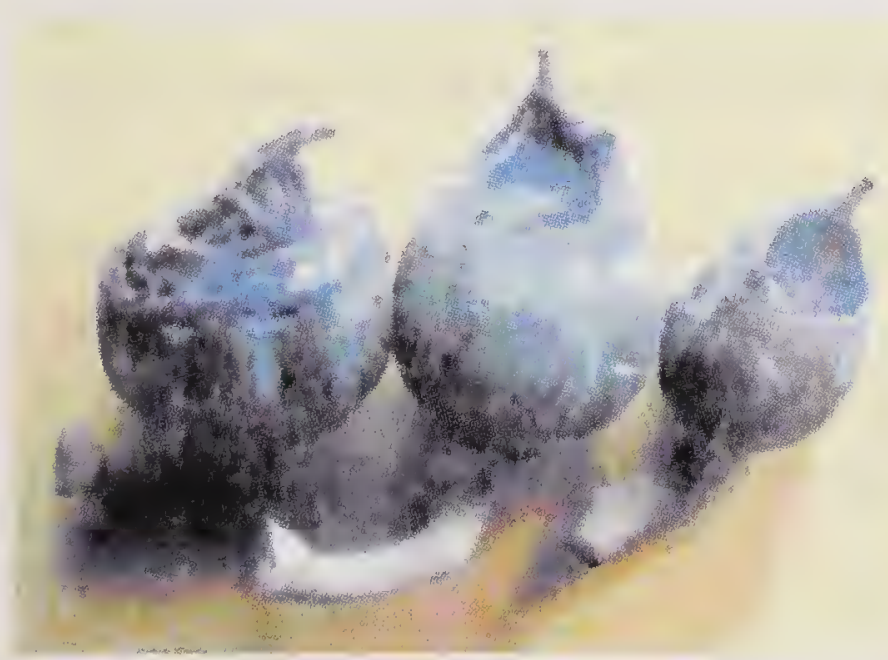

Fig. 11.2. Fruit-rot on immature papaya (Corynespora fruit-rot)

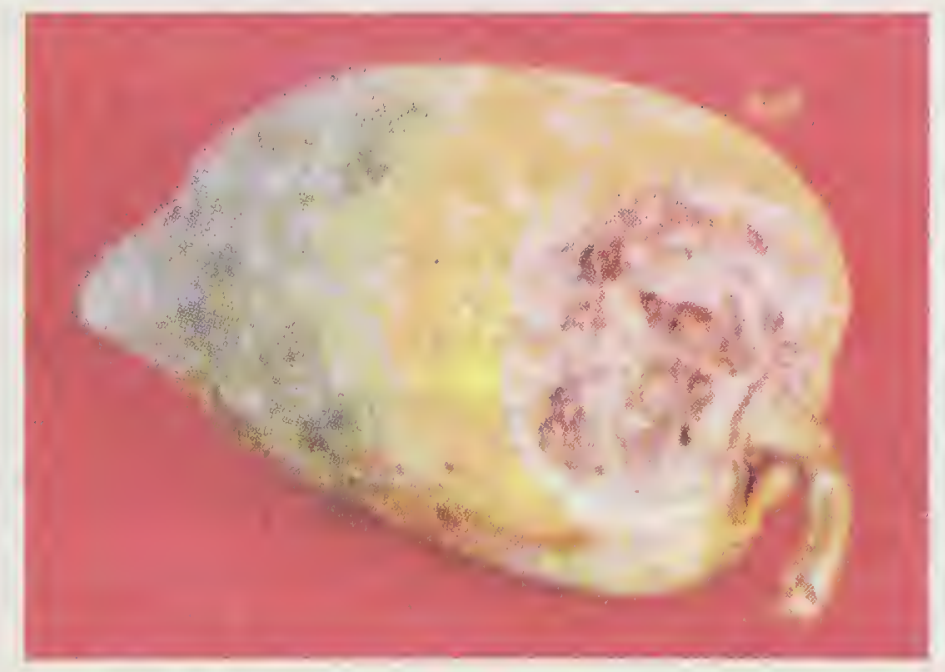

Fig. 11.3. Cornespora fruit-rot symptoms on the mature papayafruit 
OTHER ASSOCIATED PATHOGENS

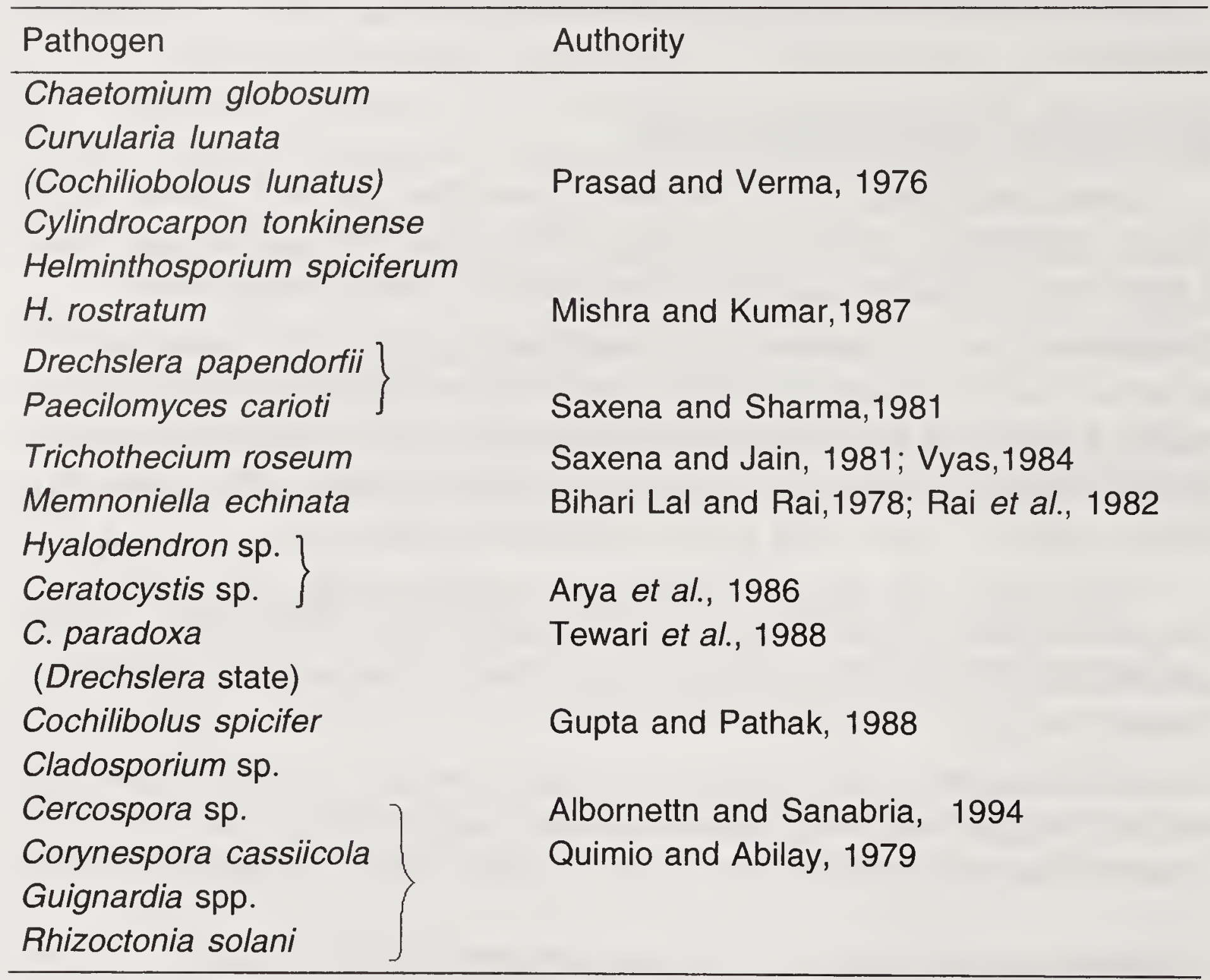

Immature fruit rotting due to Cladosporium oxysporum was reported from Gujarat (Khandar et al. 1994). The symptoms appeared as pinkish brown growth on the fruit-stalks.

\section{BACTERIAL DISEASES}

They may cause sporadic damage to papaya-fruit. External symptoms are absent. The disease can be observed when the fruit is cut open. Purple stain is caused by pigment-producing strains of Erwinia herbicola. Symptoms include violet to purple streaks in vascular tissues, and in latex ducts surrounding seed cavity.

Another disease known as internal yellowing is caused by Enterobacter cloacae. The infected fruit-pulp becomes translucent with a bright yellowlime green discolouration. Due to lack of external symptoms, the mode of infection and spread are not understood properly (Alvarez and Nishijima 1987).

\section{POST-HARVEST DISEASES MANAGEMENT}

The fruits have limited shelf-life, and a range of storage temperatures have been reported for different cultivars. Papayas at 10 and $15^{\circ} \mathrm{C}$ can be stored 
for 16 days (Azi-Abou et al. 1975); $12^{\circ} \mathrm{C}$ was also recommended (Arriola et al. 1980). If temperature is above $20^{\circ} \mathrm{C}$, fruits are liable to be infected by fungal pathogens and below $10^{\circ} \mathrm{C}$ may have chilling injuries. Low temperature storage $\left(10-15^{\circ} \mathrm{C}\right)$ with controlled atmosphere $\left(2 \% \mathrm{O}_{2}, 5 \% \mathrm{CO}_{2}\right.$ at $\left.16^{\circ} \mathrm{C}\right)$ extends storage life by two weeks.

Packing fruits in a single layer in bamboo-baskets after putting sawdust as a lining material and covering fruits with a layer of paddy-straw is desirable for long distant marketing.

Wrapping in polymeric films, use of senescence inhibitors, wax-coating of fruits and gamma irradiation increase shelf-life of harvested papayas (Mitra1997). 


\section{CHAPTER 串}

\section{Peach (Prunus persica (L.) Batsch.)}

Peaches, plums and apricots are included under drupe or stone fruits. These crops are mainly grown in Jammu and Kashmir, Himachal Pradesh and Uttar Pradesh.

Peaches are recommended for low cholesterol, low fat and also for low sodium, and as a part of diabetic diet. It is a rich source of vitamins, calcium and potassium.

\section{FUNGAL DISEASES}

\section{Brown-rot / blossom blight, c.o. Monilinia laxa (Aderh. \& Ruhl.) M. fructigena (Aderh. \& Ruhl.) Honey}

Symptoms : They appear as small, circular brown spots on fruits; observed frequently around wounds caused by insect bites. One to many spots may appear on a single fruit. The rot develops rapidly as fruit matures. The outline of the spots remains circular but the colour turns to light brown. And the surface remains smooth, not sunken. The rotten flesh becomes soft compared to healthy surroundings. Sooner rotten areas are covered with ash-coloured tufts of mycelia damaging fruit skin. The conidial mass gives fruit a brownishgrey appearance. The fruit rots entirely before the appearance of the first tuft, while in plum and pear it may appear within a day or two. The fruit-rot is most severe in peach compared to plum and pear.

The fruits may retain their form and remain attached to tree even after complete rotting, and then gradually dry into a firm mummy(Anderson 1956).

Control measures : Sanitation is important. Proper pruning and removal of mummified fruits attached to trees are important to be carried out periodically.

Spraying Captan 50WP (300g/100 litres of water) about three weeks before harvest helps in controlling infection during storage. Use of fungicides causes many problems like microbial resistance, environmental pollution and fruit contamination.

Dipping fruits in hot-water maintained at $60^{\circ} \mathrm{C}$ for 40 seconds and in sodium bicarbonate (SBC 2\%) for 40 seconds is commonly practised.

Biological control with extract of herb Coptis chinensis (common name: 
Huang Lian) at 50\% concentration (EC 50) exhibited strong inhibition of $M$. fructicola (Hou Dong et al. 2010). Antagonistic bacterium CPA-8 (Bacillus subtilis species complex) at $10^{7}$ or $10^{8} \mathrm{cfu} / \mathrm{ml}$ was also effective (Cascals 2010).

Gamma radiation at a total dose of $125-150 \mathrm{Krad}$ was reported to be promising (Beraha 1964).

\section{Rhizopus-rot / whiskers-rot, c.o Rhizopus stolonifer (Ehrenb.) Vuill.}

This is reported to be a serious rot of peach in transit and storage. The fungus spreads rapidly through containers. Often a single infected fruit results in rotting of the entire lot if the temperature is above $50^{\circ} \mathrm{F}$ or $60^{\circ} \mathrm{F}$.

Symptoms : Infection appears as water-soaked spots on the skin and enlarge rapidly to greater part of the fruit. In the advanced stages, fruis are covered with mycelial growth. Black fruiting bodies are produced in abundance. The mycelia can be seen extending out into spaces between fruits and container.

Control measures: Cuts and bruises on the fruit surface should be avoided.

Pre-harvest application of 2,6-dichloro-4-nitroaniline (DCNA 1,000 ppm) helps control storage rots. Dipping fruits in a solution of sodium ortho-phenyl phenate (SOPP, 0.2\%) and 2,6-dichloro-4-nitroaniline (100 ppm) was effective against R.stolonifer (Eckert and Sommer 1967).

Peaches treated with hot-water or hot-water suspension of 2,6-dichloro4-nitroaniline (DCNA) and Benomyl (both at $100 \mathrm{ppm}$ ) showed lesser symptoms of Rhizopus and brown-rot than those treated with unheated water $\left(70^{\circ} \mathrm{F}\right)$. Unheated suspension of DCNA or Benomyl did not control decay. Chemicals suspended in hot-water $\left(115^{\circ} \mathrm{F}\right)$ gave better control than hot-water treatment at $115^{\circ} \mathrm{F}$ (Smith 1971). Pre-cooling and maintaining low temperature (below $7^{\circ} \mathrm{C}$ ) in transit and storage are preventive for rapid disease spread.

Biological control with bacterium (Enterobacter coloacae) was reported under in-vitro studies. Bacterial suspension was applied to fruit-surface using a nylon bristled paint-brush. $R$. stolonifer concentration was adjusted to $10^{3}-10^{5}$ spores $/ \mathrm{ml}$. Its growth was inhibited by E.coloacae in $70 \%$ of the fruits, and onset of the fruit-rot slowed down in the remaining. The treatment was comparable to Dichloran application @ $12 \mathrm{~g} / 100 \mathrm{ml}$ of water (Wilson et al. 1987).

Biological control with the yeasts, Kloeckera apiculata and Candida guiliermondii, has been reported. Former yeast strain was found more effecitve.

Naturally infected fruits sprayed/inoculated with $10^{3}$ sporangiospores $/ \mathrm{ml}$ immersed in yeast Kloeckera apiculata suspensions @ $5 \times 10^{8} \mathrm{cfu} / \mathrm{ml}$ reduced decay due to Rhizopus-rots (Mc Lauglilin et al. 1992). It was more effective when the yeast was applied as an aqueous suspension in $2 \% \mathrm{CaCl}_{2}$. 
Powdery-mildew, c.o. (Sphaerotheca pannosa (Wallr.) Lev.

This is reported as the most destructive and common disease of peaches in Egypt. In India, it occurs wherever peaches are grown.

Symptoms : They appear on leaves, young shoots and fruits. On fruits, white, round spots appear. The fruits turn pinkish and finally dark-brown. Due to infection, fruit epicarp becomes leathery and hard.

Control measures : The disease can be controlled by spraying with sulphur compounds (any dithiocarbamate at $0.25 \%$ concentration) in orchard as preharvest spray.

Blue mould-rot, c.o. Penicillium expansum Thom.

Symptoms : Leisons are circular, soft and pale-brown. On peaches and apricots, there is usually a dense mass of spores.

Control measures : Prevention of physical injuries is important. Prompt cooling and storage under controlled atmosphere (CAS) helps prolong storage life.

OTHER DISEASES AND THEIR CAUSAL ORGANISMS

\begin{tabular}{ll}
\hline Disease & Causal organism \\
\hline Black mould-rot & Aspergillus niger Van Tieghm. \\
Mucor-rot & Mucor piriformis Fischer \\
Phomopsis-rot & Diaporthe perniciosa E.L. Marchal \& E.M. Marchal \\
Scab & Venturia carpophila Fischer \\
Botryodiplodia-rot & Botryodiplodia theobromae Pat. \\
Pink mould-rot & Trichothecium roseum Link. \\
Alternaria-rot & Alternaria sp. \\
Grey mould & Botrytis cinerea Pers. \\
Cladosporium-rot & Cladosporium sp. \\
Pustular-rot & Stigmina carophila (Lev.) Ellis \\
Bacterial-rot & Xanthomonas campestris Dye \\
\hline
\end{tabular}

\section{POST-HARVEST DISEASE MANAGEMENT}

Post-harvest storage experiments from Turkey have showed use of microwave power as a pre-storage treatment. This was found effective in controlling natural infection. The treatment caused no surface damage to fruits. And quality parameters of fruits also were not impaired (Karabulut and Baykal 2002). 


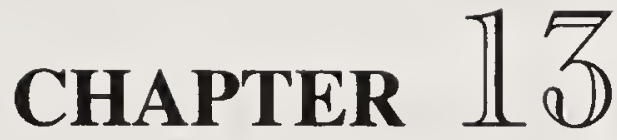 \\ Pear (Pyrus communis L.)}

Pear-fruit flesh contains stone cells. It is a good source of dietary fibre and vitamin $\mathrm{C}$. Most of the vitamin $\mathrm{C}$ and dietary fibres are contained within the fruit-skin. It is a good laxative also.

\section{FUNGAL DISEASES}

\section{Blue mould-rot, c.o. Penicillium expansum Link.}

Blue mould is one of the most destructive rots of stored pears. It is an important disease of all pear-producing countries — USA,UK, Poland, Israel, Australia and India.

Symptoms : First soft, watery, brown spots appear, which undergo rapid enlargement between $20^{\circ} \mathrm{C}$ and $25^{\circ} \mathrm{C}$. There is a distinct margin between the soft-rotted flesh and firm healthy tissue. In humid areas, masses of blue-green spores are noticed on the surface of lesions. The fungus can spread into neighbouring healthy fruits forming 'nests' of decay (Snowdon 1990).

Control measures : Careful handling and strict hygiene in orchards and packing houses needs to be practised. Squashed and rotted fruits should be destroyed before they become a source of infection. Washing water should be frequently changed and disinfected.

Storage under controlled atmosphere (CAS) helps prolonging shelf-life.

Rhizopus-rot, c.o. Rhizopus stolonifer (Ehrenb.) Vuill.

\section{$R$. oryzae Went \& Prinsen Geeligs}

Symptoms: Infection appears as water-soaked spots on the skin, which enlarge rapidly to a greater part of the fruit. The flesh becomes soft and watery. In later stages, strands of coarse white or grey growth cover surface of collapsing fruit.

\section{Mucor-rot, c.o. Mucor piriformis Fischer}

The disease is of greater importance in Canada and USA.

Symptoms : Lesions are noticed at the stem-end or calyx-end or in core region or anywhere on the fruit. Affected fruits turn dark-brown and flesh beneath becomes soft and watery. In humid atmosphere, profuse production of mould strands is seen. 
Control measures : Orchard hygiene is important. Harvesting in wet weather should be avoided. Boxes and bins must be cleaned periodically. Gentle handling is important to minimize incidence of wounds. In storehouses, $95 \%$ RH is desired, but saturated atmosphere need to be avoided.

\section{Brown-rot, c.o. Monilinia laxa (Aderh. \& Ruhl.) Honey}

Development of small, circular spots appear on the fruit. Under humid conditions, tufts of white mycelial strands break through the skin, and fungus spreads to adjacent healthy areas.

Control measures are detailed under Apple.

\section{Aspergillus-rot, c.o. Aspergillus japonicus Saito}

The disease is characterized by brown, water-soaked spots, which expand rapidly and disorganize fruit tissue within 4-5 days (Prasad 1938).

\section{Curvularia-rot, c.o. Curvularia lunata (Wakker) Boedijn} Cochliobolus lunatus R.R. Nelson \& Haasis (1964)

Affected fruits show small, deep-brown spots, scattered all-over the surface. And the spots coalesce soon, and whole fruit is spoiled within short time.

The disease can be checked by dip treatment of fruits with sodium orthophenyl phenate (SOPP) at $0.25 \%$ concentration (Vir et al. 1975).

\section{Alternaria-rot / core-rot, c.o. Alternaria alternata (Fr.) Keissler}

The disease was reported from Israel (Prusky and Ben-Arie 1981). It was identified on fruits imported from China into UK (Snowdon 1990).

Symptoms: Dark-grey mould colonizes the core cavity and proceeds to rot the surrounding flesh. Tissues that suffer physical injury are often invaded, resulting in skin blemishes. The lesions may be small black and corky or shallow dark coloured (Snowdon 1990).

Control measures: Fungicidal spray at blossoming stage as detailed in Apple is reported to be effective. Post-harvest dip or drenching with fungicides also help control storage rot. The fungicide Imazalil at $1,000 \mathrm{mg} / \mathrm{ml}$ inhibited development of Alternaria-rot in apples at $0^{\circ} \mathrm{C}$ and in naturally infected pears at $1{ }^{\circ} \mathrm{C}$ (Prusky and Ben-Arie, 1981).

\section{Bitter-rot, c.o Glomerella cingulata (Ston.) Spauld. \& Schrenk.}

Symptoms appear as small, brown spots on the fruit skin; they are often sunken slightly. In white-rot, flesh becomes soft and fruit may have a bleached or cooked appearance with drops of liquid on the rotted area.

Control measures are as detailed under bitter-rot of Apple. 
Cylindrocarpon-rot, c.o. Cylindrocarpon sp.

The disease is of minor importance, and was reported from Australia (Mc Cartney, 1967). Lesions may occur at the calyx-end in the form of an eye-rot or anywhere on the fruit-surface. The rot is brown coloured, sunken, and has a definite margin.

Fruit-rot can be controlled by orchard spraying with fungicides as detailed in Apple.

OTHER DISEASES AND THEIR CAUSAL ORGANISMS

\begin{tabular}{|c|c|c|}
\hline Disease & Causal organism & Authority \\
\hline Bull's eye-rot/ & $\begin{array}{l}\text { Pezicula malicorticis } \\
\text { (Jacks.) Nannf }\end{array}$ & \\
\hline Gloeosporium-rot & $\begin{array}{l}\text { Conidial state: } \\
\text { Gloeosporium Perrennans } \\
\text { Zeller \& Childs }\end{array}$ & \\
\hline Phacidiopycnis-rot & Phacidiopycnis malorum & \\
\hline Phytophthora-rot & $\begin{array}{l}\text { Phytophthora cactorum } \\
\text { (Lebert \& Cohn)Schoert }\end{array}$ & \\
\hline Scab & $\begin{array}{l}\text { Venturia inaequalis (CKe.) } \\
\text { Wint }\end{array}$ & \\
\hline Physalospora-rot & Physalospora obtusa & $\begin{array}{l}\text { Sreevastava and } \\
\text { Tandon, 1969b }\end{array}$ \\
\hline Black-rot/ white-rot & $\begin{array}{l}\text { Botryosphaeria obtusa } \\
\text { (Schwein) Shoemaker } \\
\text { (Dothiorella gregaria Sacc.) }\end{array}$ & $\begin{array}{l}\text { Crosse and Bennett, } \\
\text { 1951; Combrink et al., } \\
1984\end{array}$ \\
\hline Phomopsis-rot & $\begin{array}{l}\text { Diaporthe perniciosa } \\
\text { El. Marchal \& Em. Marchal }\end{array}$ & \\
\hline Grey mould & Botrytis cinerea Pers. & \\
\hline Mucor-rot & Mucor piriformis Fischer & \\
\hline Rhizopus-rot & $\begin{array}{l}\text { Rhizopus oryzae Went \& } \\
\text { Prinsen Geerlings, R.stolonifer } \\
\text { (Ehrenb.) Vuill. }\end{array}$ & \\
\hline Bacterial fruit-rot & $\begin{array}{l}\text { Erwinia aroidea (Twonsend) } \\
\text { Holland }\end{array}$ & $\begin{array}{l}\text { Chakravarti and } \\
\text { Rangarajan, } 1966\end{array}$ \\
\hline
\end{tabular}




\section{CHAPTER $\llbracket 4$ Pineapple (Ananas comosus (L.) Merr.)}

Pineapple is an important commercial fruit-crop in India. Owing to its great demand, area under its cultivation is increasing to a great extent. Next to mango, banana and citrus, pineapple is the most consumed fruit on the worldwide basis. It is a good source of vitamin $\mathrm{C}$ and is rich in carbohydrates, sugars and minerals ( $\mathrm{Ca}, \mathrm{P}, \mathrm{K})$. Pineapple contains proteolytic enzyme promelain, which breaks down proteins.

\section{FUNGAL DISEASES}

\section{Basal-rot / fruit-rot / soft-rot / stem-end rot/}

Black-rot / water-rot / water blister-rot, c.o. Chalara paradoxa (De Seynes) Sacc.

syn. Thielaviopsis paradoxa (De Seynes) Hohn. Ceratocystis paradoxa (Dade) C. Moreau.

The disease occurs in all major pineapple-growing areas. In India, the disease was first recorded by Chowdhury (1945) and later by Jamaluddin $e t$ al. (1975). Singh and Prasad (1984) reported a similar fruit-rot from Nagaland. The disease was reported from the Philippines, Fiji (Campbell 1926), Australia (Dickson 1929; Simmonds 1931; Mc Knight 1941), Puerto Rico (Liu and Rodriguez 1973), Hawaii (Cho et al. 1977), Nigeria (Adisa and Fajola 1982), Sri Lanka (Liyanage and De 1982) and several other countries.

The fungus survives on plant debris in the soil in the form of thick-walled resting spores (Chalmydospores). Infection may occur before harvest through insect punctures or growth cracks. Usually fungus gains entry through cut stem or through wounds sustained during handling. Disease becomes severe when fruits are harvested after prolonged rains (Mandal 1981). Temperature around $21-32^{\circ} \mathrm{C}$ favours disease and below $10^{\circ} \mathrm{C}$ retards it.

Disease severity depends on the degree of bruising or wounding during harvesting and packing. The level of inoculum on the fruit and storage temperature during transportation and marketing are important. 
Symptoms : They appear on the basal region of the leaves and on fruits (Figs 14.1, 14.2). Initially no symptoms are apparent on fruits. But when the fruit is cut open, soft decay is seen at the side or at the base. Affected tissues become water-soaked and their colour changes from dark-yellow to greyishblack (Bratley and Mason 1939). The affected fruits continue to rot. Black spores may be produced within the flesh but become prominent when cut tissues are exposed. In the final stages of rot, whole fruit gets covered with spores. Water-soaked lesions, followed by collapse of the fruit with exudation of sap are observed (Alice and Paily 1981).

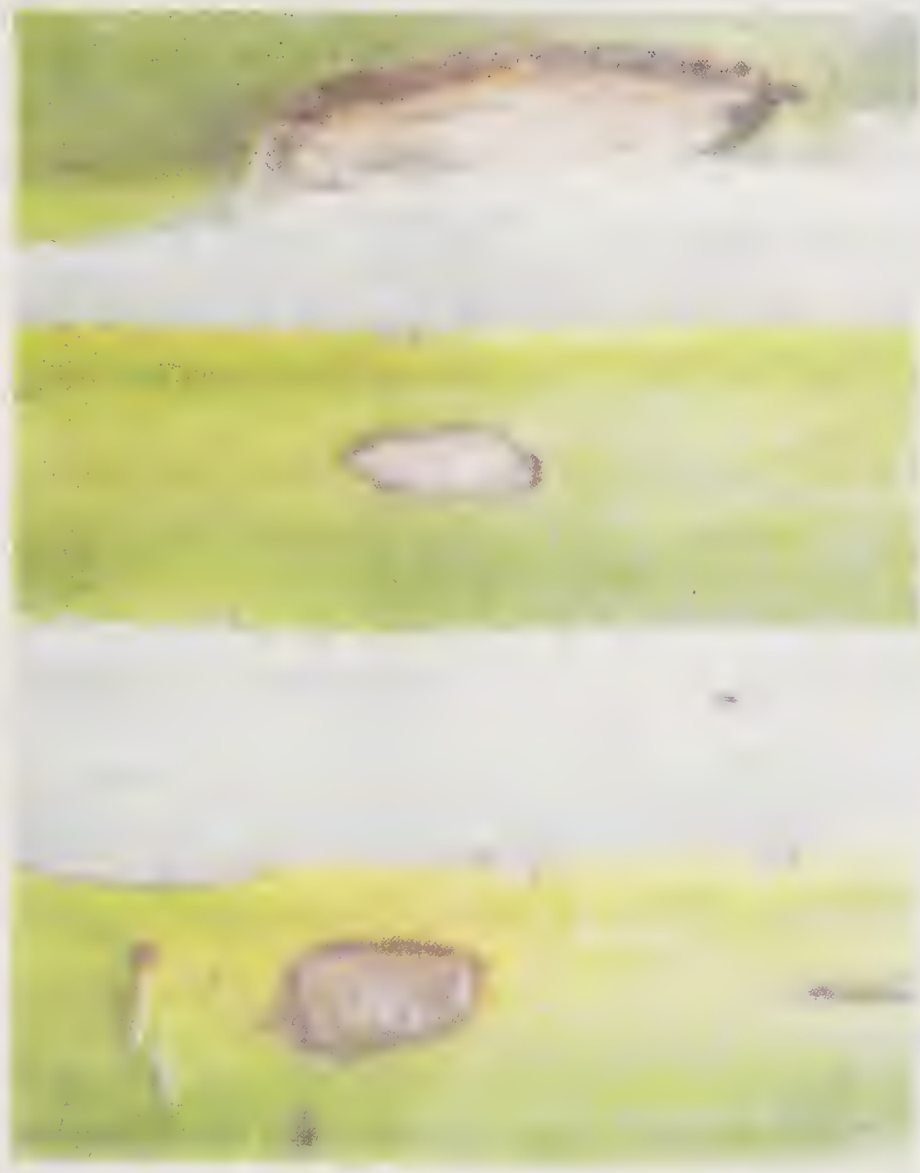

Fig. 14.1. Basal-rot : Symptoms on pineapple-leaves

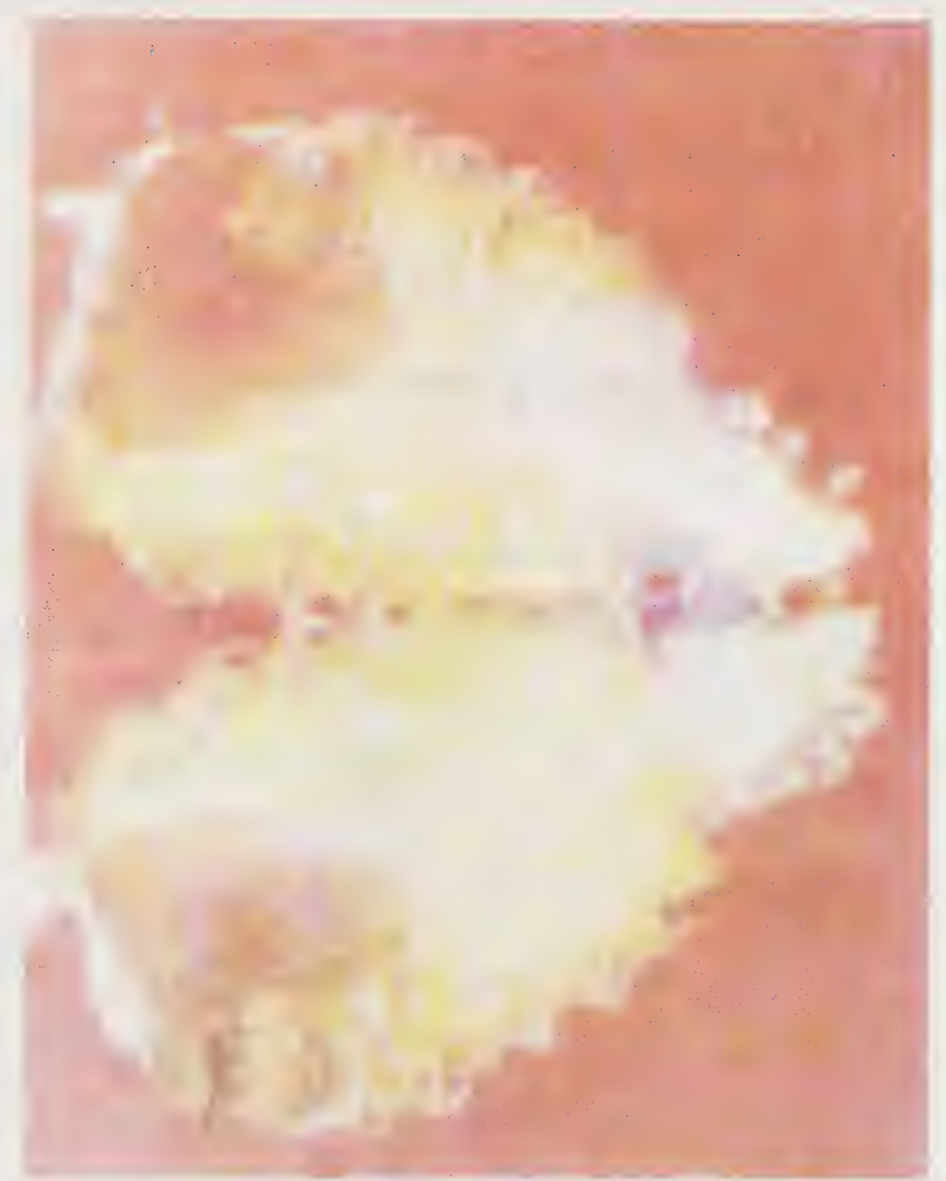

Fig. 14.2. Basal-rot: Symptoms on pineapple-fruits

Control measures : The disease can be checked by destroying affected plants. Suckers for propagation should be collected from disease-free areas. Since the fungus is soil-borne, timely disinfection of nursery soil with Brassicol or Vapam and dipping suckers in Bordeaux mixture (2:2:50) or Borax (6\%), before planting, protects the crop (Raychaudhuri and Lele, 1970). Systemic fungicides like Benomyl (500 ppm), Carbendazim (0.1\%) and Thiabendazole $(0.1 \%)$ can also be used for treating propagating materials (Sridhar 1975; Cho et al. 1977).

Stem-end-rot of fruits can be checked by exposure of harvested fruits to sunlight for 2 hours. Benzoic acid (2.5\%) in 30\% alcohol and storage at 10$12.5^{\circ} \mathrm{C}$ was found effective (Bartely and Mason 1939). Sodium ortho-phenyl phenate (SOPP) at $1-5-2.5 \%$ as well as salicylanilide at $1 \%$ (Le-Grice and Marr 1970) and TBZ 1,000 ppm or Benomyl 2,000 ppm (Sridhar 1975) were promising treatments. Dipping cut-end of the fruit-stalk in 10\% solution of benzoic acid in alcohol was reported to be effective (Pathak 1980). 
The packing cases and baskets should be treated as a preventive measure. Spraying with 3\% Formalin was found effective. Frossard (1978) incorporated Shirlan WS (1\%), Imazalil (0.01-0.02\% ), Bayletan (0.02-0.04\%) and Formol $(3 \%)$ in packing materials, and results were promising. It is important to treat fruits promptly within six hours of harvest.

Disease control was recorded during transport and subsequent storage of fruits after harvest by application of benzoic acid (2.5\%) mixed with inert Kaoline in 30\% alcohol (Mallikarjunaradhya et al. 1979). Cheriyan (1987) and Philip and Cheriyan (1995) reported efficacy of Bavistin 500 ppm (without any residual toxicity) in increasing shelf-life of harvested pineapples up to 21 days.

Under refrigerated storage, fruits remain healthy for 28 days (Cheriyan, 1987; Akamine 1976; Zaldivar 1977). Temperature at $7.5^{\circ}-12^{\circ} \mathrm{C}$ with relative humidity at $90-95 \%$ are recommended for storage. At $0-4^{\circ} \mathrm{C}$, fruits may be stored for weeks, but they may show severe chilling injury when taken out of storage.

Controlled atmosphere conditions (CA storage with $4 \%$ oxygen) helps in reducing chilling injury. Application of fruit-wax also helps in generating higher internal concentration of carbon-dioxide (up to 5\%) with reduced oxygen tension (Paul and Rohrbach 1982).

\section{Fruitlet core-rot,}

c.o. Giberella fujikuroi var, subglutinans Edward

Fusarium moniliforme var. subglutin Wollenw \& Reinking

Penicillium funiculosum Thom.

Erwinia ananas Serrano

Pseudomonas ananas Serrano

The disease was reported from most of the pineapple-producing countries like the Philippines (Serrano. 1935), South Africa (Edmonstone, 1958), Australia (Oxenham, 1962), Malaysia (Lim, 1983), Ivory Coast (Mourichon, 1983) and from several other countries.

Symptoms : They appear as light-todark brown soft-rot on the axis of individual fruitlets (Fig. 14.3). In cross-section, rot appears as a brown spot in the centre of the fruitlet. The diseased tissue may appear as black and wet or dry depending upon the humidity (Edmonstone 1958).

Fungal spores are carried into floral cavities by water splash, mites

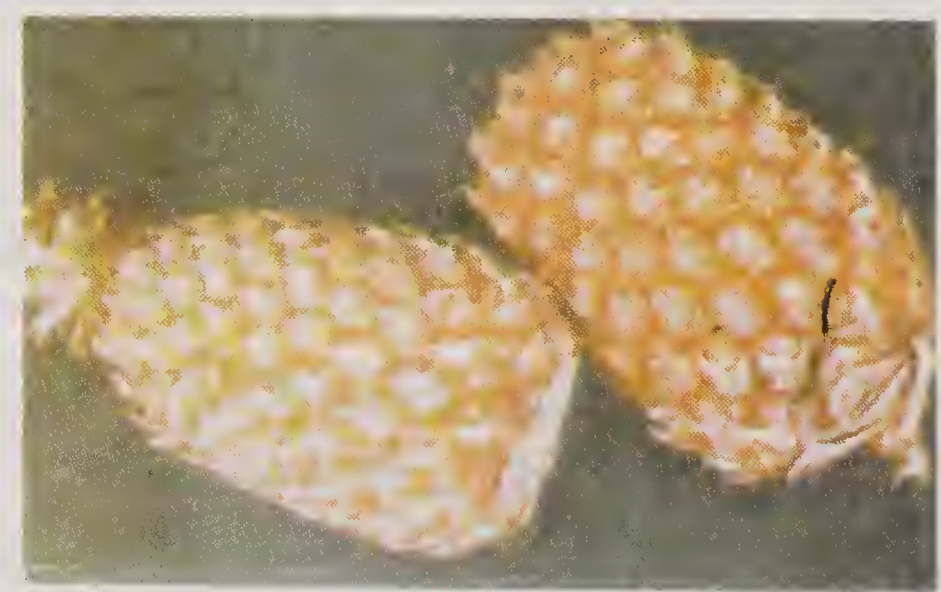

Fig. 14.3. Fruitlet core-rot of pineapple or mealy bugs. Disease incidence is more when a wet period follows a dry growing season. 
Control measures : Control of mites and mealy-bugs is important as they can spread the disease from field to field. For control of mites, Malathion/ Ekalux/ Carbaryl @ 2ml/litre of water two weeks before harvest and for control of mealy-bugs, Chlorpyriphos $(0.05 \%) /$ Fenitrothion( $0.05 \%) / D i m e t h o a t e$ $(0.05 \%)$ /Monocrotophos $(0.05 \%)$ are recommended as spray (Anon. 2007). Care should be taken that the spray fluid reaches base and side of the plant.

\section{Botryodiplodia-rot, c.o. Botryodiplodia theobromae Pat.}

Tandon and Bhargava (1962) reported the disease from India. The fungus is a wound pathogen, and infection occurs through wound/cut stemend. The fungus spreads into pulp and turns it into a brown and water-soaked mass. In advanced stage of infection, mycelial mat with abundant pycnidia is observed.

Avoid wounds and bruises on harvested fruits. Decay can be checked by storage at $10^{\circ} \mathrm{C}$.

Aspergillus-rots, c.o. Aspergillus niger Van Tiegh.

A.flavus Link. ex Fries

Johnson (1931) reported occurrence of Aspergillus spp. along with Ceatocystis paradoxa and Pencillium sp. from Queensland, Australia. The fungus produces dry-rot symptom. The fruit gets covered with black encrustation of the fungus (Fig. 14.4). Adisa and Fajola (1982) observed dry-rot caused by $A$. niger and $A$. flavus from Nigeria.

Control measures detailed under basal-rot are applicable for this also.

\section{Penicillium-rots, c.o. Penicillium spp.}

Inter-fruitlet corking and leathery pocket caused by P.funiculosum was reported from South Africa and Hawaii (Hepton and Anderson

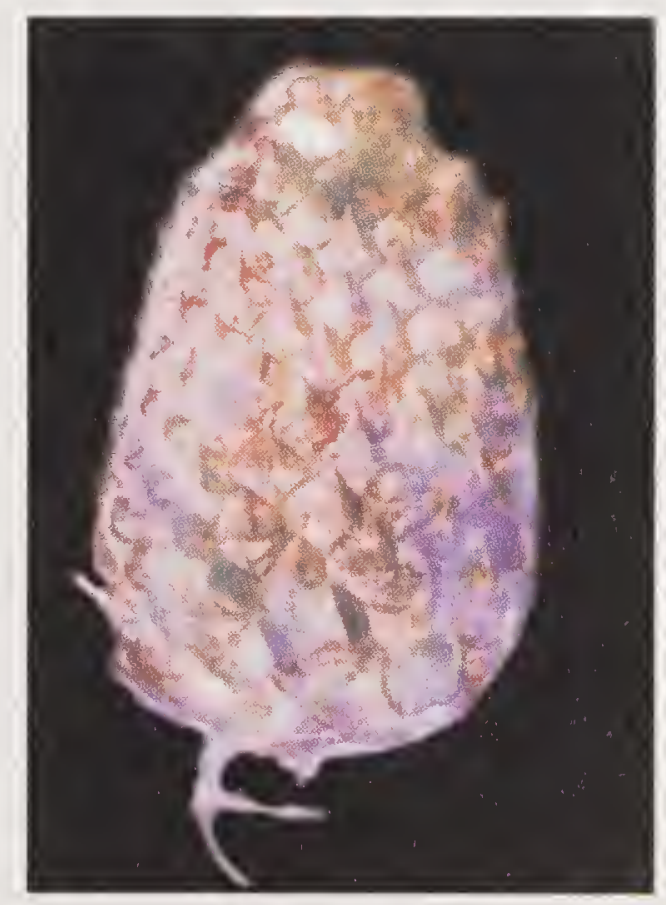

Fig. 14.4. Aspergillus-rot on pineapple 1968; Lim and Rohrbach 1980). In inter-fruitlet corking, individual flowers may be killed and affected fruit may take an unnatural glossy appearance with corky formations between fruitlets beneath the skin. Leathery pocket is characterized by cork formation at the deeper levels in ovaries at the base of the flowers. Mites (Stenotarsonemus ananas) disseminate fungus as they visit flowers. The disease is controlled by spraying an acaricide and a fungicide (Grice and Marr 1970). With the application of acaricides, pineapple fruit mite and Penicillium-induced fruit disease were reduced significantly.

Dry fruit-rots were also reported due to P.claviforme (Adisa and Fajola 1982) and P.italicum (Cheriyan 1987). Fruits rot within seven days with visible growth of fungal spore masses on the fruit-surface. 


\section{Rhizopus-rot / soft-rot, c.o. Rhizopus oryzae Went \& Prinsen Geerligs} R. stolonifer (Ehrenb.) Vuill.

The disease was reported by Adisa and Fajola (1982) from Nigeria, and accounted for $93 \%$ of losses along with Ceratocystis paradoxa. The rot was reported from Kerala also. Irregular brown lesions appear first over fruitsurface, then result in rotting of flesh.

Soft-rot due to Mucor hiemalis was also observed. Water-soaked lesions appear, and the fruit is completely covered with white-cottony growth. The pulp turns brown and juice leaks out with a fermented odour (Cheriyan 1987). Control measures : Avoid injuries or bruises on fruits during harvesting, transporting and storage. Low temperature $\left(10^{\circ} \mathrm{C}\right)$ prolongs storage life.

\section{BACTERIAL AND YEAST DISEASES AND CHILLING DISORDERS}

\section{Bacterial soft-rot / fruit collapse, c.o. Erwinia chrysanthemi}

The disease was reported to be indigenous to Peninsular Malaysia. Infection by bacterium occurs at flowering. Bacteria enter into the ovary via style and cause limited water-soaked necrosis at the base of the stylar canal within fruitlet core and remain quiescent for about two months without external symptoms. The latency of bacteria within the fruitlet core of young fruits is attributed to high polyphenol oxidase activity. Then rotting proceeds rapidly and fruits collapse within a day or two either before or after harvest. Varietal susceptibility was also recorded (Lim and Lowings 1979, 1979 a).

Occurrence of Erwinia sp. causing dry-rot of pineapple was also reported from Brazil (Melo et al. 1974).

Control measures : Bacteria are carried by pollinating insects. Lim and Lowings (1979 b) suggested that disease can be effectively controlled by spraying plants at the onset of flowering with Ethephon (2-chloro-ethylphosphonic acid). This restricts insects from visiting flowers.

\section{Pink disease}

It was originally described from Hawaii (Lyon 1915). Losses due to the disease were reported from Hawaii (Rohrabach and Pfeiffer 1976; Gossele and Swings 1986), the Philippines (Kontaxis and Hayward 1978), and several other countries. The disease so far has not been reported from India. The nature of pink-colour formation in pineapple-fruits has not been understood properly.

A myriad of bacteria associated with pineapple-plants have made identification of pink disease extremely difficult. The cycle of the disease is still unsolved. Four bacterial isolates representing three genera Gluconobacter, Acetobacter and Enterobacter-cause pink disease in pineapplefruits with slightly different symptoms. Gluconobacter symptoms are characterized by a 'cantaloup-like aroma' and a light to bright pinkish coloured raw fruit-flesh. Acetobacter infected fruits have no aroma but are light-to-dark 
brown, and Enterobacter infected ones do not exhibit any pink or brown discolouration in infected tissues. All types produce dark browning of fruitflesh on cooking. The Enterobacter was the most virulent and virulence varied significantly depending upon the harvest period, cultivars and isolates(Rohrback and Pfeiffer 1976). Attempts to identify causal agents with regard to their optional growth properties revealed the following bacteria (Cho et al. 1980): Gluconobacter oxydans; Acetobacter aceti; Erwinia herbicola.

Goossele and Swings (1986) identified Acetobacter liquefaciens from Hawaii and the USA to be associated with a pink-brown discolouration during canning process. But using molecular/genetical approaches, causal agent was identified as Pantoea citrea (Cho et al. 1997). The disease cycle is not fully understood.

The bacterium is transmitted through flower-visiting insects, and gains access to fruits through numerous florets. Pink disease is severe only if flowering takes place during the wet weather immediate after a long dry spell. Symptoms : Pink-disease symptoms are difficult to observe in the field as outward symptoms are not apparent. Even on the foliage, no visible symptoms are noticed. In severe cases, translucent appearance on sub-dermal fruit tissues is observed. Common symptoms appear when infected fruit preparations are heated during canning process. Heating results in the formation of red-to-rusty brown colouration to golden yellow tissues (Kado 2003).

Biochemical basis of the red colour formation in pineapple-juice and fruit can be attributed to the ability of Pantoea citrea to oxidize glucose into 2, 5 di-ketogluconic acid via two-step conversion (Pujol and Kado 1988, 1999, 2000). End-product heating results in the formation of a dark-red colour.

Control measures : At present, controlling this disease is relatively expensive since multiple applications of insecticides are necessary to maintain low levels of disease incidence.

Kado (2003) gave the following suggestions.

- Plant genetic engineering strategies need to be considered. Genes are used to lower substrate that leads to 2,5-di ketogluconate formation, and genes used to inhibit growth of P.citrea in fruit tissues can be incorporated in transgenic pineapple.

Biological control methods. Use of bacterial species that are antagonistic to P.citrea can be utilized. The most promising isolate is Bacillus gordonae 206 IR (1); this reduced disease incidence in combination with insecticides.

\section{Yeasty-rots}

This rotting is associated with ripe-fruits. Davies (1928) had isolated Saccharomyces sp. from decayed pineapple-fruits from South Africa. Yeast invades fruits through injuries on the fruit-surface and results in fermentation of flesh. Due to which gas may be formed, and juice may bubble out. Internal content of the fruit becomes spongy and fibrous. Some yeasts may cause glassy 
spoilage with distinct aroma (Linford 1952). Mandal (1981) reported putrefication of fruitlets into a soft spongy mass with liquid oozing out with a strong fermented odour; unidentified yeast was found associated.

Control measures : Injuries and bruises during harvesting, handling and storage are to be avoided. Exposure of harvested fruits to sunlight for 2 hours offers protection.

\section{Chilling disorder [Black heart (Endogenous brown spot)]}

The disease manifests as a chilling disorder in summer fruits following three days storage (temperature at $21^{\circ} \mathrm{C}$ ). Storage at $25^{\circ} \mathrm{C}$ was found promising (Smith 1983).

\section{POST-HARVEST MANAGEMENT}

Storage at $21^{\circ} \mathrm{C}$ along with wax-coating increased shelf-life by 12 days in pineapple $\mathrm{cv}$. Kew. Cold storage at $10-13^{\circ} \mathrm{C}$ and $85-90 \% \mathrm{RH}$ has been found suitable. Controlled atmosphere storage (CAS) conditions at temperature of $10-15^{\circ} \mathrm{C}, \mathrm{O}_{2} 2.5 \%$, and $\mathrm{CO}_{2} 5-10 \%$ was effective (Burden 1997). 


\section{CHAPTER 15}

\section{Plum (Prunus domestica L.)}

Plums are sweet and juicy, contain several antioxidants, and are known for their laxative property; attributed to the presence of dietary fibres, sorbitol and Isatin in fruits.

\section{FUNGAL DISEASES}

Brown-rot, c.o. Monilinia fructigena (Aderh \& Ruhl.) Honey (Sclerotinia fructigena)

The fungus causes blossom blight, twig blight and fruit-rot.

Symptoms : They are noticeable as fruit approaches maturity. The fruit-rot is severe in peaches but is very destructive in plums. Symptoms appear as small, circular, brown spots, frequently originating on the slight wounds, caused by insects. One to many spots may appear on a single fruit. Rot develops rapidly. Rotted flesh becomes soft compared to surrounding areas but not watery as in Rhizopus-rot. Then rotted areas are covered by ashcoloured tufts of fungi. And pustules are numerous and cover entire surface of fruit. Pustules are pronounced in plums than in peaches. The fruit retains its form and remains attached to the tree as a 'firm mummy'.

The disease causes more damage in the storehouse than in the field.

Control measures : Sanitation in the orchards is of utmost importance. Remove mummified fruits and other sources of inoculum.

Application of Captan $0.2 \%$ to trees three weeks before harvest helps in controlling storage rots.

Plum-rot, c.o. Rhizopus stolonifer (Ehrenb.) Vuill.

The rot was first recorded in India by Bhargava and Gupta (1957). Symptoms and control measures are as detailed under Rhizopus-rot of peach.

OTHER DISEASES AND THEIR CAUSAL ORGANISMS

\begin{tabular}{ll}
\hline Disease & Causal organism \\
\hline Anthracnose & Glomerella cingulata (Stonem.) Spauld. \& Schrenk. \\
Blue-mould & Penicillium expansum Thom. \\
Grey-mould & Botrytis cinerea Pers. \\
Pustular-rot & Stigmina carophylla (Lev.) M.B. Ellis \\
Alternaria-rot & Alternaria sp. \\
Powdery mildew & Sphaerotheca pannosa (Wallr. Fr.) \\
\hline
\end{tabular}




\section{CHAPTER \6}

\section{Pomegranate (Punica granatum L.)}

Pomegranate, also known as 'Anar' is one of the most favourite fruits of the tropical and subtopical regions. In India, it is cultivated commercially in Maharashtra, Andhra Pradesh and Karnataka. Its dried seeds are widely used as a condiment. The fruit and the peel are valued for medicinal properties. Fruits contain tannins, proteins, fats, carbohydrates and minerals like calcium, phosphorus, magnesium, iron and vitamins like thiamine, riboflavin, niacin and nicotinic acid.

\section{FUNGAL DISEASES}

Phomopsis fruit-rot, c.o. Phomopsis aucubicola (Brunaud) Grove

The disease was noticed on the stored fruits, and it spreads through seeds (Verma et al. 1982).

Symptoms : The disease starts from calyx-end and gradually spreads over the entire fruit. Pycnidia are noticed in abundance on fruits.

Control measures : Remove affected fruits and shoots at periodical intervals. Spraying with Dithane Z-78 $(0.2 \%)$ at bi-weekly intervals after fruit-set controls disease.

\section{Aspergillus fruit-rot, c.o: Aspergillus spp.}

Several species of Aspergillus are found associated with fruit-rot on pomegranate-A.fumigatus Fries, A. awamori Nakezawa, A. niger Van Tiegh. (Sinha 1946 ; Anon. 1950; Srivastava et al. 1964). Srivastava and Tandon (1971,1971a) recorded A.flavus Link. from Kanpur and Jodhpur. Philip (1979) recorded Aspergillus- rot due to A. niger from Thiruvananthapuram in the consignments delivered from Bengaluru. Sharma et al. (1981) observed two other Aspergillus spp.-A.niveus and A.versicolor.

Symptoms : The infected tissues turn soft and dark in colour. Sooner these are covered by mycelial growth and black/green spore masses. The diseased tissues shrink and get disintegrated after 15 days. The rotten fruits emit a fermented odour.

Penicillium fruit-rot, c.o. Penicillium spp.

Penicillium fruit-rot by Penicillium purpurogenum was reported by 
Shrivastava et al. (1993). Infected tissues become soft and fruit-surface gets covered with bluish powdery growth.

And fruit-rot caused by Penicillium herquei Bain was reported on wild pomegranate from Jammu and Kashmir (Seema and Sharma 2009).

Cladosporium fruit-rot, C.o. Cladosporium oxysporum Berk. and Curt.

In the initial stages, diseased fruits develop orange-red to dull-brown circular spots, and infected grains become olive-brown. In the advanced stages of infection, entire fruit rots (Panwar and Vyas 1974).

Fruit- rot, c.o. Pestalotiopsis versicolor (Speg.) Steyart

The disease is characterized by minute brown- to rust-coloured spots on the fruits. These spots coalesce and with the advancement of disease, necrotic patches are formed. The central portion gets depressed inward with raised margins. In case of severe infection, rind is torned open and fungus penetrates deep into the fruit, causing discolouration of seeds (Utikar et al. 1980).

Anthracnose, c.o. Glomerella cingulata (Stonen.) Spauld.

The disease may appear at the distal end or at anywhere on the fruit as discoloured area. The infected areas rot within a week.

\section{Black grain-rot, c.o. Alternaria solani Ell. \& Martin}

The disease was reported from Rajasthan. The symptoms appear as lightbrown spots around cracked areas. The fruits become pulpy and the grains become black. The disease is of minor importance.

Coleophoma fruit-spot, c.o. Coleophoma empetri (Rost.) Petrak.

The disease was reported from Maharashtra (Sherkar et al. 1980; Rao and Pandey 1992).

Symptoms : On fruits, symptoms develop as numerous, minute, circular tan brown spots, which turn dark in advanced stages. The spots coalesce and form irregular depression and hard necrotic lesions. Lesions are restricted to epidermis that bears black roundish pycnidia.

\section{Rhizopus-rot, c.o. Rhizopus arrhizus Fischer}

The symptoms appear as minute spots that increase in size, coalesce and covers fruit-rind. The internal content decays into a soft pulpy mass. Fungus grows at a wide temperature range of $10-40^{\circ} \mathrm{C}$, but maximum infection occurs between 20 and $30^{\circ} \mathrm{C}$ and at $80 \%$ relative humidity (Kanwar et al. 1973; Kanwar and Thakur 1974).

Kanwar and Thakur (1972) recorded effect of ammonium carbonate and sulphur as fumigants on the packing straw. Giberellic acid (GA) and ascorbic acid, when used as a pre-infection treatment, were effective in inhibiting R.arrhizus growth in storage for 10 days (Thakur et al. 1974). Potassium 
metabisulphite at pre- and post-inoculation trials and borax and sodium metabisulphite at pre-inoculation trials were effective (Kanwar and Thakur 1977).

Drechslera fruit-rot, c.o. Drechslera rostrata (Drechsler) Richardson \& Fraser

The fruit spot caused by Drechslera was reported by Utikar et al. (1976) on the variety Muscat. Fruits of all stages can be attacked.

Symptoms appear as numerous small, black spots scattered all-over the fruit-surface. Margin of the spot varies in colour from dark-green to orange. In advanced stages of disease development, spots enlarge and coalesce to form big dark spots. Mild infection is confined to fruit rind. And severe infection may extend up to seeds, and seeds may show discolouration. Lande and Utikar (1978) also made elaborate studies and observed pre-harvest spray with Dithane M- $45(0.25 \%)$ and Captan (0.2\%) as effective in checking growth and sporulation of fungus.

\section{Fruit-spot, c.o. Beltaraniella humicola Rama Rao}

The disease is characterized by black, circular spots, which gradually enlarge and coalesce to form big dark black spots. The infection is restricted to rind and may extend inside to pulp also (Sherkar and Utikar 1982 a).

\section{Acremonium fruit-rot, c.o. Acremonium terricola}

The disease appears as reddish brown spots; these coalesce together later to form bigger patches and ultimately result in fruit rotting (Mohale and Patil 1993).

\section{BACTERIAL DISEASES}

\section{Black-spot, c.o. Xanthomonas campestris pv. punicae}

\section{Hingorani and Singh (Dye)}

Symptoms: They are noticed on young fruits as numerous small, segregated, depressed and discoloured spots. The spots gradually increase in size and occasionally coalesce to form large, irregular necrotic patches. With advancement towards maturity, necrotic patches become corky, black and develop into typical cankers with prominent fissures. The cankerous lesions become very prominent on the fruit-surface (Upasana and Verma 2002).

Control measures : Spraying fruits before harvest with Biomycin $(0.5 \%)$ or Bacteriomycin $(0.01 \%)$ or streptomycin $(0.01 \%)$ was recorded as effective in controlling black spot on stored fruits. Bordeaux mixture (1\%) was also effective (Vanitha and Suresh 2001).

Streptocycline $500 \mathrm{ppm}+$ copper oxide 2,000 ppm was found promising (Ravikumar et al. 2006). 


\section{CHAPTER \च \\ Sapota \\ (Manilkara zapota (L.) P. Royen)}

Sapota-fruits are highly perishable and cannot be stored for long. Firm fruits can be stored up to eight weeks at $3-5^{\circ} \mathrm{C}$ with $85-90 \% \mathrm{RH}$, and ripefruits can be stored at $2-3^{\circ} \mathrm{C}$ for six weeks (Singh 1969). Low storage temperature can extend shelf-life by reducing oxidative metabolism and ethylene evolution (Lakshminarayana 1980).

\section{FUNGAL DISEASES}

\section{Black mould-rot, c.o. Aspergillus niger Van Tieghm}

This disease occurs during hot summer on injured or over-ripe fruits (Mandal and Dasgupta 1981). Infection progresses more or less radially on the surface. Later black conidial heads cover the fruit-surface and fruits become soft and crack.

Avoid injuries and bruises to fruits. Refrigerated storage at $10^{\circ} \mathrm{C}$ is found promising.

\section{Green mould-rot, c.o. Penicillium sp.}

This fungus causes extensive decay and affected tissues become soft and water-soaked. Avoid injuries and bruises to fruits. Refrigerated storage at $10^{\circ} \mathrm{C}$ is useful.

\section{Brown pedicel-end-rot, c.o. Botryodiplodia theobromae Pat.}

The disease is considered as one of the serious rots of sapota in storage. The disease was recorded from Uttar Pradesh (Srivastava et al. 1964) and from West Bengal (Mandal and Dasgupta 1982).

Water-soaked brown areas appear at the proximal pedicel-end. Edible portions become soft, and juice leaks out with a characteristic fermentative odour; and whole fruit rots within 10-12 days. Maximum decay occurs at about $30^{\circ} \mathrm{C}$.

Avoid injuries and bruises to fruits. The disease can be controlled by storage at $10^{\circ} \mathrm{C}$. (Srivastava and Tandon 1968). 
Pimple-rot, c.o. Pestalotiopsis versicolor (Speg.) Steyaert

$$
\begin{aligned}
& P \text {. glandicola (Castagne) Steyaert } \\
& P \text {. mangiferae P. Henn }
\end{aligned}
$$

The disease was recorded from Kota (Gupta and Sehgal 1974) and Kurukshetra (Dhingra et al. 1980). Water-soaked brown to dark- brown lesions appear on the fruit-surface; fruit rots within 3-4 days. A small tuft of white mycelia consisting of fluffy growth studded with black acervuli becomes visible on the fruit-surface. Jain et al. (1981) recorded it as a minor pathogen from Madhya Pradesh.

Control measures as detailed for Botryodiplodia-rot are applicable for this also.

\section{Phytophthora fruit-rot, c.o. Phytophthora palmivora (Butl.)}

Rao (1968) reported a transit and storage rot due to P. palmivora from Maharashtra. The disease appears as irregular water-soaked areas on the major portion of the fruit. The decay is deep, and eventually pulp disintegrates. The infected fruit becomes soft, pulpy, and emits a bad odour. Fungal mycelia are visible on the fruit-surface (Rao et al. 1966).

The disease is of minor importance; avoid wounds and bruises to fruits. Infected fruits should not be mixed with healthy ones. Cold storage at $10^{\circ} \mathrm{C}$ is effective.

\section{Other soft-rots}

Soft-rots caused by following fungi were also recorded.

Botryosphaeria dothidea (Mougeot Fries) Cesati \& Denotari

B.ribis Jain et al., 1981

Fusarium moniliforme Sheldon

\section{POST- HARVEST MANAGEMENT}

Storage in 100- gauge polythene bags with $1-2 \%$ vent in paper carton is found effective in enhancing shelf- life of fruits without fungal deterioration.

Cool chamber storage of fruits at $8 \pm 2{ }^{\circ} \mathrm{C}$ after vacuum filtration with $\mathrm{CaCl}_{2}$ helps increase shelf-life by 16 days ( Reddy and Nagaraju 1993). 


\section{CHAPTER $] \mathbb{8}$}

\section{Strawberry \\ (Fragaria chilensis (L.) Duchesne ex Weston)}

Strawberry is a favoured fruit of many nations in the world, is relished for flavour and extensively used in canning industry and in preparation of icecream. But fruits are highly perishable in nature.

\section{FUNGAL DISEASES}

\section{Grey mould-rot/dry-rot/brown-rot, c.o. Botrytis cinerea Pers.}

The disease is reported to be serious, and occurs in all places where crop is cultivated. The disease was reported from Israel (Aharoni and Barkai Golan 1987). It is especially prevalent in the regions where rainfall and dew occur frequently during blossoming and fruiting. Though the disease is regarded as a fruit-rot, it often starts as a blossom-blight.

Symptoms : Infection on the berries may occur at any region. Often symptoms appear on the fruit base and originate from the infected calyx. It may appear on the side or tip also. The disease progresses downward through pedicel to main fruit stem, and finally spreads to most of the fruit-cluster. On the fruit, the rot appears as a light-brown soft area that dries later. Under damp weather, fruits get coated with a fine grey fuzzy growth consisting of spore masses with black bodies (sclerotia) in abundance. In advanced stages, fruit shrivels to form a 'mummy'.

Control measures : Sanitation and cultural practices help in controlling disease. Pre-harvest Captan (0.2\%) application after flowering, followed by two more applications controlled disease successfully (Anderson 1956).

Pre-cooling and maintaining low temperature $\left(4^{\circ} \mathrm{C}\right)$ in transit protects fruits from storage rots.

Chemical method. Dipping harvested strawberries in any of the chemicalsCaptan (1,200 ppm), Sorbic acid (2,500 ppm) or Mycostatin (100 ppm), followed by storage under refrigerated conditions was reported to be effective against Botrytis and Rhizopus rots (DiMarco and Davis 1957). 
Biological control. Essential oils of Satureja sp. and Thymus sp. showed inhibitory effect against fruit-rots caused by B.cinerea, R.stolonifer, P.digitatum and A.niger. The oils are often biologically active and possess antifungal and antimicrobial properties (Nabigol and Farzaneh 2008). They also have excellent antioxidant property.

Use of radiations. Gamma rays at $2 \times 10^{5} \mathrm{KGY}$ alone or in combination with refrigeration markedly prolonged storage-life of strawberry and delayed development of Botrytis cinerea and Rhizopus nigricans without visible damage by radiations (Beraha et al. 1957).

Rhizopus-rot /leak, c.o. Rhizopus nigricans Trow.

\section{R.oryzae Went \& Prinsen Geerligs \\ R.stolonifer (Ehrenb.) Vuill. Mucor hiemalis Wehmer}

The disease was reported by Anderson (1925) during transport, storage and marketing. It is commonly called 'leak' as the juice from the diseased berries stains boxes and leaks out. In shipped berries, it often accounts for over $50 \%$ losses.

Symptoms : The disease is characterized by soft watery tissue on the fruitsurface with exudation of juice on a slight pressure. The flesh becomes soft and watery. In advanced stages, strands of coarse white or grey fungus growth can be noticed covering entire surface of the collapsing fruit.

Control measures : Use of a mulch to minimize contact with soil helps in reducing disease incidence on the harvested fruits.

Bruised or injured fruits should be discarded. Over-ripe fruits should not be used for packing.

Pre-cooling and maintaining low temperature $\left(4^{\circ} \mathrm{C}\right)$ in transit and storage prevents rapid spread of disease.

Gamma radiations as detailed under Grey mould-rot are applicable to this also (Beraha et al. 1957).

Essential oil of Satureja sp. showed inhibitory effect against fruit-rot caused by Rhizopus stolonifer (Nabigol and Farzanch 2008).

\section{Ripe fruit-rot/anthracnose, c.o. Colletrotrichum fragariae Brooks}

The disease was reported causing serious losses in Australia (Sturgess 1957; Simmonds1965) and in India (Singh1974a).

Symptoms : They appear only on the ripe-fruits, characterized by one or more light-brown/black water-soaked lesions on the fruit-surface. As a results of the infection, tissues shrivel and form compact depressed lesions. The lesion colour changes gradually from tan to dark-brown, followed by eruption of pink spore mass from acervuli. In advanced stages, lesions coalesce and produce bigger patches. Symptoms appear only on the fully coloured ripe berries. Unripe fruits do not show any symptoms (Singh 1974a). 
Control measures: Hot-water rinsing and brushing (HWRB) at $65^{\circ} \mathrm{C}$ for 20 seconds on the fruit-surface reduces decay. The treatment has no negative effects on the fruit colour, firmness, soluble solid content and titrable acidity.

Captan and systemic fungicide switch (a.i. Fuudioxonil + Cyprodinil) were evaluated for controlling anthracnose fruit-rot. Both were found effective, but switch was found better (Peres et al. 2010)

Calyx-blotch and stem-end-rot, c.o. Gnomonia fructicola (Arnaud.)Fall. Conidial stage : Zythia fragariae Laibach.

The disease was reported from the USA, Canada, and from most of the European countries. Symptoms appear as small, brown spots.

Aspergillus-rots, c.o. Aspergillus niger Van Tieghm.

Symptoms are noticed on the fruit-surface as small, black pinhead-like dots.

Essential oil of Satureja sp. showed prominent inhibitory effect even at very low concentration of $300 \mathrm{ml} /$ litre (Nabigol and Farzanch 2008).

OTHER DISEASES AND CAUSAL ORGANISMS

\begin{tabular}{lc}
\hline Disease & Causal organisms \\
\hline Leathery-rot & Phytophthora sp. \\
Black seed disease & Mycosphaeralla fragariae \\
Blue-mould & Penicillium cyclopium \\
& P. expansum Westling Thom. \\
Black-mould & Aspergillus niger Van Tieghm. \\
Cottony-rot & Sclerotinia sclerotiorum de Bary \\
Pestalotiopsis-rot & Pestalotiopsis sp. \\
Phomopsis-rot & Phomopsis obscurans (EII \& EV) \\
Pythium-rot & Pythium ultimum Trow. \\
Rhizoctonia-rot & Rhizoctonia solani Kühn \\
\hline
\end{tabular}

\section{POST-HARVEST MANAGEMENT}

Strawberry fruits immersed in a solution of pomegranate-peel extract with chitosan ( $1.25 \%$ ) prolonged storage life by $1-2$ days without any deterioration (Zhang et al. 2010). 



$$
\text { Part - B }
$$

MANAGEMENT OF POST-HARVEST

\section{DISEASES OF VEGETABLE CROPS}





\section{CHAPTER 19 Cucurbits}

\section{CUCUMBER (Cucumis sativus L.)}

The family Cucurbitaceae includes a number of economically important crop-plants like cucumbers, squashes, marrows, melons, pumpkins, chayotes (chow-chow), bittergourd, snakegourd, bottlegourd, ridgegourd, etc. Some of these are eaten raw as salad. Storage life of cucumbers is very short and they are especially prone to moisture loss and decay (Risse et al. 1987). At temperature around $12^{\circ} \mathrm{C}$, they loose their dark-green colour within a few days and begin to turn yellow (Kanellis et al. 1986), and at a very low temperature they are susceptible to chilling injuries.

\section{FUNGAL DISEASES}

\section{Cottony-leak/fruit-rot, c.o. Pythium spp.}

Pythium aphanidermatum (Edson) Fitzp., P.butleri Subram, P.debaryanum Hesse

Fruit-rot is a common disease of cucumbers (Alice 1969; Singh and Chauhan 1977; Sohi and Rawal 1977; Alice and Paily 1978; Sharma and Sumbali 1993; Philip 1998; Coursey and Booth 1972). It is more severe during rainy season. Even though infection starts in the field, it is important as a storage and transit disease.

The fungus subsists in the soil as oospores, and under favourable conditions infects roots and collar region of the young plants. On the fruits, infection occurs where some injury is on to the skin. Pythium spp. generally attack plants in juvenile stage. Tissue hardening prevents their attack and high relative humidity favours rapid disease development. Temperature between 28 and $37^{\circ} \mathrm{C}$ is ideal for disease development. High moisture, poor aeration and close planting extends juvenile stage of the plants and predispose them to disease (Singh 1992). Fungus growth is observed at $15-40^{\circ} \mathrm{C}$ but optimum growth is at $30^{\circ} \mathrm{C}$.

Symptoms : Fruits in contact with soil get infected through wounds or insect bites. The affected peel portion becomes soft, dark-green with water-soaked lesions. Fluffy / woolly white mycelia grow profusely over wounded surface 
(Fig. 19.1). Within 3-4 days, mycelial growth subsides and watery soft-rot develops. Thick viscous fluid oozes out with an offensive smell due to secondary invasion by bacteria.

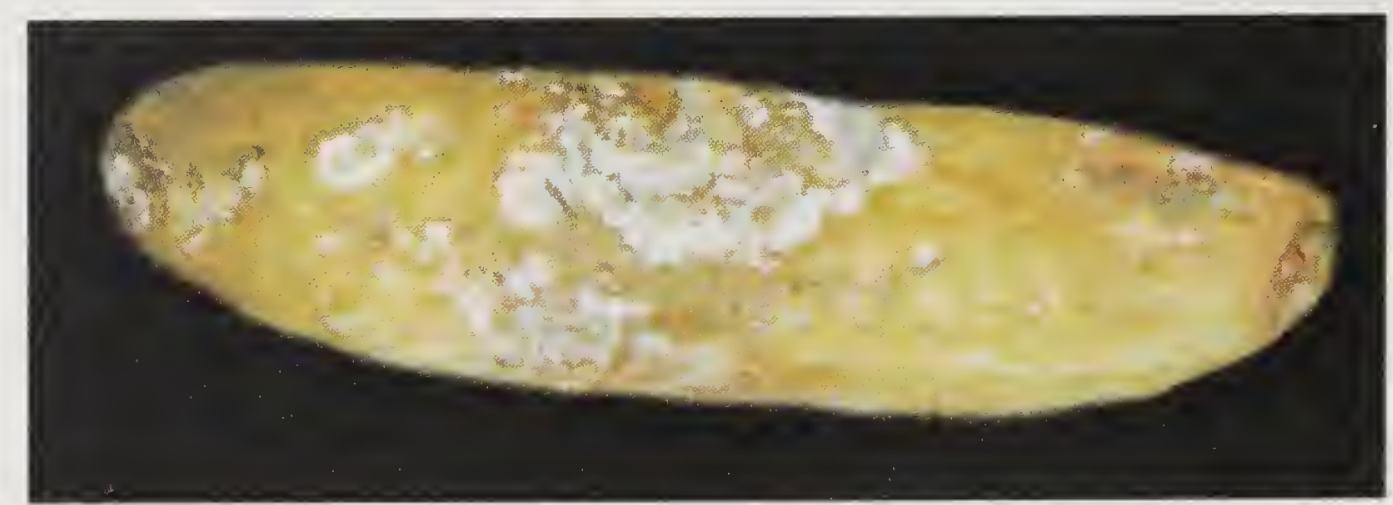

Fig. 19.1. Cottony-leak on cucumber

Reduction in sugar content and amino acids was recorded in rotten fruits collected from Punjab (Singh and Chohan 1977 a).

Control measures : Decay of the harvested fruits can be checked by storage at $10^{\circ} \mathrm{C}$ or below. Fungicide spray is necessary at the flowering stage. Irrigation should be appropriately controlled. Excessive moisture favours disease development; so adequate drainage needs to be provided. Care should be taken to minimize injury during harvesting and handling. Avoidance of fruits touching the soil reduces infection. Soil disinfection with formalin in water (1: 50) by sprinkling this on the loose soil to be soaked to a depth of 4", should be adopted. About 1 gallon (4.546 litres) of the mixture will be required for 2-3 $\mathrm{ft}^{2}(0.185-0.298 \mathrm{sqm})$ of soil.

Antibiotics and impregnated wrappers were promising for controlling cottony-leak. Pyrimidine fungicides were reported to be effective. They were specific and less phytotoxic. Milstem (Ethirimol) at $625 \mathrm{ppm}$ and Milcurb (Dimethirimol) at $750 \mathrm{ppm}$ showed in-vitro inhibition. But under in-vivo conditions, Milcurb alone at 3,000 ppm checked development of cottony-leak, when used as a dip treatment (Sharma and Wahab 1973; Wahab and Sharma 1974, 1976).

Sharma et al. (1981) reported control of the disease by soil fungi, Acrophialophora nainiana and Stachybotrytis atra, which possess antifungal activities. Under in-vitro conditions, a distinct zone of inhibition towards Pythium aphanidermatum was noticed.

Trichoderma harzianum $\left(5 \times 10^{9}\right.$ conidia/ml $)$ mixed with wheat-bran plus peat mixture $(1: 1 \mathrm{v} / \mathrm{v})$ and applied to the seed-coat controlled efficiently damping-off (Sivan et al. 1984).

Treating fruits with Hinkitol, a volatile oil extract from the Japanese Hika tree (Thujopsis dolabrata), was reported to protect at $750 \mathrm{ppm}$ with no phytotoxic effects (Aharoni et al. 1993).

Anthracnose, c.o. Glomerella cingulata (Stonem.) Spauld. \& Schrenk. Colletotrichum gloeosporioides fsp cucurbitae C. lagenarium (Pass.) Ell. \& Halst 
Serious losses due to anthracnose were reported from several countries, including the USA, Brazil (Menton et al.1979) Netherlands (Arx et al. 1961) and India (Laxminarayana and Reddy 1976a; Amin et al. 1979).

Symptoms : They develop as conspicuous dark circular spots, often numerous in numbers on the fruit-surface. The lesions become sunken and sometimes fruits show cracking (Fig. 19.2). Under humid conditions, characteristic masses of pinkish spores or conidia are formed. Sometimes due to lesions, fruits may get disfigured. The

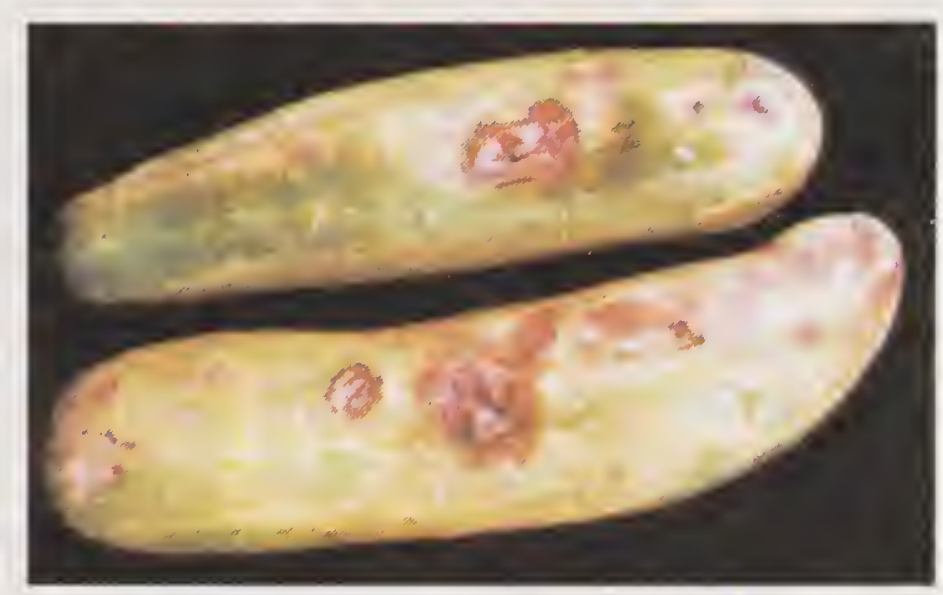

Fig. 19.2. Anthracnose on cucumber fungus is usually confined to the fruit skin; even though the skin is subsequently invaded by saprophytic organisms. Glomerella magna is also found associated in certain cases, where it may form concentric rings on the peel. Colonization of the entire fruit was also observed (Jenkins and Winstead 1964).

The fungus survives dormantly on the dead plant materials lying in the soil. The fungal conidia are transmitted by insects (Horn et al.1957), rains or irrigation water. Infection is severe particularly after heavy rains (Amin et al.1979). The spores formed on the host are washed by water, splashed by rain-drops or transported by beetles and implements. In the presence of moisture, spores germinate and penetration occurs within three days. The disease development in the fruit is in the epidemic form during heavy rains. Infection is heavy at $20-30^{\circ} \mathrm{C}$, optimum being at $25^{\circ} \mathrm{C}$ along with $\mathrm{RH}$ above $90 \%$. Under 100\% relative humidity, infection is fast (Singh 1992).

Control measures : Strict hygiene is necessary in the field for effective control. All crop debris should be removed and destroyed. Seed treatment is more effective as there is evidence of disease transmission through seeds. Seed treatment with Carbendazim, followed by spraying with Thiabendazole (0.15\%) gave good control (Om Prakash et al. 1973). Three to four sprayings with Ziram or Maneb ( $0.2 \%$ each) were also promising. Spray, when plants are two months old and repeat it at an interval of 10 days.

\section{Soft-rot, c.o. Rhizopus oryzae Went \& Prinsen Geerligs R.stolonifer (Ehrenb.) Vuill.}

Symptoms : Over-ripe fruits become more susceptible in comparison to semiripe fruits. Rotting is conspicuous as water-soaked irregular depressions and can often be mistaken as Pythium-rot; wounds or insect bites are a pre-requisite for infection. White cottony mycelia studded with black sporangial heads become prominent. The pulp gets softened and the whole fruit rots within 3-4 days (Philip 1998). 
Control measures : Wounds and insect bites on fruits should be avoided. Cut pieces should not be kept under ambient condition for more than 24 hours. Cold storage of intact fruits at $10^{\circ} \mathrm{C}$ is desirable.

\section{Choanephora-rot/soft-rot,}

c.o. Choanephora cucuribitarum (Berk. \& Rav.) Thaxter

The disease starts at the blossom-end of the fruit and develops as a soft wet-rot (Abd El-Rehim et al. 1964; Puscasu 1984). Under humid conditions, whitish growth of the fungus can be noticed with a metallic lustre. The colour turns from white to brown, and later on to purplish-black. Decay is rapid between 25 and $30^{\circ} \mathrm{C}$. Under cool environments, mould growth is not visible on the surface, and the fruit just turns brown.

The fungus survives in the soil as zygospores (sexual state) or as resting spores (chlamydospores) (Barnett and Lilly 1956; Kirk 1984; Puscasu 1984). Sporangiospores spread by wind, water or insects, and cause fresh infection.

Since disease development is favoured by excessive moisture, care should be taken to ensure good drainage, moderate irrigation, low crop density and freedom from weeds in the fields. If wet conditions are unavoidable, fungicidal spray with Ziram $(0.2 \%)$ is to be resorted to.

\section{Phytophthora-rot, c.o. Phytophthora spp.}

Several species of Phytophthora are found associated with rotting of cucumber-fruits; P.drechsleri Tucker was reported from China (Snowdon, 1991). These fungi are common soil inhabitants, causing disease under humid warm wet conditions. They produce both asexual (sporangiospores) and sexual (oospores) spores, which are spread by wind, water or insects.

Symptoms : They appear as lesions anywhere on the fruit-surface and are usually brown with an irregular margin, later becoming zoned or mottled. Under humid conditions, whitish fungal growth is observed with characteristic sporangia. Eventually skin ruptures and entire fruit decays to produce typical soft-rot. Fruits touching soil are likely to be affected.

Control measures : Fruits should be kept on the small raised platforms. Drenching soil prior to planting with copper oxychloride (COC, $0.2-0.3 \%$ ) helps controlling disease on the fruits. Damaged fruits should not be stored with sound healthy fruits.

Soil-rot, c.o. Thanatephorus cucumeris (Frank.) Donk.

Sclerotial state : Rhizoctonia solani Kühn

The disease was found in warm, wet-growing areas. It was reported from solomon Islands and the USA (Coursey and Booth 1972; Lewis and Papavizas 1980). It was also reported from Warangal (Andhra Pradesh) by Laxminaryana and Reddy (1976a). 
Symptoms : Spots are at first firm, brown and water-soaked. Later, these enlarge into irregular shaped sunken cankers. Under warm, humid conditions, rotting is rapid and infected fruits are covered with dense greyish-brown mouldy growth. The fungus is a common soil inhabitant and has both asexual/ sclerotial and sexual stages. Infection occurs on the fruits that are in contact with the soil, and rotting becomes apparent after harvesting of the crop. The optimum temperature for fungal growth is between 25 and $30^{\circ} \mathrm{C}$ and $\mathrm{RH}$ required is above $90 \%$.

Control measures : The fruits should be kept on small raised platforms. Fruit decay can be controlled by storage at $10^{\circ} \mathrm{C}$ or below. Seed treatment may prove beneficial as the fungus is reported to be seed-borne as in pumpkin, bittergourd and muskmelon (Gangopadhyay and Sharma 1976; Maholay and Sohi 1982). Land can be covered with plastic sheets to avoid soil contact (Lewis and Papavizas 1980).

\section{Brown-rot/Botryodiplodia-rot, c.o. Botryodiplodia theobromae Pat.}

The disease was formerly known as Diplodia-rot and caused serious losses in the USA, Egypt, India and other countries (Beraha et al. 1976; Satour and Shinnawy 1977; Maholay and Sohi 1982).

Symptoms : They are noticed on the over-ripe and wounded fruits. Lesions may occur anywhere on the fruit-surface. And sometimes it may occur on the stem-end region also. The advancement of the disease is very fast. The affected area becomes spongy with a water-soaked margin (Wiant 1937). Greyish-white fluffy mycelia are noticed around wounds, which further spread and may cover fruit completely (Fig. 19.3). The fungus also produces a tough layer beneath the fruit peel, causing it to become severely wrinkled. Black bodies representing pycnidia are produced in advanced stages, and a sour odour accompanies decay. Invasion of seed cavity results in blackening of seeds.

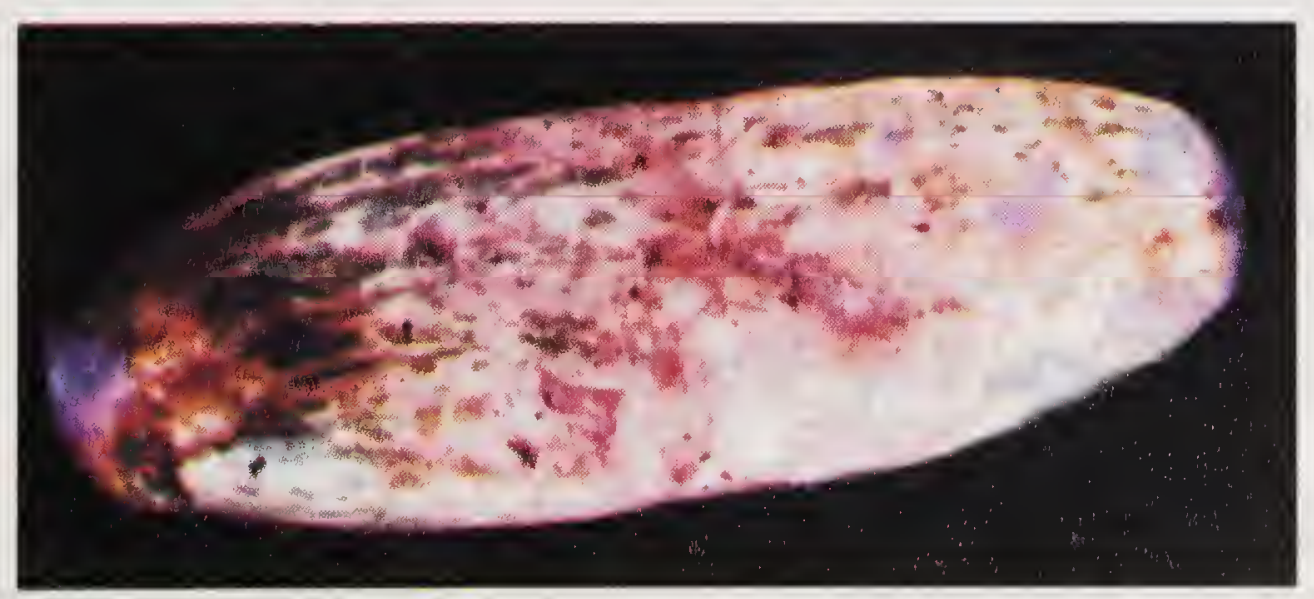

Fig. 19.3. Botryodiplodia-rot on cucumber

Control measures : Fungal spores are present in the soil and atmosphere. Care should be taken to avoid injury during harvest and handling as pathogen is wound-specific. Refrigeration prolongs storage life. Cut portions should not be kept under ambient condition for more than 24 hours. 


\section{Cladosporium-rot /gummosis /scab, c.o. Cladosporium spp.}

Cladosporium cucumerinum causes losses to the crop mainly in temperate countries like the USA, Canada, Netherlands and Germany (Strider and Winstead 1960).

Symptoms : On the immature fruits, circular (up to one $\mathrm{cm}$ in diameter), water-soaked and deeply sunken lesions appear. They tend to exude a gummy substance, which dries and darkens. Subsequently under humid conditions, a velvety silver-grey mould develops, turning to olive-green, with the formation of a dense-mat of spores. On the mature fruits, lesions are superficial and form brown corky scab. The fungus is also reported to cause symptoms on the cucurbit leaves in Rajasthan (Maharshi 1982).

The fungus survives on plant debris in soil during wet or humid weather and produces spores, which are disseminated by air currents (Narain et al. 1985). Optimum conditions favourable for disease development are $20^{\circ} \mathrm{C}$ temperature and high relative humidity. The fungus penetrates into young fruits, but in older fruits infection takes place through wounds. Incipient infections continue to develop after harvest even under refrigeration (Wiant 1937).

Control measures : Post-harvest rotting can be controlled by dipping fruits in fungicidal solution of Guazatine (100mg a.i./litre) (Wade and Morris 1982), and also by refrigeration. Storage for longer period should be avoided.

\section{Sclerotinia-rot, c.o. Sclerotinia sclerotiorum (Lib.) de Bary .}

The disease is common on fruits stored in cool temperature. Three to four sprays of culture filtrate of Trichoderma viride with Fundazole 50\% (Benomyl $500 \mathrm{ppm}$ ) and Topsin-M (Thio phenate methyl, $0.1 \%$ ) before storage were reported to be effective (Vozenilkova and Zvara 1990; Vozenilkova and Skorepa1992).

\section{Scanty cottony white-rot /Fusarium-rot, c.o. Fusarium spp.}

The disease was reported from Bhubaneshwar (Mishra and Rath 1986) and West Bengal (Dasgspta and Mandal 1989). Fusarium equiseti, F. oxysporum and $F$. moniliforme have been identified, and F.solani is most frequent.

Symptoms : They are pronounced on the injured fruits. Spread of the disease is very slow. Scanty white growth of the fungus appears on the infected region. Water-soaked areas may develop around the white growth. A dull-coloured liquid oozes out and entire fruit becomes wrinkled.

Control measures : Biological control was reported to be effective in reducing destructive effect of F.oxysporum. Seeds treated with commercial preparation of Trichoderma ('Trichodermin BL') enhanced sowing qualities and stimulated plant growth (Votika 2003). 
OTHER DISEASES AND THEIR CAUSAL ORGANISMS

\begin{tabular}{lll}
\hline Disease & Causal organism & Authority \\
\hline Black fruit-rot & $\begin{array}{l}\text { Didymella bryoniae } \\
\text { (Auersw) Rehm }\end{array}$ & $\begin{array}{l}\text { Chiu and Walker, } \\
\text { 1949; Stitterly, 1968 }\end{array}$ \\
Pink mould-rot & $\begin{array}{l}\text { Trichothecium roseum Pers } \\
\text { \& Link. }\end{array}$ & \\
Corticium rolfsii Curzi & \\
Sclerotium-rot & $\begin{array}{l}\text { Macrophomina phaseoli } \\
\text { (Maubi.) Ashby }\end{array}$ & \\
Alternaria-rot & Alternaria spp. & Sharma and \\
Curvularia-rot & $\begin{array}{l}\text { Curvularia pallescens Boedijn } \\
\text { Myrothecium-rot }\end{array}$ & $\begin{array}{l}\text { Myrothecium roridum } \\
\text { Tode ex Fries }\end{array}$ \\
Helminthosporium-rot & $\begin{array}{l}\text { Helminthosporium } \\
\text { hawaiiense, Bognic. }\end{array}$ & \\
Bacterial soft-rot & $\begin{array}{l}\text { Erwinia spp. } \\
\text { Pseudomonas sp. }\end{array}$ & \\
Bacterial-spot & Reddy, 1976a \\
\hline
\end{tabular}

\section{Seed microflora}

Nazeema (1981) reported Aspergillus flavus from cucumber seeds. A. niger and Penicillium spp. were reported as the predominant fungi from Pakistan. Others include Mucor sp., Rhizopus sp., Acremonium sp., Oospora latis, Geotrichum candidum and Cephalosporium sp. Among bacteria, Bacillus megaterium and B.subtilis were dominant over other bacterial pathogens (Alimova et al. 2002).

\section{PUMPKIN (Cucurbita pepo L.)}

Pumpkins are grown all around the world for a variety of reasons, ranging from agricultural purposes to commercial and for ornamental sales. Phytochemicals found in them may favourably affect insulin and glucose levels in human body. Pumpkin seed oil contains fatty acids like oleic acid and linolic acid.

\section{FUNGAL DISEASES}

Anthracnose, c.o Glomerella magna S.F. Jenkins and N.N Winstead Conidial state : Colletotrichum sp.

Marrows, squashes and pumpkin are generally resistant to this disease. The disease was recorded from the USA by Jenkins and Winstead (1964). Symptoms appear in the form of lesions with concentric rings, and sometimes entire fruit may be colonized.

Control measures are as detailed under anthracnose in cucumber. 


\section{Botryodiplodia-rot, c.o Botryodiplodia theobromae Pat.}

This disease is of common occurrence in tropical countries. Affected areas become soft and loose (Satour and Shinnawy 1977). Philip (1998) observed the disease on the pumpkins stored in local markets of Thiruvananthapuram. Infection is mostly around the injuries.

Symptoms : These are similar to other Botryodiplodia-rots. In advanced stage, whole fruit gets covered with greyish mycelial mat. Complete rotting of fruits may be in ten days. Finally, the fruit collapses and a dark viscous fluid with an offensive smell oozes out.

Control measures : Care should be taken to avoid injuries during harvest, handling and subsequent storage. The fruits may remain intact up to two months. Refrigeration at $10^{\circ} \mathrm{C}$ prolongs storage period. Cut pieces should not be kept for more than 24 hours under ambient condition.

\section{Choanephora-rot, c.o. Choanephora cucurbitarum (Berk. \& Rav.) Thaxter}

This fungus caused severe losses in the USA (Barnett and Lilly 1956). The disease was reported from India also (Mustafee 1972).

At the blossom-end of the fruit, appears soft wet-rot. Under the humid conditions, luxurious growth of the fungus is noticed. Decay is very rapid between 25 and $30^{\circ} \mathrm{C}$ (Snowdon 1991)

\section{Cunninghamella fruit-rot, c.o.Cunninghamella echinulata Thaxter ex Blakeslee}

The disease was reported by Grover (1965) from Punjab. Young developing fruits are vulnerable to attack and thus result in serious losses. Rotting is maximum at $28-32^{\circ} \mathrm{C}$ with $\mathrm{RH}$ of $88-100 \%$. Neklyudova (1960) from Russia reported a disease complex on young pumpkin-fruits, caused by species of Pythium and Rhizopus, which produced symptoms similar to those by Cunninghamella sp.

Symptoms : They appear on young fruits, which turn dark-brown and get covered extensively with cottony mycelial growth, bearing numerous conidial heads. Either the affected fruits get detached from the plant or the rotten fruits may remain attached to the stalk, and then become shrivelled, dried and mummified.

Control measures : Field application of fungicides (4 sprays) from flowering to just before harvest with Actidione $(0.25 \%)$ and Phaltan $(0.15 \%)$ checked disease. Phaltan checked pectinolytic enzyme activity of the fungus (Grover 1964).

\section{Cottony-leak, c.o. Pythium spp.}

The disease was reported from India and USSR.

Symptoms : They appear as soft, dark lesions anywhere on the fruit-surface, often at the stem-end. Infected tissues become water-soaked and pulp undergoes rapid breakdown. 
Control measures are as detailed under cottony-leak in cucumber.

Spongy-rot/soil-rot, c.o. Thanetophorus cucumeris (Frank.) Donk.

Sclerotial stage : Rhizoctonia solani, Kühn

Fusarium oxysporum Schlet.

A spongy-rot due to combined infection by Rhizoctonia and Fusarium was reported by Gangapadhyay and Sharma (1976) from Kullu, Himachal Pradesh. The fungus perenates in stubbles.

Symptoms : They appear after 30 days of storage, characterized by drying of fruit and blackening of outer rind. The symptoms are both external as well as internal.

External : Deep-brown to black spongy decay on the outer surface.

Internal : Drying and sponginess of the pulp and conversion of the goldenyellow colour to black. The pulp inside becomes spongy, desiccated and juiceless. Seeds turn black due to fungal growth. Radicle of the germinating seedlings becomes black and finally dead.

Control measures: The disease has been observed mostly as seed-borne. Seed treatment with Thiram $(0.2 \%)$ gives protection. Injuries during harvest and handling operations should be avoided. Refrigeration at $10^{\circ} \mathrm{C}$ prolongs storage.

\section{Soft-rot/Sclerotium fruit-rot, c.o. Sclerotium rolfsii Sacc.}

This is considered as a minor disease. Water-soaked discolouration appears on the stem-end portion of the fruit. Fruit tissues start softening and in advanced stages whole fruit is covered with mycelial mat and sclerotia (Siddaramaiah et al. 1982).The fungus is also reported to cause collar-rot of pumpkin seedlings (Singh and Seth 1974).

Control measures are as detailed in spongy-rot.

\section{Cottony white-rot, c.o. Fusarium solani (Mart.) Appel. \& Wr. F.oxysporum Schlet.}

Rotting due to F.solani f.sp.cucurbitae race 2 was recorded as a serious disease from the USA. A similar disease was recorded by Dasgupta and Mandal (1989) from West Bengal. On the stored ripe-fruits, the disease is with a characteristic oak-brown soft area around the injured site with flesh becoming combed-brown. Infection advances radially with distortions of the fruit-skin and shrinkage of flesh. F.solani is also observed to be seed-borne (Nazeema 1981), and seeds need to be treated with Thiram (0.2\%), and storage of fruits under refrigeration at $10^{\circ} \mathrm{C}$ is promising.

\section{Charcoal-rot, c.o. Macrophomina phaseolina (Tassi) Goid.}

The fungus is widespread in tropics and subtropics, and causes epidemics during hot-dry season. Symptoms appear as water-soaked spots on the skin. Under favourable condition, spots rapidly enlarge and affected areas become 
firm in texture with an indefinite boundary. As the decay advances, skin wrinkles, and minute spherical bodies (microsclerotia) develop in abundance; they appear powdery and black. Sometimes infected fruits become hollow shells with blackened interior (Snowdon 1991). Refrigerated storage at $10^{\circ} \mathrm{C}$ was found effective.

\section{Black mould-rot, c.o. Aspergillus niger Van Tieghem.}

The disease is of minor importance and occurs on cut pieces or ratbrowsed fruits. Discolouration progresses fast and sometimes seed-coat also is involved. Sporulating mass appears overnight on the surface.

Cut pieces should not be kept under ambient conditions for more than 24 hours; refrigeration at $10^{\circ} \mathrm{C}$ is effective.

\section{Phytophthora-rot, c.o. Phytophthora capsici Leonian}

Pre-and post-emergence damping-off due to Phytophthora is a serious threat to farmers in Illinois, USA.

Symptoms : Water-soaked lesions appear on the fruit-surface. As the disease advances, whitish growth of the fungus is observed.

Control measures : Soil treatment with $\mathrm{COC}(0.2-0.3 \%)$ before planting the crop minimized Phytophthora-rots. Seed treatments with Mefenoxam or Metalaxyl (at concentration of $0.5 \mathrm{mg}$ a.i. $/ \mathrm{ml}$ ) have some advantage in controlling P.capsici; gives protection for 5 weeks (Babadoost and Islam 2003).

OTHER DISEASES AND THEIR CAUSAL ORGANISMS

\begin{tabular}{|c|c|c|}
\hline Disease & Causal organism & Authority \\
\hline \multirow{4}{*}{$\begin{array}{l}\text { Grey mould-rot } \\
\text { Sour-rot } \\
\text { Cladosporium-rot } \\
\text { Seed-borne fungus }\end{array}$} & Botrytis cinerea Pers. & \\
\hline & Geotrichum candidum Link. & \\
\hline & Cladosporium spp. & \\
\hline & $\begin{array}{l}\text { Cephaliophora irregularis Thaxter } \\
\text { Rhizopus stolonifer (Ehrenb.)ex Fr. }\end{array}$ & Nazeema, 1981 \\
\hline
\end{tabular}

\section{WATERMELON (Citrullus lanatus (Thunb.) Matsum \& Nakai}

The fruit contain $6 \%$ sugar and $92 \%$ water by weight. The amino-acid citrulline was first extracted from watermelon. Watermelon-fruit is mildly diuretic and contains large amount of beta-carotene. Fruit with red flesh is a significant source of lyocopene.

\section{FUNGAL DISEASES}

Anthracnose, c.o. Glomerella cingulata (Stonem.) Spauld. \& Schrenk. Colletotrichum gloeosporioides Penz.

Anthracnose disease was reported causing serious losses on watermelons (Layton. 1937; Arx et al. 1961; Menton et al.1979). A related species of 
Colletotrichum (Glomerella magna) was recorded from the USA (Jenkins and Winstead 1964).

Symptoms, etiology and control measures are similar to those on cucumber.

Fruit-rot/cottony-leak, c.o. Pythium aphanidermatum (Edson) Fitzp. P.butleri Subram.

Singh and Chohan (1977a) recorded this disease from Punjab. It is widespread, and sometimes $50 \%$ or even more of the fruits may undergo rotting after rains. It was observed to start from the blossom-end (Singh 1992). Symptoms : The fruit-rind becomes dark-green and water-soaked. This without any aerial growth of the fungus indicates 'killing in advance' activity of the pathogen. The interior tissues become soft and watery. Decaying fruits emit bad odour due to secondary invasion by bacteria. Singh and Chohan (1977 a) studied changes in carbohydrates and soluble amino acid content due to infection; the quantity increased in chlorotic regions, and decreased in rotten areas. Drastic reduction in sucrose, glucose and fructose was also observed.

Control measures are as detailed under cottony-leak in cucumber.

Rhizopustrot, c.o Rhizopus oryzae Went \& Prinsen Geerligs R. stolonifer (Ehrenb:) Vuill.

The disease was reported from Israel (Barkai-Golan 1981). Symptoms, etiology and control measures are similar to those on cucumber.

Choanephora-rot, c.o. Choanephora cucurbitarum (Berk.) \& Rav.) Thaxt

The disease is of minor importance (Kirk 1984; Snowdon 1991). Symptoms, etiology and control measures are similar to those on cucurbits.

\section{Phytophthora-rot, c.o. Phytophthora spp.}

Several species such as Phytophthora cactorum (Leb.\& Cohn) Schroet and P.nicotiane var. parasitica have been reported to cause rotting in the USA (Norton and Roseberg1954; Brown and Evans 1983). Ullasa (1984) recorded P.nicotianae along with Fusarium oxysporum from Bengaluru. Symptoms, etiology and control measures are similar to those on cucumber.

\section{Alternaria-rot, c.o. Alternaria alternata (Fr.) Keissler}

\section{A.cucumerina (Ell.\&EV.) Elliot}

Alternaria-rot is common in all watermelon-producing countries. A.cucumerina is usually more important as a leaf-spot fungus and causes defoliation (Jackson 1959). The fungus was reported from Bengal by Gangopadhyay and Kapoor (1973).

Fruits weakened by sunscald are predisposed to be attacked by species of Alternaria (Kachawaha and Ali 1982). Fruits stored over long periods at low temperature with chilling injury may also be infected (Mc Colloch 1982). 
Symptoms : Circular to oval lesions appear,which are sunken. Affected rind turns brown under humid conditions and is rapidly covered by fungal growth, and abundant sporulation is also observed (Simmons 1967).

Control measures : Two to three sprays of Ziram (0.2\%) applied on the two months old plants and repeated at the harvest, control storage-leak. Avoid injuries on fruits at harvest, handling and storage. Refrigeration at $10^{\circ} \mathrm{C}$ prolongs storage.

\section{Cladosporium-rot, c.o. Cladosporium tenuissimum Cooke}

The fungus was recorded on watermelons from Odisha (Narain et.al. 1985). Small irregular shaped dark-brown lesions appear on the detached blossom-end. Sooner fruits wrinkle with irregular folds giving depressed appearance. Cracks are observed in larger fruits where inner pulp gets exposed. Alternaria alternata was also found associated with this fungus.

Rotting can be avoided by dipping fruits in a fungicidal solution of Guazatine (100 mg a.i./litre) (Wade and Morris 1982) and by refrigeration at $10^{\circ} \mathrm{C}$.

\section{Charcoal-rot, c.o. Macrophomina phaseolina (Tassi) Goid.}

This disease is of minor importance.

Symptoms : Dark-brown-to-black lesions appear. In some cases lesions are about half the size of the fruit with a large number of dot-like black bodies on the infected surface (Jhooty and Singh 1971). As the decay advances, fruit skin wrinkles and profuse minute spherical bodies, representing microscolerotia, are noticed. This superficial crust tends to rupture and expose watery flesh, which emits pungent odour and eventually turns black. Sometimes infected fruits become hollow shells with blackened interior. Epidemic during dry weather was also recorded (Reuveni et al. 1983).

Control measures : Citrullus colocynthis and C.vulgaris were recorded as highly resistant varieties (Singh and Chohan 1972). Seed treatment and fungicidal spray gave only partial control. When rains are infrequent, irrigate crop regularly so that plants are not weakened by drought. Refrigeration of fruits at $10^{\circ} \mathrm{C}$ is desirable.

Didymella black-rot, c.o. Didymella bryoniae (Auersw.) Rehm.

Phoma cucurbitacearum (Fr.) Sacc.

This disease is of minor importance.

Symptoms : Lesions are at first water-soaked and are roughly circular. Later they zonate sometimes and become dark, sunken and cracked. Under humid conditions, whitish mould may develop. Infected tissues shrivel and give rise to minute black bodies (pycnidia and perithecia).

Myrothecium-rot, c.o. Myrothecium roridum Tode ex Fr.

Symptoms : Dark-sunken lesions of about 1-mm diameter and fringed with 
a white growth are noticed. They support discrete greenish-black spore masses (sporodochia). The lesions may coalesce into a sticky charcoal-black sheath or become dry hard and flaky. The flesh finally becomes watery.

Control measures : The disease is seed-borne. Seed treatment with Thiram $(0.2 \%)$ is recommended. Field hygiene is also important. Fungicide Ziram $(0.2 \%)$ spray at the onset of flowering is found promising. Refrigeration is necessary to prevent deterioration.

\section{Phomopsis-rot, c.o. Diaporthe melonis (Beraha \& O'Brien) Phomopsis sp.}

Symptoms : The fungus infects developing fruits, and remains quiescent until melons mature. Symptoms appear as dark, raised spots.

Control measures : Post-harvest rotting can be avoided by fungicide dip (Berah and O' Brien 1979). Since pathogen is soil-borne, soil should be disinfected. Seed treatment with Thiram $(0.2 \%)$ and protection of fruit from insect damage or other wounds are desirable. Refrigeration at $8-10^{\circ} \mathrm{C}$ enhances storage period.

\section{Fusarium-rot, c.o. Fusarium spp.}

Several species of Fusarium are found associated, causing this rotF.equiseti, F.oxysporum, F.pallidoroseum and F.solani.

Symptoms : They may appear anywhere on the fruit-surface or on the stemend portion as white scanty growth. Surrounding area becomes water-soaked, and rotting of pulp occurs. Severe rotting in melons at Thiruvananthapuram markets was observed ( Philip 1998).

Control measures : Protect fruits from insect damage/wounds. Storage at 8$10^{\circ} \mathrm{C}$ refrigeration is promising. Cut pieces should not be kept at ambient condition for more than 12 hours.

\section{Aspergillus-rot, c.o. Aspergillus fumigatus Fries}

Injured fruits are invariably affected by this disease. Dasgupta and Mandal (1989) observed disease on the cracked fruits during May/June in West Bengal; sound fruits were free of infection.

Symptoms: Greenish fungal growth appears around the injury. It covers cracked surface. Rotting is slow and limited. Due to infection, red colour of the internal tissue gets faded.

Control measures : Avoid injuries to fruits. Storage of fruits at $8-10^{\circ} \mathrm{C}$ refrigeration is protective.

Blue-mould, c.o. Penicillium spp.

Its symptoms and control measures are similar to those of Aspergillusrot, excepting that colour of Pencillium lesions is blue. 
OTHER DISEASES AND THEIR CAUSAL ORGANISMS

\begin{tabular}{|c|c|c|}
\hline Disease & Causal organisms & Authority \\
\hline \multirow[t]{2}{*}{ Pink mould-rot } & Trichothecium roseum & \\
\hline & Link. ex Fries & $\begin{array}{l}\text { Rao, 1964; } \\
\text { Singh and Bhatnagar, } 1982\end{array}$ \\
\hline Soil-rot & $\begin{array}{l}\text { Thanetophorus cucumeris } \\
\text { Frank. (Donk.) }\end{array}$ & \\
\hline Sclerotial state: & Rhizoctonia solani Kuhn & \\
\hline Sour-rot & Geotrichum candidum Link. & \\
\hline Watery soft-rot & Sclerotinia sclerotiorum (Lib.) & de Bary \\
\hline Grey mould-rot & Botrytis cinerea Pers. & \\
\hline Bacterial soft-rot & & Dasgupta and Mandal,1989 \\
\hline
\end{tabular}

\section{MUSKMELON (Cucumis melo L.)}

Large number of the fruits in India are reported to get spoiled due to fungal infections during transport and marketing (Ojha et al. 1984; Prasad and Roy 1986).

\section{FUNGAL DISEASES}

Fruit-rot /cottony-leak, c.o. Pythium butleri Subram.

$$
\text { P. aphanidermatum (Edson) Fitzp. }
$$

The disease was reported by Prasad et al. (1988) from Bihar. It causes severe losses in muskmelon fruits. More than 50\% rotting of fruits was observed after rains (Singh and Chohan 1977). Fruit-rot incidence was found maximum at $30-35^{\circ} \mathrm{C}$ and at $100 \% \mathrm{RH}$.

Symptoms and control measures are as detailed under cucumber.

Sour-rot, c.o. Geotrichum candidum Link.

The disease is of common occurrence in California. It was observed in 'honey dew' melons (Ceponis 1966). Yeoung and Kimhakki (1996) reported disease from Korea.

Symptoms : They appear as a soft mush-discoloured decay at the stem scar region. Maximum decay occurs at $60^{\circ} \mathrm{F}$, but at $40^{\circ} \mathrm{F}$, it progresses slowly. Lewis and Sinclair (1966) associated infection with deep wounds.

Control measures : Fruits stored at $5^{\circ} \mathrm{C}$ remain firm with longer storage life (Yeoung and Kimhakki 1996).

Fusarium-rot, c.o. Fusarium semitectum Berk. \& Rav.

The disease was reported by Prasad et al. (1988) from Bihar.

Symptoms : They are as detailed under watermelon.

Due to infection, reduction in total sugars, proteins and phenol content was observed. F. semitectum was found very efficient in utilizing sugar and protein fractions of muskmelon-fruits (Prasad et al.1988). 
Fruit-rot due to Curvularia lunata from Bihar was also recorded (Prasad et al. 1988).

\section{CHAYOTE/CHOW-CHOW (Sechium edule (Jacq.) SW.)}

The crop is grown in tropics and subtropics, including West Indies, Australia, India and parts of Africa.

\section{FUNGAL DISEASES}

Alternaria-rot, c.o. Alternaria alternata (Fr.) Keissler

Circular to oval lesions appear; they may become sunken in advanced stage. Affected peel appears brown or bleached out. But under humid conditions, it is covered by dark fungal growth and abundant olive-green to dark-brown spores.

Control measures are as detailed under Alternaria-rot of watermelon.

Anthracnose, c.o. Glomerella cingulata (Stonem.) Spauld. \& Schrenk.

The disease is virulent on chayotes (Arx et al.1961; Menton et al. 1979). Symptoms and control measures are similar to anthracnose of cucumbers.

Cottony-leakJPythium-rot, c.o. Pythium spp.

Pythium debaryanum was reported on chayotes from Italy. Symptoms and control measures are similar to cottony-leak of cucumbers.

\section{Fusarium-rot, c.o Fusarium sp.}

Symptoms: White, scanty growth appears over injured sites. Infected regions rot, and rotted tissues emit foul smell (Fig. 19.4) (Philip 1998).

Control measures: Injuries and wounds should be avoided. The

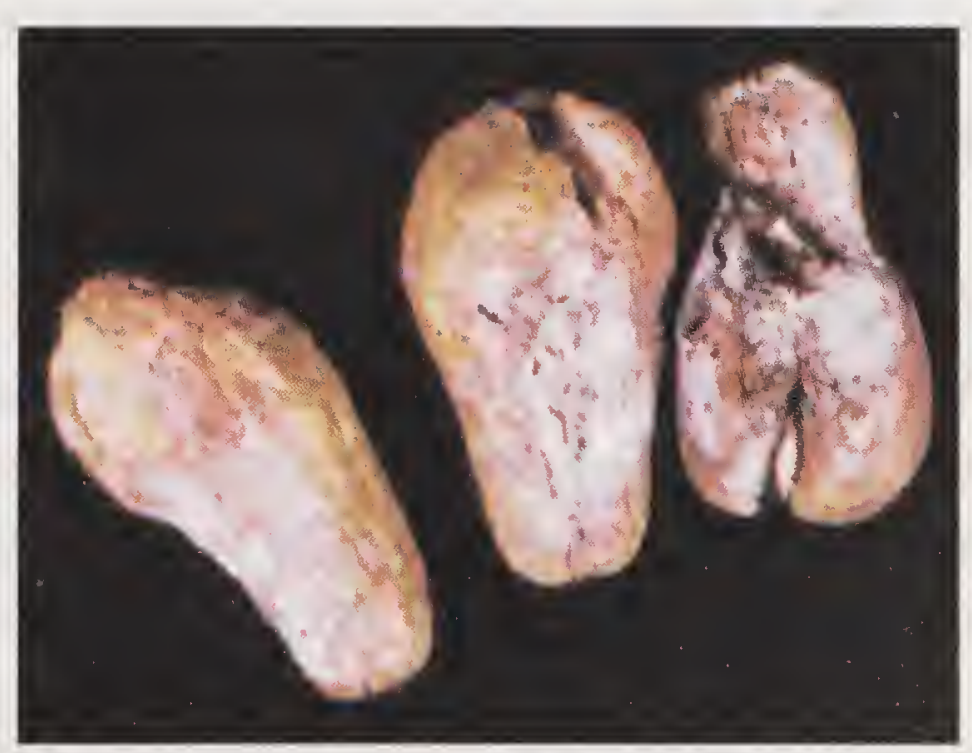

Fig. 19.4. Fusarium-rot on chow-chow fruits fruits should be stored under refrigeration.

Phytophthora-rot, c.o. Phytophthora nicotianae (Anon. 1963)

Symptoms and control measures are similar to those of cucumbers.

BITTERGOURD (Momordica charantia L. var. charantia)

The fruit is also known as bitter cucumber. It is common in India. Fruit pulp including seeds has a unique quality to lower blood glucose level (Pabarai and Sehra 1962). 


\section{FUNGAL DISEASES}

\section{Anthracnose, c.o. Colletotrichum capsici (Syd.) Butler and Bisby C.lagenarium (Pass.) Ell. \& Halst.}

Om Prakash and Singh (1977) reported this disease from Bihar and Bengaluru.

Symptoms : Irregular, circular or semi-circular lesions generally appear, surrounded by water-soaked areas. These lesions coalesce sometimes and form elongated patches. Fruit cracks open longitudinally and expose abundant pink spore mass. This is followed by fruit-rot.

Control measures : Spraying of crop before harvest with Mancozeb (0.2\%) or Nabam $(0.2 \%)$ is effective in controlling the disease under storage.

C.lagenarium is seed-borne internally (Nazeema 1981). Dubey and Ekka (2003) observed effect of seed-dressing fungicides like Thiram, Vitavax, Topsin M, Bavistin and Captan @ 2g/kg on naturally infected seeds. Complete inhibition was recorded with Vitavax and Thiram.

\section{Blossom-end-rot, c.o. Macrophomina phaseolina (Tassi) Goid.}

Slight water-soaked areas appear around the blossom-end, which extend towards the stem-end. Within 7-10 days, $50 \%$ of the fruits get covered. Black pycnidia develop over and inside the infected portion. Later infection extends deep into the pulp (Singh 1975).

The disease is of minor importance.

\section{Fruit-rot/cottony-leak, c.o. Pythium aphanidermatum(Edson) Fitzp.}

The disease was recorded in a serious form from Maharashtra and West Bengal (Rao 1966b; Mandal and Dasgupta 1981).

Symptoms : They may appear anywhere on the fruit-surface, and the fungus forms a luxuriant woolly mycelial weft on the affected fruits, which appear as if wrapped by cotton. The disease originates as a soft-rot. On this rotting portion, fungal mycelia develop abundantly during humid conditions.

The fungus is a soil inhabitant, living as a saprophyte on the dead organic matter and induces disease on the host plants. The important pre-disposing factors are abundant moisture and high temperature. A slight injury on the peel facilitates entry by the pathogen.

Control measures : Avoid injury on the harvested fruits. Refrigeration of fruits at $10^{\circ} \mathrm{C}$ is protective.

\section{Soft watery-rot, c.o. Rhizopus stolonifer (Ehrenb.) Vuill.}

The disease was reported from Karnataka and West Bengal (Hiremath and Govindu 1973; Mandal and Dasgupta 1982). On injured fruits, small watersoaked areas appear, which become yellowish-brown and are covered by a stringy coarse fungal mass. In advanced stages, fruits become soft due to tissue disintegration; and a watery-rot sets in. Mycelia invade seed-coat also. 
Control measues as detailed under Rhizopus-rot of cucumber are applicable to this disease also.

\section{Fuzzy yellowish-rot, c.o. Mucor hiemalis Wehmer}

The disease was recorded from West Bengal (Dasgupta and Mandal 1989). Over the fruit-surface, scanty mycelial growth is observed due to the disease. And very soon fruits are covered with fine fuzzy, less dense, turfy yellowish mycelia. Infected fruits become soft and brown.

Control measues are as detailed under Rhizopus-rot of cucumber.

\section{Grey white-rot, c.o. Sclerotium rolfsii Sacc.}

The disease was recorded from Karnataka and West Bengal. Small, depressed water-soaked areas appear on the fruit-surface around the injury. Infected portions become ashy-yellow and soft. Finally colour turns grey or black.

\section{Cottony white-rot, c.o. Fusarium spp.}

Several species of Fusarium are found associated with this-F. equiseti, F.oxysporum, F.solani f sp cucurbitarum and F.semitectum. The disease was reported from several states in India (Tandon and Verma 1964; Chattopadhyay and Mustafee 1967; Hiremath and Govindu1973; Gupta et al.1982; Sharma and Sumbali 1993). Disease is noticed all year-round, particularly during summer.

Symptoms : The disease starts from the distal-end of the fruit, characterized by slightly water-soaked circular to irregular rotten patch with withered ribs and skin. Under dry conditions, fruits become hard, but during wet favourable conditions, internal tissues disintegrate in brownish shade. The reddish slimy tissue on the seed surface disintegrates and separates. White to dull scanty fluffy cottony mycelia develop on the surface in moist atmosphere. Juice leaks out from fruit but without unpleasant smell (Dasgupta and Mandal1989).

Control measures : Treat seeds with Captan $0.2 \%$ or Thiram $0.2 \%$. Wounds and injuries during harvesting, transportation and storage should be avoided. Cold storage under refrigeration at $8-10^{\circ} \mathrm{C}$ is found promising.

Corynespora fruit-rot, c.o. Corynespora cassiicola (Berk. \& Curt) Wei.

The disease was recorded from the local markets in Thiruvananthapuram, and is of minor importance. Symptoms appear at the distal-end of the fruit as minute spots, which enlarge and cover the end (Fig. 19.5). Within 3-5 days, the affected portion shrinks and rots. The rest of the fruit remains healthy (Philip 1998).

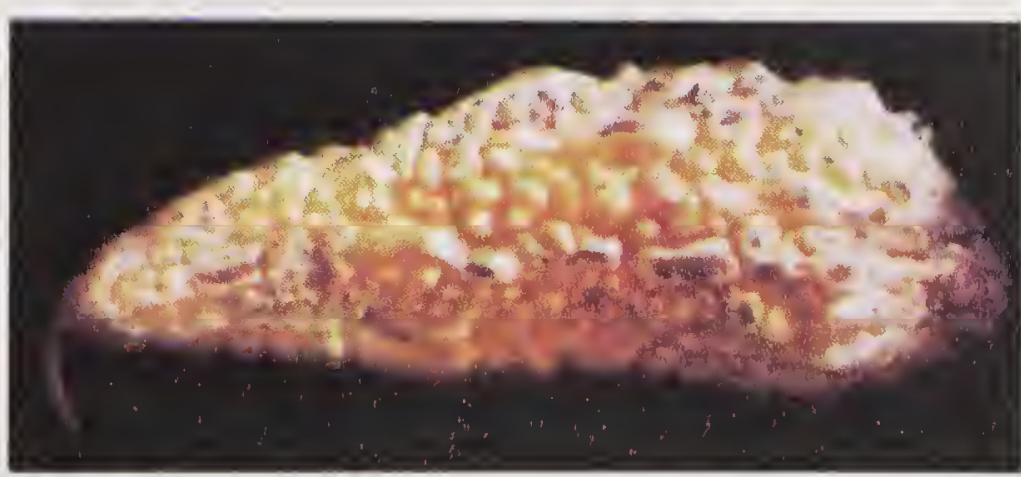

Fig. 19.5. Corynespora-rot on bittergourdfruit 
Didymella black fruit-rot, c.o. Didymella bryoniae (Fuckel.), Rehm Phoma cucurbitacearum (Fr.)Sacc.

Several names were used for the causal organism in the past, such as Mycosphaerella citrullina, M.mealanois and Ascochyta citrullina.

Small circular water-soaked lesions appear on the green fruits that quickly enlarge to form blackish spots within a week. Black, small, pinhead-like structures represent fungus asci and ascopores. Infected fruits contained $P$. cucurbitacaearum while seeds contained both $D$. bryoniae and $P$. cucurbitacearum (Singh and Shetty 1996). The disease is of minor importance.

\section{Myrothecium-rot, c.o. Myrothecium roridum Tode}

The disease was reported from Jodpur (Rajasthan). Small, circular olivegrey patches, which are slightly sunken, appear. The diseased area increases gradually, and is covered with copious growth of white woolly mycelia in concentric rings, followed by formation of a dark-green zone of sporodochia with viscoid spore mass. Typical symptoms developed at $25^{\circ} \mathrm{C}$ (Vyas and Panwar 1976).

The disease is seed-borne, and seed treatment with Captan $(0.2 \%)$ or Thiram $(0.2 \%)$ is effective.

Rhizoctonia-rot, c.o. Rhizoctonia solani Kühn

In the early stages, light-brown spots are visible on the ripe-fruits. Gradually fluffy mycelial growth and dark, fruiting bodies are noticed. Fruit decay is conspicuous in advanced cases (Vyas and Panwar 1976).

Botryodiplodia-rot, c.o. Botryodiplodia theobromae Pat. (Fig. 19.6)

Symptoms and control measures are as detailed under cucumber.

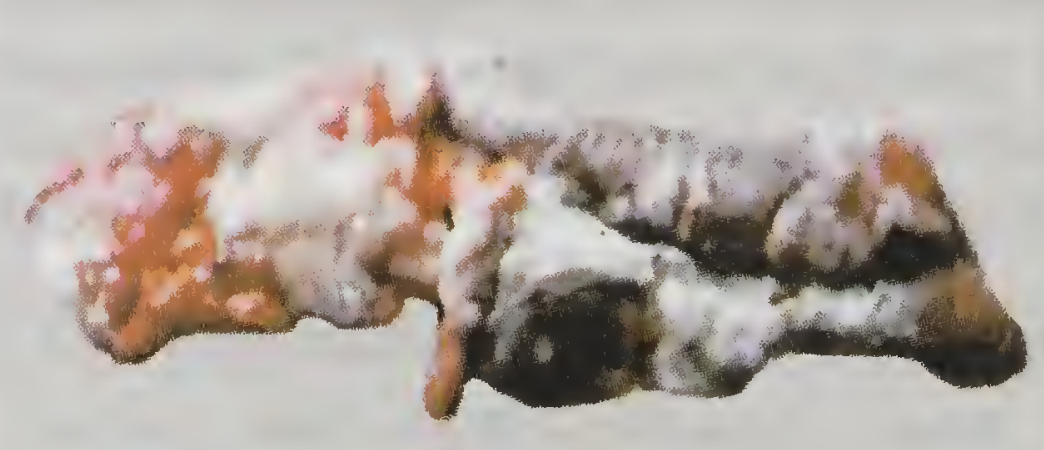

Fig. 19.6. Botryodiplodia-rot on bittergourd at advanced stage

OTHER DISEASES AND THEIR CAUSAL ORGANISMS

\begin{tabular}{lll}
\hline Disease & Causal organism & Authority \\
\hline $\begin{array}{c}\text { Curvularia fruit-rot } \\
\text { Helminthosporium }\end{array}$ & Curvularia lunata (Wakker) Boedijn & Prasad et al.,1988 \\
fruit-rot & Helminthosporium spiciferum & Roy and Choubey, \\
& (Bain.) Nicot & 1984 \\
\hline
\end{tabular}




\section{Seed mycoflora}

Aspergillus species are commonly found externally associated with seeds. These include A.niger, A.flavus and A.ochraceous. Among these, A.flavus is found associated with embryo. Along with this, Chaetomium microsporum, Botryodiplodia theobromae and Colletotrichum lagenarium were also reported (Nazeema 1981).

Dehydrated samples of bittergourd showed presence of Aspergillus spp. and their perfect stages as the most dominant ones, followed by Penicillium spp. Mycotoxin patulin was also detected (Kour and Sumbali 2006).

Control measures : Moisture content of dehydrated samples should not go beyond $7 \%$. The samples should be packed in airtight containers or sealed in polythene bags.

\section{SNAKEGOURD (Trichosanthes anguina L.)}

It is a subtropical vegetable, raised for its spikingly long fruits. It is low in calorie and contains little proteins, fats, carbohyrates and soluble fibres.

\section{FUNGAL DISEASES}

Rhizopus-rot, c.o. Rhizopus stolonifer (Ehrenb.) Vuill.

The disease occurs during rainy season. Its spread is also fast during rains. It was reported from Bengaluru (Singh et al. 1975), north India (Sharma and Sumbali 1993) and Thiruvananthapuram (Philip 1998).

Symptoms : Water-soaked patches appear on fruits. Fruit-skin becomes soft and disintegrated. Hyphae grow outwards and cover affected portion and the adjoining areas by producing tufts of whisker-like grey sporangiophores and sporangia. Within 3-4 days, mycelia grow further, and cover rest of the fruit. The fruit decays and produces watery soft-rot. The rot appears at the preharvest stage and develops during storage.

Control measures : Fruits should be protected from injuries. They should be kept under refrigeration at $8-10^{\circ} \mathrm{C}$. Cut fruits should not be kept for more than 24 hours under ambient conditions.

\section{Fusarium-rot, c.o.Fusarium spp.}

It is a common disease. Rao (1966 a) reported this disease to be serious in Maharashtra. Sahu Kritagyan and Singh (1980) observed similar rot on the pointed-gourd from Bihar. Affected fruits drop to ground. Rotting is invariably associated with different varieties and agroclimates.

Rots due to F.oxysporum and F.moniliforme were recorded under field and storage conditions from Sagar, Madhya Pradesh (Mehta and Mehta 1989). Temperature influences mode of infection. Extent of rotting is more in storage. F.oxysprum is more aggressive than F.moniliforme. These pathogens also cause 
infection in brinjal-fruits. But infection starts earlier in T. dioica and is delayed in brinjal. But in advanced stage of pathogenesis, the extent of rotting is similar. F. solani was also reported (Sharma and Sumbali 1993).

Symptoms : Injured fruits, bored by larvae, decay due to this disease. Infection starts as small, water-soaked specks around injuries and progresses rapidly into tissues. The advancing margins become lavender-green while inner centre becomes white or pinkish. White flocculent mycelia develop on the infected surface. The fungus also sporulates in the hollow centre of the fruit. And the fruit cracks at the infected site.

Control measures : Treat seeds with Captan or Thiram ( $0.2 \%$ each). Refrigeration at $8-10^{\circ} \mathrm{C}$ is recommended for storage of fruits.

\section{Alternaria-rot, c.o. Alternaria tenuissima Auct.}

The disease is common on the stored snakegourd.

Symptoms : They appear as grey spots. Adjoining spots coalesce and form larger lesions. Sometimes lesions are irregularly circular and are of varying sizes. Affected areas exhibit yellow or pink colour, and at maturity turn brown. Tissues below the lesions dry-up and are pulled away from healthy areas. Rotting starts from the stem-end region and proceeds downwards (Singh 1974).

Control measures detailed under Alternaria-rot of watermelon are applicable here also.

\section{Phytophthora fruit-rot, c.o. Phytophthora cinnamomi Rand.}

Symptoms : On fruits, symptoms appear as water-soaked lesions; mostly at the stylar-end. Lesions rapidly enlarge and develop a soft-rot with extramatrical cottony mycelial growth. Under humid conditions, fruits in contact with soil suffer more damage (Khatua et al. 1981). Singh et al. (2002) recorded an outbreak of vine and fruit-rot from eastern Uttar Pradesh; and 20-80\% yield loss was observed. Lesion size varies among varieties. Minimum temperature of $20-24^{\circ} \mathrm{C}$ and maximum of $30^{\circ} \mathrm{C}$ with regular rainfall and $\mathrm{RH}$ above $90 \%$ favoured fruit-rot developing into an epidemic.

Control measures : If Phytophthora disease is suspected, soil for planting should be treated with copper oxychloride $(0.2-0.3 \%)$. The fruit should not touch soil. Wrapping fruits individually with newspaper helps. Care should be taken to see that fruits are not damaged. Refrigerated storage at $10^{\circ} \mathrm{C}$ immediately after harvest is promising.

\section{Pythium fruit-rot, c.o. Pythium cucurbitacearum Takimoto P.aphanidermatum (Edson) Fitzp.}

Pythium-rot starts from stylar-end. Extensive mycelial growth with soft rotting of internal tissues is visible during later stages of infection. The disease was reported from West Bengal (Chaudhury 1975). 
Symptoms and control measures are similar to fruit-rot/cottony-leak of bittergourd.

Anthracnose, c.o. Glomerella cingulata (Stonem.) Spauld. \& Schrenk, Colletotrichum sp.

The disease is characterized by greyish oblong to ovoid or irregular slightly sunken lesions on the fruit-surface. Lesions often coalesce and spread longitudinally towards the distal-end. Affected areas are initially light pinkgreen to yellow and finally become dark-brown to black. Such fruits become soft, water-soaked and completely rotten. Profuse development of acervuli is noticed on the rotten areas.

Control measures are detailed under anthracnose of bittergourd.

Botryodiplodia-rot, c.o. Botryodiplodia theobromae Pat.

Fruit-rot due to B.theobromae was reported from Thiruvananthapuram (Phillip, 1998). The rotting was observed on mature fruits stored for seed purpose. Disease symptoms appear as dark patches. In the advanced stage, whole fruit gets covered with greyish mycelial mat (Fig. 19.7). It may take about 10 days for complete rotting. Pycnidial encrustations are noticed abundantly with advancement of rotting.

Control measures are as detailed under Botryodiplodia-rot of cucumber.

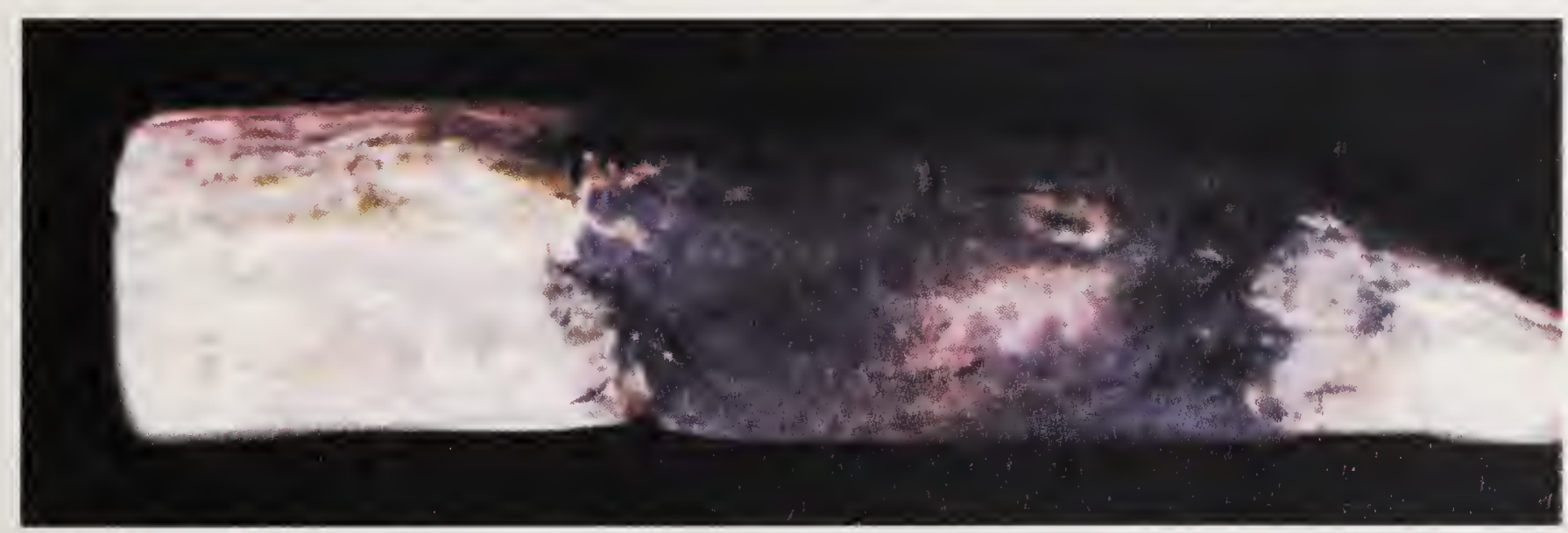

Fig. 19.7. Botryodiplodia-rot (advanced stage) on snakegourd

Charcoal-rot, c.o. Macrophomina phaseolina (Maubl.) Ashby

The disease was recorded from Punjab (Jhooty and Singh 1971). Symptoms are similar to those on watermelon. The disease is of minor importance, and it occurs on the injured fruits.

Sour-rot, c.o. Geotrichum candidum Link.

Symptoms and control measures are similar to those on tomato in the chapter on Solanaceous Crops. The disease was reported by Sharma and Sumbali (1993) from north India. 


\section{BOTTLEGOURD (Lagenaria siceraria (Mol.) Standl.)}

\section{FUNGAL DISEASES}

Anthracnose, c.o. Colletotrichum lagenarium (Pass.) Ell \& Halst.

C. capsici (Syd.) Butler and Bisby

This is a common disease; and sometimes becomes serious. Symptoms are observed on leaves and fruits. The disease was first observed by Mundkur in 1937. Later on, this was recorded by Rangaswami et al. (1970), Singh and Chohan $(1972,1980)$ and Sokhi (1994). Infection is mainly soil-borne and pathogen survives on the diseased crop residues. It can also survive as a saprophyte on straw and stubble.

Symptoms : Lesions, circular to irregular, often oval to oblong in shape appear (Madaan and Grover 1977), and under humid conditions, pink spore masses are noticed in abundance; symptoms of scab are also observed. The fruit turns dark-brown and core becomes hollow with a few damaged seeds.

Control measures : Seed infection is superficial (external), and seed treatment with Carbendazim $(0.25 \%)$ ) is effective. Seeds treated with systemic fungi toxicant Benomyl $(0.125 \%)$ protects seedlings also for 14 days (Madaan and Grover 1979).

Foliar spray of Thiabendazole (0.1-0.15\%) offers good control (Omprakash et al. 1973; Sokhi 1994). Field spraying with Difolatan (0.2\%) or Blitox $(0.5 \%)$ is observed to be effective.

\section{Seedling-blight, c.o. Rhizoctonia solani Kühn}

Fungal mycelia and sclerotia are observed on the seed surface (external). Infection occurs when seeds come in contact with soil. The disease was reported from Delhi (Suryanarayana 1978). Seed treatment with Thiram $0.2 \%$ is effective.

\section{Cottony-leak, c.o. Pythium butleri Subram. P.aphanidermatum (Edson) Fitzp.}

The disease is widespread in bottlegourd (Singh and Chohan 1977). Fungus survives at a wide range of temperature $\left(15-40^{\circ} \mathrm{C}\right)$, with optimum growth between 30 and $35^{\circ} \mathrm{C}$.

Symptoms : They may appear anywhere on the fruit-surface, and fungus forms a luxuriant woolly mycelial weft on the affected fruits, which appear as wrapped by cotton. The disease orginates as a soft-rot. On the rotting portion, fungal mycelia develop abundantly during humid environment.

Control measures : Fruits should be protected from injuries during harvesting, handling and storage. Refrigerated storage at $10^{\circ} \mathrm{C}$ is recommended.

Fusarium-rot /cottony-rot, c.o. Fusarium spp.

The disease is of common occurrence and different species of Fusarium 
have been identified-F.concolor, F.equiseti, F. semitectum, F, solani, F.oxyspourm and F. dimerum (Roy 1973; Bilgrami and Verma 1978; Singh and Chohan 1980; Garg and Gupta 1983; Sohi et al. 1984; Mishra and Rath 1986; Sharma and Sumbali 1993).

Symptoms : Discrete or coalescent water-soaked lesions appear on the peel of mature and ripe-fruits. Mycelial growth varies in colour from pink to white. Control measures : Spraying plants before harvest with Nabam or Mancozeb $(0.2 \%)$ is effective in reducing post-harvest rots. Avoid injuries on to the harvested fruits.

Botryodiplodia-rot, c.o Botryodiplodia theobromae Pat.

Fruit-rot due to $B$. theobromae was reported from Ludhiana (Punjab) by Singh and Chohan (1977). Rotting of mature fruits stored for seed purpose was also observed by Maholay and Sohi (1982) from Punjab.

Symptoms : Externally fruit-surface gets covered with ashy-grey fungal growth. Interior content including seeds also becomes black due to fungal invasion.

Control measures : Protect fruits from injuries during harvesting, handling and storage. Refrigerated storage at $10^{\circ} \mathrm{C}$ is found promising.

Sclerotinia fruit-rot, c.o. Sclerotinia sclerotiorum (Lib.) de Bary

Soft watery white-rot appears initially on the infected fruits; later on it is noticed on the leaves, vines and flowers also (Pandey and Pandey 2002). The disease is of minor importance.

\section{Sclerotium-rot, c.o. Sclerotium rolfsii Sacc.}

The disease is also known as creepy cottony-rot. Dry-rot symptoms appear on the hard-coated fruits while immature fruits become watery due to infection. On mature fruits, water-soaked lesions appear, which later get suppressed. On the infected areas, whitish mycelia spread fast. Later sclerotia develop profusely on the region. The disease was reported from Ludhiana (Punjab) (Singh and Chohan 1980) and Bengaluru (Amin and Ullasa 1981).

OTHER DISEASES AND THEIR CAUSAL ORGANISMS

\begin{tabular}{lll}
\hline Disease & Causal organism & Authority \\
\hline $\begin{array}{l}\text { Charcoal-rot } \\
\text { Alternaria-rot } \\
\text { Curvularia-rot }\end{array}$ & $\begin{array}{l}\text { Macrophomina phaseolina (Tassi) Goid. } \\
\text { Curvularia ovoidea (Hiroe and } \\
\text { Watanbe) Munt. - Cvetk }\end{array}$ & $\begin{array}{l}\text { Singh and } \\
\text { Chohan, 1980 }\end{array}$ \\
$\begin{array}{lll}\text { Grey-mould-rot } \\
\text { Fruit-rot }\end{array}$ & $\begin{array}{l}\text { Aspergillus fumigatus Fres. } \\
\text { Cylindrocarpon tonkinense Bugn. }\end{array}$ & $\begin{array}{l}\text { Bilgrami and } \\
\text { Verma, 1979 }\end{array}$ \\
& Drechslera australiensis Subram. \& & $\begin{array}{l}\text { Roy and Ojha, } \\
1984\end{array}$ \\
\hline
\end{tabular}




\section{RIDGE-GOURD (Luffa acutangula (L.) Roxb.)}

The fruit is used as a vegetable at the tender stage. When it is fully ripe, it becomes very fibrous.

\section{FUNGAL DISEASES}

\section{Fruit-rot, c.o. Fusarium oxysporum Schlet.}

The disease causes premature fruit-rot. Rao et al. (1984) reported $50 \%$ loss due to this disease from Mysore. Symptoms appear as yellow or brown sunken spots. The infected fruits show white tuft of mycelia with heavy sporulation. The lesions later extend gradually and result in complete drying of fruits. The inner tissues also show browning. Mishra and Rath (1986) recorded similar infection due to $F$. solani from Odisha.

Dry-rot of Luffa cylindrica caused by $F$. solani (Mart.) Sacc was also reported (Tandon et al. 1975) from Nainital, Bhowali. Scattered olive-grey coloured spots appear with white mycelial growth. The lesions ranged from 0.5 to $1.0 \mathrm{~cm}$ in diameter. Tandon and Kakkar (1970) reported similar fruitrot due to F.semitectum.

Control measures as detailed under Fusarium-rot of bottlegourd are applicable to this disease also.

\section{Cottony-leak, c.o. Pythium aphanidermatum (Edson) Fitzp. $P$. butleri Subram.}

It was reported from Maharashtra and West Bengal (Rao 1966b; Mandal and Dasgupta, 1980). Level of soluble free sugars in diseased L.cylindrica fruits varied with disease development (Sharma and Wahab 1975). After complete utilization of carbon sources, fungus derives its energy from proteins and amino acids.

Symptoms and control measures are similar to those described under cottony-leak of bottlegourd.

\section{Dirty grey-rot, c.o. Rhizoctonia solani Kühn}

The disease originates from the distal-end with a depressed area of about 4-5 cm and a slightly water-soaked advancing margin. It is of minor importance. Dirty coarse mycelial mass with abundant sclerotia is noticed on the fruit-surface. Rotting is fast (Mandal and Dasgupta 1981).

\section{Soft-rot, c.o. Mucor hiemalis $\mathrm{f} s \mathrm{l}$ lutens, M. circinelloides Van Tiegh.}

The symptoms are noticed on the damaged fruits and fruits bored by insect larvae. Affected fruits show water-soaked patches, followed by appearance of yellowish fuzzy mycelial growth. The rotten portion becomes slightly shrivelled, soft dull in colour and emits bad odour.

Protect harvested fruits from injuries. The fruits should be kept under refreigerated storage $\left(8-10^{\circ} \mathrm{C}\right)$. 
Sour-rot, c.o. Geotrichum candidum Link.

The disease is of minor importance. Infected fruits lose their lustre. White powdery growth appears on the surface. Infection advances radially and superficially with water-soaked margins. Infected fruits emit sour fermentative odour (Mandal and Dasgupta 1980).

Control measures are as detailed under tomato in Solanaceous Crops.

\section{Charcoal-rot, c.o. Macrophomina phaseoli (Maubl.)Ashby}

Singh and Chohan (1972a) recorded disease appearance from Punjab as light-brown water-soaked areas, usually at the pedicel-end. The rot progresses fast and may cover whole fruit. Fruits become shrivelled and internally blackened. Numerous black oval to irregular small sclerotia and a few pycnidia appear over the infected tissues. The host range of pathogen includes Luffa cylindrica Roem and L. acutangula Roxb; both are highly susceptible.

\section{Creepy-rot, c.o. Sclerotium rolfsii Sacc.}

The disease was reported from Rajasthan. It develops as small, localized patches with superficial, creepy, shining, white mycelial growth and abundant sclerotia. The symptoms are noticed on the damaged fruits or fruits bored by insect larvae. Infected fruits show water-soaked patches, followed by appearance of yellowish fuzzy mycelial growth. Rotten portion becomes slightly shrivelled, soft, dull in colour, and emits bad odour.

\section{SPONGE-GOURD (Luffa aegyptiaca Mill.)}

The plant yields a bitter tonic that is used as a diuretic and as a purgative. It is also useful in the treatment of asthma, skin diseases and spleenic enlargement.

\section{OTHER DISEASES AND THEIR CAUSAL ORGANISMS}

\begin{tabular}{lll}
\hline Disease & Causal organism & Authority \\
\hline Soft-rots & Fusarium scirpi Lamb. \& Fautr. & \\
& Alternaria alternata (Fries) Keissler & \\
& Helminthosporium spiciferum (Bain.) Nicot & \\
& Curvularia lunata (Wakker) Boedijin & \\
& Myrotheciụm roridum Tode ex Fries & \\
& Botryodip̄lodia theobromae Pat. & \\
& Pythium aphanidermatum (Edson) Fitzp. & \\
Dry-rot & Rhizopus stolonifer (Ehrenb. ex Fr.) Lind. & Tandon et al., 1975 \\
Mucor-rot & Fusarium solani (Mart.) Sacc. & Tandon et al., 1975 \\
Black-rot & Fusarium pallidoroseum (Cook) Sac. & Chitra and Arun, \\
& & 2007 \\
\hline
\end{tabular}




\section{ROUND-GOURD (Citrullus vulgaris)}

The following fungal diseases are reported on the crop.

$\begin{array}{ll}\text { Fusarium-rot } & \text { Fusarium solani (Mart.) Sacc, } \\ & \begin{array}{l}\text { F.equiseti (Corda) Sacc } \\ \text { Cylindrocarpon lichenicola }\end{array} \\ \begin{array}{l}\text { Pythium-rot/ } \\ \text { Cottony-leak }\end{array} & \begin{array}{l}\text { Pythium sp. } \\ \text { Sour-rot }\end{array} \\ \text { Geotrichum candidum Link }\end{array}$

Sharma and Sumbali, 1993.

KOVAL/IVORY-GOURD (Coccinia cordifolia auct. non (L.) Cogn.) (= C.indica Wight and Arn.)

\section{FUNGAL DISEASES}

Anthracnose, c.o. Colletotrichum lagenarium (Pass.) Ell. \& Halst.

Symptoms are similar to those on other cucurbits. Dipping fruits in coprantol, thiourea or tetracycline is found effective in checking infection during storage (Hayan et al. 1978).

\section{Fruit-rot, c.o. Rhizoctonia solani Kühn}

Symptoms are similar to those on cucumber. Reddy and Reddy (1988) from Warangal studied the role of oxidases and cell-wall degrading enzymes on pathogenesis. Activity of peroxidase and polyphenol oxidase (PO and PPO) increased considerably in infected lesions.

Fruit-rot, c.o. Bipolaris tetramera (Mc Kinney) Shoemaker

The disease was observed from local markets of Allahabad; it caused sizable economic losses. The fruit was completely covered with fungal growth.

Dithane M-45 (250, 500, 750 ppm), Ziram (500, 750, 1,000 ppm) and Anustin (Carbendazim 50\% WP at 500, 750, 1,000 ppm) as field spray were effective in disease management (Shrama 2006).

OTHER ASSOCIATED DISEASES AND THEIR CAUSAL ORGANISMS

\begin{tabular}{lll}
\hline Disease & Causal organism & Authority \\
\hline Curvularia-rot & $\begin{array}{l}\text { Curvularia lunata } \\
\text { (Wakker) Boedijin }\end{array}$ & Laxminarayana and \\
Macrophoma-rot & Macrophoma sp. & \\
\hline
\end{tabular}




\section{CHAPTER 20 \\ Solanaceous Crops}

BRINJAL/EGG-PLANT/AUBERGINE (Solanum melongena L.)

Brinjal or egg-plant is one of the most common and popular vegetable crops. Number of cultivars are grown in different parts of India. Consumer preference is based on certain characters like colour, size and shape of the fruit.

\section{FUNGAL DISEASES}

Phomopsis-blight, c. o. Phomopsis vexans (Sacc. \& Syd.) Harter Teliomorph : Diaporthe vexans Gratz.

Phomopsis-blight ranks second to bacterial wilt in causing destructiveness. It is identified as the common disease in tropical and subtropical areas. In India, it is considered as the most important disease. This disease along with leaf-spot caused by Alternaria solani reduced seed germination and yield up to $30-50 \%$. Seeds that are harvested during kharif and rabi favour maximum spore load on the seed-coat than on the other seed components. Disease transmission is also more during rabi than in kharif (Thippeswami et al. 2005).

Although the disease is prevalent throughout the world; it is common in the tropical and subtropical areas. The disease starts with foliage blight, but its most destructive phase is fruit-rot. It was first reported by Uppal et al. (1953) from Maharashtra. Later on, this was recorded by Vasudeva (1960), Neema and Agarwal (1960), Ashwani Kumar et al. (1986), John (1991), Reeny (1995) and Rajkumar (2000). In Ranchi, P. vexans was observed to cause maximum losses in brinjal-fruits and recorded a loss of $11.8 \%$ (Prasad et al. 1989).

Symptoms : On the fruit, symptoms manifest as minute, pale-straw coloured sunken spots, which coalesce and cover $75 \%$ of the area in the long-fruited varieties. The colour deepens and ultimately becomes dark-brown to black, and whole fruit rots within seven days (Fig. 20.1). Black pycnidial spots are noticed in abundance on the lesions. The lesions are prominent on the purple/ red skinned varieties also (Philip 1998). The fungus may enter through calyx, in which case whole fruit mummifies, and results in a dry-rot. 


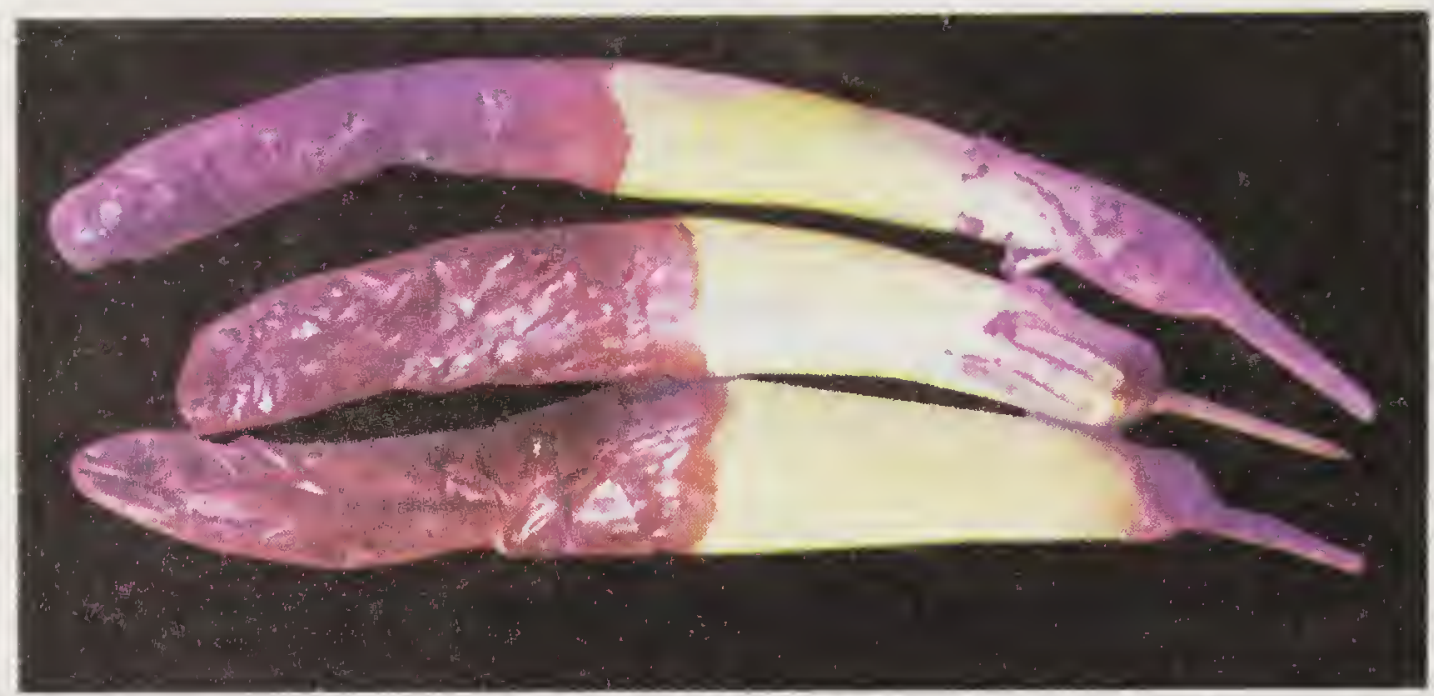

Fig. 20.1. Phomopsis-rot on brinjal

Duration of Phomopsis fruit-rot development varies in different varieties. In general, this may range from 5 to 30 days (Suga et al. 2002).

Temperature of $25^{\circ} \mathrm{C}$ and relative humidity of $90 \%$ were found conducive for development and progress of fruit-rot in Himachal Pradesh. Young fruits (10-15 days old) and an inoculum load of $>120$ spores $/ \mathrm{ml}$ were ideal conditions for infection.

Synergism was reported of Fusarium moniliforme with P.vexans in causing fruit-rot (Datar 1983). Fruits inoculated with Fusarium showed reddish-brown discolouration on the calyx and on the stem-end region. All fruits dropped on the third day of inoculation. Fusarium was re-isolated. Fruits inoculated with P.vexans exhibited typical symptoms of Phomopsis-rot with brown to black discolouration that extended from the stalk-end, resulting in softening of inner tissues. But fruit drop was not observed. Fruits inoculated simultaneously with both the pathogens dropped on the third day. Fruits were sunken and tissues were softened; fruits dropping and extent of rotting indicated that pathogens exerted a synergistic effect in causing fruit-rot.

Variability in P.vexans isolates with regard to cultural and morphological characters is also available. Kumar and Suga (2000) and Akhtar and Chaube (2006) recorded variability among isolates collected from different geographical areas in India.

This fungus is seed-borne and subsists in soil on plant debris. Kumar et al. (1990) recorded 9\% seed infection. The disease reduces seed germination and causes yield losses to the tune of 30-50\% (Thippeswamy et al. 2006). The fungus is disseminated as water-borne pycniospores and requires wet weather and high temperature for their development. Chowdhury and Hasija (1979) observed temperature of $25^{\circ} \mathrm{C}$ and relative humidity of $75 \%$ as ideal. This fungus grows well between 21 and $32.5^{\circ} \mathrm{C}$; optimum being $29^{\circ} \mathrm{C}$. Storagerot is maximum at $25^{\circ} \mathrm{C}$. And 5,10 and $40^{\circ} \mathrm{C}$ are unfavourable for disease development (Singh 1992).

Varietal resistance to fruit-rot was also observed. Ahamed (1987) recorded maximum rotting on fruits of Pusa Purple Long, followed by Pusa Oval Green, 
Pusa Dwarf, and Annamalai varieties showed minimum percentage of rotting. Similarly, Arkakusmakar, Aurangabad Local, Annamalai, Bengal Long and certified cultivars like Early Round Market, Gondegaon Local were moderately resistant (Datar and Ashtaputre 1984, 1988). This disease in destruction ranks second only to bacterial wilt. In tropical and subtropical areas, 50\% losses were recorded due to disease. Sources of resistance were reported in Solanun xanthocarpum, S.nigrum, S.toruvam, S.khasianum, S.sisymbrifolium and in certain egg-plant lines (Kalda et al. 1976; Sherif and Macnab 1986; Sokhi, 1994). Ramnagar Giant and KS 233 were reported as the best varieties from Varanasi against Phomopsis-blight, and showed resistant to moderately resistant response at the different stages of disease development (Pandey et al. 2002). Punjab Barsati was considered as a disease-escaping variety.

Control measures : The disease is serious, particularly to seed-crop as it is seed-transmitted. The spore load ranges from $0.2 \%$ in the seed-coat and $0-4 \%$ in cotyledons and embryonic areas (Thippeswami et al. 2005). Seed treatment with Captan(0.2\%), Difolatan (0.2\%), Benlate (500 ppm), Calixin(1,000 ppm) was recommednded (Singh and Chakrabarti1982). Seed treatment with Thiram @ $2 \mathrm{~g} / \mathrm{kg}$ of seed was also effective (Kumar et al. 1990).

In the nursery or field as fruits touch ground, they rot irrespective of spray of chemicals. Application of chemicals, however, reduce infection on the harvested fruits. Grewal and Jhooty (1987) observed the disease to be serious for seed-crop in Punjab, and recorded Dithane M-45 as the best fungicide, followed by Bordeaux mixture and Blitox. Palo as early as 1936 and Teco in 1980 reported effectiveness of soil drenching with Bordeaux mixture (4:4:50) and a mixture of copper oxychloride (COC) and Benlate. Copper oxychloride alone was also effective.John (1991) observed spraying at fortnightly intervals with COC-50 as the best treatment in reducing fruit-rot infection in the field. Bordeaux mixture and Dithane M-45 also recorded similar results. Seed treatment with Bavistin was also effective. Mancozeb spray on the seed-crop was considered must to contain disease (Sokhi 1.994). Mancozeb ((0.2\%), Carbendazim $(0.1 \%)$ and Captaf $(0.2 \%)$ inhibited seed-borne pathogens and increased seed germination (Thippeswami et al. 2006).

Biological control with Trichoderma harzianum and Gliocladium virens was reported. In-vitro studies on fruits inoculated with P.vexans and treated with the above cultures(@ $10^{6}$ spores/g with talc)showed very little rotting as compared to complete rotting in control fruits (Figs 20.2, 20.3) (Rajkumar 2000).

At Ludhiana, Anju and Bedi (2004) evalutated Beauveria bassiana as a biofungicide for control of Phomopsis fruit-rot. The suspension $\left(5 \times 10^{6}\right.$ \% spores/ml), when applied to brinjal-plants served as an antagonist and inhibited mycelial growth and pathogen sporulation. 


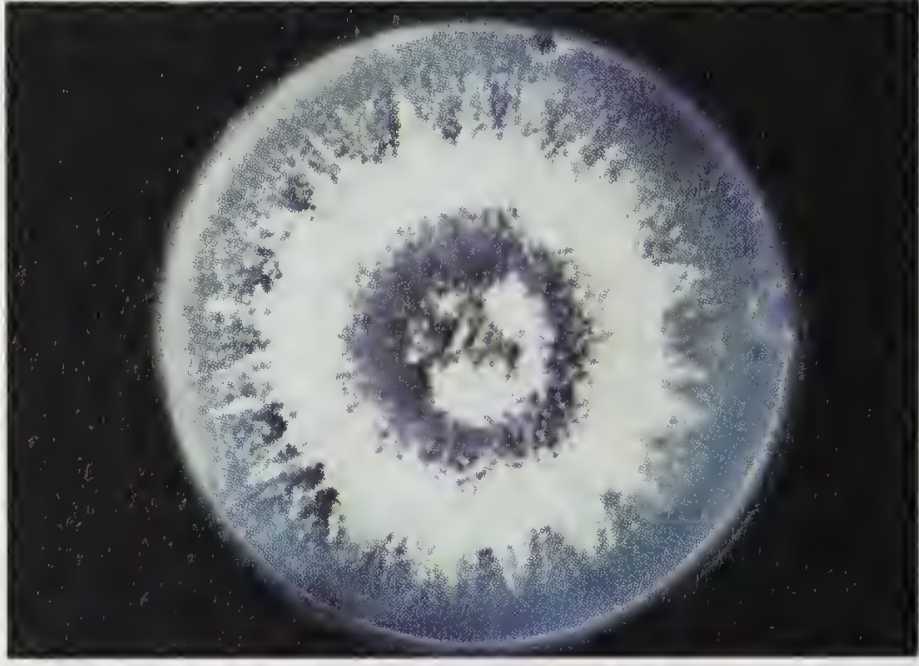

Fig. 20.2. Growth of Trichoderma harzianum

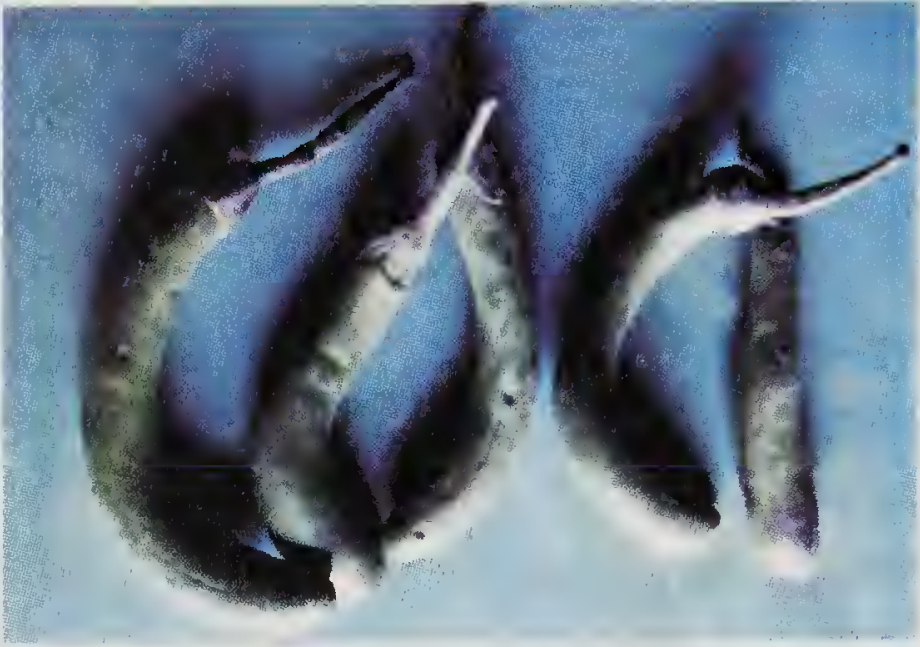

Fig. 20.3. Brinjal-fruits after treatment with biocontrol agent

Fusarium-rot, c.o. Fusarium spp.

The disease is prevalent in field and in storage. Following Fusarium species have been found associated with it.

F. moniliforme. This causal organism was reported earlier by Garofalo and Nuovo (1956). Datar (1980) observed brinjal variety Manjeri Gota as highly susceptible. The lesions formed are sunken and brown in colour with profuse pinkish growth on the calyx and stem-end region of the fruit. Mishra and Rath (1986) and Mehta and Mehta (1989) also recorded this pathogen from Sagar (Madhya Pradesh) under field and storage conditions. Rotting is observed more in storage than in field conditions.

F. solani (Mart.) Sacc. Datar (1980), Mishra and Rath (1986) and Reeny (1995) observed it as the most virulent among the Fusarium species. Cultivars differed in their reaction.

F.oxysporum Schlet. Laxminarayana and Reddy (1977) and Mehta and Mehta (1989) reported fungus from market samples. The fungus is seed-borne (Sharma and Sumbali 1993). It is more aggressive compared to other Fusarium species. Initiation of the disease takes more time with this species compared to others but in advanced stages of pathogenesis, extent of rotting is almost the same. Rot extends gradually from the stylar-end to the stalk-end of the fruit, and in a few days fruits become soft and rotten.

F. semitectum Berk. \& Rav. Kaur et al. $(1984,1985)$ recorded this from Punjab. The fungus causes both wilt and fruit-rot; $26-28 \%$ fruit-rot incidence was noticed in some varieties. Infected fruits are covered with white-pink fungal mycelia, and the fruit size reduces in severe infection. About 7-30\% rot incidence in brinjal is due to F.semitectum. This fungus is recorded to be associated with seeds also.

F. equiseti (Corda) Sacc. The disease was first observed by Garofalo and Nuovo (1956). Sharma and Sumbali (1993) in vegetable market survey in the north India also recorded this fungus on brinjal. 
In addition to these species, an unidentified Fusarium sp. was reported by Alice and Paily(1978) from Thiruvananthapuram, Kerala.

Several measures including use of chemicals are suggested by different workers. Growth regulators like 2,4-D and 2, 4-5 T (750 ppm) inhibited fungal growth in brinjal-fruit (Thakur et al. 1974).

\section{Fruit-rot, c.o. Phytophthora spp.}

Phytophthora causes leaf-blight and fruit-rot in brinjal. The frequency of fruit-rot incidence is maximum during rainy season. P.infestans and P.nicotiana var. nicotianae were generally recorded. Maximum rotting occurred at $30^{\circ} \mathrm{C}$ with a relative humidity of about $80 \%$ (Jain and Bhatnagar 1978; Jain 1982). Thankamma (1983) recorded brinjal fruit-rot from Kottayam (Kerala) during south-west monsoon. Phytophthora sp. was also reported on brinjal-fruit reaching Thiruvanthapuram markets from Tamil Nadu (Philip 1998). The symptoms produced were of soft-rot type.

Symptoms : Brownish-black circular to oval water-soaked lesions appear on the fruits. Scrapings showed presence of sporangia. Rotting tissues on maceration yielded mycelia with disorganized spongy parenchyma. Gogoi and Rathaiah (1992) recorded dry fruit-rot from Asom, where peel became hard, sunken and discoloured.

Infection starts at the calyx as water-soaked lesions. Hardening of the fruit is a characteristic symptom. A floury-white growth occurs over lesions, and as lesions grow older, Cladosporium sp. can be noticed to be overgrown on them.

Control measures : As detailed in Phomopsis-rot are applicable for this also.

Curvularia fruit-rot, c.o. Curvularia clavata B.L. Jain

This fungus causes dry-rot in brinjal-fruits. Mature fruits get infected, especially when they are wounded, and gradually lesions increase in size. The lesions are of cepia colour and measure $1-2 \mathrm{~cm}$ in diameter in advanced stages. The disease caused 4-7\% damage to fruits in Uttar Pradesh (Tandon et al. 1975a). Seed-borne nature of the fungus was also reported (Sharma and Sumbali 1993).

Seed-borne infection can be controlled by treating seeds with Captan $(0.2 \%)$.

Rhizopus-rot/soft-rot, c.o. Rhizopus stolonifer (Ehrenb.) Vuill.

Rhizopus fruit-rot is regarded as one of the most important diseases of brinjal in field, transit and storage. Ramakrishnan and Wilson (1968) and Alice (1969) in their surveys in Thiruvananthapuram local market recorded this fruitrot as the most damaging one; the disease was reported from other countires also (Coursey and Booth 1972; Bilgrami et al. 1979, 1981). 
Symptoms : They are noticed on the mature fruits as small water-soaked lesions. Soon after when the peel becomes discoloured, infected area gets darkened and extends rapidly in all directions. Peel becomes loose and tissues are sunken with considerable depression. Within 2-3 days, entire fruit becomes soft and leaky. Symptoms are also visible on fruits in the standing crop. The rotting extends to the stalk-end, and finally fruit drops to the ground (Thakur 1972). Vyas et al. (1978) recorded fruit-rot caused by $R$. nodosus from local markets of Sagar (Madhya Pradesh). The disease starts as a soft-rot from mesocarp portion of the brinjal-fruit. The fungus multiplies inside the fruit and causes discolouration and rotting of healthy tissues. Its hyphae appear prominent as white strands, and after 2-3 days, cottony mycelial growth and fruiting bodies develop on the entire mesocarp portion of the fruit.

Reeny (1995) observed R.nigricans from the local markets of Thiruvananthapuram. Water-soaked areas appeared concentrated around the injury, which was covered with mycelial growth. The mycelial mass bearing brown to black sporangia appeared profusely, especially around the margins. Brownish liquid with a characteristic odour oozed out.

Control measures : A pre-infection treatment of 2, 4-D at 500 ppm was used and was reported to be effective against R.arrhizus infection (Thakur et al. 1974).

\section{Wet-rot, c.o. Choanephora cucuribitarum (Berk. \& Rav.) Thaxter}

The disease occurs during rainy season, and was reported from Uttar Pradesh (Dublish and Singh 1976: cit Bilgrami et al. 1979) and West Bengal. Symptoms may appear anywhere on the fruit-surface, but mostly originate from the distal-end. The disease progresses fast and spoils normal colour. The affected area becomes soft, foul-smelling and pulpy. Peel gets loosened from pulp with a white. scanty fibrous superficial growth.

\section{Cottony-leak, c.o. Pythium aphanidermatum (Edson) Fitzp.}

The disease is of common occurrence (Coursey and Booth 1972; Sharma and Sumbali 1993: Reeny 1995 and Rajkumar 2000). P.butleri was also reported along with $P$. delians.

Symptoms : Water-soaked lesions appear on the fruits, which gradually enlarge to sides, and fruits rot completely within 3-7 days. Ilag (1976) observed nesting of fruits during storage. The fungus is reported to be seed-borne (Suryanarayana 1978).

Control measures : Seed treatment with Captan $(2 \mathrm{~g} / \mathrm{kg}$ of seed) eliminates seed-borne infection. Biological control with Trichoderma harzianum or Laetisaria arvalis along with Captan was reported to be effective (Jacob et al. 1988). Prior to sowing, seeds soaked in Eucalyptus leaf extract for 30 minutes offered protection. 


\section{Brown spongy-rot, c.o. Alternaria spp.}

Several species of Altemaria are reported to be associated with this rot. A.tenuis and A.solani cause seedling-blight as well as leaf-spot. Fruit-rot by A.melongenae is common. A.alternata is also reported to cause fruit-rot (Sharma and Sumbali 1993). Affected fruits become yellow and drop prematurely. The disease was reported from several states in India.Prasad and Poddar (1977) reported A. tenuis from Bihar and observed biochemical changes during pathogenesis. Changes in carbohydrate content were recorded and were also visible in free amino acid contents. Valine and leucine were utilized completely and threonine, asparagin, tyrosine and cysteine were utilized only partially. Changes in organic acids were also noticed. Complete exhaustion of fumaric acid and an increase in malic acid were observed. And succinic acid recorded no change.

Symptoms : Small, circular spots of about $0.5-1.0 \mathrm{~cm}$ diameter appear with well-defined margins. Fruit-flesh becomes spongy, turns greyish to dark-tan with deep-brown to black, scanty, superficial mycelial mass, which becomes velvetty due to sporulation (Dasgupta and Mandal 1989). Prasad and Roy (1979) observed maximum rotting at $26^{\circ} \mathrm{C}$ and $90-100 \%$ RH. Singh (1988) studied effects of N, P, K on Alternaria leaf-spot and fruit-rot in Kanpur, and observed that higher doses of nitrogen without $\mathrm{P}$ or $\mathrm{K}$ resulted in severe infection by $A$. alternata in the field trials, and high $\mathrm{P}$ or $\mathrm{K}$, together or separately, reduced disease under varying nitrogen levels.

Control measures : The seed-borne nature of the disease is well established. Mancozeb $(0.2 \%)$, Carbendazim $(0.1 \%)$ and Captan $(0.2 \%)$ are found effective in inhibiting seed-borne pathogens and in increasing seed germination (Thippeswamy et al. 2006). Seed treatment with $0.2 \%$ Thiram was also effective.

Diplodia-rot, c.o. Diplodia natalensis Pole-Evans/ Botryodiplodia theobromae Pat.

Ramakrishnan and Wilson (1968), Alice (1969) and Alice and Paily (1978) recorded disease from the local markets of Thiruvananthapuram (Kerala).

Symptoms : Straw-coloured lesions appear on fruits, which darken with age. In the advanced stages of infection, fruit-surface gets covered with mycelial growth. Along with this, black pycnidia are also present in abundance. At this stage, the fruit rots completely.

Control measures : Chemical treatments as detailed in Phomopsis-rot, control this disease also. Avoid wounds and bruises on the fruits.

\section{Ring-rot, c.o. Myrothecium roridum Tode ex Fr.}

Tandon and Srivastava (1963) and Ramnath et al. (1966) reported the disease from the local markets of Allahabad (Uttar Pradesh). Ullasa et al. (1976) recorded this disease from Karnataka. This fungus with Chaetomium 
globosum caused rotting of fruit-stalks. The extent of damage was 1-2\% only. Symptoms : Stalk-skin becomes soft and loose. In the later stages, infection proceeds towards the persistent calyx, and skin gets separated from the woody stalk. Then the fruits detach easily. Symptoms are also evident as small to large conspicuous sharply defined circular to oval flattened lesions. Affected tissues become pale to black. The rot penetrates deep into the fruit. Presence of alternating narrow concentric rings of black spore masses with white mycelial growth is the characteristic symptom.

Control measures : Chemical treatments as detailed in Phomopsis-rot control this disease also.

Soft-rot, c.o. Chrysosporium pruinosum (Gilman \& Abbot.) Carmichael

The disease was observed from Kurukshetra (Dhingra and Mehrotra 1980). Infection starts as light-yellow coloured depressed areas. Sooner the whole fruit surface becomes soft, pulpy and is covered by white growth. The entire fruit decays and emits foul smell.

OTHER DISEASES AND THEIR CAUSAL ORGANISMS

\begin{tabular}{|c|c|c|}
\hline Disease & Causal Organism & Authority \\
\hline Grey mould-rot & Botrytis cinerea & $\begin{array}{l}\text { Coursey and Booth, } 1972 ; \\
\text { Sharma and Sumbali, } 1993\end{array}$ \\
\hline Colletotrichum-rot & Colletotrichum sp. & Prasad et al.,1989 \\
\hline Cercospora-rot & Cercospora sp. & \\
\hline \multirow[t]{2}{*}{ Fruit-rot } & $\begin{array}{l}\text { Helminthosporium } \\
\text { spiciferum }\end{array}$ & \\
\hline & $\begin{array}{l}\text { Chaetomium eraticum } \\
\text { Dreschlera tetramera }\end{array}$ & Kumar et al., 1990 \\
\hline Fruit-scab & Cladosporium oxysporum & \\
\hline Yellow mould-rot & A. niger & Sharma and Sumbali, 1993 \\
\hline Paecilomyces-rot & Paecilomyces variotii & \\
\hline Rhizoctonia-rot & Rhizoctonia solani & Reeny,1995 \\
\hline Penicillium-rot & Penicillium sp. & \\
\hline Pink-rot & Trichothecium roseum & \\
\hline
\end{tabular}

\section{BACTERIAL DISEASES}

Bacterial soft-rot, c.o. Pseudomonas fluorescens Migula

The disease is considered as of minor importance, but occurs after rains in West Bengal. Infection occurs at any point on the fruit-surface but is mostly concentrated around the borer holes. The pulp becomes soft with skin remaining firm but turning orange-red with bluish-brown centre; the fruit smells offensive. 


\section{Dehydrated brinjal}

Shelf-life of brinjal-fruits usually increases with sun-drying ; and they can be utilized in off-season. But poor handling, storage and marketing facilities often leads to microbial contamination. Aspergillus spp. and Penicillium spp. are commonly found associated. Mycotoxins, Patulin and citrinin, were detected from infected samples (Kour and Sumbali 2006).

Control measures : The moisture limit of dehydrated samples should not exceed $7 \%$. The dried material should be kept in air-tight containers.

\section{Seed mycoflora}

Vidhyasekaran et al. (1980) observed fungi like Aspergillus flavus, A.niger, A.glaucus, Fusarium moniliforme and Helminthosporium tetramera on seed samples of brinjal. Fungi associated with brinjal-seeds were also studied by Pattnaik and Narain (2003) from Odisha; causing seed damage from 63 to $72 \%$. Among different cultivars, higher percentage of seeds (11-30\%) was predominantly infected by Fusarium solani, followed by Aspergillus fumigatus (8-20\%), Chaetomium globosum (5-10\%) and Penicillium sp. (614\%). Thippeswamy et al. (2004) in Karnataka observed fungi like C.capsici, Alternaria alternata, A.solani, F.oxysporum, F.solani, Phomopsis vexans, Macrophomina phaseolina and Aspergillus sp.

Control measures : Seeds are to be dried up to moisture level of $8-10 \%$. Seed treatment with Thiram at $0.2 \%$ controlled all seed-borne fungi and preserved viability and seedling vigour.

\section{CHILLI (Capsicum annuum L.)}

Chilli is one of the valuable spice crops cultivated throughout the country. High ascorbic acid was reported in chilli-fruits (cvs Bullet and Suryamukhi). India is the second largest exporter of chillies in the world. Several varieties are cultivated all-over India. Chilli cultivation is concentrated in Andhra Pradesh, Maharashtra, Karnataka and Tamil Nadu. Chilli-crop is valued for its pungency, colour and aroma. It is a good source of vitamins C, A, and B. This also contains small quantities of proteins, fats, carbohydrates and traces of minerals. The economic importance of the fruit lies in its pungency and flavour. This is due to capsicin (n-4-hydroxy-3methoxy benzyl 8-methyl trans 6 non enamide).

The sequence of fungi associated with chilli-fruits was studied by Vijayalakshmi and Rao (2003) from Andhra Pradesh. They recorded Alternaria, Fusarium and Cladosporium to be always present on chilli-fruits. Curvularia tuberculata and Fusarium solani populations increased gradually as the fruits attained maturity. While Aspergillus flavus, A.niger, A.fumigatus and Colletotrichum capsici appeared only on mature fruits. 


\section{FUNGAL DISEASES}

\section{Anthracnose/ripe-rot/fruit-rot,}

\section{c.o. Colletotrichum capsici (Syd.) Butler and Bisby}

Among the fungal diseases taking a heavy toll on chillies, anthracnose is the most important one. This is the major constraint in tropical and subtropical areas under humid conditions. The disease causes substantial reduction in yield and was reported from India by Butler and Bisby in 1918. Since then, it has been found to be serious in all chilli-growing areas. The disease becomes conspicuous only when it has already caused substantial damage to mature fruits in the field. Chowdhury (1957) reported $12-32 \%$ loss due to this disease from Asom. Crop losses ranging from 10 to $60 \%$ as well as 10 to $35 \%$ under field and storage conditions were recorded from Punjab and Haryana (Grover and Bansal 1968, 1970; Singh and Thakur 1970).

The disease causes severe damage to fruits; up to $84 \%$ in the field as well as in storage (Thind and Jhooty, 1984). Yield losses in bell-pepper during 1985-87 were estimated at 27.17\% in Himachal Pradesh (Paul and Behi 1990).

Biochemical changes due to infection were recorded in different cultivars (Sharath et al. 2004). Due to infection, shifts occurred in amino acids, carbohydrates and capsicin contents in red fruits. In diseased tissues, L-aminobutyric acid, asparagine and tyrosine were degraded completely. An increase in $\beta$ alanine, arginine, glutamic acid, glycine and threonine was observed after 5 days of infection. Leucine remained unaffected while aspartic acid and proline catabolized considerably. Capsaicin content was reduced to half. Degradation of vitamin C and capsaicin content by C. capsici and A. niger was also reported (Das 2007). Enzymes produced by pathogens play a vital role in disease development. But inhibition of enzymes production by plant products was reported by many workers (Mahadevan et al. 1965; Patil et al. 1992). Chitra et al. (2001) reported effect of Datura innoxia extracts on pectinolytic and cellulolytic enzymes production of $C$. capsici under invitro conditions.

Colletotrichum is an economically important genus. It was established by Corda in 1931. Teliomorph stage of many Colletotrichum species is Glomerella, and both stages are widely prevalent in hot and humid areas. Colletotrichum spp. are mainly responsible for diseases of fruits, vegetables, sugarcane, ornamentals etc.

Several Colletotrichum species have been recognized. And commonly encountered, and virulent form is C.dematium = C. capsici (Verma 1973; Datar and Guhule 1987). But other species like C.graminicola, C.gloeosporioides, C.piperatum, C.acutatum have also been recognized (Ramakrishnan and Wilson 1968; Grover and Bansal 1968 ; Gupta et al. 1974; Thind and Jhooty 1984; Kaur and Singh 1990; Khodke and Gahukar 1990; Kardale 1990; Sharma and Sumbali 1993; Reeny 1995; Raj Kumar 2000). 
In Argentina, Gloeosporium piperatum was observed to cause anthracnose (Laguna and Decampo 1971). Yu et al. (1987) recorded C.coccodes on Capsicum seeds from Korea. Detailed studies were carried out on cultural, morphological, physiological and comparative virulence (Vanan and Khirbat 2002; Khirbat and Vanan 2004; Akhtar and Singh 2007).

Epidemiological factors which help in perpetuation of disease include optimum temperature of $28^{\circ} \mathrm{C}$ and relative humidity of $95 \%$ (Chowdhury 1957). Besides, sunshine, age of the host also affects disease development. Fruit-rot development is maximum during rainy season in Thrivananthapuram, Kerala (Reeny 1995).

Symptoms : They appear on leaf (leaf-spot), shoot (die-back) and on fruit (fruit-rot). On mature, green fruits, they appear as small, black circular spots that spread in all directions. With advancement, the spots diffuse and become black or dirty grey. On the lesions, fungus acervuli are noticed in abundance. Grover and Bansal (1968) recorded over-wintering of Colletotrichum piperatum on red ripe-fruits and occasionally on green fruits, forming circular to elliptical lesions, which coalesce and cover 1-2 cm or more on fruit (Figs 20.4 , 20.5). Later, lesions become depressed, sunken and turn dirty-yellow to pinkish, and finally turn brown due to ageing. C.gloeosporioides appears as depressed, sunken, regular discoloured circular to irregular spots. This fungus infects semi-ripe and ripe-fruits but fail to infect green fruits (Kardale 1990). Thind and Jhooty $(1984,1990)$ observed symptoms caused by C.gloeosporoides, C.capsici and C.piperatum.

Gloeosporium piperatum was reported to cause ripe-rot of chilli-fruits (green or ripe) in Punjab, Haryana, Himachal Pradesh and Rajasthan. It attacks both spice and vegetable varieties. In Solan, disease appears in a severe form. In moist weather, small circular sunken spots appear on the green or ripe-fruits. Lesions are sunken, dirty-yellow to pinkish, turning brown with age. Acervuli are formed on infected lesions in concentric circles. Conidia cause disease spread through splashing of rain-drops or wind (Suryanarayana 1978).
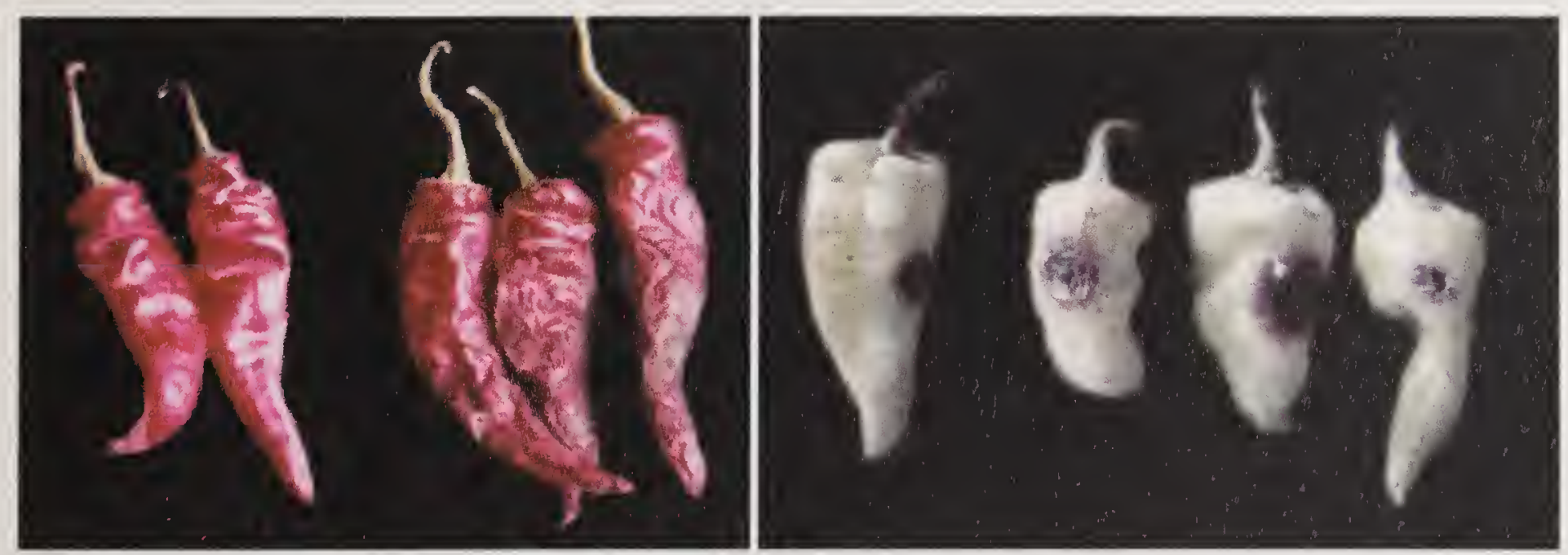

Figs 20.4, 20.5 Colletotrichum fruit-rot on chilli 
Histopathological and ultrastructural studies on C. capsici were conducted by Muthumary and Jayachandran (1994). The conidium ontogeny was well understood by employing scanning (SEM) and transmission electron microscopy (TEM) (Gehlot and Purohit (2001).

Seeds also show symptoms of infection. In advanced stages, seeds are covered by a thick mat of fungal hyphae. The pathogen survives for a short time in the soil. Infection was reported to be seed-borne (Grover and Bansal 1968; Suryanarayana 1978; Hingole and Kurundkar 2005). Varietal differences were also considerable (Grewal and Grover 1974; Yu et al. 1987). In general, seed germination is reduced by more of pre-emergence mortality than postemergence mortality.

Control measure: Management of fruit-rot resistant lines. Kadu et al. (1978) studied field reaction of chilli germplasm to anthracnose and recorded several lines to be immune as well as resistant and moderately resistant to diseases from Maharashtra. Several entries were screened and resistant lines have been evolved for different geographical areas (Ullasa et al. 1981; Singh et al. 1990; Jayalakshmi and Seetharaman 1998; Hegde and Anahosur 2001a; Kaur et al. 2005).

Seed treatment with chemicals. In anthracnose, infection is seed-borne, and pathogen survives in the seed for a short period. And during storage, seed viability is lost due to seed-borne fungi. Treatment of seeds with fungicides prior to storage offers protection (Pillayarasamy et al. 1973). Treated seeds are pelleted with maida and used for sowing later. The trial proved to be effective in eliminating seed-borne infections.

Seed treatment with Captan $(0.2 \%)$ reduces the disease in the nursery. Seed treatment with Ceresan, Thiram $(0.2 \%)$ and Brassicol $(0.25 \%)$ by weight of seeds was found suitable in eliminating seed-borne infections (Suryanarayana, 1978). In sweet-pepper, seed treatment with Captan $(0.2 \%)$ reduced disease in the nursery (Sokhi 1994). Seed treatment with Bavistin $(0.1 \%)$, Thiram $(0.2 \%)$, Captan $(0.2 \%)$ as well as Thiram $(0.2 \%)+$ Carbendazim $(0.1 \%)$ was reported to be effective in increasing seed germination and reducing disease incidence in the field (Kumar and Mahmood 1986; Perane and Joi 1989; Hegde and Kulkarni 2001; Hingole and Kurundkar 2005 and Pawar et al.2005). Captan and Thiram were effective in preventing fungal colonization and increasing seed germination, followed by Carboxin, Carbendazim and Mancozeb. Tridemorph and Ridomil were not very effective (Singh et al. 2006).

Pelleting of seeds offers good scope for inclusion of bio-ingredients, fungicides, growth regulators in small quantities. Dried seeds treated with Goucho at $5 \mathrm{~g} / \mathrm{kg}$ of seeds showed good results.

In-vitro effects of Trichoderma harzianum, $T$. viride, $T$. viride $E$ and $T$. virens (Gliocladium virens) were evaluated for their antagonistic potential 
against $C$. capsici using dual culture and poison technique at Palampur (Kaur et al. 2006). T. viride was found most effective in reducing seed infection. Untreated and infected seeds gave rise to rotten seedlings and showed necrotic lesions on primary leaves. Seed treatment with $T$. viride was effective and eradicated completely seed-borne pathogens including $C$. dematium in pea (Kumar et al. 2000). Culture filtrate and volatiles produced by $T$. viride suppressed spore germination and reduced mycelial growth (Iqbal et al. 1994; Umamaheswari and Ramakrishnan 2000).

Seed treatement with biocontrol antagonists like Pseudomonas fluorescens, Bacillus subtilis, Trichoderma viride and T.harzianum at $10^{8} \mathrm{cfu} /$ $\mathrm{ml}$ controlled damping-off caused by C. capsici (Hegde and Kulkarni 2001). The treatment was found on a par with Captan @ $3 \mathrm{~g} / \mathrm{kg}$ of seeds. Similar results were also recorded by Srinivas et al. (2006). Pure culture of P.fluorescens was effective in reducing C.capsici infection, followed by T.harzianum and fungicide-treated seeds. Inhibitory effects of leaf extracts against $C$. capsici were also reported (Gomathy and Kannabiran 2000). Leaf extracts of Solanum toruvum, Datura metel and Prosopsis julifora were found promising. Inhibition of conidial germination and mycelial growth of C.capsici was observed with aqueous leaf extract of Datura metel (Asha and Kannabiran 2001).

Field application of chemicals. Fungicides, Blitox (0.5\%), Mancozeb $(0.25 \%)$, Thiophenate methyl $(0.5 \%)$, Carbendazim (0.5\%), Zineb $(0.2 \%)$, Captafol (0.2\%), Copper oxychloride (0.25\%), Iprodine (0.2\%), Dithane M45 and Dithane Z-78 (0.2\% each) were found effective in controlling the disease in different agroclimatic regions (Viswakarma and Sitaramaiah 1985; Datar et al. 1989). In Karnataka, Carbendazim and Propiconazole were reported to be effective (Hedge and Anahosur 2001 b).

Carbendazim (0.2\%) and Chlorothalonil (0.2\%) recorded maximum inhibition of mycelial growth of anthracnose in in-vitro-grown bell pepper (Rao and Patil, 2000). In-vitro studies on C.capsici showed that Iprobenphos (Kitazin), Captan (Captaf) and Copper oxychloride (Blitox) were effective in different concentrations $(0.2,0.1$ and $0.05 \%)$ (Singha and Senapoty 2006). Iprobenphos was superior compared to others.

Dipping harvested fruits in Carbendazim 1,000 ppm or Zineb or Captafol was also recorded effective in Marathwada (Datar and Guhule 1987).

Biological control in field. Use of antagonistic microorganisms. Isolates of Trichoderma spp., pseudomonas fluorescens, fluorescent pseudomonads, Bacillus subtilis and an yeast Saccharomyces cerevisiae were screened against C.capsici in-vitro and in-vivo. Yeast $\left(5 \times 10^{5} \mathrm{spores} / \mathrm{ml}\right)$ and Bacillus subtilis $\left(10^{9} \mathrm{cfu} / \mathrm{ml}\right)$ caused maximum reduction in fruit-rot intensity and die-back, followed by $T$. viride (when sprayed 105 and 120 days after sowing) (Jayalakshmi et al. 1998). Hegde and Anahosur (2001 b) observed positive 
results with $P$. fluorescens and Nimbiciden. There was reduction in disease development. The treated chilli-fruits also recorded maximum capsicin, ascorbic acid and total sugars.

In addition to fungi and bacteria, yeasts and actinomycetes also serve as biocontrol agents. Singh and Bora (2006) from Manipur isolated Streptomyces S.124 possessing high antifungal activity against C.capsici,C.pisi and F.oxysporum.

Use of plant products. Shivapuri et al. (1997) reported that ethanol extracts of Azadirachta indica, Datura stramonium, Ocimum sanctum and Polyalthea longifolia at 5\% concentration in in-vitro were toxic to Alternaria brassicola, C.capsici, Fusarium oxysporum, Rhizoctonia solani and Sclerotinia sclerotiorum. Palmarosa (Cymbopogon martini) oil was found effective in reducing fruit-rot infection (Jayalakshmi and Seetharaman 1998). Leaf extract of Ocimum sanctum and neem oil (Melia azadirachta) also protected the crop. Choudhary et al. (1998) reported bitter temru fruit (Diospyros cordifolia) preparation as the best growth inhibitor for B.capsici, Alternaria alternata, Fusarium udum and Helminthosporium maydis. In in-vitro studies with bitter temru fruit and datura (Datura stromonium), leaf extracts inhibited maximum C. capsici growth (Bagri et al. 2004) .

Use of root extracts. Kumaran et al. (2003) observed hyphal thickening, vacuolar formation and swellings at the tip of hyphal strands of C.capsici with ethanol extract (at 5\% concentration) of Abrus precatorius and Rauvulfia tetraphylla roots. The extract showed higher control compared to Mancozeb $(0.2 \%)$ treatments. This was supported by the findings of Sariah (1995) in C.capsici and C.gloeosporioides, suggesting that this may be due to fungal toxic compounds present in the extract.

Integrated pest management. In this, biological antagonists are included along with fungicides and regular cultural practices. Sharma et al. (2004) compared 3 different pest management modules-biological, chemical and IPM, and observed IPM to be superior to others in managing chilli die-back and fruit-rot on two selected cultivars. Trichoderma harzianum as seedlingdip worked as a substitute for chemical control in nurseries.

\section{Black ripe-rot/blight/fruit-rot, c.o. Alternaria alternata (Fr.) Keissler}

The disease was reported from the USA, Italy and India. This fungus causes blighting of leaf tissues. Dark spots appear on leaves; and they die prematurely and drop. Fruit-rot is an important phase of this disease, and it causes appreciable losses during transport and storage (Coursey and Booth 1972; Hiremath and Govindu 1975; Sreekantaiah et al. 1973; Suryanarayana 1978; Uma 1981; Thind and Jhooty1984; Sharma and Sumbali 1993; Wall and Biles 1993; Bhat et al. 2000; Vijayalakshmi and Rao 2003). 
A number of Alternaria strains have been reported to initiate fruit-rot in chillies (Savulescu and Ana 1949; Thind and Jhooty 1984);including Alternaria solani (Ell \& Eve) Jones and Grout, A. tenuis, A. alternata, A. longipes, $A$. capsici annui and Alternaria sp.

A. tenuis isolates collected from conventional chilli-growing areas of southern Tamil Nadu varied in morphological and cultural characters and in virulence (Muthulakshmi et al. 1994).

Symptoms : Circular, greyish-green, water-soaked sunken spots appear anywhere on the fruit-surface. Spots gradually enlarge, become tan to mouldybrown and are covered by scanty mycelia with velvety-green sporulating mass in abundance (Mandal and Dasgupta 1981). Severe rotting of ripe-fruits was recorded from Vidarbha (Khodke and Gahukar 1990). Infected fruits showed oily, depressed, black circular to irregular lesions of various sizes. Later such fruits gave a bleached appearance. Sujatha Bai et al. (1993) recorded Alternaria fruit-rot as a malady in Tamil Nadu. The fruits get affected at maturity.

The diseased fruits ultimately turn black and rotten. Green fruits as well as leaves are not affected. Loss to the tune of $30-76 \%$ has been recorded along with depletion in content of capsicin, ascorbic acid, colour, surface wax, protein,crude fibre, starch, oleoresin and minerals like $\mathrm{P}, \mathrm{K}, \mathrm{Ca}$ and $\mathrm{Mg}$. At the time of harvest, an increase in sugar content was recorded (Wall and Biles 1993); reducing sugars increased by four times.

Control measures : A. tenuis is a wound parasite, and mechanical injuries as wounding due to tight packing will increase fruit infection. Infection is seedborne as well as soil-borne. Affected seeds fail to germinate as embryos are damaged. Seed treatments with Thiram (0.2\%),Captan (0.2\%), copper oxide $(0.5 \%)$ and Mancozeb $(0.2 \%)$ are effective (Khodke and Gahukar 1990). Sufficient care needs to be taken to avoid bruises during harvesting, transporting as well as storage. The fruits are to be stored in airy warm places to check rapid fungus development.

\section{Soft-rot, c.o. Fusarium spp.}

Soft-rot is recorded as a common disease all-round-the-year from India and elsewhere (Micosa and Ilag 1977; Uma 1981; Sokhi 1994). Infection occurs on both green and ripe-chillies. But green chillies are more susceptible. High humidity favours the disease incidence.

Fruit-rot was reported to be due to $F$. solani and $F$. diversisporum infection (Sharma et al. 1980). F. solani produces light-yellow colour at the infection site. With further advancement of rotting, tissues become soft. At this time mycelia are externally visible; and fruits smell foul and watery secretion oozes out. Finally tissues turn yellow and soft. $F$. diversisporum degrades fruit within five days of inoculation. Pedicel infection results in milky juice secretion. Rots due to $F$. moniliforme and another unidentified Fusarium sp. were reported 
by Uma (1981) from Nigeria, Datar and Guhule (1987) from Marathwada, Khodke and Gahukar (1990) from Vidarbha and Vijayalakshmi and Rao (2003) from Andhra Pradesh. Infection by $F$. solani increases gradually as fruits attain maturity. F.oxysproum was also reported by Adisa (1985) from Nigeria and Mishra and Rath (1986) from local markets of Bhubaneshwar all-round the year. F.equseti was also recorded.

Fusarium-rot was also reported on bell-pepper. F.equiseti and F.semitectum were isolated from naturally infected bell-pepper fruits (Shukla and Sharma 2000). The ideal temperature for storage of bell-pepper is between 10 and $15^{\circ} \mathrm{C}$. Disease development is higher at $25^{\circ} \mathrm{C}$ with F. semitectum and $30^{\circ} \mathrm{C}$ with F.equiseti.

Fusarium-rot on sweet-pepper was reported from Canada also. At the time of harvest, disease appeared on mature fruits as soft patches or necrotic spots at the calyx or anywhere. Seeds were also covered with orange-pink spore masses (Utkhede and Mathur 2003).

Symptoms : Small water-soaked brownish areas originate from the stylarend with scanty mycelial growth on the surface. Rotten fruits become soft and milky juice oozes out of them with an offensive smell. Under humid conditions, fluffy mycelial growth covers fruit-surface. The whole fruit becomes soft and yellow within 2-3 days.

Control measures : Measures recommended for black ripe-rot (Alternaria alternata) are also applicable to this disease.

Biological control of F. solani through seed bacterization with Pseudomonas fluorescens resulted in increased plant biomass and yield, and reduced disease intensity (Gehlot and Purohit 2002).

\section{Fruit-rot, c.o. Phytophthora capsici Sensu Late}

The disease is of common occurrence in many parts of India, and was reported by Rao (1966 b), Coursey and Booth (1972) on hot and sweet pepper also (Sokhi 1994; Jana and Khatua 2006).

Symptoms : Greyish-brown discolouration appears and advances slowly. Within 3-5 days whole fruit rots and its internal content converts into a soft mass. Sometimes Pythium sp. may also be found associated, and together with Phytophthora may cause damping-off in nurseries. Attacked seedlings suddenly topple over as their bases are rotten. The problem is severe in waterlogged as well as poorly aerated nursery beds.

The disease is also common in bell-pepper ( $C$. annum L.). Heavy losses due to fruit-rot and leaf-blight were recorded from Himachal Pradesh (Sharma and Bhardwaj 1976). Dark-green, water-soaked spots appear, which enlarge quickly and cover whole fruit-surface. Under high humidity, fruits get covered with a thick mat of fungal spores and mycelia. The pathogen is identified as P. nicotianae var. nicotianae (Breda de Haan) Waterhouse. 
Due to infection, significant decrease in total phenols and increase in ortho-di-hydroxy phenols were recorded. Sugars also was depleted (Mc Comb and Winstead1976; Bhardwaj et al. 1985).

Control measures : Seed treatment with Thiram $(0.2 \%)$ protects seeds and seedlings from infection. Providing good drainage and avoiding thick sowing reduce disease incidence. Soil sterilization of nursery beds with copper oxychloride (COC, 0.2-0.3\%) was found promising.

\section{Soft-rot/wet-rot/Rhizopus-rot, c.o.Rhizopus spp.}

Several species of Rhizopus were reported from chilli-fruits (Coursey and Booth 1972).

Symptoms : Water-soaked lesions appear. Fungus produces a wet-rot and entire fruit gets covered with mycelia within 2-3 days. Reduction (96.2\%) in ascorbic acid content was observed due to infection by $R$. stolonifer (Tandon et al. 1974).

Control measures : Storage of fruits under high humidity (above 90\%) needs to be avoided. For household storage, fruits are to be washed with water, dried and stored under refrigerated conditions at $10^{\circ} \mathrm{C}$ wrapped in newspaper in packets of $100 \mathrm{~g}$. This retains freshness and quality of fruits up to 10 days.

\section{Mucor-rot, c.o. Mucor hiemalis Wehmer}

Affected portions of fruits become water-soaked and depressed. Fluffy white mycelial growth becomes visible. The tissues become soft and watery, and a viscous liquid oozes out (Reeny 1995).

Control measures as detailed under Rhizopus-rot are applicable for this also.

Choanephora-rot / soft-rot, c.o. Choanephora cucurbitarum (Berk. \& Rav.) Thaxter

The disease was reported on hot-and-sweet pepper (Sokhi 1994). Symptoms : They are noticed anywhere on the fruit, affected tissues become soft and decayed. The fungus produces enzymes, pectin methyl esterase(PME), depolymerase (DP) and protopectinase (PP), but not polygalacturonase (PG). Activity of enzymes in chilli-fruit is more compared to that in brinjal-fruit. Changes in amino acids, ascorbic acid and carbohydrates were also reported (Chahal and Grover 1972).

Control measures : As detailed under Rhizopus-rot are applicable for this also.

Dry fruit-rot/Botryodiplodia-rot, c.o. Botryodiplodia theobromae Pat.

The disease was formerly described as Diplodia-rot, and was reported from the local markets of Maharashtra and Kerala (Rao 1965; Ramakrishnan and Wilson 1968; Alice 1969; Alice and Paily 1978). Roy (1974) also recorded the disease from Jorhat(Asom). 
Symptoms : Small lesions are visible on the fruit-surface, which gradually get depressed and irregular. And surface becomes pale and later turns greyish to almost black/green on which pycnidia are formed in abundance. The complete fruit is covered with mycelial growth and eventually fruit dries and rots.

Control measures detailed under Rhizopus-rot are applicable for this also.

\section{Brown-rot, c.o. Ceratocystis paradoxa (Dade) C. Moreau Thielavopsis paradoxa (De Seym) Hohn.}

Disease was reported from West Bengal (Mandal and Dasgupta 1989). Symptoms : Infected fruits show brown to deep-brown discolouration with depressed appearance. Brown sporulating colony can be noticed in abundance. The fruit becomes soft. Sporulating area advances, and may cover entire fruit, emitting a characteristic smell.The disease is of minor importance.

\section{Phomarot, c.o. Phoma capsici}

Initially light-brownish discolouration appears. Affected tissues become water-soaked with a light-brown border. Later tissues become ashy-grey, sunken and leathery, but they are firm. Numerous pycnidia with dirty white mycelial growth are also formed. Internal discolouration is not evident(Reeny 1995). The disease was also recorded by Rao (1966 b) from Maharashtra.

A fruit-rot by Phoma sorghina (Sacc.) Boer Dorenb was also reported by Khare et al. (1995). The fungus causes longitudinal and round spots, which are brown in colour.

\section{Seed-rot and damping-off, c.o. Rhizoctonia spp., Pythium spp.}

Infection is seed as well as soil borne. Infected seeds show only external symptoms. Seedlings show dark-brown spots and finally get blighted. It is a common nursery disease.

Control measures : Seed treatment with Thiram $(0.2 \%)$ and Brassicol $(0.25 \%)$ is effective in controlling seed-borne infection.

Seed treatment with talc-based formulations of Trichoderma viride and Pseudomonas fluorescens reduced pre-and post-emergence damping-off in chilli seedlings (Manoranjitham et al. 2000). Similar results were also reported by Gosh (2002) with T.viride, T.harzianum and Gliocladium virens in managing damping-off, caused by Pythium aphanidermatum.

Two isolates of T.harzianum $\left(1.6 \times 10^{5}, 3.6 \times 10^{4} \mathrm{cfu} / \mathrm{g}\right.$ of soil), one isolate of Thamatum ( $3.3 \times 10^{4} \mathrm{cfu} / \mathrm{g}$ of soil), five isolates of Bacillus subtilis $\left(4.2 \times 10^{6}\right.$, $4.6 \times 10^{6}, 3.8 \times 10^{5}, 4.0 \times 10^{5}, 6.2 \times 10^{5} \mathrm{cfu} / \mathrm{g}$ of soil), and one isolate of Streptomyces sp. $\left(1.9 \times 10^{4} \mathrm{cfu} / \mathrm{g}\right.$ of soil) were observed to be effective in reducing damping-off as compared to seed treatment with chemicals (Bohra et al. 2006).

Seed treatment with two neem formulations (neem oil $50 \%$ and kernel extract, $1,500 \mathrm{ppm}$ azadirachtin) at $0.5 \%$ for an hour showed lesser damping- 
off and higher dry biomass compared to treatment with Ridomil MZ 72 at $0.25 \%$ concentration (Bohra et al. 2006).

\section{Cladosporium-rot, c.o. Cladosporium spp.}

The disease is not of common occurrence. C.oxysporum was reported from Jodhpur. Olive-green to blue-green large circular spots appear on the ripe-fruits in storage. These spots soon turn ash-coloured and become dry and papery. The fluffy mycelial growth becomes visible on the lesions (Panwar and Vyas 1974). C. herbarum, C. sphaerospermum and Cladosporium sp. were also reported (Coursey and Booth 1972; Adisa 1985, Sharma and Sumbali 1993; Reeny 1995; Vijayalakshmi and Rao 2003).

\section{Periconia-rot, c.o. Periconia byssoides Pers.}

The disease is not of common occurrence. Kanaujia and Verma (1979) recorded the disease from Faizabad. Small, spherical to irregular spots of lightbrown colour appear on the affected surface. They gradually enlarge and subsequently merge to form continuous dark-brown to black patches on the fruits.

\section{Dry fruit-rot, c.o. Neocosmospora vasinfecta E.F. Smith}

Mature fruits are susceptible to infection; 5-8\% loss was reported from Nainital, Bhowali, and adjoining areas (Tandon et al. 1975). Lesions appear, ranging from 1.0 to $1.5 \mathrm{~cm}$ in diameter. Diseased tissues appear as ochraceous tawny-coloured soft areas. The lesions appear to be dry. But get covered by mycelial growth. When the fruit is cut open, dirty white mycelial mat can be seen covering seeds adjacent to necrotic areas.

\section{Stem-and fruit-rot, c.o. Sclerotinia sclerotiorum (Lib.)de Bary}

Fruit-rot, caused by S.sclerotiorum, may assume status of a potentially serious disease of bell-peppers (Capsicium annum Linn.), affecting both seedlings and mature plants in Ohio, United States. Management options of the disease are limited as information is not available on its resistance. Several accessions were screened and promising lines were evaluated (Yanar et al. 1996: Yanar and Miller 2003). The disease is of minor importance.

\section{Fruit-rot, c.o. Curvularia lunata (Wakker) Boedijin, Curvularia state of Cochliobolus lunatus Nelson \& Haasis}

The disease was noticed by Jamaluddin and Tandon (1976) during survey of markets and storage places of fruits and vegetables at Allahabad. Fruits of Capsicum annum var. Grossum Wild were found infected. Small saccardo's olive lesions, oval to irregular in shape, appeared on the diseased areas. The infection penetrated inside the fruits and caused moulding. The rot is dry in nature. Seeds are also infected; and slightly different symptoms were observed by Reeny (1995) from Thiruvananthapuram(Kerala). Vijayalakshmi and Rao (2003) also observed C. tuberculata on mature fruits. 
Fruit-rot, c.o. Chaetomium globosum Kunze ex Fr.

The disease was recorded by Jamaluddin and Tandon (1976) from Allahabad. On C.annum var. Grossum Wild, symptoms appear on the stalk or on the persistent calyx. Within a few days, they are visible on the stalkend of the fruit also. The lesions are brownish-olive in colour and develop into a soft-rot. Losses of $5-8 \%$ were noticed due to disease.

\section{Aspergillus-rot, c.o. Aspergillus spp.}

Several species of Aspergillus are found associated, including the following-A. carbonarius (Alice1969); A. niger Van Tieghem (Datar and Guhule 1987); A. flavus Link. ex Fries (Adisa 1985 and Sharma and Sumbali 1993).

Symptoms : With A. carbonarius and A. niger, symptoms appear at first as water-soaked areas. After 24 hours, small, black pinhead-like fungal growth can be noticed on these areas.

With A. flavus symptoms are similar, but fungal growth is green in colour. Control measures : They are detailed under storage studies of red chillies.

Seed treatment with Captan $(0.2 \%)$ or Thiram $(0.2 \%)$ controls disease incidence.

\section{Penicillium-rot, c.o. Penicillium italicum Wehmer}

The disease is not of common occurrence.

Symptoms : Light-brown discolouration appears and advances to form ovalshaped lesions. Fruits become soft and leaky with bluish-green spore mass, concentrated mostly at the region of the fruit-cap. Internal brown discolouration is also observed.

Control measures : They are as detailed under Aspergillus-rot.

Seed-rot, c.o. Macrophomina phaseolina (Tassi) Goid.

The disease was reported by Khodke and Gahukar (1990). Kaur et al. (2004) reported efficacy of fungal and bacterial antagonists. Seed treatment with potential isolates of Trichoderma and fluorescent Pseudomonas (commercial formulation) reduced disease incidence and increased plant bio-mass.

Seed-rot due to Cephalosporium curtipes Sacc. (Mittal, 1984), Dreschlera australiensis (Datar and Guhule 1987) and D.tetramera was also reported.

\section{OTHER DISEASES AND THEIR CAUSAL ORGANISMS}

\begin{tabular}{lll}
\hline Disease & Causal organism & Authority \\
\hline Fruit-rot & Botrytis cinerea & Coursey and Booth, 1972 \\
& Aureobasidium pullulans & Suryawanishi and Deokar, 2000 \\
& Myrothecium roridum & \\
& Nectria haematococca & Jarvis and Barrie, 1994 \\
Verticillium-rot & Verticillium psalliotae & Uma, 1981 \\
\hline
\end{tabular}




\section{BACTERIAL DISEASES}

\section{Bacterial spots, c.o. Xanthomonas campestris pv. vesicatoria Doidge} and Dye

This is the most common bacterial disease of chilli in India. The disease appears on leaves and fruits. Shekhawat and Chakravarti (1977) observed loss of $8-16 \%$ in the fruit yield due to this disease alone.

Symptoms : On green fruits, small, water-soaked spots appear, which are raised and are with a greenish-white halo, and they enlarge to about 3-6 mm in diameter. Sooner halos disappear and spots become brown to dark and get slightly sunken with a rough surface, and epidermis of the fruit rolls back. The bacterium over-winters on contaminated seeds, on the infected plant debris in the soil and on the weeds and other hosts. It penetrates leaves through stomata and fruits through wounds (Agrios 1969). Splattering rains are the main source of local dissemination and ideal temperature requirement for disease spread ranges from 22 to $34^{\circ} \mathrm{C}$ along with high humidity. The disease becomes prominent after heavy rains.

Infection is seed-borne. Even a small percentage of infected seeds can initiate severe disease incidence under favourable conditions.

Control measures : Control with an antagonistic bacterium associated with bacterial lesions was attempted (Shekawat and Chakravarti, 1977). Seed treatment was carried out to check infection. Hot-water treatment (HWT) for 30 minutes at $52^{\circ} \mathrm{C}$, followed by seed dressing with Thiram $(0.2 \%)$ was found promising (Suryanarayana 1978).

Seed-borne infection of bacterial wilt (Ralstonia solanacearum) in Capsicum sp. was also reported (Aggarwal and Sood, 2004).

\section{Bacterial-rotting, c.o. Erwinia carotovora (Jones) Holland (Arsenjevic} and Stojic 1973)

Precooling at $10^{\circ} \mathrm{C}$ was reported to be effective in delaying infection (Sherman et al. 1982). But this did not stop infection completely.

\section{Storage studies of red chillies}

Foliar application of calcium chloride before harvest was reported from Korea to improve storage quality of red sweet-pepper (Park et al. 2001). Harvested chilli-fruits are to be properly dried before storage. Sunlight drying is considered as the best method for getting healthy and quality fruits. After drying, fruits are stored for 4-6 months in different containers.

Hegde and Anahosur (2001) recorded effect of common salt (sodium chloride) on disease development, quality and biochemical constituents of chilli-fruits. Fruits were dipped in a saturated solution of common salt for 30 min, followed by drying under sunshine for 30 days, followed by storage in gunny-bags. The treated fruits retained colour and had high capsaicin, ascorbic acid and total sugars. Sharath et al. (2004) also recorded high ascorbic acid 
and capsaicin in chilli-fruits (cultivars Bullet and Suryamukhi) dehydrated at $65^{\circ} \mathrm{C}$. For storage of dried chillies, gunny bags are commonly used as they are cheap and easy for handling and transportation, and also provide adequate aeration.

Hegde and Anahosur (2001 b) observed stored sundried fruits had least development of disease, while healthy fruits mixed with infected fruits and stored in gunny-bags recorded maximum spread and development of disease.

Stored chilli-fruits exhibited varying degrees of decay like discolouration, breaking of pericarp, detachment of pedicel, and spore dust formation within and outside the fruit.

The microflora associated with dried chilli-fruits were studied in detail by Senappa et al. (1980) and Tripathi et al. (1984). Infection occurs through crevices caused by mechanical injury. When it is stored under high RH, fungal flora changes completely; A. flavus alone predominates at $95 \% \mathrm{RH}$ and no fungal growth was observed at $70 \% \mathrm{RH}$.

The extent of colonization due to different Aspergillus species is correlated with prevailing temperature and humidity. Infection by A. flavus was common on stored dry chilli-fruits during rainy season from May to August under Kerala conditions (Philip, 1998). Prasad et al. (2000) observed varying degrees of decay, discolouration, breaking of pericarp and fungal flora from different parts of India. Among the fungi, Aspergillus spp. predominated; including A.flavus, A.candidus, A.niger, A.sclerotiorum and A.terreus. Other fungi were Fusarium moniliforme, F.sporotrichoides, Syncephalastrum racemosum, Paecilomyces varioti and Penicillium coryophilum. Capsaicin content was also found decreased due to infection.

In-vitro studies with terpenoids like citral, citronellal, eugenol, faresol and nerol at $0.5 \%$ concentration showed their absolute toxicity against A.flavus and A.niger. Citral, eugenol and faresol exhibited broad spectrum of toxicity against all fungi.

\section{Seed mycoflora}

In chilli, all important diseases are seed-borne: including anthracnose and die-back (Colletotrichum capsici), seedling-blights (Rhizoctonia sp. and Fusarium spp.), damping-off (Pythium spp. and Phytophthora spp.), blights (Alternaria spp.) and bacterial leaf-spot (Xanthomonas vesicatoria). In addition to these, several other pathogens are also observed.

The following seed-borne fungi of chilli are reported from different agroclimatic regions of India. Khulbe et al. (1991) observed Didymella lycopersici and Diaporthe phaseolorum in seed samples of red pepper and bell pepper in a mild to abundant form from Kumaon and Nainital. External as well as internal seed infections were also noticed. The fungi presence could be seen on the seed-coat, endosperm and embryo.

Sokhi (1994) recorded Colletotrichum capsici, Phytophthora spp., 
Choanephora cucurbitarum and Fusarium spp. as seed-borne on sweet-pepper from Punjab.

Thippeswamy et al. (2004) from Karnataka observed on seed samples of chilli, brinjal, tomato and okra, pathogens like C.capsici, A.alternata, A.solani, F.oxysporum, F.solani, Phomopsis vexans, Macrophomina phaseolina, Aspergillus spp., Phoma sp., Curvularia lunata and Rhizopus spp.

Hingole and Kurundakar (2005) observed Fusarium moniliforme, Colletotrichum capsici, A. niger, Alternaria and Curvularia sp. from Parbhani, Marathwada.

Singh et al. (2006) recorded 14 species belonging to 10 generaAlternaria solani, A.tenuis, Aspergillus flavus, A.niger, Aspergillus sp., Chaetomium sp., Colletotrichum capsici, Curvularia lunata, Fusarium oxysporum, F.solani, Helminthosporium sp., Penicillium notatum, Penicillium sp. and Rhizopus nigricans from Faizabad and Chanchal. The common variety Jwala harboured maximum pathogens.

Pattnaik and Narain (2000) recorded Colletotrichum capsici, Curvularia lunata, Aspergillus flavus and A.niger from infected seeds from Odisha. Higher percentage of seeds was having C.capsici and C.lunata.

\section{POTATO (Solanum tuberosum L.)}

It is a starchy tuberous crop and world's fourth largest food crop, preceded by rice, wheat and maize. Potato contains vitamins and minerals as well as assortment of phytochemicals such as carotenoids and natural phenols.

\section{FUNGAL DISEASES}

\section{Dry-rot, c.o.Fusarium spp.}

This disease is of worldwide occurrence (Bilgrami et al. 1979; Khanna and Chandra 1980; Gallenberg 1989; Singh et al. 1989). And it develops usually during storage. The following species of Fusarium have been reported.

Fusarium oxysporum Mishra and Rath, 1986; Shashireka and

Narasimham, 1990; Sharma and Sumbali, 1993; Singh et al., 2004

F. moniliforme Gaur and Chenulu, 1982; Kassim, 1986

F. solani Shakywar and Pathak, 2006

F. solani var. coeruleum Gindrat 1984; Mishra and Rath, 1986

F.solani subglutinans

F.culmorum Grindrat, 1984a

F.graminacearum

Singh et al., 2004

F.chlamydosporum

F.poae

F.sambucinum (Gibberella pulicaris) Peters et al., 2001; Malyuga, 2002

F.roseum var. arthrosporoides

F.roseum culmorum 
F.roseum var. graminearum (Giberella zeae)

F.sulphureum Langerfield, 1984

F.avenaceum Gindrat, 1984a

F.equiseti Sharma and Sumbali, 1993

F.trichothecioides

Of these, F.solani, F.sambucinum and F.avenaceum are known throughout the world as pathogens of potato. F.oxysporum and F.culmorum are considered as dominant species causing dry-rot in Australia (Chamber 1973). Malyuga (2002) from Russia reported F.sambucinum (Giberella pulicaris) and F.sambucinum var. minus (G.pulicaris var. minus) as the most prominent dryrot causing organism. Nasr (2006) recorded Fusarium dry-rot as the most devastating disease in Turkey. In India, F.oxysporum is the most prevalent one, followed by F.solani and F.equiseti (Shakywar and Pathak 2006).

Symptoms : Infected tissues become light-brown to deep-brown, shrunken with crinkled peel often covered with a scanty, white fungal growth. Affected tissues become moist. Lesions are circular to oval and may enlarge up to $2-3 \mathrm{~cm}$ in diameter. Several lesions coalesce to form large wrinkled patches with deep discolouration inside. Under humid conditions, tubers may completely rot. Scanty, white fungal growth is also noticed in decaying portions

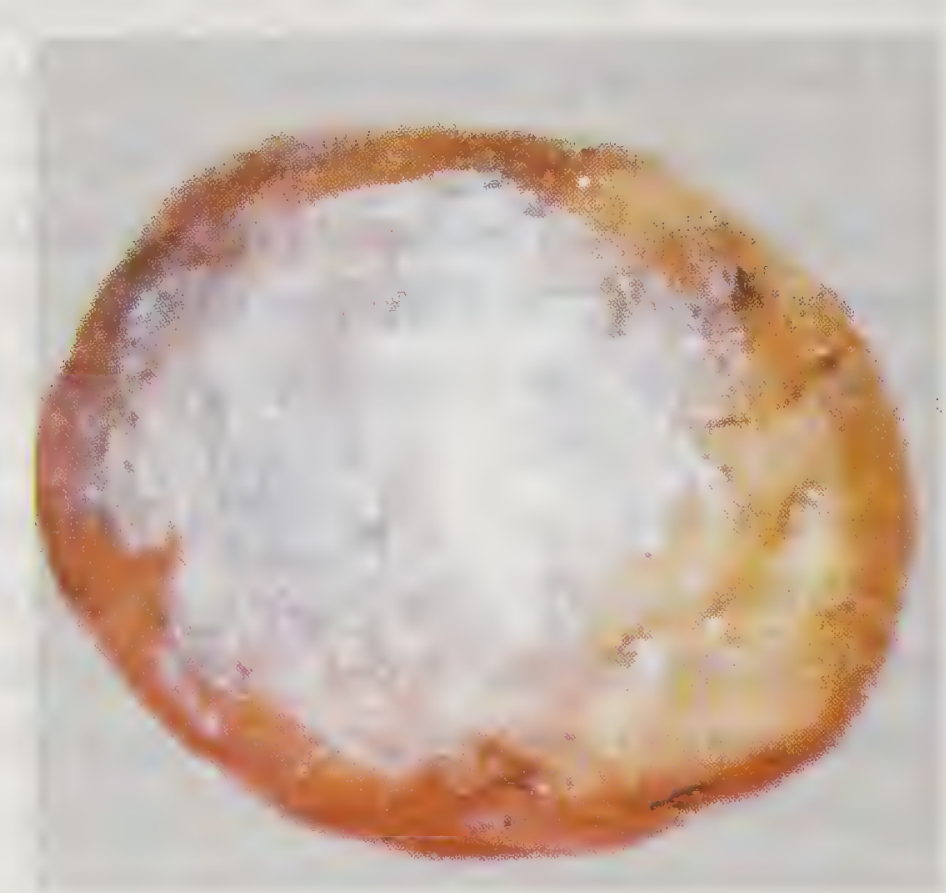

Fig. 20.6. Fusarium-rot on potato (Fig. 20.6) (Philip 1998).

Gindrat (1984) observed correlation of lesion development with storage temperature. At $5^{\circ} \mathrm{C}$, most of the pathogens were inactive but, their activity increased at $20^{\circ} \mathrm{C}$ and above. Reust et al. (1984) recorded losses ranging from 12 to $61 \%$. Maximum rotting was observed with tubers stored at higher $\mathrm{CO}_{2}$ concentration. The infective capacity of different species of Fusarium varies depending upon the varieties (Langerfield 1984), depth of wound and inoculum (Tivoli et al. 1986). Tivoli and Jouan (1981) recorded maximum rotting at $25-30^{\circ} \mathrm{C}$ with $F$. culmorum and at $15^{\circ} \mathrm{C}$ with $F$. solani var. coeruleum.

Control measures : Gaur and Chenulu (1982) observed complete control against rotting by F.moniliforme as well as Cladosporium sphaerospermum, Pestalotia versicolor and Rhizoctonia solani with Bavistin at 1,000 ppm. Sodium metabisulphite and salicylic acid at 1,000 ppm protect against decay. Weedicide 2, 4-D at $500 \mathrm{ppm}$ is also effective. Kassim (1986) observed Antracol $(0.2 \%)$ as well as Benlate $(0.2 \%)$ to be effective for pre-infection treatments. Singh et al. (1989) observed Boric acid (2\%) dip, followed by Thiabendazole $(0.1 \%)$ and Emisan $6(0.25 \%)$ as effective at pre-cooling stage. 
Dipping seed-tubers in aqueous solutions of trace elements like iron, copper and zinc decreased sprouting as well as microbial spoilage during storage at ambient conditions (Sashirekha and Narasimhan 1990).

Thiabendazole $(0.2 \%)$ was also reported to be effective. But Peters et al. (2001) from Canada reported Thiabendazole-resistant isolates of $F$. sambucinum. Resistant isolates of Fusarium were also reported from Europe and US.

\section{Late-blight, c.o. Phytophthora infestans (Mont.) de Bary}

Late-blight is a highly destructive disease of potato and causes heavy yield losses under favourable weather. Irish famine of 1845 is an example where thousands of people died of starvation and several others migrated to US and other countries.

In India, disease was reported from Nilgiri hills in 1870, and then from West Bengal, Uttar Pradesh and Asom (Baruah et al. 1985). Yield losses are due to reduction in photosynthetic capacity of plant through destruction of foliage and tuber infection. Though it is generally considered as a field disease, tubers stored also get infected by potato collected from blighted fields. Invasion of tubers by sporangia or zoospores from infected leaves or through soil causes dry- or wet-rot, according to the prevalent moisture and temperature. The fungus survives in a wide range of temperature and relative humidity.

Degree of susceptibility to late-blight varies with varieties. Use of resistant varieties such as Kufri Sherpa, Kufri Badshah and Kufri Himalini was promising for the north-western plains and hilly tracts (Singh 1992). The basis of resistance includes factors like host attribution components (Singh and Bhattacharya 1995), compatible and incompatible interactions at the cellular level (Singh et al. 1992) as well as structural basis of the late-blight resistance (Mahajan et al. 2003).

Symptoms : In storage containers, wet-rot phase is common unless ideally cool and dry conditions are maintained. In moist atmosphere, tubers get rotten fast. White tufts of mycelia and sporangiophores appear on the tuber surface. Rotten tubers may be further attacked by secondary bacteria, resulting in a slimy, soft decay.

Control measures : Disease incidence is more with increased irrigation frequency. Adjustment of irrigation and chemical desiccation of potato foliage 2-3 weeks prior to harvest of tubers were reported to be effective in reducing late-blight incidence (Dennis et al. 2003).

Diseased seed-tubers are the principal source of inoculum. Tubers should be intact, free of wounds and should be stored in cool, dry, well-aerated storehouses. Temperature at $15-25^{\circ} \mathrm{C}$ and high inoculum density favour infection. Avoiding wounding of tubers and rapid cooling of storage-bins at $10^{\circ} \mathrm{C}$ help in disease control (Salas et al. 2000). 
Chemical treatments are given usually after harvest to reduce pathogenic decay of fruits and vegetables during transit, storage and marketing. These also eradicate established infection. Treatment of tubers with TMTD (Thiram $0.2 \%$ and Mancozeb $0.2 \%$ ) protects tops and tubers against $P$. infestans (Kotikova and Gerasimova1980). Seed treatment reduces risk through seed transmission and enhances seed establishment and plant vigour (Powelson et al. 2002).

Thakur and Chenulu (1974) reported protection of tubers for 60 days by dipping seed-tubers in commercial formalin (0.3\%), and 2, 4-D and 2, 4, 5-T at $0.01 \%$ concentration each. Treatment of tubers and sprouts with systemic fungicide Ridomil MZ (Metalaxyl) $0.2 \%$ was also reported (Singh and Pundhir 2004).

Biocontrol agents like T.viride and Bacillus subtilis (commercial formulations @ 4g/kg) and fungicide Captan $(4 \mathrm{~g} / \mathrm{kg}$ ) reduced post-emergence damping-off in the field. Tuber yield was also high (Lakra 2003).

\section{Pink-rot, c. o. Phytophthora erythroseptica Pethybr., P. cryptogea Pethybr \& Bafferty, P. drechsleri Tucker; P. megasperma Drechsler}

Symptoms : Infected tubers become brown or blackened. Decayed tissues appear wet and spongy. The rotted tissues become pink-to-brown and later black.

Control measures : Use of resistant varieties. Salas et al. (2003) assessed several cultivars from North Dakota, USA, for resistance of tubers to pinkrot and leak by Pythium ultimum. Only cv. Atlantic showed some resistance to infection and colonization by P.erythroseptica.

Disease-free seed material should be planted. Application of Metalaxyl $(0.2 \%)$ during growing season as a protectant fungicide was reported.

Seed treatment with biocontrol agents has also been evaluated as a sustainable management option for controlling pink-rot. In New Zealand, Tate and Cheah (2003) used Trichoderma-based commercial products. The biocontrol products provided an organic/non-chemical alternative for controlling tuber decay through root colonization. And also assisted the crop to withstand nutritional and environmental stress.

\section{Soft-rot, c.o. Rhizopus spp.}

Soft-rot is a major disease, affecting stored potatoes in India. In Delhi, R.arrhizus was found responsible for causing decay in 8-25\% of stored potatoes (Chenulu and Thakur 1968; Thakur and Chenulu 1974; Prasad et al. 1989). R.stolonifer (Balasubramonian 1972) and R.oryzae (Mandal and Dasgupta 1981) were also reported from Delhi, Maharashtra and West Bengal. Dipping in commercial formalin $(0.3 \%)$, as well as 2,4-D and 2, 4, 5-T each at $0.01 \%$ concentration protected infected tubers for 60 days. 
Watery wound-rot/leak, c.o. Pythium butleri Subram.

P.debaryanum Hesse

P.ultimum var. ultimum Trow.

P.deliense Meurs

Symptoms : Irregular lesions appear, and the affected areas may be bordered by black line visible externally and internally. Sometimes symptoms are not visible externally. The outer tissue remains firm, enclosing the fluid; which leaks out, potato becomes hollow, hence the alternative common name is shellrot. At temperature above $25^{\circ} \mathrm{C}$, infected tubers decay completely; at $10^{\circ} \mathrm{C}$ and below, rotting is in check.

Control measures : Any seed protectants (Thiram, Dichlone, Ziram, Zineb, Maneb or Captan all at $0.2-0.25 \%$ ), applied as a dust or as a dip treatment to seed pieces of potato-tubers, control seed decay (Walker 1975). In addition to seed treatment, soil treatment is also important. Formalin dust (15 parts with 85 parts of charcoal ash) mixed thoroughly and applied to soil at $30 \mathrm{~g} / \mathrm{ft}^{2}$ to a depth of 3" was reported to be effective (Singh 1983).

\section{Target-rot/early blight, c.o. Alternaria alternata (Fr.) Keissler}

\section{A.solani Ell. \& Martin}

The disease has long been known in Europe and the USA. In India, seedpotatoes are affected and are the primary source of inoculum. Khanna and Chandra (1980) reported the disease from Uttar Pradesh.

Symptoms : Infection starts as brown pinhead-shaped lesions on the tuber surface. Several spots enlarge and coalesce to form target lesions of $1-2 \mathrm{~cm}$ diameter and $1-\mathrm{cm}$ deep. Storage of tubers at $15.6^{\circ} \mathrm{C}$ for 3 weeks, before final storage at $10^{\circ} \mathrm{C}$ results in a few smaller lesions than instant storage at $10^{\circ} \mathrm{C}$ or $4.4^{\circ} \mathrm{C}$ or pre-storage for varying periods (Nodu et al. 1982).

Control measures : Antracol and Benlate at $0.2 \%$ concentration when used as a post-harvest dip proved promising (Rai 1978; Kassim 1986). Three sprays of Ridomyl MZ 0.25\% (Metalaxyl 8\% + Mancozeb 64\%) as well as Melody Du 66.75 WP (Iprovalicarb 5.5.\% + Propineb 61.25\%) at 1.5, 2.0, and 2.5kg/ ha were effective in controlling early blight as well as late-blight during storage (Singh 2008).

\section{Black scurf, c.o. Rhizoctonia solani Kühn}

\section{Thanatephorus cucumeris (Frank) Donk.}

Rhizoctonia solani causes stem canker in the field and black scurf on the stored potatoes (Cayley et al. 1983; Harris et al. 1988).

Symptoms : Black crust appears on the peel due to sclerotia formation. The sclerotia are normally skin-deep. Due to insect or mechanical injuries, the fungus may grow in injured tissues and cause rot (Singh 1992). Spores released may cause subsequent infection to healthy tubers in the storehouse. 
Field and greenhouse testing confirmed occurrence of both tuber-borne and soil-borne inocula. Tuber-borne inoculum affected sprout and emergence and soil-borne damaged stolon (Frank and Leach 1980).

Control measures : Pre-and post-storage treatment of seed-tubers with Imazalil (200 ppm) and Thiabendazole (0.2\%) decreased the disease (Cayley et al. 1983; Tsror and Petretz Alan 2002). Seed treatments with Tolclofosmethyl/Prochloraz ( $0.25 \%$ solution), maganese chloride or mixtures were successful in commercial use for control of stem canker and black scurf (Harris et al. 1988).

The pathogen usually remains in seed or soil. Kalisena (commercial bioformulation of Aspergillus niger) applied as seed treatment reduced Macrophomina phaseolina and R.solani infections in the soil and increased yield (Sen 2000). Similar results with Trichoderma viride and Pseudomonas spp. like P.maltophila and P.fluorescens were also reported from Haryana against black scurf (Arora and Somani 2001; Gandhi and Kumar 2006).

Black scurf was significantly reduced $(72-42 \%)$ by treating tubers with freshly prepared bioformulations of T.viride (@ $1 \times 10^{7} \mathrm{cfu} / \mathrm{mg}$ ) and Bacillus subtilis strain $\mathrm{B}_{5}$ and B.cereus strain $\mathrm{B}_{4}$ (both @ $1 \times 10^{10} \mathrm{cfu} / \mathrm{mg}$ ) either applied alone or in different combinations (Somani and Arora 2010).

\section{Gangerine/skin-spot, c.o. Phoma spp.}

\section{Oospora pustulans Owen \& Wakef.}

The disease is widespread in the world. Its occurrence was reported by Prasad (1977), Smith and Wilson (1978), Cayley et al. (1983) Langerfield (1984) and Gindrat (1984) and Elphinstone et al. (1983).

Phoma species found associated with the disease include: P.exigua, P.exigua var. foveata, P.eupyrina and P.herbarum (Janke and Zott 1983; Gindrat 1984; Hamilton 1985).

Symptoms : Small, circular, shallow, brown-to-grey depressions appear. Such spots may crack off in favourable conditions. The spots may enlarge superficially to about $2-4 \mathrm{~cm}$ and develop a shallow rot. Sometimes rot may be restricted to a small area with deep and extensive rotting of internal as well as superficial tissues. Rotted areas are demarcated by a dry and grey zone. In deeper rots, button-holes may develop containing pycnidia and fungal mycelia. In the final stage of infection, tubers may be reduced to a dry shell. No rotting was observed at $15-20^{\circ} \mathrm{C}$ or at low relative humidities; few rots were noticed with increased relative humidity (Nonodu et al. 1982).

Control measures : In storage, disease was controlled by treating tubers with Imazalil (200 ppm) and Thiabendazole $(0.2 \%)$ soon after lifting them and retreated them before planting (Cayley et al. 1983). Fumigation of potatotubers stored in boxes with 2 aminobutane was also promising. 


\section{Charcoal-rot, c.o. Macrophomina phaseolina (Tassi) Goidanich}

Charcoal-rot is observed under moist, warm climates, and was reported from Bihar(Thirumalachar 1955) as a major disease. The disease was also reported from Uttar Pradesh, Punjab and West Bengal (Paharia 1960; Mandal and Dasgupta 1981). Severe losses due to this disease were reported also from Palestine. Losses ranging from 10 to $70 \%$ are generally observed, depending upon the variety and pre-disposing conditions. The fungus enters from the soil into tubers through proliferated lenticels.

Symptoms : Cloudy or black blotches appear near the eyes, followed by extensive blackening. The inner tissues develop a dry or semi-watery rot, become greyish to tan yellow; turn pinkish buff and finally become black. Sometimes cavities may develop near the eyes. Maximum decay was observed at $27^{\circ} \mathrm{C}$ and at $100 \% \mathrm{RH}$. Disappearance of amino-acids was also recorded on the $20^{\text {th }}$ day of inoculation(Rao and Usharani 1985).

Control measures : Fungal and bacterial antagonists were found promising to control charcoal-rot. Kalisena (commercially prepared bioformulation based on Aspergillus niger) introduced to soil through seed treatment retarded $M$. phaseolina in potato-planting by $79 \%$ (Sen 2000). Isolates of Trichoderma and fluorescent Pseudomonas were reported to be effective (Kaur et al. 2004).

\section{Creepy white-rot/Sclerotium-wilt, c.o. Sclerotium rolfsii Sacc.}

Sclerotium-wilt is an important disease of tropics and subtropics. It was recorded from Karnataka and West Bengal (Hiremath and Govindu 1975; Dasgupta and Mandal 1989). The disease was serious in Satar region (Maharashtra) in 1968, with an average incidence of 5\%. In northern Karnataka, $1-40 \%$ wilting of plants and up to $25 \%$ tuber infection were recorded.

Symptoms : The affected tubers show small, sunken, yellow to tan-coloured spots. White mycelial growth is noticed over the tuber surface in a fan-shaped ouline with dark-brown coloured sclerotial bodies. Tubers shrink, and gradually affected tissues become soft, watery and rots. Congregation of tubers in storage leads to rapid spread and deterioration of tubers. Affected tubers when cut open show discolouration from margin to inner tissues.

Control measures : In-vitro studies with Trichoderma spp., Pseudomonas fluorescens and Gliocladium virens showed complete inhibition of S. rolfsii growth by them. Tubers treated with T.viride or T.harzianum prior to planting at $4 \mathrm{~g} / \mathrm{kg}$ of seed-tubers reduced Sclerotium wilt in storage(Anahosur 2001).

\section{Green mould-rot, c.o. Penicillium spp.}

The disease is of seasonal importance, and was reported from Delhi (Thakur and Chenulu 1970), Madhya Pradesh (Chauhan and Sharma 1977), West Bengal (Mandal and Dasgupta, 1981) and Bihar (Prasad et al. 1989). P.cyclopium, P.harqui and P.auranteogriseum (Sharma and Sumbali, 1993) are the commonly encountered species with this disease. 
Symptoms : On the tubers stored under cool conditions, depressed areas of $2-3 \mathrm{~cm}$ in diameter appear proceeding vertically through eye-end. The peel remains intact but internal tissues become soft, irregular, brown and separated from healthy tissues. Greenish growth of fungus occurs within the cavity.

Control measures : Seed prtotectants detailed under watery wound/ leak are applicable for control of Penicillium-rots.

\section{Eye-end rot, c.o. Aspergillus spp.}

Khanna and Chandra (1980) reported the disease caused by A. fumigatus from Uttar Pradesh. A. niger was reported by Kassim (1986). Severe rotting due to an unidentified species of Aspergillus (Prasad et al. 1989) and A. flavus (Sharma and Sumbali, 1993), and dry-rot due to A. terreus (Rao and Usharani, 1985) were also reported.

Symptoms : Water-soaked lesions appear on the skin near the eyes. Rot develops fast and involves a major portion of the tuber, forming a soft-rot with a foul smell.

Control measures : Seed prtoectants detailed under watery wound/ leak are applicable for the control of Aspergillus-rots.

Waxy-rot, c.o. Geotrichum candidum Link.

Khanna and Chandra (1980) reported the disease during the rainy season from Uttar Pradesh.

Symptoms: The symptoms may appear anywhere on the tuber surface in the form of a wet-leaky rotting with a waxy growth and a foul odour(Dasgupta and Mandal 1989). The disease is severe at $20-30^{\circ} \mathrm{C}$ and $\mathrm{RH} 90-100 \%$.

Control measures are as described under the waxy-rot in tomato of Solanaceous Crops.

Botrytis-rot/soft-rot, c.o. Botrytis cinerea Pers.ex Fr.

Teliomorph : Botryotinia fuckeliana (de Bary) Whetzel

The disease is usually observed in temperate regions. It produces pit-rot on stored tubers, which appear as soft, wet and extensive with a distinct edge. When cut open, affected tissues can be seen to be soft and water-soaked with a pale-brown or occasionally a yellow margin. A faint vinegary odour could also be smelt in certain cases. The disease is usually found associated with potatoes stored under low temperature for seed purpose (Choiseul and Carnegie 2000).

Phomopsis-rot, c.o. Phomopsis tuberivora (= Phacidiopycnis tuberivora)

The disease was observed by Rai (1983) from Manali, Himachal Pradesh. Infection starts at the stem-end and gradually progresses towards healthy tissues, resulting in mummified tubers. Longitudinally cut tubers show darkbrown corky tissues with a distinct margin. No specific control measures are available. 
Tuber-rot, c.o. Gilmaniella humicola Barron

The symptoms observed on the tubers are of late-blight differentials. Minute brownish necrotic spots are noticed around lenticels and eyes. Tubers stored at $15-25^{\circ} \mathrm{C}$ are found infected. Necrotic lesions ranging from $2-4 \mathrm{~mm}$ near the lenticels to $3-6 \mathrm{~mm}$ at the eyes are noticed. Sometimes 2-5 lesions are observed around the lenticels, which coalesce and form large lesions. Infection does not develop deep into the tissues, and tubers remain firm and dry during storage. All eyes die making tubers unfit for seed purpose (Sahai 1967). No specific control measures are available.

\section{Tuber-rot/internal black-rot, c.o. Pestalotiopsis versicolor (Speg.) Steyaert}

Soft-rot causing 2\% loss was recorded from New Delhi (Gaur and Chenulu 1981). The disease incidence was high during July when the climate was warm and humidity was high. Light-brown patches appear around injuries. On cutting open tubers, white mycelial mat and black, shining cushion-shaped acervuli with dark-coloured conidia are seen.

Any seed protectants, Thiram or Captan at $0.2-0.25 \%$, when applied as dust or dip treatment to cut seed pieces of potato-tubers, controlled decay.

\section{OTHER DISEASES AND THEIR CAUSAL ORGANISMS}

\begin{tabular}{|c|c|c|}
\hline Disease & Causal organism & Authority \\
\hline $\begin{array}{l}\text { Internal patch-rot } \\
\text { Tuber-rot }\end{array}$ & $\begin{array}{l}\text { Doratomyces stemonitis } \\
\text { Cladosporium } \\
\text { sphaerospermum }\end{array}$ & $\begin{array}{l}\text { Mandal and Dasgupta, } 1981 \\
\text { Gaur and Chenulu, } 1982\end{array}$ \\
\hline Black-dot & Colletotrichum coccodes & Cayley et al., 1983 \\
\hline Skin-spot & Polyscytalum pustulans & $\begin{array}{l}\text { Hamilton,. 1985; } \\
\text { Harris et al.,1988 }\end{array}$ \\
\hline \multicolumn{2}{|c|}{ Watery soft-rot, c.o. Sclerotinia sclerotiorum } & Ginoux et al., 1984 \\
\hline \multicolumn{2}{|c|}{$\begin{array}{l}\text { Mucor-rot Mucor sp. } \\
\text { Tuber-rot Trichurus spiralis }\end{array}$} & $\begin{array}{l}\text { Rao and Usharani, } \\
1985\end{array}$ \\
\hline \multicolumn{2}{|c|}{ Dry-rot Phacidipycnis tuberivora } & Rai, 1983, \\
\hline \multicolumn{2}{|c|}{ Silver scurf Helminthosporium solani } & Harris et al. 1988 \\
\hline \multirow{2}{*}{\multicolumn{2}{|c|}{$\begin{array}{l}\text { Dry-rot Chaetomium globosum } \\
\text { Brown-rot Scopulariopsis brevicaulis }\end{array}$}} & Sharma and \\
\hline & & Sumbali, 1993 \\
\hline \multicolumn{3}{|c|}{ Gliocladium-rot Gliocladium roseum } \\
\hline
\end{tabular}

\section{BACTERIAL DISEASES}

\section{Black-leg / bacterial soft-rot, c.o. Erwinia carotovora subsp.} carotovorum Vanhall 1902, Dye 1969

Soft-rot is a common storage and transit disease. The bacteria also cause black-leg and wilt of plants in fields. The most destructive soft-rots are caused 
by the bacterium of the genus Erwinia. Of these, E. carotovora has been recorded as the most prevalent one(Elphinstone et al. 1983; Colyer and Mount 1983; Panno and Kohler1984; Cappellini et al. 1984; Hussian et al. 2002). In India, the disease was investigated in detail by Trivedi and Patel (1972). The soft-rot of tubers may occur in the field when soil is moist and temperature is high or it may occur during transit and storage.

Symptoms : Small, water-soaked lesions appear, which enlarge rapidly. Tuber surface becomes discoloured, depressed and wrinkled. And the tubers are transformed partially or totally, slowly or quickly into a soft, decayed pulpy mass (Fig. 20.7). The mass is held together by a corky epidermis, which is resistant to attack by the pathogen. Kushalappa and Zulfiquar (2001) observed lesion development at $16^{\circ} \mathrm{C}$ after storage for 60 days. Campos et al. (1982) observed $13 \%$ and $45 \%$ incidence due

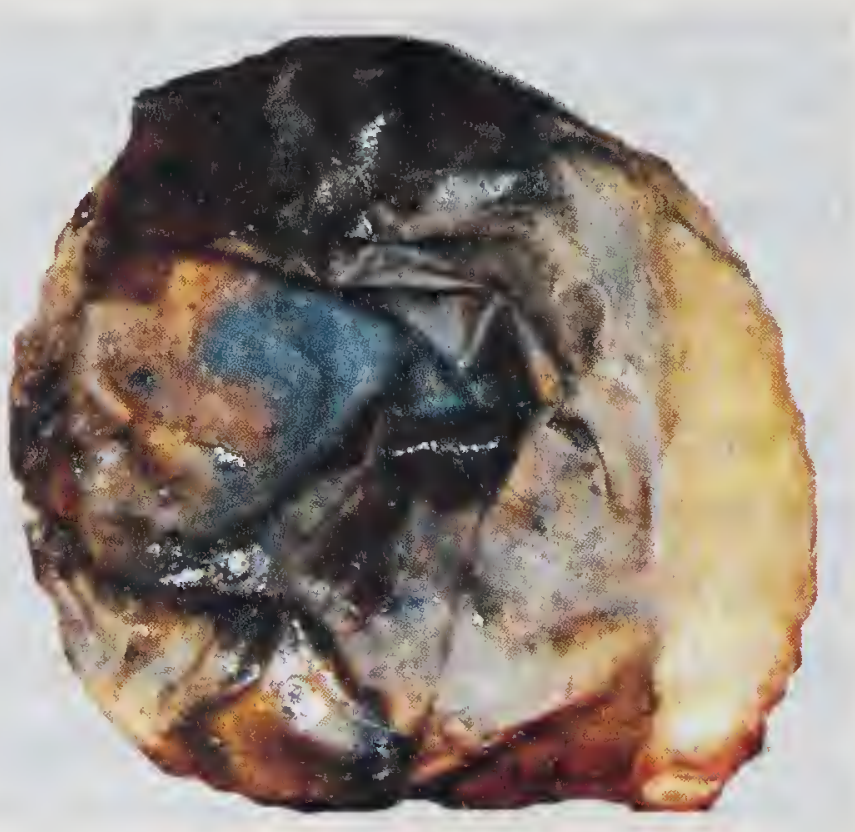

Fig. 20.7. Bacterial-rot on potato to E.cartovora pv. carotovora and $E$. carotovora pv. atroseptica, respectively. In addition, they also observed certain pectolytic clostridia. Workman and Holm (1984) reported that black-spot and soft-rot both were caused by E. carotovora subsp. atroseptica. They compared tubers of 11 clones for various characters like Redox potential (R ), ascorbic acid (A), dry matter (DM) and potash (K) for different storage periods, and observed significant differences among clonal types.

Bacteria produce pectolytic and celluloytic enzymes, causing breakdown of pectic substances of middle lamella and cell wall, resulting maceration of cell tissues. Mahmoud et al. (1981, 1981 a) studied susceptibility of potatotubers to soft-rot and black-leg pathogens, and observed their rotting ability in relation to enzymes secreted. E. atroseptica isolate showed high depolymerase (DP) and cellulase (CX) activity than E. carotovora isolates, and reverse was the situation with glucosidase activity. But dehydrogenase activity was similar in all isolates.

When a soft-rot tuber is cut open, colourless putrid mass turns pinky-red on exposure to air, and rapidly becomes brownish-red to brown-black. The cut tubers have only a slight smell. But due to secondary bacteria, that gain entry into the rotting mass, a strong repulsive smell is felt. The organisms survive saprophytically on diseased tubers left in the field. The disease severity is maximum at $20-23^{\circ} \mathrm{C}$ (Bartz and Kelman 1984). Clonal variation is also significant. The bacterial and the plant gene expression is also well understood (Yang et al. 1989). The stored tubers are infected through insects, which crawl on them and bacteria may enter through wounds. Elphinstone et al. (1983) 
studied sources and pathways of contamination during grading, and observed that susceptibility increased with early harvesting of crop and vice versa was the case with resistant ones. The chief source of primary inoculum in the storage is the infected tubers. The bacteria also survive, both internally and externally on the vectors, Drosphila melanogaster and D. busckii; they enhance longevity of nonspore-forming Erwinia cells. The pupae as well as maggots act as the source for field and storage phase, and bacteria enter through injuries sustained during harvest as well as insect and freezing injuries.

Tubers cool stored at $3-6^{\circ} \mathrm{C}$ had elevated levels of reducing sugars, and developed more soft-rot compared to tubers stored at $21-29^{\circ} \mathrm{C}$ (Otazu and Secor 1981).

Control measures : They include surface sterilization of seed-tubers with $10 \%$ chlorine bleach (Colyer and Mount 1983) and treatment of tubers with TMTD (Thiram 0.2\% and Mancozeb 0.2\%) (Kotikova and Gerasimova 1980). Dipping seed-potatoes in aqueous solutions of trace elements like iron, copper and zinc decreased both sprouting and microbial spoilage during storage at ambient conditions (Sashirekha and Narasimhan 1990).

Water extracts of plants Cannabis sativa, Calotropsis procera, Cenchrus ciliaris and Solanum surratense were observed to have anitibacterial activity in in-vitro studies against the rot-producing bacteria-E. carotovora, subsp. atroseptica, E.carotovora subsp. carotovora and E. chrysanthami (Pal and Jalali 1990).

\section{Brown-rot/bacterial-wilt/ring disease,}

\section{c.o. Pseudomonas solanacearum (Smith 1896)}

(Ralstonia solanacearum (Smith 1896) Yabuchi et al. 1996)

This bacterium has been reported from several countries. Paul (1998) in a study on the dry temperature zone of Himachal Pradesh observed bacterial wilt to the tune of $2-12 \%$, and found it to be introduced through seed.

Symptoms : The bacterium causes wilting, stunting and yellowing of foliage, followed by collaspse of the plant. The name 'ring' disease denotes brown ring that is formed in tubers due to discolouration of vascular bundles. The skin of the tubers is often discoloured. In severely affected tubers, eye-buds blacken. Ciampi Panno (1984) observed vascular ring-rot in stored tubers caused by race 3 of $P$. solanacearum from Chile. The infected tubers when cut across and squeezed release greyish-white bacterial ooze. The pathogen survives in seed-tubers. The infected tubers on storage continue to rot and hence become unsuitable for seed purpose. Infected and surface contaminated seed-tubers serve as the primary source of infection in the field (Singh 1992).

Control measures : The disease can be controlled by planting clean tubers and seed material. In epidemic areas, seed-tubers should be treated with $0.2 \%$ streptocyline for $30 \mathrm{~min}$ after giving $5-\mathrm{mm}$ deep cut. No resistant varieties are available. 


\section{Common scab, c.o. Streptomyces scabiei (Thaxter) Lambert and Loria, 1989}

Scab is a common field disease. But may spread in storage under favourable environment. The greatest loss due to the disease is the reduction in the market value of the tubers due to rough-and-blemished skin.

The disease is reported as a problem to seed-potato production in the north-western zone of India; $80-100 \%$ of tubers were found severely infected. The disease is introduced into new areas and fields through infected seeds (Vashisth 1977).

Symptoms : Two types of lesions are generally seen. They are shallow and deep lesions. In shallow scab, the affected tubers show superficial roughened areas, and sunken below often is the plain of healthy tissue. The lesions consist of corky tissues that arise from abnormal proliferation of periderm cells due to pathogen attack. In deep-pitted scab, lesions are 1-3 mm or more in depth and are darker in comparison to shallow scab. These lesions are corky and may coalesce to cover entire surface.

The disease is significantly reduced when soil $p \mathrm{H}$ is brought below 5.2. Watering suppresses disease by increasing activities of antagonistic bacteria (Bacillus subtilis). Green manuring with soybean or by including it in crop rotation also increases population of antagonistic bacteria. Superphosphate also reduces scabbiness.

Control measures : In India, no resistant varieties are available. Tubers with deep lesions should not be used for seed purpose. Tubers can be disinfected by keeping in $0.25 \%$ suspension of a mercurial fungicide like Emissan- 6 or Agallol-6 or Aretan for $10 \mathrm{~min}$. Elemental sulphur application to soil reduces $p \mathrm{H}$ and hence is recommended for use. Penta chloro nitro benzene (PCNB/ Brassicol at 20-30 kg/ha) is also effective in controlling scab as well as black scurf. Resistance to common scab has been observed in red-skin varieties like Kufri Sindhuri and in some hybrids of Solanum andigena $\times S$. tuberosum (Singh 1992).

Seed-potatoes infected with scab (Streptomyces acidi scabies) were disinfected with streptocycline (200 ppm) and copper fungicide $(0.5 \%)$. This combination was also reported to be effective for controlling seed-potato scab, caused by S. turgidi scabies (Souma et al. 2002).

Cool chamber technology has been identified as a low-cost storage technique to preserve freshness of farm products. Total inhibition of sprouting in potatoes for three months with minimum physical loss in weight was achieved through treatment with iso propyl $\mathrm{N}$-(3-chloro phenyl carbonate) at $50-100 \mathrm{mg} / \mathrm{kg}$ of potatoes before storage in the cool chambers (Anon. 1997).

\section{TOMATO (Lycopersicon esculentum Mill.)}

Tomato contains carotene and most powerful antioxidant,lycopene. Lycopene offers protection against sunburn and harmful ultra-violet rays. 
Storage losses in tomato are caused by rotting, senescence and physiological loss in weight. About $20 \%$ of loss is estimated to be caused by fungal diseases. Tomato fruit-rots are of global occurrence. They were reported from Florida (Gonzalez and Owen 1962), Texas (Ashworth and King 1962), Nigeria (Adisa 1985), and from many states in India.

\section{FUNGAL DISEASES}

\section{Buck eye-rot, c.o. Phytophthora nicotianae var. parasitica}

The disease was reported from several parts of the world. Critopoulos (1954) recorded symptoms due to three species of Phytophthora-P. capsici, $P$. drechslera and $P$. parasitica. Of these, $P$. capsici is considered the most vigorous type, as it affects rapid decay by forming a compact tuft of sporangia and mycelia over the fruit-surface. The disease was serious in Solan (Himachal Pradesh) (Jain et al. 1958), Bengaluru (Sohi and Sokhi 1972 ), Ooty (Sokhi and Sohi 1974) and Ranchi (Gupta et al. 1989). Madaan and Ullasa (1990) in a survey on farms, markets and processing units in Karnataka observed buck eye-rot as the major disease.

The fungus also causes damping-off in the nursery and collar-rot as well as blossom-blight on the adult plants in Himachal Pradesh (Sharma and Sohi 1975). Symptoms are common on the fruits that are in close proximity to soil, and appear subsequently on to the fruits above the ground level. Infection is caused by water-splash or by contact with soil. Lesion development on fruits coming in contact with soil was common in Mexico (Fernandez et al. 2003).

Symptoms : Brownish circular spots are formed on the immature fruits at the blossom-end. The concentric rings resemble markings on a buck eye-nut. The spots may be small or may cover a major portion of the fruit-surface. There is no rotting of peel, but internal pulp may be discoloured up to the core. The fruits remain firm and retain their shape till they are spoiled by saprophytic fungi (Sokhi and Sohi 1982; Singh 1992). Variation in symptoms is also common. Grey-coloured lesions surrounded by water-soaked areas are common on tomato-fruits. When green fruits are attacked, they show brownish circular spots at the blossom-end, and subsequently they get shrunk and mummified.

Buck eye-rot of tomato does not occur in the dry weather (Sharma et al. 1980). High soil moisture is required for disease development. Infection occurs only when the host cells are gorged with water. Fruits in contact with the soil, which has been saturated for about 12 hours, get infected. The fungus attacks at a temperature as low as $13^{\circ} \mathrm{C}$ and as high as $35^{\circ} \mathrm{C}$; the optimum is between 24 and $30^{\circ} \mathrm{C}$. At Solan( Himachal Pradesh), it was observed that local temperature during cropping season was not important. The disease incidence was affected with the amount of rainfall. Fruit-rot occurs only when fruits come in contact with the infested soil. After infection, spores produced on 
fruits are carried by wind, water and other agencies to other fruits. The disease is not generally seed-borne, although fruits are infected. But, Sharma and Sohi (1975) observed mycelia remaining viable inside the seed for more than 1 and $1 \frac{1}{2}$ years. Infected seeds do not germinate. Alcock (1931) also reported seed-borne nature of P.parasitica on tomato.

Control measures : Certain cultivars are resistant to fruit-rot. Buck eye-rot on tomato is a serious disease in the hilly areas of Tamil Nadu, Himachal Pradesh and Karnataka. Accessions LA 22.05 and LA 1428 were recorded as resistant (Kumar et al. 1997). The disease resistance is reported to be controlled by a dominant gene (Rattan and Saini 1979; Sokhi 1994). High soil moisture favours infection. The fungus remains viable for more than 2 years in the soil (Sharma et al. 1980), and this is correlated with high ascorbic acid content of fruits. Spraying crop with Difolatan (0.3\%) is effective in checking disease incidence (Sokhi and Sohi1982). Fungicides impregnated wrappers did not show promising results (Ullasa 1990). Fungicidal sprays with Ridomil MZ (0.2\%) and Dithane M-45 (0.25\%) (Verma et al. 1994) and copper oxychloride (0.2\%) (Bhardwaj et al. 1995) were reported to be effective.

\section{Fusarium-rot, c.o. Fusarium spp.}

The disease was recorded on leaves and stems also. Preston (1943) recorded Fusarium occurrence on the stems of tomato-plants from the UK. Later Stevens and McColloch (1947) recorded fruit-rot from the USA. Thirumalachar and Misra (1953) also recorded leaf-spot of tomato from Bihar. Damping-off in the nursery was also recorded (Ganesan and Sinha 2002).

Madaan and Ullasa (1990) considered this as the major fruit disease, next to buck eye-rot in Karnataka. F. moniliforme was reported as early as 1936 by Wollenweber and Hochapfel and later by Khanna and Chandra (1975a).Several species of Fusarium have been found associated with ripe and stored tomatoes-fruit-rot due to F. nivale (Thakur and Yadev 1971), F. semitectum (Bilgrami and Verma 1979; Nedumaran and Vidhyasekaran 1982), F. solani (Garg and Gupta 1979; Sharma and Sumbali1993), F.roseum (Thomas et al. 1981); and dry-rot due to F. equiseti (Adisa 1985; Sharma and Chaudhary 2004). But in Solan under storage, Thapa and Sharma (1976) observed negligible losses by fruit-rot, caused by Fusarium sp. F. solani and $F$. oxysporum were recorded usually on the fruits reaching Thiruvananthapuram markets (Kerala) from Bengaluru and Coimbatore (Reeny 1995). Fusarium sp. was also recorded during storage (Pandey 2006).

Symptoms : Water-soaked lesions are initiated anywhere on the fruit-surface. They gradually increase in size and the tissues beneath them become depressed and sunken. Sometimes irregular cracking of fruits is also observed. Dirty white mycelia are seen along the cracks. Older lesions show white mycelia along the cracks. White to salmon-coloured cottony growth of the fungus consisting of profusely branched hyphae with spores is also noticed. As the 
disease progresses rapidly, inner tissues loose their turgidity, disintegrate, and a yellow juice with an unpleasant odour leaks out.

Tomikawa and Kobyashi (1990) reported that in varieties resistant to fruitrot, caused by $F$. oxysporum, fungus was not able to reach the ovary, as styles had dropped off much earlier.

Control measures : Khanna and Chandra (1976a) studied effect of 1-200 potencies of several homeopathic drugs on the spore germination of $F$. roseum, and observed its complete inhibition. Tomato-fruits given pre-and post inoculation dips with homeopathic drugs, Kali iodide 149 and Thuja occidentalis 87 showed no rotting on subsequent storage. Paper-liners impregnated with Carbendazim (Bavistin), Mancozeb and Captan and stored at $25 \pm 1^{\circ} \mathrm{C}$ were effective against rots caused by $F$. pallidoroseum and $F$. equiseti (Sharma 2006; Singh and Jain 2007).

\section{Phoma-rot, c.o. Phoma spp.}

Phoma destructiva Plowr causes fruit-rot in cold climate and fruit-rot as well as stem-blight in warm climate. Transit-and-storage rot was recorded by Srivastava and Tandon (1966), Hasija and Batra (1979) and Pankaja (1983). P. exigua and P.sorghina were also recorded (Reddy et.al.1980, 1984; Adisa, 1985). Along with Rhizoctonia solani, P. exigua was found aggressive and reduced complex carbohydrates to simple sugars within 6-8 days. Didymella lycopersici Kleb (Anamorph Phoma lycopersici Cook and Phoma destructiva)was also recorded as a causal agent of stem canker and fruit-rot (Jones and Burch 1988, 1988 a; Sharma and Chaudhary 2004).

Symptoms : Firm sunken lesions occur on any part of the fruit, but are mostly concentrated at the stem-end region as small, slightly depressed spots. Infected tissues become brown and later black. Minute black bodies representing pycnidia are produced over the peel, and in humid conditions, white or pinkish spores (conidia) ooze out in large numbers. The fungus persists in soil and on crop debris. Initial infection takes place when spores are splashed on to plants with irrigation. Lesions typically develop at the wound sites on the stem. Infection of fruits takes place via cracks formed on the stem and or through injuries, and results in rapid rotting and fruit-rot. Lesions on ripe-fruits are more conspicuous than on green fruits. In the field, lesions develop as small, circular, depressed water-soaked areas. Later, they become leathery with prominent pycnidia (Grover 1965). Fruits shortly before harvest appear healthy and sound but when packed, lesions develop during transit and storage.

Disease development is favoured by temperature between 15 and $35^{\circ} \mathrm{C}$, maximum being at $25^{\circ} \mathrm{C}$. Rate of rotting increases with increased relative humidity. Uninjured fruits are rarely attacked (Hasija and Batra 1979).

P. lycopersici Kleb was also reported as a storage pathogen (Sharma 2006). Vitamin $\mathrm{C}$ content as well as reduction in sugars and amino acids were 
recorded in fruits infected by $P$. exigua (Reddy et al. 1980, 1984). Production of cellulolytic enzymes (cx) was also recorded. Maximum quantity of enzyme was recorded on the $9^{\text {th }}$ day on fruits inoculated with $P$. destructiva that were kept at $10-30^{\circ} \mathrm{C}$. Infection is seed-borne. The pathogen persists in diseased crop debris also.

\section{Alternaria-rot, c.o. Alternaria spp.}

The disease was recorded from most tomato-growing countries like Canada, France, USA, Germany etc (Mc colloch and Worthington 1952; Stinson et al.1981; Blancard et al. 1984). The disease was reported from India also (Rao 1965; Kassim 1986; Gupta et al. 1989; Sharma and Chaudhary 2004; Sharma et al. 2004). The fungus causes dark olive-green spots on tomato. It also causes early blight symptoms on leaves. Storage-rot due to A.solani Soraeur was reported by Rao (1965), Mehta et al. (1975) and Kore and Gole (1990). Sharma and Sumbali (1993) conducted extensive surveys at whole sale, retail markets and at consumer level to assess various vegetable-rot causing fungi in parts of north India, and reported A.alternata to be responsible for causing dark olive-green rot on tomato. In Himachal Pradesh, Sharma et al. (2004) also observed $4.8-11.75 \%$ fruit-rot due to Alternaria-rot. Temperature range of $20-25^{\circ} \mathrm{C}$ was reported ideal for growth and sporulation, and no infection was observed at $0-5^{\circ} \mathrm{C}$. The fungus is a common inhabitant of soil and air, and survives on plant debris. Infection generally occurs through dead flower parts, insect injuries, cracks at the stem-end or on tissues weakened by sunscald, chilling injury etc.

Variability among isolates of Alternaria was also reported. Varma et al. (2007) reported morphological, pathological and molecular variabilities by random amplified polymorphic (DNA RAPD) technique.

Symptoms : Lesions may appear anywhere on the fruit-surface. Mostly they are concentrated at the stem-end or the blossom-end as black, circular or oval-sunken spots (Fig. 20.8). The inner tissues turn soft and become dark-brown to black with a cylindrical dry-core (Pearson and Hall 1973, 1975). Lesions of different

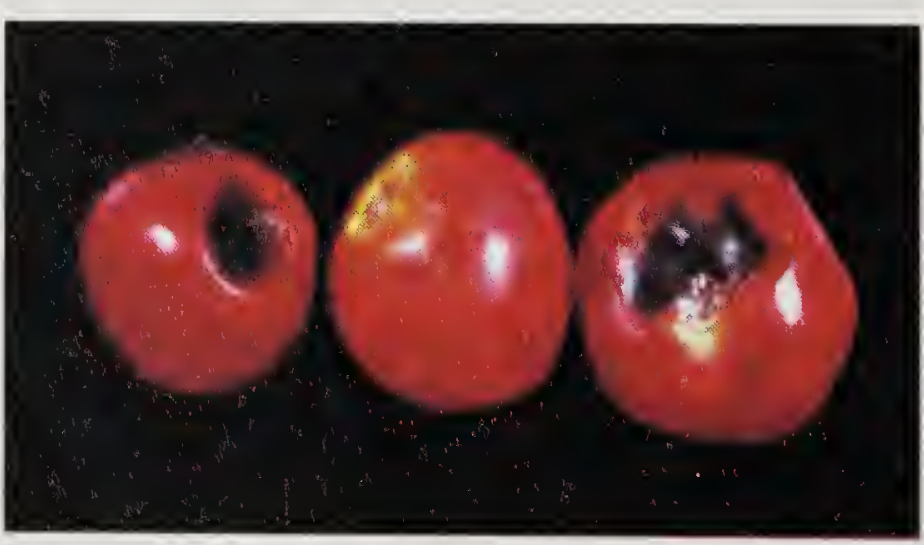

Fig. 20.8. Alternaria-rot on tomato diameter were also recorded by Zeitter and Wein (1984). Under humid conditions, dense, velvety olive-green spore masses were visible. Profuse sporulation of $A$.alternata was also noticed (Philip 1998).

Mehta et al. $\left(1975,1975\right.$ a) observed temperature of $28^{\circ} \mathrm{C}, \mathrm{RH} 100 \%$ and 4-8 days old inoculum as most effective for disease incidence. Metabolic changes as well as changes in the composition of sugars, organic acids, amino acids and phenolic substances were also reported. 
Control measures : Storage at $10-15^{\circ} \mathrm{C}$ offers satisfactory results. Chemical methods are available for controlling fruit-rot. Dharam Vir et al. (1967) observed efficacy of Aureofungin as a fruit-dip and a wrap-treatment in controlling fruit-rot during transit. Kassim (1986) reported use of Antracol $(0.2 \%)$ and Benlate $(0.2 \%)$ as pre-infection treatment. In general, non-systemic fungicides are recorded to be superior than systemic fungicides. Ruchisood and Sharma (2002) observed Indofil M-45 (at 250, 500 and 1,000 ppm) as the best protectant and eradicant, followed by Ridomil $(0.2 \%)$ or Captan $(0.2 \%)$ against fruit-rot.

Bavistin + Dithane M-45@100 ppm each, followed by Bavistin@200 ppm was effective in inhibiting fungal growth in Lattur. Trichoderma harzianum, T. viride and T. hamatatum were effective, but T. harzianum was the best in managing tomato early blight (Throat et al. 2005).

The fungus is seed-borne. Khulbe and Sati (1987) from Kumaon area identified on tomato-seeds several species of Alternaria, besides the common A. solani. This included A. tenuis, A. alternata, A. raphami and A. brassicae. The pathogan may survive on the infected crop residue. Since it is seed-borne, seed treatment is effective in eliminating infection.

Chandravanshi et al. (1994) made in-vitro studies with the commonly available non-systemic and systemic fungicides. Results showed that Carbendazim $(0.2 \%)$ persisted for 90 days.

\section{Rhizopus soft-rot, c.o. Rhizopus spp.}

The disease is of worldwide importance. But is commonly reported from tropical areas along with bacterial soft-rot and sour-rot (Mc Collach et al. 1968). R.stolonifer and $R$. arrhizus are the common pathogens (Thakur 1972; Thakur et al. 1974; Sonoda et al. 1982; Okoli and Erinle 1990; Sharma and Sumbali 1993; Reeny1995; Sharma and Chaudhary 2004). R. nigricans produces characteristic nests of rotted fruits (Eckert and Kolbezen 1962).

Symptoms: Disease symptoms may appear anywhere on the fruit-surface but concentrate mostly around injuries. The tissues become soft and water-soaked but not discoloured. Decay spreads throughout the fruit, which often ruptures with profuse leakage. Coarse white fungal growth with globular spore heads also appear profusely. Later entire fruit becomes ash-coloured. Humid conditions support copious growth of the fungus. The fruit collapses soon and a thick, viscous fluid oozes out (Philip 1998).

Control measures : Thakur et al. (1974) recorded 2, 4-D at $500 \mathrm{ppm}$ as an effective pre-infection treatment in inhibiting $R$. arrhizus growth. Use of growth regulators in low concentrations is also effective. Control with coconut oil, groundnut oil, palm-kernel oil as well as pure vegetable oil and liquid paraffin was also reported by Adisa (1955) from Nigeria. Mature ripe or half ripened tomatoes dipped in $75 \%$ palm-kernel oil and stored at $15^{\circ} \mathrm{C}$ gave protection against spoilage by $R$. oryzae, P.sorghina, C. lunata and F.equiseti. 


\section{Soft-rot/ Mucor-rot, c.o. Mucor hiemalis Wehmer Mucorsp.}

Mucor was reported by Reeny (1995) from Thiruvananthapuram. Softrot due to Mucor was also commonly noticed. Moline (1984) and Moline and Kuti (1984) made comparative studies with Mucor spp. from Czechoslovakia. They recorded $M$. piriformis on mature green and ripe- red tomatoes. The fungus causes maximum decay within 2-3 days, accompanied by a watery ooze.

Symptoms : Water-soaked lesions are noticed on the fruit-surface. They are later covered by white cottony growth of fungus. The disease causes extensive damage to tomatoes in storage.

Control measures : As detailed under Rhizopus soft-rot are applicable to this disease also.

\section{Cottony-leak/damping-off, c.o. Pythium spp.}

The disease was recorded from all the tomato-growing areas. Pythium aphanidermatum was recorded from the USA (Pearson and Hall 1973) and other countries including India (Tripathi and Grover 1977). Other Pythium species involved include P. myriotylium, P. arrhenomonas (Sonoda1973) and $P$. butleri (Sharma and Sumbali 1993).

Ganesan and Sinha (2002) and Pandey and Pandey (2005) recorded Fusarium oxysporum $\mathrm{f}$ sp lycopersicum, Sclerotium rolfsii, Rhizoctonia solani, Alternaria solani, Colletotrichum capscii and Macrophomina phaseolina in addition to Pythium in tomato nurseries as causal agents of damping-off.

Symptoms : Soft, water-soaked lesions may occur anywhere on the fruitsurface. The lesions enlarge rapidly until entire fruit is infected. Skin splits and profuse leakage occurs. The fungus is present in the soil, and infection occurs during wet-warm weather. The rotting is maximum at $25-35^{\circ} \mathrm{C}$. During transport and storage, infected tomatoes undergo a wet collapse (Ilag 1976).

Control measures : Seed and soil application of Trichoderma spp. and Gliocladium virens managed successfully damping-off of vegetables as is detailed in cucumber, pea (Sivan et al. 1984; Lifshitz et al. 1986; Sawant and Mukhopadhyay 1990; Hazarika and Das 1998). The biocontrol potential of Trichoderma viride as well as T. harzianum and G. virens of Asom and Tamil Nadu was evaluated against $P$. aphanidermatum, incitant of damping-off. Seed treatment with Asom strain of $T$. harzianum recorded highest seedling stand (Hazarika et al. 2000). Anandh and Prakasam (2001) reported effect of activated Trichoderma formulation in managing damping-off in tomato.

Rammoorthy et al. (2002) observed enhanced resistance in tomato and hot pepper to Pythium through seed treatment with flourescent pseudomonads. Pseudomonas fluorescens applied along with neem-cake recorded $50 \%$ increase in seed germination (Ganesan and Sinha 2002). 
Thiruvadainambi et al. (2004) also recorded disease control through seed treatment with $P$. fluorescens, followed by soil application with farmyard manure.

Biological control with different species of Trichoderma showed T. viride as the best against F.solani, S. rolsfii and P.aphanidermatum in tomato, followed by T.virens. In soils with mixed infection, T. konengii and Bacillus subtilis resulted in best seedling emergence (Pandey and Pandey 2005).

\section{Soil-rot/Rhizoctonia fruit-rot, c.o. Rhizoctonia solani Kühn}

The disease occurs on the fruits which are in the close proximity of the soil; and infection occurs during transport and storage also (Gonzalez and Owen 1962). The injuries sustained during harvest, transit and storage play a key role in the development of symptoms during storage. Thapa and Sharma (1976) recorded negligible losses from Solan, while Rajkumar (2000) recorded this fungus to be frequently associated with fruit-rots in the Thiruvananthapuram markets.

Symptoms : Lesions formed are circular with a dark border and a pale centre. Within two days, splitting of fruit-skin occurs in all directions and the fruit- surface gets covered with dense flocculent mycelia (Fig. 20.9). Profuse growth of sclerotia is also noticed. Inner tissues also become soft and watery. Reddy et al. (1980, 1984) and Reeny (1995) recorded fungus from rotten tomato-fruits also.

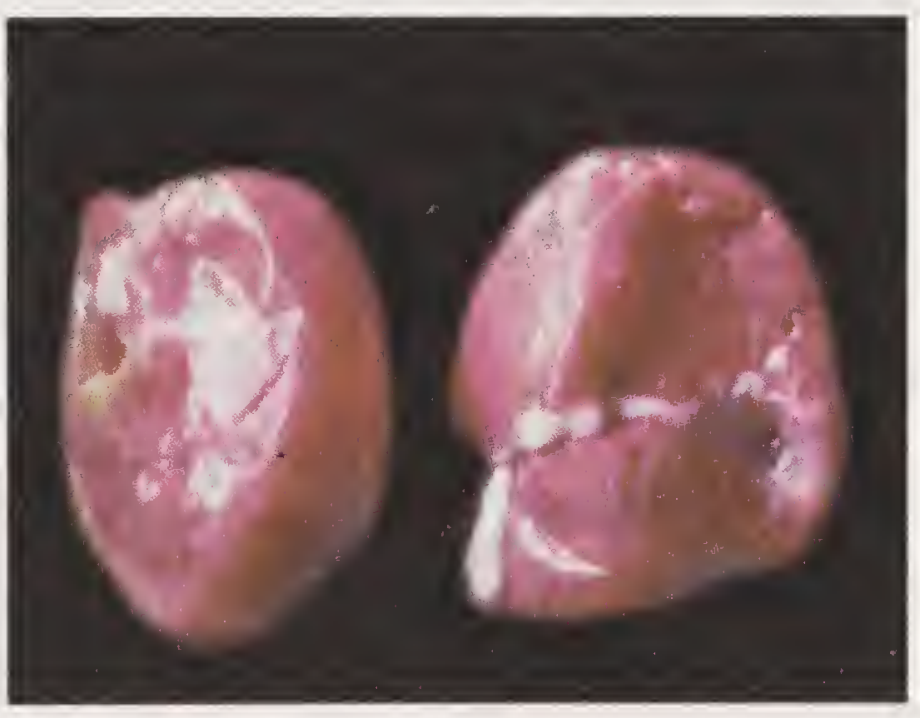

Fig. 20.9. Rhizoctonia fruit-rot Changes in the levels of sugars, amino acids and vitamin $C$ were also observed.

Control measures : Care should be taken that fruits do not touch the soil. Ashworth and King (1962) observed reduction of damping-off caused by $R$. solani in nurseries raised on beds covered with polyethylene sheets.

\section{Sour-rot, c.o. Geotrichum candidum Link.}

Butler (1960) reported high losses due to this disease. Mc Colloch et al. (1968) recorded the disease to be common in the tropical regions. The fungus was reported on many other fruits, besides tomatoes (Shankhpal and Hatwalne 1974). In India, the disease was reported by Jamaluddin et al. (1971, 1975); Shankhpal and Hatwalne (1976); Madaan and Ullasa (1990); Okoli and Erinle (1990); and Sharma and Chaudhury(2004). The morphology, pathogenecity and aggressiveness of the two isolates-G. candidum and G. penicilliarumwere studied by Mall and Mall (1982) and Moline (1984). G. candidum was observed to be virulent and pathogenic even though fungus was considered a weak parasite that colonized broken/ruptured fruits. 
Symptoms : At first, water-soaked lesions appear, mostly around the stem-end region. After 2-3 days of infection, fungal growth is observed in the form of white-waxy powdery growth that causes typical starshaped cracks (Fig. 20.10). The fungal spores are carried to healthy fruits by common fruit-fly, Drosophila melanogaster (Butler

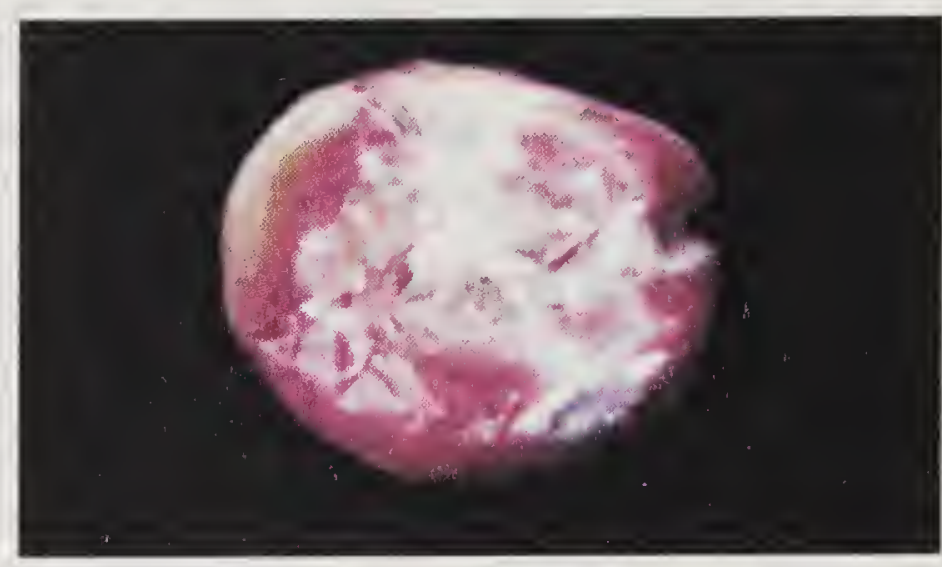

Fig. 20.10. Geotrichum-rot (advanced stage) on tomato 1961; Philip 1998; Rajkumar 2000).

The fungus survives at a temperature range of $10-35^{\circ} \mathrm{C}$ with a maximum rotting at $25^{\circ} \mathrm{C}$; minimum or no rotting at $10^{\circ} \mathrm{C}$ and below (Tandon et al. 1974).

Control measures : The latex of Euphorbia hirta has been found effective against this fruit-rot and fruit-fly Drosophila buskii, which carries spores to healthy fruits. The latex acts as a repellent (Purnima and Saxena 1990).

\section{Aspergillus-rot, c.o. Aspergillus spp.}

The disease due to A.niger is common under tropical conditions and is observed on the fully ripened fruits (Kassim 1986). The disease spreads through contact.

Symptoms : Water-soaked lesions appear on the affected fruits. The affected skin ruptures and produces open lesions, which are covered with black spores. The inner tissues become soft, develop rot and convert into a soft pulpy mass. Rotting was also observed (Pandey 2006).

Rotting due to A.flavus was recorded by Reeny (1995). Initially, the rot starts as water-soaked lesions that rupture the skin and juice with a fermentative odour leaks out (Fig. 20.11). The tissues become soft and mycelia with greenish sporulation are observed on the infection site. From Nigeria, infection due to A. flavus and A.fumigatus was recorded by Adisa

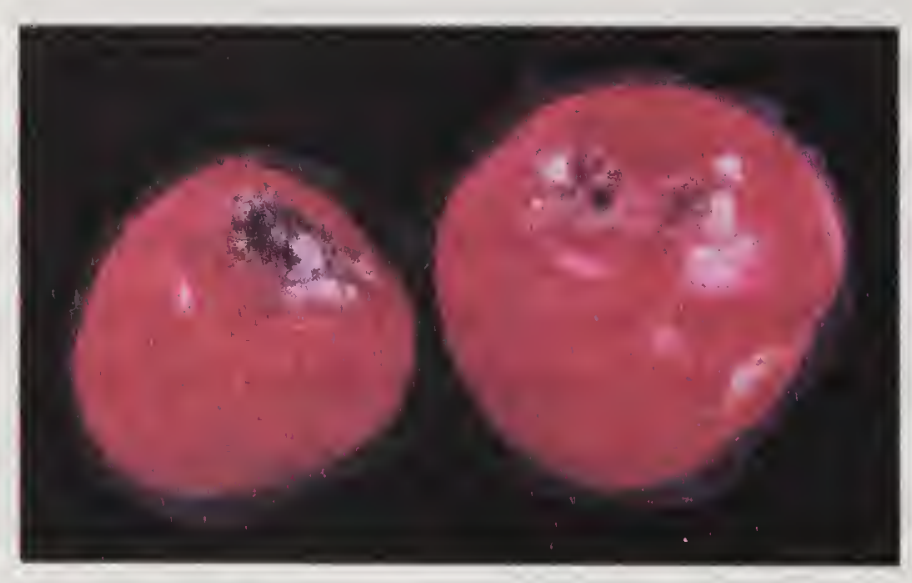

Fig. 20.11. Aspergillus-rot on tomato (1985) and both moulds in vivo were found to produce pectinolytic enzymes, polygalacturonase and pectin methyl transeliminase. Similarly, they produced amylases and cellulolytic enzymes. Maximum production of both enzymes by A. flavus was at $25^{\circ} \mathrm{C}$ and $p \mathrm{H} 6.8$ and by $A$. fumigatus at $35-40^{\circ} \mathrm{C}$ and $p \mathrm{H} 7.0$.

Control measures : The crude water extract of Withania somnifera was recorded as effective. The extract showed potentiality of controlling fungus and its vector Drosophila buskii (Purnima and Saxena 2002). 
Ring-rot/Myrothecium-rot, c.o. Myrothecium roridum Tode ex Fr.

Ring-rot usually causes losses in outdoor and greenhouse crops. The disease was recorded to cause losses in Cuba, Mexico, USA etc. Madaan and Ullasa (1990) reported the disease from Bengaluru, Karnataka along with several other fungi.

Symptoms : The disease appears on the fully ripened tomato-fruits. The diseased area gradually increases in size and gets covered by copious growth of concentric circles of white woolly mycelia, followed by dark-green zone of sporodochia with viscid spore mass. The junction between the healthy and diseased areas remains clearly well defined (Tandon and Srivastava 1963; Gaur and Pathak 1979).

Tomato is an important source of vitamin $\mathrm{C}$ (ascorbic acid), and reduction in ascorbic acid content was noticed due to infection by $M$. roridum (Jamaludeen et al. 1974). Kapoor and Tandon (1969) observed similar results with tomato infected by Drechslera australiense.

Control measures : Seed treatment with Captan/Thiram (0.2\%) controls seedborne infection.

\section{Sclerotium-rot, c.o. Sclerotium rolfsii Sacc.}

In Gaya (Bihar), a loss exceeding 10\% in yield was recorded. Fruits remaining in contact with the soil are mostly affected.

Symptoms : The fruit is covered by white mycelial fungal growth. Soon the mycelia get blighted, turn brown and produce sclerotia in abundance. By this time, the fruit becomes soft and cracks open with a watery exudate. Rotting is restricted to narrow zone of the green fruit. Temperature range of $25-30^{\circ} \mathrm{C}$ was recorded as optimum for rotting (Prasad et al. 1984, 1988) under conditions prevailing in Gaya. It was also recorded by Ganesan and Sinha (2002) and Sharma and Chaudhary (2004).

Control measures are as detailed under Soil-rot/Rhizoctonia fruit-rot. Fruits should not be allowed to touch the soil.

\section{Cylindrocladium-rot, c.o. Cylindrocladium scoparium Morgan}

Jamaludeen et al. (1974 a) and Jamaludeen (1977) observed disease in a serious form from the local markets of Allahabad. About 20-25\% of the fruits rotted within 10 days of infection. Under natural conditions, the infection is observed through stem-end as well as from skin-cracks in the ripe fruits. The disease is severe from December to March.

Characteristic disease symptoms, small, circular soft areas appear on the fruit. As the decay progresses, some light-brown mycelia changing to darkbrown with age as well as hyaline conidia appear over the infected areas. The entire fruit gets covered within two weeks. The mycelial coating becomes compact on the fruit-skin, and the inner tissues turn soft and ultimately fruits shrivel and rot. Rotting of fruits is most severe at $25-28^{\circ} \mathrm{C}$. The growth and 
sporulation of the fungus is favoured by the vitamin, thiamine. The disease is of minor importance.

\section{Cladosporium-rot, c.o. Cladosporium spp.}

Several species of Cladosporium are found associated with storage-rot. These include Cladosporium oxysporum, C. herbarum, C. sphaerospermum, C. cladosporioides and C. fulvum (Coursey and Booth 1972; Singh et al. 1987; Sharma and Sumbali1993; Sharma and Chaudhuri 2004). C. herbarum was recorded on tomato from Italy and Norway and on peppers in the USA (Ramsey and Heiberg 1952).

Symptoms : Lesions on the fruits are at first circular, firm, sunken and jetblack with sharply delimited pale-brown border. Under humid conditions, copious growth of brownish green to black spores is noticed. Maximum infection is recorded at $30^{\circ} \mathrm{C}$ and $95 \%$ relative humidity.

Control measures : Pre-infection treatments with Captafol (0.2\%), Captan $(0.2 \%)$, Benlate (Benomyl) $500 \mathrm{ppm}$ and Blitox-50 (0.5\%) were found effective in reducing storage-rots by $75 \%$. Spraying fruits with different oilsoap emulsions is also recorded as effective in maintaining firmness of fruits and also freshness for 5-10 days longer. Differential toxicity of oils to fungi was also reported.

\section{Irregular target-spot, c.o. Phomopsis fusiformis, N.C. Mandal and M.K.Dasgupta sp.nov.}

The perfect stage of Phomopsis, viz. Diaporthe phaseolorum var. sojae (Lehmann) Wehmeyer was reported on tomato from the USA (Lutterell 1947). Phomopsis spp. was recorded by Coursey and Booth (1972) also.

Symptoms : Soft-water soaked lesions appear near the pedicel-end and later enlarge up to $3-4 \mathrm{~cm}$ in diameter. The centre becomes pale to amber and occasionally brown to dark-brown. Irregular zonations are observed. The affected fruit becomes shrivelled, slightly wrinkled and cracked. Fungus growth is visible on the infected surface (Mandal and Dasgupta 1984). The disease is of minor importance.

\section{Watery soft-rot, c.o. Sclerotinia sclerotiorum (Lib.) de Bary}

Ginoux and Blancard (1984) reported the disease from France.Lesions appear anywhere on the fruit surface. Under warm moist conditions, lesions are enveloped sooner by white fungal growth. At first, white, irregular shaped bodies representing sclerotia develop with white exuding drops of liquid. Later they become black, dry and hard. The fungus is present in the soil. The disease is not common in Indian conditions.

\section{Fruit-spot, c.o. Corynespora cassiicola (Berk.\& Curt.) Wei}

The fungus generally causes leaf-spots on tomato. Fruit infection is also common. Winds and rains perpetuate the disease. Lesions on fruits appear as 
small necrotic pits or freckles (Volin and Pohronezny 1989).The disease was reported from Florida also.

Control measures as detailed in Cladosporium-rot are applicable here also.

\section{Botrytis-rot, c.o. Botrytis cinerea Pers.ex Fr.}

This is considered as a major disease in the temperate countries. The disease is also known as ghost-spot (Botryotinia fuckeliana de Bary Whetzel, Anamorph: Botrytis cinerea). The disease was reported from the UK, US and Netherlands. Barkai-Golan et al. (1990) observed stimulation of ethylene production in fruits by $B$. cinerea and Geotrichum candidum infection in normal and non-ripening tomatoes. Inoculation of fruits at the time of harvesting with the above-mentioned pathogens stimulates ethylene production, which in turn hastens the development of symptoms.

Symptoms : Pale circular haloes are noticed on the shoulder of the fruit. At the centre of each halo, a dark point often raised may be apparent. Numerous lesions are visible. The conspicuous symptom is the roughness of skin.

Control measures : Fallikk et al. (2002) from Israel reported hot-water rinsing $\left(52^{\circ} \mathrm{C}\right)$ and brushing (HWRB) effective in reducing decay and chilling injuries. The treatments also enhanced resistance of fruits against $B$. cinerea. Application of hexanoic acid to tomato-plants was reported to be effective in post-infection control of B. cinerea (Leya et al. 2008).

The fungal antagonist Ulocladium atrum has been recorded as a promising candidate for control of B. cinerea (Kohl and Molhoek 2002).

\section{Pink mould-rot, c.o. Trichothecium roseum Link. ex Fries}

The disease is generally considered as of minor importance. Occasional losses in greenhouse crop were reported from the USA (Welch et al. 1975). It was reported by Jamaluddin and Tandon (1976) from Allahabad. The infection starts from the stalk-end of the fruits and causes pale-vinaceous pink growth on the surface. In the final stage, fruits become pulpy, and spore-laden juice with a disagreeable odour oozes out. Nearly 10\% damage was recorded in Red Currant.

\section{Choanephora-rot, c.o. Choanephora cucurbitarum (Berk. \& Rav.) Thaxter}

Star-shaped cracks appear on fruits in the early stages of infection. Centre of the infection becomes depressed and soft. The skin gets easily loosened from the pulp with a white scanty superficial growth. As the lesions advance, secondary infection by saprophytic fungi occurs (Reeny 1995).

Control measures as detailed under Rhizopus-rot are applicable to this disease also.

\section{Septoria leaf-spot/fruit-rot, c.o. Septoria lycopersici Speg.}

The disease is of worldwide distribution. It causes defoliation and fruitrot. The fungus is seed-borne. It also persists on the infected crop refuse. Seed 
treatment and foliage spray was reported to keep disease under check (Suryanarayana 1978).

\section{OTHER DISEASES AND THEIR CAUSAL ORGANISMS}

\begin{tabular}{|c|c|c|}
\hline Disease & Causal organism & Authority \\
\hline \multirow[t]{2}{*}{ Fruit-rot } & Drechslera australiense & $\begin{array}{l}\text { Kapoor and Tandon, 1969, } \\
\text { 1969a, } 1970\end{array}$ \\
\hline & $\begin{array}{l}\text { Chaetomium brasiliense } \\
\text { Monoascus rubber }\end{array}$ & Rath et al., 1990 \\
\hline Anthracnose & $\begin{array}{l}\text { Colletotrichum capsici } \\
\text { (Syd.) Butler and Bisby } \\
\text { C. phomoides (Sacc.) } \\
\text { Chester } \\
\text { C.gloeosporioides Penz. }\end{array}$ & $\begin{array}{l}\text { Thapa and Sharma, 1976; } \\
\text { Gupta et al. 1989; Sharma } \\
\text { and Choudhary, 2004; } \\
\text { Pandey, } 2006\end{array}$ \\
\hline Pleospora-rot & Pleospora lycopersici & Coursey and Booth, 1972 \\
\hline Stemphylium-rot & $\begin{array}{l}\text { Stemphylium vesicarium } \\
\text { S. botryosum Wallr }\end{array}$ & $\begin{array}{l}\text { Bartz, 1962; Chary et al., } \\
\text { 1980; Blancard,1992 }\end{array}$ \\
\hline Nigrospora-rot & $\begin{array}{l}\text { Nigrospora (Khuskia) } \\
\text { (Berk. \& Br.) Petch }\end{array}$ & Chary et al., 1980 \\
\hline Curvularia-rot & $\begin{array}{l}\text { Curvularia lunata (Walker) } \\
\text { Boedijin }\end{array}$ & Adisa, 1985 \\
\hline Blue mould-rot & $\begin{array}{l}\text { Penicillium digitatum } \\
P . \text { auranteogriseum } \\
\text { Penicillium sp. }\end{array}$ & $\begin{array}{l}\text { Kassim,1986; Shrivastava } \\
\text { et al., 1993; Pandey, } 2006\end{array}$ \\
\hline Bipolaris-rot & Bipolaris spicifera & Sharma and Sumbali, 1993 \\
\hline Cylindrocarpon-rot & $\begin{array}{l}\text { Cylindrocarpon } \\
\text { tonkinense }\end{array}$ & Jamaluddin, 1976 \\
\hline Stem-end-rot & Didymella lycopersici Kleb & $\begin{array}{l}\text { Sharma and Choudhury, } \\
2004\end{array}$ \\
\hline
\end{tabular}

\section{BACTERIAL DISEASES}

\section{Bacterial soft-rot,}

c.o. Erwinia carotovora (Jones) Holland (Arsenjevic and Stojic1973)

Pseudomonas aeruginosa, $P$. marginalis and $P$. syringae pv. tomato

Symptoms : Lesions on the fruits are initially soft and slightly depressed with water-soaked margins. Rotting becomes rapid and skin crumbles and splits with profuse leakage. The bacteria are found in soil and in plant debris and are disseminated by wind, water, insects and human-beings. Infection may occur through wounds in the skin or through cut-ends. Heavy rains increases likelihood of infection. Water condensing on the packed fruits results in increased bacterial decay, as that helps in easy dissemination.

Control meausres: Vigneautt et al. (2000) observed tomato-fruits hydrocooled with a suspension of $E$. carotovora subsp. carotovora, containing 
50-200 mg of free chlorine/litre at $p \mathrm{H} 7$ free of decay for ten days at $20^{\circ} \mathrm{C}$ storage.

\section{Bacterial fruit-rot, c.o. Corynebacterium michiganense (E.F. Smith) Jensen}

Symptoms : The bacterium causes brown streaks on the stem and necrotic lesions on the leaves, wilting of the plants and cankerous lesions on the fruits, which ultimately rot. On green fruits, infection causes water-soaked spots, which get surrounded with a halo, resulting in fruit-rot in transit and storage. Local dissemination occurs from open cankers.

The bacterium is seed-borne, and 7\% infection was recorded (Nedumaran and Vidhyasekaran 1982a). Infected seeds showed less viability (7-15\% reduction) with reduced seedling vigour. The infected seeds when sown in a non-infested soil, spread pathogen in the new area, and may survive in the soil for several years (Neergaard 1977).

Control measures : Rotation with non-solanaceous crops is useful. Keep the fields free of weeds by cultivating. Avoid overhead irrigation; instead use drip irrigation or soaker hoses for watering.

Bacterial-spot, c. o. Xanthomonas campestris pv. vesicatoria (Doidge) Dye

It is an important disease of tomato and pepper, grown under warm humid conditions (Goode and Sasser 1980; Ramoss and Volin 1987).

Symptoms : Dark, raised spots appear on the infected tomato-fruits and each spot is surrounded by a water-soaked border. As lesions enlarge, margins aquire a lobbed appearance. Meanwhile the centre disintegrates and sinks down to form a fibrous pit. The bacterium attacks all the above-ground parts, including fruits.

Distribution of pathogenic groups and races in X. campestris pv. vesicatoria in India was studied in detail by Chand et al. (1994), and categorized isolates into two pathogenic groups- $3.4 \%$ belonged to tomato group (XCVT) and $96.6 \%$ to pepper tomato group (XCVPT). All XCVPT isolates from tomato and pepper were specific to tomato and produced cankerous lesions.

Control measures : Three applications of Agrimycin-100 (15\% streptomycine and $1.5 \%$ terramycin) are effective in reducing disease intensity. Seed treatement is also effective (Patel et al. 1950; Kishun and Sohi 1982).

Small spots on fruits caused by Clavibacter michiganensis subsp. michiganensis were also reported.

\section{Seed microflora}

Stored tomato-seeds carried a wide spectra of fungal spores (Nazeema 1981). Alimova et al. (2002) recorded Aspergillus spp. and Penicillium spp. in abundance on seed-coats. Fusarium oxysporum, Stemphylium, Oospora 
latis, Sclerotinia sclerotiorum and bacterial spores of Pseudomonas sp. and Erwinia sp. were also recorded.

Control measures : Trichoderma harzianum was recorded with high antagonistic activity against all the above-mentioned pathogens. Greatest growth inhibition was observed after three days. Seed treatment with $T$. viride @ $0.4 \%\left(2 \times 10^{9} \mathrm{cfu} / \mathrm{g}\right)$, T.harzianum @ $1.0 \%\left(10^{9} \mathrm{cfu} / \mathrm{g}\right)$, P.fluorescens @ 1.0\% $\left(10^{9} \mathrm{cfu} / \mathrm{g}\right)$ and a mixture of P. fluorescens and A. niger@ 0.8\% $\left(3.28 \times 10^{8}\right.$ $\mathrm{cfu} / \mathrm{g})$ as well as Thiram $(0.2 \%)$ reduced post-emergence mortality and increased plant vigour and yield (Hooda et al. 2008).

\section{POST-HARVEST DISEASES MANAGEMENT}

Enhancement of resistance in fruits through the induction of defencerelated enzymes involved in the phenyl propanoid pathway is being attempted against Pythium in tomato and in hot-pepper.

- Providing good drainage in the nursery beds, avoiding thick sowing, and soil sterilization by steam, dry heat, formalin (40\% formaldehyde) are common practices. Soil solarization by exposure to sunlight helps controlling soil-borne diseases.

- Cool-chamber technology is identified as a low-cost storage technique, which helps preserve freshness of farm produce (Anon. 1997). Cool chambers help to increase shelf-life of tomatoes. Physiological loss in weight (PLW) is also less compared to low temperature storage.

- Fruit-rots caused by $R$. oryzae, Curvularia lunata, Phoma sorghina and Fusarium equiseti are controlled by storage at $10-15^{\circ} \mathrm{C}$ (Adisa 1985).

- Hydro-cooling before storage, followed by storage at $10^{\circ} \mathrm{C}$ for seven days, are reported to be effective.

- Hot-water rinsing and brushing (HWRB) is assuming importance in Israel, as it reduces chilling injury and enhances resistance against Botrytis cinerea in freshly harvested tomatoes (Fallik et al. 2002).

- Seed treatment with Thiram (0.2\%) protects seedlings against the attack of soil-borne pathogens. Kassim (1986) observed Antracol and Benlate ( $0.2 \%$ each) to be effective for pre-infection treatments. Singh et al.(1989) proved efficacy of Guzatine (100 mg a.i/litre) as a fungicide of low mammalian toxicity with no residual hazards.

- Fungicide impregnated paper-liners protect against storage-rots caused by Colletotrichum gloeosporioides, Cladosporium oxysposrum, Fusarium pallidoroseum, F. equiseti, Geotrichum candidum, Phoma lycopersici and Sclerotium rolfsii. Fruits kept in wooden boxes with Carbendazim (Bavistin) $500 \mathrm{ppm}$ or Mancozeb (Indofil M-45) impregnated tissuepapers and stored at $25 \pm 1{ }^{\circ} \mathrm{C}$ also showed promising results (Sharma 2006). 
- The biocontrol potential of Trichoderma spp. in damping-off disease has already been recorded. It has been documented that seed and soil application of Trichoderma spp. and Gliocladium virens managed damping-off on vegetables, cucumber, pea and tomato.

- Application of Pseudomonas fluorescens along with neem-cake recorded increased seed germination (Ganesan and Sinha 2002). Pandey and Pandey (2005) observed variable responses to biocontrol agents against soil pathogens in tomato.

- A combination of Bavistin $(0.05 \%)+$ stay fresh was found most effective in improving shelf-life and maintaining fruit quality for 17 days (Barua et al. 2010). 


\section{CHAPTER 21 \\ Legume Crops}

With the growing demand for nutritional security, legumes are becoming important as a plant-based source of proteins for human nutrition. Legumes are made up of $20-25 \%$ proteins and are rich in dietary fibres with little or no oil. Protein component of legumes is rich in essential amino acids like lysine and methionine, making them nutritionally complementary to cereals, which are deficient in these two amino acids. The important legumes-crops include the following.

GARDEN-PEA (Pisum sativum L.)

\section{FUNGAL DISEASES}

\section{Mycosphaerella/Ascochyta, \\ c.o. Ascochyta pinoides (Berk. \&Blox) \\ Mycosphaerella pinoides (Berk. \& Blox) Stone.}

The disease is of worldwide importance and may pose serious threat to garden-pea if weather conditions are favourable to it during the cropping season. Walker (1975) described three diseases of garden-peaMycosphaerella-blight, Ascochyta-leaf and pod-spot and Ascochyta foot-rot. The disease has been known in Europe for centuries. In the United States, Mycosphaerella-blight and Ascochyta foot-rot are most important. A.pisi, A.pinodella and M.pinoides were reported from Czechoslovakia (Moravick 1982).

Antigenic relationship among isolates of A. raibei (Uma Devi et al. 1991) and their variability (Singh and Madendra Pal 1993) were studied. Presence of five races in A. raibei on the basis of disease reaction on different host genotypes was reported.

Symptoms : Round, tan-brown spots, up to $9 \mathrm{~mm}$ in diameter, appear on the leaves, stems and pods. Spots on the pods are surrounded by a black and thickened edge having pale-brown centre. The fungus penetrates into seeds also. Heavily infected seeds remain small and shrivel up. Infection is seedborne. A. pinodella produces brown to purple, round spots on the pods, leaves and stems. The spots in this case are fewer with clear zonations. A. pisi also produces symptoms on the pods. All fungi are seed-borne, but can also survive 
on the diseased crop debris. When seed germinates, seedling tip dies and this serve as the substrate for fungal growth and subsequently produces pycnidia and conidia for furthur spread.

Cold weather with abundant moisture on leaves favour disease development. Frequent rains help building up of inoculum/epidemics. Relative humidity above $90 \%$ is most conducive. Elimination of seed-borne inoculum and destruction of crop refuse are of utmost importance.

Control measures : Seed infection can be controlled by soaking seeds in $0.2 \%$ Thiram/ Captan suspension for $24 \mathrm{hr}$ at $30^{\circ} \mathrm{C}$ (Suryanarayana 1978). Trichoderma harzianum (Chaudhary and Gangwane1989) and seed treatment with Captan, Thiram (all at $0.2 \%$ ) or with organomercurials give protection against seed-borne fungi (Hwang et al. 1991; Singh, 1992).

\section{Cottony white-rot /collar-rot, c.o. Fusarium spp.}

Fusarium-rot was reported from Kurukshetra and Karnal (Dhingra and Mehrotra 1980). Collar-rot disease of pea (Fusarium solani f.sp. pisi) causes heavy reduction in yield of green pods and grains (Maheswari et al. 1983).

Sympotms : Pods are infected with yellowish to creamy watery lesions, which become suppressed, and after 3-4 days are covered with white, fluffy growth. Fusarium semitectum Berk and Rav was isolated from infected lesions. Dasgupta and Mandal (1989) observed water-soaked bleached areas on pods during late winter due to F.oxysporum, which later turn greyish. The seeds become soft with brown markings on the seed-coat. White floccose fungal growth develops on the surface as well inside the pods. The rotten material produces offensive smell.

Control measures : Collar-rot could be controlled by integration of biological and chemical methods (Kumar and Dubey 2001). Isolates of Trichoderma viride, T. harzianum and Gliocladium virens (at $10^{6}$ spores $/ \mathrm{ml} / 10 \mathrm{~g}$ seed) along with seed-dressing fungicides were used. Seeds treated with Captan $(1 \mathrm{~g} / \mathrm{kg})$ $+T$. harzianum recorded good germination and least disease incidence along with highest green pod yield, which was similar with seeds treated with $T$. harzianum alone, T. harzianum + Thiram, Carboxin + G. virens and G. virens alone. Mishra et.al. (2002) observed chlamydospore based formulation of bioagents to be superior in shelf-life and bio-efficacy against soil-borne pathogens, including F.oxysporum.

For integrated management of pea diseases, Kapoor et al. $(2004$, 2006) reported use of two local bioagents, T.koningii and T.harzianum. Their concentration was maintained at $1-2 \times 10^{7} \mathrm{cfu} / \mathrm{g}$ of the formulation. For soil application, the bioagent was used @ $2.5 \mathrm{~kg} / 65 \mathrm{~kg}$ of FYM/ha. Integration of seed treatement with neem-based biopesticide Wanis $(0.2 \%)$ and T.koningii reduced pea root-rot/wilt disease complex (RRWC) at Palampur( Himachal Pradesh). T.harzianum was more effective against white-rot. Wanis $(0.1 \%)$ was 
highly effective against F.oxysporum $\mathrm{f}$ sp pisi and $F$. solani $\mathrm{f}$ sp pisi and Sclerotinia sclerotiorum.

\section{Soft-rot, c.o. Rhizopus oryzae}

This disease was recorded from West Bengal (Mandal and Dasgupta1981). It appears on physiologically weak and half-filled seeds. The decay appears in patches and starts on the pod, which becomes water-soaked, bleached, white and coarse with stringy mycelial growth on and within the pod. The seeds become soft and pods emit a soury fermentative odour. Sprinkling water on the green pods favours disease incidence. R.stolonifer was also reported on peas (Sharma and Sumbali 1993).

\section{Pod-rot/white-rot, c.o. Sclerotinia sclerotiorum (Lib.) de Bary Sclerotium cepivorum Berk.}

White-rot is rated as the most important disease, as it causes heavy losses in yield in different pea-growing areas of Himachal Pradesh and Rajasthan. Under favourable conditions, it causes total crop failure also.

Symptoms : White growth appears on the pods. Rotting of pods and seeds is common. The fungus was reported by Sharma and Sumbali (1993). Sharma and Kapoor (1997) recorded important epidemiological aspects of white-rot. Disease symptoms appear between 10 and $25^{\circ} \mathrm{C}$ (with optimum at $20-25^{\circ} \mathrm{C}$ ). The sclerotia survive for more than a year in the soil.

Control measures : Seed treatment with Bavistin $(0.1 \%)+$ Thiram $(0.2 \%)$ in $1: 1$ at $2.5 \mathrm{~g} / \mathrm{kg}$, and three fortnightly sprays with Bavistin, starting at flower initiation, provided excellent control (Suga 2000). Seed treatment with T.harzianum mixed with Carbendazim( $0.1 \%) @ 2 \mathrm{~g} / \mathrm{kg}$ of seed protected seedlings from pre and post emergence phase of mortality, resulting in $100 \%$ final stand of plants. And T.harzianum in combination with Captan $(0.2 \%)$ or Mancozeb (0.2\%) also recorded similar results (Khan et al. 2004).

Adams and Ayers (1981) recorded Sporodesmium sclerotivorum functioning as a biocontrol agent to S.sclerotiorum and S. cepivorum under natural field conditions. They observed that 100 spores/g of soil brought decline of S. sclerotiorum and S.cepivorum sclertotia under field conditions.

T. viride, T. hamatatum, T. viride isolate $\mathrm{B}$ and isolate $\mathrm{E}$ were mass multiplied on wheat-bran agar and spore suspensions were used for the study. The volatile and non-volatile metabolites of Trichoderma spp. significantly reduced mycelial growth and germination of S. sclerotiorum in the field (Kapil and Kapoor 2005).

Wanis, the neem-based biopesticide, at 0.5 and $0.1 \%$ concentration was effective in controlling $S$. sclerotiorum in fields.

Anthracnose, c.o. Colletotrichum pisi Pat.

This is considered as a minor disease. Brown spots appear on the leaves, 
stems and pods. The causal fungus survives on crop debris and seeds. The optimum temperature for infection is $20-24^{\circ} \mathrm{C}$. Control measures recommended for Ascochyta-blight are applicable to this disease also.

\section{Powdery-mildew, c.o. Erysiphe polygoni DC, E.pisi DC}

It is a common disease in several pea-growing areas of India, and was recorded from Maharashtra, Karnataka, Uttar Pradesh, Delhi and Himachal Pradesh.

Symptoms : Powdery white-spots appear on the upper side of the leaves and the corresponding portions underneath become chlorotic. Upper leaves fail to develop fully. Infection appears on pods, which shrivel and dry-up. The fungus survives as dormant mycelia below the seed-coat. Pre-soaking of seeds in cold-water for six hours, followed by hot-water treatment at $50^{\circ} \mathrm{C}$ for ten min have been suggested to check seed-borne infection (Suryanarayana 1978).

Control measures: Powdery mildew causes more damage to seed-crop than to vegetable-crop. Seed treatment with Carbendazim and sowing in October and November reduce disease incidence. Manipulations of sowing time are reported to reduce disease incidence in different localities (Sokhi 1994). Swarnamutki is considered as a powdery mildew resistant high-yielding garden-pea variety.

In Himachal Pradesh, the disease was controlled by field application of Bayleton $(0.025 \%)$ or Contaf $(0.025 \%)$ at the time of disease appearance, followed by $2-3$ sprays of Karathane $(0.05 \%)$. Seed treatment only delayed disease appearance (Banyal 2000).

\section{Downy-mildew, c.o. Peronospora pisi Sydow}

The disease is common in the Indo-Gangetic plain. It is also reported from Europe and North America.

Symptoms : They appear on leaves and on pods. The patches are pale-green, more or less elliptical with blotches on the sides of the pods and irregular elongated lesions are along the dorsal sutures of the pods. The seeds beneath the lesions are undersized and aborted. And the disease is primarily soil-borne.

Control measures : The primary inoculum is in the soil. Sanitation and crop rotation will help in reducing primary infection. Oospores present in the soil can be inactivated if rotation of two to three years is followed.

Seed treatment with Fosetyl aluminium or Metalaxyl (0.2\%) protect crop from early attack (David 1990).

\section{Alternaria blight, c.o Alternaria spp.}

The fungus is seed-borne. Dark patches are noticed on the seed-coat. Similar lesions on the cotyledons are also noticed. The radicle blights eventually. Reduction in germination is also noticed. Thiram $(0.2 \%)$ soak treatment is effective in reducing seed infection. 
Seed-rot, c.o. Aspergillus flavus Link. ex Fries (Rati and Ramalingam 1974)

This is responsible for non-emergence of seedlings. Seed-rot by Pythium spp. was also reported.

Control measures : Seeds should be dried to a moisture level of $7 \%$. Seed treatment with $0.2 \%$ Captan or Thiram is effective.

Seed-rot of pea in soil infested with Pythium spp. or Rhizoctonia solani is controlled with Trichoderma hamatum ( $10^{5}$ conidia/millilitre). The conidial suspension in water with a spreader and sticker is applied to seeds (Harman et al. 1981). Similar studies with Penicillium oxalicum against pre-emergence damping-off by the application of conidia (harvested from Zapek-Dox agar medium and applied directly to seeds) were also reported (Windels 1981).

Seed treatment with culture filtrate of Trichoderma (collected from the cultures grown on malt extract, washed with sterile water, sieved through cheese cloth and centrifuged) containing $3 \times 10^{8}$ conidia per mililitre was also reported as effective in controlling pre-emergence damping-off in peas (Liftshitz et al. 1986).

OTHER DISEASES AND THEIR CAUSAL ORGANISMS

\begin{tabular}{|c|c|c|}
\hline Disease & Causal organism & Authority \\
\hline Brown-rot & Humicola grisea & Sharma and \\
\hline Yellow-mould & Aspergillus flavus & Sumbali, 1993 \\
\hline Powdery-mildew & $\begin{array}{l}\text { Erysiphe spp. } \\
\text { Oidium spp. }\end{array}$ & \\
\hline Phytophthora-rot & $\begin{array}{l}\text { Phytophthora nicotianae } \\
\text { var.parasitica }\end{array}$ & Snowdon, 1991 \\
\hline Helminthosporium-rot & Helminthosporium victoriae & \\
\hline Septoria blight/blotch & Septoria pisi & \\
\hline Yeast-spot & Nematospora coryli parasitica & \\
\hline
\end{tabular}

\section{BACTERIAL DISEASES}

Bacterial blight, c.o. Pseudomonas syringae pv. pisi (Sackett) Young et al.

The disease was reported from the UK also(Ball and Reeves 1992). The disease is seed-borne, and is widely distributed throughout the world; up to $25 \%$ losses have been reported.

Symptoms : Water-soaked spots appear on the pods. The lesions retain their water-soaked or greasy appearance with little change in colour. The bacteria survive on crop residues and seeds, and are carried by irrigation water and water splashes created by rainfall or blown by moist-wind, and perpetuate disease.

Control measures : Avoid use of early-maturing varieties, as they are susceptible. Wide spacing between plants, proper drainage, removal of weeds and restricted irrigation help minimizing disease incidence. 


\section{VIRAL DISEASES}

\section{Pea mosaic, c.o. Pea mosaic virus (Osborn1935), Common pea mosaic virus, Red clover mosaic virus Zaumeyer (Raychaudhuri and Nariani 1977).}

Symptoms : The diseased plants look pale, weak and stunted,and flowering is delayed. Comparatively fewer pods are formed on the affected plants, which remain small in size and contain a few seeds (Sreenivasan and Nariani 1966).

Control measures : The virus is not carried through seeds. Losses due to the disease can be minimized by growing pea varieties, Canners Perfection, Horal, Hundredfold and Little Marval, which are resistant (Raychaudhuri and Nariani 1977).

Another viral disease of pea has been described from Uttar Pradesh. Its characteristic symptoms are streaking and necrosis of different plant parts. Pods developed during the period have purple spots or pits with a few underdeveloped seeds or none at all. Pods are smaller, generally underdeveloped, seedless and malformed. Association of Pea streak Carla virus was also recorded (Singh 1998).

\section{Seed mycoflora}

The following fungi are observed on the seeds.

\begin{tabular}{l|l} 
Cladosporium sp. & \\
Aspergillus spp. & Chapentie and Nicot, 1978 \\
Penicillium spp. & \\
Ascochyta sp. & \\
Fusarium solanif sp pisi & Harman et al., 1981 \\
Alternaria alternata & \\
Gliocladium virens & \\
Cladosporium cladosporioides & \\
C. herbarum & \\
Rhizopus stolonifer & \\
R. nigricans & \\
Pythium aphanidermatum & Verma and Dohroo, 2005 \\
P.ultimum & \\
Absidia cylindrospora & \\
Alternaria alternata & \\
Aspergillus flavus & \\
A. niger & \\
Penicillium sp. & \\
P. chrysogenum &
\end{tabular}

COWPEA (Vigna unguiculata (L.) Walp.)

Cowpea is cultivated throughout the country as a vegetable-pulse crop. During rainy weather, diseases attack all the aerial parts of the crop, and affect adversely pod quality and yield. 
Maheshwari and Mathur (1987) observed changes in proteins and in the content of the reducing and non-reducing sugars due to infection under different temperatures and relative humidities. In general, deterioration was maximum at higher temperature and relative humidity. Also infection by $A$. nidulans was more deleterious in comparison to $A$. terreus. Studies on the nitrate reductase (NR) and urease (UR) activities with seedlings raised from seeds infected by A. niger and A. flavus were made by Dayal et al. (2001); their activities had lowered significantly.

\section{FUNGAL DISEASES}

Dry root-rot, c.o. Macrophomina phaseoli (Tassi) Goid.

The fungus causes failure of seed germination and the seedling blights. The pathogen is seed as well as soil-borne.

Management of pea charcoal-rot was attempted using biocontrol agents and plant products by Ushamalini et al. (1997). Soil application with neemcake (Azadirachta indica)@150 kg/ha and farmyard manure (10 tonnes /ha) reduced charcoal-rot incidence significantly and increased yield by enhancing antagonistic activity of the native microflora. They observed increased seed germination by soaking in 10\% leaf extracts of Adenocalyma allinaceum and Vitis negundo. Neem showed medicinal, antifungal and pest-control properties (Desai and Kulkarni 2001).

Pelleting of cowpea seeds with Trichoderma viride either alone or in combination with Carbendazim inhibited $M$. phaseoli growth. The treatment increased germination and reduced post-emergence mortality under pot-culture experiments (Algarsamy and Sivaprkasam 1988). Seed treatment with Trichoderma viride and T. harzianum is also effective in addition to the above in reducing root-rot incidence.

\section{Myrothecium-rot, c.o. Myrothecium roridum Tode ex Fries}

Severe decay of cowpea pods was recorded from the local markets of Bhagalpur. The disease caused about $5-11 \%$ loss. The disease is common on moth-bean (Vigna aconitifolia) also (Singh and Srivastava 1989).

Symptoms : They appear as scattered discoloured lesions, that later cover the entire pod. The whole pod becomes rotten within 5-7 days. Heavily infected pods bear no seeds or less number of seeds that are smaller in size.

Control measures : Spraying Bavistin $0.1 \%$, starting with flower initiation, controlled the disease.

Anthracnose, c.o. Colletotrichum lindemuthianum $\mathrm{Br}$ \& Cav. (= Glomerella lindemuthiananum (Sacc. \& Mag. Shear)

Serious attack due to anthracnose was reported from Bengaluru (Sohi and Rawal 1977, 1984); disease affected adversely pod quality and yield. 
Symptoms: They are noticed on the emerging cotyledons as sunken black spots. Infected seedlings get blighted. Stems and leaves are also affected. Black stem cankers develop on the adult plants. Lesions appear on the pods, which later spread and cause pod-rot. Seeds get infected. Badly affected seeds show dark lesions and lightly affected show only discolouration. Lesions on seeds are not clearly visible on the varieties with dark seed coats. The disease organism is seed-borne, and fungus persists in the infected crop residues.

Control measures: Seed-borne infection can be partially controlled with Thiram or Captan (Suryanarayana 1978). Spraying Bavistin (0.1\%), Benomyl $(0.1 \%)$ and Difolatan $(0.3 \%)$ was found effective; this reduced infection and increased yield (Sohi and Rawal 1977).

Adebanjo and Bankole (2004) from Germany recorded biological control with isolates of Trichoderma viride and Bacillus subtilis; this reduced significantly seedling infection from the anthracnose-infested seeds in the potculture experiments.

\section{Pod-rot, c.o. Choanephora cucurbitarum (Berk.\& Rav.) Thaxter}

The disease was reported from Kerala, India (Wilson and Jose 1968).

Symptoms : Water-soaked areas appear on the pods, which later develop wetrot symptoms during storage. Young as well as mature pods are infected. Fungal whitish luxuriant growth is noticed in the advanced stages of infection. Black pinhead-like structures representing sporangia are also present in abundance. The disease is of minor importance.

\section{Cottony-leak, c.o. Pythium butleri Subram.}

The disease was recorded from the local markets of West Bengal. Rotting starts anywhere on the pod surface as water-soaked areas.

Symptoms : Affected pods turn slightly dull and coppery. Infection progresses very fast and pods may be affected overnight. Sprinkling of water by vendors over stored cowpea heaps to retain freshness accelerates decay. White fluffy mycelia wrap over heap. Seeds also become soft and rotten (Dasgupta and Mandal 1989).

Control measures : Refigerated storage at $10^{\circ} \mathrm{C}$ is effective. Rotted materials should not be mixed with healthy pods.

\section{OTHER DISEASES AND THEIR CAUSAL ORGANISMS}

\begin{tabular}{lll}
\hline Disease & Causal organism & Authority \\
\hline Leaf-spot & Cercospora canescens & Suryanarayana, 1978 \\
Snuffy mould-rot & Aspergillus aculeatus & \\
Cottony pink-rot & Fusarium moniliforme & Das Gupta and Mandal, \\
Fuzzy brownish-rot & Mucor hiemalis & 1989 \\
\hline
\end{tabular}




\section{Seed mycoflora}

Cowpea seed mycoflora has been studied from the different parts of the world. From Kerala, Nazeema (1981) observed Aspergillus niger, A. flavus, A.ochraceous and Botryodiplodia theobromae as externally seed-borne and also frequently associated. But fungi like Drechslera rostrata, Penicillium sp. and Rhizopus stolonifer were internally seed-borne. Nazeema et al. (1982) recorded $38 \%$ inhibition of cowpea seed germination on treating with culture filtrate of D. rostrata.

The following fungi were also reported.

\section{Curvularia sp.}

Drechslera sp.

Diplodia sp.

Chaetomium sp.

Pestalotiopsis sp.

Aspergillus sp.

Macrophomina phaseolina

Colletotrichum sp.

Kanapathi Pillai, 1982

from Malaysia

Aspergillus parasiticus produced the potent mycotoxin (Aflatoxin $\mathrm{B}_{1}$ ) in cultures (Seenappa et al. 1983) from Tanzania.

Aspergillus flavus

A.fumigatus

A. nidulans

A. niger

A.terreus

B. Fusarium moniliforme

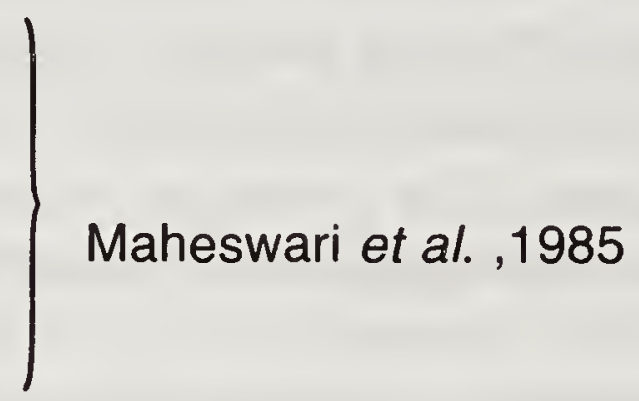

Seeds infected by Aspergillus flavus showed depletion of non-reducing sugars and increase in reducing sugars (Maheswari and Mathur 1985).

Aspergillus spp.

Penicillium spp.

Penicillium chrysogenum

Alternaria alternata

Fusarium spp.

Aspergillus flavus, A. niger

Curvularia lunata

Penicillium sp.

Macrophomina phaseolina

Fusarium oxysporum fsp. tracheiphilum

Alternaria alternata

Curvularia lunata

Aspergillus flavus, $A$. niger

Rhizopus stolonifer

Penicillium spp.

Muthe Gowda and Sullia,1987

Saad Shama et al., 1988

Ushamalini et al., 1998

from Tamil Nadu

Among the different fungi associated, M. phaseolina, F.oxysporum,

$A$. flavus and $A$. niger were predominant in terms of intensity and occurrence. 


\begin{tabular}{l|l}
$\begin{array}{l}\text { A.flavus } \\
\text { A.niger } \\
\text { F.oxysporum } \\
\text { F.equiseti }\end{array}$ & Kritzinger et al., 2002 \\
A.flavus & Usha et al. 2008
\end{tabular}

Use of essential oils (thyme and clove) on storage fungi, germination and emergence of cowpea seedlings recorded inhibition of growth of all associated fungi at 500 and 1,000 ppm level (Kritzinger et al. 2002).

\section{BACTERIAL DISEASES}

\section{Bacterial-blight/bacterial-spot/bacterial-canker,}

\section{c.o. Xanthomonas axonopodis pv. vignicola}

The disease is prevalent in India under the natural conditions. Infection starts from leaf margins, indicating entry of bacteria through hydathodes. This is followed by typical blight symptoms.

Symptoms : In case of severe infection, brown cankerous lesions are noticed on the stem, peduncle and inflorescence. Pods may show discolouration in the affected regions. The diseased pods produce smaller, wrinkled and infected seeds. Seeds show symptoms on the emerging cotyledons. The affected cotyledons turn reddish and wrinkled, followed by necrotic lesions on the stem and leaves. Growing tip of the plant dies resulting in the death of the plant. Control measures : Infection is seed-borne. It is both external and internal. Variability in growth and pathogenicity of bacteria was recorded by Singh $e t$ al. (2000). Resistant varieties are not available. Use of healthy seeds is the only practical remedy.

\section{VIRUS DISEASES}

\section{Cowpea mosaic virus}

This virus produces yellow green patches on leaves. Mottling is conspicuous and affected plants get stunted. Some strains of this virus are seedtransmitted also. Exposing seeds for four days at $30^{\circ} \mathrm{C}$, inactivate virus in the seeds (Suryanarayana 1978).

Mali and Kulthe (1980) made comparative studies on the seed-borne virus isolates from cowpea, and identified them as BYMV, a member of poty virus group, based on the host range, physical properties and electron microscopic studies. Seed transmission ranged from 14 to $41 \%$. Cowpea is known to be affected simultaneously by several other viruses, including seed-borne viruses (Kühn 1964; Harrison and Gudauskas 1968).

Mali et al. (1983) made extensive studies on the transmission through seeds of the bean yellow mosaic (BYMV), cowpea aphid borne mosaic (CAMV) and cucumber mosaic virus (CMV) in 23 cowpea varieties, collected 
from Badnapur (Maharashtra). The extent of seed transmission was observed through visual symptoms together with the identity of the viruses and was checked through their reaction on test plants by serological tests. Cowpea varieties recorded positive as well as negative seed transmission. Mali et al (1989) also made sero-diagnosis of six cowpea seed-borne viruses from Maharashtra. Seed transmission was confirmed, and they were identified as (i) Sunnhemp mosaic tobamo virus, (ii) Cowpea mild mottle virus (iii) Southern bean mosaic sobemo virus (iv) Pea aphid-borne black eye cowpea mosaic poty virus, (v) Black eye cowpea mosaic poty virus and (vi) Cucumber mosaic cucumo virus. It may be noted that many viruses, including stable ones, occurring in high concentration in leaves are not transmitted through seeds. For true seed transmission, virus must enter and survive in the embryo. A strain of cowpea mosaic virus not transmitted through seeds was also recorded. This virus was unable to move into cotyledons due to obliterated passage; in the dried seed tissues, virus was absent due to dehydration (Singh and Singh 1984).

Control measures : Use of resistant varieties like $\mathrm{Co} 1$ is promising. Spraying Malathion (50 EC) $2 \%$ is recommended for controlling aphids. Biopesticide, neem garlic emulsion (stock solution prepared with neem oil $200 \mathrm{ml}+$ garlic $200 \mathrm{~g}$ crushed and mixed with $300 \mathrm{ml}$ water $+30 \mathrm{~g}$ soap mixed with water), is used. Solution diluted to a concentration of $10 \%$ is used for spraying plants (Anon. 2007).

\section{Cowpea mild mottle virus}

The virus is seed-borne. Deformed and discoloured seeds show highest virus transmission. Virus is detected in testas, cotyledons and embryo (Sawant and Nahre 1994). Another seed-borne virus, cowpea seed-borne mosaic virus (aphid borne, poty group) was observed to the tune of 15-20\% from Pune (Summanwar et al. 1994).

Seed-borne virus can be eliminated by soaking cowpea seeds in $5 \%$ trisodium phosphate (TSP) solution for 24 hours before sowing, followed by spraying TSP $3 \%$ + Ekalux $3 \mathrm{ml} /$ litre to the standing crop.

\section{COMMON BEAN /RAJMASH/FRENCHBEAN}

(Phaselous vulgaris L.)

All beans coming under genus Phaseolus have been included.

\section{FUNGAL DISEASES}

\section{Anthracnose,}

c.o. Colletotrichum lindemuthianum (Sacc. \& Magn.) Brios \& Cav.

The disease is of worldwide importance and occurs wherever crop is grown. It is absent in drylands or surface irrigated fields. The fungus infects vegetable-beans and cowpea. 
Epidemiology of anthracnose on Frenchbean was worked out by Sindhan and Bose (1981). The fungus is essentially seed-borne and subsists on the diseased crop debris in soil. Relative humidity of $90 \%$ and above is essential for infection. Water is required for dissemination of spores. Kumar et al. (1999) investigated recurrence and development of anthracnose in Himachal Pradesh by $C$. lindemuthianum on kidney-beans with weather variables. Heavy and frequent rains with moderate temperature $\left(19-25^{\circ} \mathrm{C}\right)$ and relative humidity above $70 \%$ favoured disease in its vertical and horizontal spread. They also screened 60 genotypes under field and artificial epiphytotics for disease resistance, and recorded two accessions as resistant to all races.

Symptoms : Fungus attacks all aerial parts of the plant. On seedlings, cotyledons show small to large, brown to black sunken spots, which may bear pink-spore masses of fungus in the wet weather. On pods, spots are first small but later enlarge with purple borders (Fig. 21.1). Similar lesions may develop on the stem also. Mature seeds from diseased

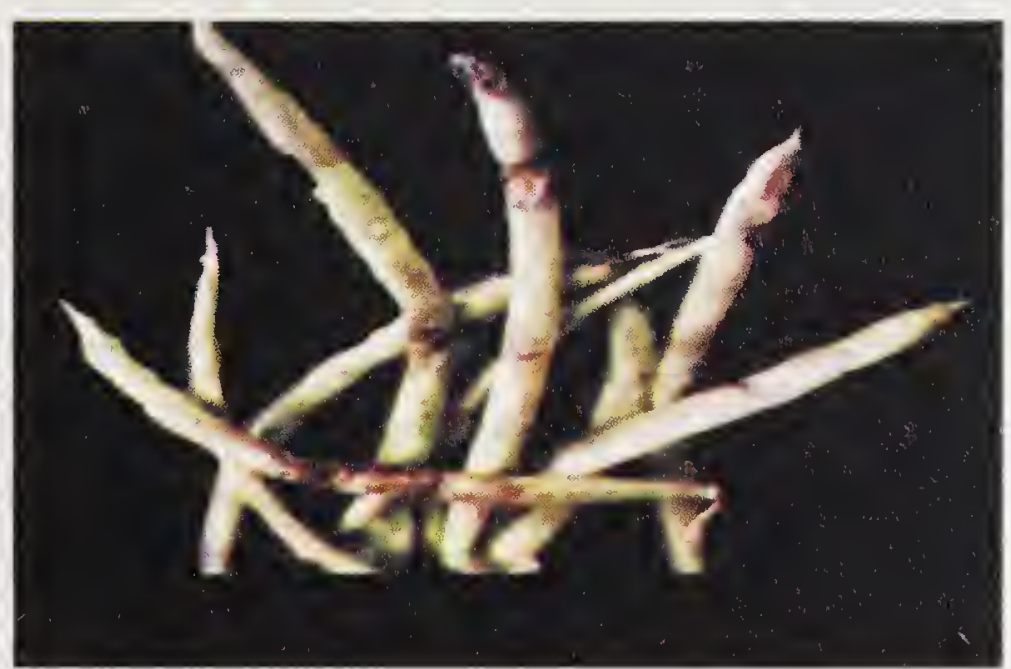

Fig. 21.1. Anthracnose on common beans pods may or may not be stained. If stained, various shades of brown are seen. Seedlings emerging from such seeds may show typical lesions on cotyledons (Singh 1992).

Control measures : Disease incidence and severity was more in highly susceptible cultivar, Jawala. And seed-borne infection caused more yield losses compound to background contamination. Pod infection exerts direct affect on the seed yield. Reduction in seed number per pod and seed weight was also observed (Sharma et al. 2008). In healthy seed crops, disease is delayed by 4-6 weeks. Seed treatment with organo-mercurials like Agallol, Aretan, Emisan $(0.25 \%$ each) or with systemic fungicides, Bavistin, Vitavax $(0.5 \%)$ or Ziram $(0.2 \%)$ reduces seed-borne inoculum. Seed treatment with Carbendazim $(0.1$ $\%$ ) or Carbendazim $50 \mathrm{WP}+$ Thiram 75WP $(0.2 \%)$, followed by foliar spray of Mancozeb (0.25\%) after 45, 60 and 75 days after sowing (Sharma and Suga 1995), was recommended. Bavistin, Thiram, Dithane M-45 and Hexacap were reported to be effective in improving seed germination and seedling vigour (Paul 2002).

Khati and Hooda (2006) tested several genotypes, and observed IPR 964 possessing multiple resistance against $C$. lindemuthianum.

\section{Brown-rot/Fusarium-rot, c.o. Fusarium spp.}

Several species of Fusarium found associated are F. equiseti, F. semitectum and $F$. solani (Tandon and Verma 1964). Sharma and Sumbali (1993) recorded $F$. oxysporum on garden-beans. 
Rio et al. (1991) from Puerto Rico reported $F$. equiseti as predominantly seed-borne. They observed internal infection. F. semitectum (F.pallidoroseum) was also observed along with several other fungi. Presence of Fusarium spp. is noticed specifically on the freshly harvested crops.

Symptoms : Dasgupta and Mandal (1989) observed circular spots with black centre and brown margins on the infected pods. The spots are small, sunken, water-soaked that coalesce later and form blighted patches. Under humid conditions, abundant sporulation appears and rest of the period, only scanty mycelial growth is visible. A brown tint is noticed on the seed surface but no discolouration is observed during early stages of infection. The disease spreads through contact among pods. Mixed infection is also noticed.

Control measures : Seed treatment with Captan $(0.2 \%)$ or Thiram $(0.2 \%)$ is effective in controlling seed-borne infection.

Ascochyta pod-spot, c.o Ascochyta spp.

This is a minor disease of lima-bean and some other species of Phaseolus. The disease occurs on many other vegetables-okra, pepper and egg-plant. The fungus mostly causes leaf-spots but may also infect stem and pods. Assochyta fabae was also noticed on faba-beans.

Symptoms : On pods, lesions are elongated, and on them fewer fruiting bodies are produced. The fungus was also reported causing seed-and pod-rot in butterbeans in Bengaluru (Maholay 1982). On pods, circular zonate rings of lightbrown discolouration appear. Pathogen is seed-borne. Partially infected seeds are orange and heavily infected seeds are buff-coloured with leathery soft tissues.

In Bengaluru,Sharma and Sohi (1980) observed on Frenchbean symptoms of pre-and post-emergence mortality, collar-rot, stem-canker and pod-rot. Seeds on artificial inoculation recorded maximum pre- and post-emergence mortality.The fungus is seed-borne and soil-borne. The disease is favoured by mild rains and relatively low temperatures. Fungal growth occurs at $20-24^{\circ} \mathrm{C}$, and optimum temperature for reproduction is $27.5^{\circ} \mathrm{C}$.

Control measures : Seed dressing with Thiabendazole $(0.1 \%) /$ Metalaxyl $(0.1 \%)$ coupled with a post-emergence spray was recorded to be effective (Jellis et al. 1988).

\section{Rhizoctonia disease/ collar-rot,}

c.o. Rhizoctonia bataticola (Taub.) Butler

(Macrophomina phaseolina (Tassi) Goid.

This is an important field disease of Frenchbean, and has been reported to cause heavy losses in Bengaluru and Himachal Pradesh. Its severity ranged from 15 to 25\% (Sharma and Sohi 1980; Banyal et al. 2002). Dillard and Wallis (1986) reported $R$. solani from New York. 
Symptoms : The fungus causes pre-and post-emergence mortality, collar-rot, stem-canker and pod-rot (Sharma and Sohi 1980; Banyal et al. 2002). Seed transmission of $R$. solani was reported on $P$. vulgaris and $P$. lunatus (Leach and Pierpont 1956, 1958).

Control measures: Use of resistant varieties. IPR 96-4 has been identified as a resistant genotype against $R$. solani and Fusarium spp. (Khati and Hooda 2006).

Seed treatment reduces disease in the field and increases plant stand (Mukhopadhyay 1994). Seed treatments with Captan (0.2\%), Carboxin (5g/ $\mathrm{kg}$ seed), Benomyl (500ppm) and Thiram ( $0.2 \%)$ were reported to be effective (Oliveira et al. 1997).

Bioagent-based integrated management of collar-rot of Frenchbean has been reported from Jharkand. Seed treatement with Vitavax $(0.1 \%)+$ Trichoderma viride $\left(19 \times 10^{3} / \mathrm{cfug}\right) @ 2 \mathrm{~g} / \mathrm{kg}$ of seed resulted in maximum seed germination and minimum disease incidence (Dubey 2002). Kumar and Dubey (2002) in their studies on web-blight (Thanatephorus cucumeris/ Rhizoctonia solani) of winged-bean (Psophocarpus tetragonolobus) observed integration of seed treatment ( $G$. virens @ $10^{6}$ spores $/ \mathrm{ml} / 10 \mathrm{~g}$ seed + Vitavax @ $1 \mathrm{~g} / 1 \mathrm{~kg}$ of seeds) and spraying Tilt (Propiconazole) giving minimum disease incidence and high pod yield in fields.

\section{White mould /Sclerotinia-rot/soft-rot,}

\section{c.o. Sclerotinia sclerotiorum (Lib.) de Bary}

Gupta et al. (1997) observed the disease from Himachal Pradesh. Watersoaked lesions are noticed on leaves, stem and branches. Infected portions on pods show white mycelial growth. The disease is severe in wet and cool weather. Pods in contact with the soil are seriously damaged. Under in-vitro studies, Trichoderma harzianum showed highest radial growth after two weeks of incubation on $1.5 \%$ water extract of farmyard manure. In fields also, seeds treated with $T$. harzianum along with $0.05 \%$ Carbendazim in $1.0 \%$ FYM amended soil reduced disease incidence (Gohain and Das 2006).

The fungus is reported to cause 'nesting' on bean-pods and other vegetables in transit and storage at a very low temperature. The mycelia grow superficially on the substrate and bind decayed material together into a cottony mass. Chief diagnostic characteristic of soft-rot is conspicuous mycelia in the early stages and profuse sclerotia in the later stages. The host tissues become soft and watery as the disease progresses, and finally gets desiccated.

\section{Angular leaf-spot of beans, c.o. Phaeoisariopsis griseola (Sacc). Ferr.} Isariopsis griseola Sacc.

The disease was first reported from India (Sreenivasan 1953). It is widely present on Frenchbean, which is an important kharif pulse and vegetable crop in the hilly terrains of India, and has been reported from Nilgris, Karnataka, 
Himachal Pradesh and Uttar Pradesh (Sohi et al. 1963; Bose and Sindhan 1973; Singh and Sharma 1975 and Ponnappa et al. 1976).

Symptoms : The disease damages extensively foliage and pods in all commercial varieties; 40-70\% loss in green pods yield was reported (Singh and Saini 1980). Angular leaf spots ranging from 5 to $8.5 \mathrm{~mm}$ are noticed. Round lesions appear on unifoliate leaves and pods also. It is observed that higher temperature gives rise to small spots and lower temperature to large spots and occurrence is optimum at $15^{\circ} \mathrm{C}$. The lesions cease to appear above $30^{\circ} \mathrm{C}$ (Verma and Sharma 1984).

Control measures : Almost all-grown varieties are highly susceptible. Singh and Sharma (1975) and Gupta et al. (2000) observed certain lines to possess good degree of resistance against angular leaf spot under natural epiphytotic conditions. These lines could be exploited for resistance breeding against the disease. Brock (1951) from Australia also reported resistant lines.

Seed treatment followed by spraying with Carbendazim $(0.1 \%)$ was reported to be effective (Bhardwaj and Thakur 1992). Rajappan and Yesuraja (1999) evaluated efficacy on seed germination of talc-based formulation of T. viride (obtained from TNAU, Coimbatore) @ $4 \mathrm{~g} / \mathrm{kg}$ of seeds. The treatment improved seed germination, reduced angular leaf spot, and recorded highest green pod yield; on a par with Carbendazim (Bavistin 50\%) @ $2 \mathrm{~g} / \mathrm{kg}$ of seeds.

\section{Black-rot, c.o. Alternaria alternata (Fr.) Keissler}

This is one of the common diseases of broad-bean (Vicia faba), observed during February-March. Infection is carried from the field. The disease was reported by Vasudeva (1960) and Mandal and Dasgupta (1981).

Symptoms: The spots are circular to irregular, measuring $0.5-2.0 \mathrm{~cm}$ in diameter with a brown outer rim, which gradually enlarge and coalesce. Grey to brown mycelia and abundant spores appear over lesions. Under humid conditions, surface becomes black, and infected bean emits a characteristic bad odour. Seeds also become soft.

Mode of perpetuation and spread of Alternaria-blight was reported by Dubey and Patel (2000). The fungus remains viable in infected seeds up to 15 months under laboratory conditions and 13 months in the soil. Infected seeds serve as the primary source of inoculum for the pathogen and the secondary spread is through air-borne conidia.

\section{Damping-off, c.o. Pythium spp.}

Bhargava and Gupta (1957) surveyed on the market diseases of fruits and vegetables in Kumaon and reported cottony-leak of beans, caused by Pythium sp.

Symptoms: They appear on Frenchbean pods. Damped-off pods contain oospores which serve as an inoculum source for damping-off on to the ground (Devaki and Bhat 1992). A cottony-leak due to Pythium aphanidermatum was also recorded on garden-beans (Sharma and Sumbali 1993). 
Control measures : Fluroscent pseudomonads and certain Bacillius spp. are known to control fungal and bacterial-rot diseases in common-bean. Ahmadzadeh et al. (2003) observed fluorescent Pseudomonas to be effective against seed-rot, caused by $P$. ultimum in Iran.

\section{Phoma-rot, c.o. Phoma medicaginis Malbr.\& Roum}

The disease was recorded from Kumaon (Dhyani et al. 1989). The fungus infects leaves, pods and seeds. Seed treatment with Thiram $(0.2 \%)$ and Captafol $(0.2 \%)$ offers protection.

\section{Pod-blemish, c.o. Cladosporium tenuissimum Cook.}

Brownish blemishes are noticed on damaged pods. Blackish-green sporeballs are also seen in masses. This is accompanied by rotting. Seeds decay into a black mass (Dasgupta and Mandal 1989).

Seed treatment is as detailed in Rhizoctonia disease/collar-rot.

\section{Soft-rot, c.o. Rhizopus oryzae Went \& Prinsen Geerligs Mucor sp.}

Soft-rot is one of the major diseases, noticed during humid period. Infection can originate anywhere on the pod surface as water-soaked discoloured areas. Later, the beans can be seen adhering or clinging together and forming a 'nest rot' (Philip 1998); and these pods give fermentative odour. The disease is very common in the markets of Thiruvananthapuram during rainy season when gunny bags packed tightly with beans coming from Bengaluru are loosened and distributed for sale.

Control measures : The beans should not be packed tightly. They should be spread out with sufficient ventilation.

\section{Diaporthe pod-blight,}

\section{c.o. Diaporthe phaseolorum (Cook. and Ellis) Saccardo}

This disease was reported on Lima-beans (Phaseolus lunatus). Older pods are frequently attacked. Lesions on maturing pods may occur on any point. As the pods mature, lesions spread in all directions. By this time, the pods turn black and the plant starts wilting. If infection occurs before seed formation, pods may be seedless or if seeds are formed, they may get dark and shrivelled. The fungus perpetuates through seeds and on the crop refuse left in the field. Affected seeds do not germinate normally. Even if germination occurs, seedlings die soon. Rapid infection occurs at $25.5-30.5^{\circ} \mathrm{C}$ (Singh 1992).

Seed treatment with Thiram $(0.2 \%)$ and Captafol $(0.2 \%)$ was effective.

\section{Black mould-rot, c.o. Aspergillus niger Van Tiegh.}

The disease was reported on injured beans. Water-soaked areas appear; their progress is very slow, they are up to $2-3 \mathrm{~cm}$ in diameter. Black conidial 
heads appear over the fruit-surface and affected area becomes dull. Secondary invaders were also found associated (Dasgupta and Mandal 1989). Sharma and Sumbali (1993) recorded this fungus on garden-beans. Aspergillus spp. were reported in stored seeds by Kalakutski et al. (1988) from the USSR. A. repens spread was most rapid, followed by $A$. sydowii, A. candidus and $A$. versicolor. Seed treatment is effective in eliminating all seed-borne fungi (Sharma and Sugha 1995).

Seed treatment with Thiram $(0.2 \%)$ and Captafol $(0.2 \%)$ protected the crop.

\section{Seed-rot, c.o. Aspergillus flavus Link. ex Fries}

Aspergillus flavus was reported as pathogenic to germinating seeds and seedlings of different crops. Seeds of Phaseolus vulgaris, Dolichos lab lab, Vigna catjang etc were found heavily infected by A. flavus. The fungus spreads from seed-coat to cotyledons and to other parts, depending on the stage of the emergence, and leads to following types of infections (Rati and Ramalingam 1974).

- Seed-rot. All parts of the seeds, excepting seed-coat get liquefied. Rotting seeds show abundant sporulation on the seed-coat with no sign on the radicle or the plumule.

- Non-emergence of cotyledons. Due to the formation of mycelial mat, cotyledons fail to emerge resulting in death of the seedling.

- Infection of plumule. The fungus sporulates in the cotyledonary cavity and infects plumule, resulting in death of seedling.

- Cotyledonary infection. The infected cotyledons show circular, sunken brown spots of various sizes, visible on both the sides of the cotyledons. The fungus sporulates and infected cotyledons fall-off earlier than healthy ones. Different species of Aspergillus were reported by Nazeema(1981) from Kerala. A. flavus produces also potent toxin, aflatoxin $\mathrm{B}_{1}$.

Control measures : The disease is seed-borne. Hence seed treatment with Captan $0.2 \%$ or Thiram $0.2 \%$ was found effective. Seeds are to be dried properly; their moisture content should not exceed $7 \%$.

\section{Myrothecium-rot, c.o. Myrothecium verucarria Alb. \& Schwein}

Bihari Lal and Chaturvedi (1994) reported disease from the local markets of Allahabad. The disease appears on the lateral side of the fruits and is prevalent from November to February. Small, nearly circular spots are initiated with a light brown centre surrounded by a dark brown band. The decay is confined to the fruit skin in the initial stages, but later penetrates deep into the mesocarp. Dark-green sporodochia appear on the infected area after 9-10 days. 


\section{BACTERIAL DISEASES}

\section{Bacterial blight/fuscous blight, c.o. Xanthomonas phaseoli (Smith) X.axonopodis pv. phaseoli}

Bacterial blight of common-bean (Phaseolus vulgaris) was first described from the United States. The causal organism was described by E.F. Smith in 1897. The disease is widespread in the US and Canada and in all states of India. Symptoms appear as irregular red to brown spots that coalesce to form large patches. Affected leaves become shrivelled, distorted, and are shed prematurely. Young developing and infected pods also become shrivelled and dried-up. Systemically invaded and fully developed pods show water-soaking along the sutures and affect also the funiculus. Local infections on the podwalls appear initially as small, water-soaked spots, which later enlarge and become depressed and turn brown. Seeds from severely diseased pods shrivel (Patel and Jindal 1972). Walker(1975) also reported shrivelling and discolouration, depending upon the extent of infection.

Infection is seed-borne. It is present on the seed-coat. Even $0.5 \%$ seed infection can start an epidemic. Bacterial blight continues as a major problem in the high rainfall areas. Sources of resistance to $X$. axonopodis have been reported in Phascolus coccineus and $P$. acutifolius. Transfer of resistance was from these species to Frenchbeans by interspecific hybridization (Kaushal and Kumar 2000; Kumar et al. 2005).

Rapid plaque methods have been developed for detecting scanty infections. Seed treatment with antibiotics like streptocycline (100 ppm) reduces seed-borne infection. Use of certified disease-free seeds is effective in containing disease.

Use of resistant varieties has been recorded. The genotype IPR 96-4 was reported to possess multiple resistance against X.campestris pv. phaseoli (Khati and Hooda 2006).

Integrated management strategies for fuscous blight and floury leaf spot of rajmash with Pseudomonas fluorescens strain RPB 14 were suggested by Mondal (2004). Foliar application of bacteria at the seedling stage ( $10^{7} \mathrm{cfu} /$ $\mathrm{ml}$ ) and flowering stage $\left(10^{6} \mathrm{cfu} / \mathrm{ml}\right)$, followed by a single spray of Carbendazim(50 WP( $0.05 \%)$ at the pod-development stage helped protecting plant from both the diseases. The treatment also increased seed yield.

\section{Halo-blight, c.o. Pseudomonas phaseolicola (Berk.)}

The disease is widespread in the United States and Canada. Patel and Jindal (1972) reported occurrence of bean common blight and bean halo blight on Phaseolus vulgaris from India also. Its symptoms are similar to those of bacterial blight. The disease is introduced through the infected seed. When the seed is infected, bacteria develop in the seed-coat of the germinating seed and contaminate surface of the expanded cotyledons, penetrating through rifts in the cuticle and progress intercellularly until reach vascular system. The 
disease develops under relatively cool environment. Pods are infected locally or by systemic invasion and halos may appear around spots on pods. The formation of halos occurs most strikingly at $20^{\circ} \mathrm{C}$ or below (Walker 1975).

\section{VIRUS DISEASES}

Bean mosaic virus. Causal virus: Phaseolus virus 1. Infected plants are stunted and are bushy in appearance. Leaves develop mottling blisters and lamina curls downwards. Most of the flowers were shed and setting of pods was delayed (Yaraguntaiah and Nariani 1963). The virus is sap-transmissible as well as carried through seed.

Another virus (Rubbery bean, Phaseolus coccineus, mosaic virus) was also reported on Frenchbean. This virus is also seed-borne.

\section{Seed-borne viral diseases}

The mosaic disease of beans was first observed by Iwanowski from Russia in 1899. The disease incited by seed-borne virus is now known as common mosaic. It is found throughout the United States and in many parts of the world and causes severe yield reductions.

On the susceptible varieties, common mosaic on leaves causes in varying degree vein clearing and mottling. Pods show ordinarily no symptoms, but under certain conditions, chlorotic spots may appear, and sometimes a glossy sheen (hydrosis) of immature pods is noticeable. The virus affects seed quality also. More than 50\% of seeds can be infected (Walker, 1975). Jimenez and Nelson (1986) identified two viruses on Phaseolus vulgaris-southern bean mosaic virus (SBMV) and cowpea chlorotic mottle virus (CCMV). Both viruses were isolated from seed and field collected bean tissues. Davis and Hampt (1986) also observed CMV isolates to be seed-borne in P.vulgaris, and seed transmission varied depending upon the varieties. In India, Suryanarayana (1978) recorded yellow bean mosaic virus (Phaseolus virus No.1/common bean mosaic virus) affecting different species of Phaseolus, Dolichos bean, peas and soybean. The virus is seed-borne but is transmitted through aphids and also through sap. Another virus (Runner bean,Phaseolus coccineus mosaic virus) also affects Frenchbean. The virus is up to $42 \%$ seed-borne on runner bean. Development of tolerant or resistant varieties is the only possible means for control.

\section{Seed microflora}

Trichothecium roseum Pers. on Faba-bean

Fusarium equiseti (Corda) Sacc.

F. semitectum Sacc. ( $F$. pallidoroseum)

Aspergillus spp.

Penicillium spp.

Rio et al., 1991

Chaetomium sp.

Mucor sp.

Bacillus licheniformis

Flavobactersp. 
Flavobacter sp. and Fusarium spp. were observed on the freshly harvested seeds, and Bacillus spp. and Aspergillus spp. were recorded from stored seeds. The composition of the microflora serves as a good indicator and is used in testing seed quality in Honduras (Rio et al. 1991).

\section{OTHER DISEASES AND THEIR CAUSAL ORGANISMS}

\begin{tabular}{ll}
\hline Disease & Causal organism \\
\hline Rust of beans & Uromyces appendiculatus \\
Sclerotium-rot & Corticium rolfsii \\
Helminthosporium-rot & Helminthosporium victoriae \\
Septoria-blight/blotch & Septoria pisi \\
Yeast-spot & Nematospora coryli parasitica \\
Phoma-rot & Phoma medicaginis Dhyani et al., 1989 \\
\hline
\end{tabular}

CLUSTERBEAN (Cyamopsis tetragonoloba (L.) Taub.)

Clusterbean popularly known as guar is an important crop, cultivated throughout India all-round the year for feed, fodder and vegetable purposes. The crop assumes great industrial importance owing to the presence of gum in its endosperm. The gum has diversified uses in many industries.

\section{FUNGAL DISEASES}

\section{Seed-rot/damping-off, c.o. Sclerotium rolfsii Sacc.}

The disease causes considerable losses in yield. Sclerotium rolfsii is a soilborne parasite with a wide host range (Aycook 1966); survives in the soil for more than four years as dormant sclerotia (Anil Kumar and Gowda 1984). Survival of sclerotia in the soil for a long time and extensive host range make difficult to control this fungus by crop rotation.

Symptoms : The pathogen causes seed-rot and damping-off of seedlings. At later stages of plant growth, infected plants exhibit foot-rot near the soil line and results in wilting of the host-plant.

Control measures : Soil fumigation was recorded to be effective (Hersenzon and Palti 1958). But was not economical for low-income group (Harrison 1961). Studies conducted by Ganesan (1997) at Bengaluru recorded soaking of seeds in $0.2 \%$ solution of Dithane M-45 to be effective in controlling the disease. Brassicol applied twice as soil drench, four days prior to sowing along with Foltaf and Dithane M-45 and Brassicol was also found effective.

Macrophomina-rot, c.o. Macrophomina phaseolina (Tassi) Goid.

Jaiman and Jain (2004) recorded this disease from Rajasthan. Though it is seed-borne, the pathogen appears at the seedling stage, and at maturity causes losses in yield. The disease was also reported by Bhatia et al. (1998). 
Seed treatment with fungicides, Bavistin(0.1\%), Topsin $(0.1 \%)$, Captan (0.2\%), Indofil M. $45(0.2 \%)$ and Thiram (0.2\%), improved germination.

\section{Black mould-rot, c.o. Aspergillus niger van Tiegh.}

The diseased fruits show black conidial heads at the injured site, surrounded by water-soaked areas. The inner tissues become moderately soft and blackened.

\section{BACTERIAL DISEASES}

\section{Bacterial soft-rot, c.o. Pseudomonas fluorescens}

The disease manifests as a water-soaked area, which starts mostly from the pedicel-end. But the symptoms may occur elsewhere also on the fruitsurface. Pinhead-like black dots are noticed on the infected area.

\section{Bacterial-blight, c.o. Xanthomonas campestris pv. cyamopsidis (Patel et al.)Dye \\ $X$. axonopodis pv. cyamopsidis (Patel) Vauterine}

Bacterial blight is considered a serious disease of guar, limiting profitable production of seed and fodder. It is known to be internally seed-borne (Srivastava and Rao 1963), and provides primary inoculum for secondary spread (Lodha and Gupta 1981).

Control measures : Gandhi et al. (1978) and Lodha (1984) evaluated several genotypes from Jodhpur and found none to be resistant. But Mitter et.al 1997 recorded field resistance in certain varieties. Seed treatment and spraying of streptomycine at 35 and 49 days after sowing was advocated for the disease control (Lodha and Ram 1993). The treatment proved effective in reducing disease intensity and in increasing grain yield of gaur. Lodha (2001) observed antagonistic potential of a white sterile fungus and of a bacterium Bacillus subtilis isolated from the phylloplane microflora in managing bacterial-blight. The antagonist cultures were multiplied on potato dextrose broth for 10 days, homogenized, diluted with water and used for spraying on to plants. This resulted in reduced disease incidence.

Dipping of clusterbean seeds for three hours in streptocycline aqueous solution $(0.02 \%)$ was very effective in controlling bacterial-blight (Rathore 2000).

Garlic-clove water/ethyl acetate extract (at 1, 10, 100, 1,000, 10,000 mg/ $\mathrm{ml})$ provided maximum inhibition of the bacterium at all concentrations (Sunilkumar et al. 2002).

Bacterial-blight has also been reported from Karnataka (Chakravarthy et al. 2004), where the crop is grown for vegetable and seed purposes. The disease occurred in a serious form and caused about $58 \%$ yield losses. Survey of the seed samples in the major clusterbean-growing districts during kharif 2002 and 2003 showed bacterial incidence in $70 \%$ of the seed samples. Plants raised from naturally infected seeds were diseased. 


\section{Seed mycoflora}

The mycoflora associated with clusterbean seeds from Haryana was recorded by Karwasra and Singh (1982). This included the following.

Aspergillus spp.

Alternaria cyamopsidis

Chaetomium spp.

Curvularia spp.
Helminthosporium spp.

Fusarium spp.

Penicillium spp.

Rhizopus spp.

The bacterium included Xanthomonas cyamopsidis ( $X$. axonopodis pv. cyamopsidis)

Bhatia et al. (1998) recorded following fungal species-Alternaria, Aspergillus, Cladosporium, Colletotrichum, Curvularia, Drechslera, Fusarium, Gliocladium, Macrophomina, Myrothecium, Penicillium, Phoma, Pleosporium and Rhizopus.

En-Nagerabi and Elashafie (2001) at Sudan with the Sudanese gaur seeds noticed Aspergillus spp. as the prominent group, followed by Rhizopus and Curvularia. However, they could not detect any aflatoxin in Aspergillusinfected seeds.

Seed samples of clusterbean recorded X.axonopodis pv. cyamopsidis

(Chakravarthy et al. 2004).

Jaiman and Jain (2008) recorded the following fungi.

$\begin{array}{ll}\text { Macrophomina phaseolina } & \text { Pleosporium } \\ \text { Alternaria alternata } & \text { Phoma sp. } \\ \text { Cladosporium sp. } & \text { Gleocladium sp. } \\ \text { Colletotrichum } \mathrm{sp} . & \text { Myrothecium sp. } \\ \text { Curvularia sp. } & \text { Penicillium } \mathrm{sp} . \\ \text { Fusarium } \mathrm{sp} . & \text { Rhizopus } \mathrm{sp} .\end{array}$

Shivanna et al. (1992) observed seed treatment with Thiram (0.2\%) effective when used individually or in combination; followed by Carbendazim $(0.1 \%)$ and Zineb(0.2\%). Carbendazim was effective against Fusarium and Phoma was least effective against Alternaria.

Captan $(0.2 \%)$ and Zineb $(0.2 \%)$ reduced significantly Alternaria, Cladosporium, Colletotrichum and Myrothecium sp. Seed treatment with Benomyl was also recommended. Movement of Benomyl from seeds to seedlings was also reported (Claramma et al. 1984).

\section{WINGED-BEAN/GOA-BEAN/FOXTAIL-BEAN}

(Psophocarpus tetragonolobus L.)

This is considered an underutilized pulse vegetable. Its protein content varies from 22 to $25 \%$. The crop is not affected by many diseases. 


\section{FUNGAL DISEASES}

Web-blight, c.o Thanatephorus cucumeris (Frank Donk) Kühn

Anamorph : Rhizoctonia solani

The disease occurs in a severe form(7-70\%), and this limits crop cultivation. Sharma and Sohi (1980) reported this for the first time. Its symptoms are similar to other Rhizoctonia diseases.

Fungicides, Vitavax, Bavistin, Blitox-50, Contaf, Tilt, Captaf and SAFF all at the recommended doses as well as seed treatment with Gliocladium virens $\left(10^{6}\right.$ spores $\left./ \mathrm{ml}\right)+\operatorname{Vitavax}(1 \mathrm{~g} / \mathrm{kg}$ of seed $)$ and spraying of Tilt (Propiconazole) minimized disease incidence and increased pod yield (Kumar and Dubey 2002).

\section{DOLICHOS-BEAN/INDIAN BEAN}

(Dolichos lab lab L.)

Dolichos-bean is one of the important pulse crops, grown extensively in the south Gujarat during rabi season. Diseases inflict heavy losses on the crop. Like other crops, it is attacked by many fungal, bacterial and virus diseases (Naik and Sabalapara 2006).

\section{FUNGAL DISEASES}

Pod-rot, c.o. Botryodiplodia theobromae Pat.

Severe pod-rot of dolichoss-bean was recorded from the College of Agriculture, Vellayani, Thiruvanthapuram (Philip and Menon 1974). Infection was confined mainly to pods nearing maturity. The pods show brownish discolouration and become dark-brown to black. Infected pods shrivel and ultimately dry-up. Fungal pycnidia appear during storage. Vines bearing infected pods show die-back symptoms also.

Fusarium-rot, c.o. F. oxysporum Schlet.

The disease was recorded by Mishra and Rath (1986) from Bhubaneshwar. The disease occurs on stored beans after harvest.

\section{Phoma-rot, c.o. Phoma herbarum Westend}

The disease was reported from Sagar, Madhya Pradesh (Chile et al. 1992). The fungus causes brown spots. Diseased parts become soft and watery. Seeds inside the pods are also affected.

Pod-rot, c.o. Geotrichum candidum Link.

The disease was observed from Gwalior markets. White, sunken spots appear with light-yellow margin. With advancement of infection, pods shrivel at the infected and diseased portions on the pods; exhibiting white powdery appearance. Inside seeds are also infected (Saxena et al. 1983). 


\section{Soft-rot, c.o. Rhizopus oryzae Went \& Prinsen Geerligs}

The decay appears in patches as water-soaked areas. Later these areas are covered by white stringy mycelial mat. Sprinkling water on the pods favours infection and results in 'nest rot' like symptoms (Fig. 21.2).

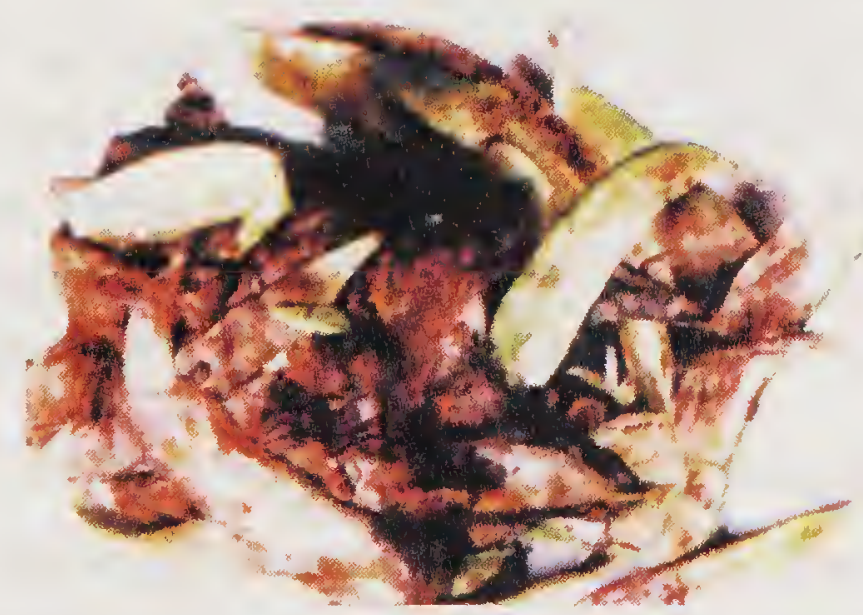

Fig. 21.2. Rhizopus-rot/nest rot on dolichos-bean

\section{BACTERIAL DISEASES}

\section{Fuscous-blight, c.o. Xanthomonas phaseoli var. fuscans}

This disease spreads through seeds. The disease was reported by Patel and Jindal (1972).

Symptoms : On leaves, stem and pods dry and necrotic spots appear, but they sometimes are water-soaked or have translucent border. Lesions on pods are raised and brown. The bacteria and the phages of Xanthomonas are widely distributed in India and manifest through infected seeds, diseased plant materials and soil (Jindal and Patel 1981).

Control measures : Seed treatment with solar heat/hot-water $\left(52^{\circ} \mathrm{C}\right.$ for 30 minutes), followed by chemical treatment (streptocycline $0.1 \%+$ Captan $0.2 \%$ ) before sowing coupled with a spraying schedule was reported to be effective from Ludhiana (Thind and Kumar 1985) in increasing grain yield in contrast to seed treatment/ foliar sprays carried out separately.

\section{Seed mycoflora}

Aspergillus flavus is commonly recorded from seeds. Abundant sporulation is noticed on the seed-coat, and is reported to be responsible for non-emergence of seed (Rati and Ramalingam 1974).

Control measures are as detailed under seed-rot (A.flavus) in common beans (Phaseolus vulgaris).

SWORD-BEAN (Canavalia gladiata (Jacq.)DC)

\section{FUNGAL DISEASES}

\section{Black-rot C.o. Coleophoma empetri (Rostr.) Patrak}

The disease was reported from Warangal(Andhra Pradesh) by Laxminarayana and Reddy (1976). The disease starts initially as dark-brown 
to black spots on the fruits, which coalesce later to form irregular lesions. In advanced stages, lesions assume bigger size and small, round, black bodies are embedded on them.

Pink-rot, c.o. Trichothecium roseum (Pers.)

Singh and Shrivastava (1979) reported this disease from Bihar. Dark brown to black, shallow spots are seen to be scattered over the fruit-surface. These are later covered with light pink velvety spore masses and fungal hyphae. The decay is confined to fruit skin in the early phase of infection. As the disease advances, symptoms spread to deeper zones of fruits.

Collar-rot, c.o. Sclerotium rolfsii Sacc.

The decay was noticed at the collar region of the plants. Samraj and Jose (1969) reported the disease from the College of Agriculture, Vellayani.

Symptoms : The rotting results in complete bark decay at the soil level. In bush-type varieties, sword-beans are seen touching the ground. Since fungus is soil-borne, chances of fruits getting infected and their further decay during storage is likely to occur; even though not reported.

Control measures : Fruits should not be touching the soil. 


\title{
CHAPTER Q
}

\section{Cole Crops}

\author{
CABBAGE [Brassica oleracea (L.) con var. capitata (L.) \\ Alef. var. capitata]
}

Cabbage-head may be round or flat with smooth leaves. This vegetable is a source of vitamin $\mathrm{B}_{4}, \mathrm{~B}_{5}, \mathrm{~B}_{6}$ and vit. C. Minerals like iron, calcium, magnesium and potassium are also present. Anticancerous properties have also been recorded.

\section{FUNGAL DISEASES}

\section{Target-spot c.o. Alternaria brassicae (Berk.)Sacc.}

Leaf-spot A. brassicola (Sch.) Wittish

Black curd-rot, $A$. alternata (Fr.) Keissler

The disease was reported from Karnataka (Hiremath and Govindu 1975), West Bengal (Mandal and Das Gupta 1981), Haryana (Duhan and Suhag 1990) and Kerala (Philip 1998).

Symptoms : Infection starts as small lesions on leaves, and develop into zonate spots or large rots depending upon the weather. If rotten leaves are not removed, whole head gets rotten and blackened within 8-10 days. Under high humidity, spots spread quickly. The symptoms are prominent on the outer leaves. Rotten head gives out a characteristic smell (Figs 22.1, 22.2). Vendors usually remove outer scales before marketing the heads.

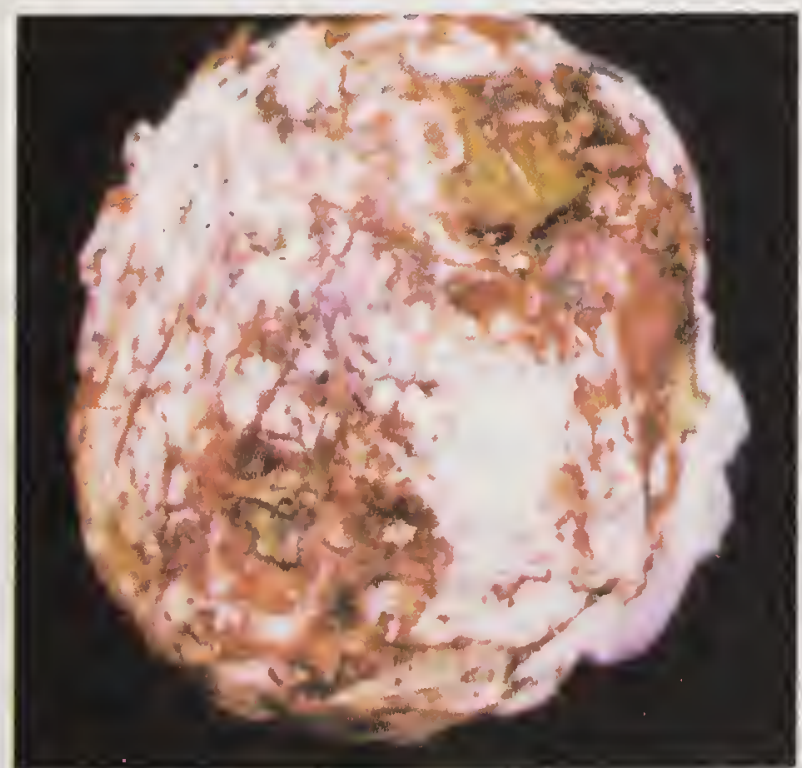

Fig. 22.1. Alternaria-rot on cabbage

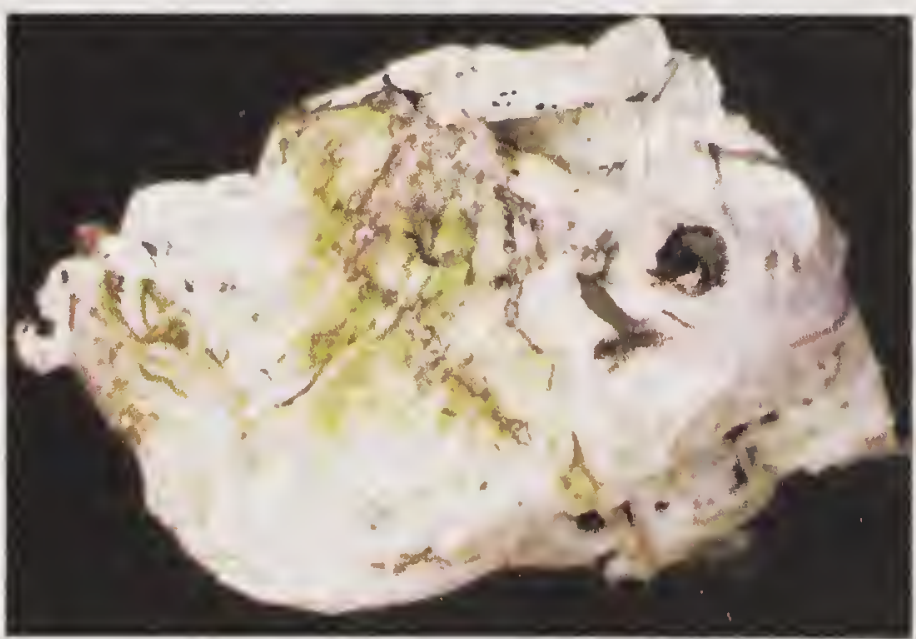

Fig. 22.2. Alternaria-rot on detached leaf of cabbage 
Dew or rain consistently for 9 hours caused infection, and optimum temperature was $26^{\circ} \mathrm{C}$ (Singh 1992). All Alternaria species are seed-borne pathogen. Inoculum of Alternaria spp. remains lodged deep into cabbage and cauliflower seed tissues (Richardson 1970; Maude and Huperson-Jones 1978, 1980. Mohd et al. (1994) recorded all three species of Alternaria to be pathogenic. Mehta et al.(2000) evaluated 59 Brassica genotypes comprising different groups under epidemic conditions against $A$. brassicae and observed that all genotypes were susceptible. Disease infection on pods is found to be favoured by high relative humidity, intermittent drizzling and moderate temperature (Duhan and Suhag 1990).

Variability among different isolates of A. brassicae was also recorded (Kumar et al. 2002). Isolates were distinguished based on the thermal sensitivity. Differential sensitivity of $A$. brassicae isolates to fungicides was also recorded from Hisar (Srivastava et al. 2002). A. tenuis was occasionally reported.Pathogen produces spots on heads as well as blacken them.

Control measures : Hot-water treatment at $50^{\circ} \mathrm{C}$ for $30 \mathrm{~min}$ is effective for seed-borne inoculum.

Pre-harvest treatment with fungicides reduces decay during storage. The heads are to be sprayed with Mancozeb $(0.2 \%)$ or Folpet $(0.2 \%)$ in the fields and later kept under cool-storage conditions at $0-1{ }^{\circ} \mathrm{C}$. Tasca and Trandaf (1984) observed it to be effective up to 136 days in Romania. Spraying on the heads with Emisan $6(0.25 \%)$ or Ridomil MZ-72 (0.2\%) was also recommended as all isolates were highly sensitive to these chemicals (Srivastava et al. 2002).

Curd-rot is also considered a disease syndrome. It includes four different types of rot. It is initiated by Fusarium equiseti, followed by other fungi and bacteria, including Rhizopus stolonifer, Pythium aphanidermatum, Alternaria brassicae, Erwinia caritovora, etc ( Chakrabarty 1990).

\section{Rhizoctonia-rot, c.o. Thanatephorus cucumeris (Frank) Donk.}

Sclerotial stage: Rhizoctonia solani Kühn

The disease was reported on cabbage from Germany, USA and many other countries (Williams and Walker 1966; Abawi and Martin 1985), and also on Chinese cabbage from the USA, South Korea and West Indies (Rajnauth 1987).

Symptoms : In the bottom-rot phase, elongated, sunken black lesions develop on the under surface of the mid-ribs, and circular spots appear on the lower parts of the leaves. Small, irregular shaped lesions are also recorded on the top of the heads. These gradually coalesce and darken resulting in head-rot. As decay progresses, dark web-like fungal growth spreads over the surface, giving rise to a mass of flat, brown, resting bodies (sclerotia).

Control measures : Seedling diseases have been managed by seed treatment and soil amendment. Seed treatment with Trichoderma harzianum multiplied 
on sorghum and dried @ 10g/kg of seed + soil application of T.harzianum @ $20 \mathrm{~g} /$ pot or when it was directly applied to seed-beds enhanced seed germination as well as growth of cabbage seedlings. Since the disease is soilborne, control measures also include sterilization of seed-bed, followed by careful management of field and crop rotation. After harvesting, infected plant material should be promptly destroyed.

\section{Ring-spot, c.o. Mycosphaerella brassicicola (Duby) Lindau}

The disease is widespread and important in cold, temporate countries USA (Nelson and Pound 1959), UK (Dring1961), New Zealand and Australia (Wicks et al. 1987). It is prevalent in India also. Infection occurs over 12 to $28^{\circ} \mathrm{C}$; optimum is between 16 and $20^{\circ} \mathrm{C}$.

Symptoms : The spots are conspicuous on leaves. Circular spots may show small irregular lesions of brown and grey concentric zones with a well-defined border. Occasionally affected areas are irregular and are uniformly dark with leathery texture. Presence of large spots on the heads reduce their market value (Singh 1992).

Control measures : The disease is seed-borne. Seed treatment with Captan $(0.2 \%)$ or soaking seeds for $24 \mathrm{hr}$ in a suspension of Thiram $(0.2 \%)$ at $30^{\circ} \mathrm{C}$ was found promising. Seed treatment along with strict hygiene in seed-bed and field is necessary. Refuse of the previous crop is a potential source of inoculum and should be properly disposed. Pre-harvest application of fungicides as is detailed in Alternaria-rot, followed by prompt cooling and low temperature storage after harvest helps minimizing decay.

\section{Grey mould-rot, c.o. Botryotinia fuckelina (de Bary) Whetzel Botrytis cinerea Pers.}

Grey mould is of major importance in cool, temperate countries- UK, USSR, USA (Tahovonen 1981; Brokenshire and Prudie 1984; Davies and Heale 1985).

Symptoms : Brown, water-soaked areas develop on leaf or stem tissues. In humid conditions, whitish growth develops, which may later darken and give rise to a dense mass of brownish-grey spores. The disease is usually more after harvest. Pre-disposing factors ińclude freezing damage, mechanical injuries and prior infection. Once established, grey-mould subsequently progresses into the sound healthy tissues also and produces 'nest rot' in store. Optimum growth temperature for the fungus is approximately $20^{\circ} \mathrm{C}$; significant decay occurs at very low temperature also. The fungus was reported to produce ethylene gas in storage, which hastens ageing and pre-disposes cabbage to further infection. The factors affecting post-harvest infection of stored cabbage were studied by Yoder and Whaler (1985).

Control measures : Pre-cooling before storage and maintaining storage and transit temperature as near as to $0^{\circ} \mathrm{C}$ has been recommended as essential. 
Fusarium-rot, c.o. Fusarium spp.

The disease was frequently recorded on stored cabbage from Canada and USA (Adair 1971). F. equiseti, F.moniliforme and F. oxysporum were also recorded from Kumaon (Harbola and Khulbe 1994). F. roseum was also reported.

Symptoms : The fungus produces a yellow pigment on the surface of the infected tissues. Due to infection, rapid ageing occurs. Decay cannot be checked by modified atmosphere storage.

Control measures : Storage losses can be minimized by spraying Mancozeb $(0.2 \%)$ or Folpet $(0.2 \%)$ on heads in the fields, and later storing them at $0-1{ }^{\circ} \mathrm{C}$ (Tasca and Trandaf 1984).

\section{Pythium-rot /damping-off, c.o. Pythium spp.}

Damping-off is a major seedling disease in the nurseries. It was recorded as early as 1925 by Drechsler from the USA. Several Pythium species were reported to be associated. Infection takes place through wounds or in contact with wet soil. The progress of the disease is usually rapid.

Symptoms : Tissues become water-soaked, loosen cohesion, and liquid exudes as in bacterial soft-rot. The fungus is intracellular and inconspicuous in the early stages of decay. Later it produces characteristic soft/wet decay. Eventually fluffy or depressed white, aerial mycelia appear on the surface of the decayed tissues. The rot is likely to be masked by secondary bacteria, which cause soft-rot.

Control measures : They are as detailed under Fusarium-rot.

\section{Brown-head, c.o. Phytophthora porri Foister}

Semb (1971) and Geeson (1976) recorded Phytophthora sp., and reported the disease from the UK.

Symptoms : The outer wrapper leaves show desiccated appearance. The centre becomes dark-brown with discolouration advancing upwards from the stem base. Sometimes scanty mycelial growth may appear within stem cavities and in between heart leaves.

Control measures : They are as detailed under Fusarium-rot.

\section{Head-rot, c.o. Rhizopus oryzae Went \& Prinsen Geerligs R. stolonifer(Ehrenb.) Vuill.}

The disease was reported from Karnataka (Hiremath and Govindu 1975) and West Bengal (Dasgupta and Mandal 1989).

Symptoms : The leafy heads turn brown and rot. Floccose growth of the fungus is also noticed (Fig. 22.3).

Control measures : Sanitation of the storage room is important. Debris should be removed promptly and walls, floors and containers should be disinfested before the crop storage. Since bruises act as portal of invasion, care in 


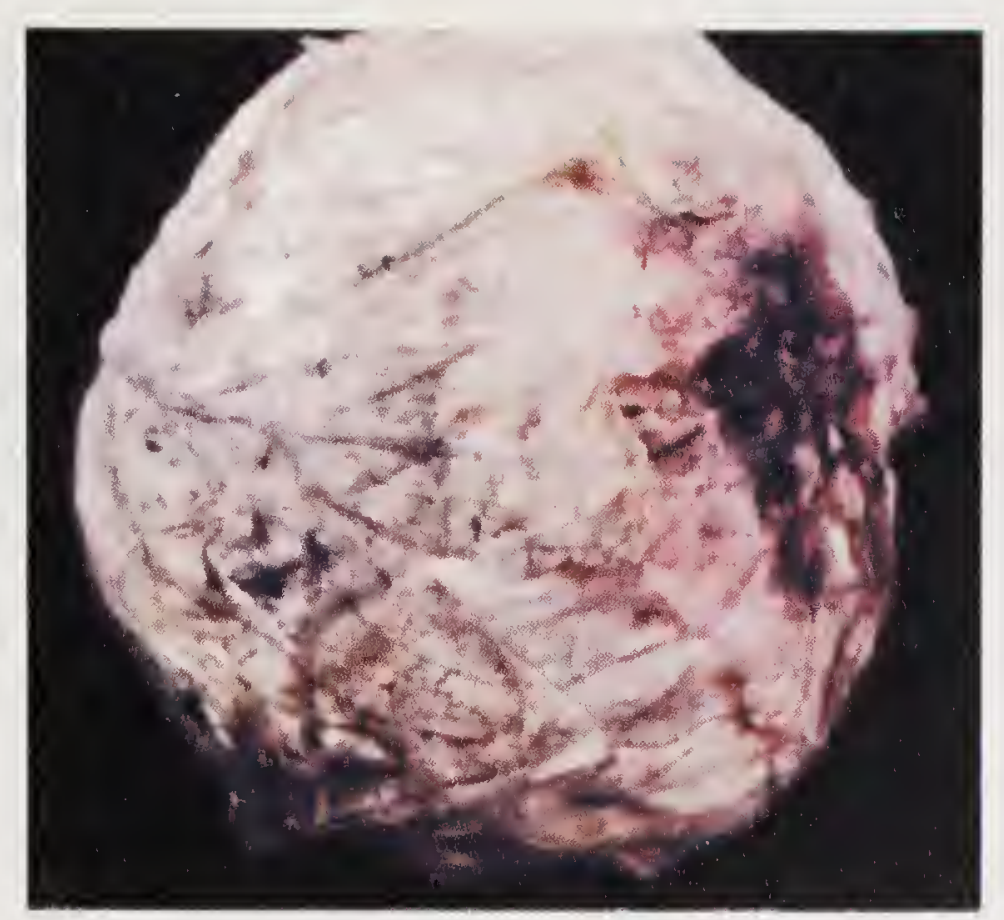

Fig. 22.3. Mixed infection (Rhizopus, Alternaria and bacteria) on cabbage

harvesting and handling is crucial, and regulation of storehouse temperature is also essential. The normal procedure is to raise storehouse temperature to $28-32^{\circ} \mathrm{C}$ for 2 weeks and then lower down to $5^{\circ} \mathrm{C}$ (Walker 1975).

\section{Black-leg, c.o. Phoma lingam (Tode ex Fr.) Desm. Leptosphaeria maculans (Desm.)}

It is a common disease in the USA and Australia, and is also reported from Maharashtra. The disease was introduced into India through imported seeds.

Symptoms : The plants may get infected from seed-beds or at anytime during their growth. Ash-grey spots studded with tiny black dots are noticed on the leaves and stems. Girdling of stem is noticed, as a result of which plant wilts and dies. On seed stalks and pods of seed-plants, lesions are elliptical.

Control measures : The fungus is seed-borne. Fungicidal dust treatments generally are not effective in eliminating seed-borne infection. Hot-water treatment at $50^{\circ} \mathrm{C}$ for 30 minutes is effective; fresh vigorous seeds alone can withstand the treatment. Thiram-soak treatment (dipping of seeds in Thiram $(0.2 \%)$ solution for 24 hours at $30^{\circ} \mathrm{C}$ ) is recommended (Suryanarayana 1978).

Efficacy of pre-harvest treatment of heads with Mancozeb (0.2\%) or Folpel $(0.2 \%)$ in the field, followed by pre-cooling before loading and storage at $0-1{ }^{\circ} \mathrm{C}$ was reported as effective (Tasca and Trandeaf 1984).

\section{Watery soft-rot, c.o. Sclerotinia minor Jagger}

The disease was reported from Italy, USA (Davis, 1925; Dillard and Hunter, 1986), Australia and India. In Australia, Sclerotinia minor tends to prevail in inland areas during summer when a dry period is followed by rains or irrigation. S. sclerotiorum is more prevalent under cool moist conditions (Letham et al. 1978).

Symptoms : Lesions at first appear pinkish-brown and water-soaked. Under dry conditions, the rot may remain firm, but is usually soft, and breakdowns 
with much leakage. Small black bodies (sclerotia) develop on and within the tissue. The optimum temperature for decay is approximately $20^{\circ} \mathrm{C}$. Crops grown for seed are particularly susceptible to attack. Seeds may be infected internally or may be contaminated with sclerotia.

Control measures : Use of disease-free seeds and weed control are important. Recommended cultural measures include removal of infected leaves at weekly intervals and mulching with pine-needles or sunflower-head residues (Sharma and Sharma 1986). The disease can be held in check by pre-cooling and maintaining storage and transit temperature at $0^{\circ} \mathrm{C}$.

\section{Powdery-mildew, c.o. Erysiphe cruciferarum Opiz ex Junell Conidial stage : Oidium $\mathrm{sp}$.}

Powdery-mildew is common in semi-arid regions such as Middle East (Al-Hassan 1973; Oran 1974) but causes occasional losses in temperate countries after a warm dry spell (Walker and Williams 1965).

Symptoms : In susceptible cultivars, small patches of whitish growth may be seen on the upper leaf surface. Finally, entire leaf gets covered. In partially resistant cultivars, symptoms are noticed as minute black flecks on the leaves. Although primarily is a field disease, it may cause serious post-harvest losses also.

Control measures : The disease is to be controlled in the field itself. Dusting with sulphur is commonly practised as it acts both as an eradiant and protectant. Spraying with Karathane (Dinocap ) at $0.1 \%$ is also effective. Three to four sprays at 10 days interval, starting when the first symptom appears is reported to be effective (Nene and Thapilyal 1982).

OTHER DISEASES AND THEIR CAUSAL ORGANISMS

\begin{tabular}{|c|c|c|}
\hline Disease & Causal organism & Authority \\
\hline Light leaf-spot & $\begin{array}{l}\text { Pyrenopeziza brassicae Sutton \& Rawl. } \\
\text { Cylindrosporium concentricum Grev. }\end{array}$ & \\
\hline Anthracnose & Colletotrichum hugginsianum & \\
\hline Cercospora-spot & Cercospora brasssicae & Snowdon, 1991 \\
\hline Choanephora-rot & Choanephora cucurbitarum & \\
\hline
\end{tabular}

\section{BACTERIAL DISEASES}

Black-rot, c.o. Xanthomonas campestris pv. campestris (Pammel.) Dowson

This was reported on cabbage for the first time in 1929 in India. The disease is important in tropical, subptropical and humid continental regions (Williams 1980).

Symptoms : Yellow brown V-shaped lesions appear at the leaf region. When cut transversly, a ring of black dots becomes visible. 
This is essentially a field disease but predisposes crop to infection by secondary soft-rot bacteria. Since the bacteria require moisture for infection, it is important to ensure that harvested crops are dried sufficiently to withstand long-term storage.

Control measures : Use of post-harvest fungicide dips for cabbage results in retention of liquid between the leaves. This should be avoided and replaced by efficient ventilation (Snowdon 1991).

The pathogen is seed-borne (Archana et al. 2008). Hot-water treatment at $50^{\circ} \mathrm{C}$ for 30 minutes, followed by seed dressing with Thiram $(0.2 \%)$ are required. During storage viability of cabbage-seeds falls rapidly. After a year of storage, viability falls from 58 to $5 \%$. Hot-water treatment, followed by dip in streptocycline (100 ppm) were promising (Singh 1992).

Soft-rot/ stalk-rot, c.o. Erwinia carotovora subsp. carotovoa,

\section{E. carotovora subsp. atroseptica}

Losses due to stalk-rot in the stored cabbage may reach up to $30 \%$. Infection occurs from soil (Keller and Knosel 1980). High nitrogen doses in the field enhances stalk-rot in the stored cabbage (Mirow and Knosel 1982).

Symptoms : Water-soaked lesions appear. Tissues become extremely soft, followed by a slimy decay. Secondary bacteria impart disagreeable odour to decayed tissues. Hot-humid weather is particularly conducive for infection (Kikumoto 1980; Ho 1985). Insects are also carriers of bacteria (Fritz and Honma 1987).

Control measures : They include field hygiene and application of balanced fertilizers. Copper fungicides also protect the crop (Brokenshire and Robertson 1986). Insect control is necessary(Kikumoto 1980). Care should be taken to avoid injuries during harvesting and storage.

\section{Bacterial-spot, c.o. Pseudomonas syringae pv. maculicola (Mc Culloh) Young et al.}

Symptoms : At first, spots are water-soaked and circular; turn brownish-grey with dark border later. Then they are irregularly angular and coalescent. The disease appears during wet season and infection occurs through natural openings. Suggested control measures include crop rotation and use of healthy seeds.

Cold storage was reported to increase incidence of spotting disorders due to bacterial soft-rot in Ontario, Canada (Warner et al. 2003).

OTHER BACTERIAL DISEASES AND THEIR CAUSAL ORGANISMS

\begin{tabular}{lll}
\hline Disease & Causal organism & Authority \\
\hline Slimy soft-rot & Pseudomonas marginalis & Brocklehurst and \\
& pv. marginalis (Brown) Stevens & Lund, 1981 \\
Bacterial zonate spot & $\begin{array}{l}\text { Pseudomonas cichori (Swingle) } \\
\text { Stapp. }\end{array}$ & \\
\hline
\end{tabular}


CAULIFLOWER [Brassica oleracea (L.) con var. botrytis (L.)

Alef. var.botrytis]

Cauliflower is low in fat and carbohydrates but high in dietary fibre and vitamin C. Sulforaphane, a compound released when cauliflower is chopped or chewed, offers protection against cancer.

\section{FUNGAL DISEASES}

\section{Black curd-rot/dark leaf-spot/Alternaria-rot, c.o.}

Alternaria brassicicola (Schw.) Wilts.

A. brassica (Berk.) Sacc.

The disease is common in many parts of the world. Alternaria alternata was recorded from the USA, Germany, Finland and many other countries. In India, the disease was reported from Karnataka (Hiremath and Govindu 1975), West Bengal (Mandal and Dasgupta 1980; Duhan and Suhag 1990) and Kumaon, Himachal Pradesh (Harbola and Khulbe 1994). Three species of Alternaria - A. brassicae, A. brassicola and A. alternata are recorded as pathogens of seed-borne nature (Mohd et al. 1994). Survey of Brassica seeds showed that $60 \%$ of the samples were infected with A. brassicola and $10 \%$ were with $A$. brassicae. Significant differences among isolates were recorded. A. tenuissima was also reported from Kumaon.

Symptoms : Infected curds show erratic dark-brown patches, which finally become blackish and soft, extending to deeper tissues and emit bad odour. Water sprinkling over curds aggravate the disease. Sporulating mass is noticed around advancing margins only (Fig. 22.4).

A. brassicicola produces small black spots (up to $1 \mathrm{~cm}$ in diameter) on leaves, stems and pods. In humid weather, spots may coalesce together to form bigger circular lesions. Concentric rings are also seen on these

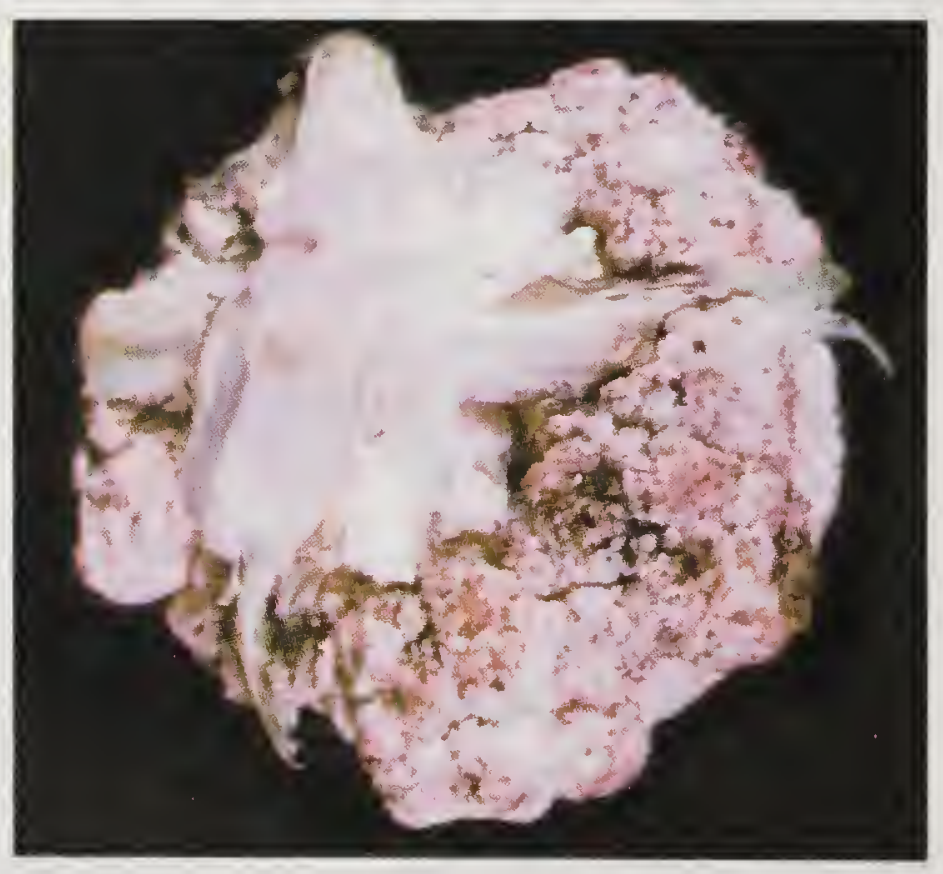

Fig. 22.4. Alternaria-rot on cauliflower spots. When lesions appear on the tips of the pods, they split. The fungus from pods penetrates inside them and reaches seeds. Affected seeds are shrivelled. The disease is important on the seed-crop as the pathogen attacks pods and seeds. Infected seeds fail to germinate or produce diseased seedlings (Wu and Lu 1984; Dauhan and Suhag 1989).

This disease has become a major constraint for successful cultivation of cauliflower for seed. The disease symptoms on pods are favoured by high relative humidity, intermittent drizzling and moderate temperature (Duhan and Suhag 1990). The inoculum remains lodged deep into the seed tissues 
(Richardson 1970, Mohd et al. 1994). It reduces seed quality, causes seedling mortality, leaf spot, curd blight and seed infection. Siliqua infection reduces number of seeds/siliqua. Heavy yield losses are also reported. The fungal mycelium is also recorded in different parts of the seeds (Prasad and Vishunavat 2002, 2003, 2006). Seed yield losses were maximum in midmaturing variety Pant Shubhra.

Control measures : Hot-water treatment of seeds at $50^{\circ} \mathrm{C}$ for 30 minutes is effective (Sokhi 1994). Thiram applied as dust to seeds $(8.5 \mathrm{~g} / \mathrm{kg})$ eliminates superficial infection, but not deep-seated infection. Thiram suspension maintained at $30^{\circ} \mathrm{C}$ is effective in eliminating deep-seated infections (Suryanaryana 1978). Spraying crop with copper oxychloride (0.5-0.75\%), Maneb (0.2\%),Zineb (0.25\%) was recommended (Singh 1992).

Srivastava et al. (2002a) tested efficacy of 10 fungicides with 12 isolates of A.brassicae and observed all of them highly sensitive to chemicals, including Emisan-6 and Ridomil MZ-72.

Biological control of seed-borne Alternaria on cruciferous plants with powdery preparation of Streptomyces was reported from Finland (Tahvenen and Avikainen 1987).

Damping-off, c.o. Pythium aphanidermatum (Edson)Fitzp.

Rhizoctonia solani Kühn

Damping-off due to $P$. aphanidermatum was reported by Shyam et al. (1987) and Harbola and Khulbe (1994).

Symptoms : The fungi causes pre-emergent and post-emergent damping-off in nurseries.

Control measures : Bhardwaj et al. (1987) studied effect of seed and soil treatments on the incidence of damping-off and black-rot in cauliflower seedlings. Mishra et al. (2000) recorded soil solarization effective in reducing significantly pre-and post-emergent damping-off in nurseries. Sen (2000) controlled the fungus by a combined treatment of seed and soil with commercial preparations of Aspergillus niger (Kalisena SD and Kalisena SL).

Effect of seed treatment with biotic agents and biotic elicitors on the reduction of damping-off was also recorded (Sharing and Socin 2005).

Lower disease incidence, was recorded with Bion treatment, followed by Trichoderma harzianum (labortatry formulation), Kalisena SD (commercial preparation of $A$. niger) and Bavistin(0.1\%). Efficiency of T. harzianum and $A$. niger on plant vigour index was higher than that of chemicals.

Soft curd-rot, c.o. Rhizopus stolonifer (Ehrenb.) Vuill.

Fusarium equiseti (Corda),

F. semitectum Sacc.

Soft-rot causes heavy losses. The disease was reported from Karnataka (Hiremath and Govindu 1975). It is common when there is a glut in the market and produce is subjected to rough handling. 
Symptoms : The rot may be partial or total; surface becomes discoloured. Decay appears in patches, progresses fast and involves whole curd that starts emitting bad odour (Fig. 22.5). $R$. stolonifier produces brown soft decay accompanied with extra matrical stringy mycelia. Fusarium spp. are often observed as secondary invaders.

Control measures : Sanitation of storage rooms is important. Debris should be removed promptly and

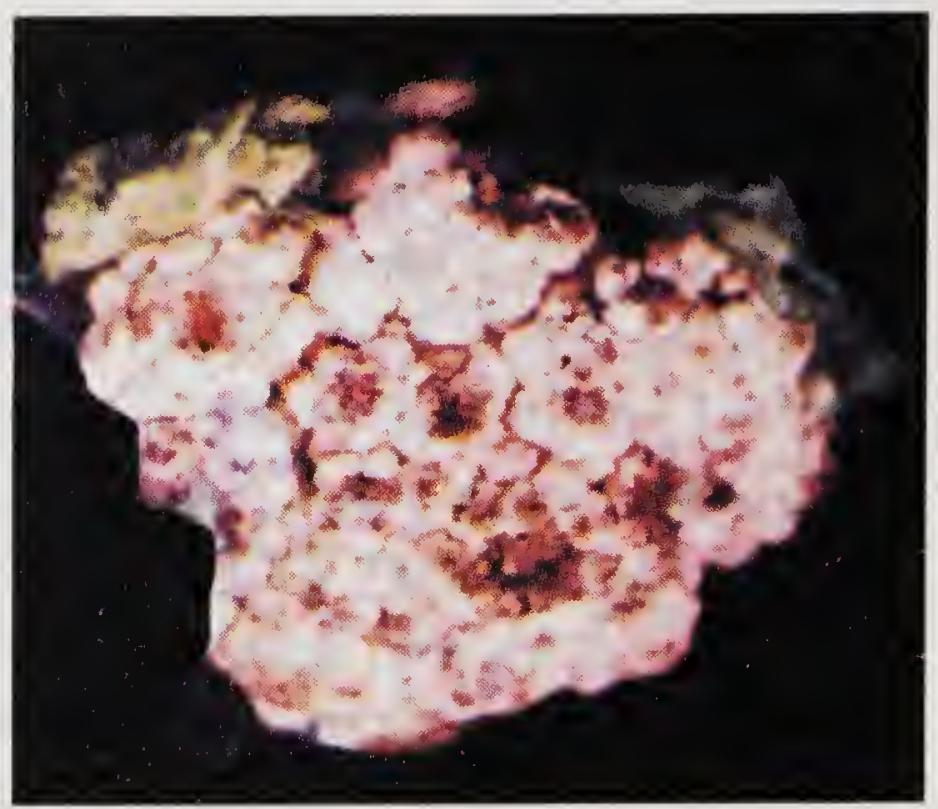

Fig. 22.5. Mixed infection (Alternaria and Rhizopus) on cauliflower walls, floor and containers should be disinfected before storage of curds. Since bruises become portal of invasion, care in harvesting and handling is important. Cold storage at $5^{\circ} \mathrm{C}$ is recommended.

Sclerotinia stalk-rot/white-rot, c.o. Sclerotinia sclerotiorum (Lib.) de Bary

The disease is considered as one of the most destructive diseases of the vegetables in the cold and moist areas of the world and occurs on cabbage, cauliflower, kale, brussel's sprouts, broccoli and chinese cabbage. It is mainly observed in Himachal Pradesh. Losses are more than 30\%, and average seed yield also decreases considerably (Verma and Sharma 1999).

Symptoms : Symptoms are noticed on leaf, stem and curd. When curds are affected, rotting results in, and this gives rise to large cavities, which are lined inside by fluffy mycelia and fungal sclerotia. The rotting may start from any point, but usually it starts from the centre. In the seed-crop, fungus attacks inflorescence, on which mycelia and sclerotia can be noticed.

Sharma et at. (1984) observed high protease activity and synthesis of protein. Khare and Bompiex (1976) also observed similar symptom with $S$. sclerotiorum in mustard.

Control measures : Soil solarization has been reported to be effective in disease management (Quais et al. 2002). Benlate (0.2\%) was also found promising. Enzyme production was under check in plants sprayed with Benlate.

Seed-crop production was threatened by this disease in Himachal Pradesh. Singh and Gangopadhyay (1984) observed $0.1 \%$ spray of Methyl Benzmidazole Carbamate (MBC) at 10 days interval effective. Bavistin was also reported effective. Maximum reduction in disease incidence was recorded with Bavistin 50\% (1.5g/litre) (Quais et al. 2005). Even though fungicides are effective, chemical control measures are not economical and also not ecofriendly because of their residual toxicity. 
Application of farmyard manure was reported to reduce white-rot (Sokhi 1994). Hybrid seeds of cauliflower infected by S. sclerotiorum could be saved by application of Kalisena SL (commercial preparation of $A$. niger) in the sick fields after harvest (Sen 2000). Culture filtrates of Trichoderma harzianum were also recorded to be effective in reducing disease incidence; seed yield increased with its treatment. Integrated disease management with Kalisena, T. harzianum + A. niger; Booty (T. viride $)+$ Kalisena and Booty alone was found promising in increasing seed production (Quais et al. 2005).

Cauliflower heads could be successfully stored at zero energy chambers; this recorded lower physiological loss in weight (Mangal et al. 2000).

Rhizoctonia-rot, c.o Thanatephorus cucumeris (Frank) Donk. Rhizoctonia solani Kühn

The disease has been reported from several countries. Management of seedling disease through seed treatment and soil amendment was reported. Its symptoms and control measures are as described under Rhizoctonia-rot in cabbage.

Choanephora-rot, c.o. Choanephora cucurbitarum (Berk. \& Rav.) Thaxter

The disease has been reported to cause post-harvest rot during transit and storage (Pavgi and Singh 1970). In the field, greyish-brown spots appear on leaves, which are later covered with a silvery bloom of mould growth. The curd may undergo a soft wet decay. Mandal and Dasgupta (1985) observed a watery-rot from West Bengal. The rot was observed in cool atmosphere.

Control measures : Storage of cauliflower heads at zero energy chambers has been recorded to be effective.

\section{Curd-smudge/Cladosporium-rot, c.o. Cladosporium spp.}

The disease has been reported from several countries, including India (Chakraborthy et al. 1989). In Taiwan, the causal organism identified was Cladosporium tenuissimum, and it was observed to be seed-borne. Superficial colonization of cauliflower curd tissue was reported from California. Curd smudge caused by Cladosporium has been reported from temperate countries also (Laemmlen 1986).

Symptoms : Infection results in small, circular, black mycelial aggregations over the curd surface. Fungal growth occurs in cool weather with light rains, followed by several days of heavy dew.

Control measures : The disease can be controlled by using jet sprays of chlorine water, followed by chlorine dip (100-400 ppm).

\section{Grey mould-rot, c.o. Botryotinia fuckeliana (de Bary) Whetzel Botrytis cinerea Pers.}

Grey mould-rot is of major importance in cool temperate countries UK (Brokenshire and Prudie 1984; Davies and Heale 1985). 
Symptoms : They appear on the curds. Under humid conditions, whitish mould develops that darkens subsequently and gives rise to a dense mass of brownish-grey spores. Once established, the fungus penetrates into sound healthy tissues and produces severe 'nesting'.

Control measures : Pre-cooling before storage and maintaining storage and transit temperature near to $0^{\circ} \mathrm{C}$ have been recorded as effective.

Nigrospora-rot, c.o. Nigrospora sphaerica (Sacc.) Mason

The disease was recorded from Egypt. Symptoms include brown patches on the curd and on the stalklet as elongated sunken blackish-brown spots with raised edges.

\title{
Downy-mildew, c.o. Peronospora parasitica (Pers.) de Bary
}

The disease was reported on cauliflower heads from Kumaon (Chakraborthy et al. 1989). Seed treatment with Metalaxyl before sowing gives promising results. Spraying with Mancozeb and Ridomil MZ-72 (0.25\%) each at 10-14 days interval in the field reduces post-harvest rot.

Ring-spot, c.o. Mycosphaerella brassicicola (Duby) Lindau

Oblong or irregular spots may occur on seeds, stems and siliqua. Phytosanitary measures coupled with appropriate crop rotation keep disease in abeyance. Carbendazim (0.1\%), Ridomil MZ (0.25\%) and Mancozeb (0.2\%) are found effective in controlling the disease in the field.

Powdery mildew, c.o. Erysiphe cruciferarum Opiz ex June, Oidium sp.

The disease is common in semi-arid regions such as the Middle East (Al-Hassan 1973). Symptoms and control measures are as detailed under Powdery mildew in cabbage.

\section{Light leaf-spot, c.o. Pyrenopeziza brassicae Sutton \& Rawi Cylindrosporium concentricum Grev.}

\section{Seed mycoflora}

\author{
Absidia orchidis \\ Alternaria alternata, $A$. brassicola \\ Aspergillus flavus, $A$. nidulans, $A$. niger \\ Fusarium solani \\ Penicillium chrysogenum \\ Rhizoctonia solani \\ Rhizopus oryzae \\ Torula herbarum \\ Xanthomonas campestris \\ Actinonmycetes
}

Sharma and Sach Dev, 1984

Occurrence of Alternaria, Aspergillus and Rhizopus was more on deformed seeds. Surface disinfection resulted in increased germination. 
Other fungi reported include the following.

$\left.\begin{array}{l}\text { Chaetomium globosum } \\ \text { Fusarium equiseti } \\ \text { F. lateritium } \\ \text { Phoma tropica } \\ \text { Rhialophora sp. } \\ \text { Cordana musae }\end{array}\right\}$

Chakraborthy et al., 1989

\section{BACTERIAL DISEASES}

\section{Black-rot/bacterial-rot, c.o. Xanthomonas campestris pv. campestris}

This is an important disease having worldwide distribution. In India, it is reported from Himachal Pradesh. It is quite serious in seed-producing centres, and is prevalent in India since 1949 (Patel et al. 1949).

Symptoms : They occur near leaf margins. Infection is systemic and affects inflorescence, pods and seeds. In seeds, it is present in the seed-coat. Seeds are also externally contaminated and infection is reported to be active for three years. The disease symptoms may also occur at the base of the curdlet, where vein-rot appears (Dasgupta and Mandal 1989) (Fig. 22.6). Cauliflower heads gets discoloured due to infection.

Control measures : The disease is

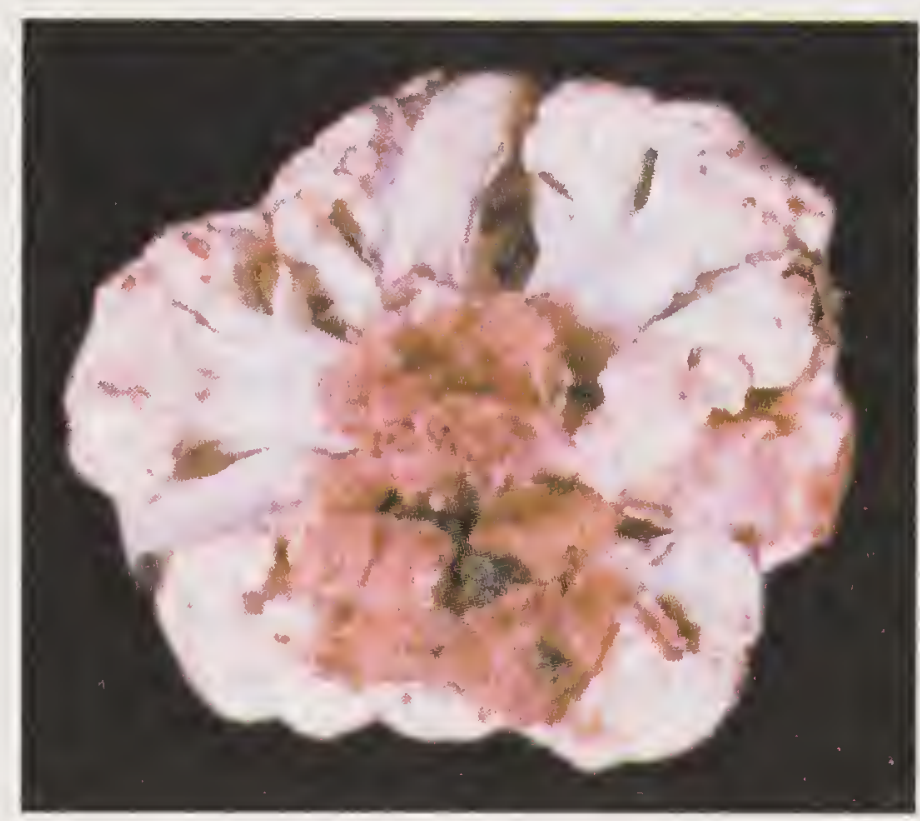

Fig. 22.6. Bacterial-rot on cauliflower internally seed-borne and is difficult to be controlled under glasshouse conditions. Treatment of seeds with hotwater at $50^{\circ} \mathrm{C}$ for 30 minutes, followed by seed dressing with Thiram $(0.2 \%)$ are recommended. This is also effective for controlling other seed-borne fungi like Alternaria, Fusarium, Chaetomium, Aspergillus, Penicillium and Rhizopus (Suryanarayana 1978). Bharadwaj et al. (1987) studied effect of seed and soil treatments on the incidence of damping-off and black-rot in cauliflower seedlings and observed control by sowing hot-water treated seeds $\left(52^{\circ} \mathrm{C}\right.$ for $30 \mathrm{~min}$ ) in $2 \%$ formalin-treated soil. Hot-water treatment was also recorded as effective in disinfection of black-rot bacteria (Sokhi 1994). Dipping seeds for 3 hours in streptocycline $(0.01 \%)+$ Mancozeb $(0.25 \%)$ was most effective and resulted in disease control. Integerated seed treatment with streptocycline $(0.01 \%)+$ Mancozeb $(0.25 \%)$ for 3 hours and foliar sprays coupled with a mulch of eucalyptus leaves also resulted in $60 \%$ disease control (Jarial and Shyam 2003). 


\section{Bacterial soft-rot, c.o. Erwinia carotovora ssp carotovora}

\section{E. carotovora ssp atroseptica Van Hall 1902}

Cauliflower curds are especially vulnerable to attack. Secondary bacteria impart disagreeable odour to decaying tissues. Hot-humid weather is particulary conducive for infection (Kikumoto 1980). Insects are also responsible for carrying and introducing bacteria through wounds (Fritz and Honma 1987). Infection can also occur during harvesting and handling through cut stem or through wounds. Infected tissues are stimulated to produce ethylene.

Symptoms : Water-soaked lesions appear, later tissues become extremely soft, followed by slimy decay.

Control measures : They include field hygiene along with destruction of insects. Care should be taken to avoid injuries during harvesting and handling. Cultivation of resistant cultivars should also be encouraged.

\section{Bacterial-spot, c.o. Pseudomonas syringae pv. maculicola}

The spots are at first water-soaked and circular. Later they turn brownish grey with dark borders, irregularly angular and coalescent. The disease occurs in wet season and infection takes place through stomata. Control measures include crop rotation and use of healthy seeds.

\section{Soft-rot, c.o. Pseudomonas viridiflava (Barkh.) Dowson.}

The disease was reported from Newzealand. Irregular dark-green watersoaked lesions appear. In advanced stages, tissues become brown, soft and watery and emit putrid odour (Wilkie et al. 1973).

\section{KNOL-KHOL/KOHL-RABI \\ [Brassica oleracea (L.) con var. acephala (DC.) \\ Alef.var. gongylodes (L.)]}

The crop is cultivated in Europe and in parts of India, especially in Kashmir. Its leaves are used as a vegetable in soup preparation. It is rich in minerals,calcium, magnesium, potassium, sodium and sulphur.

\section{FUNGAL DISEASES}

Alternaria-rot, c.o. Alternaria brassicae (Berk.) Sacc.,

A. brassicola (Sch.)

Wittish A. alternata (Fr.) Keiss.

Symptoms and control measures are as detailed under Alternaria-rot of cabbage. 
Cole Crops-Knol-Khol/Kohl-Rabi

231

Watery soft-rot, coo. Sclerotinia minor Jagger

Symptoms and control measures are as detailed under Watery soft-rot of cabbage.

Damping-off, c.o. Pythium spp.

Rhizoctonia solan Kühn

Seed treatment with commercial preparation of Trichoderma viride $(2 \mathrm{~g} /$ $100 \mathrm{~g}$ of seeds along with soil drenching by Captan (75\% WP) $1.5-2.5 \mathrm{~g}$ ai/ litre of water) reduced disease incidence. 


\section{CHAPTER Q}

\section{Root Crops}

\section{BEET ROOT/ SUGARBEET (Beta vulgaris L.)}

The chemical process to obtain sugar from sugarbeet roots was developed by the German Scientist Margyraf in 1747. The modern beet sugar factories have come into existence in the first quarter of the $20^{\text {th }}$ century. In India, sugarbeet is an introduced crop from Europe.

\section{FUNGAL DISEASES}

\section{Sclerotium root-rot/creepy white-rot, c.o. Sclerotium rolfsii Saccardo}

Walker (1975) recorded the disease from the USA as Southern blight or Sclerotium-rot. The disease is not so important in countries where beet root matures in falling down temperatures. In India, this disease is one of the limiting factors for successful cultivation, and is recorded as the most destructive disease (Srivastava 2004). It can be serious if maturity period of the crop coincides with hot weather. Increase in disease incidence caused corresponding decrease in root yield. Infection of more than $10 \%$ root area caused significant decrease in sucrose content (Sharma and Pathak 1994).

In north India, symptoms appear in the latter part of February till MarchApril when weather warms up. In the early stages of infection, symptoms are not visible on the aerial parts.

Symptoms : With the advancement of disease, symptoms appear on the roots, and leaves show yellowing and wilting. Such plants can be easily pulled out. The fleshy root can completely or partially decay. White strands of fungal mycelia and numerous brown sclerotia are noticed on the decaying root parts. The inner red tissues become dull, flaccid or even dry or shrivelled. Under humid conditions, entire root rots, and within 2-3 days forms 'nests' within the heap. Seedling-blight was also reported from India (Mukhopadhyay and Sharma 1968).

Sclerotium rolfsii has a wide host range and survives as saprophyte on the crop refuse. Sclerotia left in the field on contact with any plant residue germinate at temperature above $28^{\circ} \mathrm{C}$ (Singh 1992). The physiology of the fungus was studied in detail by Mathur and Sarbhoy (1976). 
Control measures : Certain cultivars like Resista Poly, Cerco Poly and Extra Poly were found moderately resistant under artificial epiphytotic conditions. (Mukhopadhyay 1976).

Nitrogen $(160 \mathrm{~kg})$ in the form of ammonium sulphate or calcium ammonium nitrate significantly reduced root-rot in the field. Soil drenching with Chloroneb or Quintozene @ 12kg/ha after planting was found effective. Brassicol (15kg/300 litres of water) as a soil drench around roots and Bavistin at $10 \mathrm{~g} / \mathrm{kg}$ of seeds were also promising (Singh 1992).

The effectiveness of certain chemicals which are known to induce defence mechanism in plants against their potential pathogens is well understood (Sinha, 1989). Based on this, management of fruit-rot through seed soaking with non-conventional chemicals has also been reported. Root-rot was reduced maximum when seeds were pre-soaked in 2, 4, 5 trichloro phenoxy acetic acid solution $\left(10^{-4} \mathrm{M}\right.$ viz, $\left.7.59 \%\right)$, followed by zinc chloride $\left(10^{-4} \mathrm{M}\right.$ viz., $\left.12.08 \%\right)$ or chitosan $(0.3 \%)$; they were also reported to be effective in producing maximum root yield, foliage growth and sugar yield (Das and Raj 2004). These chemicals have no phytotoxic effect. Chitosan, a polymer of glucose amine, increased chitinase activity and degraded chitin content of fungal cell walls (Marek et al. 2000).

Wells et al. (1972) isolated antagonistic microflora from diseased sclerotia of $S$. rolfsii and later developed techniques for controlling pathogen in the field by using Trichoderma harzianum. Backman and Rodriguz (1975) reported diatomaceous earth granules impregnated with $10 \%$ molasses to be suitable for growth and delivery of T. harzianum. Mathur and Sarbhoy (1978) recorded disease control under in-vitro conditions. T. viride and T. harzianum cultures multiplied on sand with maize meal medium $(9: 1) \mathrm{v} / \mathrm{v}$ with water were applied to sugar-beet plants. Soil application of T. harzianum cultures to the field was also reported (Upadhyay and Mukhopadhyay 1986). T. harzianum directly attacked and lysed mycelia and sclerotia of $S$. rolfsii. The type of interaction was through hyphal coiling. T. harzianum applied in the form of sorghum culture to S.rolsfii-infested soil gave 76-88\% disease control. Penta chloro benzene(PCNB) at low concentrations when integrated with $T$. harzianum also showed similar results.

\section{Dry root-rot/Rhizoctonia root-rot, c.o. Rhizoctonia solani Kühn Thanatephorus cucumeris (Frank) Donk.}

The disease is important as it causes dry-rot of fleshy roots. It consists of a brown spongy decay, starting at the root surface and extending several centimetres deep into the flesh. As the roots grow up, open cankers are formed on them. The disease is detailed under potato. $R$. solani also causes postemergence damping-off. The treatments offered for Sclerotium-rot are applicable to this disease also (Singh 1992). Planting of seeds that have been primed and/or treated with Rhizobacteria (Suslow and Schroth 1982) may reduce disease incidence in the field. Integerated control of Rhizoctonia crown- 
and root-rot through fungicides and an antagonistic bacteria (Bacillus sp. strain MSU-127) was promising. The bacteria was grown in the cultural broth at $28^{\circ} \mathrm{C}$, centrifuged, decanted and used at a concentration of $10^{8} \mathrm{cfu} /$ ml. This applied in combination with fungicide Azoxystrobin (76 gai/ha) reduced disease incidence and gave good root and sucrose yields (Sebastin et al. 2001).

\section{Damping-off and seedling diseases}

Seedling diseases are caused by a number of soil- and seed-borne pathogens, including Phoma betae (Heilberg and Ramsey 1948), Rhizoctonia solani (Afansiev 1948, 1956), Sclerotium rolfsii (Mukhopadhyay and Sharma 1968),Alternaria spp. (Ilyaletdinov and Agatev 1970), Aphanomyces cochliodes (Lewis and Papavizas 1971), Pythium aphanidermatum and Fusarium spp.

A survey of seedling diseases of sugarbeet in India by Sen et al. (1974) revealed that seedling-blight, black-leg, collar-rot and damping-off syndromes are incited by $S$. rolfsii, $R$. solani, $R$. bataticola, Fusarium spp. and Alternaria spp. Of these, the first three were noticed to cause acute mortality and reduction in sugarbeet stands in the field.

Control measures : $S$. rolfsii and $R$. solani could be controlled by seed treatment with Penta chloro nitro benzene (PCNB) $5.0 \mathrm{~g} / \mathrm{kg}$ of seeds. Incorporation of this fungicide as seed pellet was superior. Pelletting with Brassicol @ 10g/10 kg of seeds was most effective. Bavistin (5-10 g/kg of seeds mixed with Bentonite clay as base and methyl cellulose as sticker) as seed pellets was also effective (Singh et al. 1982).

Biological control of $P$. aphanidermatum with $T$. harzianum also was recorded (Mukhopadhyay and Chandra 1985). In dual-culture experiments, T. harzianum $(50 \mu \mathrm{g} / \mathrm{ml})$ exhibited antagonism towards sugarbeet isolates of P. aphanidermatum. P. aphanidermatum stopped growing on contact with the -mycelia of $T$. harzianum. $T$. harzianum hyphae were found coiled around those of $P$. aphanidermatum, and their protoplasm was disintegrated completely. A synergistic effect leading to enhanced control of damping-off was also observed when both T. harzianum and Metalaxyl were used in combination. Seedling diseases can be effectively managed through seed treatments; seed polishing and seed pelletting with biocontrol agents, and cultural practices. Pelleting of seeds with Bentonite clay as base material and methyl cellulose as sticker was found effective. Pelleting with fungicides protects against seedling diseases in comparison to conventional seed treatments (Srivastava 2004).

\section{Cottony white-rot, c.o. Fusarium spp.}

The disease was recorded from Maharashtra, Karnataka, West Bengal, etc. It was also recorded on beet roots coming to the local markets of Thiruvananthapuram( Kerala) from Bengaluru and Coimbatore (Philip 1998). 
Symptoms : On uninjured roots, white powdery growth is noticed. Infection appears as water-soaked patches with scattered whitish growth. Under humid conditions, entire root surface is covered with whitish cottony fluffy growth (Fig. 23.1).

Control measures : Storage of roots at $4-13^{\circ} \mathrm{C}$ is effective in controlling infection and in increasing storage life (Musa and Saleh 1988).

Rhizopus root-rot, c.o.

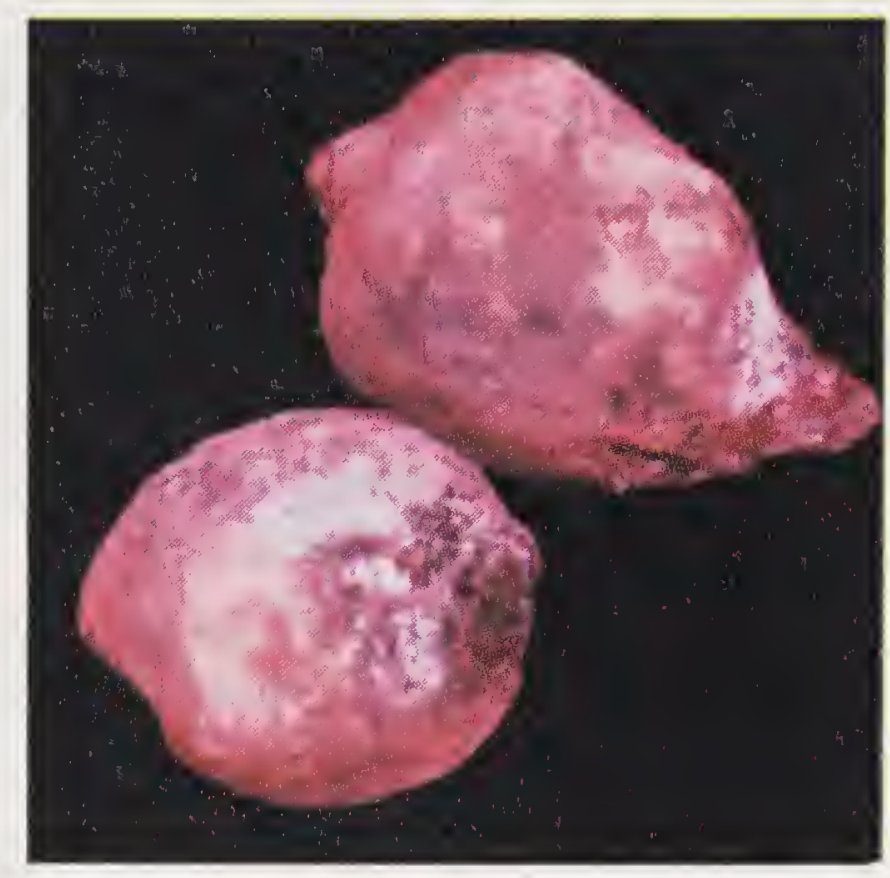

Fig. 23.1. Fusarium-rot on beet root

\section{Rhizopus oryzae Went \& Prinsen Geerligs}

The disease is of a common occurrence in North America. In India, the disease was recorded from Lucknow (Srivastava and Misra 1972).

Symptoms : In nature, the disease starts as a soft-rot and progresses infecting rapidly healthy tissues. Later, it covers entire root surface with profuse fungal growth. Complete rotting takes place within 10-15 days. The diseased tissues turn yellowish brown and emit unpleasant odour. In fields, increased atmospheric temperature has been observed to enhance incidence of the disease.

Control measures : Storage of roots at $4-13^{\circ} \mathrm{C}$ is effective in controlling infection and in increasing storage life (Musa and Saleh 1988).

\section{Macrophomina root-rot, c.o. Macrophomina phaseolina (Tassi) Goid.}

Karadimos et al. (2002) reported root-rot from Thessaloniki in Greece. Diseased plants appear in patches in the field. Rotted roots showed white yellow mustard coloured lesions in the internal surface. In advanced stages, tissues become mummified.

Control measures : Storage of roots at $4-13^{\circ} \mathrm{C}$ is found effective in controlling disease.

\section{Cercospora leaf-spot, c.o. Cercospora beticola Sacc.}

It is a common disease, particularly in the warm parts of the world. In the plains, disease appears in February-March and in hills during August and September on seed-crops. Lower leaves near the ground are attacked first. Infection is seed as well as soil-borne. Seed-borne infection is both superficial as well as deep-seated.

Three years rotation, deep ploughing, irrigation and fertilizer applications are recommended to control the disease. If the disease appears late in the season, it may not warrant any costly treatment. However, if losses are expected, 3-4 sprayings with a fungicide like Dithane M-45 @ $2.5 \mathrm{~kg} / \mathrm{ha}$ at 
10 days interval are recommended (Singh 1992). Seed-borne infection can be reduced by using aged seeds. Thiram-soak treatment is also effective in checking the disease.

\section{Black-leg/Phoma leaf-spot, c.o: Phoma betae (Oudemans) Frank.}

It is an important disease recorded from Europe, UK and the USA; and in India it is recorded from Punjab, Uttar Pradesh and Kalpa Valley in Himachal Pradesh. When infected seeds are sown, seedlings may die even before emergence or they may get blighted after emergence. The fungus attacks flower-stalks and seed-clusters. Under favourable conditions, pathogen spreads downwards and reaches roots, and such roots decay in storage.

Thiram-soak treatment (soaking in Thiram $0.2 \%$ for 24 hours in water kept at $\left.30^{\circ} \mathrm{C}\right)$, followed by Prochloraz treatment $(0.25 \mathrm{ml}$ of $25 \%$ solution/ $100 \mathrm{~g}$ of seeds) resulted in reduction of infected seedlings accompanied by lessening of storage-rot (Bugbee and Cole 1981). Proper spacing and drainage are also recommended.

\section{Rust, c.o. Uromyces betae}

The disease is common in Europe, Canada, Australia, New Zealand and South Africa. It is also common in the plains of northern India. Leaves are the main target of attack. Pustules appear on seed-stalks and also on seed-clusters.

\section{Seed mycoflora}

Sugarbeet seeds harbour a number of fungi, which are known to cause considerable damage to flowers, seeds and seedlings. It includes many seedborne pathogens - Cercospora beticola, Phoma betae, Rhizopus oryzae, Alternaria alternata and Fusarium spp. Among these, P. betae is the most important seed-borne pathogen, causing damping-off, leaf-spot, stem-, crownand storage-rots. The population of these fungi can be minimized by seed treatment with Organo mercurials, Thiram, Chloroneb, Carboxyl, Metalaxyl, PCNB, Carbendazim etc. Treatment with a combination of fungicides is better than use of a single fungicide (Srivastava 2004).

\section{CARROT [Daucus carota (L.) subsp. sativus (Hoffm) Arcang.]}

Carrot is a valuable dietary item. Its orange colour is due to the presence of betacarotene, the precursor of vitamin $\mathrm{A}$; besides vitamin $\mathrm{A}$, it contains vitamins $\mathrm{B}$ and $\mathrm{C}$. It is also rich in sugars.

\section{FUNGAL DISEASES}

\section{Watery soft-rot, c.o. Sclerotinia sclerotiorum (Lib.) De Bary}

The disease was first reported from Belgium by Coemans in 1860 on carrot fields and by Rostrup in 1871 on stored carrots. Both authors observations indicated S. sclerotiorum as the parasite responsible for rotting of carrots. But it was Anton De Bary (1886) who confirmed pathogenecity 
of this fungus. Since then it has been reported from at least 20 carrot-producing countries. The disease has assumed importance because of its sporadic and devastating nature and lack of effective control measure (Kora et al. 2003).

The disease occur at the post-harvest stage and affects crop's shelf-life in storage. Transit and market losses of 30-50\% were recorded from US and other countries. Every infected root has the potential to develop as the source of inoculum for new infection. Infection occurs at a wide range of temperature $\left(0-23^{\circ} \mathrm{C}\right)$.

Control measures : Pre-harvest cultural practices are important in reducing susceptibility during long-term storage. Balanced fertilizers with adequate potassium are important.

- Excess use of nitrogen is to be avoided.

- Mechanical injuries during harvest should be minimized.

- Pre-cooling before storage as well as maintaining a transit-and-storage temperature at $0^{\circ} \mathrm{C}$ are effective.

Biological control measures. The coelomycete fungus Coniothyrium minitans is hyperparasitic on S. sclerotiorum.Foliar application on the crop with a commercial bio-fungicide containing fungus was reported as effective (Turner and Tribe 1976).

- Several Trichoderma spp., including T. harzianum have demonstrated biocontrol activity against soil-borne pathogens including S.sclerotiorum.

- Mycorrhizae (Glomus entra radices and Glomus etunicatum) inoculations on carrot at seedling stage help provide protection during storage.

- Soil amendments have a suppressive effect. Amendment of field soil with an organic formulation of the fermented agricultural wastes or allyl alcohol, suppressed germination of sclerotia, enhanced colonization by Trichoderma spp. (Huang et al. 1997).

- Chitosan, the naturally derived polysaccharide, possesses antifungal properties to S. sclerotiorum, and is used for post-harvest treatment of Sclerotinia root-rot of carrot in storage (Cheah et al. 1997).

- Non-ionizing ultraviolet (UV-C radiation) can effectively elicit accumulation of antifungal phytoalexin in carrot roots and can induce systemic resistance to subsequent infection by S.sclerotiorum (Mercier et al. 1993).

- Ozone treatment was reported to have some fungistatic effect on $S$. sclerotiorum, and has been proposed as an alternative disinfectant to stored carrots (Liew and Prange 1994).

\section{Cottony white-rot, c.o. Fusarium spp.}

Cottony white-rot is a very serious disease of carrot all-over the world under field and storage. In India, $F$. oxysporum was recorded from Uttar Pradesh (Srivastava et al. 1964) and Karnataka (Hiremath and Govindu 1973), F. solani from West Bengal (Dasgupta and Mandal 1989) and Fusarium sp. from Maharashtra (Rao 1966) and Thiruvananthapuram (Philip 1998). During 
the rainy season, the disease was noticed on the roots that were brought to the local markets of Thiruvananthapuram from Coimbatore.

Symptoms : Symptoms may appear anywhere but are usually noticed on the distal-end as water-soaked areas. Gradually, lesions enlarge and become circular to irregular patches. The tissues putrefy. On the surface, scanty white mycelial mass develops (Fig. 23.2). Infected tissues emit a characteristic smell. Seeds are infected when they come in contact with the contaminated soil.

Control measures : Infection is seed as well as soil borne. Seed treatment with

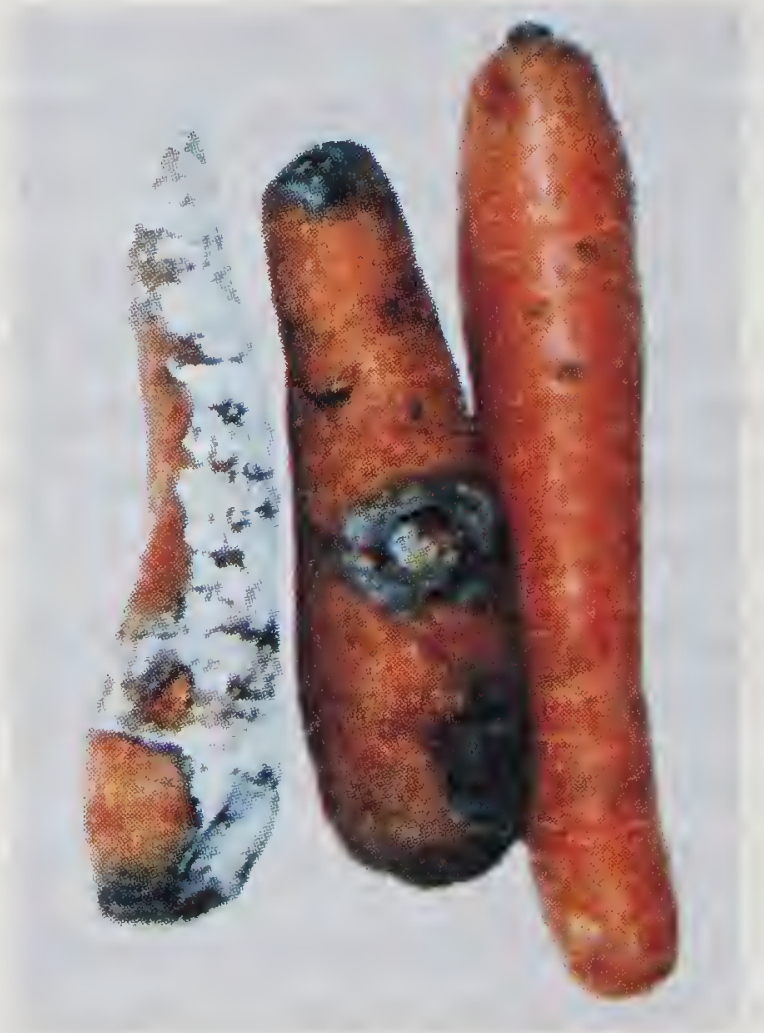

Fig. 23.2. Fusarium-rot on carrot $0.2 \%$ Thiram is effective in reducing infection. Storage of carrot roots at 4$10^{\circ} \mathrm{C}$ protects crop from infection.

\section{Rhizoctonia root-rot, c.o Rhizoctonia carotae Rader}

This disease on carrot was first reported from the USA (Rader 1948). Walker (1975) recorded a semi-soft rot from Wisconsin. Niza et al. (1981) observed disease from the local markets of Thiruvananthapuram. Small whitish growth is observed, and the tissues become soft. The pith enlarges and tissues beneath them become watery and emit foul smell. The rot develops rapidly and within a week root gets putrified.

\section{Sour-rot, c.o. Geotrichum candidum Link.}

This is considered a serious post-harvest disease of carrot in the USA (Wright et al. 1964). In India, it was recorded from West Bengal (Mandal and Dasgupta 1980) and from Haryana (Suhag and Duhan 1979). Losses as high as $80 \%$ were observed in 'Chanteny type' carrot (introduced from Holland) as compared to $50 \%$ in the local varieties of Haryana.

Symptoms : The first indication of the disease is the appearance of the irregular or circular water-soaked patches on the roots within 10 days. White cottony mycelial growth tends to spread by making conspicuous grooves within root tissues, which disintegrate and cause leaves to topple over and die. On injured roots during and after rains, the disease appears as watersoaked patches and spreads rapidly. Tissues emit sour offensive smell, and powdery white or scum-like growth is noticed over the root surface. Yeast is also found associated. Fungus disseminates with the aid of fruit-fly Drosophila melanogaster as well as through contact (Philip 1998).

Infection is observed on roots kept under ambient conditions $\left(28 \pm 2^{\circ} \mathrm{C}\right)$ after 5-6 days of storage. 
Control measures : Storage of roots at refrigerated conditions of $4-5^{\circ} \mathrm{C}$ is beneficial. Control measures as detailed under sour-rot of tomato, under Solanaceous crops is applicable here also.

Soft-rot, c.o. Rhizopus oryzae Went \& Prinsen Geerligs $R$. stolonifer (Ehrenb.) Vuill.

Soft-rot was recorded from Karnataka (Hiremath and Govindu 1973) and West Bengal (Mandal and Dasgupta 1982).

Symptoms : The disease occurs extensively on the injured roots during rains. The rot develops at the injured site; water-soaked areas appear, and within 24 hours roots will be covered completely with fungal mycelia.

Control measures : Sanitation of the storage-room is important. Debris should be removed promptly, and walls, floor, and containers should be disinfected before crop storage. Since bruises are portal of invasion, care is essential in harvesting and handling. Cold storage at $10-15^{\circ} \mathrm{C}$ was found promising.

Black-rot, c.o. Alternaria alternata (Fr.) Keissler, A. dauci and A. tenuis Aunet

This is a seed-borne disease. Leaf-blight caused by A. dauci was reported from the UK, Europe and the USA. In India, it is common in Asom, Maharashtra and Karantaka. The fungus survives on the infected crop debris in the soil. Infected seeds often fail to germinate. Sometimes seedlings emerge, which soon get blighted. On the lower part of the stem, long chestnut-brown to black stripes appear. Later on, whole stem rots and dries up. On carrot roots also black sunken lesions are produced, which under improper storage enlarge causing rotting of the tissues. Inflorescence, fruits and seeds are also infected.

Seed infections can be controlled by Thiram $(0.2 \%)$-soak treatment (Suryanarayana 1978).

\section{OTHER FUNGAL DISEASES}

Sclerotium-rot, c.o. Sclerotium rolfsii Sacc.

Thielaviopsis-rot, c.o. Thielaviopsis basicola, T.thielavioides (Cereatocystis paradoxa)

Crater-rot, c.o. Athelia orachnidea

Grey-mould, c.o. Botryotinia fuckeliana

Conidial state, Botrytis cinerea
Mandal and Dasgupta (1982)

Weber and Tribe( 2004)

Snowdon (1991)

\section{BACTERIAL DISEASES}

\section{Bacterial-blight/root-scab, c.o. Xanthomonas campestris pv. carotae}

The disease was recorded to be severe on the seed-crop. The bacterium is seed-borne and thus gets disseminated to far and wide places. Fleshy roots are damaged. The symptoms are first noticed on leaves. The inflorescence in a seed-crop dies if infection occurs before unfolding of the umbel. The bacterium requires dew or rain for spread. The optimum temperature for 
infection is $25-30^{\circ} \mathrm{C}$. Between crop seasons, the bacterium survives in soil or on crop-refuse and seeds.

Symptoms : Bacteria are washed down from foliage to soil and infect fleshy roots. Brown to maroon lesions are formed on the fleshy roots, which later develop into slightly raised or depressed laterally expanded pustules, showing flakes of dead tissues. When these pustules crack open, bacterial ooze comes out.

Control measures : They include selection of site, long crop rotation and hot-water treatment of seeds at $50^{\circ} \mathrm{C}$ for 15 minutes (Singh 1992).

\section{Bacterial soft-rot, c.o. Erwinia carotovora (Jones) Halland (Arsenjevic and Stojic 1973)}

This was recorded by Agrios (1969). The disease is found all-over the world, and causes serious damage to carrots, potatoes, raddish, onion, hyacinth, iris etc. It develops during transit and storage, and results in higher losses than any other bacterial disease.

Symptoms : Serious decay occurs within a few hours in storage or during marketing. Soft-rot causes severe economic losses by reducing market value of the produce. Chand and Kishun (1989) observed water-soaked brown spots on the lower parts of the roots. Spots develop rapidly and spread to the core of the root, from where they progress from inside to outside. In advanced stages, infected parts become soft due to maceration of the tissues and emit foul smell. Control measures : Avoid wounds and bruises during harvesting, handling and storage. Roots should be dried under shade before storage; storage at 4$5^{\circ} \mathrm{C}$ was reported effective.

OTHER BACTERIAL DISEASES AND THEIR CAUSAL ORGANISMS

\begin{tabular}{ll}
\hline Disease & Causal organism \\
\hline Soft dark-rot & Pectobacterium carotovorum, Erwinia sp. \\
Light soft-rot & Xanthomonas sp. \\
Watery brown-spot & Pseudomonas sp. \\
Dry crush spot & Erwinia sp. \\
\hline
\end{tabular}

RADISH (Raphanus sativus L.)

It is an edible root vegetable that was domesticated in Europe in pre-Roman times. It is pungent or sweet in taste with a lot of juice. It is rich in ascorbic acid, folic acid and poti-ium.

\section{FUNGAL DISEASES}

\section{Waxy-rot, c.o. Endomyces reessii}

Mandal and Dasgupta (1980) observed the disease from West Bengal. The disease is recorded during humid weather. Rot generally appears from tapered 
end. The root becomes gradually soft and cortex gets separated from the stele, but the fibro-vascular system remains intact. It also emits characteristic foul smell. Powdery or slimy growth appears over the infected surface. The infection spreads by contact.The disease is of minor importance.

Charcoal-rot, c.o. Macrophomina phaseoli (Maubl. ) Ashby

The disease was reported from India (Pavagi and Singh 1970; Mandal and Dasgupta 1980). During rains, freshly harvested roots carry severe infection of charcoal-rot, and decay is observed in storage.

\section{Seedling-blight and leaf-spot, c.o. Alternaria spp.}

The disease occurs in plants kept for seed-purpose (Sokhi 1994). When too many spots are on the leaves, they die prematurely. Infection is seed-borne. In soil, pathogen survives on the infected crop residue. Seed-borne infection may be external as well as internal.

Seed treatment with fungicides gives only partial control. Hot-water treatment at $50^{\circ} \mathrm{C}$ for 20 minutes, followed by protective treatment at $50^{\circ} \mathrm{C}$ with Thiram $0.2 \%$, have been recommended (Suryanarayana 1978).

\section{Fusarium-rot, c.o. Fusarium sp.}

Symptoms and control measures are as detailed under carrot (Fig. 23.3).

\section{White-rust, c.o. Albugo candida}

The disease is worldwide in occurrence. It is common in India also. Symptoms are noticed as blisters on leaves, stems and inflorescence. Inflorescence becomes hypertrophied and sterile with oospores.

Use of clean seeds or seeds collected from disease-free areas help eliminating disease.

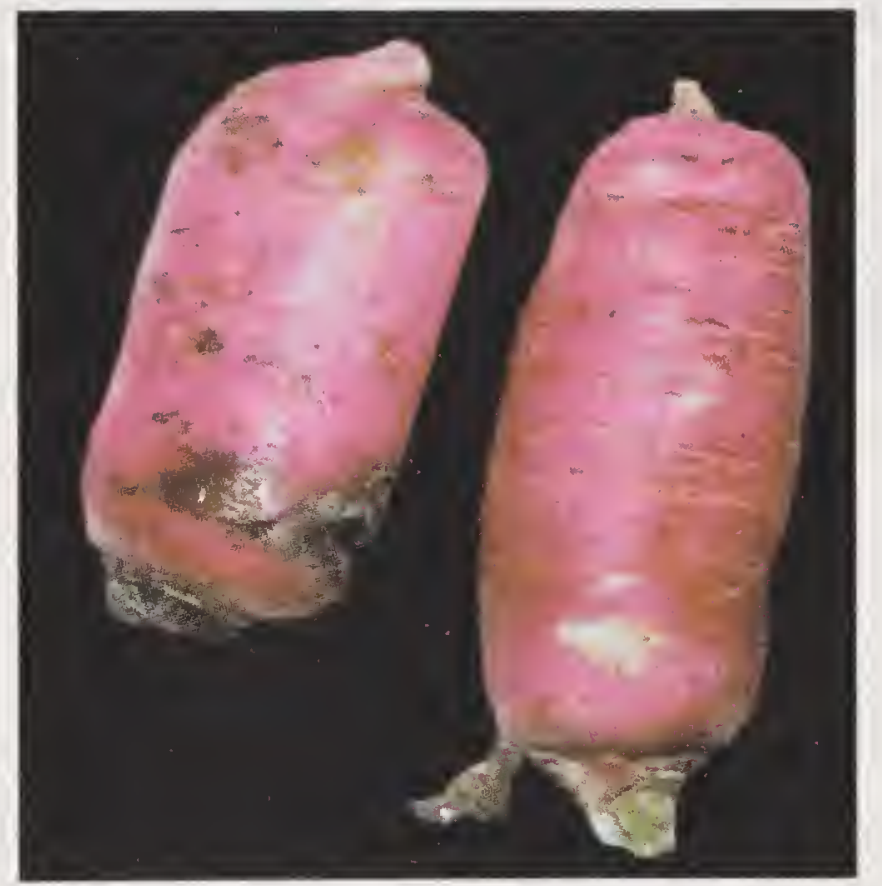

Fig. 23.3 Fusarium-rot on radish

\section{Seed mycloflora}

The following fungi have been recorded

Alternaria alternata

Aspergillus flavus Sad et al., 1990

$\left.\begin{array}{l}\text { A. niger } \\ \text { A.quadrilineatus } \\ \text { Curvularia lunata } \\ \text { Fusarium oxysporum } \\ \text { Rhizoctonia solani }\end{array}\right\}$

Srivastava et al., 2002

Seed treatments with fungicides like Bavistin (Carbendazim), Ridomil, Captan, Dithane M-45 (Mancozeb) and Thiram were promising. 


\section{CHAPTER Q4}

\section{Bulb Crops}

\section{ONION (Allium cepa L.)}

Onion is an important vegetable-crop in India. India is the second largest producer of onions in the world. But nearly $40 \%$ of the produce is lost during post-harvest handling; microbial spoilage alone constitutes $15-20 \%$ of the total loss (Pantastico and Banstista 1976). Out of Rs 31,700 lakh earned in 1994 as foreign exchange from fruits and vegetables, 1,900 lakh were earned from fresh onions alone (Sokhi 1994).

Genus Allium consists of around 450 species; many of which are widely used as spices from time immemorial. Onion is used as a salad or in the cooked, fried, boiled or baked form like flakes, powder, paste etc. Small onions have better medicinal value than common 'savala' onions. They are medium in calorific value and have low amount of proteins and vitamins.

Onions contain chemical compounds with potential anti-inflammatory, anti-cholesterol, anticanerous and antioxidant properties. As onions are sliced or eaten, the allyl propyl disulphide present in them, comes in contact with the air and produces allyl sulphide. This compound irritates the skin, mucous membrane and eyes.

Storability of bulbs vary from region to region. Storage life is correlated with dry matter content. The mean temperature during storage has profound influence on sprouting and subsequent loss in weight. Weight loss in onion increases with sprouting (Karmarker and Joshi 1941; Ward 1976).

\section{FUNGAL DISEASES}

\section{Black mould-rot, c.o. Aspergillus niger van Tiegh.}

Black mould-rot is considered as one of the common diseases all-over the world (Venkatanarayan and Delvi 1951; Coursey and Booth 1972; Curtis et al. 1974). Quadri et al. (1982) reported spoilage as high as $80 \%$. A. niger being a soil saprophyte is ubiquitous in nature and attacks onions by producing enzymes/toxins and gets established on the bulb or other tissues. Periodic survey of onion storage by Gupta and Srivastava (1984) showed 30-40\% rotting due to pathogenic organisms under favourable conditions (temperature about $30^{\circ} \mathrm{C}$ and RH 99\%). Of this, $20 \%$ loss was by A. niger alone. High 
temperature prevailing during harvest, followed by ill-ventilated storage increases susceptibility, and the disease attains high severity (Ahir and Maharshi 2008). Virulent nature of the fungus during transport and storage was recorded from Odisha (Narain and Omprakash 1968), Bengaluru(Sohi 1977), Haryana (Dang and Singh 1982), West Bengal and Meghalaya (Dasgupta and Mandal 1989), Tamil Nadu (Rajam 1992) and Karnal (Srivastava et al. 2001).

The toxic nature of the metabolites of $A$. niger and their role in onion-rot disease is also well understood. The cultural filtrate reduces spore germination and disorganizes succulent scales and green leaf tissues of onion varieties, Red Globe, Red Patna and White Globe. The toxic principle is thermostable and acts as a protoplasmic poison to host tissues. Studies conducted in Uttar Pradesh by Sharma and Roy (1978) showed that the fungus appeared to be confined only to outer dry scales, and caused dry-rot.

Symptoms : In general, symptoms appear both as dry and wet rot. White mycelia develop in the initial stages, followed by black spores formation (Fig. 24.1). In about 10 days, bulbs become shapeless, turn black and pulpy. With a little pressure, entire bulb gets crushed. A. aculeatus was also reported from West Bengal. In dry-rot phase, black thin lines appear between the outermost scales as well

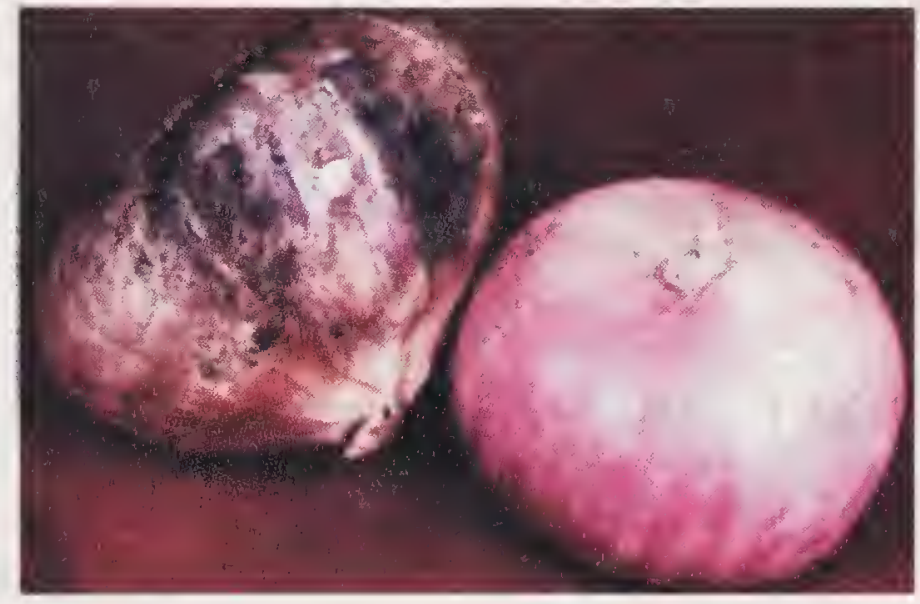

Fig. 24.1. Aspergillus-rot on onion as on the stalk region. Both red and white scaled cultivars are affected (Das gupta and Mandal, 1989). Similar type of symptoms were also recorded by Philip (1998) on onion varieties in the local markets of Thiruvananthapuram from Kerala. During rainy season, problem is acute. Infected bulbs become soft and emit offensive odour. Infection causes reduction in pungency also. Sometimes disease is observed in combination with bacterial-rot. Association of A. flavus was also reported (Sharma and Sumbali 1993).

Control measures : Srinivasan and Shanmugam (2006) reported curing of onion-bulbs by wind or row method, and storage by hanging method was effective in reducing disease incidence.

Evaluation of cultivars for resistance to A.niger was studied by Naik et al. 2008. Severity of black-mould infection varied among genotypes. Among the genotypes, Arka Kalayan and Arka Pitamber showed less severity $(<10 \%)$ to black-mould till 30 days after storage and reached $20 \%$ severity by 45 days and thereafter increased steadily and reached $35-40 \%$ by 90 days after storage.

Studies conducted in Ethiopia with Shallot bulbs (Allium cepa var. ascalonicum) showed that storage materials had significant impact on the keeping-quality. The bulbs stored in sacks, lost weight and had highest rate of sprouting and rotting (Jemal 1999). Sreenivasan et al. (2002) recorded that 
higher doses of calcium in the form of gypsum ( $400 \mathrm{~kg} / \mathrm{ha}$ ) and lower dose of nitrogen in the form of urea $(50 \mathrm{~kg} / \mathrm{ha})$ application to the field and advancing harvest of onion-bulbs by 15 days to be effective in reducing bulb spoilage in storage. Kosweesuak et al. (2002) developed a Bordeaux mixture screening protocol for effective control.

Curing of onion for five days in the field, followed by five days drying under shade and storage in crates was also practised for minimizing storage losses. Brice et al. (1997) reported storing of onions in nets. This helps to lengthen storage life. For storage, bottom and side ventilated storage structures (with sidewalls made of bamboo and plastered with clay and cowdung) were also used (Anon. 2003). Bottom ventilated single-row storage structures with thatched roof were recorded as the best for small farmers due to low severity (15-25\%) of onion moulds.

Chemical and biological control. Carbendazim (0.1\%) applied as foliar spray to the standing crop recorded maximum reduction of A.niger during storage (Raju and Naik 2006). Double spray was also found better. In addition, post-harvest fumigation of onion-bulbs with sodium metabisulphite, which released sulphur dioxide for four hours or dipping bulbs in acetic acid $(0.4 \%)$ markedly reduced disease incidence.

Companion (Carbendazim + Mancozeb 0.2\%), Rovral (Iprodiome 0.2\%) and Indofil M 45, Mancozeb ( $0.2 \%)$ along with bioagents T. harzianum and T. viride ( spraying cultural filtrate directly to plants) were observed to be effective in reducing disease incidence (Ahir and Maharshi 2008).

Essential oil of Cymbopogon flexuosus was reported to have fungi toxicity against major storage pathogens like $A$. niger and $F$. oxysporum. The oil when used as a fumigant at $500 \mathrm{ppm}$ killed a wide range of fungi harboured on the scales (Dixit and Tiwari 1994). Cymbopogon oil also showed absolute inhibition at the lowest concentration of $250 \mathrm{ppm}$.

\section{White soft-rot/basal-rot, c.o. Fusarium spp., F. solani (Mart.) Sacc. F. oxysporum Schlet.}

The disease was reported from several parts of the world. Marlatt (1958) reported basal-rot of onion due to Fusarium oxysporum f. ceapae from Arizona. Since then it has been reported from several countries. Mathur and Sankhla (1963) observed disease in a severe form from Kota( Rajasthan). Coursey and Booth (1972) also recognized basal-rot caused by Fusarium oxysporum Schlet and Fusarium spp. The disease was also reported from Haryana (Dang and Thakur 1972; Dang and Singh 1982), Madhya Pradesh (Rao and Agarwal 1977), Karnataka (Hiremath and Govindu 1975), New Delhi (Gupta and Srivastava 1984),West Bengal (Dasgupta and Mandal 1989) and Karnal (Srivastava et al. 2001). F. proliferatum was reported on onion-bulbs from Washington (Toit et al. 2003). Salmon-pink discolouration was prominent on the outer 3-4 layers. The disease was recorded from India also. 
Symptoms : They start with yellowing of leaves from tip downwards, which shrivel later with or without necrosis along with the retarded root system. Affected plants could be easily pulled out. Wet- or dry-rot is noticed on bulbs beginning from the base of the outer scales and progressively advances towards the tip. In plants showing complete collapse of leaves, the bulbs becomes rotten, while others with partial rotting continue to rot during storage. The pathogen invades only through injuries. This fungus failed to infect Allium sativum.

The infected portion becomes macerated and soft with shrinkage and appears as pale-white. Complete internal rotting is evident within 7-10 days.

Control measures : The disease can be kept under control with fumigation. In in-vitro studies, ammonia-releasing fumigants (ammonium bicarbonate $0.65 \mathrm{~g},+$ Bentonite clay $1.26 \mathrm{~g}+$ Talc $0.24 \mathrm{~g}$; ammonium sulphate $5 \mathrm{~g}$ +sodium carbonate $0.38 \mathrm{~g}$, diphenyl amine $62 \mathrm{mg}$ ) and sulphur-dioxide-releasing materials ( sodium metabisulphite $(40 \%)+$ sodium carbonate $(5 \%)$ kept in dessicators) were used. Pre-treatments arrested disease development in inoculated bulbs. But when applied as post-infection treatments, their efficiency decreased considerably (Dang and Thakur 1972).

\section{Purple-blotch/-blight, c.o. Alternaria porri Neerg}

It is a common disease occurring in several onion-growing countries, and has become a widespread problem in Punjab, causing 20-25\% losses (Pandotra1964). The disease becomes a limiting factor in seed production, especially in humid areas. Initial inoculum originates from plant debris (Hussain 1960; Pandotra 1965). Sohi (1977) reported A. solani and A. cepulicola under humid conditions of Bengaluru. Gupta and Pathak(1984) assessed losses in bulb and seed yield due to the disease in onion variety 'Nasik Red'from Jaipur. The disease severity levels were assessed based on the increase in the coefficient of disease index (CODEX). Increased losses in bulb yield and seed yield were recorded with increase in the CODEX levels. More than 50\% yield losses were recorded from Punjab. The relationship between disease progression and weather variables is of paramount importance in managing disease (Razdan et al. 2008). Maximum disease severity was observed in the variety Royal Select and minimum was in Pankaj. Disease infection rate remained high at the initial storage but declined progressively due to adverse weather conditions and lack of tissue availability.

Symptoms : Small, sunken lesions appear with a purple tint on leaves. Lesions enlarge rapidly resulting in girdling of leaves, which ultimately results in fall of inflorescence stalk. Infection spreads downwards to the bulb. Affected plants do not produce flowers. Bulb decay continues during storage also. This is considered as the most damaging disease for bulb and seed crop (Sokhi 1994).

It is generally observed that in seed-crop, flower-stalks infected with $A$. porri usually have thrip injuries that predisposes onion-plants to infection. 
With artificial inoculation also, A. porri causes infection on onion-stalks with different grades of thrip injuries. Infection is more on stalks, which have moderate to severe thrips attack. In case of severe thrips attack, purple lesions merge with one another and form large irregular blotches (Thind and Jhooty 1982). Ajrekar as early as 1922 had reported possibility of thrip infection from Bombay (Mumbai at present).

Khare and Neema $(1981,1984)$ studied occurrence of the disease from Jabalpur( Madhya Pradesh). They observed epidemic form on two months old plants. The epidemiological factors that favoured infection included average temperature ranging from 22 to $25^{\circ} \mathrm{C}$ with relative humidity of over $90 \%$. Maximum sporulation occurred at 8 AM under field conditions immediately after rains. Relative humidity of $100 \%$ for more than 4 hours and temperature of $22-25^{\circ} \mathrm{C}$ appeared optimum for infection. The interaction of temperature and relative humidity determines severity of purple blotch (Boelema and Ehlers 1967). Disease outbreak is also dependent on the amount of initial inoculum.

Control measures : Captan, Thiram and Aureofungin gave good control against storage rots( Sohi 1977). Field sprays with Blitox (0.3\%), Dithane M$45(0.2 \%)$ and Difolatan $(0.3 \%)$ were effective in controlling disease incidence/ intensity, and thereby increasing seed yield (Gupta et al. 1985). From Rajasthan, Mathur and Sharma (2006) reported effectiveness of Mancozeb as seed and foliar spray in reducing seed-borne infection; 4-5 sprays of Mancozeb $(0.25-0.3 \%)+$ Metasystox $(0.05 \%)+$ Sandovot as sticker were reported to be effective for purple-blotch and Stemphylium-blight.

\section{Charcoal-rot, c.o. Macrophomina phaseolina (Tassi) Goid.}

The disease was reported from Madhya Pradesh (Garg and Chauhan 1981). Externally both healthy and diseased bulbs appear similar, but diseased bulbs show ashy discolouration. On close examination, after peeling outermost dry scales, dark charcoal coloured blemishes with pinhead-like sclerotial bodies on one or two scales below the outer dry papery scales can be noticed. The scales become papery, dry, brittle later, and slough off easily. Infection starts with a white discolouration which gradually increases, followed by formation of jet-black sclerotial bodies after a week. Chandra and Tandon (1965) reported the fungus on garlic-bulbs also.

Control measures detailed under purple-blotch are promising for this also.

\section{Grey-mould/neck-rot, c.o. Botrytis allii Munn/Botryotinia spp.}

The first description of onion neck-rot was that of Sorauer from Germany in 1876. Since then the disease has been reported from the USA and UK. It at present has been reported from many countries. David and Irene (1966) reported it from Israel. Walker (1975) distinguished three species of Botrytis. But the most common is grey-mould species, Botrytis allii. The pathogen also 
infects shallot (Allium ascalconicum Linn.) and garlic. Ramsey and Lorbeer (1986) recorded 'Flower blight' on onions kept for seed purpose. All florets or seed capsules were blighted due to infection. Infection occurs near the flower base. The cardinal temperature varies with species. Three isolates (B.allii, B. cinerea and B. byssoidea) were recorded. B. porri was also identified on onion-seed samples from Canada (Toit and Derie 2002).

The disease is found common on bulbs after harvest. Onions for seed production are damaged. Infection takes place through neck tissues or through the stem-end or wounds.

Symptoms : Softening of the affected scale-tissues occurs first, which take on a sunken and cooked appearance. This remains characteristic of the advancing region of decay, which is separated from the healthy tissue by a definite margin. Mycelial presence on the outer zone of the decaying tissue is scanty, but increases gradually in older diseased areas; tissues become greyish and a dense mycelial mat develops soon over the surface of scales. Under moderately humid conditions, conidial production is fast. The disease progresses rapidly down to scales which were infected originally at the neck. The spread from scale to scale proceeds slowly. The advancing margins have a distinct water-soaked appearance. Older tissues continue to decay and sclerotia appear first as whitish compact mass of mycelia, which become darker with age until assuming appearance of hard black, rounded kernel-like bodies, which are spherical, oblong or irregular and vary from 1 to $5 \mathrm{~mm}$ in length. They are usually formed on the outer surface of the scales or are slightly embedded in the host tissue. At this stage, bulb undergoes desiccation, followed by premature sprouting. The older decayed bulb gives 'mummy' appearance. The fungus may cause white necrotic lesions on leaves and seedstalks. It may also damage seeds.

The fungus over-winters as sclerotia in the soil or bulbs. Decayed bulbs may serve as a source of inoculum. Blast or leaf spotting during growing season may also be incited. Neck-rot is an extremely spasmodic disease as it is favoured by cool, moist weather. Conidial production, germination and mycelial growth occur over a wide temperature range. Infection and postinfection decay of bulbs are favoured at 15 and $20^{\circ} \mathrm{C}$. Succulence of the neck tissue at harvest time is important in determining infection. Rapid drying out of decayed neck tissue may check further disease progress. White-bulb varieties of onion are more affected than coloured varieties. It has been observed that certain phenolic substances in the dry, outer coloured scales are antibiotic to $B$. allii. Since these materials are contained chiefly in the outer scales and only in the outer epidermal cells of the succulent scales, infection may occur when succulent neck tissue is exposed at harvest. Infected umbels do not produce seeds (David and Irene 1966).

Control measures : It is advised to grow only coloured varieties and also avoid wounding during harvesting. Artificial curing of the bulbs should be 
done. Warm dry air is forced through bulbs in bins until outer scales are quite free from moisture. This process reduces neck-rot as well as smudge and bacterial soft-rot. The blast phase of the foliage can be reduced by spraying Ferbam $0.2 \%$ (Walker, 1975). Spraying of fungicides as detailed under purpleblotch is applicable here also.

\section{Smut, c.o. Urocystis cepulae Frost}

Onion smut made its first appearance in Europe. A specimen of the fungus in the Persoon herbarium in France, collected around 1834, leaves no doubt about its European origin. The disease was introduced into the USA, India, Egypt, New Zealand and Canada. In the USA, the disease was reported from northern states (Walker 1975). The fungus is restricted to genus Allium, within which there are considerable number of susceptible species. Common hosts, besides onion, are A. porrum and A. fistulosum. The disease has also been reported from India.

Symptoms : Streaks appear on the leaves. Spots are seen even on cotyledons. On older leaves, spots are formed from tip to base. These lesions after sometime rupture and expose spores, which look-like black powder; infected plants die. In India, desi varieties are commonly attacked. Infection is through spores present on seeds and bulbs. Spores (chlamydospores) survive in soil for several years (Suryanarayana 1978).

Raut et al. (1984) observed symptoms due to severe infection in stored onions from Vidarbha on both white and colured onions. But conspicuous symptoms occurred only on white varieties. Onion scales show presence of smut. Black spore masses in sori contain teliospores. When such onions are planted, emerging seedlings contact disease in situ and serve as the primary source of inoculum. Infection in storehouses occurs through infected bulbs carried from the field, and spreads during cleaning operations. Storage under high humidity favours disease spread. No symptoms are observed during summer period.

The optimum temperature for teliospore germination, hyphal fragment germination and vegetative growth is between 13 and $22^{\circ} \mathrm{C}$. Above $25^{\circ} \mathrm{C}$, there is reduction in germination (Walker 1975). Disease initiation by seed-borne inoculum is doubtful, although spores are noticed on seeds as well as on bulbs. Seeds appear to be a means of spreading disease into newer areas.

Control measures : Seed treatment with Thiram $(0.2 \%)$ is found promising (Larson and Walker 1953). Captan, Hexachlorobenzene (HCB) or Folpet (all at $0.2 \%$ concentration) are being used as substitute for Thiram. Granule formulation of fungicides (Thiram, Captan or Phaltan 50\% a.i.) mixed with an insecticide and applied to soil by dribbling into furrows along with seeds has been found effective (Newhall and Brann 1960). Seed treatment with Thiram $(0.2 \%)$ or Captan $(0.2 \%)$ along with furrow application was also recommended (Singh 1992). 


\section{Onion-smudge, c.o. Colletotrichum circinans Berkley}

The disease was first described by Berkley from England in 1851. It is common in Europe and United States. It occurs primarily on white-bulb varieties. Slight shrinkage and premature sprouting occurs in storehouses.

Symptoms : They are confined to scales and lower portions of unthickened leaves. Minute fungus stromata appear just beneath the host cuticle. They are dark-green at first and later with age become black. The stromata may be scattered promiscuously over the bulb surface or they may be congregated in smudgy spots around a few infection centres. The spots are roughly circular. On underlying scales, similar spots are seen surrounded by yellowish borders. Under humid conditions, pinkish fungal growth becomes visible on black stroma. In addition to $C$. circinans, other species, $C$. chardoniana Noila and C. allii Averena were also recorded to be pathogenic (Singh 1992). Optimum temperature for conidia germination is $26^{\circ} \mathrm{C}$. The disease can develop from 10 to $32^{\circ} \mathrm{C}$. Moisture is essential for conidial germination, and rain-drop splashes help in dispersal.

Control measures : Use of coloured onion varieties is the best method for control of onion-smudge as well as neck-rot. These varieties are resistant due to the presence of protocatehuic acid and catechol. Rafika et al. (2006) from Tunisia reported red onions with longer storage life than white ones. Storage life is correlated with dry-matter content.

The crop may be protected with fungicidal sprays (Zineb or Maneb @ $0.2 \%$ ) to reduce inoculum load. Drying of bulbs before storage with hot-air at $37-48^{\circ} \mathrm{C}$ is a pre-requisite. Chemical treatment of bulbs before storage with $0.2 \%$ Thiram/Captan/Difolatan was also found promising. Artificial curing and storage environment are same as described under onion neck-rot.

The fungus was reported to cause severe curls or twister disease of onion seedlings from Patna (Sinha and Singh1994). Whitish spots were observed on leaves, followed by acute chlorosis. The leaves curl or twist several times and result in stunting of plants. The disease was reported to be serious from Brazil and Nigeria. Seedling disease was controlled by two sprayings of Mancozeb $(0.25 \%)$ at 15 days interval.

\section{White-rot, c.o. Sclerotium cepivora Berk.}

Berkley first described the disease from England in 1841. The first authentic record of white-rot was from North America in 1918. Since then it has been reported from Europe, Egypt, India, Ceylon, Australia, South Africa and New Zealand (Swaminathan et al. 2002). The host range includes shallot (A. ascalonicum), leek (A. porrum), welsh onion (A. fistulosum) and wild garlic (A. canadense), besides onion and garlic.

Chandra and Tandon (1964) recorded soft-rot of stored onions from Allahabad. The disease was found throughout the year.Symptoms appeared as dirty white-spots on the outer scales giving a water-soaked appearance to 
affected area. Gradually spots increase in size and spotted region becomes soft. Finally whole bulb becomes pulpy.

Symptoms : They may appear at any time during the growing period. Fungus germination is stimulated by a thermo-stable substance released from Allium roots. Initial symptoms appear as yellowing and die-back of leaves, beginning at the tip and progressing downwards. A gradual decline of the plant may continue for some days or weeks. Coinciding with early symptoms, the disease appears on subterranean portions of the host-plant also. Roots and scales succumb to infection and become covered with white superficial fluffy mycelia.

A semi-watery decay destroys root and scales. By this time, black spherical sclerotia of pinhead size appear on the surface or are embedded within the decayed tissue. If bulbs are infected late, disease continues as a storage-rot (Walker 1975).Dhyani and Chauhan (1975) recorded heavy losses from Madhya Pradesh. An acid reaction of $p \mathrm{H} 6.0$ and a soil moisture of $25 \%$ favour infection. Sohi (1977) observed incidence (up to 60\%)in onion-bulbs (cvs Nasik Red, Bellary Red and Pusa selection) from Bengaluru.

Control measures : The disease can be controlled by containing sclerotial liberation from diseased bulbs. Disinfection and heavy manuring of soil helps in controlling disease in field conditions. Captan $(0.2 \%)$, Thiram $(0.2 \%)$ and Aureofungin $(100 \mathrm{ppm})$ showed good control against storage-rot with $25 \%$ spoilage against $50 \%$ in control. Liming of soil reduces incidence.

S. rolfsii is a non-specialized soil pathogen with a host range of over 500 species (Punja 1988). Storage utility is dependent on varieties.

Successful biocontrol of S.rolfsii/S.cepivora with cultures of Trichoderma spp. was reported (Sreenivasa Prasad and Rao, 1993; Desai and Schlosser, 1999). The sclerotia were exposed to infection by Trichoderma spp isolates. by placing 40-50 sclerotia at the outer periphery of colonies grown on potato dextrose agar ( PDA). After $24 \mathrm{hr}$ of incubation at $25 \pm 1{ }^{\circ} \mathrm{C}$, Trichoderma overgrew sclerotia. Isolates of T.harzianum, T. hamatatum and T. koningii killed all sclerotia by penetration, followed by colonization and death of sclerotia.

\section{Soft-rot, c.o. Cephalosporium curtipes Saccardo}

This disease occurs on stored onions. The fungus produces dark-brown coloured rotting that spreads to interior tissues. Scales separate easily with application of a little pressure. Scales maintain their form, but rotting beginning becomes evident by the secretion of yellowish brown liquid (Sharma and Roy 1978). The disease is of minor importance.

\section{Downy mildew, c.o. Perenospora sp.}

Mirakhur et al. (1977) reported downy mildew from Kashmir. The disease is common in the north-eastern areas adjoining Himachal Pradesh and Jammu and Kashmir. Devlash and Sugha (1977) reported downy mildew and its impact on yield from Himachal Pradesh. 
The disease is severe on seed-stalks than on bulb-crops. Onion-seed production was reported to be reduced by $60-70 \%$ in Punjab. The disease incidence was so high that many cultivators were compelled to abandon onion cultivation in certain pockets in Kashmir. The disease was observed to be severe after rains when temperature was $24 \pm 3^{\circ} \mathrm{C}$ and $\mathrm{RH}$ was $80-85 \%$ (Gupta and Srivastava 1984).

Symptoms : They are noticed on foliage including stalks. Stalks bearing flowers wither and result in yield reduction. The bulbs become moist and spongy.

Control measures : Difolatan $(0.1 \%)$ as well as Cuman (0.1\%) protected standing crop against downy mildew and this increased yield.

\section{Stemphylium-blight, c.o. Stemphylium botryosum \\ (Pleospora herbarum Pers. ex Fr. Rab), \\ S. vesicarium}

Stemphylium-blight is an important seed-and soil-borne disease reported from Jharkhand and Haryana (Jakhar et al. 1994). S. vesicarium is normally a weak pathogen but assumes severe form during prolonged wet period. In Haryana, Gupta and Srivastava (2000) observed certain varieties resistant to the blight.

Control measures : Mathur and Sharma (2006) evaluated fungicides against $S$. vesicarium in Rajasthan, and observed seed treatment and foliar spray of Mancozeb (0.2\%) effective in controlling the disease. Seed treatment $(0.2 \%)$, root dip $(0.1 \%)$ and foliar spray two times with $0.1 \%$ Hexaconazole reduced disease incidence.

Seed treatment, root-dip and two foliar sprays $(0.2 \%$ each) with Pseudomonas fluorescens recorded lower disease index and increased crop yield. P. fluorescens and other bacterial epiphytes were reported to be effective for other diseases also (Barnwal et al. 2003).

Onion-seeds were dipped overnight in rhizobacterial formulation of Pseudomonas fluorescens (PF-1), prepared by suspending $20 \mathrm{mg}$ of bacterial suspension in $1 \mathrm{ml}$ of water. The treated seeds recorded reduced disease incidence and increase in yield.

Leaf extracts (aqueous) of plants like Azadirachta indica Juss and Datura metel Linn. were reported to be effective in lowering disease intensity (Prasad and Barnwal 2004). Effect of leaf extracts of different botanicals on the growth inhibition of pathogens in vivo were also reported (Datar 1994; Varshney 2001; Malick and Singh 2002).

\section{Bulb-rot, c.o. Geotrichum sp.}

Miller (1987) observed bulb-rot due to Geotrichum sp. from south Texas in United States. The inoculated bulbs developed small water-soaked translucent lesions after three days of incubation at $20^{\circ} \mathrm{C}$. The disease is of minor importance in India. 
Penicillium-rot/blue mould-rot, c.o. Penicillium digitatum Sac (Naik et al. 2008)

This is considered as an important pathogen associated with storage-rot. Penicillium-rot caused by Penicillium ducaluxi was also reported (Gupta and Srivastava 1984).

Pre-harvest spray to the crop with SAFF(Carbendazim 12\% + Mancozeb $63 \%$ ) at $0.5 \%, 0.10 \%$ and $0.15 \%$ concentrations and Benomyl (Benlate) at $0.1-0.15 \%$ provided complete protection against blue mould. However, disease increased with storage duration (Raju and Naik 2006).

Rhizopus-rot caused by Rhizopus stolonifer was recorded by Gupta and Srivastava (1984) from Jaipur.

\section{POST-HARVEST DISEASES MANAGEMENT}

Post-harvest factors - field curing, grading, packing and transportation - determine quality of onion-bulbs. The length of the time required for curing depends on the weather factors. When temperature is low, bulbs are cured artificially. Onion-bulbs collected from fungicide-treated plots (sprayed with Bavistin $0.1 \%$ and streptocycline $0.02 \%$ ) and stored in crates recorded minimum storage losses (Srivastava et al. 2001; Gupta et al. 2001). Pre-storage treatments with Thiram (0.2\%), Ridomil Mz-7WP, Mancozeb + Metalaxyl $0.2 \%$, and Captan $(0.2 \%)$ were reported to be effective in improving seed and storage viability.

Sulphur and calcium carbonate treatments were also effective in preventing bulb-rot. High temperatures and long periods of pre-drying reduced rotting and sprouting significantly. Drying at $45^{\circ} \mathrm{C}$ for 48 hours at 15 days interval for 120 days was recorded promising (Lim et al. 2002).

\section{BACTERIAL DISEASES}

In Jaipur, highest magnitude of rotting (60\% of total rotting) of onions was observed on account of bacterial rots (Gupta and Srivastava 1984).

\section{Bacterial soft-rot, c.o. Erwinia carotovora f sp carotovora, E. aroidea}

The disease was reported from different parts of the world, including India (Smith et al. 1966; Raju and Raj 1980). Onion is an important commercial crop in the Cuddapah district of Andhra Pradesh. It suffers heavy losses in storage. Rotting was common in the popular variety Bellary Big. Loss of 0.2$28 \%$ was recorded; considerable reduction in weight was also noted.

Symptoms : Two types of symptoms are noticed. In the first type, on removal of outer scales of apparently healthy onion-bulbs, rot of inner scales is noticed with large, irregular water-soaked areas (Fig. 24.2). Yellowish colour extends from neck downwards; foul smell is also produced. The rotting portions become slimy in advanced stages. And slimy liquid yielding bacteria oozes out when neck is pressed. 
In the second type, on the removal of outer scales, soft-rot with large irregular dirty white watersoaked areas, extending from neck to base or vice versa, is observed. Aspergillus niger is also found associated with bacteria (Raju and Raj 1980). The disease is described in detail under soft-rot of potato and black-leg of crucifers.

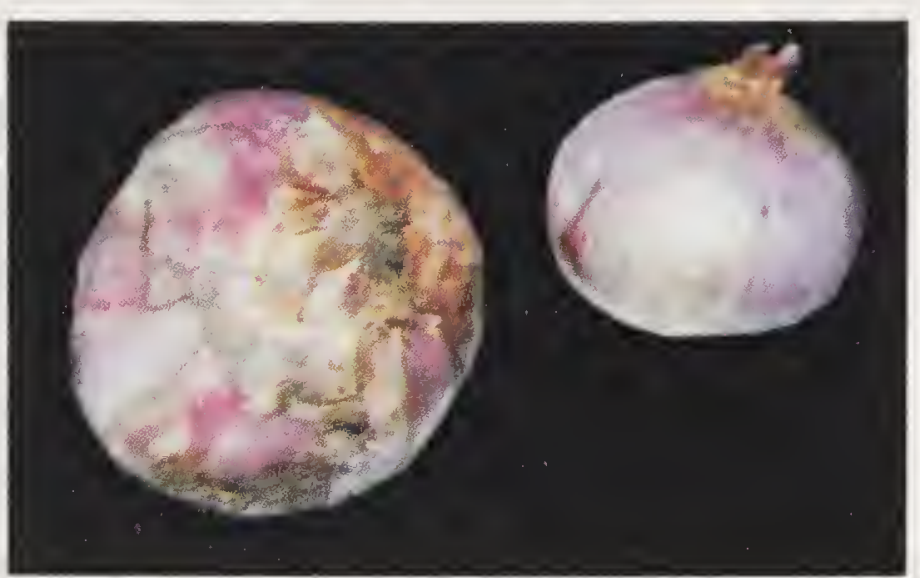

Fig. 24.2. Bacterial-rot on onion

Sero-diagnosis of E. carotovora var. carotovora on onion-seed was made by Sendhilvel et al.(2002)from Tamil Nadu. Polyclonal antibodies specific to bacteria were produced to identify and detect pathogen by indirect ELISA.

Control measures : In the field, planting should be done in well-drained areas; by allowing sufficient space among plants for adequate ventilation. Over head irrigation should be avoided. Susceptible varieties should be rotated with cereals or other non-susceptible crops (Agrios 1969).

Debris should be removed from warehouses and walls should be distinfested with solutions containing formaldehyde, copper sulphate (1\%) or mercuric chloride ( $1 \mathrm{~g}$ in $1,000 \mathrm{ml}$ of water). Onions need to be dried properly before storage. Storage temperature should be around $4^{\circ} \mathrm{C}$.

Biological control. Fluorescent Pseudomonas strain (FP 7) isolated from tomato rhizosphere showed promising results. Talc-based formulations of the antagonist, prepared by the method of Vidyasekaran and Muthamilan (1995), was used. In in vitro, Pseudomonas strain and Bacillus subtilis reduced growth of soft-rot bacteria. Seed treatment was effective in checking seed-borne Erwinia carotovora var. carotovora. Formalin at $2 \%$ concentration also checked Erwinia carotovora growth (Sendhilvel et al. 2005).

\section{Bacterial stalk-rot, c.o. Pseudomonas spp.}

Bacterial soft-rot of onion, caused by Pseudomonas alliicolal Burkholderia gladioli pv. alliicola and P. capsici, was reported by several workers outside India (Burkholder 1942, 1950). Hingorani and Malla (1951) from Delhi observed that most of the bulbs received in the IARI for trials were soft and emitted foul odour. On examination, they noticed bacteria, identified as P.marginalis (Brown) Steeven. Dowson (1941) also reported similar rots in onion and potato. Swarup et al. (1973) recorded stalk-rot due to $P$. alliicola (Burk.) Starr \& Burk. from Uttar Pradesh, where the disease was restricted to seed-crop alone. Up to $90 \%$ of the affected plants showed rotting. Infection was noticed on onion Kalyanpur Red;14-50\% of flower-stalks recorded rotting. Ram and Swarup (1979, 1979 a) reported disease from Uttar Pradesh. The disease incidence ranged from 12.8 to $35.6 \%$ in seed-crop and $8.5-30 \%$ in bulb-crop of different onion varieties. Plant debris left in the field 
acted as inoculum. The bacteria survive on bulbs and cause dry-rot during storage. Seed, soil and irrigation water do not play a role in disease cycle. Production of enzymes and toxins was also studied in-vitro.

Gupta and Srivastava (1984) observed that $30-40 \%$ of rotting was built in storage due to pathogenic organisms. Under favourable conditions ( $\mathrm{RH}$ $99 \%$, temperature around $30^{\circ} \mathrm{C}$ ), rotting up to $80 \%$ was noticed. Among the pathogens recorded, bacterial-rot caused by Pseudomonas sp. was maximum, and covered $60 \%$ of the total rotting, followed by black-mould, Aspergillus niger (20\%). Phytopathogenic species of Pseudomonas such as P. tabaci, $P$. marginalis, $P$. glycinea were also reported to produce toxins in in-vitro (Ceponis and Friedman 1959; Hoitink and Sinden, 1970; Srivastava et al. 2001).

Staglellini et al. (1990) from Venezuela observed bacterial disease affecting leaves and bulbs causing soft bulb-rot. The affected plants produced hollow bulbs, intermediate bulb scales and withered leaves with scorched appearance. Pseudomonas solalacearum and P. cepacea were isolated.

Control measures are as detailed under the bacterial soft-rot.

\section{Bulb-decay, c.o. Enterobacter coloacae}

The bulb decay was reported from Colorado (Schwartz and Otto, 2000)on sweet Spanish onion cultivars (A. cepta Linn.). Only mature and firm bulbs were infected. Symptoms associated with the disease are brownish discolouration and breakdown of inner scales.

\section{Seed mycroflora}

Wilcox and Balogh (1999) recorded following bacteria from onion in Nigeria - Staphylococcus aureus, S. epidermis, Listeria monocytogenes, $L$. denitrificans and Micrococcus luteus. During storage, Listeria, especially $L$. monocytogenes, became dominant on all cultivars. L. monocytogenes was frequently encountered on flesh and processed foods (Fuchs and Surendran, 1989; Hicks and Lund, 1991). In general, fungal contamination of onion cultivars was higher in the beginning of the storage. Aspergillus, Rhizopus, Monilia and Geortrichum species occurred both on the neck and body. Some potential mycotoxin-producing strains of Penicillium spp. viz. P. griseofulvum, P.islandicum. P. viridicatum and P.cyclopium, and Aspergillus spp. were also observed with prolonged storage.

\section{GARLIC (Allium sativum L.)}

Garlic is widely used for its medicinal importance. Red varieties are superior. Asia is the biggest producer of garlic. China ranks first, followed by Korea and India. Garlic is imported from China to meet Indian domestic demand. It is a carminative and gastric stimulant and helps in digestion and absorption of food. Besides all these, garlic is also used in reducing cholesterol 
concentration in the blood, and is used in case of flatulence also. It is good for pulmonary tuberculosis, sterility and impotence, cough and red eyes (Saha 2003). It is widely used as an insect repellent.

\section{FUNGAL DISEASES}

\section{Black mould-rot, c.o. Aspergillus niger Van Tieghem}

The disease is reported from almost all states of India. Philip (1998) recorded it throughout the year from the local markets of Thiruvananthapuram(Kerala).

Symptoms : The fungus manifests itself with black copious growth. Dustlike fungal spores remain concealed between scales. In advanced stages, black copious mass of spores can be seen inside the bulb. The individual bulb shrivels and becomes light in weight. Infected bulbs have rotten smell. A. niger was also reported by Sharma and Sumbali (1993).

Control measures : Bulbs should be cured thoroughly and stored in cold storage at $60-70 \% \mathrm{RH}$. Irradiation of bulbs with gamma radiations( $6 \mathrm{Krad}$ ) is suitable for long-term storage.

Rhizopus-rot/shrivelled bulb-rot, c.o. Rhizopus oryzae Went \& Geerlings

The disease was reported from Rajasthan (Mathur and Sankhala 1963), Bhubaneshwar( Rath and Mohanty 1978) and from West Bengal (Dasgupta and Mandal 1989). It causes much damage, especially during winter.

Symptoms : Affected bulbs become disfigured, shrivelled and turn into a pinkish mass. Sometimes dirty, white, fluffy mycelial mat develops on the surface. The disease is prevalent throughout the year. $R$. oryzae is a typical wound parasite and a storage pathogen. Due to infection, garlic-cloves get partially or completely rotten.

Control measures : Garlic bulbs for seed purpose are to be treated with $0.1 \%$ mercuric chloride or $0.03 \%$ formalin (if stored for table purpose) at periodic intervals of 10-15 days to avoid or minimize storage losses (Rath and Mohanty 1978).

Internal bulb-rot, c.o. Macrophomina phaseolina (Tassi) Goid.

\section{M. phaseoli (Maubl.) Ashby}

The rot due to M. phaseolina was reported from the USA (Alstatt and Smith 1943) and other countries. In India, it was reported from Uttar Pradesh (Chandra and Tandon 1965) on garlic-bulbs. Externally both diseased and healthy bulds appear similar. But on closer examination after peeling outer scales, black pinhead-like sclerotia become visible on the inner scales. Sclerotia are smooth, black and hard.

Symptoms : As the result of the infection, edible yellow fleshy portion of the scale gets reduced to a hard brown mass without usual pungent smell. 
Scales become papery, dry, and slough-off easily (Garg and Chauhan 1981). Cross inoculation was successful with Allium cepa. The disease was also reported from Odisha and West Bengal (Rath and Mohanty 1978 a, 1989).

Control measures : Treating garlic-bulbs with $0.03 \%$ formalin or $2 \%$ boric acid immediately after harvest was promising in minimizing storage loss due to fungal infection (Rath and Mohanty 1978).

\section{White-rot, c.o. Sclerotium cepivora, Berk. S. rolfsii Sacc.}

The disease was first reported from the USA by Berkeley in 1841(Asthana 1945). Thakur et al. (1962) and Kamat et al. (1977) recorded the disease from Uttar Pradesh and Maharashtra. The disease is favoured by a slightly acidic reaction and 25\% soil moisture (Dhyani and Chauhan1975).

Symptoms : The disease appears in the form of dirty, white-spots on the fleshy cloves. The spots increase in size with increased storage time. The cloves also turn brown, shrunken, light and hard. Tiny black sclerotia appear on cloves. This disease appears throughout the year. Severe infection is reported from July-to October. It is difficult to assess correctly the loss due to hidden nature of infection.

Control measures as detailed under white-rot of onion are applicable here also.

\section{Smut, c.o. Urocystis cepulae Frost}

The disease was reported from Vidarbha (Raut et al. 1984). Severe infection on stored garlic and onion was noticed; $80 \%$ of the bulbs were infected. Bulbs (carried) from the field spread the disease during cleaning operation. No symptoms were noticed during summer. The disease spreads in stored onion under periods of high humidity only.

Seed treatment with Thiram $(0.2 \%)$ is desirable. The bulbs should be cured properly.

\section{Garlic-bulb canker, c.o. Embellisia allii}

The disease was reported from Japan, Korea and Washington (Taniguchi et al. 1994; Lee et al. 2002; Dugan et al. 2004). In Australia in 1983-84, it was intercepted on garlic-bulbs imported from Hong Kong (Bertus 1984). The pathogen is not known to occur in India and pathogenicity in Allium spp. has not been studied. However Latha et al. (2007) observed interception of Embellisia allii on garlic-bulbs imported from China. 


\section{CHAPTER 25 \\ Miscellaneous Vegetables}

AMARANTHUS (Amaranthus sp.)

Amaranthus is an important leafy vegetable grown extensively in India. It is a rich source of many vitamins and minerals; serious pests and diseases are not reported on this crop.

\section{FUNGAL DISEASES}

\section{Leaf-blight, c.o. Colletotrichum capsici (Syd.) Butler \& Bisby}

A severe leaf-blight of A. caudatus, locally known as Rajgira', was reported by Somani et al. (1976) from Akola.It is characterized by irregular, dark-brown spots on the leaf lamina, which later elongate along with the veins and veinlets. As the result of the development of the necrotic area on both the sides of the veins, leaf becomes brittle ultimately. The necrotic region becomes greyish black, on which many minute submerged pin-point acervuli are seen.

A. caudatus is widely cultivated throughout the plains of India as a garden, ornamental and pot-herb. Hill tribals cultivate this as a regular crop because of its edible grains.

Control measures are not generally practised.

\section{Foliar-blight, c.o. Rhizoctonia solani Kühn}

\section{Thanatephorus cucumeris (Frank) Donk}

The disease was reported from Asom (Baruah et al. 1985). and from Kerala on A. tricolour (Kamala Nayar et al. 1996).

Symptoms : Small, irregular whitish-cream spots appear on leaves in 1. greenhouse and in the field and they enlarge under high humidity. As the spots age, they become translucent and light-green with irregular margin. Severely infected leaves show shot-hole symptoms as the infected tissues get dislodged by air currents leading to defoliation. On the underside of the leaves, hymenial layer of Thanatephorus cucumeris is observed as a powdery mass. Infection is not visible on the plant stem (Gokulapalan et al. 2000). 
Control measures : Green amaranth Co 1 is a resistant variety. Spray plants at weekly intervals, 14 days prior to harvest with Mancozeb@ $4 \mathrm{~g} /$ litre in cowdung supernatent (cowdung diluted with water) as fine droplets. The plants should be covered properly so that spray solution reaches undersurface of the leaves also.

The following fungi are also reported.

Alternaria alternata

Cladosporium cladosporiodes, F. moniliforme, Penicillium sp., Phoma amaranthus, Rhizopus oryzae and Trichoderma viride

\section{DRUMSTICK/MORINGA FRUIT (Moringa oleifera Lam.)}

Moringa fruits at mature stage are considered a delicious and nutritious vegetable. Its flesh is rich in protein, vit. A, vit. C, minerals, crude fibres and phosphorus.

The fruit is affected by the following diseases only.

\section{Corky lesion, c.o. Fusarium acuminatum}

Lesions roughly ovoid, raised, and $0.2-0.3 \mathrm{~cm}$ in diameter appear on fully mature fruits. The upper portion is covered by caramine-red mycelial mass of fungus, and finally the rot becomes soft (Mandal and Dasgupta 1978) (Fig. 25.1).

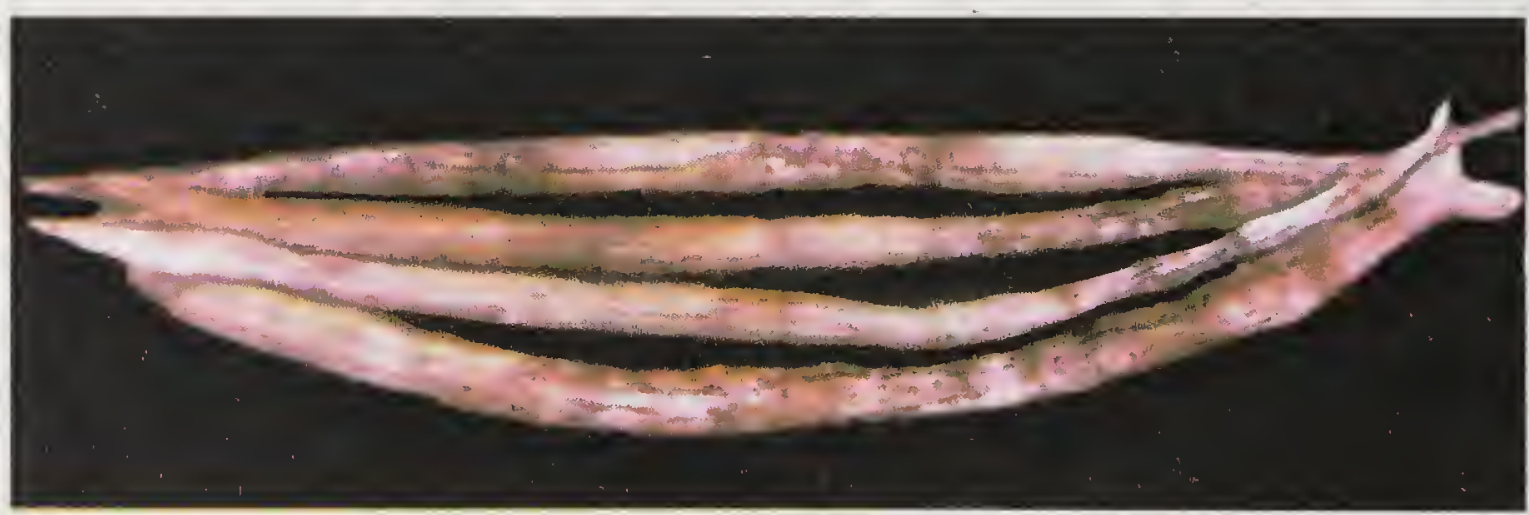

Fig. 25.1. Mixed infection of Fusarium and Rhizopus on drumstick

Avoid injuries to the fruit at the time of harvest. Cold storage at $10^{\circ} \mathrm{C}$ is promising in controlling storage rots.

\section{Distal-end rot, c.o. Rhizopus oryzae Went \& Prinsen Geerligs}

Infection appears in the form of water-soaked lesions on the young fruits. Infected fruits emit out characteristic smell. Rahman et al. (2001) studied physico-chemical composition of healthy and diseased fruits at different maturity levels. Total sugar, starch and vit. $\mathrm{C}$ content were reduced due to infection. Enzyme catalase and protease activity increased but of polyphenol oxidase and ascorbic acid oxidase decreased remarkably.

Avoid injuries to the fruit at the time of harvest. Cold storage at $10^{\circ} \mathrm{C}$ is effective in controlling storage rots. 


\section{LADY'S FINGER/OKRA/BHENDI}

(Abelmoschus esculentus (L.) Moench.)

Okra is a popular vegetable cultivated all-over India, and it is used in daily diet by majority of Indians. The fruits are rich in pectin and also contain iron and calcium. They are mucilaginous in nature, and are commonly used for thickening soups, stews and sauces.

\section{FUNGAL DISEASES}

\section{Dry-rot, c.o. Aspergillus flavus Link. ex Fries}

The disease was reported from Madhya Pradesh (Jain et al. 1982). Infection starts from the apical end, resulting in complete drying of the fruit within 10-12 days. The mouldy growth of the fungus is clearly visible on the fruit surface. Refrigerated storage at $10^{\circ} \mathrm{C}$ is promising.

\section{Cottony-leak, c.o. Pythium butleri Subram. \\ $P$. aphanidermatum (Edson) Fitzp.}

Mandal and Dasgupta (1981) recorded it as the most serious disease of lady's finger, prevalent in West Bengal. The infection is serious from March to September in wet weather, particularly in borer damaged or injured fruits. Philip (1998) recorded fruit-rot from the local markets of Thiruvananthapuram. Symptoms : Water-soaked lesions appear around broken areas. The rot advances rapidly and within 3-4 days whole fruit becomes slimy and rotten. Scanty white growth of the fungus is also visible,and fruits emit offensive smell. Singh (1992) recorded Phytophthora palmivora also. The disease spreads fast through contact and causes decay of entire lot at high humidity, coupled with temperature around $30^{\circ} \mathrm{C}$. At later stages, Pseudomonas fluorescens, Erwinia herbicola and Entrobacter sp. hasten rotting. The former two were recorded weakly pathogenic (Dasgupta and Mandal 1989).

Control measures : Bruised or injured fruits should not be used for storage. The fruits should not be tightly packed in gunny bags or kept in a heaped position during the wet weather. Sprinkling of water over fruits should also be avoided. The fruits should be spread out, not touching one another. Storage of fruits at $10^{\circ} \mathrm{C}$ is promising.

Grey blight-rot, c.o. Sclerotium rolfsii, Sacc.

Rhizoctonia solani Kühn

The disease was recorded from West Bengal.

Symptoms : Water-soaked dull areas appear, lacking in lustre, with white thick stranded oppressed 259and rough cottony mycelial growth over the host surface (Fig. 25.2). At high humidities, sclerotical knots or mustard-like reddish-brown hard sclerotia appear. Affected fruits are devoid of its natural odour. The infection spreads by contact (Dasgupta and Mandal 1989). Philip 
(1998) observed similar symptoms on bhindi fruits in the local markets of Thiruvananthapuram during rainy season from April to July. Typical mycelia and sclerotia were observed. The fungus grows faster and covers the fruit within 3-4 days.

Seedling blight due to $R$. solani was recorded by

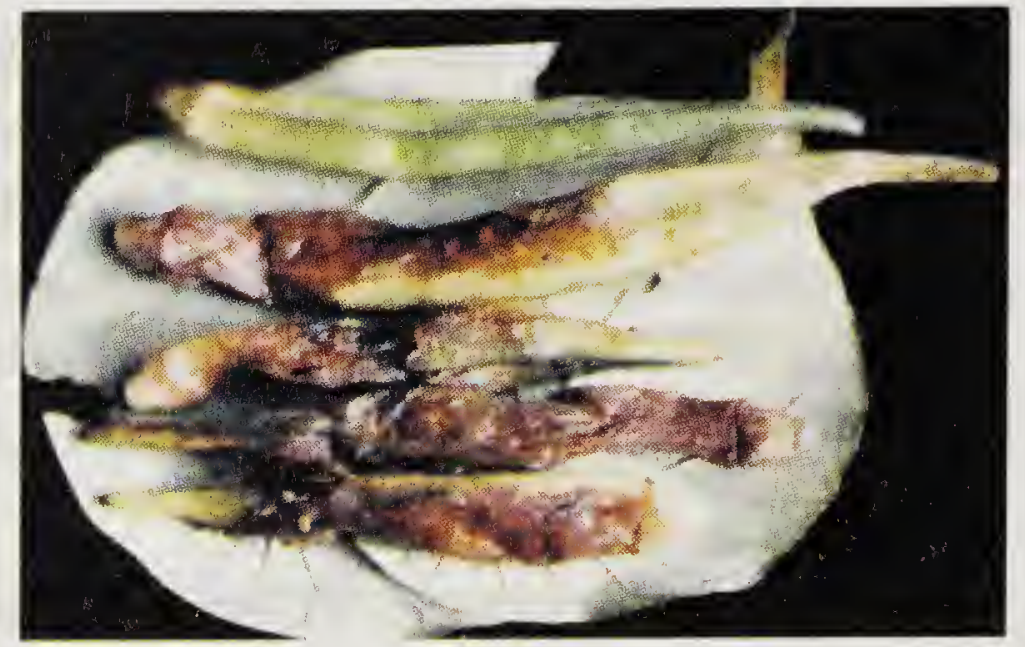

Fig. 25.2. Rhizoctonia-rot on lady's finger Suryanrayana (1978) as an important disease in India. The pathogen causes failure of germination. It also causes root-rot and blight on other parts. Sometimes seed-crop is heavily infested. The variety Pusa Sawani is highly susceptible. The disease was observed in a severe form in the seed-production plots of Karnal. Root system and the stem up to a considerable height are affected. Fruits are seriously damaged and seeds are covered with mycelia and sclerotia. Seed infection is both external and internal.

Control measures: Hot-water treatment at $50^{\circ} \mathrm{C}$ for $30 \mathrm{~min}$, followed by protective dressing with Thiram $(0.2 \%)$, are recommended. Seeds should be procured from disease-free areas. Areas with heavy infection should not be used for raising seed-crop for at least 3-4 years. Infected fruits should not be mixed with healthy fruits.

\section{Mucor-rot, c.o. Mucor hiemalis Wehmer}

Philip (1998) observed the disease from the local markets of Thiruvananthapuram during the south-west monsoon period. 'Nest rot' type of symptoms are noticed. Fruits can be seen clinging together in clusters. This is usually noticed when fruits tightly packed in gunny bags are released/unpacked. Fruits become water soaked and get covered with profuse mycelial growth (Fig. 25.3).

Control measures : Fruits should not be kept in a tightly packed position. Refrigerated storage at $10^{\circ} \mathrm{C}$ is

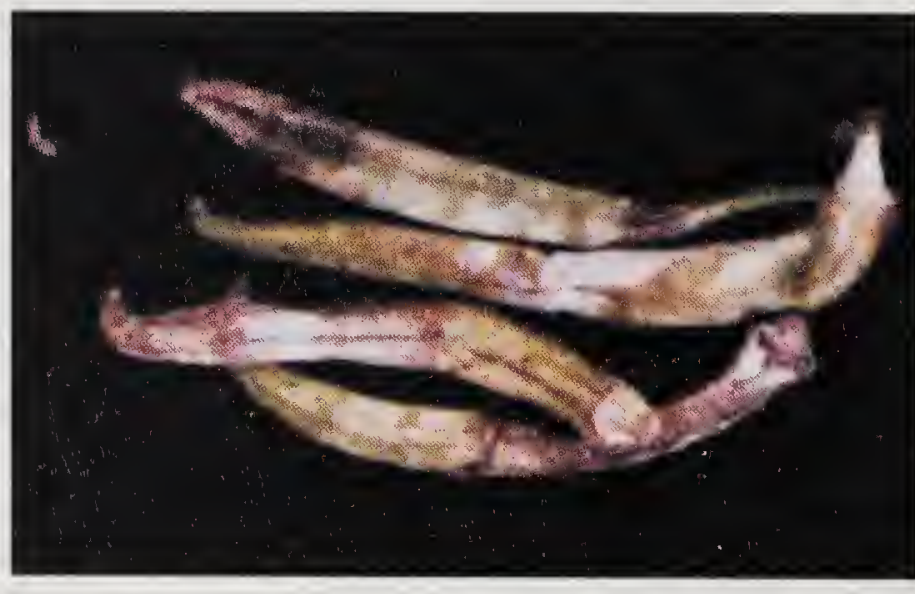

Fig. 25.3. Mucor-rot on lady's finger promising.

\section{Fusarium-blight, c.o. Fusarium sp.}

Seed-borne infection was recorded (Suryanarayana 1978). Infected seeds often fail to germinate. If seedlings emerge, they get blighted. Seed-borne infection is both superficial as well as deep seated (Gangopadhyay and Kapoor 1977). Seed treatment with Thiram $(0.2 \%)$ is effective in controlling infection. 
Hema et al. (1991) reported Carbendazim and Triflumizole effective as slurry against Fusarium spp.

Patel et al. (2004) noticed efficacy of seed treatment with Bavistin, followed by Agrozim, Derosal and Pausin-M (@ 2g/kg of seeds) against okrawilt under field conditions.

\section{Seed-rot, c.o. Phoma destructiva Plower}

Pankaja (1983) observed seed-rot due to $P$. destructiva on seed samples of bhindi collected from Mysore. About 8-30\% infection was recorded. Considerable variation in the length of plumule and radicle was also observed.

Seed treatment with Captan $(0.2 \%)$ or Thiram $(0.2 \%)$ is found effective.

\section{Pod-spot, Ascochyta abelmoschi}

The disease was reported from the USA and Brazil. In India, it is common in Himachal Pradesh. Its symptoms appear on leaves and fruits. The disease spreads by fruit borers. Infection is seed-borne. It also survives on infected crop tissues, lying in the field (Suryanarayana 1978). An Ascochyta sp. causing pod-rot with an ash-grey centre was also recorded by Singh(1992). In advanced stages, fruits shrivel and dry-up.

Seed treatment with Captan $(0.2 \%)$ or Thiram $(0.2 \%)$ is effective.

Colletotrichum fruit-rot, c.o. Colletotrichum capsici (Syd.) Butler \& Bisby, C. hibisci

Both fungi are recorded to cause fruit-rot (Singh 1992). Sanitation and spraying with Zineb, Maneb or Captan (all at 0.2\%) in fields control the disease.

\section{Seed mycoflora}

Seed-borne fungal pathogens have a major role in seedling diseases and cause considerable losses to crop. The fungi include the following.

Fusarium oxysporum, Pestalotiopsis versicolor Pattnaik and Narain, 2000 Aspergillus tamari, A. flavus

Okra seeds showed infection range of $61-74 \%$. At higher moisture levels (7.5-10\%), this was more compared to seeds stored at 5\% moisture level. Cellfree culture filtrates of $C$. capsici, $F$. solani and $F$. oxysporum reduced seed germination, and seedling, shoot and root growth. In controlling seed-borne fungi, fungicides Bagallol, Mancozeb and Thiram (all at $0.2 \%$ ) proved effective.

Other fungi included are:

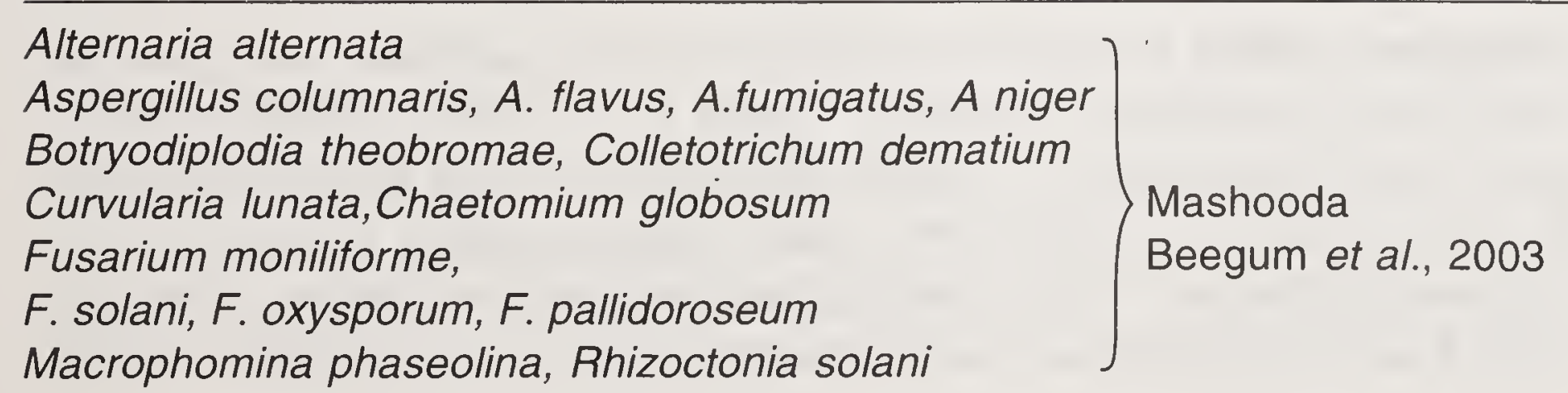


Rhizopus stolonifer

Trichothecium roseum

Colletotrichum capsici

Alternaria alternata, A. solani,

F.oxysporum, F. solani

Phomopsis vexans, Macrophomina phaseolina

Aspergillus spp., Phoma sp.

Curvularia lunata

Rhizopus spp.

Thippeswamy et al., 2004

Seed treatment with fungicides is practised for controlling seed-borne infection.

Carbendazim (Bavistin) and Chlorothalonil (all at $0.25 \%$ ) were found effective against most of the seed-borne pathogens. But were ineffective for A.alternata. Triflumizole $(0.30 \%)$ was promising against A.alternata (Hema et al. 1991).

Seeds treated with Thiram and stored in polythene bags remained viable for longer periods compared to seeds stored in cloth-bags (Vijaykumar, 2001). Dithane M-45 and Captan(all at $0.2 \%$ ) are also effective in inhibiting seedborne pathogens and in increasing seed germination.

Effect of seed treatment along with biocontrol agents was reported from Haryana. Bavistin, Benlate, Captan, Dithane M-45, Ridomil MZ, Vitavax@ $2 \mathrm{~g} / \mathrm{kg}$ and commercial formulation of biocontrol agent Echoderma (T. viride@ $4 \mathrm{~g} / \mathrm{kg}$ of seeds) enhanced seed germination and reduced seedling infection. Seed leachate and seed extract of okra are also reported to inhibit spore germination of $F$. oxysporum, Alternaria alternata and A. niger( Shrisail et al. 2002, 2002 a). Indofil M-45 and Captan (0.2\% each) are also reported to be effective in inhibiting seed-borne pathogens - Macrophomina phaseolina and A. alternata.

The concept of plant growth promoting rhizobacteria (PGPR) for promotion of plant growth is gaining worldwide acceptance. Mashooda Beegum et al.(2003) reported effectiveness of PGPR isolates and tested them against seedborne fungal diseases and evaluated their potential against seed-borne diseases of okra. Among the different bacterial isolates, Bacillus pumilus, B. pasteurii, and two strains of $B$. subtilis were observed to be effective in improving crop growth in greenhouses and in fields. The colonization of these bacterial strains reduced incidence of seed mycoflora, and thus indirectly enhanced percentage of seed germination and vigour index of seedlings.

Biological control. Continuous use of seed-dressing fungicides causes pesticidal hazards and environomental pollution. Gurjar et al. (2004) recorded biocontrol agents like T. harzianum, T. viride, Gliocladium virens and Pseudomonas fluorescens effective. Seeds were coated with sporulating cultures of these biocontrol agents for 2 hours, dried in shade and used for planting in the field. Treated seeds exhibited increased germination and reduced seedling mortality. 
Biocontrol agents besides mycoparasitizing, also act as agressive competitors to the pathogen. Production of antibiotics by biocontrol agents has also been reported. Mixing of seeds with biocontrol agents (commercial formulation of Trichoderma )helps controlling seed-borne infections.

Control of seed-borne fungi with Pseudomonas fluorescens and with an aqueous leaf extract of Lawsonia inermis was also reported. Complete inhibition of A. flavus and Macrophomina phaseolina was shown. But inhibition was less to A.niger and F. moniliforme infection (Beebi and Rasheed 2007). 


\section{CHAPTER 2)}

\section{Spices and Condiments}

GINGER (Zingiber officinale Rose.)

Ginger is one of the important spice crops of India, known for its medicinal properties. The crop is cultivated in all the agroclimatic zones from Himachal Pradesh to Kerala. A gap of 4-5 months exists between the harvesting and the subsequent planting in the succeeding season. During this period, the seed-rhizomes are stored by farmers in the conventional pits. Storing seed-rhizomes results in $34 \%$ post-harvest losses and also reduces quantity and quality of seed-ginger (Sharma and Dohroo 1982).

\section{FUNGAL DISEASES}

\section{Soft-rot/rhizome-rot, c.o. Pythium spp., Fusarium spp.}

Soft-rot of ginger is a serious disease, threatening ginger cultivation, and is reported to be of worldwide occurrence. In India, the disease was first reported by Butler (1907) from Gujarat, followed by Subramanium (1919) from Bihar and Uppal (1940) from Bombay. It was also reported from Ceylon (Park 1941). P. aphanidermatum is considered as the common pathogen associated with soft-rot.

The disease was recorded in 1949 from Wyanadu, Kerala (formerly Tamil Nadu) which is situated at an elevation of 1,000 m amsl(Ramakrishan 1949). The fungus was identified as Pythium vexans de Bary. Sahare and Asthana (1962) reported P. monospermum and $P$. gracile in addition to Pythium species, mentioned earlier. Haware and Joshi (1974a) during a survey in Madhya Pradesh observed the disease to be widespread. Pre-emergence and postemergence damping-off were commonly observed. Isolations from infected plants were $P$. deliens Meurs, $P$. zingiberum (Ichitani and Goto 1982), $P$. pleroticum (Dohroo and Sharma 1985) and P. myriotylum (Mathur et al. 1992; Lodha et al. 1994). Along with Pythium spp., several species of Fusarium like F.solani, F. moniliforme, F.oxysporum and F.equiseti were also found associated (Rosenberg 1962; Dohroo 1972; Haware and Joshi 1972; Rath et al. 1978; Dohroo, 1988; Mathur et al. 2002; Dohroo 2001). Besides these, Verticillium and Chlamydosporium were reported (Dohroo 1989; Ram et al. 2000; Dohroo 2001). 
Chauhan and Patel (1990) studied etiology of rhizome-rot and observed $P$. aphanidermatum and $F$. solani together or separately responsible for rotting. Combined infection by both resulted in rapid drying of fruit shoot, followed by rhizome rotting.

Symptoms : Initial symptoms are visible on leaves. Soon entire foliage turns yellow, followed by drying and withering. This ultimately results in plant death. Dead leaves droop and hang along the stem. The basal portion becomes water-soaked, soft and later gets shrivelled. The symptoms are also noticed on rhizomes. They become discoloured and gradually rot (Fig. 26.1). The roots also show rotting. The infected rhizomes

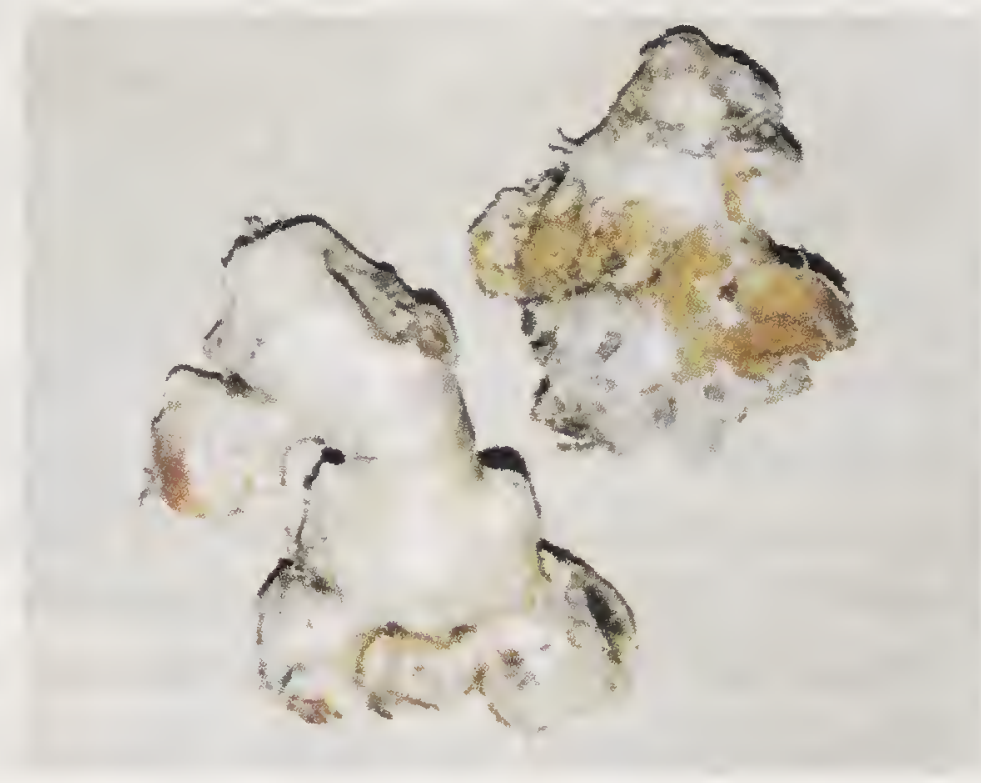

Fig. 26.1. Mixed imfection of Fusarium and Pythium on ginger

continue to rot in storage also. The disease is severe in fields where drainage is poor. Storage-rot is considered complex as it is soil-borne as well as seedborne.

In Himachal Pradesh, conventional pits of different sizes ranging from 1 to 5 metres are used for storage. These pits are exposed to varying temperatures and relative humidities $\left(12-18^{\circ} \mathrm{C}, 60-80 \% \mathrm{RH}\right)$. It is observed that storage temperature and relative humidity are directly correlated with the rot. Three types of symptoms are generally noticed (Dohroo 2001).

- Soft-rot, c.o P.ultimum: The surface of the diseased rhizomes turns brown to black, followed by maceration of tissues, leading to decomposition of rhizome with fibro-vascular strands remaining as such.

- Dry-rot, c.o F.oxysporum: The affected rhizomes show no external symptoms. Internal tissues become brown and yellow. Discolouration is seen in the rhizome pith region. Tissues become black.

- Red-rot, c.o V.chlamydosporium: The affected rhizomes show superficial mycelial growth and internal tissues become discoloured.

Indrasenan and Paily (1982) collected rotten specimens from Amblavayal (Kerala) and studied pectic enzymes role in tissue maceration. Dohroo (1989a) observed rise in peroxidase and polyphenol oxidase activities three days after infection by $P$. pleroticum and $F$. equiseti (dry-rot), followed by a sharp decline. Polyphenol activity was not detected in healthy rhizomes.

A technique for rapid detection of vegetative hyphal body (VHB) on a selective isolation medium is also available from Japan (Shimizu and Itchitani, 1982). This helps in easy identity of an isolate for undertaking control measures. 
The host range of the pathogen includes beans, peas, balsams, spinach, carnations and barley. Highly resistant or immune plants include carrot, chrysanthemum, cabbage and zinnia (Ichitani and Konyo1981).

In the rhizome-rot of ginger as well as in turmeric, association of maggots of Dipteran fly Mimegralla was noticed. Etiological studies under controlled conditions indicate Pythium to be the primary pathogen and maggots as the secondary colonizers of dead tissues (Anandaraj and Sarma 2000).

Control measures : The pathogen is seed-and soil-borne. Disease management of rhizome-rot by soil solarization and pesticides was reported (Balakrishnan et al.1994; Mathur et al. 2002). Disease in the field is positively correlated with its occurrence in storage. Siddiqui and Kaushal (2001) observed positive correlation between incubation period and storage-rot. Medium nitrogen and low potassium were effective in reducing disease incidence (Rao et al. 2004). The following control measures are also suggested.

Evolving/screening resistant varieties. Dohroo (1989) tested 10 cultivars and observed SG 66 to have the lowest disease incidence by $F$. oxysporum, which caused seed transmission, pre-emergence rot and yellows in ginger. Screening of ginger varieties against rhizome-rot complex/yellow disease caused by $F$. oxysporum, $F$. solani and $F$. equiseti, showed only variety ZO 16 to be resistant from Odisha (Senapati and Sugata 2005).

Pre-treatment of rhizomes with chemicals. Sundaram (1955) recorded efficacy of mercuric chloride and wettable ceresan as seed treatment chemicals. Seed-rhizomes treated with Dithane Z-78 (0.15\%), Perenox $(0.3 \%)$, BM $(0.4 \%)$, Ceresan $(0.25 \%)$ and mercuric chloride $(0.1 \%)$ showed disease suppression in the field (Sahare and Asthana 1962). Rath et al. (1978) recommended seed treatment with Arasan and soil fumigation with Trizone to be effective under warm and humid storage conditions in Odisha. Due to the ban on mercury compounds, efforts are concentrated on systemic and non-systemic fungicides. Dohroo and Sharma (1983) studied efficacy of chemicals under storage experiments in pits against wet-rot caused by $P$. pleroticum and dry-rot $(F$. equiseti), and observed maximum control with Antracol (0.25\%). Antracol is recommended as it is of low toxicity and is found to control both storage rots in Solan (Himachal Pradesh). Rhizomes are dipped in fungicidal solution for 30 minutes. Dipping in fungicidal suspension of Bayleton (Triadimefon), Fenaminosulf, Difolatan (Captafol), Syllit (Dodine), Ridomil (Metalaxyl) is effective in reducing infection by $P$. aphanidermatum and $F$. solani. Seed treatment with Metalaxyl formulations, followed by soil drench for about one month after sowing gave control of rhizome-rot caused by $P$. aphanidermatum (Rathaiah 1987; Ramachandran et al. 1989). Similar results with Metalaxyl were also reported from Gujarat. Matalaxyl formulations and Bordeaux mixture $(3,000$ ppm) gave best inhibition of Pythium-rot and Fusarium-rot respectively when used singly or in combination (Chauhan and Patel 1990). In Himachal Pradesh, 
Dohroo and Paramer (1993) observed pre-storage treatment of rhizomes with Dithane M-45 or Captan for 60 min effective in inhibiting rhizome sprouting, surface shrivelling and discolouration.

Soil solarization and pesticides also recorded as an effective field treatment for managing rhizome-rot (c.o., P. aphanidermatum) (Balakrishnan et al. 1994; Mathur et al. 2002). A combination of treatments with Dithane M-45 (0.3\%) + Bavistin (0.2\%), followed by $T$. harzianum (slurry treatment in cowdung) were reported effective in managing storage-rots (Dohroo and Negi 2000).

Treatment of seed-rhizomes with Mancozeb (0.3\%) and drenching seedbeds with cheshnut compound or with $1 \%$ Bordeaux mixture or $0.3 \%$ Mancozeb was also reported (Anon. 2007).

Biological control measures. Ghorpade and Ajri (1982) studied effectiveness of different oilseed cakes. All of them reduced disease incidence in the field and increased yield. The disease incidence was significantly suppressed by pelleting or by amendment in the field just before sowing with Trichoderma species. T. viride suppressed rhizome-rot caused by $P$. myriotylum, but was ineffective to Fusarium solani under in-vitro conditions due to activity of volatile and non-volatile substances produced by antagonists. The growth of the pathogen was inhibited completely. The oogonia formation was also inhibited.

Several biocontrol agents(BCAs) like T.harzianum, T. aureoviride, T. longibrachiatum and rarely Gliocladium virens are reported to protect through production of volatile and non-volatile diffusible antibiotics or through mycoparasitism (Lodha and Webster 1990; Lodha et al. 1994). Rhizomes pelleted with BCAs and sown in the field showed their establishment in the field to be several folds higher. Significantly higher number of sprouts, lower disease incidence, and higher yields were also recorded. T. viride was observed more effective than G. virens. Both Trichoderma and Gliocladium are known as potent antagonists to fungal pathogerns (Papavizas 1985). The effect of resident biocontrol agents for seed treatment was also studied. Rhizosphere establishment and proliferation of BCAs applied on seeds for suppression of soil-borne diseases were also reported (Elad et al. 1982; Mukhopadhyay et al. 1992; Clique and Schffer 1996; Ram et al. 2000).

Balakrishnan et al. (1994) reported efficacy of T. viride, T. harzianum I, II, T. hamatum and one isolate of G. virens in comparison to Dithane M-45. Seed germination was uniform in all the treatments. But less disease incidence and increased yield were recorded from biocontrol-treated plots. Pre-storage treatment of rhizomes with Topsin-M as well as Dithane M-45 or Bavistin, followed by $T$. harzianum slurry treatment showed promising results (Dohroo and Negi 2000). Dohroo (2001 a) studied population dynamics of naturally occurring T. harzianum Rifai and observed its antagonistic potential against rhizome-rot.

Effects of Trichoderma, fluorescent pseudomonads and their combination in disease suppression were also reported (Beena and Sarma 2000). 
The role of different chemicals, especially COC (Fytolan $0.5 \%$ ), as well as use of $T$. harzianum (cfu $9.9 \times 10^{8} / \mathrm{g} @ 5 \mathrm{ml}$ injected into pots with hypodermic syringe) against management of ginger diseases (Pythium sp., Fusarium oxysporum and Ralstonia solanacearum) in Sikkim was noticed (Rajan et al. 2002).

Rhizomes treated with $0.3 \%$ Mancozeb and inoculated with native arbuscular mycorrhizae/Trichoderma viride/Pseudomonas fluorescens (commercial preparations) and planted in beds previously treated with cheshnut compound/ Bordeaux mixture (1\%)/ Mancozeb (0.3\%) showed good results (Anon. 2007).

An integrated strategy for soft-rot management is required. This includes use of disease-free planting material, seed treatment with chemicals/pelleting with BCAs, adoption of suitable cultural practices, isolation and destruction of infected plants, providing adequate drainage, soil solarization and chemical control measures in combination with bio-antagonists.

\section{Ginger-yellows, c.o. Fusarium oxysporum Schlecht}

Ginger-yellows was first recorded by Trujillo (1963) from United States. Wilting occurs due to vascular infection by the fungus. The disease is common in the ginger-growing areas of Madhya Pradesh (Haware and Joshi 1974a). It is characterized by yellowing of leaves and wilting of adult-plants, thus leading to poor yields. The fungus causes rhizome-rot and post-emergence death of seedlings. Primary infection occurs from infected rhizomes. Sharma and Dohroo (1990) recorded occurrence and distribution of fungus causing ginger-yellows from Himachal Pradesh. F. solani and F. oxysporum were also reported from Jhansi and Sikkim (Siddique and Kaushal 2001; Rajan et al. 2002).

Five species of Fusarium were recorded. Among these isolates, $F$. oxysporum is the major cause of yellows in all ginger-growing areas, followed by F. solani, F. moniliforme (Giberella fujikuroi), F. graminearum (G. zeae) and F. equiseti. Variability in F. oxysporum $\mathrm{f}$ sp zingiberi was also reported (Dohroo and Sharma 1992); among the three isolates, Isolate I was more aggressive and caused $100 \%$ mortality of plants in the field and $87.5 \%$ rhizome-rot during storage, followed by II and III, which caused 60 and $80 \%$ mortality and 10 $25 \%$ rhizome-rot under storage (after 14 and 15 days of inoculation).

Rhizome treatment with Benlate $(0.25 \%)$, followed by foliar spray of Dithane M-45(0.3\%), was reported to be effective in controlling rhizome-rot and pre-emergence death of seedlings (Haware and Joshi 1974a).

\section{Creepy white rhizome-rot, c.o. Sclerotium rolfsii Sacc.}

The fungus grows superficially on the infected rhizomes. Rarely internal infection is also noticed. Sundaram $(1951,1953)$ recorded the disease from Tamil Nadu and Mehrotra (1952) from Allahabad. Fusarium roseum Link. is also associated under Allahabad conditions. During rainy season, gingerrhizome gets covered with white aerial growth. It is considered as an 
occasional, secondary or wound invader of ginger-rhizome. The disease is reported from Maharashtra (Rao 1968) and West Bengal (Dasgupta and Mandal 1989) and from Kerala (Philip 1998). It is prevalent throughout the year and has maximum intensity during rainy season. The affected rhizomes become moderately soft and the tissues below become water-soaked, brown and sunken.

Sundaram (1955) recorded dipping of rhizomes in mercuric chloride (1: 1,000) solution and wettable sulphur promising.

\section{Black-rot, c.o. Memnoniella echimata}

Sharma and Joshi (1976) recorded disease from Madhya Pradesh. Infection goes unnoticed in the early stages. But the infected rhizomes soon dry-out, get shrivelled and become grey-black to jet-black with black spore masses at the infection site that present a sooty appearance. The disease is of minor importance.

\section{Dry-rot, c.o. Macrophomina phaseoli (Maubl.) Ashby}

\section{Fusarium sp.}

The disease was reported from Kasaragod ( north Kerala) (Sharma and Nambiar 1974). The rot persists in storage. Affected plants have slight yellowing of leaves in the initial stages, and in advanced stages, whole plant presents a blighted appearance. Unlike soft-rot, stem base does not decay and plant does not snap away at the collar region on a slight pull. During advanced stages, rhizomes appear shrunken and inner tissues show discolouration and start disintegration. Later rhizome inner core shows dark sclerotia adhering loosely to fibrous tissues. The affected tissues does not exhibit any wet-rot; rhizomes only shrink and dry-up. Hence it is termed 'dry-rot'. Treatment of seed-rhizomes with Topsin-M $(0.2 \%)$ for 60 minutes is effective in controlling infection.

Internal dry-rot, c.o. Botryodiplodia theobromae Pat. (Diplodia natalensis)

The disease was recorded on the dried ginger samples from Alleppey (Kerala). Infection of rhizome results in blackish discolouration in internal tissues. Tissues later become more or less powdery, consisting of darkcoloured fungus mycelial bits intermingled with fibrous strands of the host material. Early infection is not visible by external appearance. In advanced stages, rhizomes become shrunken and dry (Wilson and Balgopalan 1971).

Control measures : Ginger should be dried properly before storage. Moisture limit of dried ginger should not go beyond $7 \%$.

\section{Red-rot, c.o. Nectria inventa}

The disease was reported from Madhya Pradesh (Sharma and Joshi 1976) and Himachal Pradesh (Dohroo and Paramer 1993). It is characterized by 
small, irregular shiny light-brown patches, which turn dark-brown to brickred. The scales become papery and peel off easily. Rhizomes become dry and shrunken.

\section{Geotrichum-rot, c.o. Geotrichum candidum Link.}

The disease was reported by Mishra and Rath (1998) from the local markets of Bhubaneshwar(Odisha). The fungus caused complete rotting of inoculated ginger in 15 days at $25^{\circ} \mathrm{C}$ and $100 \% \mathrm{RH}$.

\section{Grey-rot, c.o. Trichurus spiralis}

The disease was reported from Madhya Pradesh (Sharma and Joshi 1976). Infection starts from the rhizome cut-end or other wounds, ending in dry-rot. Numerous greyish black bristle-like synnemata develop on the infected surface, and sometimes entire rhizome gets covered by fungal mass.

In addition to the above mentioned diseases, rhizome-rots due to Acremonium killense Grütz (Sharma and Joshi 1976) and A. strictum WGams (Sharma and Jain, 1977) were also reported from Jabalpur. Fungal rots due to Aspergillus niger and A. flavus were also reported.

\section{BACTERIAL DISEASES}

Bacterial wilt, c.o. Ralstonia solanacearum (Smith 1896)

(Yabuuchi et al. 1996)

Pseudomonas solanacearum (Smith 1896) Smith 1914

The disease causes extensive losses in ginger production in India and many other tropical countries. Its outbreak is associated with planting of seedrhizomes with latent infection (Indrasenan et al. 1982). The pathogen is recorded as seed-borne (Hayward 1991). The disease was reported from Sikkim also (Rajan et al. 2002). No effective chemical or biocontrol methods are available for reducing its spoilage during storage. Shanmugam et al. (2002) identified ambient storage temperature detrimental to the pathogen, and studied survival of $R$. solanacearum in ginger-rhizomes at different temperatures. Rhizomes stored at $15^{\circ} \mathrm{C}$ and above were completely rotten. Even storage at $4^{\circ} \mathrm{C}$ could not completely eliminate bacteria.

Control measures : Management of wilt in hilly areas of Darjeeling was achieved with antibiotic terramycin $(500 \mathrm{ppm})$ given as a seed protectant. Streptocycline and chloramphenicol at $500 \mathrm{ppm}$ were effective (Ray et al. 2004).

\section{Soft-rot, c.o. Erwinia sp.}

The disease was reported from Queensland, Australia (Pegg et al. 1974). An unspecified rot was also reported from Kasaragod, Kerala (Anon. 1974). 


\section{Storage studies}

Storage rots affect availablity of healthy seed-rhizomes to farmers. Different fungi are found associated, affecting rhizome health during storage. Pre-storage rhizome treatment with Topsin-M $(0.2 \%)$ for 60 minutes reduced storage-rot incidence, loss in rhizome weight, and increased rhizome recovery from storage pits.

\section{TURMERIC (Curcuma longa L.)}

Turmeric is an important constituent of condiments and spices. It is used in wool and silk industries, and is also a component of ayurvedic medicines. Storage of turmeric is a problem.

\section{FUNGAL DISEASES}

\section{Rhizome-rot, c.o. Pythium spp.}

The disease was first reported from Sri Lanka. Since then, it has been recorded from several parts of the world. In India, the disease was reported from Andhra Pradesh and Tamil Nadu (Rama Krishnan and Sowmini 1954). In Asom also the disease was reported on turmeric cultivars obtained from Andhra Pradesh (Rathaiah 1982). The fungus was identified as P. myriotylum Drechsl.

The study has shown that in addition to $P$. aphanidermatum, which is the common pathogen, other species like $P$. graminicolum and $P$. myriotylum also cause infection. Rhizome-rot is also reported to be caused by Fusarium solani (Dohroo 1988).

Symptoms : The disease is first recognized by dehydration and yellowing of lower-most leaves; similar to ginger. Irregularly dry patches develop on the leaf blade that gradually wilts. The base of the pseudostem becomes watersoaked and readily breaks away from the rhizome when pulled out. Toppling of affected tillers also occurs. In certain cases, youngest unfolded leaf rots, starting from the base. Such plants remain stunted and die slowly. At harvest, affected rhizome is left as a shell with fibrous tissues inside. Contaminated seed-rhizomes serve as the primary inoculum for turmeric rhizome-rot in the main field.

Control measures : Use of resistant cultivars. Cultivars Mydukur, Tekurpet and Duggirala are highly susceptible and $\mathrm{Ca} 69$ and Shillong are resistant in Asom. The rhizome-rot resistant cultivars are also immune or tolerant to leaf-spot caused by Taphrina maculans.

Dipping seed-rhizomes in Ridomil (0.2\%) along with soil drenching with Ridomil at the first appearance of symptoms considerably reduced rhizomerot. Significant increase in yield was also reported. Treatment of rhizomes with Mancozeb $0.25 \%$ after harvest and before planting was reported to be effective against rhizome-rot caused by P.graminicolum. 
Biological control. Reddy et al.(2002) established suppressive role of antagonistic microorganisms like T. harzianum, Gliocladium spp. against F. solani through in-vitro studies by dual-culture method and by VAM pot culture experiments. Among them, T. harzianum was most effective. VAMtreated plants also showed reduced disease incidence. Organic amendments were reported effective in managing rhizome-rot caused by Fusarium sp. Vermi compost@ 0.4 tonne/ha, followed by spraying with Carbendazim $0.1 \%$ was reported minimizing disease incidence and maximizing yield (Uma Devi 2008).

\section{Cottony white-or pink-rot, c.o. Fusarium moniliforme Sheldon F. solani (Mart.) Sacc.}

Cottony white-or pink-rot is common in Himachal Pradesh during early summer (Dohroo 1985) and on the freshly harvested produce in the markets of West Bengal (Dasgupta and Mandal 1989).

Symptoms : The rot starts from the stem-end of the rhizomes or on the wounded areas. The infected tissues become slightly pale and softened. This region is covered by sparse to dense white or pink mycelial growth, depending on the presence of $F$. moniliforme or $F$. solani with a characteristic smell.

Control measures : Biocontrol measures mentioned under rhizome-rot (c.o. Pythium spp.) are applicable here also.

\section{Sclerotium-rot, c.o. Sclerotium rolfsii Sacc.}

Sclerotium-rot of turmeric is regarded as a serious problem in Guntur district of Andhra Pradesh.

Symptoms : Rhizomes get partly dried and shrunken and become light weighed compared to normal ones. When cut open, a characteristic cavity with profuse mycelial growth can be noticed. Sclerotia with profuse mycelia are noticed abundantly on the surface of the affected rhizomes.

Control measures : Treatment of seed-rhizomes soon after harvest with fungicides, Ceresan wet $(0.25-0.5 \%)$ or Aretan $(0.5 \%)$ or Mercuric chloride $(0.1 \%)$, was found promising (Reddy and Rao 1973).

\section{Storage-rot/Aspergillus-rot, c.o. Aspergillus spp.}

Turmeric is generally stored in heaps, where temperature ranges from 30 to $32^{\circ} \mathrm{C}$. This is in contrast to open atmosphere temperature $\left(25-38^{\circ} \mathrm{C}\right)$. With the advancement of rains, rotting occurs. Up to $70 \%$ rotting was reported due to several Aspergillus species (Sharma and Roy 1984). The most important one was A. flavus. Maximum rotting occurs at $35^{\circ} \mathrm{C}$ and no rotting was observed at $15^{\circ} \mathrm{C}$. Similarly rotting is maximum at high humidity. A. flavus grows best at $35^{\circ} \mathrm{C}$. This results in shrivelling and cracking of rhizomes and fungus enters through this. Turmeric rhizomes should be dried to a moisture limit of $7 \%$. 
The other fungi associated with storage-rots include the following.

Cladosporium cladosporioides (Fres) de Vries

Cephalosporium acremonium

Sharma and Roy, 1984 a, 1986.

Dreschslera tetramera

Fusarium culmorum, F. nivale, F. oxysporum

Macrophomina phaseolina (Tassi.) Goid.

Together these fungi caused $100 \%$ infection and showed decay (22-25\%) of rhizome tissues after 21 days of inoculation. They are the most virulent ones and could penetrate and establish infection through intact host tissues. Other fungi isolated could spoil only $7-15 \%$ of tissues. Temperature of $28-$ $32^{\circ} \mathrm{C}$ coupled with $60 \% \mathrm{RH}$ provide most conducive environment for maximum fungal spoilage.

Macrophomina phaseolina and Cladosporium cladosporioides were the most virulent and widespread fungal pathogens. Temperature of $28-32{ }^{\circ} \mathrm{C}$ coupled with $60 \%$ RH or more provided the most conductive environment for the maximum spoilage of rhizome tissues by both the pathogens (Sharma and Roy 1986).

Kumar and Roy (1990) observed maximum post-harvest rotting in September and minimum during May in Delhi markets. The fungi associated included the following. Aspergillus flavus Link. ex Fries; A. niger Van Tieghm; Cladosporium cladosporioides; Drechslera (Leptosphaeria) rostrata; Fusarium moniliforme (Giberella fujikuroi); F. oxysporum; Macrophomina phaseolina; Pythium aphanidermatum; Rhizoctonia solani (Corticium rolfsii).

The post-harvest pathogens associated with turmeric decay as recorded from the markets and storage godown of Odisha(Naik et al. 2004) included the following:Aspergillus flavus, A. niger; Fusarium moniliforme, F. solani; Rhizopus spp.

The conidial germination of these fungi was maximum within the $25-30^{\circ} \mathrm{C}$ with $100 \%$ relative humidity. Fungicides, Sixer $(0.3 \%)$, Carbendazim and Mancozeb, were effective in reducing storage rots.

Koul and Sumbali (2008) observed Aspergillus flavus on dried ginger and turmeric. Analysis revealed presence of aflatoxin $B_{1}$ and $B_{2}$ in varied concentrations.

Control measures : The rhizomes for seed-purpose should be dried properly under shade and should be treated with Mancozeb (0.25\%) after harvest and before planting. Ginger and turmeric for medicinal purposes should be dried to a moisture level of $7 \%$ and should be kept in air-tight containers. The dried rhizomes can be kept under cold storage $\left(0-22^{\circ} \mathrm{C}\right.$ and $\left.60-70 \% \mathrm{RH}\right)$ or irradiated with $6 \mathrm{Krad}$ of gamma rays. 


\section{Part - C \\ MANAGEMENT OF POST-HARVEST DISEASES OF TROPICAL ROOT / TUBER CROPS}




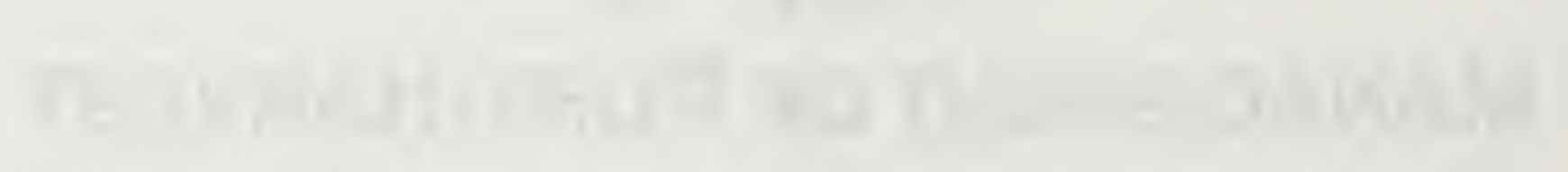

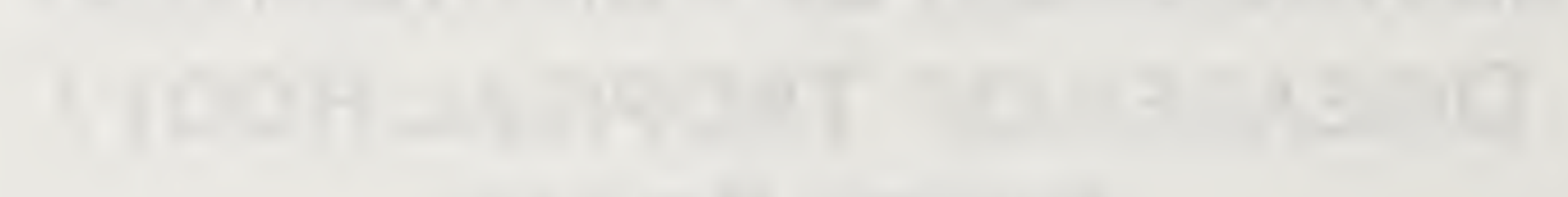

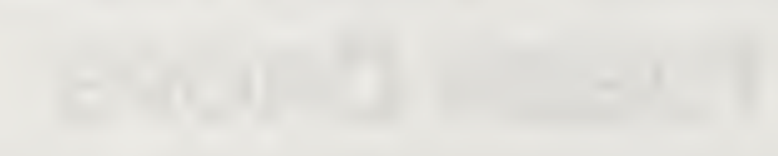




\section{CHAPTER \&7 \\ Tropical Root/Tuber Crops}

\section{TAPIOCA/CASSAVA (Manihot esculenta Crantz.)}

Cassava / tapioca is considered an important tuber-crop in the tropics. It is rich in carbohydrate and low in saturated fat, cholestrol and sodium. The trends in terms of area and production are observed high for cassava compared to other root crops due to its high demand as food, feed, and as a source of ethanol. It has attained the status of a commercial crop, especially in Tamil Nadu and Karnataka.

Storage rots are common problems in cassava. Certain cultivars are more susceptible to root-rots than others (Lozano and Terry 1976). The roots cannot be kept fresh for more than 3-4 days after harvest unless proper precautionary measures are taken care of. Two types of deteriorations, physiological and pathological, are generally noticed (Booth 1973; Anon. 1974, 1975).

Storage rots exhibit a rapid post-harvest physiological deterioration (PPD), and this occurs within 24-72 hours after harvest. PPD is an enzymatically mediated oxidative process with parallels to plant wound and defense response; in which reactive oxygen species (ROS) together with enzyme systems and compounds that modulate them play the central role (Beeching et al. 2006). It involves changes in gene expression, protein synthesis and accumulation of secondary metabolites. Research on the generation of transgenic cassava with improved nutritional traits and longer storage potential is on-going (Owiti et al. 2006).

The primary deterioration commences immediately after harvest and becomes visible in less than 48 hours. At this stage, tubers develop bluish vascular streaks, which are mainly due to biochemical and physical changes. This deterioration is closely followed by microbial deterioration. Among microorganisms, Penicillium, Aspergillus, Rhizopus, Bacillus species and yeasts are the dominating ones (Amla and Sankar 1975).

During storage, Maini and Balagopalan (1978) observed reduction in starch, hydrocyanic acid and drymatter and increase in total sugars. Dehydration resulted in cracks on the rind, followed by invasion of microorganisms. Biochemical nature of the primary deterioration is not fully understood even though a close association between polyphenol oxidation catalysed by polyphenol oxidase and vascular streak formation was reported 
(Padmaja et al. 1980, 1980a). This finding was also supported by Plumbley et al. (1981). Secondary deterioration is caused by release of several enzymes by pathogens (Balagopalan et.al. 1980). Enzymes are cellulase, amylase, pectin esterase (PE), polygalacturonase (PG) and polygalacturonate transeliminase (PGTE). These enzymes cleave polysaccharides of tubers and thus make available free sugars. These sugars may further support growth and multiplication of microorganisms (Padmaja et al. 1982). Maximum degrading enzyme activities were detected on the fourth and sixth days of storage.

Balagopalan and Padmaja (1985) also studied changes in cassava-tubers after storage for eight weeks. Tubers were stored in soil pits as well as in sand pits. Reduction in dry matter, starch, $\mathrm{HCN}$ and an increase in sugar content were recorded in tubers stored in soil pits as well as in sand pits.

Rapid perishability of harvested cassava-tubers is a serious factor limiting its utilization potential. Techniques to store cassava-tubers in the fresh state are essential for increasing its food and feed use as well as for expanding industrial uses of cassava-tubers.

Fresh cassava-tubers dipped for one minute in $2.2 \%$ aqueous emulsion of a fungicidal wax (petroleum wax), drained and dried could be stored at room temperature for 16 days with a wastage of $10 \%$ (Subrahmanyan and Mathur 1956; Subramanyan et al. 1958).

Insecticides and fungicides like methyl bromide, formalin, hypochlorites were also suggested for storing tubers. However, none of these extended the shelf-life beyond five days.

Cold storage is reported to be effective. Majumdar et al. (1956) stored tapioca-tubers for about $6 \frac{1}{2}$ months at a temperature of $32-35^{\circ} \mathrm{F}$ and $\mathrm{RH} 85$ $90 \%$.

Madhavan Pillai and Sreemulanathan (1969) observed that under controlled conditions of relative humidity, tubers could be preserved up to 23 months. Earthenware pots having saturated humidity can be used as storage containers. Effect in storage of preservation media like sand, soil, moist saw dust was also well studied (Madhavan Pillai et al. 1970; Balagopalan and Padmaja, 1985). Tubers free from damage were stored in pits containing sand, soil and sawdust in various proportions. Tubers were interlayered with moist preservation medium. This helped in increasing shelf-life by a month without affecting cooking quality. Biochemical changes monitored during storage indicated only slight decrease in starch content and moderate increase in sugar content.

Small quantities of tubers can be preserved for several days by using simple techniques such as reburial, or coating with mud or placing them under water. Burying tubers in trenches or covering them with soil or a mixture of straw and soil gave good results (Ingram and Humphries 1972). Booth (1975) was able to store tubers up to three months in field clamps similar to those used for storing potatoes in Europe. It was reported that cassava could be 
stored in boxes with moist saw-dust at room temperature. Cassava roots like many other root and tuber crops could be cured at temperature from 25 to $40^{\circ} \mathrm{C}$ (Lozana and Terry 1976). Storage studies carried out by Raja et al. (1978) showed that cassava-tubers showed better resistance to spoilage when stored at suitable environments - high and constant RH $(<86 \%)$ and temperature not more than $27-28^{\circ} \mathrm{C}$. Restricted aeration in the storage system also helped retain freshness of tubers. Under such conditions, tubers can be stored for a limited period even without any chemical preservatives.

Sreemulanathan et al. (1980) studied efficacy of wooden chambers and vacuum desiccators as storage containers. They found that weight loss could be reduced in wooden chambers and vacuum desiccators.

The possibility of using cassava-leaves as an interlaying material for largescale storage of tubers was investigated by Aiyer et al. (1980). Storage with fresh leaves of cassava for 2-3 days is a local practice in Thiruvanthapuram. Clamp storage method was studied in which leaves were used as interlaying material and damage of tubers was assessed in comparison with control. It was found that after 28 days of storage, almost $68 \%$ of tubers remained undamaged.

Efficacy of dipping cassava tubers in Mertec (Thiabendazole) solution, followed by packing in polythene bags was studied (Anon. 1985). These tubers retained their freshness up to two weeks. Balagopalan and Padamaja (1985) developed a storage system to prolong shelf-life of cassava-tubers. Moist laterite soil, river sand and saw dust were used as the medium for preservation of tubers. Tubers free from damage with intact neck portion were used. Pits of $61 \mathrm{~cm} \times 61 \mathrm{~cm} \times 61 \mathrm{~cm}$ dimensions and packed with a layer of moist medium (35-45\% moisture) were used. The selected tubers were spread in pits with alternate layers of moist medium. The moist medium prevented cassava-tubers from dehydration, controlled aeration and slowed down various enzymatic activities in the tubers, which ultimately prevented deterioration. The study helped prolong shelf-life of tubers by a month without affecting their cooking quality. Tubers kept for a week did not show changes in nutritional properties, like moisture, acidity, protein, lipid, carbohydrate, total sugars, ash and calorific value (Sahore et al. 2007).

The effect of pre-packing materials like plastics bags and film wraps was also studied well (Oudit 1976). Prasad and Neelakantan (1985 provided ventilation by punching holes on the surface, tied with twine threads and stored at room temperature. Quality parameters like colour, vascular streaking, appearance, odour, shelf-life and organoleptic qualities were evaluated. Prepacking in polythene bags gave an acceptable shelf-life up to 120 hours depending upon the varieties. Vascular streaking and weight loss were also minimized (Data et al. 2002). Packing in polyethylene bags with 16 holes ( $2 \mathrm{~mm} \mathrm{dia/hole)} \mathrm{was} \mathrm{reported} \mathrm{to} \mathrm{increase} \mathrm{shelf-life} \mathrm{of} \mathrm{roots} \mathrm{up} \mathrm{to} \mathrm{10-14} \mathrm{days.}$ For prolonged storage, dipping undamaged roots in Thiabendazole $(0.4 \%)$ for 
5 minutes is also recommended. Crate is also observed as a better transport container than straw-sacks.

Cassava-tubers are commonly stored in the form of dry chips. Tubers are either sliced and dried or parboiled and then dried in the sun. This is practised by farmers in Kerala. But these chips stored in gunny bags are often spoiled by fungi, bacteria and insects (Balagopalan et al. 1974; Balagopalan and Nair, 1976; Balagopalan and Padmaja, 1985). The predominant fungi were Rhizopus, Penicillium, Aspergillus, Fusarium and yeasts (Thankappan 1994). Insect damage is also considerable. Nature and extent of damage caused by insectpests, Aracerus fasciculatus, Sitophilus oryzae and Tribolium, castaneum, on stored cassava-chips was also studied (Ramla Beevi et al. 1980).

Tapioca chips dipped in $0.5 \%$ sodium hypochiorite (NAOCI) for 2-3 minutes, washed with freshwater and dried at $70^{\circ} \mathrm{C}$ were found to have shelflife up to 90 days as compared to 25 days shelf-life of untreated chips. Bacterial load also reduced considerably in treated chips (Nair et al. 1976).

Effect of storage period on the moisture content and insect infestation in dried cassava-chips and cassava-flour stored in different packaging systems was also studied in Thiruvananthapuram (Anon.1986); moisture content increased in both the cases. Polythene-lined jute bags were found superior to other packing materials for storage of cassava-chips and flour.

Drying systems for tuber chips (artificial dryers) are also available. But fuel cost is high. This can be overcome if combined or complemented with solar heat/and or heat from agricultural waste. Such a system has been developed at the Central Tuber Crops Research Institute, Thiruvananthapuram. The system consists of a double cylinder vertical drying chamber, an agricultural waste burner, a cyclone separator and a blonder. These components are accommodated in a shed; the roof of which is used as a flat-plate solar collector. Provisions are made in the system to draw heated air either from the solar collector or from the burner or from both at regulated propositions. The system can dry $2 \mathrm{~m}^{3}$ of cassava or other tuber-chips in one batch (Kurup and Nanda 1994).

\section{FUNGAL DISEASES}

Rhizopus-rot, c.o. Rhizopus spp.

The occurrence of Rhizopus sp. and Bacillus sp. in cassava causing root discolouration and increased acidity was reported from the Central Food Technological Research Institute, Mysore (Majumdar 1957).

Due to microbial infection, tubers become soft, discoloured and develop undesirable odour (Booth, 1976). In advanced cases, root surface gets covered with white cottony growth of the fungus and its black sporangia heads. Balagopalan et al. (1980) reported secondary deterioration due to R.oryzae. Philip (1981) also recorded $R$. arrhizus and Mucor hiemalis. 
As control measures, avoid wounds and bruises on the tubers. Injured tubers should not be kept for more than 12 hours under ambient conditions.

\section{Botryodiplodia-rot, c.o. Botryodiplodia theobromae Pat.}

The disease is very common in tropical countries. The fungus is a wound pathogen. Mechanical injuries accelerate infection.

Symptoms : Infected tubers may appear healthy externally; skin may be wrinkled. Blackish white growth of the fungus is visible on the cut ends. Internal tissues become soft and brown. Infection continues and finally root becomes mummified (Figs 27.1, 27.2). Numerous pycnidia may be observed on the surface. The fungus survives on crop debris, epecially as pycnidia on stem-cuttings used for planting (Philip 1998).

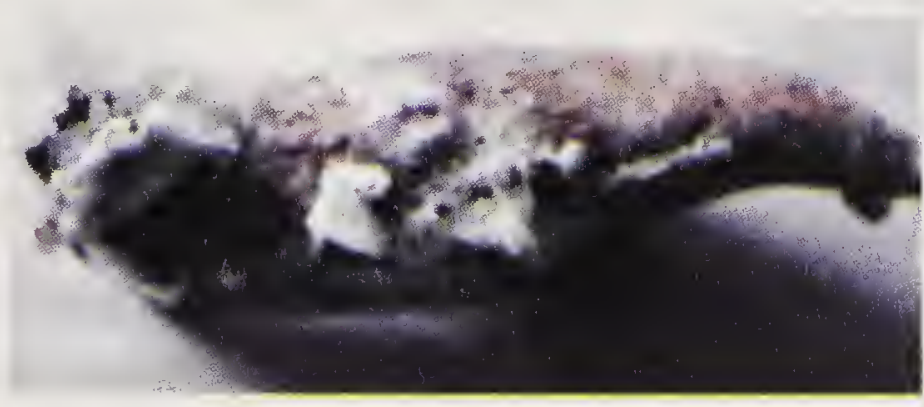

Fig. 27.1. Botryodiplodia-rot (advanced stage) on tapioca
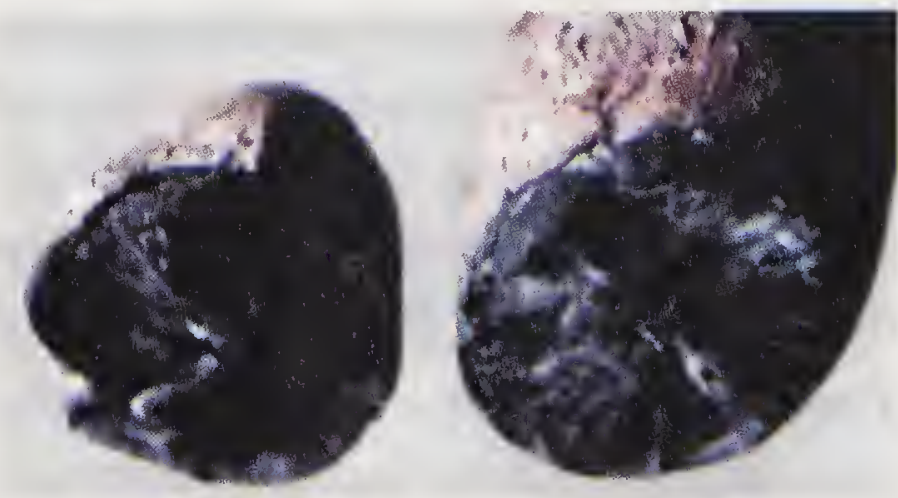

Fig. 27.2. Botryodiplodia-rot (Cross section) on tapioca

Set-rot due to Diplodia.natalensis (=B. theobromae) was also reported. Control measures : Wounds and bruises on tubers should be avoided. Use of healthy planting material is the best means to control the disease occurring on stem-cuttings/sets. Dipping cuttings in any of the fungicidal solutions (Benlate $0.1 \%$, Bavistin $0.1 \%$, Vitavax $0.1 \%$ or Thiram $0.2 \%$ ) for 15 minutes, followed by drying in the shade and then planting in the field (Sivaprakasam et.al. 1976) are effective in checking disease in the field.

Dry-rot, c.o. Fusarium solani (Mart.) Sacc.

Dry-rot of cassava-tuber was reported from Tamil Nadu (Sivaprakasam et al. 1977; Johnson et al. 2000).

The infected tubers are usually hard, and colour of the pulp instead of being white varies from brown to reddish-brown and dark-brown. Streaks are seen inside the tubers. Diseased tubers are unfit for consumption. Dry-rot is the characteristic. But under humid conditions, white mould growth with softrot symptoms are also recorded. The fungus survives in the soil, and infection occurs through mechanical injuries. F. dimerum was reported to be associated predominantly (Jayashree et.al. 2002).

As a control measure avoid wounds and bruises on the tubers. Injured tubers should not be kept for more than 12 hours under ambient conditions. 
Phytophthora-rot, c.o. Phytophthora drechsleri

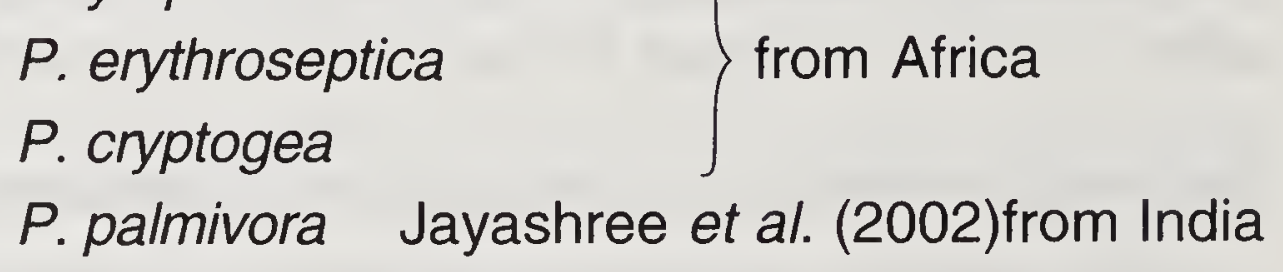

Along with Phytophthora several other fungi were also observed.

Tuber-rot caused by Phytophthora is an important disease and causes severe losses to farmers. The rot is noticed at the time of maturity (Oliveros et al. 1974; Snowdon 1991; Johnson and Palaniswami 1999; Johnson et.al. 2000).

The disease was recorded from Namakkal taluks around Salem in Tamil nadu. Its incidence was high and caused $48.5 \%$ tuber yield loss.

Symptoms : Dark, round to irregular water-soaked lesions appear on mature tubers. Rotting continues during storage. White mycelial mat of the pathogen develops around the lesions. The lesions enlarge in size and cause internal browning. Oozing of internal fluid and shirvelling of the tubers are also noticed. Infected tubers emit a characteristic smell, and rot continues for 5-7 days (Jeeva et al. 2008).

Control measures : Application of neemcake @ $250 \mathrm{~kg} / \mathrm{ha}$ and incorporation of a native strain of Trichoderma $\left(10^{6} / \mathrm{ml}\right)$ multiplied on sorghum-grains when applied to soil controlled effectively the disease (Jeeva et al. 2008).

Biocontrol of the disease with a fluorescent Pseudomonas (Pf) isolated from urdbean was also reported. Its efficiency was tested against the pathogen in in-vitro. Application of bacterial cultures to soil significantly reduced disease incidence. Carbendazim application appeared less effective in contrast to Pf treatment in reducing disease incidence and in increasing tuber yield (Jayashree et al. 2002).

\section{OTHER DISEASES}

Tuber-rots caused by different fungi are as follows.

\begin{tabular}{ll}
\hline Aspergillus niger & Kanaujia, 1979, Philip, 1981 \\
$\begin{array}{l}\text { A. flavus } \\
\text { Corticium rolfsii }\end{array}$ & \\
Trichoderma harzianum & Snowdon, 1991 \\
$\begin{array}{l}\text { Pythium spp. } \\
\text { Pythium myriotylum }\end{array}$ & \\
$\begin{array}{l}\text { Rhizoctonia solani } \\
\text { Sclertoium rolfsii }\end{array}$ & Jayashree et al. 2002 \\
\hline
\end{tabular}

\section{BACTERIAL DISEASES}

\section{Bacterial soft-rot, c.o. Xanthomonas campestris pv. manihotis}

Lozano (1987) reported biocontrol of root-rot pathogens like X.campestris, Pythium spp. and Diplodia natalensis with bacterial antagonists, Pseudomonas putida and P.fluorescens. 
Bacterial soft-rot caused by Erwinia carotovora, was also reported. Philip (1981) reported Bacillus subtilis and Enterobacter aerogens on deteriorated tubers. The disease is of minor importance.

\section{Sequence of occurrence of microflora}

Among the microorganisms, $R$. arrhizus and $M$. hiemalis occurred as initial colonizers, followed by Aspergillus spp. and Fusarium sp. B. theobromae appeared at the terminal stage of rotting and by the seventh day it completely enveloped tubers with its luxuriant mycelial growth. Bacteria are also observed at the final stages. Ultimately tubers become soft, discoloured and turn brownish with an unpleasant odour (Philip 1981).

\section{SWEET-POTATO (Ipomoea batatas (L.) Lam.)}

India is the largest sweet-potato producing country in the South-Asia. The crop is grown throughout the country as a secondary food crop. It is subjected to several forms of post-harvest losses like physical damage, weight loss,pathological decay, sprouting and weevil infestation.

Sweet-potato is harvested by digging out tubers. This results in bruises and damages. Damaged tubers show symptoms of rotting during storage. The affected tubers can be rercognized easily by water-soaked appearance and mushy decay with a mild alcoholic odour (Anon. 1982). The tubers are cured by spreading in the sun for about seven days and storing in well-ventilated rooms (Nanda 1984). Weevil-infested sweet-potatoes should be discarded from storage.

Sweet-potato tubers stored under ambient conditions without any prior curing sprout. The crop is subjected to physical damage, weight loss, pathological decay, sprouting and weevil infestation (Ray and Balagopalan 1997).

Farmers store tubers up to four to five months. The common method of storage in Odisha is to dig a pit or heap graded tubers. The heap is then covered with paddy-straw and plastered with mud or cow-dung slurry(Anon. 1989). The tribal farmers of southern Odisha store tubers by adopting a clamp method of storage up to six months during comparatively cooler periods of November to March. In this method, tubers are heaped in a corner of their hut, near the wall, covered with a layer of paddy-straw, followed by plastering with soilcowdung mixture. The huts are usually dark and cool inside even during the day time.

Storage studies conducted at the Intenational Potato Centre, New Delhi, showed that weight loss of roots stored for 30 days could be reduced from 25.73 to $7.94 \%$ by storing them in sand. After 90 days, weight loss was $16 \%$ (Dayal et al. 1990). Mukhopadhya et al. (1991) studied storage of tubers with locally available materials like sawdust, red earth, earthern pot, wood ash, white sand, local earth and waste carbon-paper for 90 days and observed local earth as the most economical medium for storage. But marketable tuber recovery was more with waste carbon-paper. 
Storage of sweet-potato tubers without deterioration is usually difficult because of heavy infestation by weevil Cylas formicarius Fab. Harvested tubers may contain any of the weevil stages. Tubers heaped on the floor of a godown and completely covered up to 5-cm depth with dried earth or woodash were observed to be free of weevil infestation on dehydration for two months (Rajamma1984).

Sprouting is not observed under chilling and cold storage. Under chilling (storage temp. $10-15.5^{\circ} \mathrm{C}$, RH $80-85 \%$ ) in the pre-cooling chamber of the cold store, sweet-potato tubers could be maintained in good condition for a storage period of 45 days with a marginal increase in total sugars. Under cold storage, internal necrosis and tuber decay were observed within 15 days of storage (Anon. 1983).

Curing and storage practices are difficult under Indian conditions. Storing sweet-potato in beds of sand or soil is suitable for restricting rotting and weevil infestation (Ray et al.1994). Curing induces suberization of exposed parenchyma cells, and this helps in the development of a wound-periderm. Storage of tubers at approximately $90 \% \mathrm{RH}$ and temperature of $26-30^{\circ} \mathrm{C}$ is ideal for curing and wound healing.

Hydro-warming or dipping tubers in hot-water maintained at $40-45^{\circ} \mathrm{C}$ for 5-10 minutes showed promise ( Ray et al. 1994).

Pre-harvest foliar spray of malic hydrazide and cycocel resulted in suppression of sprouting in tubers. Tubers stored under evaporative cool chamber were of longer shelf-life (Shedge 2009).

\section{FUNGAL DISEASES}

\section{Rhizopus-rot, c.o. Rhizopus spp.}

The disease has been reported from several countries including India(Ramsey et al.1959; Coursey and Booth 1972; Rao 1966; Sinha and Prasad 1986; Dasgupta and Mandal 1989).

Rhizopus-rot is the most common and important storage disease of sweetpotato. Rhizopus nigricans and $R$. stolonifer are commonly found associated. The host range studies indicated that potato, tomato, dioscorea and apple are also infected by this pathogen.

Symptoms : The infected tubers quickly turn soft and moist at both ends. Symptoms develop only after fleshy roots are harvested or occasionally in the field following flooding. The tubers develop wet- or dry-rot depending on the humidity. When skin ruptures, a straw-coloured liquid drips out. And when the skin is intact affected tubers lose moisture and become shrivelled and mummified. On the surface of the affected tubers, thick tufts of superficial mycelia and black fruiting structures of the pathogen are seen. Maximum infection occurs during harvest. 
Addy et al. (1987) studied metabolic aspects and observed significant increase in protein, OD phenols and total phenols after eight days of infection. They noticed that the DNA content of the tubers remained constant for two days and then showed a declining trend. The possible role of pectolytic and cellulolytic enzymes in roots colonized by $R$. stolonifer was recorded by Srivastava et al. (1959). Proteolytic enzymes role in pathogenesis was also well documented (Balasubramoniam 1972). Ray and Balagopalan (1997) observed phenol accumulation by $R$. oryzae in storage. Infected tubers exhibited five times more phenol accumulation than uninfected tubers, and this suggests that the fungus contributes partly to phenol pool of infected tubers.

Control measures : Among the 50 varieties tested by Thankappan (1994), 10 lines showed resistance to Rhizopus-rot. Careful handling of tubers during harvest and transport so as to avoid wounding and proper curing of roots before storage essential. Storehouses are to be thoroughly cleaned and walls and floor washed with $2.5 \%$ solution of copper sulphate. The temperature and the relative humidity are to be maintained at $26.5-30^{\circ} \mathrm{C}$ and $90 \%$. This condition should be maintained for 10-14 days during which rapid healing of wounds occur. This should be followed by storage at $13^{\circ} \mathrm{C}$ and $\mathrm{RH} 85-95 \%$.

As a chemical treatment, 2, 6, dichloro-4-nitroaniline has been approved for use on sweet-potatoes in the USA with $10 \mathrm{ppm}$ tolerance. When it was applied at 3-4 ppm, the chemical was highly effective in preventing soft-rot development (Martin 1967).

Java black-rot, c.o. Botryodiplodia theobromae Pat.

Of all the storage-rots of sweet-potato in India, Java black-rot is the most significant one.

Symptoms : Infected tissues are at first yellowish brown and fairly firm and later become dark-black. After 6-8 weeks, affected roots show dark patches externally. Numerous pycnidia develop internally. The tissues turn yellow and later become coal-black. Finally roots shrivel, become brittle and mummified (Ray et al. 1994 ; Ray and Misra 1995).

The isolates from the infected tubers differed slightly in their physiological and cultural characters. Infections occurred at harvest and during subsequent handling and transportation. Like all post-harvest pathogens, the inoculum of B. theobromae is present in air and soil. Wounding predisposes tissues to infection. Maximum decay (98.8\%) of stored sweet-potatoes occur at $30^{\circ} \mathrm{C}$; decrease in storage temperature means less decay. The fungus grows best between 28 and $30^{\circ} \mathrm{C}$.

Control measures : Post-harvest losses can be substantially reduced by storing tubers below $25^{\circ} \mathrm{C}$. High relative humidity favours rotting, and it was appreciably high up to $85 \%$ RH but decreased gradually below $70 \%$. Stroage below 70\% RH is reported to be effective. Phenol accumulation in tubers was also recorded (Ray and Balagopalan, 1997). 
Since tubers are mostly used as a food commodity, application of fungicides should be mostly avoided. Alternately, hydro-warming i.e. dipping tubers in water at $40-45^{\circ} \mathrm{C}$ for $5-10$ minutes has been recorded as effective in controlling rots (Ray and Balagopalan 1997).

\section{Black-rot, c.o. Ceratocystis fimbriata Ell. \& Halst.}

The pathogen is an ascomycetous fungus. It was previously known by synonyms Ceratostomella fimbriatum (Ell.\& Halst.) Elliot, Ophiostoma fimbriatum (Ell. \& Halst.), Sphaeronema fimbriatum (Ell. \& Halst.) Sacc. and Endoconidiophora fimbriata (Ell. \& Halst.) Davidson

Historically, black-rot is recorded as one of the significant diseases of sweetpotato. Black-rot is the common name used for the decay of fleshy roots, and is also applied to symptoms that occur on the sprouts and vines in the field. The disease can cause severe losses in storage, or in plant beds in the field.

Symptoms : Fleshy storage roots infected by black-rot pathogen develop firm black-rot. Externally symptoms appear grey to black when dry, and darkgreenish black when moistened. The periderm remains intact on the overdecayed cortical tissues. Lesions enlarge but do not usually extend below vascular ring, unless they are invaded by secondary organisms. The lesions are usually centred on wounds, lenticels or lateral roots. When infected tubers are used as seed material, symptoms develop on the emerging plants. Below ground portions of the sprouts may rot or may have numerous cankers, The cankers are also dark black and sunken. Secondary symptoms may vary depending upon the severity of the infection and may include stunting, wilting,yellowing, drooping of leaves and in some cases death of sprouts. The symptoms are similar to those produced by Fusarium stem canker(Clark and Moyer1988). Black-rot can develop over a range of environments, and optimum temperature for development is $23-27^{\circ} \mathrm{C}$.

Control measures : Sanitation, rotation and careful sorting of tubers before storage are essential for containing the rot. Washing tubers in $1 \%$ solution of Borax is effective in controlling infection. After sun-drying for an hour, the roots are placed in aerated containers and stored in properly ventilated rooms. Seed treatment with Thiabendazole $(0.1 \%)$ was recommended in the USA. Proper curing at $30-35^{\circ} \mathrm{C}$ and at $85-90 \%$ RH for 5-10 days immediately after harvest reduced incidence of infection (Clark and Moyer 1988).

Another black-rot, c.o. Cochliobolus lunatus (Curvularia lunata), was reported by Ray and Balagopalan(1997) from Thiruvananthapuram. When fresh tubers are inoculated with the mycelium of C.lunatus, tubers become swollen and spongy within 8-10 days and flesh turns brown, and finally black. Usually this disease is confused with black-rot caused by Ceratocystis fimbriata.

\section{Fusarium-rot, c.o. Fusarium spp.}

Fusarium-rot is common in areas where sweet-potatoes are stored for longer period. The disease was reported by Harter and Weimer( 1919), Martin 
and Persoon (1951), Moyer et al. (1982) and Clark and Moyer( 1988). The incidence is more in temperate climate. The causal agents are $F$. oxysporum and F. solani (Clark, 1992); F. pallidoroseum was also reported (Ray and Balagopalan, 1997).

Symptoms : The rot is noticed on fleshy storage roots. Occasionally this occurs prior to harvest on roots that have been mechanically injured by growthcracks or by feeding of nematodes, insects or rodents. Surface rot lesions are circular, light to dark-brown, firm and dry. They usually do not extend into root beyond the vascular ring. When infected roots are stored for extended periods, tissues within and around the lesions dry and become shrunken. The root eventually becomes hard and mummified.

Fusarium spp. that cause disease of sweet-potato can persist in the soil for several years, primarily as chlamydospores. Strains of $F$. oxysporum and F.solani that cause surface-rot and root-rot enter roots only through wounds formed during harvesting, and during storage, root-rot develops. But the disease does not spread to other roots in storage unless new wounds occur on the infected roots. F. oxysporum does not spread from infected mother roots to sprouts, but F.solani can spread in this manner and can cause stem canker.

Control measures : Hydro-warming of the tubers as detailed under the Java black-rot is applicable here also.

\section{Charcoal-rot, c.o. Macrophomina phaseoli (Maubl.) Ashby}

The disease is common in the USA and other parts of the world (Dhingra and Sinclair 1978). In India, it was reported from Maharashtra (Patel et al. 1949 in Bilgrami et al. 1979) and from West Bengal (Mandal and Dasgupta 1980).

The fungus was once thought to be sterile and was named Sclerotium bataticola Taub. (Syn. Rhizoctonia bataticola). It produces pycnidia as well as sclerotia, and is now recognized as Macrophomina phaseoli. The fungus is soil-borne and survives as sclerotia.

Symptoms : They develop from cut- end. Symptoms begin as reddish brown, firm moist-rot, initially restricted to the cortex of the storage root from the cut end. As the decay progresses, pathogen crosses vascular cambium, and pith rots progressively. Two distinct zones become apparent. Ultimately the affected tissues become charcoal-black, hard and mummified. The disease is favoured by relatively high temperature with an optimum of $29-31^{\circ} \mathrm{C}$. It is common in storage houses, where crates are closer to heaters( Clark and Moyer 1988).

Control measures : Hydro-warming of tubers as detailed under Java black rot is applicable here also.

\section{Dry-rot, c.o. Phomopsis batatae \\ Diaporthe phaseolorum var. batatis (Harter \& Field)}

The disease may cause serious damage in storage. The rot usually begins at the stem-end of the root and later involves the whole root. The diseased 
roots are shrunken and shrivelled. Their surface is covered with numerous mounds, and under these fructifications of the fungus are seen in a coal-black stroma. The internal tissues decay and become coal-black.

\section{Circular-spot, c.o. Sclerotium rolfsii Sacc.}

Circular-spots/ lesions occur only on the fleshy storage roots. The extent of lesion development varies considerably among genotypes. But on commercially grown varieties, they usually range from 1 to $2 \mathrm{~cm}$ in diameter. The lesion surface is brown with a margin that may be slightly darker than the rest. The tissues within the lesion are yellowish-brown to brown, soft and mushy. The root becomes leathery in texture as the lesions dry. Generally lesions are shallow, 1-5-mm deep and do not usually extend beyond vascular cambium. Circular lesions do not crack at harvest, but may crack as they dry in storage (Martin 1953; Aycock 1966).

\section{Scurf, c.o. Monilochaetes infuscans Ell. \& Halst.ex Harter}

The disease earlier known as 'soil stain' is very common in the USA, many islands of the Pacific and Japan. It becomes serious with the use of infected planting materials. The disease is of minor importance.

Symptoms : They are restricted to underground portions of the plant. Dark brown to black spots develop on the fleshy storage roots. The spots slowly enlarge and may coalesce until entire root surface is affected and discoloured. The symptoms are restricted to periderm and do not directly affect cortex. Severely affected tubers may develop small cracks. Scurf lesions continue to enlarge when sweet-potatoes are in storage, and new lesions may develop only at higher relative humidities (Harter 1916; Daines 1955; Clark and Watson 1983).

A combination of sanitiation procedures and fungicide application (Thiabendazole 0.1\%) is recommended as control measure (Martin 1972).

\section{Black mould-rot, c.o. Aspergillus niger Van Tieghm.}

Infection starts around wounded areas and appears as small water-soaked dull areas with a white mycelial growth, followed by profuse black sporulation of the fungus. The infection advances in irregular patches. Generally disease develops at a temperature of above $35^{\circ} \mathrm{C}$ (Dasgupta and Mandal 1989). Ray and Misra (1995) had also isolated A.terreus, A. flavus and A.fumigatus from sweet-potato tubers.

\section{Green mould-rot, c.o. Penicillium digitatum Sacc.}

Blue mould-rot due to Penicillium sp. was reported by Coursey and Booth (1972) from Solomon Islands, and by $P$. digitatum was reported from Karnataka (Ravichandran and Sullia1983).

Symptoms : Initially water-soaked discolourations appear. Spots develop on the root surface, followed by abundant growth of the fungal mycelium, which later turns green due to the colour of the spore mass. 


\section{Brown soft-rot, c.o. Rhizoctonia solani Kühn}

Ravichandran and Sullia (1983) described the disease from Karnataka. Initially pale-brown spots appear on the root surface. The affected roots shrivel. Eventually entire surface gets covered with fungal growth. Sclerotia are also noticed.Contact with infected roots should be avoided.

\section{Slimy brown-patch, c.o. Myrothecium roridum (Tode ex Fr.)}

The disease was reported from Karnataka (Ravichandran and Sullia 1983). The symptoms initiate as brown patches with a grey coating. Later root gets covered by a large number of dark sporodochia with slimy spore mass. The disease is of minor importance.

\section{Shiny black-rot, c.o. Arthrinium phaeospermum Corda and Ellis}

The disease was reported from Karnataka (Ravichandran and Sullia 1983). The symptoms appear as black circular spots along with the shiny black spore masses over the spots. The disease is of minor importance.

\section{Sunken brown-spot, c.o. Stemphylium botryosum Wallr.}

Ravichandran and Sullia (1983) first reported the disease from Karnataka. The dark-brown spots appear and that are covered by greyish mycelium. In advanced stages, roots decay and on applying a gentle pressure, conidia ooze out. The internal contents turn grey and granular.

Hydro-warming as detailed under Java black-rot is applicable here also.

\section{Waxy-rot, c.o. Geotrichum candidum Link.}

The disease is of minor importance and occurs on injured or physiologically weakened tubers. The characteristic symptom is watery, slow and shallow partial rot of tubers with a white powdery wax-like growth (Mandal and Dasgupta, 1980).

Control measures as detailed under tomato of Solanaceous crops are applicable here also.

\section{Violet root-rot, c.o. Helicobasidium mompa Tanaka}

The disease develops only in the field. Decay of fibrous roots progresses from tip and may eventually destroy entire root system. Storage roots usually decay from the distal-end towards the proximal end. The entire root usually rots but remains are held together by a thick mantle of hyphae over its surface. This coarse network is at first white but gradually turns pink to brown, and eventually develops characteristic violet colour. The disease is common in China, Korea and Japan. The disease has not been reported from India.

\section{Phymatotrichum root-rot, c.o. Phymatotrichum omnivorum Shear}

The disease is also known as cottony root-rot or Texas root-rot. The symptoms appear as circular spots in the field. The decay is firm and dry, 
and is initially associated to root surface. It often progresses from one end of the root; the interior of the root is not affected until rot is quite advanced. The outside of the root may be dark-brown to black at first but as decay proceeds, distinctive mycelia appear as white protuberances with brown to buff strands. By the time infected sweet-potatoes are dug, entire root below the ground system may be severely decomposed and fleshy storage roots may become hard, dry, buff to brown and mummified (Clark and Moyer 1988). The disease has not been reported from India.

\section{Foot-rot, c.o. Plendomus desturens Harter}

This is of minor importance. The pathogen grows down the stem into the storage root and causes slow decay (Martin 1972).

The disease is not reported from India.

OTHER STORAGE DISEASES AND CAUSAL ORGANISMS

\begin{tabular}{lll}
\hline $\begin{array}{l}\text { Grey mould-rot } \\
\text { Mucor-rot }\end{array}$ & $\begin{array}{l}\text { Botrytis spp. } \\
\text { Mucor spp. }\end{array}$ & Snowdon, 1991 \\
Watery soft-rot & $\begin{array}{l}\text { Sclerotinia minor } \\
\text { S. sclerotiorum }\end{array}$ & \\
Trichoderma-rot & \begin{tabular}{l} 
Trichoderma koningii \\
\hline
\end{tabular} & Ray and Balagopalan, 1997 \\
\hline
\end{tabular}

\section{PROKARYOTES AND BACTERIAL DISEASES}

Soil-rot/ Streptomyces-pox/ground-rot/scab, c.o. Streptomyces ipomoea (Person \& W.J. Martin) Waksman

Soil-rot is common in sweet-potato-growing areas of United States and Japan. The disease may lower roots market value but does not appear to develop further in storage.

Symptoms : The most common symptom is the 'scab' type of lesions on the storage roots. These lesions are circular to irregular in outline and are usually less than 5-mm deep. They are composed of dark-brown to black necrotic corky areas with frequent cracks radiating from the centre. The lesions vary in diameter.

\section{Bacterial stem-and root-rot/bacterial soft-rot,}

c.o. Erwinia chrysanthemi Burkh Holder, M C Fadden \& Dimmock.

The bacterium is readily differentiated from other soft-rotting Erwinia by its pattern of carbohydrate utilization, sensitivity to erythromycin, production of gas from glucose, higher optimum temperature for growth, etc.

Economic losses due to bacterial stem-and root-rot were reported for the first time from Georgia, USA, in 1974. Storage roots often have a dark-black margin and appear to be restricted. Some storage roots appear healthy from outside but are decayed internally. Black streaks may appear in the vascular 
tissue of storage roots. Mother roots often decay totally in plant beds (Martin and Dukes 1977; Schaad and Brenner 1977). Infections may remain latent below $27^{\circ} \mathrm{C}$. But symptoms may develop quickly with the advent of higher temperature $\left(30^{\circ} \mathrm{C}\right.$ or higher).

\section{Aroids and Yams}

COLOCASIA (Arum/Aroids/Cocoyam) (Colocasia esculenta (L.) Schott) (Xanthosoma sagittifolium (L.) Schtt.)

Tubers of colocasia and Xanthosoma rank only after yams and cassava as staple food. These tubers provide easily digestible starch and contain protein, vit. C, thiamine, riboflavin and niacin (Coursey 1968).

The corms and roots are frequently affected by fungal pathogens both in the field and in the storage, resulting in heavy losses.

\section{FUNGAL DISEASES}

\section{Corm-rot, c.o Phytophthora colocasiae Raciborski \\ $P$. nicotianae B.de Haan}

The disease is commonly found in wetlands and in poorly drained soils. The disease was reported on stored corms from British Solomon islands (Jackson and Gollifer 1975).

Symptoms : The damage may be confined to few corms or may be widespread resulting in $100 \%$ loss depending upon the weather. Corms may become slimy or water-soaked and their skin may slip off easily. Intermittent rain, cloudy weather and temperature of $22-28^{\circ} \mathrm{C}$ are ideal for rapid spread of the disease. Control measures : Use of healthy planting material, harvesting crop at the right time, removal of crop debris and strict field sanitation have been recorded as control measures. Storage in soil, kept in well-drained pits, remained free of infection up to four weeks.

Use of resistant cultivars was promising. Cultivars, Kadma local, Nadia local and Muktakeshi were reported to be immune from Ranchi and JCC 24 and JCC 25 were resistant varieties from Asom ( Kumar and Dubey 1996; Alam et al. 1996).

Spraying Metalaxyl $(0.3 \%)$ in the field at 2-3-week interval proved effective in controlling the disease. Metalaxyl mixed with Mancozeb $(0.2 \%)$ or Zineb $(0.2 \%)$ is also effective.

Integration of dipping corms for a hour in a fungicidal solution of Carbendazim $(0.1 \%)+$ Mancozeb $(0.2 \%)$ before sowing with three foliar sprays with Ridomil $\mathrm{MZ}(0.25 \%)$, starting with the disease appearance, contained the disease (Sharma et al. 2004).

Essential oils of Nepeta hindostana and Ocimum canum possess antifungal properties against corm-rot (Chouhan et al. 1994). 


\section{Internal soft-rot, c.o Pythium spp.}

Soft-rot due to Pythium spp. is common. P. ultimum and P. splendens were recorded from Puerto Rico and Solomon Islands (Alvarez and Cartaz, 1971; Jackson and Gollifer, 1975). Isolations revealed P. splendens and P. myriotylum in abundance along with other fungi. Infection resulted in complete decay.

Control measures : To reduce losses, leave petiole bases of cormels and roots that delay infection.

Colocasia tubers treatment with Captan $(0.2 \%)$ or Thiram $(0.2 \%)$ or copper oxychloride (COC) at $0.5 \%$ is effective. Soil treatment with the same chemicals is also promising.

Watery soft-rot, c.o. Rhizopus stolonifer (Ehrenb.) Vuill.

The disease is generally reported to be of minor importance. Burton (1970) reported the fungus to cause severe losses in corms along with other fungi. Dasgupta and Mandal (1989) recorded the disease after rains on physiologically impaired or injured tubers as water-soaked spots, which gradually increased, and were covered by a stringy extra matrical mycelial mass giving bad odour. The rot rarely involves inner tissues, which turn watery and soft.

Avoid wounds and bruises on the harvested produce. Removal of dirt and soil particles, followed by air-drying /curing and storing in cool dry atmosphere at $50 \% \mathrm{RH}$ is effective.

\section{Root and corm-rot,c.o. Sclerotium rolfsii Sacc.}

Rhizoctonia sp.

Harter as early as 1916 reported the disease; it is of worldwide importance. It was recorded from Nigeria (Bailey 1966), Chicago (Burton 1970), Solomon Islands (Gollifer and Booth 1973; Jackson and Gollifer 1975). In India, Satya Prasad and Rao (1979) recorded the disease from Hyderabad. Rotted corms of taro produced radiating mycelia with abundant sclerotia on rotted corms. This fungus also attacked onion-bulbs, ginger, brinjal, soybean and chilli-fruits (Rama Rao and Usha Raja 1977; Roy 1977).

The diseased plant may also exhibit symptoms like chlorosis and collapse of petioles at the collar region. In severe cases, corms and root underneath are also affected. This leads to wilting of the whole plant.

Inhibitory effects of some host constituents on Sclerotium-rot were also reported (Nwufo and Fajola 1981; Arinze 1997). Phenol oxidase as well as peroxidase activities and plant growth inhibitory substances were observed to be significantly higher in the peripheral zone of rot compared to other areas in all the varieties infested by $S$. rolfsii.

Losses could be minimized by proper selection of tubers, removal of dirt and soil particles, followed by air-drying / curing and storing in cool dry atmosphere at 50\% relative humidity. Immersion of seed-tubers in seeddressing chemicals like plant-wax, Agrosan GN or Ceresan wet at $50 \mathrm{ppm}$ 
for 30 minutes was reported to be effective in controlling the disease (Goyal et al. 1974).

\section{Black-rot/spongy black-rot,}

\section{c.o. Botryodiplodia theobromae Pat.}

The disease was reported as the most important one from the South-East Nigeria. D'Souza and Moniz (1968) observed the disease on Colocasia antiquorum Schott from Maharashtra. The affected tubers become spongy or dry and powdery depending upon the storage conditions. This fungus may invade undamaged tubers also under high relative humidity.

Losses could be minimized by proper selection of tubers, removal of dust and soil particles, followed by air-drying/curing and storing in cool dry atmosphere at 50\% RH. Storage under dry and low temperature conditions reduces incidence of corm-rot.

\section{Dry-rot, c.o. Fusarium spp.}

The disease was reported from several parts of the world. F. solani was recorded as early as 1916 by Harter. The disease is common in Egypt (Michali et al. 1969), Solomon Islands (Gollifer and Booth 1975; Jackson and Gollifer 1975) and Nigeria (Ogundana 1975; Nwufo and Fajola 1981). In India, dryrot of $C$. antiquorum due to $F$. caerulinum was reported from Uttar Pradesh, Rajasthan and Madhya Pradesh (Sharma and Upadhyay 1977) and from Bhubaneshwar (Mishra and Rath 1986).

Rotting becomes a major problem towards the end of the storage period. The rot starts as small lesions and is confined to the sides of the corm around points, from where cormels have been detached. The affected area develops a brown discolouration. Aspergillus niger also produces a dry-rot with a characteristic purple brown colour. F. solani is more important in Nigeria (Nwufo and Fajola, 1981). Sharma and Upadhyay (1977) observed dried and shrunken corms, brownish black in colour with deposition of white powdery growth. Corms become light, and browning of the tissues progresses in all directions. Complete rotting and drying is observed within 60 days. Rotten tubers emit a musty odour. Ogundana (1975) also reported $F$. moniliforme from $X$. sagittifolium.

A soft-rot (c.o., Cylindrocarpon lichenicola $=$ Fusarium lichenicola) was also reported from Hyderabad (Usharani and Rama Rao 1981). The rot spreads gradually in stored tubers and finally whole corm transforms into a mass.

Losses can be minimized by using intact tubers for storage, removal of roots and soil from the corm, cleaning in water, followed by a disinfectant solution, air-drying / curing and storing in cool, airy rooms with about $50 \%$ relative humidity (Thankappan 1994). Seed treatment with Manocozeb (0.2\%) is also found effective in controlling storage rots. 


\section{ELEPHANT-FOOT YAM (Amorphophallus campanulatus Blume ex Decne)}

It is a cheap source of carbohydrate, and is rich in minerals and vitamins (vit. A and vit. B). Calcium oxalate present in the corm causes irritation to tongue. This is high in wild types and less in cultivated varieties. The yam is high in fibre and omega-3 fatty acid, and has a low glycemic index value. Hence, the yam is good for people suffering from diabetics.

Post-harvest rotting of elephant-foot yam is commonly encountered by cultivators. The yams need to be stored properly during off-season for using them as seed material for the next planting season.

Storage of elephant-foot yam corms is a problem to farmers due to their loss in weight and rotting when stored in heaps for the next season planting. Weight loss, sprouting and spoilage are reported in yams and sweet-potato tubers (Coursey and Walker 1960; Passam 1977; Balagopalan and Padmaja 1985; Picha 1986). About 50-60\% moisture loss during the first four months of storage was reported in room temperature, and corms stored in white-sand recorded only 30-32\% moisture loss (Anon. 1990). Sprouting and rotting of seed-corms in storage reduce seed quality to a great extent. Das et al. (1995) evaluated different low-cost storage methods and observed that relatively high temperature prevailed under covered area. Weight loss enhanced with advancement of storage period irrespective of the storage media and was much more in uncovered lot. But the loss could be reduced by keeping a water-tray below the stored seed-corms. The moisture loss and sprouting of seed-corm were reduced by storing seed-corms under dry soil and dry ash. Mondal et.al. (2004) observed similar results from West Bengal. The comparative efficacy is recorded as soil $>$ sawdust $>$ sand. Seed-corms treated during storage with Captafol $(0.2 \%)$ gave highest results, followed by treatments with Bavistin $(0.1 \%)$ and Blitox $(0.5 \%)$.

\section{FUNGAL DISEASES}

\section{Soft corm-rot, c.o. Sclerotium rolfsii Sacc./ Rhizoctonia solani Kühn}

Coursey and Booth (1972) reported disease from Solomon Islands. In India, the disease was recorded from Maharashtra(Uppal et.al. 1925( cited Vasudeva, 1960), West Bengal (Roy 1949; Mandal and Dasgupta 1981), Rajasthan (Tyagi and Sharma, 1977) and from Tamil Nadu (Siva Prakasam and Kandaswami 1982).

Symptoms : No external symptoms are noticed. The affected area becomes soft after 5-7 days, and white mycelial growth becomes visible on the outer corm skin (Fig. 27.3). Sclerotia are also noticed in abundance. They are white at first but gradually become brown and later dark-brown. The disease causes extensive decay during rainy season, and is favoured by high relative humidity and temperature around $30^{\circ} \mathrm{C}$. 
Mandal and Das Gupta (1980) recorded dirty grey-rot due to Rhizoctonia solani (Thanatephorus cucumeris) as a major disease on harvested yams during late rainy season in West Bengal. The infected corms showed rotting in the form of a shallow cone. Water-soaked areas appear, which gradually enlarge and attain diameter of about $5-10 \mathrm{~cm}$. The natural flesh colour of the corm is transformed into ivory black. Simliar symptoms were also noticed by Philip

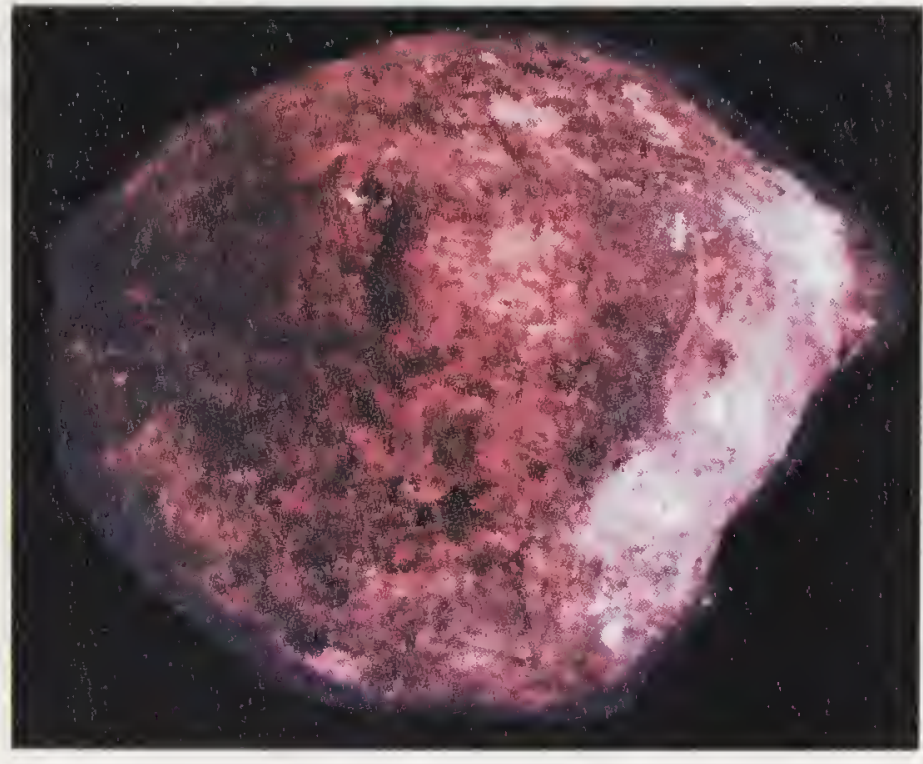

Fig. 27.3. Rhizoctonia-rot on elephantfoot yam

(1998) on yams harvested from Idukki district in Kerala, which were transported to Thiruvananthapuram markets during the onam festival season; $50-75 \%$ rotting was recorded in certain cases. The pathogen is carried from field through wounds and causes severe damage during storage.

Other important pathogens causing soft-rot of elephant-foot yam tubers include Phytophthora colocasiae, Botryodiplodia theobromae, Fusarium sp. and Rhizopus sp.

Bacterial-rot caused by Erwinia carotovora was also reported to cause serious damage to yam-tubers. Storage at higher temperature with poor aeration helps in building-up of inoculum. Tuber-rot caused by nematodefungal-bacterial complex was also reported (Misra et al. 2006).

Control measures: Biological control. Treatment of yam-setts with Ampalaya (Momordica charantia) crude ethanolic/acetonic extracts, followed by regular spraying with the same extracts up to 6 months after planting protected the crop against yam anthracnose. The degree of protection was better than that of Benlate in Philippines (Palomar et.al. 2004).

Tyagi and Sharma (1977) observed disease control in the field with Trichoderma harzianum combined with fungicidal application.

Effect of T.harzianum on plant growth and intensity of collar-rot was also recorded from Asom. Soil application of T.harzianum $\left(10^{9}\right.$ conidia/ml $)$ increased plant height, canopy size, lowered disease incidence, and yielded more. Corms treated with Captan $(0.2 \%)$, followed by two soil applications of T.harzianum, as well as corms cut and dipped overnight in conidial suspension of T.harzianum, dried in shade and then used for planting showed promise (Gogoi et al. 2004).

Trichoderma-based management of collar-rot and tuber-rot was reported from Varanasi and Uttar Pradesh. Treatment of planting material with fresh cowdung slurry mixed with Trichoderma formulation $\left(10^{6}\right.$ spores $\left./ \mathrm{ml}\right)$ @ $\mathrm{g}$ / kg along with neemcake@250 g/ pit at the time of planting and application 
of Trichoderma enriched cowdung compost in soil @ 4 tonnes/ha were found best package for effective management (Misra et al.2006).

\section{Fungi on Yam Chips}

The following fungi are recorded on yam-chips in storage from Nigeria (Amusa and Moor 2001):

Penicillium oxalicum Lind.

Rhizopus stolonifer (Ehrenb.) Vuill.

Fusarium oxysporum Schlect.

Botryodiplodia theobromae Pat.

Aspergillus niger Van Tieghm.

A.flavus Link. ex Fries

Drechslera sp.

\section{DIOSCOREA/GREATER YAM (Dioscorea alata $\mathrm{L}$.)}

The genus Dioscorea includes several edible and wild varieties; of which $D$. alata (greater yam) and $D$. esculenta(lesser yam) are very popular in India. The crop is harvested once in a year and usually stored in traditional ways. It is rich in starch and other nutrients. The crop is extensively cultivated in Africa.

The yams of the genus $D$. prazeri Prain and Burkill are the main source of 'Diosgenin', a steroidal sapogenin. It is an important starting material for synthesis of cortisones, sex hormones and oral contraceptives (Sharma and Chatterjee, 1982).

Biochemical changes in yam-tubers during storage were recorded by Sundaresan et al. (1990). Three species - D. alata, D. esculenta and D. rotundata - were stored under ambient conditions and monitored periodically. The following observations were made:

- Starch content was found reduced;

- Total free sugars remained constant;

- Total polyphenols did not show any variation in D. rotundata. But in the other two species, the level increased by $13 \%$;

- Moisture loss was rapid. In D. rotundata, a decrease of $23 \%$ was recorded while in D. alata and D. esculenta, net decrease within 4 months was $10 \%$ and $6 \%$, respectively.

Avoiding mechanical injuries is the most important factor to be remembered in the storage of yams. The point of entry for the rot organisms is through wounds or due to senescence of sound tubers, resulting in autolytic breakdown, followed by decay. Yam-tubers remain without any change in nutritional properties (moisture, acidity, protein, lipid, carbohydrate, total sugars, ash and calorific value) up to four weeks and thereafter show alterations (Sahore et al. 2007).

A widely used traditional method of yam storage in S. Africa is the use of outdoor yam-barns. The barn consists of a framework of vertical poles 3-m 
high and $50-\mathrm{cm}$ apart, held together by horizontal poles. The tubers are tied individually in a horizontal position to vertical poles (On Wuema1978). Storage of tubers individually in horizontal position in open-sided bamboo or wooden shelves is also followed in Nigeria (Ikediobi 1985).

James (1990) in his studies on the storage for seed purpose observed weight loss in the open barn higher than the covered barn storage in pits. Mud plastered ventilated covers and mud-plastered heaps showed $87-100 \%$ sprouting. Sand heap and dry soil heap were also tried. Among the different storage practices, placing on racks in the covered barns was found promising.

Regulated air movement around the tubers resulted in low moisture loss. Moisture loss was enhanced at medium and at high fan speed because of the evaporation effect of the moving air (Osi Mozie 1996).

Tubers exposed to $12.5 \mathrm{krads}$ of gamma radiations could be stored for eight months without sprouting. But, exposure to doses above 5 krades caused damage to internal tissues (Adesuyil 1976).

\section{FUNGAL DISEASES}

\section{Brown dry-rot/wet-rot, c.o. Botryodiplodia theobromae Pat.}

The disease is of common occurrence and has been reported from several countries like Brazil, Ghana, Ivory Coast, Nigeria, Fiji etc (Okafor 1966; Coursey 1967; Ogunda et al. 1970; Okigbo and Ikedugwu 2000). Prasad and Bhatnagar (1970) reported rot under storage conditions with a loss of $10-29 \%$ from Rajasthan.

Symptoms : Rotten tubers turn grey internally and get dried up. The tissues turn fibrous and becomes light in weight. The bark remains intact, covering internal rotten portion. In the initial stages, the inner tissues become crispy, light grey and develop cracking. Infected tubers generally fail to sprout. Under high humidity, wet-rot sets in and turns tubers into watery mass. Together with Macrophomina phaseoli and Hendersonia tortuloidia, B. theobromae caused rotting in stored $D$. alata, $D$. coyenensis and $D$. rotundata in Nigeria (Okafor1966).

Control measures : Dipping cut ends of tubers in fungicides like Benomyl (Benlate 1,000 ppm, 2,000 ppm) and Bavistin (1,000 ppm, 2,000 ppm) controlled rot during storage (Bammi et al. 1972; Sarma 1984).

Tuber-rot, c.o Fusarium solani (Mart.) Sacc.

The disease was reported from Darjeeling on D.prazeri. High incidence of tuber-rot with graded severity was noticed from different plantations in Darjeeling hills. F. oxysporum, F.chlamydosporum and F.solani were recorded. Wounds, bruises, insect damage etc are the pre-disposing factors. The symptoms appear as dirty light-brown to dark-brown discolourations at the entry point. The tissues sooner become soft and emit offensive smell. The skin 
turns dark-brown, wrinkled and get covered with a crust of conidiophores bearing micro and macro conidia (Sharma and Chatterjee 1980,1982).

Fusarium sp. was also reported by Nwachukwu (2003) on D. rotunda. The rotting extent increased with storage time. Extensive rotting occurred in combination with Aspergillus sp. and Penicillium sp.

Application of Dithane M-45(0.2\%) to stored tubers inhibited mould growth.

\section{Rhizopus-rot, c.o. Rhizopus oryzae Went \& Prinsen Geerligs}

Reni (2002) reported the disease. The wounds created by nematodes on the tubers surface act as an entry point through which fungal infection occurs. The fungus also causes decay of yams in storage. $R$. stolonifer was also recorded to affect stored tubers of $D$. prazeri.

Control measures detailed under Botryodiplodia-rot are applicable in this case also.

\section{Hard brown dry-rot, c.o.Penicillium sclerotigenum}

The disease was reported from China, Nigeria,United Kingdom etc (Yamamoto et al.1955;Okafor, 1966; Coursey, 1967; Ogundana et al. 1970, 1971). Agarwal and Gupta(1973, 1977) reported the disease from Uttar Pradesh on D.alata. It is a wound parasite and infection occurs at $25^{\circ} \mathrm{C}$ and at $80 \%$ relative humidity.

Penicillium oxalicum was also reported to cause dry-rot on several species of yams - D. alata, D. cyanensis, D. dumetorum, D. esculenta and D. rotundata. Penicillium sp. was also reported. The extent of rot increased with storage time. Combination of Aspergillus and Penicillium caused extensive decay (Nwachukwu 2003).

Symptoms : Infected tubers show complete drying of tissues. Slight shrinkage and darkening of the affected parts is the initial symptom. The rot progresses rapidly and occupies interior areas. With further advancement, skin gets wrinkled. Underlying tissues become dry and develop cavities lined with white fungal mycelia. Blue-green sporulating masses in colonies are noticed on the upper surface. Tubers become hard and light in weight. Philip (1998) also observed disease on the vertically cut tubers. Irregular or star-like colonies, dark-green in colour, are noticed in abundance.

Control measures : Cut tubers for seed-purpose should be treated with Mancozeb $(0.2 \%)$ before storage.

\section{Aspergillus-rot}

It is considered as an important post-harvest rot of Dioscorea during transport and marketing (Maheswari et al. 1983). A flavus and A.fumigatus were also reported.

Cut-tubers for seed-purpose should be treated with Mancozeb $(0.2 \%)$ before storage. 


\section{OTHER ASSOCIATED FUNGI}

Ogundana et al. $(1970,1971)$ from Africa reported Botryodiplodia theobromae, Fusarium moniliforme, F.poae. F. solani, F. coeruleum, Mucor circinelloides, Rhizopus stolonifer, Penicillium sclerotigenum and Trichoderma viride from stored yams.

Several other fungi, Alternaria alternata, A. solani, Helminthosporium sp., Verticillium sp., Cephalosporium indicum, Curvularia pallescens and C. lunata, were recorded on stored yams (Sharma and Chatterjee 1980; Okigbo and Ikedugwu 2000).

Ray et al. (2000) observed following microorganisms from OdishaAspergillus awamori, A. versicolor, B.theobromae, F.solani, P. decumbens, and $P$.purpurogenum. These fungi caused primary dry-rot, while bacteria Serratia sp. and Erwinia sp. caused primary and secondary soft-rots.

\section{POST-HARVEST MANAGEMENT}

\section{Chemical protection}

Dipping cut ends of the tubers in fungicides Benomyl (1,000 ppm, 2,000 ppm) and Bavistin (1,000 ppm, 2,000 ppm) were effective in controlling rot during storage (Bammi et al. 1972; Sarma 1984).

\section{Biological control}

Okigbo and Ikediugwu (2001) controlled storage rots of Dioscorea successfully in Nigeria with Trichoderma viride. Conidial suspensions were sprayed on yams (white yam, $D$. rotundata) that were kept for six months; $T$. viride successfully displaced all naturally occurring mycoflora on the surface of yam-tubers. The fungi included Rhizopus sp., Aspergillus niger, Fusarium solani and Neurospores sp. Most of these fungi were opportunistic pathogens, waiting for any wound to penetrate tuber (Ogundana et al. 1970).

T. viride produces antibiotic substances that causes lysis of fungi (Padmodaya and Reddy 1996; Calistru et al. 1997). Alternately, T. viride may also colonize micro-sites faster than naturally occurring fungi (Gohi and Vala 1996). Okigho (1995) and Calistru et al.(1997) reported complete inhibition of spore germination by $T$. viride.

Antifungal microorganisms isolated from cowdung effectively inhibited growth of several fungi in vitro as well as on fresh yam-tubers (Swain et al. 2006). Treatment of yams-tubers and foliar spray at 15, 30, 45, 60 days after planting with 5\% 'Panchagavya' (fermented mixture of cowdung and urine, milk, buttermilk and ghee) kept plants free of any disease and increased tuber yield (Nayak et al. 2006). This is also mentioned in the ancient book 'Vrikshayurveda'. 


\section{Appendix 1}

\section{Fungal Spores}

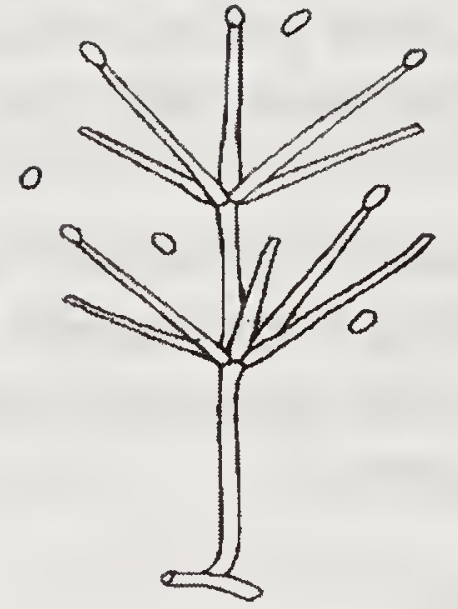

Verticillium

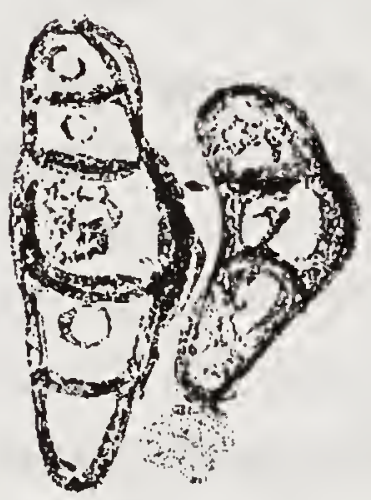

Cunvularia
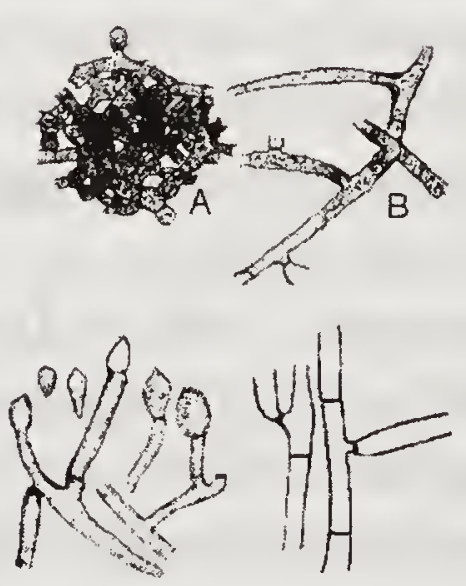

Thanatephorus (Rhizoctonia)

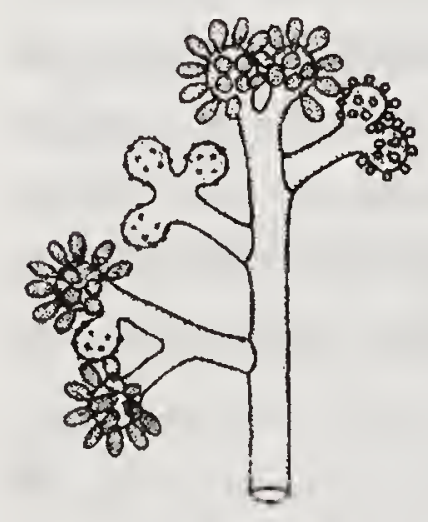

Botrytis

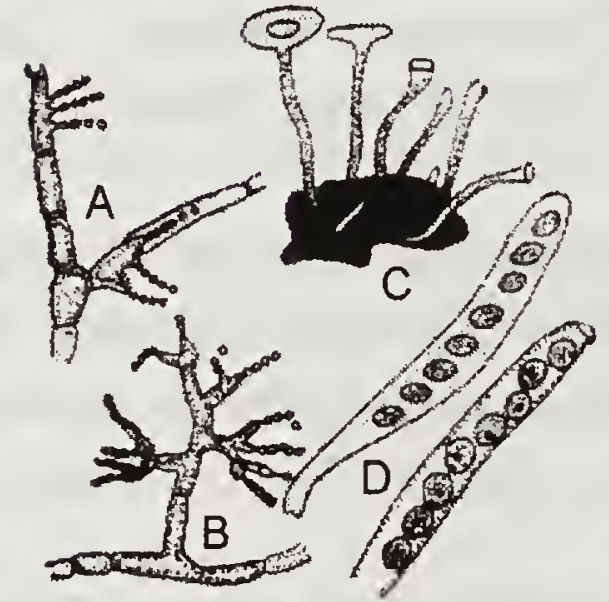

Sclerotinia sclerotiorum

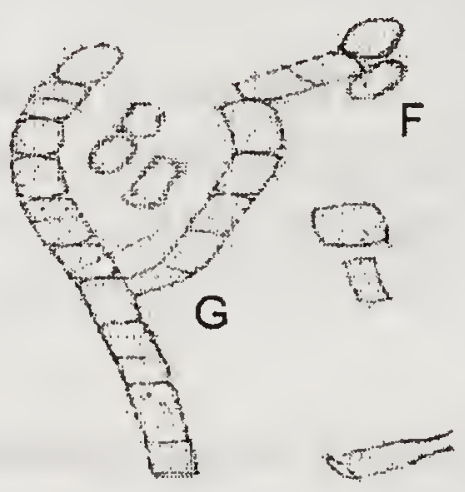

Geotrichum candidum

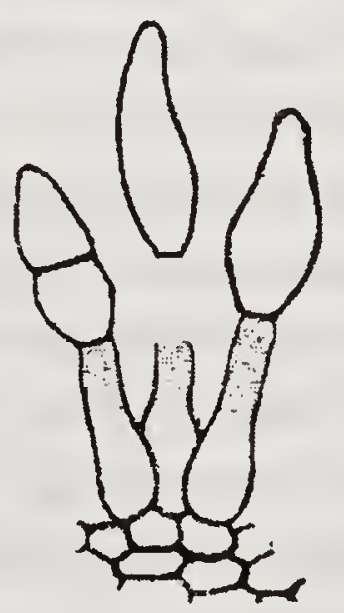

Pilocaea pomi

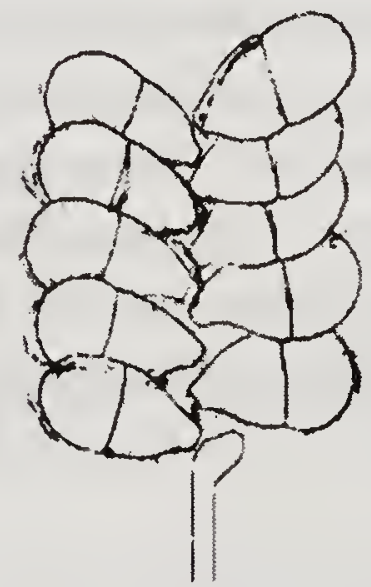

Trichothecium

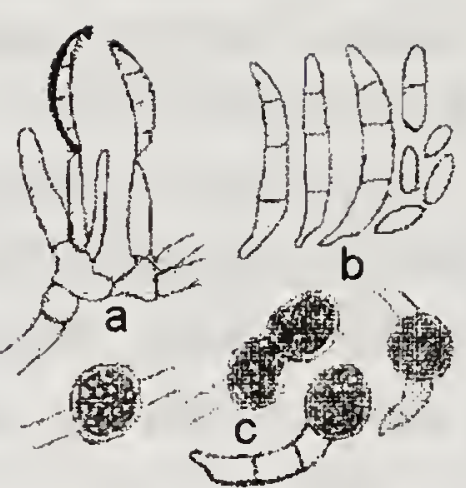

Fusarium
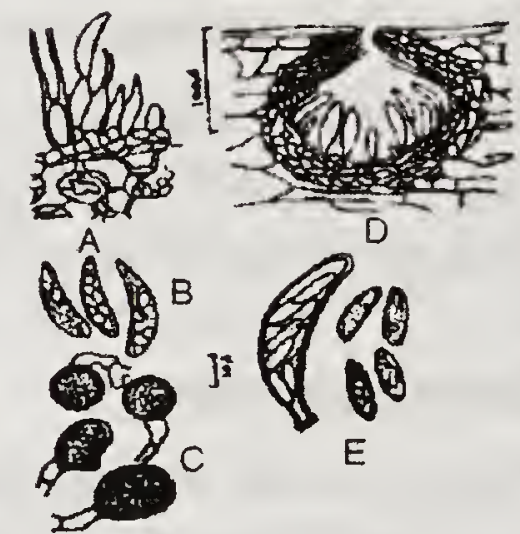

Glomerella cingulata

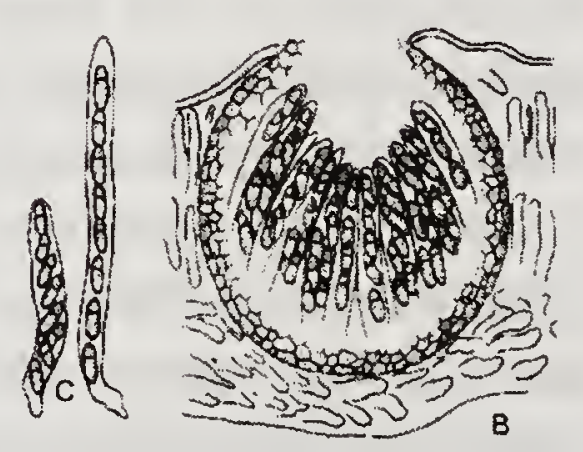

Venturia inaequalis 


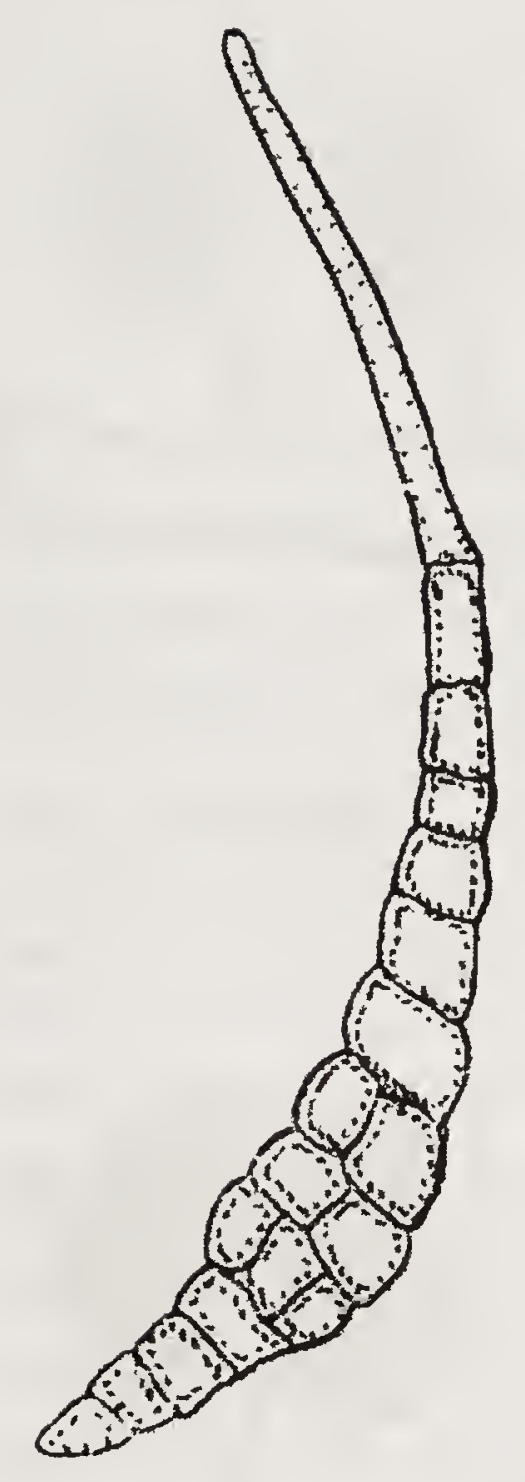

Alternaria

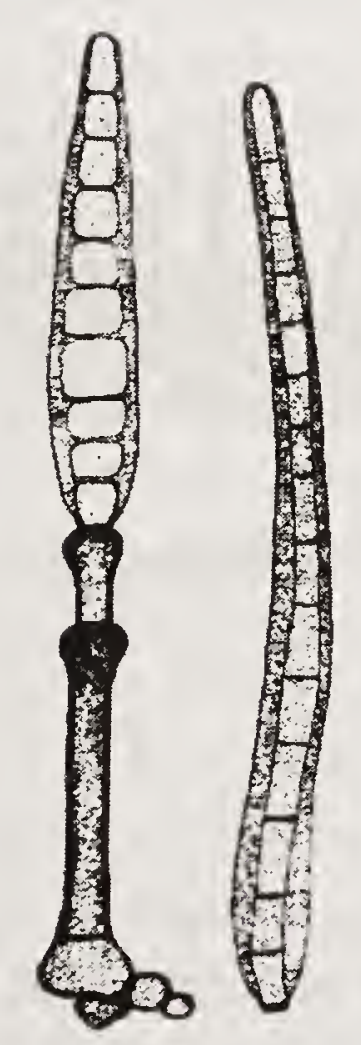

Corynespora
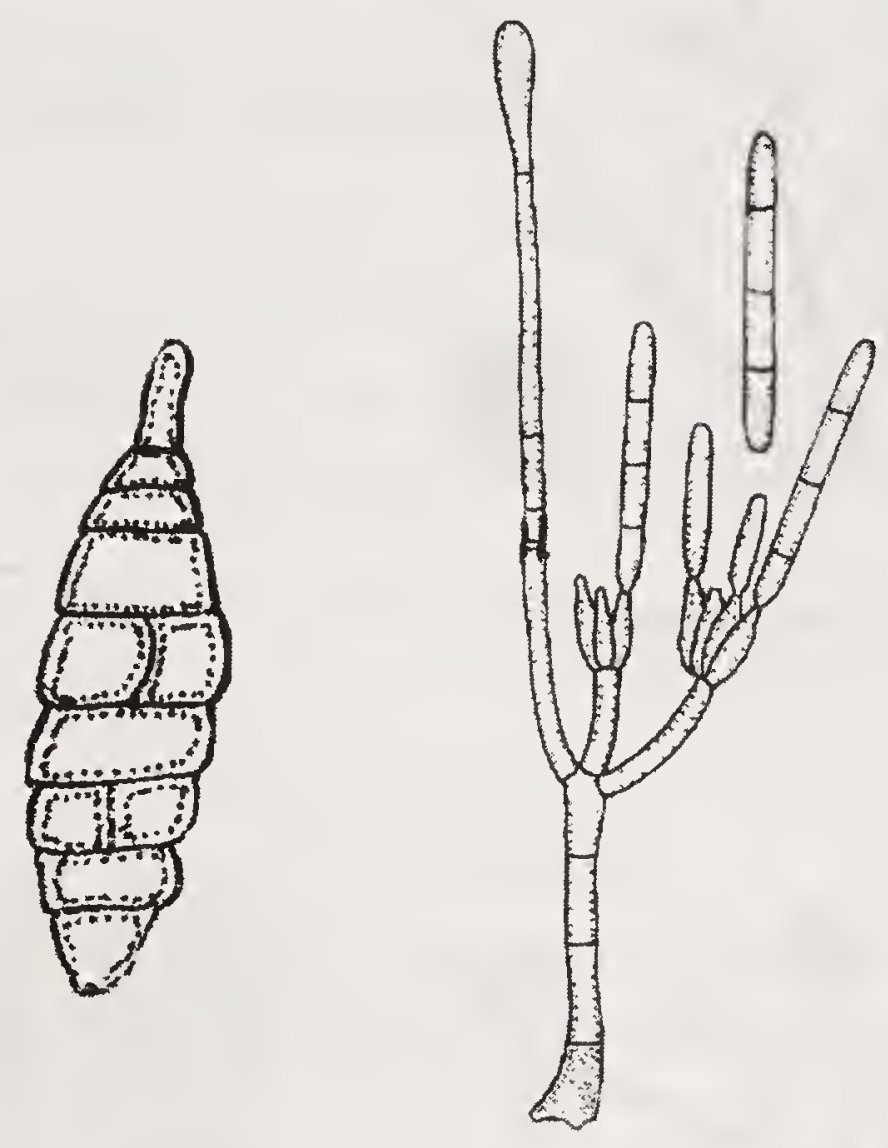

Cylindrocladium
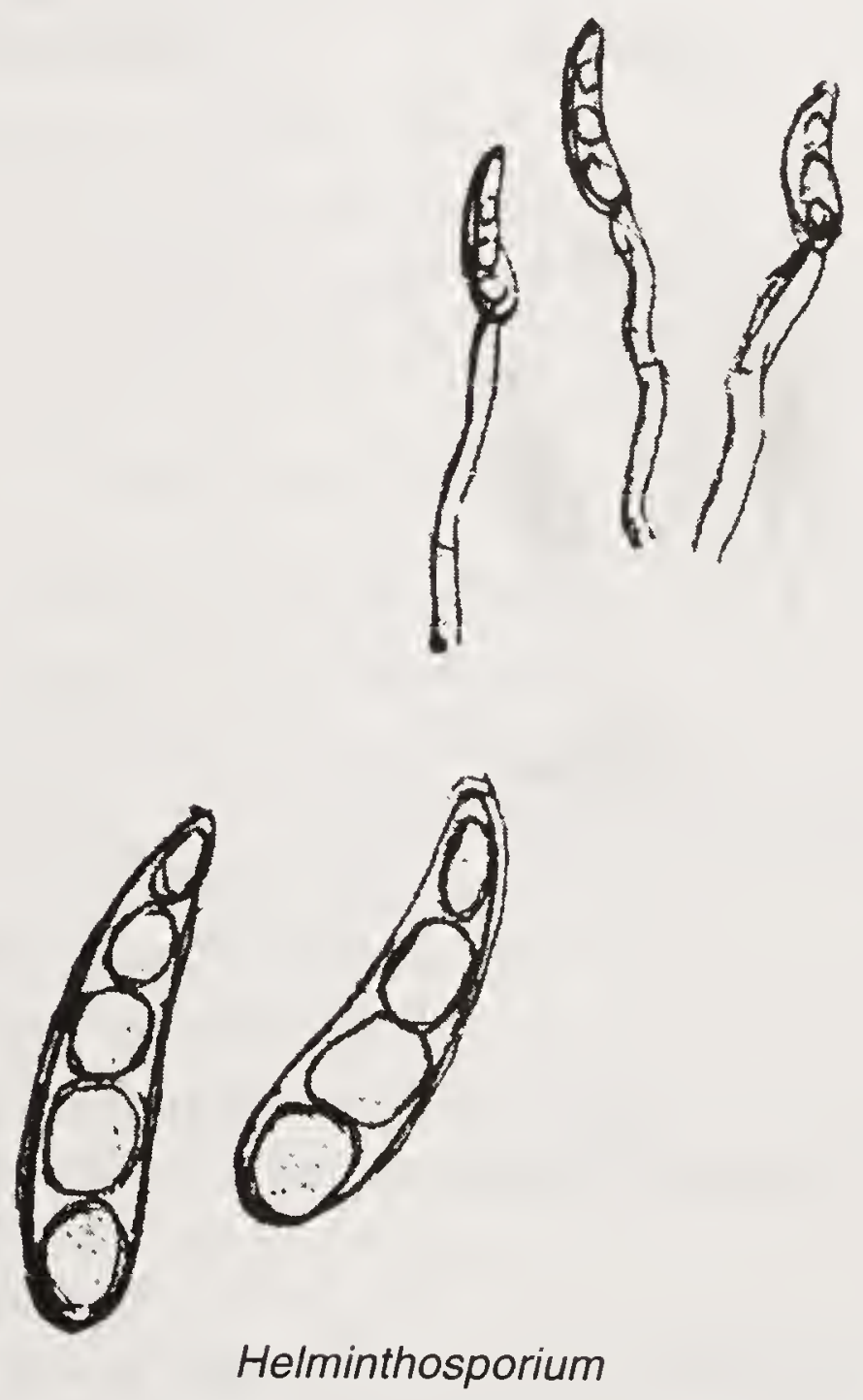


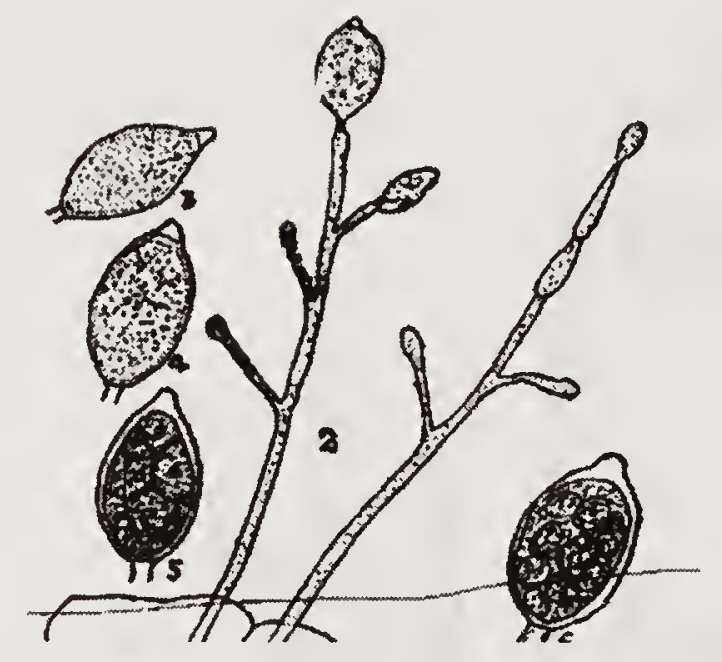

Phytophthora

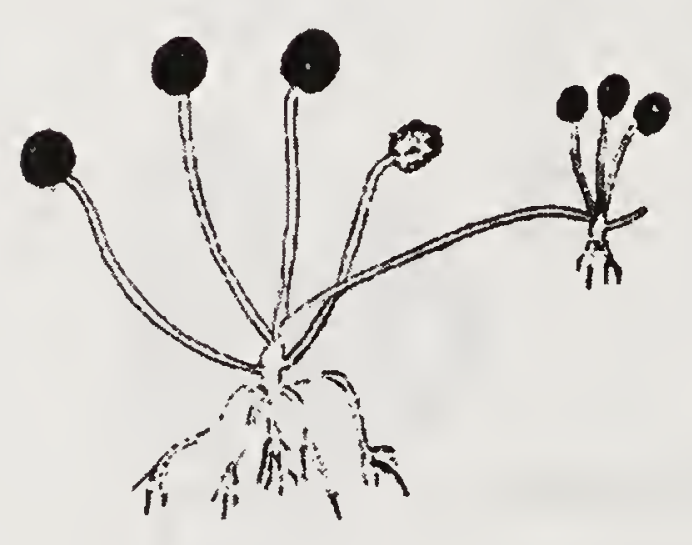

Rhizopus

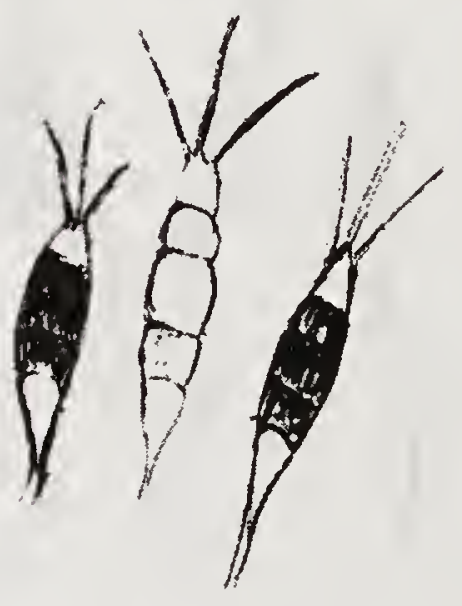

Pestalotia

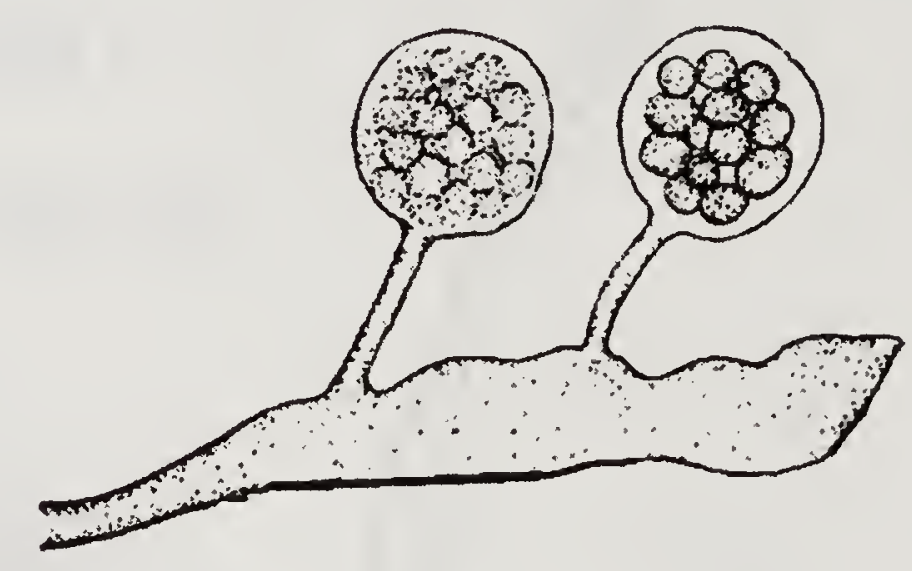

Pythium

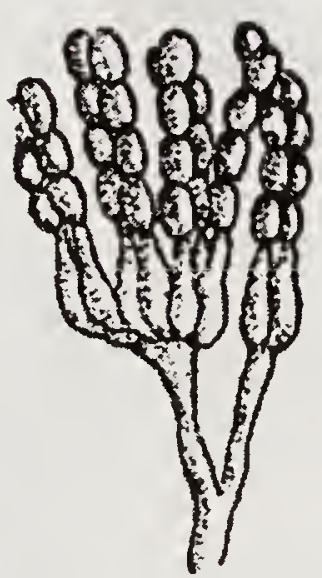

Penicillium

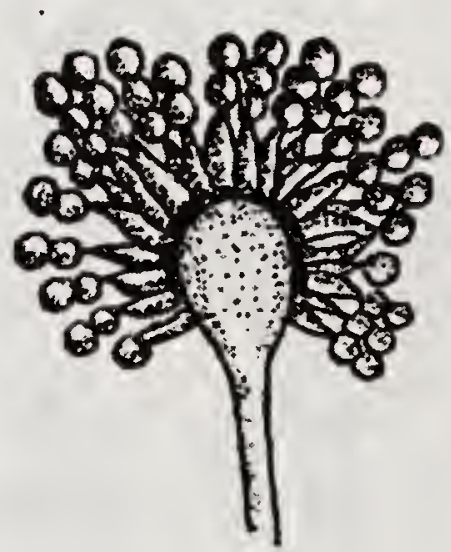

Aspergillus

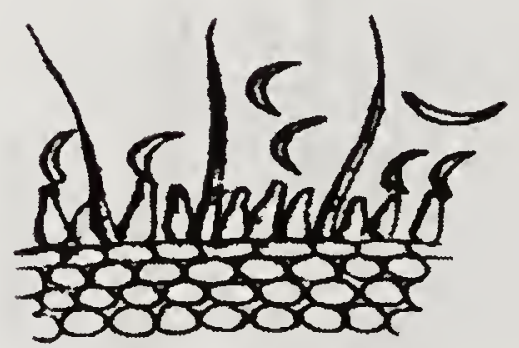

Colletotrichum 


\section{References}

Abawi, G. S. and Martin, S. B. 1985. Plant Dis. 69: 158-61.

Abd-El-Rehim, Elarosi. H. and Michai, S. H. 1964. Alexandria J. Agric Research 12: 123-28.

Abhilasha, Akbar, B. R., Vivek, K. P., Bishnu, M. B., Deeba, K. and Gupta, P. 2008. J. Mycol. Plant Pathol. 38: 405-06.

Acosta, R. M., Nieto, A. D., Nieto, A. R., Mena, N. G., Teliz, D. and Vaquera, H. H. 2001. Revista Chapingo Serie Horticulturae 7: 131-41.

Adair, C. N. 1971. Plant Dis. Reptr. 55: 864-68.

Adams, P. B. and Ayres, W. A. 1981. Phytopathology 71: 90-93.

Adams, P. B. and Papavizas, G. C. 1971. Phytopathology 61: 1253-56.

Adaskaveg, J. E., Fortster, H. and Sommer, N. F. 2002. In: Post-harvest Technology of Horticultral

Crops. (Ed.) Kader, A. A. University of California Agricultural and Natural Resources, Oakland.

Adebanjo, A. and Bankole, S. A. 2004. J. Basic Microbiology 44: 3-9.

Adesuyl, S. A. 1976. Nig. J. Plant Prot. 2: 34-39.

Addy, S. K., Singh, A. and Srivastava, S. 1987. Curri. Sci. 56: 713-14.

Adisa, V. A. 1983. Nahrung 27: 669-74.

Adisa, V. A 1985. Indian Phytopath. 38: 427-30.

Adisa, V. A and Fajola, A. O. 1982. Fitopatol Brasiliensis 7: 97-103.

Afanasiev, N. M. 1948. Phytopathology 38: 205-12.

Afanasiev, N. M. 1956. J. Amer. Soc. Sug Beet. Technol. 9: 178-79.

Agarwal, D. K. and Sarbhoy, A. K. 1976. Indian Phytopath. 29: 100.

Agarwal, P. and Agarwal, G. P. 1982. Proc. Indian Natl. Acad. Sci. B 48: 422-26.

Agarwal, P. C., Majumdar, A., Usha Dev. and Khetarpal, R. K. 1990. Indian J. Agric. Sci. 60 : 361-63.

Agarwal, P. C., Singh, B., Usha, D., Indra, R., Chand, D. and Khetarpal, R. K. 2006. Curr. Sci. 91 : 347-49.

Agarwal, S. B. and Gupta, M. N. 1973. Indian Phytopath. 26: 577-78.

Agarwal, S. B. and Gupta, M. N. 1977. Indian Phytopath. 30: 479-82.

Agarwal, S. C. and Kotasthane, S. R. 1971. Indian Phytopath. 24: 401-02.

Agarwal, V. K., Mathur, S. B. and Neergaard, P. 1972. Indian Phytopath. 25: 91-100.

Agarwal, V. K., Nene, Y. L. and Beniwal. 1976. Indian Phytopath. 29: 444-46.

Agarwala, R. K. and Sharma, V. C. 1968. Indian Phytopath. 21: 294-98.

Aggarwal, P. and Sood, A. K. 2004. Indian Phytopath. 57: 371.

Agnihotri, S., Pallavi, A. and Prabha, B. 2008. Indian Phytopath. 61: 403.

Agrios, G. N. 1969. Plant Pathology. Academic Press Inc., Newyork and London, pp. 629.

Ahamed. 1985. Indian Phytopath. 38: 418-22.

Ahamed, Q. 1987. Indian Phytopath. 40: 98-99.

Aharoni, Y. and Barkai Golan, R. 1987. Journal of Horticultural Science 62: 177-81.

Aharoni, Y., Copel, A. and Fallick, E. 1993. NZ. J. Crop. Hort. Sci. 21: 165-69. 
Ahir, R. R. and Maharshi, R. P. 2008. Indian Phytopath. 61: 130-31.

Ahmadzadeh, M., Sharifi, T., Hejuroud, G., Zad, J., Okh Ovvat, M. and Mohammudi, M. 2003. Iranian J. Agric. Sci. 34: 793-807.

Ajrekar, S. L. 1922. Bombay Dept of Agriculture-Annual Report. (1921-1922): 102-04.

Akamine, E. K. 1976. Hort. Sci. 11: 586-88.

Akamine, E. K. and Arisumi, T. 1953. Proc. Amer. Soc. Hort Sci. 61: 270-74.

Akhtar, J. and Chaube, H. S. 2006. Indian Phytopath. 59: 439-44.

Akhtar, J. and Singh, M. K. 2007. Indian Phytopath. 60: 63-67.

Alagarasamy, G. and Sivaprakasam, K. 1988. J. Biological Control 2: 121-23.

Alam, S., Gogoi, R., Narzari, B. D. and Goswami, R. 1996. Assam Agricultural University, Jorhat, Assam. In : Tropical Tuber Crops: Problems, Prospects and Future Strategies. CTCRI, Thiruvananthapuram, Kerala. (Eds) Kurup, G. T., Potty, V. P., Padmaja, G., Kabeerathumma, S. and Santha, V. Pillai, pp. 597.

Albornettn, J. and Sanabria de, A. 1994. Revista dela Facultad de Agronomia Universidad Central de Venezuela 20: 13-20.

Alcock, N. L. 1931. Trans. Bot. Soc. Edin. 30: 332-37.

Al-Hassan, K. K. 1973. FAO. Plant Protection Bulletin 21: 88-91.

Ali, S. S. and Shukla, A. 1981. Curr. Sci. 50: 232-33.

Alicbuson, R. V. and Schafer, L. A. 1958. Philipp. Agric. 42: 319-22.

Alice, K. J. 1969. M. Sc(Ag. ) Thesis. Kerala University, Kerala.

Alice, K. J. and Paily, P. V. 1978. Proceedings. Symposium on Post-harvest Pathology. Kerala Agricultural University, Kerala.

Alice, K. J. and Paily, P. V. 1981. Proceedings. Third International Symposium on Plant Pathology. IARI, New Delhi.

Alimova, P. K., Zakharova, N. G., Asghar, M. G. Fattahkova, A. N. and Garusav, A. V. 2002. Pakistan J. Scientific and Industrial Research 45: 191-96.

Allan, M. A., Schiller, C. T. and Tomenageo. 1998. Phytopathology 88 (9) : S-3.

Alstatt, G. E. and Smith, H. P. 1943. Rev. Appl. Mycol. 22: 462.

Alvarez, A. M. and Nishijima, W. T. 1987. Plant Dis. 71: 681-86.

Alvarez, A. M., Hylim, J. W. and Ogata, J. N. 1977. Plant Dis. Reptr. 61: 731-35.

Alvarez, G. L. A. and Cartaz, M. A. C. 1971. Puerto Rico Univ J. Agric. 55: 78.

Ambardar, V. K. and Singh, S. K. 1995. Indian Phytopath. 48: 358-59.

Amin, K. S. and Ullasa, B. A. 1981. Indian Phytopath. 34: 253-54.

Amin, K. S. and Ullasa, B. A and Sohi, H. S. 1979. Indian J. Agric Sci. 491: 53-57.

Amla, B. L. and Sankar, J. V. 1975. J. Root Crops 11: 24-31.

Amusa, N. A. and Moor. 2001. J. Agric. Res. Ibadan, Nigeria 35-39.

Anahosur, K. H. 2001. Indian Phytopath. 54: 158-66.

Anandaraj, M. and Sarma, Y. R. 2000. Indian Phytopath. 53 : 369.

Anandh, K. and Prakasam, V. 2001. South Indian Hort. 49: 275-77

Ananthanarayanan, A. and Seshadri, K. 1965. Indian Phytopath. 18: 367-72.

Anderson, H. W. 1925. Phytopathology 15: 122-24.

Anderson, H. W. 1956. Diseases of Fruit Crops. Mc Grow Hill Book Co. Ltd New York, Toronto and London.

Andrews, J. H. 1992. Ann. Rev. Phytopathol. 30: 630-35.

Anil Kumar, T. B. and Gowda, P. K. T. 1984. Pesticides 1: 43-46.

Anil Kumar, T. B. and Jalali, B. L. 1984. Indian Phytopath. 37: 394. 
Anju, B. C. and Bedi, J. S. 2004. Pl Dis. Res. 19: 155.

Anon. 1950. Annual Report. Indian J. Agri. Sci. 20: 107-42.

Anon. 1963. Report. Dept Agric., Mauritius 1962. 43-47.

Anon. 1967. Res. Dept Agric., Mauritius 1963. 59-63.

Anon. 1971. Pest Control in Bananas. PANS Manual no: 1. New Ed., pp. 128.

Anon. 1974. Annual Report, CPCRI, Kasaragod (Kerala). 1973, pp. 149-51.

Anon. 1974. CIAT Annual Report, California, Coloumbia.

Anon. 1975. CIAT Annual Report, California, Coloumbia

Anon. 1977. Annual Report, ICRISAT. Hyderabad (Andhra Pradesh).

Anon. 1982. Annual Report, CTCRI, Trivandrum (Kerala), pp. 182-83.

Anon. 1983 Annual Report. CTCRI, Trivandrum (Kerala), pp. 17-21.

Anon. 1983a. Mango Cultivation. Ext. Bull. 19, Indian Institute of Horticultural Research, Bengaluru (Karnataka).

Anon. 1985. Annual Report. CTCRI Trivandrum (Kerala), pp. 17-21.

Anon. 1986. Annual Report. CTCRI Trivandrum (Kerala); pp. 140-43.

Anon. 1989. Annual Report. CTCRI Trivandrum (Kerala), pp. 96-99.

Anon. 1990. Storage pests of tuber crops. CTCRI News 7 (2): 1-2.

Anon. 1997. ICAR News. Zero energy cool chamber, pp. 1-4.

Anon. 2003. ICAR News, pp. 18-19.

Anon. 2007. Package of Practice Recommendations, KAU, Thrissur, Kerala.

Anuja, G. 2001. Indian Phytopath. 54: 503.

Anuja, G. 2002. Indian Phytopath. 55: 99-101.

Anuja, G. 2003. Bharatiya Krishi Anusandhan Patrika 18: 30-36.

Aragaki, M., Kimoto, W. S. and Uchida, J. Y. 1981. Plant Dis. 65: 744-45.

Archana, S., Yogesh, K. N. and Kumar. 2008. J. Mycol Plant Pathol. 38: 65-72.

Arinze, A. E. 1997. J. Root Crops 23: 124-30.

Arisumi, 1956. Hawaii Agric. Sta. Tech. Bull. 29: 16.

Arora, R. K. and Somani, A. K. 2001. Indian Potato Association 28: 88-89.

Arras, Agabbio, M. Fiori, G. M. and Malttoni, S. L. 2001. Rivista di Frutticolturae di ortofloriocoltura. 63(ii) : 17-22.

Arriola, de, M. C. de, Calzada, J. F., Menchu, J. F., Rolz, C. and Garcia, R. 1980. Papaya. In: Tropical and Sub-tropical Fruits. (Eds)Nagy, S. and Shaw, P. E., AVI, USA, pp. 216-340.

Arsenijevic, M. and Stojic. 1973. Zast Bilja 23: 183-92.

Arx, J. A., Von. and Veldom, F. J. J. A. 1961. Phytopath Z. 41: 228-35.

Arya, A. 1988. Indian Phytopath. 41: 214-19.

Arya, A. and Lal. B., Agrwal, R. and Srivastava, R. C. 1986. Indian. J. Mycol. Plant Pathol. 17: 265-69.

Arya, A., Dwivedi, D. K., Pandey, R. S., Shukla D. N., Bhargava, S. N. and Bihari Lal, 1981. Indian Phytopath. 34: 359-60.

Asha, A. N. and Kannabiran, B. 2001. Indian Phytopath. 54: 373-75.

Ashwanikumar, L., Aulakha, K. S. and Kamat, R. 1986. Indian Phytopath. 39: 988-89.

Ashworth, L. J. and King, W. R. 1962. Phytopathology 52: 723.

Asthana, R. P. 1945. Proceedings. Indian Acad. Sci. 22: 168.

Aulakha, K. S. and Grover, R. K. 1968. Plant Dis. Reptr. 52: 555-58.

Avissar, I. and Pesis, E. 1991. Ann. appl. Biol. 118: 229-37. 
Awasthi, D. P., Sarkar, S. and Kaiser, S. A. K. M. 2004. Indian Phytopath. 57: 354.

Aycook, R. 1966. North Carolina. Agric Exp Sta. Tech. Bull. No. 174.

Aziz-Abou, A. B., Nabawy, El. S. M. and Zaki, H. A. 1975. Scientia Horticulturae 3: 173-77.

Babadoost, M. and Islam, S. Z. 2003. Plant Dis. 87: 63-68.

Babarinsa, F. A., Nwangwa, S. C. and Williams, J. O. 2001. Trop. Sci. 41: 50-53.

Babu, K. J., Laxminarayan, P. and Reddy, S. M. 1982. Curr. Sci. 51: 892-93.

Babu, R. M. and Reddy, S. M. 1986. Natl. Acad. Sci. Letters. 9: 133-34.

Babu, R. M. and Seetharaman, K. 2002. Research on Crops 3: 177-80.

Backman, P. A. and Rodriguz, K. 1975. Phytopathology 65: 819-21.

Bagri, R. K., Choudhary, S. L and Rai, P. K. 2004. Indian Phytopath. 57: 107-09.

Bagwan, N. B. and Meshram, B. M. 2001. Madras Agric. J. 88: 386-87.

Bai, D. H. 1977. Korean J. Plant Protection 16: 245-47.

Bailey, A. A. 1966. A check-list of plant diseases in Nigeria. Fed. Dept. Agric. Res. memo. 96: 37.

Bala, R., Bhardwaj, L. N., VedRam and Sharma, G. K. 2001. Plant Dis. Res. 16: 119-22.

Balagopalan, C. and Nair, P. G. 1976. J. Root Crops 2: (2): 57-58.

Balagopalan, C. and Padmaja, G. 1985. Tech Bull. No. 3. CTCRI. Thiruvananthapuram(Kerala).

Balagopalan, C., Bhavani Devi, S. and Pillai, K. B. 1974. Agric. Res. J., Kerala 12 : 80-81.

Balagopalan, C., Maini, S. B., Potty, V. P. and Pillai, K. 1974. Proceedings. Seminar on Postharvest Technology of Cassava held at Thiruvananthapuram(Kerala).

Balagopalan, C., Maini, S. B., Potty, V. P., Pillai, K. and Padmaja, G. 1980. Proceedings. Seminar on Post-harvest Technology of Cassava held at Thiruvananthapuram(Kerala).

Balakrishnan, P., Usman, N. M. and Sarma, Y. R. 1994. Indian Phytopath. 47: 334.

Balasubramonian, 1972. Indian Phytopath. 25: 475-77.

Ball, S. and Reeves, J. 1992. Technique for the Rapid Detection of Plant Pathogens. (Eds) Duncan, J. M and Torrence, L. J. Blackwell Scientific Publication, Oxford, UK.

Bamba, R. and Sumbali, G. 2006. Indian Phytopath. 59: 194-98.

Bammi, P. K., Rao, V. R., Randhawa, G. S. and Selvaraj, Y. 1972. Plant Dis. Reptr. 56: 990-91.

Bancroft, M. N., Gardner, P. D., Eckert, J. W. and Baritelle, J. L. 1984. Plant Dis. 68: 24.

Bandyopadhyay, I. and Chauduri, S. 2004. Indian Phytopath. 57: 353.

Banyal, D. K. 2000. Indian Phytopath. 53: 363.

Banyal, D. K., Singh, A. and Rana, S. K. 2002. Indian Phytopath. 55: 399.

Baracer, J. 1981. Revue Horticole 198: 53-54.

Barbetti, M. J. 1980. Aust J. Exp. Agric. Anim. Husb. 20: 247-51.

Barkai-Golan, R. 1981. Special publication. Vocanic center. No. 194.

Barkai-Golan, R., Lavy, N. G. and Kopilovitch, E. 1990. Hort. Abstract 60: 47.

Barmore, C. R. and Brown, G. E. 1978. Plant Dis. Reptr. 62: 541-45.

Barmore, C. R. and Brown, G. E. 1981. Phytopathology 71: 328-31.

Barnett, H. L. and Lilly, V. G. 1956. Mycologia 48: 617-27.

Barnwal, M. K., Prasad, S. M. and Maiti, D. 2003. Indian Phytopath. 56: 291-92.

Bartz, J. A. 1962. Proc. Fla St. Hort Soc. 4: 117-19.

Bartz, J. A. and Kelman, A. 1984. Amer. Potato J. 61: 485-93.

Barua, P. C., Deka, B. C. and Buragohain, J. 2010. Indian J. Horticulture 67: 249-54.

Baruah, H. K., Baruah, P. and Baruah, A. 1985. Textbook of Plant Pathology. Oxford \& IBH Publishing Co. New Delhi, Bombay, Calcutta, pp. 498.

Bastiaanse, H., Bellaire, L. De Lde, Lassonis, L., Mission, C. and Jijakli, M. H. 2010. Biological Control 53: 100-07. 
Batzer, J. C., Gdeason, M. L., Nutter, F. W. (Jr), Weldon, B. and Dixon, P. M. 2002. Plant Dis. 86: $1325-32$.

Bautista, B. S., Barrera, N. L. L., Bravo, L. L. and Bermudez, T. K. 2002. Revista Mexicana de Fitopatologia. 20: 8-12.

Beebi, R. P. M. and Rasheed, A. 2007. J. Mycol. Plant Pathol. 37: 485-90.

Beeching, J. R., Teilly, K., Bernal, D., Cortes, D. F. and Tohme, J. 2006. Proceedings. $14^{\text {th }}$ ISTRC Symposium on Tropical Root Crops held at CTCRI, Thiruvananthapuram (Kerala).

Beena, N. and Sarma, Y. R. 2000. Indian Phytopath. 53: 373.

Behr, L. and Urban, E. 1986. Archiv fir Phytopatholigice and pflazenschutz. 22: 41-48.

Ben-Yehoshua, S. 1985. Hort Science 20: 32-37.

Benoist, M. 1981. Revue Horticole 198: 55.

Beraha, L. 1964. Phytopathology 54: 755-59.

Beraha, L. and O'Brien, M. J. 1979. Phytopath. Z. 94: 199-207.

Beraha, L., Towner, D. B. and Camp, T. H. 1976. Plant Dis. Reptr. 60: 420-22.

Beraha, L., Ramsey, G. B., Smith, M. A. and Wright, W. R. 1957. Phytopathology 47: 4

Bergamini, A. and Giongo, L. 2002. Acta Horticulturae 595: 79-82.

Bhagchandani, A., Netrapal, P. M., Narendra Singh and Choudhuri, B. 1980. Indian Hort. 24: 7-9.

Bharat, N. K. and Sharma, S. K. 1994. Indian J. Plant Pathol. 12: 45-80.

Bhardwaj, C. L. and Thakur, D. R. 1992. Indian J. Mycol. Plant Pathol. 22: 232-35.

Bhardwaj, C. L., Thakur, D. R. and Janwal, R. S. 1995. Indian J. Agri. Sci. 65: 149-51.

Bhardwaj, L. N., Shyam, K. R. and Thakur, P. D. 1987. Pesticides 21: 13-16.

Bhardwaj, S. S., Sharma, S. L and Thakur, P. D. 1985. Indian Phytopath. 38: 759.

Bhargava, K. S and Gupta, S. C. 1957. Hort. Advance 1: 65-67.

Bhargava, P. K. 1995. Indian Phytopath. 48: 283-85.

Bhargava S. N. and Singh, A. P. 1974. Indian Phytopath. 27: 613-14.

Bhargava S. N. and Singh, A. P. 1975. Indian J. Hort. 32: 190.

Bhargava S. N., Bhargava, V. and Singh, A. P. 1976. Curr. Sci. 45: 268-69.

Bhargava S. N., Gosh, A. H., Srivastava, M. P., Singh, R. H. and Tandon, R. N. 1965. Proc. Natl. Acad. Sci. (India) 35: 393-98.

Bhatia, A., Singh, T. and Singh. D. 1998. J. Mycol. Plant Pathol. 28: 231-35.

Bhatt, H. R. and Jadeja, K. B. 2008. J. Mycol. Plant Pathol. 38: 264.

Bhatt, J. C., Gahlain, A. and Pant, S. K. 2000. Indian Phytopath. 53: 495.

Bhuvaneshwari, V. and Subba Rao, M. 2001. Indian Phytopath. 54: 493-94.

Bhuvaneshwari, V. and Subba Rao, M. 2003. J. Mycol. Plant Pathol. 33: 442-43.

Bihari Lal and Arya, A. 1980. Natl. Acad. Sci. Letters 3: 73-74.

Bihari Lal and Chaturvedi, S. C. 1994. Indian Phytopath. 47: 312.

Bihari Lal and Malaviya, A. 1994. Indian Phytopath. 47: 312.

Bihari Lal and Rai, R. N. 1978. Indian J. Mycol. Plant Pathol. 8: 81.

Bihari Lal, Arya, A., Rai, R. N. and Tewari, D. K. 1980. Natl. Acad. Sci. Letter 5: 183-85.

Bihari Lal., Rai, R. N., Arun, A. and Tewari, D. K. 1980. Golden Jubilee Session. Natl. Acad. Sci. letters 8: 361-62.

Bilgrami, K. S., Jamaluddin and Rizwi, M. A. 1979. Fungi of India. Part I. Today and Tomorrows. New Delhi, pp. 467.

Bilgrami, K. S., Jamaluddin and Rizwi, M. A. 1981. Fungi of India. Part II. Today and Tomorrows, New Delhi. 
Bilgrami, K. S., Prasad, T., Jamaluddin. and Roy, A. K. 1976. Indian Phytopath. 29: 374-77.

Bilgrami, R. S. and Verma, R. 1978. Proceedings. Symposium on Physiology of Parasitism. Jabalpur University.

Bilgrami, R. S. and Verma, R. 1979. Indian Phytopath. 32: 481-83.

Bisach, M., Minervini, G. and Zerbetto, F. 1986. Vitis 25: 118-28.

Bitancourt, A. A. and Jenkins, A. F. 1946. Arquivos do institute Biologico, Sao Paulo 17: 205-28.

Bizzetto, A. and Homechin, M. 1997. Revista Brasileria de Sementes 19: 295-303.

Blancard, D. 1992. A Colour Atlas of Tomato Diseases. Wolf publishing Ltd, London, pp. 212 Blancard, D., Jamme, M. and Lemaire, J. M. 1984. Revue Horticole 252: 11-13, 16-17.

Blanipied, G. D. and Purnasiri, A. 1968. Plant Dis. Reptr. 52: 865-71.

Boelema, B. H. and Ehlers, J. H. 1967. Fmg S. Africa. 43: 15.

Bohra, B. N., Vyas and Mistry, K. B. 2006. Indian Phytopath. 59: 223-26.

Bolkan, H. A., Cupertino, F. P. Dianesse, J. C. and Takatsu, A. 1976. Plant Dis. Reptr. 60: 605-09. Boniface, J. C. 1982. EPPO Bull. 12: 55-60.

Bonn, J. Van Der. 1980. J. Hort. Sci. 55: 313-21.

Bonn, J. Van Der. 1981. Hort. Abstracts 51: 6759.

Borah, P. K., Jindal, J. K. and Verma, J. P. 2000. Indian Phytopath. 53: 384-94

Borecka, H. 1977. Acta Agro Botanica 30: 229-38.

Bose, S. K. 1969. Progve Hort. 1: 29-36, 65-88.

Bose, S. K. and Mehta, P. R. 1951. Plant Protection Bulletin, New Delhi 3: 46-48.

Bose, S. K. and Sindhan, G. S. 1973. Progve Hort. 4: 69-75.

Bose, P. C. and Singh, C. 1980. Pesticides 14 (8): 30-31

Bosshard, E., Schiiepp, H. and Siegfried, W. 1987. Eur. Mediterr. Plant Prot. Organ. Bull. 17: 655.

Booth, R. H. 1973. Proceedings. International Symposium on Tropical Root Crops. Ibadan, Nigeria.

Booth, R. H. 1974. Trop Sci. 16 (2) : 49-63.

Booth, R. H. 1975. Cassava Storage. CIAT. California, Colombia

Booth, R. H. 1976. Experimental Agriculture 12: 103-11.

Brackmann, A., Steffens, C. A., Neuwald, D. A. and Sestari. 2003. Ciencia Rural 33: 647-50.

Bramlage, W. J. and Shipway, M. R. 1967. Proc. Amer. Soc. Hort Sci. 90: 475-83.

Bratley, C. O. and Mason, A. S. 1939. United States Department of Agriculture. Circular No. 511.

Brice, J., Currah, L., Malins, A. and Bancroft, A. 1997. Onion storage in the tropics: A Practical Guide to Methods of Storage and their Selection. Chatham: Natural Resources Institute.

Brock, R. D. 1951. J. Aust. Inst Agric. Sci. 27: 25-30.

Brocklehurst, T. F. and Lund, B. M. 1981. J. Applied Bacteriology50: 259-66.

Brodrick, H. T., Jacobs, C. J., Swartz., H. D. and Mulder, N. J. 1972. Citrus Grower. Sub-tropical Fruit J. 467: 5-21.

Brook, P. J. 1977. Newz. J. Agric. 20: 547-55.

Brooks, C. 1944. J. Agric. Res. 68: 368-81.

Brooks, C. and Cooley, J. S. 1917. J. Agric. Res. 11: 287-317.

Brooks, C. and Harley, C. P. 1934. Agric. Res. 49: 55-69.

Broome, J. C., Englsih, J. T. Marois, J. J., Latore, B. A. and Aviles, J. C. 1995. Phytopathology 85: 97-102.

Brown, G. E. 1975. Phytopathology 65: 404-09.

Brown, G. E. and Albrigo, L. G. 1970. Proceedings. Fla St. Hort. Soc. 83: 222-25. 
Brown, G. E. and Albrigo, L. G. 1972. Phytopathology 62: 1434.

Brown, G. E and Barmore, C. R. 1977. Phytopathology 67: 120-23.

Brown, J. G. and Evans, M. M. 1983. Tech Bull. Arizona Agric Expt sta. No: 51: 45-65.

Brown, G. E. and Mc Cornack, A. A. 1972. Plant Dis. Reptr. 56: 909-12.

Brown, M. E., Howard, E. M. and Knight, B. C. 1970. Plant Path. 19: 198.

Brown, G. E., Mc Cornack and Smoot, J. J. 1967. Plant Dis. Reptr. 51: 95-98.

Bugbee, W. M. and Cole, D. F. 1981. Phytopathology 71: 357-59.

Burden, O. J. 1968. Queensland. Agric. Anim. Sci. 25: 135-44.

Burden, J. N. 1997. In: Post-harvest Physiology and Storage of Tropical and Sub Tropical Fruits. CAB. International, UK, pp. 448.

Burkholder, W. H. 1942. Phytopathology 32: 141-49

Burkholder, W. H. 1950. Phytopathology 40: 115-17.

Burton, C. L. 1970. Trop. Agric. (Trinidad) 47: 303-13.

Butler, E. J 1907. Mem. Dept Agric. India (Bot Ser). 1: 70.

Butler, E. J. 1960. Phytopathology 50: 665-72.

Butler, E. J. 1961. Phytopathology 51: 250-55.

Butler, E. J. and Kulkarni, G. S. 1913. Memoirs of the Department of Agriculture, India.

Butler, E. J, Webster, R. K and Eckert, J. W. 1965. Phytopathology 55: 1262-68.

Byrde, R. J. W. and Willetts, H. J. 1977. The Brown Rot Fungi-Biology and Control. Pergamon Press. New York, pp. 171.

Calistru, C., Mc Clan, M. and Berjak, P. 1997. Mycopathologia 137: 115-24.

Campbell, J. G. C. 1926. Annual Report, Fiji. Dep. Agric. pp. 3-4.

Campos, E., Maher, E. A. and Kelman, A. 1982. Plant Dis. 66: 543-46.

Capdeville, de, Wilson, C. L., Beer, S. V. and Aist, J. R. 2002. Phytopathology 92: 900-08.

Capoor, S. P. 1952. Indian J. Agric. Sci. 22: 271-74.

Cappellini, R. A., Ceponis, M. J., Wells, M. and Ligutner, G. W. 1984. Plant Dis. 68: 1018-20.

Cappellini, R. A., Ceponis, M. J., Wells, M. and Ligutner, G. W. 1988. Plant Dis. 72: 81-85.

Cascals, C., Texidio, N., Vinas, L., Silvera, E., Lanarca, N. and Usalli, J. 2010. European J. Plant Pathology 128: 51-63.

Caygill, J. C., Cooke, R. D., Moore, D. J., Read, S. J. and Passam, H. C. 1976. Report. Tropical Products Institute(London), pp. 124.

Cayley, G. R., Hide, G. A., Read, P. J. and Dune, Y. 1983. Potato Research 26: 163-73.

Ceponis, M. J. 1966. Pl. Dis. Reptr. 50: 222-24.

Ceponis, M. J. and Butterfield, J. E. 1974. Plant Dis. 58 : 558-60

Ceponis, M. J. and Friedman, B. A. 1959. Phytopathology 49: 141-44.

Cha, J. S., Pujol, C., Duscusin, A. R., Macion, E. A., Lucas, L. N., Hubbard, C. H. and Kado, C. I. 1994. Mol. Ecol. 3: 609.

Chahal, A. S. and Grover, R. K. 1972. Indian Phytopath. 25: 257-260 ; 530-33.

Chahal, D. C. and Malhi, C. S. 1969. Indian J. Hort. 26 (1-2): 186-92.

Chakrabarti, N. 1983. Indian Phytopath. 36: 556.

Chakrabarti, P. K., 1990. Indian J. Agric Sci. 60: 779-80.

Chakraborty, N. and Nandi, B. 1976. Sci \& Cult. 42: 290-91.

Chakraborty, N., Chattopadhyay, N. C. and Nandi, B. 1977. Curr. Sci. 46: 93.

Chakraborthy, P. K., Shyam, K. R. and Bhardwaj, S. S. 1989. Indian J. Mycol and Plant Pathol. 19: 118-20.

Chakravarti, B. P. and Rangarajan, M. 1966. Pl. Dis. Reptr. 50: 701-02. 
Chakravarthy, C. N., Krishnappa, M. and Thippeswamy, B. 2004. Indian Phytopath. 57: 379.

Chakravorty, D. K. and Srivastava, D. N. 1964. Curr. Sci. 33: 285.

Chamber, S. S. C. 1973. Aust. J. Experimental Agriculture and Animal Husbandary 13: 718-23.

Chambers, K. R. 1990. Amer. J. Enology \& Viticulture 41: 265-68.

Chand, H., Khirbat, S. K., Singhal, H. R., Jalil, B. L. and Singh, R. 1988. Indian Phytopath. 41: 75-79.

Chand, J. N., Kondal, M. R. and Aggarwal, R. K. 1968. Indian Phytopath. 21: 257-63.

Chand, R. and Kishun, R. 1989. Indian Phytopath. 42: 137-38.

Chand, R., Singh, R. and Singh, P. K. 1994. Indian Phytopath. 47: 251-55.

Chander, M. S. and Thind, T. S. 1995. Indian J. Mycol Plant Pathol. 24: 25-33.

Chandra, J. and Pathak, V. N. 1992. Indian Phytopath. 45: 126-27.

Chandras, S. and Tandon, R. N. 1964. Curr. Sci. 33: 532.

Chandras, S. and Tandon, R. N. 1965. Curr. Sci. 34: 56-57.

Chandrasekaran, A. and Rajappan, K. 2002. Plant Disease Research 17: 72-73.

Chandrasekaran, A. and Shanmugam, A. 1982. Proceedings. National Seminar on Seed Pathology. TNAU, Coimbatore (Tamil Nadu).

Chandravanshi, S. S., Singh, B. P. and Thakur. 1994. Indian Phytopath. 47: 241-44.

Chapentie, M. A. and Nicot, J. 1978. Bulletin dela Societe Mycologique de France 94: 289-98.

Chaplin, G. R., Cole, S. P., Landrigan, M., Nuevo, P. A., Lam, P. F. and Graham, D. 1991. Acta Horticulturae 291: 461-71.

Chapon, J. F. 2002. Infos-ctifil. 184: 31-34.

Chary, S. J., Kumar, B. P. and Reddy, S. M. 1980. Indian Phytopath. 33: 624-25.

Charya, M. A. S. and Reddy, S, M. 1980. Indian Phytopath. 33: 112-13.

Charya, M. A. S. and Reddy, S, M. 1984. Indian Phytopath. 37: 537-38.

Chatrath, M. S., Vir, D. and Gupta, J. P. 1968. Indian Phytopath. 21: 264-68.

Chattopadhyay, S. B. and Mustaffee, T. 1967. Bull. Bot. Soc., Bengal 21: 103-06.

Chau, K. F. and Alvarez, A. M. 1983. Hort Sci. 18: 953-55.

Chaudhury, S. 1975. Curr. Sci. 44: 68.

Chaudhury, M. and Gangawane, L. W. 1989. Indian Botanical Reporter 8: 81-82.

Chaudhury, S., Ray, D. P., Das, B. K. and Sahu, G. S. 2003. Orissa J. Horticulture 31: 54-57.

Chauhan, H. L. and Patel, M. H. 1990. Indian J. Agric Sci. 60: 80-81.

Chauhan, R. K. S. and Sharma, B. L. 1977. Indian Phytopath. 30: 142.

Chauhan, V. B., Singh, P. N. and Singh, R. B. 1994. Indian J. Plant Pathol. 12: 51-57.

Chaval, P. P. K. and Chabra, H. K. 1984. J. Res. Punjab Agric Univ. 21: 642-44.

Chavan, A. M., Danai, S. P. and Mukadam, D. S. 1994. Indian Phytopath. 47: 354.

Cheah, L. H., Page, B. B. and Shepherd, R. 1997. NewZ. J. Hortic. Sci. 25: 921.

Cheema, G. S., Karmarkar, D. V. and Joshi, B. M. 1950. Indian J. Agric Sci. 20: 259.

Cheema, S. S. and Jeyarajan, R. 1971. Hindustan Antibiotics Bull. 13: 65-66.

Chen, C., Wong, J. Y., Bao, Y. Y. and Bian, X. R. 2002. China Fruits 3: 40-42.

Chenulu, V. V. and Thakur, D. P. 1968. IPS. Bull. 4: 65-70.

Chenulu, V. V. and Thakur, D. P. 1968a. Indian Phytopath. 21: 140.

Cheriyan, A. 1987. M. Sc. (Ag.) Thesis. Kerala Agricultural University.

Cheriyan, T. T. and Varghese, K. I. M. 2007. Indian Phytopath. 60: 112-14.

Chhatpur, H. S., Ghai, G., Matto, A. K. and Modi, V. V. 1972. Acta Horticulturae 291: 461-71.

Chib, H. S., Gupta, B. R., Andorta, P. S. and Dar, C. N. 1985. Indian J. Mycol. Plant Pathol. 13: 353-54. 
Chikkasubbanna, V. and Babu, P. 2007. Agro India 30-31.

Chile, C., Khare, A., Kachwaha, M., Mehta, A. and Mehta, P, 1992. Indian Phytopath. 45: 387

Chin, D. A. 1967. Res. Dep. Jamaica 65: 7-20.

Chitra, A. and Arun, A. 2007. J. Mycol Plant Pathol. 37: 530-31.

Chitra, H., Gomathy, V. and Kannabiran, B. 2001. Indian Phytopath. 54: 253-55.

Chiu, W. F. W. and Walker, J. C. 1949. Agric Res. 78: 589.

Cho, J. J., Hayward, A. C. and Rohrbach, K. G. 1980. Anton. Van. Leewenhoek. 46: 191-204.

Cho, J. J., Rohrbach, K. G. and Apt, W. J. 1977. Phytopathology 67: 700-03.

Choiseul, J. W. and Carnegie. 2000. Plant Dis. 84: 806.

Chopra, S., Mehta, A. and Mehta, P. 1993. Indian J. Mycol Plant Pathol. 23: 129-31.

Choudhary, S. L., Sain, S. K., Joshi. and Gupta, R. R. 1998. Indian J. Mycol Plant Pathol. 28: 71.

Chouhan, V. B., Walker, H. M. 1960. Report. West African Stored Products. Res Unit, pp. 61-64.

Chouhan, V. B., Singh, P. N. and Singh, R. B. 1994. Indian J. Plant Pathol. 12: 51-57.

Chowdhury, S. 1949. Indian J. Agric. Sci. 15: 135-39.

Chowdhury, S. 1950. Trans. Brit. Mycol. Soc. 33: 317-21.

Chowdhury, S. 1957. Indian Phytopath. 10: 55-61.

Chowdhury, S. R. and Hasija, S. K. 1979. Indian Phytopath. 32: 495-96.

Chye, S. T., Wan, S. T. and Ghani, A. A. 1982. Sains Malaysana 21: 31.

Ciampi Panno, L. 1984. Plant Dis. 68: 822-23.

Claramma, L. and Singh, R. D. 1984. Indian Phytopath. 37: 529.

Clark, C. A. 1992. Post-harvest News Information 3: 75-79.

Clark, C. A. and Moyer, J. W. 1988. Compendium of Sweet Potato Diseases. American Phytopathlogical Society, Washington.

Clark, C. A. and Watson, B. 1983. Plant Dis. 67: 907-09.

Clique, S. and Schffer, R. T. 1996. European J. Plant Path. 102: 247-55.

Cole, J. S. and Zvenyika, Z. 1988. Plant Pathol. 37: 271-77.

Colyer, P. D. and Mount, M. S. 1983. Amer. Potato J. : 566-68.

Combrink, J. C., Fourie, J. F. and Grobbelaar, C. J. 1984. Phytophylactica 16: 251-53.

Conway, W. S. 1982. Plant Dis. 66: 402-03.

Conway, W. S., Sam, C. E., Abbott, J. A. and Burton, B. D. 1991. Plant Dis. 75: 620-22.

Coquinot, J. P. and Richard, L. 1992. Review of Plant Pathology 71: 682.

Couey, H. M. 1965. Phytopathology 55: 525-27.

Couey, H. M., Alvarez, A. M. and Nelson, M. G. 1984. Plant Dis. 68: 436-37.

Coursey, D. G. 1961. J. Sci. Food and Agric. 12: 574-80.

Coursey, D. G. 1968. World Crops 22: 25-30.

Coursey, D. G. and Booth, R. H. 1972. Rev. Plant Path. 51: 751-65.

Crisosto, C. H., Garner, D. and Crisosto, G. 2002. Post-harvest Biology and Technology 26: 181-89.

Crisosto, C. H. and Similanick, J. 2002. Rivista di Frutticolturae di ortofloriocoltura 64 (5) : 30-38.

Critopoulos, P. D. 1954. Phytopathology 44: 551.

Critopoulos, P. D. 1961. Phytopathology 51: 524-28.

Crosse, J. E. and Bennett, M. 1951. Report, East Malling Res. Station for 1950, pp. 137-38.

Curtis, R. W., Stevenson, W. R. and Tuite, J. 1974. Appl. Microbiol. 28: 362-65.

Daines, R. H. 1955. Plant Dis. Reptr. 39: 617. 
Dalvi, M. B., Godese, S. K., Shinde, A. K and Patil, B. P. 2002. Indian J. Agric Sci. 72: 223-24.

Dang, J. K. and Singh, J. P. 1982. J. Res., HAU 12: 509-13.

Dang, J. K. and Thakur, D. P. 1972. Indian Phytopath. 25: 359-61.

Daquioag, V. R. and Quimio, J. H. 1979. Philipp. Phytopath. 15: 35-46.

Das, P. K., Sen, H., Banarje, N. C. and Panda, P. K. 1995. J. Root Crops 21: 102-06.

Das Ramesh. 2007. J. Mycol. Plant Pathol. 37: 410-12.

Das, S. and Raj, S. K. 2004. Indian Phytopath. 57: 112-13.

Dasgupta, M. K. and Mandal, N. C. 1989. Post-harvest Pathology of Perishables. Oxford \& IBH Publishing co. Pvt Ltd, New Delhi, Bombay, Calcutta, pp. 623.

Dastur, J. F. 1916. Agric. India 11: 142.

Data, E. S., Cagasan, E. G. and Layola, J. B. 2002. Annals. Tropical Res. 24: 71-89.

Datar, V. V. 1980. Curr. Sci. $49: 555$.

Datar, V. V. 1983. Indian Phytopath. 36: 136.

Datar, V. V. 1994. Acta Horticulturae 635 : 259-63.

Datar, V. V. 1994. Indian Phytopath. 47: 292-93.

Datar, V. V. 2007. Indian Phytopath. 60: 156-161.

Datar, V. V. and Ashtaputre, J. C. 1984. Indian Phytopath. 37: 402.

Datar, V. V. and Ashtaputre, J. C. 1988. Indian Phytopath. 41: 637-38

Datar, V. V. and Guhule, K. K. 1987. Indian Phytopath. 40: 289.

Datar, V. V. Sontakke, M. B. and Purnadore, N. D. 1989. Indian Phytopath. 42: 301.

David, N. and Irene, D. 1966. Plant Dis. Reptr. 50: 21.

David, P. 1990. Plant Pathology in Agriculture. Cambridge Univ. Press, pp. 385.

Davies, R. 1928. Dept. Agric. Sci. Bull., pp. 77.

Davies, R. M. and Heale, J. B. 1985. Plant Pathol. 34: 408-14.

Davis, R. F., Beckman, P. A., Kabana, R. R. and Burelle, N. K. 1991. Phytopathology 81: Abst. 1153.

Davis, W. H. 1925. Phytopathology 15: 249-59.

Davis, W. H. and Hampt, R. O. 1986. Phytopathology 76: 999-1004.

Dawn, C. P., Ambrose and Devdas, C. T. 2007. Agro India, pp. 26-27.

Dayal, T. R., Upadhyay, M. D. and Mehra, S. K. 1990. Proceedings. National Symposium on Recent Advances in the Production and Utilization of Tropical Tuber Crops. Indian Society for Root Crops.

Dayal, S., Kumar, S., Kumar, M., Singh, S. P., Kumar, V. and Prasad, B. K. 2001. Indian Phytopath. 54: 370-72.

Daykin, M. E. and Milholland, R. D. 1984. Phytopathology 74: 710-14.

Dennis, A. J., Mel, M. and Thomas, F. C. 2003. Plant Dis. 87: 977-82.

Deokate, A. S., Khilare, V. C. and Gangawane, L. V. 2002. Indian Phytopath. 55: 107-08.

Dercole, N. and Nipoti, P. 1981. Rivista di Patologia vegetable 17: 35-43.

Dercole, N. and Sportelli, M. 1982. Informatore Fitopatoligia 32 : 51-54.

Desai, S. A. and Kulkarni, S. 2001. Indian J. Plant Pathol. 19: 100-02.

Desai, S. A. and Schlosser, E. 1999. Indian Phytopath. 52: 47-50.

Devaki, N. S. A. and Bhat, S. S. 1992. Indian Phytopath. 45: 124-26.

Develash, R. K. and Sugha, S. K. 1997. Indian Phytopath. 50: 127-29.

Dhaliwal, H. J. S., Thind, T. S. and Mohan, C. 2004. Plant Dis. Res. 19: 141-43.

Dhar, V., Rathore, Y. S. and De, R. K. 1994. Indian Phytopath. 47: 313

Dhar, V., Chaudharry, R. G., Singh, R. A., Naimuddin. and Srivastavs, D. P. 2000. Indian Phytopath. 53: 353 . 
Dharm, Vir. 1977. Curr. Sci. 46: 92.

Dharm, Vir. and Gaur, A. 1971. Curr. Sci. 40: 387.

Dharm, Vir., Raychaudhuri, S. P. and Thriumalachar, M. J. 1967. Indian Phytopath. 20: 301-04.

Dharm, Vir. and Sharma, R. 1965. Indian Phytopath. 18: 390-91.

Dhawan, S. 1982. Curr. Sci. 51: 140.

Dhingra, O. D. and Khare, M. N. 1971. Curr. Sci. 40: 612-13.

Dhingra, O. D. and Khare, M. N. 1974. JNKV. Res. J. 8: 260.

Dhingra, O. D., Khare, M. N. and Chand., J. N. 1970. Curr. Sci. 39: 498-99.

Dhingra, O. D., Mehrotra, R. S. and Aneja, K. R. 1980. Indian Phytopath. 33: 330.

Dhingra, R. and Mehrotra, R. S. 1980. Indian Phytopath. 33: 475-76.

Dhingra, O. D. and Sinclair, J. B. 1978. Anotated Bibiliography of Macrophomina phaseolina (1905-1975). Univ. Illinois, USA.

Dhuria, H. S., Chopra, S. K. and Khokhar. V. V. 1977. Proceedings. International Symposium on Citriculture. Bangalore, Karnataka.

Dhyani, A. P., Sati, M. C. and Khulbe, R. P. 1989. Madras Agric. J. 76: 717-18.

Dhyani, S. C. and Chauhan, S. K. 1975. Indian Phytopath. 28: 570-71.

Diaz., A. and Perez, G. G. 1980. Centro Agricola 7: (2)89-96.

Diaz Polanco and Bastida, P. R. 1971. Agronomia Tropical 21: 129-34.

Dickman, M. B. and Alvarez, A. M. 1983. Plant Dis. 67: 748-50.

Dickson, B. T. 1929. J. Aust. Counc. Sci. Indus. Res. 2: 94-97.

Dillard, H. R. and Hunter, J. E. 1986. Plant Dis. 70: 26-28.

Dillard, H. R. and Wallis, G. 1986. Phytopathology 76: 651.

Di Marco, G. R. and Davis, B. H. 1957. Phytopathology 47: 241.

Dixit, V. and Tiwari, R. 1994. Indian Phytopath. 47: 315.

Dohroo, N. P. 1988. Indian Phytopath. 41: 504.

Dohroo, N. P. 1989. Plant Dis. Res. 4: 73-74.

Dohroo, N. P. 1989a. Indian Phytopath. 42: 167.

Dohroo, N. P. 2001. Indian Phytopath. 54: 49-54.

Dohroo, N. P. 2001 a. Indian J. Plant Pathol. 19: 39-43.

Dohroo, N. P. and Negi, H. R. 2001. Indian Phytopath. 54: 49-54.

Dohroo, N. P. and Paramer, Y. S. 1993. Indian Phytopath. 46: 296.

Dohroo, N. P. and Sharma, S. L. 1983. Indian Phytopath. 36: 691-93.

Dohroo, N. P. and Sharma S. K. 1985. Indian Phytopath. 38: 391.

Dohroo, N. P. and Sharma S. K. 1992. Indian Phytopath. 49: 247-48.

Dorrance, A. E., Kleinhenz., Mc. Clure, S. A. and Tuttle, N. T. 2003. Plant Dis. 87: 533;-38.

Dorrance, A. E., Mc Clare, S. A. 2001. Plant Dis. 85: 1063-67.

Dowson, W. J. 1941. Ann. appl. Biol. 28: 102-06.

Drechsler, C. 1925. Phytopathology 15: 482-85.

Dring, D. M. 1961. Trans. Brit. Mycol Soc. 44: 253-64.

Dubey, R. C., Himanshu, V., Tripathi, P. and Tiwari, S. D. 2001. Indian Phytopath. 54: 264-66.

Dubey, S. C. 2002. Indian Phytopath. 55: 230-31.

Dubey, S. C. 2003. Indian Phytopath. 56: 413-17.

Dubey, S. C. and Ekka, S. 2003. Indian Phytopath. 56: 218-19.

Dubey, S. C. and Patel, B. 2000. Indian Phytopath. 53: 175-77.

Dubey, S. C. and Singh, B. 2004. Indian Phytopath. 57: 342. 
Dugan, F. M., Hellier, B. C. and Lupien, S. L. 2004. APS Pacific Region (Abstracts). Portland, Oregon.

Duhan, J. C. and Suhag, L. S. 1989. Indian Phytopath. 42: 87-94.

Duhan, J. C. and Suhag, L. S. 1990. Indian Phytopath. 43: 231-36.

Dukade, G. M. 1985. Indian J. Plant Prot. 13: 55-56.

Durgapal, J. C. 1971. Indian Phytopath. 24: 379-82.

Durigan, T. F., Teixeira, G. H., DeA., Castanharo, N. M. and Domarco, R. E. 2004. Acta Horticulturae 645: 601-04.

D'souza, T. F. and Moniz, L. 1968. Indian J. Microbiol. 8: 45-46.

Dwivedi, B. K., Pandey, G., Hemlata, P. and Pandey, R. C. 2001. Bioved 12: 31-33.

Eckert, J. W. and Brown, G. E. 1986. Citrus Fruits. (Eds) Wardowski, W. F., Nafy. S. and Grierson, W. AVI Publishing Corporation, West Port, CT, USA.

Eckert, J. W. and Kolbezen, M. J. 1962. Phytopathology 52: 180-83.

Eckert, J. W. and Ratnayake, M. 1983. Phytopathology 73: 746-50.

Eckert, W. and Sommer, N. F. 1967. Ann. Rev. Phytopath. 5: 391-432.

Edmonstone, S. C. P. 1958. South Afric J. Agric Sci. 1: 111-20.

Edney, K. L. 1978. Ann. appl. Biol. 88: 31-36.

Edward J. C., Nain, Z. and Shankar, G. 1964. Allhabad Fmr. 38: 59-61.

Elad, Y., Kalfon, A. and Chet, Y. 1982. Plant \& Soil 66: 279-81.

EL-Helay., Ibrahim, A. F., Michali, S. H. and Abdel, A. F. R 1972. Phytopathol. Medit. 11: 202-04.

El-Neshawy, S. M., El-Morsy, F. M. S. Oosterhaven, J. and Peppelenbos, H. W. 2003. Acta Horticulturae 600: 95-102.

El-Tobgi, K. M. K. and Mahamoud, G. A. 2010. Archives of Phytopathology and Plant Protection 40: (41)430-37.

Ellis, M. A., Foor, S. P. and Sinclair, J. B. 1976. Phytopathology 66: 249.

Elphinstone, J. G., Perombecom, M. C., Lowe, R., Fox, R. A. and Pashwood, E. P. 1983. Report. Scotish Crop Research Institute, pp. 107-09.

En-Nagerabi, S. A. F. and Elashafie, A. L. 2001. Tropic. Sci. 41: 31-35.

Erkan, M., Pekmezci, M., Gubbuk, H. and Karasahin, I. 2004. Turkish J. Agric. Forestry 28 : 43-48.

Erkan, M., and Sommer, N. F. 1967. Ann. Rev. Phytopath. 5: 391-432.

Ersek, T. 1960. Acta Phytopathologica Academiae Scientiarum Hunguricae13: 365-67.

Ershad, D. 1972. Iran J. Plant Pathology 8: 7-16.

Esguerra, E. B., Valerio, J. R. F. and Lizada, M. C. C. 2004. Acta Horticultrae 645: 551-56.

Fallik, E., Ilic, Z., Alkalai, T. S., Copel, A. and Polevaya, Y. 2002. Advances in Horticultural Science 16: 3-6

Fang, C. T., Chen, H. Y. and Chu, C. L. 1964. Acta Phytopath. Sinca7: 21-23.

Farooqui, W. A., Ahmad, M and Khalid, Z. M. 1978. Proc. Fla St. Hort Soc. 91: 122-24.

Fawcett, H. S. 1936. Citrus Diseases and their Control. Mc Graw Hill Book. Co., Inc. New York.

Fernadez, S. P., Rodriguez, A. and Sanchez, Y. 2003. Plant Dis. 87: 872.

Fernando, M. 1937. Trop. Agriculturist 89: 381-87.

Ferreira, J. H. S. 1990. South African J. Enology\&Viticulture 11: 38-41.

Fitzel, 1979. Plant Dis. Reptr. 63: 738-40.

Fitzel, R. D. and Peak, C. M. 1984. Ann. appl. Biol. 104: 53-59.

Fochessati, A, 1981. Hort Abstracts 51(9) : 592

Fonesca, M. J., Cecon, P. R., Salomao, L. C. C. 2004. Acta Horticulturae 645: 557-63. 
Fonesca, M. J., Salomao, L. C. C., Cecon, P. R. and Puschmann, R, 2001. Revista Brasileirade Armazenamento 26: 28-35.

Forney, C. F., Rij, R. E., Dennis, A. R. and Smilanick, J. L. 1991. Hort Sci. 26: 1512-14.

Frank, J. A. and Leach, S. S. 1980. Phytopathology 70: 51-53.

Fritz, V. A. and Honma, S. 1987. J Amer. Soc. Hort. Sci. 112: 41-44.

Frossard, P. 1978. Fruits 33: 91-99.

Fuchs, J. G., Haseli, A. and Tamma, L. 2002. Proeedings. 10 International Conference on Cultivation Techniques and Phytopathological Problems in Organic Fruit Growing and Viticulture. Weinsberg, Germany.

Fuchs, R. S. and Surendran, P. K. 1989. Letters in Applied Bacteriology 9: 49-51

Fuchs, Y. and Sommer, N. F. 1967. Ann. Rev. Phytopath. 5: 391-432.

Fuchs, Y., Zauberman, G., Yanko, U. and Homsly, S. 1975. Trop. Sci. 17: 211-16.

Gabler, F. M., Faseel, R., Mercier, J. and Simlanick, J. L. 2006. Plant Dis. 90: 1019-25.

Gade, R. M., Zote, K. K. and Mayee, C. D. 2007. Indian Phytopath. 60 : 24-30.

Gadewar, A. V. and Rout, N. K. 1975. Indian J. Mycol Plant Pathol. 6: 108-09.

Gadre, U. A. 1979. AICFIP. Mango workers meeting. Panaji, Goa, Tech. Doc. 13: 204.

Gallenberg, D. J. 1989. Phytopathology 79: 1194.

Gamagae, S. U., Sivakumar, D. and Wiujesundera, R. L. C. 2004. Crop Protection 23: 575-79.

Gandhi, S. K., Chand, J. N. and Saini, M. L. 1978. Forage Res. 4: 159-62.

Gandhi, S. K. and Kumar. 2006. J. Mycol Plant Pathol. 36: 459.

Ganesan, G. 1997. Indian Phytopath. 50: 508-12.

Ganesan, G. and Sinha, P. 2002. Indian Phytopath. 55: 389.

Gangopadhyaya, S. and Kapoor, K. S. 1973. Indian Phytopath. 26: 751-53.

Gangopadhyaya, S. and Kapoor, K. S. 1977. Indian J. Mycol Plant Pathol. 7: 147-49.

Gangopadhyaya, S. and Sharma, R. K. 1976. Indian Phytopath. 29: 423-27.

Garcha, H. S. and Singh, V. 1980. Indian Phytopath. 33: $42-47$.

Garg, N. and Om Prakash 2004. ICAR News $10: 15$.

Garg, N., Om Prakash and Pathak, R. K. 2004. J. Mycol. Plant Pathol. 34: 228-30.

Garg P. K. and Gupta, M. N. 1979. Indian Phytopath. 32: 332-33.

Garg P. K. and Gupta, M. N. 1983. Indian J. Mycol Plant Pathol. 13 : 119.

Garg, R. P. and Chauhan, R. K. S. 1981. Indian Phytopath. 34: 501-02.

Garofalo, F. and Nuovo, G. 1956. Bot. Ital. NS 62: 545-46.

Gaur, A. and Chenulu, V. V. 1981. Curr. Sci. 50: 322-23.

Gaur, A. and Chenulu, V. V. 1982. Indian Phytopath. 35: 628-32.

Gaur, A. S. C. and Pathak, V. M. 1979. Indian J. Mycol. Plant Pathol. 9: 109-10.

Gaur, R. B. and Sharma, R. N. 2008. Indian Phytopath. 61: 395.

Gaur, R. B. and Sharma, R. N. 2010. Indian Phytopath. 63: 345-47.

Geeson, J. D. 1976. Plant Pathology 25: 115-16.

Gehlot, P. and Purohit, D. K. 2001. Indian Phytopath. 54: 215-18.

Gehlot, P. and Purohit, D. K. 2002. J. Mycol. Plant Pathol. 32: 133.

Georgieva, M. and Kotev. S. 1997. Bulgarski PlodovzeleNchutsii Konservi 16 : 23-26.

Gerlach, W. 1977. Phytopath. Z. 88: 280-84.

Ghorpade, S. A. and Ajri, D. S. 1982. J. Maharashtra Agric. Univ. 7: 272-73.

Ghosh, A. K., Tandon, R. N., Bhargava, S. N. and Srivastava, M. P. 1965. Naturwise 16: 478-80.

Gindrat, D. 1984. Revue Suissed Agriculture 16: 279-84. 
Gindrat, D. 1984 a Revue Suissed Agriculture 16: 313-18.

Ginoux, G. and Blancard, D. 1984. Revue Horticole 245: 45-50.

Ginsburg, L., Eksteen, G. J. and Visagie, 1976. Hort. Abstracts 47: 6265.

Gogoi, N. K., Phookan, A. K. and Narzany, B. D. 2004, J. Root Crops 30 : 76-79.

Gogoi, R. and Rathaiah, Y. 1992. Indian Phytopath. 45: 262-63.

Gohain, D. and Das, B. C. 2006. Indian Phytopath. 59: 398.

Gohi, V. P. and Vala, D. G. 1982. Indian Phytopath. 35: 628-36.

Gohi, V. P. and Vala, D. G. 1996. Madras Agric. J. 83: 396-97.

Gohi, S. C., Vala, D. G. and Pathak, V. M. 1979. Indian J. Mycol. Plant Pathol. 9: 109-110.

Gokulapalan, Kamala Nayar and Umamaheswaran, K. 2000. J. Mycol. Plant Pathol. 30: 239-41.

Gollifer, D. E. and Booth, R. H. 1973. Ann. appl. Biol. 73: 349-366.

Gomathi, V. and Kannabiran, B. 2000. Indian Phytopath. 53: 305-308.

Gonzalez, L. C. and Owen, J. H. 1962. Phytopathology 52: 82-85.

Goode, M. J. and Sasser, M. 1980. Plant Dis. 64: 831-34.

Gopalkrishna, N., Khune, N. N. and Bhombe, B. B. 1978. Curr. Sci. 47: 778.

Gordiilo, Q. L. and Hermandez, L. E. 1980. Ciencias dela Agricutltra 7: 11-17.

Gosh, A. K., Bhargava, S. N. and Tandon, R. N. 1966. Indian Phytopath. 19: 262-66.

Gosh, S. K. 2002. J. Mycopathological Research 40: 117-19.

Gossele, F. and Swings, J. 1986. J. Phytopath. 116: 167-75.

Goyal, J. P., Nair, S. M., Pathak, V. N., Sharma, H. C. and Prasada, R. 1974. Beihftee Nova Hedwingle 47: 205.

Goyal, S. K. and Jain, M. P. 1998. International J. Tropical Plant Disease 16: 195-202.

Grewal, A. S. and Grover, R. K. 1974. Indian Phytopath. 27: 603-04.

Grewal, J. S. and Laha, S. K. 1983. Indian Phytopath. 36: 516-20.

Grewal, J. S., Laha, Rewal and Neena, M. 1991. Proceedings. BARI/ICRISAT Group meeting.

Grewal, K., Grover and Jhooty, J. S. 1987. Indian Phytopath. 40: 263-64.

Grewal, R. K., Kaur, S. and Kaur, P. 1984. Indian Phytopath. 37: 582.

Grice, D. S. Le. and Marr, G. S. 1970. Phytophylactica 2: 63-64.

Griffe, P. J. and Burden, O. J. 1974. Ann. appl. Biol. 77: 11-16.

Grover, R. K. 1964. Phytopathology 54: 130-33.

Grover, R. K. 1965. Indian Phytopath. 18: 257-65; 388.

Grover, R. K and Bansal, R. D. 1968. Indian Phytopath. 21: 116-18.

Grover, R. K and Bansal, R. D. 1970. Indian Phytopath. 23: 664-68.

Guha, H. S., Chatterjee, B. and Sammaddar, K. R. 1989. Indian Phytopath. 42: 312.

Gupta, A. and Aneja, K. R. 2001. Proceedings. Natl. Acad Sciences, India. Biologicial Science 71: 245-53.

Gupta A. K. and Pathak, V. N. 1988. Indian Phytopath. 41: 479-80.

Gupta, D. and Sharma, J. N. 2008. Indian Phytopath. 61: 386.

Gupta, D. R., Chile, S. K. and Vyas, K. M. 1982. Indian Phytopath. 35: 351.

Gupta, G. K. 1990. Indian J. Plant Protection 18: 157-65.

Gupta, I. J. and Sehgal, S. P. 1974. Indian Phytopath. 27: 616-17.

Gupta, I. J. and Sharma, S. K. 1978. Indian J. Mycol. Plant Pathol. 8: 37.

Gupta, I. J. and Sharma, S. K. 1981. Pesticides 15: 17-18; 24.

Gupta, J. H. and Srivastava, V. P. 1979. AICFIP. Mango workers meeting, Panaji, Goa. Tech.

Doc. 13: 206. 
Gupta, J. P. and Chatrath, M. S. 1983. Indian Phytopath. 36: 263-66.

Gupta, J. P. and Dutt, K. 1974. Pesticides 8: 33-34.

Gupta, J. R., Charath, M. S. and Khan, A. M. 1973. Indian Phytopath. 26: 506-09 \& 650-653. Gupta, O. P., Singh, J. P. and Gupta A. K. 1980. Haryana Agric. Univ. J. Res. 10: 495-98.

Gupta, R. B. L and Pathak, V. N. 1984. Indian Phytopath. 37: 404.

Gupta, R. B. L., Singh, G. and Mathur, R. L. 1974. Indian Phytopath. 27: 421-22.

Gupta, R. P. and Srivastava, P. K. 1984. Indian Phytopath. 37: 404.

Gupta, R. P. and Srivastava, P. K. 2000. Indian Phytopath. 53: 359.

Gupta, R. P., Srivastava, P. K. and Sharma, R. C. 2001. Indian Phytopath. 54: 501.

Gupta, S. K., Shyam, K. R. and Dohroo, N. P. 1997. Indian Phytopath. 50: 593.

Gupta, S. K., Shyam, K. R. and Pandey, U. B. 1985. Indian Phytopath. 38: 604.

Gupta, S. K., Mathew, K. A., Shyam, K. R. and Sharma, A. K. 2000. Indian Phytopath. 53: 488-89.

Gupta, S. L. 1956. Sci. \& Cult. 22: 167-68.

Gupta, U., Prasad, S. and Rai, K. K. 1989. Indian Phytopath. 42: 298.

Gupta, V. K. 1999. Indian Phytopath. 52: 105-13.

Gupta, Y. K., Roy, A. N., Sobha, Y. and Gupta, M. N. 1979. Indian Phytopath. 32: 623-24.

Gurjar, K. L., Singh, S. D. and Rawal, P. 2004. Plant Dis. Res. 19: 44-46.

Gutierrez, A. O., Nieto, A. D., Martimez, D. M. T., Domngciez, A. J. L., Delgadillo, S. F. and Alonso, G. J. G. 2002. Revista Chapingo Serie Horticulturae 8: 283-301.

Gutter, Y. and Yanco. 1971. Israel J. Agric. Res. 21: 105.

Guyde, C., Beer, S. V., Watkins, C. B., Wilson, C. L., Tedeschi, L. and Aist, J. R. 2003. Plant Dis. 87: 39-44.

Habibunnisa. 1995. Proceedings. Horti-National 95. Kerala Horticulture Development Programme, Thiruvananthapuram, Kerala.

Hafiz, A. 1952. Phytopathology 42: 422-24.

Hajare, S. N., Saxena, S., Kumar, S., Wadhawan, S., More, V., Mishra, B. B., Parte, M. N., Gautam, S. and Sharma, A. 2010. Radiation Physics and Chemistry 79: 994-1004.

Hall, D. J., Bice, J. R. and Lewis, P. J. 1978. Proc. Fla Sta. Hort. Soc. 91: 159-61.

Hamilton, G. A. 1985. Eppo. Bull. 15: 25-28.

Harbola, P. and Khulbe, R. D. 1994. Indian J. Mycol. Plant Pathol. 24: 58-59

Harding, P. R. and Savage, D. C. 1962. Plant Dis. Reptr. 46: 804-07.

Harding, P. R. and Schade, J. E. 1967. Plant Dis. Reptr. 51: 51-53.

Harman, G. E., Chet, I. and Baker, R. 1981. Phytopathology 71: 569-72.

Harne, S. M. and Neema, K. G. 1969. JNKV Res. J. 32: 130-31.

Harris, R. I., Greig, R. J. and Atkinson, R. J. 1988. In: Brighton Crop Protection Conference. Pests and Diseases 3.

Harrison, A. L. 1961. Phytopathology 51: 124-27.

Harrison, A. N. and Gudauskas, T. 1968. Plant Dis. Reptr. 52: 509-11.

Harter, L. C. 1916. J. Agric. Res. 6: 549-557 ; 787-91.

Harter, L. C. and Weimer, J. L. 1919. Phytopathology 9: 465-69.

Harvey, J. M. 1959. Plant Dis. Reptr. 43: 889-92.

Harvey, J. M. and Pentzer, W. T. 1960. Hdbk No. 189. USDA, Washington.

Hasija, S. K. and Batra, S. 1979. Indian Phytopath. 32: 327-28.

Hasija, S. K. and Batra, S. 1982. Indian Phytopath. 35: 384-87.

Haware, M. R and Joshi, L. K. 1972. Ginger Technical Bulletin No: 12 J. N. Krishi Viswavidhyalaya, Jabalpur, Madhya Pradesh. 
Haware, M. R and Joshi, L. K. 1973. Indian Phytopath. 26: 754

Haware, M. R and Joshi, L. K. 1974. Indian Phytopath. 27: 158-61.

Haware, M. R and Joshi, L. K. 1974a. Indian Phytopath. 27: 236-37.

Hayan, A., Khan, A. M., Khan, M. W., Rashid, A. D. and Saxena, S. K. 1978. Pesticides 12 : 31-33.

Hayward, A. C. 1991. Ann. Rev. Phytopath. 29: 65-87.

Hazarika, D. K. and Das, K. K. 1998. Plant Dis. Res. 13: 101-05.

Hazarika, D. K., Sarmah, R., Pramanik., Hazarika, K. and Phookan, A. K. 2000. Indian J. Plant Pathol. 18: 36-39.

He Dan., Zheng, X. D., Yin, Y. M., Sun Ping and Zhang, H. 2003. Botanical Bulletin of Academia Sinica 44: 211-16.

Hegde, G. M. and Anahosour, K. H. 2001. Karnataka J. Agric. Sciences 14: 681-85.

Hegde, G. M. and Anahosour, K. H. 2001 a. Karnataka J. Agric. Sciences 14: 686-90.

Hegde, G. M. and Anahosour, K. H. 2001 b. Karnataka J. Agric. Sciences 14: 836-38.

Hegde, G. M., Anahosour, K. H. and Kulkarni, G. M. S. 2001. Karnataka J. Agric. Sciences 14: 829-30.

Heilberg, B. C. and Ramsey, G. B. 1948. Phytopathology 38: 343-47.

Hema, L. R., Shivanna, M. B., Kumar, V., Krishnappa, M., Prakash, H. S. and Shetty, H. S. 1991. Indian J. Agric Sci. 60: 778-82.

Hendrix, F. F. (Jr). 1991. Plant Dis. 75: 742-43.

Henning, A. A. and Yuyama, M. M. 1999. Revista Brasileria de Sementes 21: 18-26.

Hepton, A. and Anderson, E. J. 1968. Phytopathology 58: 74-78.

Hersenzon, A. Z. and Palti, J. 1958. Ktavim 9: 147-51.

Hewitt, W. B. 1974. Bull. Calif. Agric Expt Sta. No: 868, pp. 52.

Hicks, S. L. and Lund, B. M. 1991. J. Applied Bacteriology 70: 308-14.

Hingole, D. G. and Kurundakar, B. P. 2005. Indian Phytopath. 58: 358.

Hingorani, M. K. and Malla, D. 1951. Indian Phytopath. 4: 58-59.

Hiremath, P. C. 2002. J. Mycology Plant Pathol. 32: 133.

Hiremath, P. C. and Govindu, H. C. 1973. Mysore J. Agric. Sci. 7: 428-35.

Hiremath, P. C. and Govindu, H. C. 1975. Mysore J. Agric. Sci. 9: 427-33.

Ho, B. L. 1985. Research Bull. Malaysian Agric Res. Dept. 13: 28-37.

Hoitink, H. A. J. and Sinder, S. L. 1970. Phytopathology 60: 1236-37.

Holmes, J. and Rich, A. E. 1970. Phytopathology 60: 1052-54.

Holz, G., Coertge, S. and Basson, E. J. 1997. Phytopathology 87 : 543.

Hooda, K. S., Bhatt, J. C., Joshi, D., Sushil., S. N. and Gupta, H. S. 2008. Indian Phytopath. 61: 331-36.

Horn, N. L., Wilson, W. F. and Glamalva, M. 1957. Plant Dis. Reptr. 41: 69-71.

Hou Dong Yao, Yan Chu nqi, Liu haixi, Ge xizhen, Xu Weijian. and Tian Ping Fang. 2010. Crop Protection 29(9) : 979-84.

Huang, H. C., Huang, J. W., Snaidon, G. and Erickson, R. S. 1997. Can. J. Plant Pathol. 19: 43-46.

Hui, Y. H. 2008. Handbook of Fruits and Fruit Processing, pp. 606-11. Wiley India, New Delhi.

Hunter, J. E. and Buddenhagen, I. W. 1972. Trop. Agric. 49: 61-71.

Hunter, J. E., Buddenhagen, I. W. and Kojima, E. S. 1969. Plant Dis. Reptr. 53: $279-84$.

Husein, M. A., Mahdy, T. K. and Ibrahim, A. A. 2001. Assiut Journal of Agricultural Sciences 32: $18-20$

Hussain, M., Khan, S. M. and Khan, M. A. 2002. Palestine J. Phytopathology 14: 114-16.

Hussain, S. M. 1960. Diss. Abstr. 21: 6. 
Hwang, B., Kim, J., Yong, Y. and Kim, K. 2002. J. Korean Soc. Hort Sci. 43: 195-200.

Hwang, S. F., Lopetinsky, K. and Evans, L. R. 1991. Canadian Plant Disease Survey 71: 169-72. Ichitani, T. and Goto, H. 1982. Annals. Phytopathological Society, Japan 48: 674-76. Ichitani, T. and Konyo, Y. 1981. Proceedings. Kansai Plant Protection Society 23: 1-7. Ikedidugwa, F. E. O. 1980. Trans. Brit. Mycol. Soc. 75: 316-19.

Ikediobi, C. O. 1985. Bio-chemistry and physiology of yam storage. In: Advances in Yam Research. (Ed). Godson Osuji. Biochemical Society of Nigeria.

Ilag, L. L. 1976. Plant Dis. Reptr. 60: 12-13.

Ilyaletdinov, S. N. and Agataev, 1970. Sakh Svelkla 15: 34.

Illyas, M. B., Ellis, M. A. and Sinclair, J. B. 1975. Plant Dis. Reptr. 59: 360-69.

Indrasenan, G. and Paily, P. V. 1982. Agric Res. J. Kerala 20: 1-3.

Indrasenan, G., Kumar., K. V., Mathew, J. and Mammen, M. K. 1982. Agric Res. J. Kerala 20: 73-75.

Ingram and Humphris. 1972. Proceedings. ISTRC, CIAT, California.

Iqbal, S. M., Rauf, C. A., Rahat. S. and Akhtar, C. M. 1994. Sahar J. Agric. 10: 575-79.

Isshiki, A., Ohtani, K., Kyo, M., Yamamot, H. and Akimitsu, K. 2003. Phytopathology 93 : 768-73.

Jackson, C. R. 1959. Phytopathology 49: 731-33.

Jackson, G. V. H. and Gollifer, D. E. 1975. Ann. appl. Biol. 80: 217-30.

Jacob, C. K., Sivaprakasam, K. and Jeyarajan, R. 1988. J. Biological Control 2: 117-19.

Jacobs, C. J., Brodrick, H. T., Swarts, H. D. and Mulder, N. J. 1973. Plant Dis. Reptr. 57: 173-76.

Jadeja, K. B. and Bhatt, H. R. 2008. J. Mycol. Plant Pathol. 38: 325.

Jadeja, K. B. and Vaishanav, M. U. 2000. Indian Phytopath. 53: 492.

Jagadeesh, S. L., Rokhade, A. K. and Lingaraju, S. 2001. J. Maharashtra Agric. University 26 : 297-300.

Jagannathan, R. and Sampath, R. 1995. Horti-National 95. Proceedings. Kerala Horticulture Development Programme. Thiruvananthapuram, Kerala.

Jain, S. S. 1956. Indian J. Hort. 13: 102-04.

Jain, S. S., Juneja, S. L., Seth, P. K. and Shlam, H. S. 1958. Proceedings. $50^{\text {th }}$ Ind. Sci. Cong. Part 11 Sect. $x: 621$.

Jain, S. K., Saxena, A. K. and Saksena, S. B. 1981. Indian Phytopath. 34: 403.

Jakhar, S. S., Suhag, L. S. and Duhan, J. C. 1994. Crop Res. 8: 562-64.

Jarvis, W. R. and Barrie, S. D. 1994. Plant Dis. 78: 926.

Jamaluddin. 1975. Proc. Natl Acad, Sci., India 45 B : 213-14.

Jamaluddin. 1975 a. Indian Phytopath. 28: 530-31.

Jamaluddin. 1976. Curr. Sci. 45: 811.

Jamaluddin. 1977. Curr. Sci. 46: 320.

Jamaluddin. 1979. Indian Phytopath. 32: 313-14.

Jamaluddin, Bilgrami, K. S. and Prasad, T. 1977. Curr. Sci. 46: 461.

Jamaluddin and Tandon, M. P. 1976. Indian Phytopath. 29: 74-75.

Jamaluddin and Tandon, R. N. 1971. Curr. Sci. 40: 415-16.

Jamaluddin, Tandon, M. P. and Tandon, R. N. 1974. Indian Phytopath. 27: 429-30.

Jamaluddin, Tandon, M. P. and Tandon, R. N. 1974a. Indian Phytopath. 27: 489-90.

Jamaluddin, and Tandon, M. P. and Tandon, R. N. 1975. Proc. Natl. Acad. Sci., India. 45(B): 217-20.

Jamaluddin, Tandon, M. P. and Tandon, R. N. 1975a. Indian Phytopath. 28: 530-31. 
Jamaluddin, Tandon, M. P. and Tandon, R. N. 1975b. Indian Phytopath. 28: 550-51.

James George, 1990. Proceedings. National symposium. In: Recent Advances in the Production and Utilization of Tropical Tuber Crops (Ed) N. G. Nair.

Janisiewicz, W. J. 1987. Phytopathology 77: 481-85.

Janisiewicz, W. J., Conway, W. S. and Sams, C. E. 1997. Phytopathology 87: 5-47.

Janisiewicz, W. J., Peterson, P. L. and Bors, R. 1994. Plant Dis. 78: 466-70.

Janisiewicz, W. J., Yourman, L. Roitman, J. and Mahoney, N. 1991. Plant Dis. 75: 490-94.

Jana, M. and Khatua, D. C. 2006. Indian Phytopath. 59: 382.

Janke, C. and Zott, A. 1983. Arch Phytopathol. Pfischutz. 19: 115-19.

Janke, M. P. and Bhatnagar, M. K. 1978. Arch Phytopathol. Pfischutz. 8: 818

Jarial, K. and Shyam, K. R. 2003. Pl. Dis. Res. 18: 152-58.

Jarvis, W. R. and Traquair, J. A. 1984. Plant Dis. 68: 718-19.

Jawanda, J. S. 1966. Punjab Hort. J. 6: 88-103.

Jawanda, J. S., Singh., R. and Vij, V. K. 1977. Proceedings. International Symposium on Citriculture. Bangalore, Karnataka.

Jawanda, J. S., Singh., R. and Vij, V. K. 1978. Punjab Hort. J. 18: 149-53.

Jayalekshmi, C. and Seethraman, K. 1998. South Indian Horticulture 46: 104-05.

Jayalekshmi, C., Durairaj, P., Seetharamn, K. and Sivaprakasam, K. 1998. Indian Phytopath. 51: $180-83$.

Jayashree, V., Shanmugam, I., Johnson, I., Raghuchander and Samiyappan, R. R. 2002. Indian Phytopath. 55: 519-21.

Jeeva, M. L., Misra, R. S. and Hegde, V. 2008. In: Advanced Techniques in Quality Planting Material Production and Commercial Cultivation of Tropical Tuber Crops, pp. 179-94. (Ed.) Nedubcheziam. M. ICAR Bhubaneshwar, Odisha.

Jeger, M. J., Green, E. S., Tresh, J. M., Johnanson, A., Waller, J. M. and Brown, A. E. 1995. In: Banana and Plantains, pp. 317-81. (Ed.) Gowen, S. Chapman and Hall, London.

Jellis, G. J., Bolton, N. J. E. and Clarke, M. H. E. 1988. In: Brighton Crop Protection Conference. Pests and Diseases.

Jenkins, S. F. and Winstead, N. N. 1964. Phytopathology $54: 452-54$.

Jhooty, J. S. and Singh, R. S. 1971. Indian Phytopath. 24 : 578-79.

Jhooty, J. S. and Bains, S. S. 1972. Indian Phytopath. 25: 509-12.

Jiang, Y. M., Zhu, X. R. and Li, Y. B. 2001. J. Food Agr. Enviorn 1(2): 76: 81.

Jijakli, M. H., Lepoivre, P., Tossut, P. and Thonard, P. 1993. Mededeling en van de faculteit. Gent. 58: 1349-58.

Jimenez, G. and Nelson, M. R. 1986. Phytopathology 76: 374.

Jindal, J. K. and Patel, P. N. 1981. Phytopath Z. 100: 97-100.

Jindal, K. K. and Thind, B. S. 1994. Plant Dis. Res. 9: 10-19.

Jofee, A. Z. and Nadelm, S. 1972. Fruits 27: 117-19.

John, J. 1991. M.Sc. (Ag.) Thesis. Kerala Agricultural University, Trichur, Kerala.

Johnson, I. and Palaniswami, A. 1999. Indian J. Mycol Plant Pathol. 29: 323-32.

Johnson, I., Palaniswami, A., Babu. S. and Nanda Kumar, R. 2000. Plant Dis. 18: 1-20.

Jones, M. and Burch, K. B. 1998. Mycotaxon 32: 133-42.

Jones, M. and Burch, K. B. 1998 a. Mycotaxon 32: 253-65.

Jones, C. W. and Mc Carter, S. N. 1974. Phytopathology 64: 1204-06.

Johansson. 1934. Svensk Botaisk Tidskrift. 28: 384-404.

Johnson, E. M., Sutton, T. B. and Hodges, C. S. 1997. Phytopathology 87: 88-95.

Johnson, G. I., Murihead, I. and Rappel, L. M. 1989. ASEAN Food Journal 4: 139-41. 
Johnson, J. R. 1931. Rev Agric. Puerto Rico. 26: 4-11.

Kachawaha, J. and Ali, S. S. 1982. Acta Botanica indica 10 : 206-09.

Kachawaha, M., Chile, A., Khare, V., Mehta, A. and Mehta, P. 1992. Indian J. Mycol. Plant Pathol. 22: 211.

Kader, A. A. 1985. In: Proceedings. National symposium on Controlled Atmosphere Research. N. C. USA.

Kado, C. I. 2003. APS Net Feature. March 2003. University of California.

Kadu, K. I., More, B. B. and Utkar, P. G. 1978. Indian Phytopath. 31: 378-79.

Kaiser, W. J. 1970. Plant Dis. Reptr. 54: 246-50.

Kaiser, S. A. K. M., Dhua, R. S. and Banik, A. K. 2001. Journal Mycopathological Research 39: 91-94.

Kalakutskii, L. V., Dudina, Z. N. and Kononkov, P. F. 1988. Biol. Bull. Acad. Science, USSR 15: 275-82.

Kalda, T. S., Swarup, V. and Choudhary, B. 1976. Veg Sci. 4: 65-70.

Kale, K. B., Kolte, S. O. and Peshney, N. L. 1994. Indian Phytopath. 47: 253-55.

Kalyanasundaram, R. 1955. J. Indian Bot Soc. 34: 43-46.

Kamala Nayar, Gokulapalan, C. and Nair, M. C. 1996. Indian Phyopath. 49: 407.

Kamat, M. N., Rao, V. G. and Subramonium, V. 1977. Revude Mycol (France) 41: 171-79.

Kanapathi Pillai, V. S. 1982. Trans. Brit. Mycol. Soc. 78: 503-08.

Kanaujia, R. S. 1979. Indian Phyopath. 32 : 464-65.

Kanaujia, R. S. and Verma, R. S. 1979. Indian Phyopath. 32: 445.

Kanellis, A. K., Morris, L. L. and Saltveil, M. E. 1986. Hort. Sci. 21: 1165-66.

Kannaiyan, J., Nene, Y. L. 1977. Tropical Grain Legume Bull. No. 9.

Kannaiyan, J., Nene, Y. L., Reddy, M. V., Ryan, J. G. and Raju, T. N. 1984. Trop. Pest management 30: $62-71$.

Kanwar, S. M. 1988. Apples. In: Production Technology and Economics, pp. 899. Mc Graw Hill Publishing Company, New Delhi.

Kanwar, Z. S. and Thakur, D. P. 1972. Sci. \& Cult. 38: 450-52.

Kanwar, Z. S. and Thakur, D. P. 1974. Pesticides 8: 43-44.

Kanwar, Z. S. and Thakur, D. P. 1977. Haryana J. Hort. Sci. 6: 140-44.

Kanwar, Z. S., Thakur, D. P. and Kadina, D. P. 1973. Indian Phytopath. 26: 742-43.

Kapoor, A. S and Kumar, P. 2004. Plant Dis. Res. 19: 155-56.

Kapoor, A. S. and Sharma, R. 2002. Indian Phytopath. 55: 403.

Kapoor, I. J. 1982. Indian Phytopath. 35: 699-700.

Kapoor, I. J., Kumar, P. and Sharma, R. 2002. Indian Phytopath. 55: 374-75.

Kapoor, I. J., Paul, Y. S. and Singh, A. 2006. Indian Phytopath. 59: 467 - 74.

Kapoor, I. J., Paul, Y. S., Kottaisamy, K. and Meenakshi. 2004. Indian Phytopath. 57: 370.

Kapoor, I. J. and Tandon, R. N. 1969. Curr. Sci. 38: 120-21.

Kapoor, I. J. and Tandon, R. N. 1969 a. Indian Phytopath. 22: 408-10.

Kapoor, I. J. and Tandon, R. N. 1970. Indian Phytopath. 23: 122-25 \& 133-35.

Kapoor, I. J. and Tandon, R. N. 1971. Phytopath Z. 70: 137-44.

Kapil, R. and Kapoor, A. S. 2005. Indian Phytopath. 58: 10-16.

Kapur, S. P. and Chohan, J. S. 1968. J. Res. Punjab Agric. University 5: 56-57.

Kapur, S. P. and Chohan, J. S. 1974. Indian Phytopath. 27: 251-52.

Kapur, S. P. and Chohan, J. S. 1974a. Indian Phytopath. 27: 252-53.

Karabulut, O. A., Baykal, N. 2002. Post harvest biology and Technology 26: 237-40. 
Karadimos, D. A., Karaoglandis, G. S. and Klonar, K. 2002. Plant Dis. 86: 1051.

Kardale, D. S. 1990. Indian Phytopath. 43: 315.

Karmarkar, D. V. and Joshi, B. M. 1941. Indian J. Agric Sci. 11: 82-94.

Karmarkar, D. V. and Joshi, B. M. 1942. Indian J. Agric Sci. 12: 993.

Kartha, K. K. and Neema, K. G. 1969. Indian Phytopath. 22: 471-73.

Karwasra, S. S. and Singh, M. 1982. Indian Phytopath. 35: 501-02.

Kasar, S. R. and Memane, S. A. 1994. Indian Phytopath. 47: 347.

Kassim, M. Y. 1986. Indian Phytopath. 39: 243-44.

Kaur, G. R., Kaur, S. and Kaur, P. 1984. Indian Phytopath. 37: 582.

Kaul, J. L. and Lall, B. S. 1975. Sci. \& Cult. 41: 29.

Kaul, J. L. and Munjal, R. L. 1980. Indian Phytopath. 30: 484.

Kaul, J. L. and Munjal, R. L. 1981. Indian Phytopath. 34: 80-82.

Kaul, J. L. and Munjal, R. L. 1982. J. Mycol. Plant Pathol. 12: 179-81.

Kaul, J. L. and Munjal, R. L. 1983. Ind. J. Mycol. Plant Pathol. 18: 137-39.

Kaunt, V. K. and Agarwal, V. K. 2002. Indian Phytopath. 55: 384.

Kaunt, V. K. and Rashmi, N. 1994. Indian Phytopath. 47: 291.

Kaur, M., Sharma, O. P. and Sharma, P. N. 2005. Indian Phytopath. 58: 232-34.

Kaur, M., Sharma, O. P. and Sharma, P. N. 2006. Indian Phytopath. 59: 243-45.

Kaur, P., Singh, R. S., Kaur, J., Munshi, G. D. and Rewal, H. S. 2004. Plant Dis. Res. 19: 159-6.

Kaur, S., Cheema, D. S. and Ompraksh, J. 1989. Indian Phytopath. 42: 277.

Kaur, S., Kaur, G. and Singh, D. 1985. Indian Phytopath. 38: 736-37.

Kaur, S. and Singh, J. 1990. Indian Phytopath. 43: 108-10.

Kaushal, R. P. and Kumar, A. 2000. Indian Phytopath. 53: 366.

Kaushik, C. D., Chand, J. W. and Thakur, D. P. 1969. J. Appl. Sci. 1: 15-17.

Kaushik, C. D., Thakur, D. P. and Chand, J. W. 1972. Indian Phytopath. 25: 61-64.

Kayanasoon, P. and Mathur, R. S. 1961. Proc. Natl. Acad. Sci., India 31: 416-21.

Kehri, H. K. and Chandra, S. 1991. Indian Phytopath. 44: 60-63.

Keller, H. and Knosel, P. 1980. Pflanzenschutzdienestes 32: 161-63.

Khan, A. H. 1954. Mycopathologia 10: 289-302.

Khan, M. R., Hussain, M. M., Laskar, H. K. and Saha. M. L. 1990. Bangladesh J. Bot. 19: 73-78.

Khan, M. R., Patni, C. S. and Khan, R. 2004. Indian Phytopath. 57: 343.

Khan., Y. D. and Raut, J. G. 1994. Indian Phytopath. 47: 345.

Khan, Y. D. Somani, R. B. and Totawar, M. V. 2001. Annals Plant Physiology 13: 151-55.

Khandar, R. R., Andharia, J. H., Dhruj, I. U. and Vaishanav, M. U. 1993. Indian J. Mycol. Pl. Pathol. 23: 221.

Khanna, K. K. and Chandra, S. 1974. Curr. Sci. 43: 491-92.

Khanna, K. K. and Chandra, S. 1975. Plant Dis. Reptr. 59: 329-30.

Khanna, K. K. and Chandra, S. 1975a. Indian Phytopath. 28: 292-93.

Khanna, K. K. and Chandra, S. 1976. Curr. Sci. 45: 70.

Khanna, K. K. and Chandra, S. 1976a. Indian Phytopath. 29: 269-72.

Khanna, K. K. and Chandra, S. 1977. Plant Dis. Reptr. 61: 362-66

Khanna, K. K. and Chandra, S. 1980. Indian J. Mycol. Plant Pathol. 10: 81-82.

Khare, A. and Kumar, K. 2004. Indian Phytopath. 57: 328.

Khare, A. and Neema, K. G. 1981. Indian Phytopath. 34: 214-21.

Khare, A. and Neema, K. G. 1984. Indian Phytopath. 37: 327-28. 
Khare, K. B and Bompeix, G. 1976. Revu de Mycologia, France 40: 65-84.

Khare, D., Atri, D. C. and Shrivastava, C. J. 1995. Indian Phytopath. 48: 111.

Khare, U. K. and Goswami, V. G. 1996. Indian Phytopath. 49: 167-69.

Khati, P. and Hooda, K. S. 2006. Indian Phytopath. 59: 521-22.

Khatoon, P. K., Zaidi and Prakash, D. 1984. Indian Phytopath. 37: 394.

Khatua, D. C., Chakravarty, D. K. and Sen, C. 1981. Indian Phytopath. 34 : 373-74.

Khilare, V. C. and Gangawane, L. V. 2002. Indian Phytopath. 55: 73-74.

Khirbat, S. K. and Vanan, T. 2004. Indian Phytopath. 57: 371-72.

Khodke, S. W. and Gahukar, K. B. 1990. Indian Phytopath. 43: 315.

Khulbe, R. D. and Sati, M. C. 1987. Indian Phytopath. 40: 106.

Khulbe, R. D., Dhyani, A. P. and Sati, M. C. 1988. Indian Phytopath. 41: 480.

Khumbare, G. B. and Chaudhari, K. G. 1979. J. Maharashtra Agric. Univ. 4: 230-31.

Kikumoto, T. 1980. Report. Inst. Agric. Res. Tohoko uni. 31: 19-41.

Kim, M. and Ko, K. 2004. Korean J. Hort. Science \& Technology 22: 43-49.

Kirk, P. M. 1984. Mycological papers. No. 152.

Kirpatrick, B. L., Sinclair, J. B. and Thapiliyal, P. N. 1972. Amer. Phytopathol. Soc. Fungicide and Nematicide Tests 28: 151.

Kishun, R. 2008. Indian Phytopath. 61: 381.

Kishun, R. and Sohi, H. S. 1982. Indian Phytopath. 35: 323-25.

Klerk, C. A. 1990. Deciduous Fruit Grower 40: 172-77.

Kohl, J. and Molhoek, W. 2002. Gewasbescherming 33: 115-19.

Kokkalos, T. I. 1973. Tech. Paper. Min Agric. and Natural Resources, Cyperus 3: 9.

Kokkalos, T. I. 1986. Amer. J. Enology \& Viticulture 37: 149-51.

Kolandaisamy, S. and Arjunan, G. 1978. RABI Progress Report. AICP on Pulses, TNAU, Coimbatore, Tamil Nadu.

Koning, G., Tekrony, D. M. and Ghabrial, S. A. 2003. Plant Dis. 87: 413-17.

Kontaxis, D. G. and Hayward, A. C. 1978. Plant Dis. Reptr. 62: 446-50.

Kora, C., Mc Donald, M. R. and Boland, G. J. 2003. Plant Dis. 87: 456-70.

Kore, S. S. and Gole, H. D. 1990. Indian Phytopath. 43: 314.

Korsten, L., Devillier, E. E. and Lonsade, J. H. 1993. South African Mango growers Assocaition. Year book 13: 117-21.

Kosweesuak., Huang Jennwen., Wang, J., Shanmugha Sundaran, S. and Chang, W. 2002. J. Amer. Soc. Horticultural Science 127: 697-702.

Kothari, K. L. 1968. Indian Hort. 12: 9-10.

Kotikova, G. S. H. and Gerasimova, A. V. 1980. Bulletin Vsesoyuznogo Nachno-Issed ovatel skog Instituta zachchity rasteni 37: 39-41.

Kotze, J. M., Viljoen, N. M. and Steyn, P. L. 1976. Citrus \& Sub tropical Fruit Journal 11: 5-7.

Koul, A. and Sumbali, G. 2008. J. Mycol. Plant Pathol. 38: 531-33.

Kour, H. and Sumbali, G. 2006. Indian Phytopath. 59: 460-66.

Kousalya, G. and Jeyarajan, R. 1990. J. BiologicaL Control 4: 70-71

Kousalya, G. and Krishnamohan, G. 1982. National Seminar on Seed Pathology. TNAU, Coimbatore, Tamil Nadu.

Krishnaiah, J., Prasad, S. and Thirupathain, V. 1987. Indian Phytopath. $40: 426-28$.

Krishnamurthy, S. and Rao, D. V. S. 2001. Indian J. Hort. 58: $(1,2): 152-63$.

Krishnappa, M. and Ramesh, B. M. 2004. Indian Phytopath. 57: 379. 
Kritzinger, Q., Aveling, T. A. S. and Marasas, W. F. O. 2002. Seed Science and Technology 30: 609-10.

Kühn, C. W. 1964. Phytopathology 54: 739-40.

Kulik, M. M. and Schoen, J. F. 1981. Phytopathology 71: 544-47.

Kulkarni, S. N. and Sharma, O. P. 1975. JNKV Res. J. 9: 70.

Kumar, A., Sharma, P. N., Sharma, O. P. and Tyagi, P. D. 1999. Plant Dis. Res. 52: 393.

Kumar, D. 1998. Indian J. Horticulture 55: 134-38.

Kumar, D. and Singh, T. 2005. Phytomorphology 55: 33-38.

Kumar, D. and Sugha, S. K. 2000. Indian Phytopath. 53: 361.

Kumar, H. and Roy, A. N. 1990. Indian J. Agric. Sci. 60: 189-91.

Kumar, K. 1994. Indian Phytopath. 47: 294.

Kumar, K., Khare, A. and Kumar, K. 2000. Indian J. Plant Pathol. 18: 28 - 31.

Kumar, M. and Dubey, S. C. 2002. Indian Phytopath. 55: 152-57.

Kumar, M., Prasad, B. and Mandal, G. 2000. Interacademicia (India) 4: 382-85.

Kumar, P. 2004. Plant Dis. Res. 19: 155-56.

Kumar, P., Anjuja and Kumar, K. 2000. Annals Pl. Protec. Sci. 8: 30-32.

Kumar, P., Kaushal, R. P. and Sharma, R. 2005. Indian Phytopath. 58: 136-42.

Kumar, P., Singh, J. and Kumar, K. 1990. Indian Phytopath. 43: 273.

Kumar, R. and Gupta, O. P. 1990. HAU J. Res. 17: 30-38.

Kumar, R. S., Dubey, S. C. 1996. Bisra Agricultural Univesity, Ranchi, Bihar In : Tropical Tuber Crops, Problems, Prospects and Future Strategies. (Eds) Kurup et al. CTCRI, Thiruvananthapuram, Kerala.

Kumar, R. S., and Dubey, S. C. 2001. Indian Phytopath. 54: 62-66.

Kumar, S. and Mahmood, M. 1986. Pesticides 20: 28-29.

Kumar, S., Mehta, N., Sangwan, M. S. and Kadian, O. P. 2002. Plant Dis. Res. 55: 398-99.

Kumar, V., Kumar, A., Verma, A. and Kharwar, A. N. 2004. Plant Dis. Res. 57: 359.

Kumar, V., Singh, B. M. and Sugha, S. K. 1997. Plant Dis. Res. 12: 90-91.

Kumaran, R. S., Gomathi, V. and Kannabiran, B. 2003. Plant Dis. Res. 56: 114-16.

Kumawat, B. L. and Jain, K. 2003. Plant Dis. Res. 56: 117-18.

Kuramoto, T. and Yamada, S. 1976. Plant Dis. Reptr. 60: 809-12.

Kundesen, G. C., Eschen, D. S., Dandurand, L. N. and Bin, L. 1991. Plant Dis. 65: 466-70.

Kurup, G. T. and Nanda, K. S. 1994 In: Advances in Horticulture: Tuber Crops - Vol. 8. (Eds) Chadha, K. L and Nair, G. G. Malhotra Publishing House, New Delhi.

Kushalappa, A. C. and Zulfiquar, M. 2001. Potato Research 44: 233-42.

Ladiniya, M. S., Dey, S. K. and Bhullai, J. S. 1990. Pesticides 24: 27-28 ;31.

Laemmlen, F. F. 1986. Phytopathology 76: 844.

Laguna, I. G. and Decampo, D. M. 1971. Rev. Fac. Agronvet B Aires. 19: 47-52.

Laguna, I. G. and Salazar, L. G. 1984. Turrialba 34: 105-06.

Lakra, P. S. 2003. Plant Dis. Res. 18: 73-74.

Lakshmi, K. P. R., Rao, S. V. R. and Haribabu, K. 2003. South Indian Hort. 51: 12-24.

Lakshminarayana, S. 1973. J. Hort. Sci. 48: 227-33.

Lakshminarayana, S. 1980. In: Tropical and Subtropical Fruits, pp. 415. (Eds) Nagy, S. and Shaw, P. E. AVI Publishing Company, Westport, Connecticut.

Lal, B. and Arya, A. 1982. Indian Phytopath. 35: 261-64.

Lal, K. A., Akbar, B. R., Pandey, V. K., Bishnu, M. B., Deeba, K. and Gupta, P. 2008. J. Mycol. Plant Pathol. 38: 405.

Lande, P. S. and Utikar, P. G. 1978. Indian J. Mycol. Plant Pathol. 8: 205. 
Lang, A., Behboudian, M. H., Kidd, J. and Brown, H. 2001. Acta Horticulturae 557: 433-39.

Langerfield, E. 1984. Biologische Budsartalt fur land and forstwirstschaft, Berlin-Dahlem. 22: 43-52.

Larson, R. H. and Walker, J. C. 1953. Phytopathology 43: 596-97.

Latha, S., Sathyanarayna, N. and Reddy, O. R. 2007. Indian Phytopath. 60: 126-27.

Latiff, A. F., El-Azzouri, M. M. and Khattab, M. M. 1975. Beitrage Tropischem Landwritschft. Vetennrmedizin 13: 323-28.

Laxminarayana, P. and Reddy, S. M. 1975. Indian Phytopath. 28: 529-30.

Laxminarayana, P. and Reddy, S. M. 1976. Curr. Sci. 45: 530.

Laxminarayana, P. and Reddy, S. M. 1976a. Indian Phytopath. 29: 57-59.

Laxminarayana, P. and Reddy, S. M. 1977. Indian J. Mycol. Plant Pathol. 7: 214-19.

Layton, D. V. 1937. Res. Bull. Iowa Agric. Exp. Sta. No. 1: 37-67.

Leach, C. M. and Pierpont, M. 1956. Plant Dis. Reptr. 40: 907.

Leach, C. M. and Pierpont, M. 1958. Plant Dis. Reptr. 42: 240.

Lee, H. M., Kim, C. J. and Hunyu, S. 2002. Mycobiol. 30: 240-43.

Lee, V. A. and Wu, W. S. 1984. Plant Prot. Bull., Taiwan 28: 101-09.

Le-Grice, D. S. and Marr, G. S. 1970. S. Afr. Fmg. 46: 9-17.

Leibinger, W., Breuken, B., Hahn, M. and Mendgen, K. 1997. Phytopathology 87: 1103-10.

Lekshmi, S. and Gupta, J. P. 1997. Indian Phytopath. 50: 358-61.

Letham, D. B., Huett, D. O. and Trimboli, D. S. 1978. Agric Gazette, New Southwales 89: 31-32.

Lewis, J. A. and Papavizas, G. C. 1971. Plant Dis. Reptr. 55: 440-44.

Lewis, J. A. and Papavizas, G. C. 1980. Phytopathology 70: 85-89.

Lewis, J. A. and Sinclair, J. B. 1966. Plant Dis. Reptr. 50: 681.

Leya, M. L., Passam, H. C., Reilly, P. J. A. and Wall Bridge, A. 1975. Tropic. Sci. 17: 61-74.

Leya, M. O., Vicedo, B., Finit, I., Flors, V., Amo, G. Del., Real, M. D., Augustine, P. G. and Bosch,

C. G. 2008. Plant Pathology 57: 1038-46.

Liao, C. H. 1975. Taiwan Agric. Bull. 32: 62-66.

Liew, C. L. and Prang, R. K. 1994. J. Am. Soc. Hort. Sci. 119: 563-67.

Lifshitz, R., Windham, M. T. and Baker, R. 1986. Phytopathology 76: 720-25.

Lim, C., Lim, J. M., Kang, S. and Cho, J. G. 2002. Korean journal of Horticultural Science \& Technology 20: 314-15.

Lim, G. and Tang, M. C. 1984. Intenatl. J. Tropic. Plant Dis. 2: 191.

Lim, J., Lim, J. and Cha, B. 2002. Plant Pathology Journal 18: 161-64.

Lim, T. K. and Rohrbach, K. G. 1980. Phytopathology 70: 663-65.

Lim, T. K. and Wai, O. C. 1986. Fitopatoligia Braseileira. 11: 67-74.

Lim, W. H. 1983. MARDI. Research Bulletin 11: 179.

Lim, W. H. and Lowings, P. H. 1979. Report MARDI. W., Malaysia.

Lim, W. H. and Lowings, P. H. 1979 a. Plant Dis. Reptr. 63: 170-74.

Lim, W. H. and Lowings, P. H. 1979 b. Expt. Agric. 15: 331-34.

Linford, M. B. 1952. F. A. O. Plant Protection Bulletin 1: 21-25.

Liu, L. J. 1972. J. Agric. Univ. Pruerto Rico. 56: 171-80.

Liu, L. J. and Rodriguez, M. A. 1973. J. Agric. Univ. Puerto Rico 57: 117-28.

Liyanage, A. and De, S. 1982. Annual Review. RRI, Sri Lanka, pp. 47-70.

Lodha, S. 1984. Indian Phytopath. 37: 438-40.

Lodha, S. 2001. Indian Phytopath. 54: 133-34. 
Lodha, S. and Gupta, G. K. 1981. Third Internatioal Symposium on Plant Pathology, pp. 95-96. IARI, New Delhi.

Lodha, S. and Ram, A. K. 1993. Ann. Arid Zone 32: 237-40.

Lodha, S. and Webster, J. 1990. Mycological Research 94: 1006-08.

Lodha, S., Mathur, K., Ram, D. and Poonia, J. 1994. ICAR Multilocational project on Rhizome rot of Ginger. Rajasthan Agricultural University, Udaipur.

Lonsdale, J. H. 1993. South African Mango Growers Association Year book 13: 109-15.

Lonsdale, J. H. and Droomer, L. 1994. South African Mango Growers Association Year book 14: 59-61.

Lozano, J. C. 1987. Proceedings. ISTRC. California.

Lozano, J. C. and Terry, E. R. 1976. Proceedings. ISTRC. California.

Lukezic, F. L., Kaiser, W. J. and Martinez, M. M. 1967. Can J. Bot. 45: 413-21.

Lumsdan, R. D., Walter, J. F. and Baker, C. P. 1996. Can J. Plant Pathol. 18: 463-68.

Lupeschen, N. S. 1964. Phytopathology 54: 129-32.

Luttrell, E. S. 1946. Phytopathology 36: 905-24.

Luttrell, E. S. 1947. Phytopathology 37: 445-65.

Luttrell, E. S. and Murphy, M. M. 1953. Phytopathology 43: 629-33.

Luvis, D. A., Shorey, H. H., Smilanick, J. L., Thompson, J. F., Gump, B. H. and Knutson, J. 1992.

Report. Univ Calif. Div Agric Sci. Oakland.

Lyon, H. L. 1915. Plant Rec. 13: 125-29.

Madaan, M. S. and Ullasa, B. A. 1990. Indian Phytopath. 43: 288.

Madaan,, R. L. and Grover, R. K. 1977. Indian Phytopath. 30: 392-98.

Madaan, R. L. and Grover, R. K. 1979. Indian Phytopath. 32: 210-12.

Madhavan Pillai, K. S. and Sreemulanathan, H. 1969. Bull. Industrial Testing and Research Lab, Trivandrum, Kerala.

Madhavan Pillai, K. S., Sreemulanathan, H. and Chettiar, A. R. 1970. Bull. Industrial Testing and Research Lab, Trivandrum, Kerala.

Madhukar, J. and Reddy, S. M. 1990. Indian Phytopath. 43: 234-35.

Madhukar, J. and Reddy, S. M. 1991. Indian Phytopath. 44: 125.

Mahadevan, A., Kuc, J. and Williams, E. B. 1965. Phytopathology 55: 1000-03.

Mahajan, B. V. C. and Chopra, S. K. 1992. New Agriculturist 3: 137-45.

Mahajan, M., Thind, T. S. and Dhillon, M. 2003. Indian Phytopath. 56: 443-45.

Mahajan, S. B. and Kurundakar, B. P. 2008. Indian Phytopath. 61: 375.

Maharshi, R. P. 1982. Indian Phytopath. 35: 136.

Mahamoodabadi, K., Rhemi, M. and Banihashemi, Z. 2000. Iranian J. Plant Pathology 36: 245-59.

Mahendra Pal. 1984. Indian Phytopath. 37: 548-50.

Mahendra Pal. 1996. Indian Phytopath. 49: 129-31.

Maheswari, P. K. and Mathur, S. K. 1985. Acta Botanica Indica 13: 198-202.

Maheswari, P. K. and Mathur, S. K. 1987. Alexandrian J. Agric Res. 32: 289-93.

Maheswari, P. K., Mathur, S. K. and Mathur, A. 1985. Acta Botanica Indica 13: 221-23.

Maheswari, S. K., Jhooty, J. S. and Gupta, J. S. 1983. Agric. Sci. Digest 3: 139-41.

Maheswari, V. K., Gupta, M. N. and Agarwal, V. K. 1983. Natl. Acad. Sci. Lett. 6: 179-82.

Mahmoud, S. A. Z., Ishac, Y. Z., Hafiz, A. A. M., Farag, N. S. and Fawzi, F. G. 1981. Ainhams Unvty No. 1590, pp. 15.

Mahmoud, S. A. Z., Ishac, Y. Z., Hafiz, A. A. M., Farag, N. S. and Fawzi, F. G. 1981 a. Ainhams Unvty No. 1599, pp. 17. 
Maholay, M. N. 1982. Proceedings. National Seminar on Seed Pathology. TNAU, Coimbatore, Tamil Nadu.

Maholay, M. N. and Sohi, H. S. 1982. Indian J. Mycol. Plant Pathol. 12: 32-36.

Maini, S. B. and Balagopalan, C. 1978. J. Root Crops 4: 31-33.

Majumdar, G. and Modi, V. V. 1980. Curr. Sci. 49: 821-22.

Majumdar, S. K. 1957. Bull. CFTRI. Mysore 5: 108.

Majumdar, V. C. and Pathak, V. N. 1977. J. Mycol. Plant Pathol. 7: 17-20.

Majumdar, V. L. and Pathak, V. N. 1997. J. Mycol. Plant Pathol. 27: 17-20.

Malcom, P. 1937. Tropical Agriculturist 89: 3-7.

Mali, V. R., Khalikar, P. V. and Gaushal, D H. 1983. Indian Phytopath. 36: 343.

Mali, V. R. and Kulthe, K. S. 1980. Indian Phytopath. 33: 415-18.

Mali, V. R., Mundhe, G. E. and Sharikh. W. R. 1989. Indian J. Virology 5: 45-55.

Malick, V. K. and Singh, S. 2002. Indian Phytopath. 55: 395.

Malik, H. C. and Bhargava, K. S. 1978. Curr. Sci. 47: 349.

Mall, S. and Mall, O. P. 1982. Indian Phytopath. 35: 562-65.

Mallikarjunaradhya, S., Bhat, A. V., Crown, J. K., Rao, A. R. V., Ramana, K. V. R. and Narasimhan, P. 1979. J. Fd Sci. Technol. 16: 232-34.

Malyuga, A. A. 2002. Zashchitai Karantin Rastenii. 2: 43-44.

Manandhar, J. B., Hartman G. and Sinclair, J. B. 1986. Phytopathology 76: 282-85

Mandal, N. C. 1981. Post harvest diseases of fruits and vegetables in West Bengal. In: Postharvest Pathology of Perishables (Eds) Dasgupta and Mandal N. C. 1989. Oxford \& IBH Publishing Co Pvt Ltd, New Delhi, Bombay, Calcutta, pp. 623.

Mandal and Dasgupta, M. K. 1980. Indian J. Mycol. Plant Pathol. 10: 31.

Mandal and Dasgupta, M. K. 1981. Ann. agric. Res. 2: 73-85.

Mandal and Dasgupta, M. K. 1982. Indian Phytopath. 35: 645-49.

Mandal and Dasgupta, M. K. 1982a. Indian J. Mycol. Res. 21: 95-98.

Mandal and Dasgupta, M. K. 1983. Environ. Ecol. 1: 255-58.

Mandal and Dasgupta, M. K. 1983a. Indian J. Mycol. Plant Pathol. 13: 73-76.

Mandal and Dasgupta, M. K. 1984. Vitis 23: 202-04.

Mandal and Dasgupta, M. K. 1984a. Indian Phytopath. 37: 673-76.

Mangal, J. L., Kumar, J., Batra, V., Singh, J. and Arora, S. K. 2000. Haryana Horticultural Science 29: 130-32.

Mani, T. M., Jeyarajan, R. and Ramakrishnan, G. 1994. Indian Phytopath. 47: 289.

Manicom, B. Q. 1986. Ann. appl. Biol. 109: 129-35.

Mann, S. S. and Randhawa, J. S. 1978. Progve Hort. 10: 34-41.

Mann, S. S. and Sandhanwalia, H. S. 1977. Proceedings. International Symposium on Citriculture, Bangalore, Karnataka.

Mann, S. S. and Singh. R. N. 1975. Prgve. Hort. 7: 11-17.

Manoranjitham, S. K., Mundhe, G. E. and Sharikh, W. R. 1989. Indian J. Virology 5: 45-55.

Manoranjitham, S. K., Prakasam, V., Rajappan, K. and Amritha, G. 2000. Indian J. Mycol. Plant Pathol. 30: 225-28.

Mansour, K. M., El-Tobshy, Z. M., Nelson, K. E. and Fahmy, B. A. 1984. Egypt J. Hort. 11: 11-18.

Marek, S. M., Roberts, C. A., Karr, A. L. and Sleeper, D. A. 2000 Crop Sci. 40: 713-16.

Marlatt, R. B. 1958. Plant Dis. Reptr. 42: 667.

Marois, J. J., Bledsoe, A. M., Gubler, W. D. and Luvisi, D. A. 1986. Plant Dis. 70: 1050-52.

Martin W. J. 1953. Phytopathology 43: 432-33 
Martin W. J. 1967. Proceedings. International Symposium on Tropical Root Crops held at the University of $\mathrm{W}$. Indies.

Martin W. J. 1972. Plant Dis. Reptr. 56: 219-23.

Martin W. J. and Dukes, P. D. 1977. Plant Dis. Reptr. 61: 158-61.

Martin W. J. and Persoon, L. H. 1951. Phytopathology 41: 228-30.

Mary, C. A, 1998. In: Fruit Crops, pp. 211. (Ed. ) Philip. S. Kalyani Publishers Ludhiana, New Delhi, Noida, Kolkata, Cuttack, India.

Mashooda Beegum, V., Ravisankar, R. and Lokesh, S. 2003. Indian Phytopath. 56: 156-58.

Mathur, K and Sharma, S. N. 2006. J. Mycol. Plant Pathol. 36: 323-24.

Mathur, K., Ram, D. and Poonia, J. 1994. ICAR Multilocational Project on Rhizome Rot of Ginger. Rajasthan, Agric Unvty, Udaipur, India.

Mathur, K., Lodha, B. C, Ram, D. and Dorjee, S. 1992. In: Advances in Science and Technology of Seeds, pp. 196-223. (Eds) Kham, A. A. and Fu, J. R. Science Press, Beijing, China. Mathur, M., Ram, D., Poonia, J. and Lodha, B. C. 2002. Indian Phytopath. 55: 345-47.

Mathur, S. B. and Sankhla, H. C. 1963. Curr. Sci. 32: 420.

Mathur, S. B. and Paul Neergaard. 1972. Indian Phytopath. 25: 91-100.

Mathur, S. B. and Sarbhoy, A. K. 1976. Indian Phytopath. 29: 454-55.

Mathur, S. B. and Sarbhoy, A. K. 1978. Indian Phytopath. 31: 365-66.

Mati Jevic, D. 1980. Zastita Bilja 31: 365-71.

Maude, R. B. and Hupherson-Jones, F. M. 1980. Ann. appl. Biol. 95: 311-19.

Maude, R. B. and Hupherson-Jones, F. M. 1978. Report. National Vegetable Research Station (1977): 95-96.

May, B. K. and Fickak, A. 2003. Drying Technology 21: 1127-35.

Mc Cartney, W. O. 1967. Plant Dis. Reptr. 51: 278: 81.

Mc Cellan, W. D. and Hewitt, W. B. 1973. Phytopathology 63: 1151-57.

Mc Colloch, L. P. 1982. Marketing Research Report, USDA. No. 518.

Mc Colloch, L. P. and Worthington, J. J. 1952. Phytopathology 42: 425-27.

Mc Colloch, L. P. and Wright, W. R. 1986. Marketing Res. Rep. Agric. Res. Serv, USDA 754: 9

Mc Colloch, L. P., Cook, H. T. and Wright, W. R. 1968. Agri Hdbk, USDA 28: 74.

Mc Gee, D. C., Brandt, C. L. and Burris, J. S. 1980. Phytopathology 70: 615-17.

Mc Guire, R. G. and Kelmen, A. 1984. Phytopathology 74: 1250-56.

Mc Knight, T. 1941. Queensland Agric. J. 55: 180-82.

Mc Laughlin, R. J., Wilson, C. L., Dorby, S., Ben-arie, R. and Chalutz, E. 1992. Plant Dis. 76: 470-73.

Mc Millan, R. T. 1984. Proc. Fla. Sta. Hort. Soc. 97: 344-45.

Medilicot, A. P. 1986. In: Post Harvest Physiology and Storage of Tropical and Sub-tropical Fruits, pp. 423. (Ed. ) Mitra, S. (1997). CAB. International, UK, USA.

Medilicot, A. P. and Sigrist, J. M. M. S. O. 1990. J. Amer. Soc. Hort. Sci. 15: 430-34.

Mehrotra, B. S. 1952. Indian Phytopath. 5: 52-54.

Mehta, A. and Mehta, P. 1989. Indian Phytopath. 42 : 192-95.

Mehta, N., Sangwan, M. S. and Kumar, R. 2000. Indian Phytopath. 53: 359.

Mehta, P., Vyas, K. M. and Sakesena, S. B. 1975. Indian Phytopath. 28: 247-52.

Mehta, P., Vyas, K. M. and Sakesena, S. B. 1975 a. Indian Phytopath. 28: 252-55.

Melksham, K. J., Weckert, M. A. and Steel, C. C. 2002. Aust. Plant Pathology 31: 193-94.

Melo, S. A. P. de., Araujo and Sussuna, J. 1974. Rev. Agric. 49: 124.

Menon, M. R., Nair, M. C., Varma, A. S. and Devi, L. R. 1979. Curr. Sci. 48: 444. 
Menton, J. O. M., Kimati, H. and Costa, C. P. 1979. Phytopathologica 50 : 140-47.

Mercier, J., Arul, J., Ponnampalam, R. and Boulet, M. 1993. J. Phytopathol. 137: 44-54.

Meredith, D. S. 1960. Ann. appl. Biol. 48: 279-90.

Meredith, D. S. 1961. Ann. appl. Biol. 49: 671-74.

Meredith, D. S. 1961 a. Trans. Brit. Mycol. Soc. 44: 95-104.

Meredith, D. S. 1971. Trop. Agric. Trin. 48: 35-50.

Merino, S. R., Eugenio, M. M., Ramos, A. W. and Hermandez, S. R. 1985. Bureau Plant Industry, Ministry of Agriculture and Food. Manila, Phillippines. pp. 89.

Meshram, B. M. 1994. Indian Phytopath. 47: 344.

Michali, S. H., Elaroni, H. and Khairy, E. A. 1969. J. Phytopath., UAR 1: 23.

Micosa, R. S. and Ilag, L. L. 1977. Philipp. Phytopath. 13: 14, 23.

Midha, S. K. and Chohan, J. S. 1967. Indian Phytopath. 20: 215-19.

Miller, M. E. 1987. Phytopathology 77: 642.

Miller, W. R., Risse, L. A. and Mc Donald, R. E. 1987. Hort Abstracts 57: 125.

Miller, W. R., Hale, P. W., Splading, D. H. and Davis, P. 1983. Hort Sci. 18: 957-58.

Mirakhur, R. H., Dhar, A. K. and Kaw, M. R. 1977. Indian Phytopath. 30: 576-77.

Mirow, H. and Knosel, D. 1982. Pflanzenschutzdientes 34: 97-99

Mishra, A. K. and Om Prakash. 1986. Annual Report, pp. 67-68, CIHNP, Lucknow.

Mishra, A. K. and Om Prakash. 1992. Indian Phytopath. 45: 172-75.

Mishra, B. and Kumar, S. 1987. Indian Phytopth. 40: 287.

Mishra, B., Om Prakash and Misra, A. P. 1974. Indian Phytopath. 27: 257-58.

Mishra, B. and Rath, G. C. 1998. Indian J. Mycol. Plant Pathol. 18: 213.

Mishra, B. P. and Kumar, S. 1993. Indian J. Plant Pathol. 11: 45-47.

Mishra, D. and Rath, G. C. 1986. Indian Phytopath. 39: 273.

Mishra, D. K. and Narain, A. 1994. Indian Phytopath. 47: 236-40.

Mishra, D. K. and Roy, A. K. 1994. Indian Phytopath. 47: 319.

Mishra, D. S., Dwivedi, T. S. and Singh U. S. 2002. Indian Phytopath. 35: 381.

Mishra, D. S., Singh, M., Singh, M., Pandey, S. N. and Singh, U. S. 2002. Indian Phytopath. 55: 381.

Mishra, E. and Naik, R. P. 1984. Indian Phytopath. 37: 387-88.

Mishra, R. S., Sharma, K. and Mishra, A. 2006. $14^{\text {th }}$ Triennial Symposium of the International Society for Root Crops. CTCRI, Thiruvananthapuram, Kerala.

Mishra, R. S., Nedunchezhiyan, M., Rana Singh. and Jeeva, M. L. 2006a. $14^{\text {th }}$ Triennial Symposium of the International Society for Root Crops. CTCRI. Thiruvananthapuram, Kerala.

Mishra, S. K., Vishwakarma, S. N. and Chaube, H. S. 2000. Indian Phytopath. 53: 354.

Mitra, D. and Chowdhury, A. 2001. J. Mycopathological Research 39: 35-38.

Mitra, M. 1929. Trans. Brit. Mycol. Soc. 14: 249-54.

Mitra, S. 1997. Post Harvest Physiology and Storage of Tropical and Subtropical Fruits. CAB International, UK, USA.

Mittal, R. K. 1984. Indian Phytopath. 37: 585.

Mittal, S. P., Dabas, B. S., Thomas, T. A. and Chopra, D. P. 1977. Proceedings. Workshop on Guar Research and Production. Jodhpur, Rajasthan.

Mitter, N., Grewal, J. S. and Pal, M. 1997. Indian Phytopath. 50: 490-98.

Mitter, N., Pal, M. and Singh, P. J. 1997 a. Indian Phytopath. 50: 332-36.

Moffett, M. L., Peterson, R. A. and Wood, B. A. 1979. Austra. Pl. Path. 8: 54-56.

Mohale, P. S. and Patil, B. G. 1993. Indian Phytopath. 46: 323. 
Mohan, A. and Sharma, R. K. 1977. Proceedings. International Symposium on Citriculture, pp. 54-56. Bangalore, Karnataka.

Mohan, S. and Lakshmanan, P. 1989. South Indian Hort. 35: 448.

Mohd, A. F., Mohd, I. K. and Saxena, S. K. 1994. Indian Phytopath. 47: 419-21.

Moline, H. E. 1984. Plant Dis. 68: 46-48.

Moline, H. E. and Kuti, J. O. 1984. Plant Dis. 68: 524-26

Mondal, K. 2004. Indian Phytopath. 57: 135-39.

Mondal, S., Sen, H., Tarafdar, J. and Chattopadhyay, A. 2004. Proceedings

National semiar on Root and Tubercrops. Bhubaneshwar, Odisha.

Mondal, S., Sen, H., Tarafdar, J. and Chattopadhyay, A. 2006. J. Root Crops 32: 166-70.

Mor, H., Steincaup, R. and Barash, I. 1984. Phytopathology 74: 921-24.

Morales, M. A. R., Alvarez, A. M. and Sanchez, A. L. 1981. Agricultura Tecinia 41: 187-91.

Moravcik, E. 1982. Polnohospodarstvo 25: 59-66.

Moreau, C. 1954. Fruits d' outremer 9: 51-59.

Morgan, D. P. and Michailides, T. J. 2004. Plant Dis. 88: 1047

Mourichon, X. 1983. Fruits 38: 601-09.

Moyer, J. W., Campbell, C. L. and Averre, C. W. 1982. Plant Dis. 66: 65-66.

Mukherjee, K. G. and Tewari, J. P. 1969. PANS 15: 235-36.

Mukherjee, P. K. 1970. Proceedings. Seminar on Citrus and Guava. Lucknow University, Lukhnow, Uttar Pradesh.

Mukherjee, P. K. and Bhattacharya, S. K. 1969. Plant Dis. Reptr. 49: 405-08.

Mukherjee, P. K., Haware, M. P. and Raghu, K. 1997. Indian Phytopath. 50: 485-89.

Mukherjee, P. K. and Singh, S. N. 1977. Proceedings. International Symposium on Citriculture, Bangalore, Karnataka.

Mukhopadhdyay, A. N. 1968. Fungicide Nematicide Tests. APS. 124.

Mukhopadhdyay, A. N. 1971. Mycopath. Mycol. appli. 44: 265-70.

Mukhopadhdyay, A. N. 1976. Indian Phytopath. 29: 102.

Mukhopadhdyay, A. N. 1994. Indian Phytopath. 47: 19-26.

Mukhopadhdyay, A. N. and Chandra, I. 1985. Indian Phytopath. 38: 610.

Mukhopadhdyay, A. N. and Sharma. 1968. Indian Phytopath. 21: 353.

Mukhopadhdyay, A. N., Sen, H. and Jane, P. K. 1991. J. Root Crops 17: 71-72.

Mukhopadhdyay, A. N., Shrestha, S. M. and Mukherjee, P. K. 1992. FAO. Plant Protec. Bull. 40: 1-10; 21-30.

Mundkur, B. B. 1937. Curr. Sci. 12 : 647.

Murrata, T. 1997. In: Post Harvest Physiology and Storage of Tropical and Sub-tropical Fruits pp. 423, CAB International.

Musa, S. K. and Saleh, S. M. 1988. Proceedings of the Eigth Symposium of the International Society for Tropical Root Crops, Bangkok.

Mustafee, T. P. 1972. Sci. \& Cult. 38 : 142-43.

Muthe Gowda and Suillia, S. B. 1987. Acta Botanica Indica 15: 165-69.

Muthulekshmi, P., Seetharaman, K. and Sivaprakasam. K. 1994. Indian Phytopath. 47: 288.

Muthumary, J. and Jayachandran, J. A. 1994. Indian Phytopath. 47: 292.

Muthumary, D. S., Dwivedi, T. S. and Singh, U. S. 2002. Indian Phytopath. 55: 381.

Muthumary, S. M., Singh, M., Pandey, S. N. and Singh, U. S. 2002. Indian Phytopath. 55: 381.

Muthuswami, S. M., Sadasivan, R., Sundararaju, J. S. and Vasudevan, V. 1971. Indian J. Agric. Sci. 41: 479-84. 
Nabigol, A. and Farzaneh, M. 2008. III International Conference on Post harvest Unlimited, Berllin, Germany.

Naik, B. M. and Sabalpara, A. N. 2006. Indian Phytopath. 59: 523-24.

Naik, M. K., Raju, K., Devika Rani, G. S., Krishnaprasad. and VeereGowda. 2008. Indian Phytopath. 61: 311-16.

Naik, R. P., Mishra, B. and Behera, P. K. 2004. Indian Phytopath. 57: 354.

Naik, S. L. and Joshi, L. K. 1973. Hindustan Antibiotic Bull. 16: 81-83.

Nain, A. S., Singhort, R. S. and Kumar, J. 2000. Haryana J. Hort. Sci. 29: 63-64.

Nair, N. G. 1985. Aust. J. Agric. Res. 36: 435-42.

Nair, N. G. 1990. Australian and Newzeland Wine Industry J. 5: 218-20.

Nair, K. 1999. (Personal communication)

Nair, P. G., Balagopalan, C. and Maini, S. B. 1978. J. Root Crops 4: 25-30.

Nallathampi, P., Nagaraju, A. and Umamaheswari, C. 2010. Indian Phytopath. 63: 308-12.

Nanda, S. K. 1984. Indian Farming 33: 64-66.

Naqvi, S. A. M. H. 1993. Indian Phytopath. 46: 190-193.

Naqvi, S. A. M. H. 2001. Indian Phytopath. 54: 502.

Naqvi, S. A. M. H. 2004. Indian Phytopath. 57: 338.

Narain, A. and Das, D. C. 1970. Indian Phytopath. 23: 484-90.

Narain, A. and Omprakash. 1968. Indian Phytopath. 21: 217-20.

Narain, A. and Panigrahi, C. 1971. Indian Phytopath. 24: 593-95.

Narain, A., Swain, N. C., Sahoo, K. C., Dash, S. K. and Shukla, V. D. 1985. Indian Phytopath. 38: 149-50.

Nasr, E. 2006. Indian Phytopath. 59: 142-47.

Nayak, N., Mishra, R., Mishra, B. P. and Satapathy, M. R. 2006. In: Root and Tuber Crops. CTCRI, ICAR, Bhubaneshwar.

Nazareno, N. R. X. DE. and Boschetto, N. 2002. Fitopatologia Brasilieira 27: 224.

Nazeema, A. 1981. M.Sc. (Ag. ) Thesis. Kerala Agricultural University. Thrissur.

Nazeema, A., Balakrishnan, S. and Nair, M. C. 1982. Proceedings. National Seminar on Seed Pathology. TNAU, Coimbatore, Tamil Nadu.

Nedumaran, S. and Vidhyasekaran, P. 1982. Indian Phytopath. 35: 322.

Nedumaran, S. and Vidhyasekaran, P. 1982a. Indian Phytopath. 35: 510-11.

Neema, K. G. and Agarwal, G. P. 1960. Proc. Natl. Acad. Sci., India 30: 55-58

Neergaard, P. 1977. Seed Pathology. Vol. I, pp. 839. The MacMillan Press Ltd, London.

Neklyudova, Mme, E. T. 1960. Diseases of pumpkin. Zaschi, Rast. Moskva 5: 55-56.

Nelson, K. E. 1951. Phytopathology 41: 859-64.

Nelson, M. R. and Pound, G. S. 1959. Phytopathology 49: 633-40.

Nene, Y. L. 1985. Indian Phytopath. 38: 1-10.

Neto, F. J. B. and West, S. H. 1989. Seed Technology 13: 122-35.

Newhall, A. G, and Brann J. L. 1960. Plant Dis. Reptr. 44: 269-72.

Nicholson, J. R. and Sinclair, J. B. 1971. Plant Dis. Reptr. 55: 911-12.

Nicoli, C., Roncadar, I., Serafini, G. A., Vancini, D., Stringari, G. and Nicolussi, L. 1979. Vignevini 6: 31-38.

Niza, Rehumath., Abraham, M. and Marykutty Samuel. 1981. Indian Plytopath. 34: 392-93

Nnodu, E. C., Harrison, M. D. and Parke, R. V. 1982. Amer: Potato J. 59: 297-311; 313-25.

Northover, J. 1975. Plant Dis. Reptr. 59: 969-71

Norton, D. C. and Roseberg, D. W. 1954. Plant Dis. Reptr. 38: 854. 
Nunes, U. T., Texido, N., Ochoa, D. E. X. and Vinas, I. 2001. Pest Management Science 57: 1093-99.

Nwachukwu, E. 2003. J. Mycol Plant Pathol. 33: 395-98.

Nwufo and Fajola, A. O. 1981. J. Root Crops 7: 53-59.

Ogundana, S. K. 1975. Third International Symposium on Biodegradation, pp. 645-49, Applied Science Publishers, London.

Ogundana, S. K., Naqvi, S. H. Z. and Ekundayo, J. A. 1970. Trans. Brit. Mycol. Soc. 54: 445-51.

Ogundana, S. K., Naqvi, S. H. Z. and Ekundayo, J. A. 1971. Trans. Brit. Mycol. Soc. 56: 73-80.

Ois Mozie. 1996. Trop. Sci. $36:$ 65-67.

Ojha, N. L., Roy. A. K. and Prasad, A. K. 1984. Indian Bot. Reptr. 3: 159-60.

Okafor, N. 1966. Expl. Agric. 2: 179-82.

Okigbo, R. N. 1995. Ph. D. Thesis. Unversity of Benin, West Africa.

Okigbo, R. N. and Ikidivgwu, F. E. O. 2000. International J. Tropic Plant Dis. 18: 51-60.

Okigbo, R. N. and Ikidivgwu, F. E. O. 2001. Trop. Sci. 41: 85-89.

Okoli, C. A. N. and Erinle, I. D. 1990. J. Stored Products Res. 26: 77-79.

Oliveira, J. A., Andrade, M. J. B, De and Fraga, A. C. 1997. Revista Brasilieira de sementes 19 : 91-95.

Oliveros, B., Lozano, J. C. and Booth, R. H. 1974. Plant Dis. Reptr. 58: 703-05.

Om Gupta and Neema, K. G. 1979. Indian Phytopath. 32: 106-07.

Om Gupta and Neema, K. G. 1979 a. Indian Phytopath. 32: 470-71.

Om Prakash, Mishra, B. and Misra, A. P. 1974 Indian Phytopath. 27 : 123-24.

Om Prakash and Pandey, B. K. 2000. Indian Phytopath. 53: 92-94.

Om Prakash and Singh, S. J. 1977. Indian Phytopath. 30: 290-91.

Om Prakash, Sohi, H. S. and Sokhi, S. S. 1973. Indian J. Hort. 31: 278-82.

On Wuema, I. C. 1978. The Tropical Tuber Crops. John Wiley \& sons. New York.

Oran, Y. K. 1974. J. Turkish Phytopathology 3: 1-27.

Orian, G. 1960. Rev. Agr. Suer. Mourice 29: 128-30.

Orpin, C., Bauer, A., Bieri, R., Faugeron, J. M. and Siddi, G. 1986. British Crop Protection Conference. Pests and Diseases, Vol. 1

Otazu, V. and Secor, G. A. 1981. Phytopathology 71: 290-95.

Oudit, D. D. 1976. J. Agric. Soc. 76: 63-66.

Owiti, J., Gruissem, W. and Zhang, P. 2006. Proceedings. 14 ${ }^{\text {th }}$ ISTRC Symposium. CTCRI. Thiruvananthapuram, Kerala.

Pabarai, A. R. and Sehra, K. B. 1962. Indian J. Pharmacy 24: 209-13.

Padmaja, G., Balagopalan, C. and Potty, V. P. 1980. Proceedings. Seminar on Post-harvest Technology of Cassava. AFST (India), Thiruvananthapuram, Kerala.

Padmaja, G., Balagopalan, C. and Potty, V. P. 1980a. Proceedings. Seminar on Post-harvest Technology of Cassava. AFST (India), Thiruvananthapuram, Kerala.

Padmaja, G., Balagopalan, C. and Potty, V. P. 1982. J. Root Crops 8: 35-40.

Padmodaya, B. and Reddy, H. R. 1996. Indian J. Mycol. Plant Pathol. 26: 266-70.

Paharia, K. D. 1960. Indian Potato J. 2: 1-11.

Pal, V. and Jalali, I. 1990. Indian Phytopath. 43: 284.

Pal, T. Yamdagni, R. and Jindal, P. C. 1979. HAU J. Res. 9: 235-40.

Palejwala, V. A. and Modi, V. V. 1985. Phytopath Z. 112: 63-68.

Palkidas, A. G. 1957. Lousiana St Univ. Bull. 357. 
Palm, G., Klopp, K. and Kruse, P. 2002. Proceedings. $10^{\text {th }}$ Intenational Conference on Cultivation, Technique and Phytopathologic problems in Organic Fruit Growing and Viticulture. Weinsberg, Germany.

Palo, M. A. 1936. Philipp J. Agric. 7: 289-315.

Palomar, M., Landerito, O., Molato, A. P., Doreem, S. C. and Victoria, G. P. Annals of Tropical Research 26: 77-95.

Palou, M., Crisosto, C. H., Garner, P., Basinal, L. M., Simlanick, J. L. and Zoffoli, J. P. 2002. Amer J. Enology \& Viticulture 2: 110-15.

Pandey, A. and Verma, K. V. R. V. 1992. Indian Phytopath. 45: 213-16.

Pandey, B. K. and Pandey, M. K. 2005a. Indian Phytopath. 58: 366.

Pandey, K. K. 2006. J. Mycol. Plant Pathol. 36: 104-05.

Pandey, K. K. and Pandey, P. K. 2002. Indian Phytopath. 55: 362.

Pandey, K. K. and Pandey, P. K. 2005. Indian Phytopath. 58: 329-31.

Pandey, R. M. and Sharma, H. C. 1998. The Litchi. Indian Council of Agricultural Research, New Delhi.

Pandey, R. S., Bhargava, S. N., Sukla D. N. and Khati, D. V. S. 1979. Indian Phytopath. 32: $479-$ 80.

Pandey, R. S., Dwivedi, D. K., Shukla, D. N. and Bhargava, S. N. 1980. Natl. Acad. Sci Lett. 3: 263-64.

Pandey, R. S., Pandey, Kalloo, G. and Chaurasia, S. N. S. 2002. Indian Phytopath. 55: 507-09.

Pandey, R. S., Shukla, D. N., Khati, D. V. S. and Bhargava, S. N. 1980. Indian Phytopath. 33: 49.

Pandotra, V. R. 1964. Proc. Indian Acad. Sci. Sect B. 60: 336-40.

Pandotra, V. R. 1965. Proc. Indian Acad. Sci. Sect B. 61: 326-30.

Pandotra, V. R. 1976. Indian J. Mycol. Plant Pathol. 6: 182.

Pankaj, S., Singh, S. D. and Rawal, P. 2003. Plant Dis. Res. (Ludhiana) 18: 16-20.

Pankaja, S. 1983. Indian Phytopath. 36: 205.

Panno, C. L. and Kohler, P. P. 1983. Phyton, Argetina 43: 221-26.

Pant, R. and Mukhopadhyay, A. N. 2001. Indian Phytopath. 54: 346-50.

Pantastico, E. B. 1975. Post-harvest Physiology, Handling and Utilization of Tropical and Subtropical Fruits and Vegetables. AVI. Publ Comp. Inc., West Port, Connecticut, USA.

Pantastico, E. B. and Bantista, O. K. 1976. Hort. Sci. 11: 122-24.

Panwar, K. S. and Vyas, N. L. 1973. Curr. Sci. 42: 217-18.

Panwar, K. S. and Vyas, N. L. 1974. Indian Phytopath. 27: 121-22.

Panwar, V. H. and Patel, M. K. 1957. Indian Phytopath. 10: 115-20.

Papavizas, G. C. 1985. Ann. Rev. Phytopath. 23: 23-54.

Parashar, R. D. and Chohan, J. S. 1966. Indian Phytopath. 19: 315-16.

Park, M. 1941. Rep. Dir Agric., Ceylon. 1939. D, pp. 20-22.

Park, S. M., Lee, Y. and Jeong, C. 2001. Korean J. Horticultural Science \& Technology 19: 12-16 Passam, H. C. 1977. Trop. Sci. 19: 29-39.

Patel, D. S., KedarNath, Patel, R. L. and Patel, S. I. 2008. J. Mycol Plant Pathol. 38: 658-60.

Patel, M. K., Kamat, M. N. and Hingorani, G. M. 1950. Indian Phytopath. 3: 165-76.

Patel, M. K., Kulkarni, Y. S. and Dhande, G. W. 1950. Indian Phytopath. 3: 95-97.

Patel, M. L., Abhyanker, S. G. and Kulkrni, Y. S. 1949. Indian Phytopath. 2: 58-61.

Patel, N. N., Gohel, V. P. and Vala, D. G. 2004. Plant Dis. Res. 19: 47-48.

Patel, P. N. and Jindal, J. K. 1970. Fourth Annual Workshop on Pulse Crops. ICAR, Ludhiana.

Patel, P. N. and Jindal, J. K. 1972. Indian Phytopath. 25: 387-91. 
Patel, P. N. and Pathak, V. N. 1966. Indian J. Mycol Plant Pathol. 26: 9-13

Patel, P. N. and Pathak, V. N. 1995. Indian Phytopath. 48: 86-89.

Patel, R. B. 1972. Curr. Sci. 41: 194-95.

Pathak, V. N. 1997. Indian Phytopath. 50: 161-85.

Pathak, V. N., 1980. Diseases of Fruit Crops, pp. 309. Oxford \& IBH Publishing co., New Delhi, Bombay, Calcutta.

Pathak, V. N. and Prasad, N. 1969. Lbyodia 32: 220.

Pathak, V. N. and Sekhawat, P. S. 1976. Indian Phytopath. 29: 315-17.

Pathak, V. N. and Srivastava, D. N. 1967. Trop. Agriculturist 123 : 75-77.

Pathak, V. N. and Srivastava, D. N. 1969 Phytopath Z. 65: 164-65.

Pathak, V. N., Sharma, N. C. and Bhatnagar L. G. 1972. Third Internatioanl Symposium on Subtropic and Tropic Horticulture, Bangalore, pp. 118-19.

Patil, D. L. and Magar, N. C. 1975. Sci. \& Cult. 41: 497-500.

Patil, J. and Shohan, H. 1983. Plant Dis. 67: 703-05.

Patil, L. K. and Moniz, L. 1969. J. University Poona 36: 107-09.

Patil, P. V. 2004. Indian Phytopath. 57: 389.

Patil, R. K., Patel, K. D., Sharma, A,. and Pathak, V. N. 1992. Indian J. Mycol. Plant Pathol. 22: 199-200.

Pattnaik, M. and Narain, A. 2000. Indian J. Plant Pathol. 18: 19-27.

Paul, R. E. and Rohrbach, K. G. 1982. J. American Soc. Hort. Sci. 448-52.

Paul, Y. S. 1998. Indian J. Plant Pathol. 16: 7-8.

Paul, Y. S. 2002. J. Mycol. Plant Pathol. 32: 167-73.

Paul, Y. S. and Behi, M. K. 1990. Seed Res. 1: 656-59.

Pavgi and Singh, S. L. 1970. FAO. Plant Protection Bull. 18: 67-68.

Pawar, N. P., Solanki, R. B., Mirza, F. N. B. and Somwanshi, S. D. 2005. Indian Phytopath. 58: 357.

Pearson, R. C. and Hall, D. H. 1973. Plant Dis. Reptr. 57: 1066-69.

Pearson, R. C. and Hall, D. H. 1975. Phytopathology 65: 812-13.

Pearson, R. C., Dubose, B. and Korf, R. P. 1986. Phytopathology 76: 656.

Pearson, R. C. Riegal, D. G. and Massey, L. M. 1985. Viticulture-Enologia 9: 255-66.

Pegg, K. G., Moffet, M. L. and Colbran, R. C. 1974. Queensland Agric J. 100: 611-18.

Pennock, W. and Maldonaldo, G. 1962. J. Agric. Univ., Puerto Rico 46: 272.

Perane, R. R. and Joi, M. B. 1989. J. Maharashtra. Agric. Univ. 14: 3.

Peres, A. P., Nasser, L. C. B. and Macha Do, J. D. A. C. 2002. Fitopatologia Brasileira 27: 123-27.

Peres, N. A., Seijo, T. E. and Turechek, W. W. 2010. Crop Protection 29: 1105-10.

Perring, M. A. 1986. J. Sci. Food Agric. 37: 591-606.

Peshney, N. L. and Mahant, S. F. 1994. Indian Phytopath. 47: 350.

Peters, I. K., Mac Donald and Mac Issac, K. A. 2001. Plant Dis. 85: 1030.

Philip, C. T., Kartha, K. K., Joshi, K, K. and Neema, K. G. 1969. JNKV. Res. J. 3: 40-43.

Philip, S. 1979. Indian Pytopath. 32: 332.

Philip, S. 1981. Agric. Res. J., Kerala 17: 126-27.

Philip, S. 1998. NARP Trials on Market Diseases of Vegetables. College of Agriculture, Vellayani, Kerala Agricultural University.

Philip, S. 2002. Fruit Crops, pp. 211. Kalyani Publishers, Ludhiana, New Delhi, Noida, Kolkata, Cuttack. 
Philip, S. and Cheriyan, A. 1995. Proceedings. Horti-National. Kerala Horticultural Development Programme. Thiruvananthapuram, Kerala.

Philip, S. and Cheriyan, A. 1999. Proceedings. Kerala Horticultural Development Programme. Thiruvananthapuram, Kerala.

Philip, S. and Menon, M. R. 1974. Agric. Res. J., Kerala 12: 200.

Philip, S. and Nair, K. 1999. General observations on the diseases of banana in the College of Agriculture, Vellayani (Unpublished)

Philip, S. Wilson, K. I. and Abraham, M. 1980. Agric Res. J., Kerala 1: 128-29.

Philips, C. A. 1970. Trop Agric. (Trin) 47: 1-7.

Picha, D. N. 1986. J. Am. Soc. Hort. Sci. 111: 889-89.

Pienaar, R. S. 1969. South African Citrus J. 422: 25-27.

Pierson, C. F., Ceponis, M. J. and Mc Colloch, L. P. 1971. Market Diseases of Apples, Pears and Quinces. USDA Hdbk. No. 376. Agric Res. Serv. USDA.

Pieters, R. and Tahiri, A. 1986. FAO. Plant Prot. Bull. 34: 99-105.

Pillayarasamy, N. K., Sivaprakasam, K. T. and Subbarajan. 1973. Madras Agric J. 60: 618.

Pioli, R. N., Mozzoni, L. and Morandi, L. N. 2004. Plant Dis. 88: 2220.

Pitt, J. I., Spotts, R. A., Holmes, R. J. and Cruickshank, R. H. 1991. Phytopathology 81: 1108.

Plumbley, A. R., Hughes, A. P. and Mariott, J. 1981. J. Sci. Fd. Agric. 32: 723.

Podile, A. R. and Dube, H. C. 1988. Indian Phytopath. 41: 289.

Ponnappa, K. M., Hiremath, P. C. and Sulladamath, V. V. 1976. Curr. Sci. 45: 836-37.

Porat, R., Daus, A., Weiss, B., Cohen, L. and Dorby, S. 2002. J. Hort. Science and Biotechnology 77: 441-45.

Powelson, M. L., Ludy, R., Pritipilo, H., Inglis, D. A., Gundersen, B. and Dierie, M. 2002. Plant Health Progress. St Paul, USA, Plant Management Network.

Pradeep, K., Ahiya Kumid, P. and Kumar, K. 2000. Ann. Pl. Prot. Sci. 8: 30-32.

Prasad, A. K. and Roy, A. K. 1986. Indian Botanical Reporter 5: 83-84.

Prasad, A. K. and Singh, R. D. 1960. Curr. Sci. 29: 66 - 67.

Prasad, B. 1977. J. Indian Potato Assoc. 4: 36-39.

Prasad, B. K., Deepa Rani Sahoo, Manojkumar and Naresh Narayan. 2000. Indian Phytopath. 53: $42-44$.

Prasad, B. K., Thakur, S. P. and Sinha. 1984. Indian Phytopath. 37: 738.

Prasad, B. K., Thakur, S. P., and Sinha. and Narayan, N. 1988. Indian Phytopath. 41: 256-57.

Prasad, H. H. 1938. Indian. J. Agri Sci. 8: 549-51.

Prasad, J. S. and Verma, R. A. B. 1976. Indian Phytopath. 29: 84-85.

Prasad, K. V. S. and Neelakantan, S. 1985. Indian Phytopath. 33: 136-39.

Prasad, L. and Vishunavat, K. 2002. Indian Phytopath. 55: 377.

Prasad, L. and Vishunavat, K. 2003. Indian Phytopath. 56: 448-50.

Prasad, L. and Vishunavat, K. 2006. Indian Phytopath. 59: 185-89.

Prasad, M. M., Roy, A. K. and Anjana Krishnan, A. 1988. Indian Phytopath. 41 : 641-42.

Prasad, M. M. 1977a. Curr. Sci. 46: 197-98.

Prasad, M. M. and Poddar, K. D. 1977. Physiology of Microorganisms. (Ed. ) Bilgrami, K. S.

Today and Tomorrow's New Delhi.

Prasad, N. and Bhatnagar, M. K. 1970. South Indian Hort. 23: 117-18.

Prasad, S., Gupta, H. and Rai, K. K. 1989. Indian Phytopath. 42: 229.

Prasad, S., Mishra, B., Gupta, V. and Rai, K. K. 1989. J Res. Bisra Agric Unvty 1: 173-74.

Prasad, S. M. and Barnwal, M. K. 2004. Indian Phytopath. 57: 110-11. 
Prasad, S. S. and Bilgrami, R. S. 1973. Indian Phytopath. 26: 517-22.

Prasad, S. S. and Bilgrami, R. S, 1975. Proc. Natl. Acad Sci. India 45 B: 40-42.

Prasanth, P. and Patil, P. V. 2007. Indian Phytopath. 60: 482-88.

Pratella, G. 1983. Informatore Fitopatologico 33: 17-25.

Prasannakumar, M. K., Nargund, V. B. and Lakshminarayana. 2007. J. Plant Dis. Sci. 2: 73-76.

Preston, N. C. 1943. Trans. Brit. Mycol. Soc. 26: 158.

Prusky, D. and Ben-Aire, R. 1981. Ann. appl. Biol. 98: 87-92.

Prusky, D., Fuchs, Y. and Yanco, U. 1983. Plant Dis. 67: 816-18.

Prusky, D., Ilag, L., Ackerman, M., Kobiler, I. and Fuchs, Y. 2004. Acta Horticulturae 645: 129-36.

Prusky, D., Shalom, Y., Kobiler, I., Akerman, M. and Fuchs, Y. 2002. Post harvest Biology and Technology 25: 339-47.

Pujol, C. J. and Kado, C. I. 1998. Plasmid 40: 169-71.

Pujol, C. J. and Kado, C. I. 1999. Microbiol. 145: 1217-26.

Pujol, C. J. and Kado, C. I. 2000. J. Bacteriol. 182: 2230-37.

Punja. Z. K. 1988. Adv. Plant Pathol. 523-24.

Purnima, D. and Saxena, S. K. 2002. Indian Phytopath. 55: 112-13.

Purnima, S. S. and Saxena, S. K. 1990. Indian Phytopath. 43: 462-64.

Puscasu, A. 1984. Horticultura 33 (7): 6-8.

Qadri, S. M. H., Srivastava, K. J., Bhonde, S. R., Pandey, U. B. and Bhagchandani, P. M. 1982. Pesticides 16: 11-16.

Qais, K. A., Sharma, P. and Bahdur, P. 2002. Indian Phytopath. 55: 364.

Qais, K. Z., Bahdur, P. and Sharma, P. 2005. Indian Phytopath. 58: 167-73.

Quazi, M. H. and Freebairn, H. T. 1970. Botanical Gazette 131: 5-14.

Quimio, T. H. 1976. Philippine Phytopathology 12: 40-50.

Quimio, T. H. and Abilay, L. E. 1979. Philippine Phytopathology 15: 158-61.

Quimio, T. H. and Quimio, A. J. 1974. Philippine Phytopathology 10: 85-87.

Raabe, R. D. and Holtzmann, O. V. 1964. Hawai Farm Sci. 13: 1-2.

Rader, W. M. E. 1948. Phytopathology 38: 440-52.

Rafika, S. B., Mejda, D. R., Mohamed, B. K. and Hatem, C. 2006. Tropic. Sci. 46: 105-12.

Raganathan, K., Shanmugham, N. and Krishnamurthy, C. S. 1972. Curr. Sci. 41: 343-44.

Raguchander, T., Rajappan, K. and Samiappan, R. 1997. Indian Phytopath. 50: 229-34.

Rahman, M. Z., Saud, Z. A. and Absar, N. 2001. Indian Phytopath. 54: 293-98.

Rai, J. N. 1956. Proc. Indian Acad. Sci. 43 B: 55-61.

Rai, M. and Singh, D. V. 1982. Proceedings. National Seminar on Seed Pathology. TNAU, Coimbatore, Tamil Nadu.

Rai, M., Bihari Lal and Arya, A. 1982. Indian J. Mycol. Plant Pathol. 12: 264-66.

Rai, P. K. 1979. Curr. Sci. 48: 1044-45.

Rai, R. N. and Bihari Lal, 1984. Indian Phytopath. 37: 566.

Rai, R. P. 1983. Indian Phytopath. 36: 582-83.

Raina, G. L., Bedi, P. S. and Dutt, S. 1971. Plant Dis. Reptr. 55: 283-84.

Raja, K. C. M., Abraham, E. and Sreemulanathan, H. 1980. Proceedings. Seminar on Postharvest Technology of Cassava. AFST, Thiruvananthapuram, Kerala.

Rajagopalan, B. 1971. M. Sc. (Ag. ) Thesis. University of Kerala, College of Agriculture, Vellayani, Thiruvananthapuram, Kerala. 
Rajagopalan, B. and Wilson, K. I. 1972. Plant Dis. Reptr. 56: 323-24.

Rajagopalan, B. and Wilson, K. I. 1972 a. Agric. Res. J., Kerala 10: 194-95.

Rajam, S. R. 1992. M. Sc. (Ag. ) Thesis. TNAU, Coimbatore, Tamil Nadu.

Rajamma, P. 1984. J. Food Sci. Techno. (India) 21: 185-87.

Rajan, P. P., Gupta, S. R., Sarma, Y. R. and Jackson, G. V. H. 2002. Indian Phytopath. 55: 173-77.

Rajappan, K. and Yesuraja, I. 1999. Indian Phytopath. 52: 177-78.

Rajkumar, P., Kaliappan, R., Dawn, C. P. and Ambros. 2008. Madras Agric J. 95: 162-69.

Rajkumar, T. 2000. M.Sc. (Ag. ) Thesis. Kerala Agricultrual University, Thiruvananthapuram, Kerala.

Rajnauth, G. 1987. Trop. Agric. 64: 356-58.

Raju, K. and Naik, M. K. 2006. Indian Phytopath. 59: 133-41.

Raju, K. S. and Raj, R. B. 1980. Maairas Agric. J. 37: 194-95.

Ram, B. and Naidu, R. 1976. Pesticides 10: (9) 32-39.

Ram, K. and Swarup, J. 1979. Indian Phytopath. 32: 328-29.

Ram, K. and Swarup, J. 1979a. Indian Phytopath. 32 : 389.

Ram, V. and Vir, D. 1983. Pesticides 17 (5) : 28-29.

Ram, V. and Vir, D. 1986. Indian Phytopath. 39: 594-95.

Ram, D., Mathur, K., Lodha, B. C. and Webster, J. 2000. Indian Phytopath. 53: 450-54.

Rama Rao, P. and UshaRaja. 1977. All India Symposium on Physiology of Host Pathogen Interaction. Univ. of Madras, Abst 36-38

Ramabadran, R., Pannirselvam, P. and Ponnaiah, C. 1982. Proceedings. National Seminar on Seed Pathology. TNAU. Coimbatore, Tamil Nadu.

Ramachandran, N., Dake, G. N. and Sarma, Y. R. 1989. Indian Phytopath. 42: 530-33.

Ramakrishnan, C. K. and Wilson, K. I. 1968. Kerala. Agric Res. J. 6: 136-38.

Ramakrishnan, T. S. 1949. Indian Phytopath. 2: 27-30.

Ramakrishnan, T. S. and Sowmini, C. K. 1954. Indian Phytopath. 7: 152-58.

Ramamoorthy, V., Raghuchander, T. and Samiyappan, R. 2002. European J. Plant Pathol. 108: 429-41.

Ramanujam, T. and Nair, S. G. 1982. J. Root Crops $8:$ 49-54.

Ramla Beevi, A., Visalakshi, A. and Mammen, K. V. 1980. Proceedings. Seminar on Post-harvest Technology of Cassava. AFST. Thiruvananthapuram, Kerala

Ramnath., Seth, M. L. and Raychaudhuri, S. P. 1966. Indian Phytopath. 19: 224-55.

Ramoss, L. J. and Volin, R. B. 1987. Phytopathology 77: 1311-17.

Ramsey, G. B. and Heiberg, B. C. 1952. Plant Dis. Reptr. 36: 481-82.

Ramsey, G. B., Fredman, B. A. and Smith, M. A. 1959. USDA Hdbk no. 155. Agri. Res. Serv. USDA.

Ramsey, G. R. and Lorbeer, J. W. 1986. Phytopathology 76: 599-600 ; 612-16.

Rangaswami, G. 1978. Diseases of Crop Plants in India, pp. 504. Prentice Hall, New Delhi.

Rangaswami, G., Rao, R. R. and Lakshmanan, P. 1959 a. Curr. Sci. 28: 167

Rangaswami, G., Rao, R. R. and Lakshmanan, P. 1959 b. Phytopathology 49: 221-26.

Rangaswami, G., Seshadri, V. S. and Lucy Channamma. 1970. Fungi of South India, pp. 250. UAS. Bengaluru, Karnataka.

Ranjan, J. K. and Chakraborti, A. K. 2003. Ann. Agric. Res. News. Series 24: (1) 59-63.

Rao, A. P., Rao, V. V. R. and Pandit, S. V. 1977. Indian J. Mycol Plant Pathol. 7: 71.

Rao, B. M., Prakash, H. S. and Shetty, H. S. 1984. Indian Phytopath. 37: 584. 
Rao, D. P. C. and Agarwal, S. C. 1975. Indian J. Mycol. Plant Pathol. 5: 8.

Rao, D. P. C. and Agarwal, S. C. 1977. Curr. Sci. 46: 162-63.

Rao, J. S. P., Chakraborty, A., Raj, S. K., Hore, J. and Das, S. 2004. Indian Phytopath. 57: 350.

Rao, K. N., Reddy, V., Girisham, S. and Reddy, S. M. 2008. Indian Phytopath. 61: 155-63.

Rao, M. S. L. and Patil, M. 2000. Indian J. Plant Pathol. 18: 96.

Rao, R. and Usharani, P. 1985. Indian Phytopath. 38: 605.

Rao., R., Desai, M. K. and Kulkarni, M. B. 1966. Mycopath et Mycol. appl. 28: 241-48.

Rao, S. N., Rao, C. H. S. and Rao, P. B. 1962. Andhra Agric. J. 9: 134-35.

Rao, V. G. 1964. Plant Dis. Reptr. 48: 629-33.

Rao, V. G. 1965. Mycopath. et Mycol. appl. 27: 129-34; 157-63.

Rao, V. G. 1966 a. Mycopath. et Mycol. appl. 28: 165-76.

Rao, V. G. 1966 b. J. Univ. Poona, Sci. and Tech. Sect. 30: 54-66.

Rao, V. G. 1968. J. Univ. Poona, Sci. and Tech. Sect. 34 (Suppl): 21-50.

Rao, V. G. 1973. Indian Phytopath. 26: 24-27.

Rao, V. G. and Pandey, A. 1992. Indian Phytopath. $45: 136$.

Rao, V. K. and Krishnappa K. 1999. Indian Phytopath. 52: 84-85.

Raoof, M. A. and Om Prakash. 1983 Indian J. Mycol Plant Pathol. 13: 348-49.

Rath, G. C. and Mohanty, G. N. 1978. Sci. \& Cult. 44: 467-68.

Rath, G. C. and Mohanty, G. N. 1978a. Indian Phytopath. 31: 256-58.

Rath, G. C., Mishra, D. and Mishra, B. 1978. Indian Phytopath. 31: 387.

Rath, G. C., Mishra, D., Nandi, R. K. and Mohanty, S. 1990. Orissa J. Agric. Res. 3: 9-12.

Rathaiah, Y. 1982. Indian Phytopath. 35: 297-99.

Rathaiah, Y. 1987. Pesticides 21: 29-30.

Rathi, Y. P. S. 2004. Indian Phytopath. 57: 336.

Rathore, B. 2000. Plant Dis. Res. 15: 89-92.

Rathore, B. S. 2008. Indian Phytopath. 61: 375.

Rathore, V. P. S., Kusum, M. and Lodha, B. C. 1992. Indian Phytopath. 45: 253-54.

Rati, E. and Ramalingam, A. 1974. Indian Phytopath. 27: 579-82.

Ratnam, C. V. and Nema, K. G. 1967. Andhra Agric. J. 14: 60-65.

Rattan, R. S. and Saini, S. S. 1979. Euphytica 28: 315-17.

Raut, B, J. and Somani, R. B. 1985. Indian Phytopath. 38: 599-600.

Raut, J. G. and Ahire, S. P. 1988. PKV Research Journal 12: 136-38.

Raut, J. G., Khune, N. N., Mogh, P. G. and Wangikar, P. D. 1984. Indian Phytopath. 37: 166-67.

Ravichandran, V. and Sullia, S. B. 1983. Curr. Sci. 32: 1031.

Ravikumar, R., Shama Rao., Yen Jereapp, S. P. and Patil, H. B. 2006. International Symposium on Pomegranate and Minor Mediteranian Fruits, Adana, Turkey.

Rawal, R. D. and Saxena, A. K. 1993. Indian Phytopath. 46: 339.

Ray, B. M., Prakash, H. S. and Shetty, H. S. 1984. Indian Phytopath. 37: 584.

Ray, R. C. 1997. J. Root Crops 23: 100-06.

Ray, R. C. and Balagopalan, C. 1997. Post-harvest Spoilage of Sweet-potato. CTCRI

Publication, pp. 31.

Ray, R. C., Choudhury, S. R. and Balagopalan, C. 1994. Adv. Hort. Sci. 8: 159-63.

Ray, R. C., Nedunchezian, M. and Balagopalan, C. 2000. Ann. Trop. Research. 22: 31-40.

Ray, S. K., Chakraborty, A. and Biswas, J. 2004. Indian Phytopath. 57: 356

Raychaudhuri, S. P. and Lele, V. C. 1970. Indian Farming 20: 11-14. 
Raychaudhuri, S. P and Nariani, T. K. 1977. Virus and Mycoplasma Diseases of Plants in India, pp. 102. Oxford \& IBH Publishing Co. New Delhi.

Razdan, V. K., Shahanaz, E. and Kumar, S. 2008. Indian Phytopath. 61: 90-94.

Reddy, G. S. and Shanker. 1983. Pesticides 17(2): 8-10.

Reddy, M. N., Devi, M. C. and Sreedevi, N. V. 2002 Indian Phytopath. 55: 388.

Reddy, P. B. and Reddy, S. M. 1988. Indian Phytopath. 41 : 138-41.

Reddy, S. and Rao, G. P. 1973. Indian Phytopath. 26: 24-27.

Reddy, S. M., Pradeepkumar, B. and Reddy, S. R. 1980. Indian Phytopath. 33: 511-12.

Reddy, S. M., Pradeepkumar, B., Chary, S. J. and Reddy S. R. 1984. Indian Phytopath. 37: 555-56.

Reddy, T. N., Reddy, T. R., Sankaraiah, V. and Dilip, B. 2004. Andhra. Agric J. 51: 433.

Reddy, T. V. and Nagaraju, C. V. 1993. (Abst) : Golden Jubilee Symposium on Horticultural Research: Changing Scenario, pp. 360. Horticultural Society of India, New Delhi.

Reeny, M. Z. 1995. M. Sc. (Ag. ) Thesis. Kerala Agricultral University, Thiruvananthapuram, Kerala.

Reni, V. 2002. Indian Phytopath. $54: 362$.

Retmales, J., Defilippi, B. G., Arias, M., Castillo, P. and Manriquez, 2003. Post harvest Biology and Technology 29 (2) : 177-82.

Reust, W., Schwartz, A. and Aerny, J. 1984. Potato Research 27: 75-84.

Reuveni, M., Sheglov, D. and Cohen, Y. 2003. Plant Dis. 87: 933-36.

Reuveni, R., Nachmias, A. and Kirkun, J. 1983. Plant Dis. 67 : 280-81.

Reuveni, R. P. 1983. Indian Phytopath. 36: 582-83.

Rewal, H. S. and Bedi, P. S. 1976. Indian Phytopath. 29: 102.

Richmond, A. E. and Dewey, D. H. 1969. J. Amer. Soc. Hort. Sci. 94: 245-46.

Richardson, M. J. 1970. Proceedings. International. Seed Test Assoc. 35: 207-23.

Rio, L. D., Hepperly, P. and Beaver, J. 1991. Agric University, Puerto Rico 75: 125-37.

Rippon, R. E., Holmas, M. G. and Gilbert, W. S. 1973. Aust J. Exp. Agric. Anim Husb. 13: 465-69.

Risse, L. A., Chun, D., Mc Donald, R. E. and Miller, W. R. 1987. Hort. Sci. 22: 274-76.

Rivera-Lopez, J., Ordorica-Falomir, C. and Wesche-Ebeling P. 1999. Food Chem. 65: 195-200.

Rohrbach, K. G. and Pfeiffer, J. B. 1976. Phytopathology 66: 396-99.

Rosenberg, M. 1962. Rep. Hawaii Agric Expt. Sta. Honolulu. Hawaii. 1978. J. Root Crops 4: 1-6.

Roy, A. K. 1973. FAO. Plant Prot. Bull. 21 : 116-17.

Roy, A. K. 1974. Indian Phytopath. 27: 620.

Roy, A. K. 1977. Indian Pytopath. 30: 425-26.

Roy, A. K. and Chouby, N. 1984. Indian Phytopath. 37: 179-81.

Roy, A. K. and Ojah, N. L. 1984. Indian Phytopath. 37: 405.

Roy, M. K. 1975. Plant Dis. Reptr 59: 61-64.

Roy; S. G., Saha, G. and Khatua, D. C. 2004. Indian Phytopath. 57: 357.

Roy, T. C. 1949. Fungi of Bengal. Bot. Soc., Bengal, Calcutta.

Ruchisood and Sharma, R. L. 2002. Indian Phytopath. 55: 402.

Rupe, J. C. and Ferris, R. S. 1986. Phytopathology 76: 273.

Saad Shama, Ragunathan, A. N. and Shetty, H. S. 1988. Seed Sci. \& Technol. 16: 541-48.

Sad, R. N., Singh, R. N., Narayanan, N., Singh, S. P., Kumar, S. and Prasada, B. K. 1990. Indian Phytopath. 43: 197-200.

Sadasivam, R., Muthuswamy, S. and Sundra Raj, J. S. 1971. Indian Horticulture 16 (2): 3.

Sadhu, B. P. and De, A. B. 1992. Indian Phytopath. 45 : 473. 
Saha, B. C. 2003. ICAR News 18.

Sahai, D. 1967. Curr. Sci. 36: 645-46.

Sahani, M. L. 1971. Pesticides 5: 18.

Saharan, G. S. and Gupta, V. K. 1972. Plant Dis. Reptr. 46: 693-94.

Sahare, K. C. and Asthana, R. P. 1962. Indian Phytopath. 15: 77-78.

Sahare, K. C. and Raychaudhuri, S. P. 1963. Indian Phytopath. 16: 316-18.

Sahore, D. A., Nemlin, G. J. and Kamenan. 2007. Trop. Sci. 47: 81-82.

Sahukritagyan, S. P. and Singh, S. P. 1980. Indian Phytopath. 33 : 308-09.

Saikia, U. N. 1976. Indian Phytopath. 29: 61.

Salas, B., Gray, A. S., Taylor, R. J. and Neil, G. G. 2003. Plant Dis. 87: 91-97.

Salas, B., Stack, R. W., Secor, G. A. and Gudmestad, N. C. 2000. Plant Dis. 84: 1327-33.

Sall, M. A. and Hirschfelt, D. J. 1981. Calif. Plant Pathology 53: 1-3.

Samraj, J. and Jose, P. C. 1969. Sci. \& Cult. 35: 623-24.

Sams, C. E. and Conway, W. S. 1985. Plant Dis. 69: 747-50.

Sanchez, D. 1990. Agric. Res (Washington) 38: 15-17.

Sanhueza, R. M. V. and Cattanio M. E. 2003. Summa Phytopathologica 29: 182-87.

Saraswathi and Azakiamanavalan. 1977. South Indian Hort. 45: 83-87

Sariah, M. 1995. Malaysain Applied Biology 23: 53-60.

Sarig, P., Zahavi, T., Zutkhi, Y., Yanni, S., Lisken, N. and Ben-Arie, R. 1986. Physiol. Mol. Plant Pathol. 48: 403-15.

Sarkar, K. P. 1974. Indian Phytopath. 27: 115-16.

Sarma, P. 1984. Indian Phytopath. 37: 721-22.

Sashirekha, M. N. and Narasimhan, P. 1990. Ann. appl. Biol. 117: 645-52.

Sathyanarayanaswamy, G. and Sreeramulu, P. 1962. Andhra. Agric J. 9: 175-80.

Satour, M. and Shinnawy, S. 1997. Agric Review 55: 13-115.

Satya Prasad and Rao, R. 1979. Indian Phytopath. 32: 472-73.

Savulescu, P. and Ana. 1949. J. Rev. Mycol. 27: 458.

Sawant, D. M. and Nahre, S. S. 1994. Indian Phytopath. 47: 345.

Sawant, I. S. and Mukhopadhyay, A. N. 1990. Indian Phytopath. 43: 535-41.

Sawant, I. S. and Mukhopadhyay, A. N. 1974. Indian Phytopath. 27: 417-19.

Sawant, S. D. and Sawant, I. 2001. Indian Phytopath. 54: 501.

Saxena, A., Joshi, I. J. and Saksena, S. B. 1983. Indian Phytopath. 36: 581-82.

Saxena, A. K. and Jain, S. K. 1981. Curr. Sci. 50: 96.

Saxena, A. K. and Rawal, R. D. 2004. Indian Phytopath. 57: 351.

Saxena, A. K. and Saksena, S. B. 1984. Indian J. Mycol. Plant Pathol. 14: 91.

Saxena, P., Rathi, Y. P. S. and Tripathi, H. S. 2004. Indian Phytopath. 57: 341.

Saxena, R. M. and Sharma, K. D. 1981. Agric. Sci. Digest India 1(2): 140-42.

Schaad, N. W. and Brenner, D. 1977. Phytopathology 67: 302-08.

Schlub., R. H., Lockwood, J. L. and Komanda, H. 1981. Phytopathology 71: 693-97.

Schmitthenner, A. F., Hoitink, A. J. and Koretz, M. E. 1971. Phytopathology 61: 852-57.

Schwartz, H. F. and Otto, K. 2000. Plant Dis. 84: 808.

Scopes, N. and Ledieu, M. 1980 (eds). BCPC Publications. London.

Scott, K. J. and Roberts, E. A. 1967. Aust. J. Exp. Agric. and Anim. Husb. 7: 283-86.

Scott, K. J., Mc Glasson, W. B. and Roberts, E. A. 1970. Aust J. Exp. Agric. and Anim. Husb. 10: 237-40. 
Scott, K. J., Brown, B. I., Chaplin, G. R., Wilcox, M. E. and Bain, J. M. 1982. Scientia Horticultura 16: $253-62$.

Scott, K. J., Oloughlin, J., England, B. and Roberts, E. A. 1985. Australian J. Agric. Res. 36: 305-13.

Scruno, L., Faretra, F., Cariddi, C., Antonacci, E. and Buffo, S. A. 1991. Pest. Sci. 31: 37-44.

Sebastin Barry, J., Jacobsen, A. B. K., Joyce, L. A., Eckhoff and Bergman, J. W. 2001. Plant Dis. 85: 718-28.

Seema, Z. and Sharma Y. P. 2009. Madras Agric. J. 62: 533-35.

Seenappa, M., Stobbs, L. W. and Kempton, A. G. 1980. Phytopathology 70: 218-22.

Seenappa, M., Keswani, C. C. and Kundya, T. M. 1983. Mycopathologia 83: 103-06.

Semb, L. 1971. Acta Horticulture 20: 32-35.

Sen, B. 2000. Indian Phytopath. 53: 243-49.

Sen, C., Srivastava, S. N. and Agnihotri, V. P. 1974. Indian Phytopath. 27: 596-602.

Senapati, A. K. and Sugata, G. 2005. Indian Phytopath. 58: 437-39.

Sendhilvel, V., Marimuthu, T., Raguchander, T. and Samiyappan. R. 2002. Indian Phytopath. 55: 360 .

Sendhilvel, V., Marimuthu, T., Raguchander, T. and Prabakar. K. 2005. Madras Agric. J. 92: 49-58.

Sepiah, M., Subhi, A. and Lan, P. F. 1991. ASEAN Food J. 6: 14-18.

Serdan, M., Kang, J. C., Anderson, B. and Crous, P. W. 2002. Mycological Research 106: 561-69.

Serrano, F. B. 1935. Philippine J. Sci. 57: 29-62.

Sethuraman, K. and Vidhyasekaran, P. 1994. Indian Phytopath. 47: 289.

Sethuraman, K., Revathy, N. and Mavannam, M. 2003. Legume Research 26: 218-20.

Shahi, R. K., Singh, R. B. and Doshi, J. K. 1998. Indian J. Plant Pathol. 16: 50-54.

Shailabala and Tripathi, H. S. 2004. Indian Phytopath. 57: 99-100.

Shailabala and Tripathi, H. S. 2004a. J. Mycol. Plant Pathol. 34: 851-52.

Shakywar, R. C. and Pathak, S. P. 2006. Indian Phytopath. 59: 386.

Shankhpal, K. V., Chakraborty, S., Srinivasa Rao, P. and Kabir, J. 2004. Andhra Agric. J. 51: 456.

Shankhpal, K. V. and Hatwalne, V. G. 1974. Indian Phytopath. 27: 445-46.

Shankhpal, K. V. and Hatwalne, V. G. 1975. Sci. \& Cult. 41: 396-97.

Shankhpal, K. V. and Hatwalne, V. G. 1976. Curr. Sci. 45: 565-66.

Shanmugam, V., Kumar, A. and Sarma, Y. R. 2002. Indian Phytopath. 55: 386.

Sharath, R. S., Chakraborty, S., Srinivasa Rao, P. and Kabir, J. 2004. Andhra Agric. J. 51: 456.

Sharma, B. B. and Wahab, S. 1973. Ghana J. Sci. 13: 140-147.

Sharma, B. B. and Wahab, S. 1975. Indian Phytopath. 28: 308-09.

Sharma, B. K., Nayital, S. C. and Chaubey, A. K., 1981. Indian Phytopath. 34: 89-90

Sharma, B. K., Nayital, S. C., Chaubey, A. K., Khan, A. R. and Sankhyan. N. K. 2004. Indian Phytopath. 57: 370.

Sharma, B. S. and Pathak, V. N. 1994. Indian Phytopath. 47: 408-11.

Sharma, C. L. and Kapoor, A. S. 1997. Indian Phytopath. 50: 342-49.

Sharma, I. and Dubey, G. S. 1985. Indian Phytopath. 38: 624.

Sharma, I. and Gosh, R. 2000. In: Plant Diseases, pp. $49-71$ (Ed) Trivedi, P. C. Avishakar Distributors, Jaipur.

Sharma, I. M., Harender, R. and Kaul, J. L. 1994. Indian Phytopath. 47: 197-200.

Sharma, J. N. 2004. Indian Phytopath. 57: 366 
Sharma, J. N. and Kaul, J. L. 1990. Indian J. Mycol. Plant Pathol. 20: 47-48.

Sharma, J. N. and Kaul, J. L. 1997. Indian Phytopath. 50: 396-01.

Sharma, J. N. and Sharma, P. 2006. Phytomorphology 56: 61.

Sharma, K. D. and Upadhyay, S. K. 1977. Indian Phytopath. 30: 419-20.

Sharma, K. S. and Sumbali, G. 1993. Indian J. Mycol. Plant Pathol. 23: 241-46.

Sharma, M. P. and Roy, A. N. 1984. Pesticides (11): 26-28.

Sharma, M. P. and Roy, A. N. 1984a. Curr. Sci. 53: 16.

Sharma, N. 2003. Indian J. Plant Pathol. 21: 114-15.

Sharma, N., Pallavi, A. and Srivastava, S. 2004. Indian J. Plant Pathol. 22: 120-122, 136-37.

Sharma, N. D. and Jain, A. C. 1977. PANS 23: 474-81.

Sharma, N. D. and Joshi, L. K. 1976. Sci. \& Cult. 42: 176-78.

Sharma, N. D. and Joshi, L. K. 1979. Pesticides 13: (8) 37-40.

Sharma, P. and Chatterjee, S. K. 1980. Indian Phytopath. 33: 354-56.

Sharma, P. and Chatterjee, S. K. 1982. Indian Phytopath. 35: 165-66.

Sharma, P. and Chaudhuri, M. 2004. J. Mycol. Plant Pathol. 34: 906-08.

Sharma, P. and Sain, S. K. 2005. Indian Phytopath. 58: 395-401.

Sharma, P., Singh, S. D. and Rawal, P. 2003. Plant Dis. Res. 18: 16-20.

Sharma, P., Kulshrestah, G., Gopal, M. and Kadu, L. N. 2004. Indian Phytopath. 57: 427-34.

Sharma, P. N. and Sharma, O. P. 2000. Indian Phytopath. 53: 365.

Sharma, P. N., Sharma, O. P., Padder, B. A. and Kapil, R. 2008. Indian Phytopath. 61: 323-30.

Sharma, P. N. and Sugha, S. K. 1995. Indian Phytopath. 48: 304-07.

Sharma, R. B. and Roy, A. N. 1978. Curr. Sci. 47: 60-61.

Sharma, R. B., Roy, A. N. and Yadav, S. K. 1978. Indian J. Mycol. Plant Pathol. 6: 77.

Sharma, R. B., Sharma, R. C. and Verma, K. D. 2001. Indian Phytopath. 54: 502.

Sharma, R. B., Sinha, B. P. and Roy, A. N. 1981. Indian Phytopath. 27: 121-22.

Sharma, R. C. and Dharma, Vir. 1984. International J. Tropic. Plant Dis. 2: 5-7.

Sharma, R. C. and Dharma, Vir. 1985. Pesticides 20 (9) : 14-15.

Sharma, R. C. and Dharma, Vir. 1985 a. Indian J. Mycol. Plant Pathol. 15: 200.

Sharma, R. C. and Sharma, S. L. 1986. Indian J. Plant Pathology 4: 126-28.

Sharma, R. C., Sinha, S. L. and Indu, S. 1984. Indian Phytopath. 37: 531-34.

Sharma, R. L. 2008. J. Mycol. Plant Pathol. 38: 385-86.

Sharma, R. L. and Kaul, J. L. 1987. Indian Phytopath. 40: 245-48.

Sharma, R. L. and Kaul, J. L. 1988. Indian Phytopath. 41: 152-53.

Sharma, R. N. and Maharshi, R. P. 1985. Pestcides 20 (9) : 14-15.

Sharma, R. N. and Maharshi, R. P. 1985 a. Indian J. Mycol. Plant Pathol. 15: 200.

Sharma, R. N. and Manju, C. 2004. Indian J. Mycol. Plant Pathol. 34: 906.

Sharma, R. N., Maharshi, R. P. and Gaur, R. B. 2008. J. Mycol. Plant Pathol. 38: 211-15.

Sharma, R. N., Maharshi, R. P. and Gaur, R. B. 2010. Indian Phytopath. 63: 278-81.

Sharma, S. K. 1994. J. Biol Control. 8: 115-17.

Sharma, S. K. and Dohroo, N. P. 1982. Proceedings. National Seminar on Ginger and Turmeric. CPCRI, Kerala.

Sharma, S. K. and Dohroo, N. P. 1984. Curr. Sci 53: 16.

Sharma, S. K. and Dohroo, N. P. 1990. Plant Dis. Research 5: 200-02.

Sharma, S. L. and Bhardwaj, S. S. 1976. Indian Phytopath. 29: 93-94.

Sharma, S. L. and Sach Dev, G. 1984. Indian Phytopath. 37: 403. 
Sharma, S. L. and Sohi, H. S. 1975. Indian Phytopath. 28: 130.

Sharma, S. L., Chowfla, S. C. and Sohi, H. S. 1980. Indian Phytopath. 33: 150

Sharma, S. R. and Sohi, H. S. 1980. Indian Phytopath. 33: 366-68.

Sharma, S. K., Verma, B. R. and Sharma, B. K. 1999. Indian Phytopath. 52: 44-46.

Sharma, Vishnupriya. 2006. Indian Phytopath. 59: 161-63.

Sharma, V. P. and Sharma, S. K. 1990. Plant Dis. Res. 5: 198-99.

Sharma, Y. R. and Nambiar, K. K. N. 1974. Curr. Sci. 43: 487-88.

Sharma, Y. R. and Nigam, M. 2000. Int. J. Trop. Plant Dis. 18: 131-40.

Sharples, R. O. and Hims, M. J. 1986. Report. East Malling Research Station. 1985. pp. 115-16.

Shedge, M. S., Khandekar and Bhagwat, N. R. 2009. J. Root Crops 35: 78-85.

Shekhawat, G. S. and Patel, P. N. 1975. Z. Pfischutz. 82: 129-38.

Shekhawat, P. S. and Chakrvarti, B. P. 1977. Indian Phytopath. 30: 358-60.

Sherif, A. F. and Macnab, A. A. 1986. Vegetable Diseases and their Control.pp. 381-96. A WileyInterscience Publication, USA.

Sherkar, B. V. and Utikar, P. G. 1982. Indian J. Mycol. Plant Pathol. 12: 51.

Sherkar, B. V. and Utikar, P. G. 1982 a. Indian J. Mycol. Plant Pathol. 12: 50.

Sherkar, B. V. and Utikar, P. G. and More, B. B. 1980. Indian Phytopath. 33: 330.

Sherman, M., Kasmire, R. F., Shuter, K. D. and Botts, D. A. 1982. Hort. Sci. 251-52.

Shetty, H. S. 1989. Proceedings. National Seminar on Seed Science. Technology University of Mysore, pp. 279-83.

Shimizu, T. and Itchitani, I. 1982. Annals of the Phytopathological Society of Japan 48: 691-94.

Shivanna, M. B., Meera, M. S. and Shetty, H. S. 1992. Indian Phytopath. 45: 373-76.

Shivapuri, A., Sharma, O. P. and Jhamaria, S. L. 1997. J. Mycol. Plant Pathol. 13: 15.

Sholberg, P. L., Bedford, K. E. and Stokes, S. 2003. Plant Dis. 87: 1067-71.

Sholberg, P. L., Haag, P. D., Hambleton, S. and Boulay, H. 2003. Plant Dis. 87: 1268.

Sholberg, P. L., Reynolds, A. G. and Gaunce, A. P. 1966. Plant Dis. 80: 1425-28.

Shreemali, J. 1972. Indian Phytopath. 24: 826-28.

Shrisail, L. I., Gupta, P. C. and Kadan, O. P. 2002a. Indian Phytopath. 55: 405-06.

Shrisail, L. I., Gupta, P. C. and Singh, N. 2002. Indian Phytopath. 55: 405.

Shrivastava, V., Rajak, R. C. and Pandey, A. K. 1993. Indian Phytopath. 46: 195.

Shukla, A. and Sharma, R. L. 2000. Indian Phytopath. 53: 366.

Shukla, A. C., Shahi, S. K. and Dikshit, A. 2000. Indian Phytopath. 54: 468-71.

Shyam, K. R., Chakraborty, P. K., Bhardwaj, S. S. and Dohroo, M. N. P. 1987. Indian J. Plant Pathol. 5: 118.

Siddaramaiah, A. H., Kulkarni, S. and Hedge, R. K. 1982. Indian Phytopath. 38 : 705-06.

Siddiqui, M. Z. and Kaushal, V. K. 2001. Flora and Fauna (Jhansi) 7: 25-27.

Silvis, H., Thompson, A. K., Musa, S. K., Salih, O. M. and Abdualla, Y. M. 1976. Trop. Agric. 53: 89-94.

Simmonds, J. H. 1931. Queensland J. Agric. sciences 36: 394-98.

Simmonds, J. H. 1947. Queensland J. Agric. sciences 52: 329.

Simmons, E. G. 1967. Mycologia 50: 67-92.

Simmons, J. H. 1965. Queensland J. Agric. and Animal sciences 22: 437-59.

Sindhan, G. S. and Bose, S. K. 1981. Indian Phytopath. 34: 484.

Singh. 1974. Indian Phytopath. 27: 433-34.

Singh. 1974a. Indian Phytopath. 27: 384-85. 
Singh. 1975. Indian Phytopath. 28: 108-09.

Singh, A. 2008. Indian Phytopath. 61: 134-35.

Singh, A., Verma, K. S. and Mohan, C. 2008. J. Mycol. Plant Pathol. 38: 245.

Singh, A. P. and Bhargava, S. N. 1977. Indian J. Hort. 34: 309-12, 362-63.

Singh, A. and Bhownik, T. P. 1985. Indian Phytopath. 38: 35-38.

Singh, A. K. and Chaudhari, K. C. B. 1974. Curr. Sci. 43: 726.

Singh, A. K. and Saini, S. S. 1980. Euphytica 29: 175-76.

Singh, A. K. and Singh, R. P. 2004. Indian Phytopath. 57: 341

Singh, A. K. and Singh, A. K. 1984. Indian Phytopath. 37: 568-70.

Singh, A. P. and Prasad, K. 1984. Indian Phytopath. 37: 585.

Singh, A. S. and Thakur, D. P. 1979. Curr. Sci. 48: 512-13.

Singh, A. S. and Thakur, A. K. 2002. Indian Phytopath. 55: 282-285.

Singh, A. S. and Thakur, 2003. Plant Dis. Res. $18: 5-11$.

Singh, B., Usha, Dev, Indra Rani, Chand, D. and Khetrapal, R. K. 2006. Curr. Sci. 91: 347-49.

Singh, B. M. and Sharma, Y. R. 1975. Indian Phytopath. 28: 435-36.

Singh, B. P., Garg I. D. and Bhattacharya, S. K. 1992. Asian Potato J. 33: 24-27.

Singh, B. P., Saxena, S. K. and Nagaich, B. B. 1989. Indian Plant Prot. 17: 91-95.

Singh, B. P., Sharma, S. and Yamadagni, R. 1985. Indian Phytopath. 38: 531-32.

Singh, D. and Chakrabarti, A. K. 1982. Indian Phytopath. 35: 314-15.

Singh, D., Gupta, A. and Maheswari, V. K. 2000. Indian Phytopath. 53: 344.

Singh, D. and Jain, R. K. 2004. Plant Dis. Res. 19: 36-39.

Singh, D., Sarkar, P. C., Sharma, R. R. and Srivastava, S. 2008. Indian Phytopath. 61: 79-82.

Singh, D., Sharma, R. R., Samuel, D. V. K. and Pal, R. K. 2009. Indian Phytopath. 62: 478-83.

Singh, D. V. and Seth, M. L. 1974. Indian Phytopath. 27: 631-32.

Singh, G., Rippon, L. E. and Gilbert, W. S. 1977. Austra J. Expt. Agric. Anim. Husb. 17: 167-70.

Singh, G. P. and Khare, K. B. 1977. Curr. Sci. 46: 167.

Singh, H., Singh, J. and Kaur, S. 1990. Journal of Research, PAU 27: 419-20.

Singh, H. N. P., Prasad, M. M. and Kumari, S. 1994. Indian Phytopath. 47: 319.

Singh, I. and Chohan, J. S 1973. Indian J. Mycol. Plant Pathol. 3: 728-29.

Singh, I. and Chohan, J. S. 1974. Indian Phytopath. 27: 239-40.

Singh, I. and Chohan, J. S. 1977. Indian Phytopath. $30: 379-83$.

Singh, I. and Chohan, J. S. 1977a. Indian Phytopath. 30 : 145.

Singh, I. and Chohan, J. S. 1980. Indian Phytopath. 33 : 598-99.

Singh, J. N., Maurya, A. N. and Upadhyay, R. K. 1993. In: (Abst) Golden Jubilee Symposium on Horticultural Research Changing Scenario, pp. 216-217. Horticultural Society of India. New Delhi.

Singh, J. P. and Bhatnagar, D. K. 1982. Haryana. Agric. Univ. J. Research 12: 295-97.

Singh, J. P. and Kainsa, R. L. 1983. Indian Phytopath. 36: 72-76.

Singh, J. P. and Sharma, S. K. 1982. Indian Phytopath. 35: 273-76.

Singh, K. and Shetty, P. V. 1996. Indian Phytopath. 49 : 294-96.

Singh, K., Srivastava, S. N. and Misra, S. R. 1982. Indian Phytopath. 35: 639-41.

Singh, K. K. and Mathur, P. B. 1953. Bull. CFTRI, Mysore 2 (7): 181-82.

Singh, K. P. and Pundhir, V. S. 2004. J. Mycol. Plant Pathol. 34: 91-92.

Singh, L. and Srivastava, S. N. 1985. Indian Phytopath. 38: 616.

Singh, L. S. and Bora, T. C. 2006. Indian Phytopath. 59: 400. 
Singh, M. 1998. Farm Science Journal 3: 21-23.

Singh, M. and Jain, R. L. 2007. J. Mycol. Plant Pathol. 37: 449-50.

Singh, N. and Gangopadhyay. 1984. Pesticides 18 (12): 23-24.

Singh, O. V., Agarwal, V. K. and Nene, Y. L. 1973. Indian Phytopath. 26: 260-67.

Singh, P. and Mahendra Pal 1995. Indian Phytopath. 48: 279-84.

Singh, P. and Sinha, K. K. 1985. Indian Phytopath. 38: 560-61.

Singh, P. J., Mahendra Pal. and Deva Kumar, C. 1998. Indian Phytopath. 51: 254-57.

Singh, P. K., Pathak, M., Bajpai, R. K. and Mall, T. P. 2008. Indian Phytopath. 61: 411-12.

Singh, P. L. and Shrivastava, A. K. 1970. Curr. Sci. $48: 169$.

Singh, R. 1969. (Ed. ) Fruits. National Book Trust India, New Delhi.

Singh, R. and Chahal, S. S. 1994. Indian Phytopath. 47: 307.

Singh, R. and Mahendra Pal. 1993. Indian J. Mycol. Plant Pathol. 23: 51-57.

Singh, R., Kaur, R. G. and Rattan, G. S. 2004. J. Mycol. Plant Pathol. 34: 957-59.

Singh, R. H. 2000. Indian Phytopath. 53: 359.

Singh, R. H. and Tandon, R. N. 1971. Indian Phytopath. 24: 807-08.

Singh, R. N. 1998. Indian J. Plant Pathol. 16: 5-6.

Singh, R. P., Singh, A. K. and Singh, K. 2006. Indian Phytopath. 59: 388-89.

Singh, R. S. 1992. Plant Diseases. V'th Edition, pp. 598. Oxford \& IBH Publishing Co., New Delhi, Bombay, Calcutta.

Singh, R. S. and Chohan, J. S. 1972. Plant Dis. Reptr. 56 : 115-18.

Singh, R. S. and Chohan, J. S. 1972a. Indian Phytopath. 25: 463-64

Singh, R. S. and Chohan, J. S. 1982. Indian J. Mycol. Plant Pathol. 12: 81-82.

Singh, S. 2003. Ann. Agric. Res. New Series 24: 498-01.

Singh, S., Thakur, D. P. and Singh, J. P. 1987. Hort. Abstracts 57: 209

Singh, S. J. 1972. Sydowia Annales Mycologie 26 (1-6) : 204-06.

Singh, S. J., Omprakash. and Tewari, R. P. 1975. Indian Phytopath. 28 : 107-08.

Singh, S. K. and Srivastava, H. P 1989. Indian Phytopath. 42: 164-66.

Singh, S. K., Tuli, L., Singh, U. P. and Prithiviraj. B. 2001. Indian Phytopath. 54: 128-38.

Singh, S. N. and Shukla, P. 1999. Indian Phytopath. 52: 63-65.

Singh, T., Roy, M. K. and Roy, S. K. 1989. Indian Phytopath. 42: 165.

Singh, U. and Thapliyal, P. N. 1999. Indian Phytopath. 52: 79-81.

Singh, U. B. 1941. Indian J. Agric. Sci. 11: 902-05.

Singh, U. P., Prithiviraj, B., Khiste, S., Kumar, V., Srivastava, J. S., Manickam, M. and Singh A.

1999. Indian Phytopath. 52: 18-23.

Singh, V., Pathak, S. P. and Chakravarti, D. K. 2002. Indian Phytopath. 55: 378.

Singh, V., Singh, R. P. and Singh, R. V. 2008. Indian Phytopath. 61: 415.

Singh, Y. and Sumbali, G. 2004. J. Mycol. Plant Pathol. 34: 910-16.

Singh, Y. and Sumbali, G. 2004 a. Indian Phytopath. 57: 68-69.

Singh, Y. and Sumbali, G. 2008. Indian Phytopath. 61: 471-77.

Singha, R. and Senapoty, D. 2006. Indian Phytopath. 59: 399.

Sinha, S. 1946. Proc. Indian. Acad. Sci. 24B: 198-05.

Sinha, A. K. 1989. Basic Research for Crop Disease Management, pp 187-200. (Ed.) Vidyasekaran, P. Daya Publishing house New Delhi.

Sinha, D. C. and Prasad, K. K. 1986. Indian Phytopath. 39: 89-90.

Sinha, D. P. and Hinda, M. N. 1988. Indian Phytopath. 41: 466-77. 
Sinha, J. N. and Singh, A. P. 1994. Indian Phytopath. 47: 214.

Sinha, M. K., Roy, A. K. and Prasad, T. 1981. Curr. Sci. 47: 550-51.

Sirdhana, B. S. and Jain, A. C. 1962. Sci. \& Cult. 28: 185-86.

Sitterly, W. R. 1968. Plant Dis. Reptr. 52: 49.

Sivan, A., Elad, Y. and Chet, I. 1984. Phytopathology 74: 498-01.

Sivaprakasam, K. and Kandaswamy, T. K. 1982. Indian Phytopath. 35: 721-22.

Sivaprakasam, K., Krishnamohan, G. and Kandaswany, T. K. 1976. Madras Agric. J. 63: 424-25.

Sivaprakasam, K., Krishnamohan, G., Ramakrishnan, G. and Subramanian, C. L. 1977. Madras Agric. J. 64: 424-25.

Smith. 1971. Plant Dis. Reptr. 55: 228-30.

Smith, L. G. 1983. Trop. Agric. 60: 31-35.

Smith, M. A. and Ramsey, G. B. 1950. Phytopathology 40: 1132-35.

Smith, M. A. and Ramsey, G. B. 1956. Phytopathology 46: 210-13.

Smith, W. L. and Wilson, J. B. 1978. Market Diseases of Potato. USDA Hdbk. No. 479. Agric. Res. Serv., USA.

Smith, W. L., Mc Colloch, L. P. and Friedman, B. A. 1966. Market Diseases of Asparagus, Onions, Beans, Peas, Carrot, Celary and Related Vegetables. USDA Hdbk. No. 303. Agri Res. Serv., USA.

Smoot, J. J., Houck, L. G. and Johnson, H. B. 1971. USDA Hdbk No. 398.

Snowdon, A. L. 1990. Post-harvest Diseases and Disorders of Fruits and Vegetables (coloured atlas). Vol. I, pp. 302. Univ. Cambridge. Wolf Publishing Co. Ltd, London.

Snowdon, A. L. 1991 Post-harvest Diseases and Disorders of Fruits and Vegetables (coloured atlas). Vol. I, pp. 415. Univ. Cambridge. Wolf Publishing Co. Ltd, London.

Sohi, H. S. 1975. IIHR. Ann. Rep., pp. 129.

Sohi, H. S. 1977. Indian Phytopath. 30: 149.

Sohi, H. S., Choulwar, S. B. and Kores, S. S. 1990. Punjab University Sci. 41: 109-11.

Sohi, H. S., Kalara, J. S. and Bhatia, S. 1984. Indian J. Mycol. Plant Pathol. 14: 23.

Sohi, H. S., Sharma, S. L. and Verma, B. R. 1963. Annual Report. Dept of Agriculture, Himachal Pradesh.

Sohi, H. S. and Rawal, R. D. 1977. Indian Phytopath. 30: 149, 379-83.

Sohi, H. S. and Sridhar, T. S. 1969. Indian J. Hort. 26: 155.

Sohi, H. S. and Sridhar, T. S. 1971. Indian Hort. 16: 9-10, 23.

Sohi, H. S. and Sridhar, T. S. 1984. Pesticides 18 (5): 13-14.

Sohi, H. S. and Sokhi, S. S. 1972. Indian Hort. 17: 17-19.

Sohi, H. S., Sokhi, S. S. and Tewari, R. P. 1973. Phytopath. Mediterranean 12: 114-16.

Sohi, S. L. and Gupta, M. S. 1977. Proceedings. International Symposium on Citriculture. Bengaluru, Karnataka.

Sokhi, S. S. 1994. Indian Phytopath. 47: 345-46.

Sokhi, S. S. 1994a. Indian Phytopath. 47: 371-76.

Sokhi, S. S. and Sohi, H. S. 1974. Indian Phytopath. 27: 444-45.

Sokhi, S. S. and Sohi, H. S. 1982. Indian Phytopath. 35: 675-76.

Solanke, R. B. and Kore, S. S. 1994. Indian Phytopath. 47: 345-46.

Somani, A. K. and Arora, R. K. 2010. Indian Phytopath. 63: 23-25.

Somani, R. B., Kodemelwar, R. V. and Wangikar, P. D. 1976. Indian Phytopath. 29: 311.

Sonali, V., Thakur, V. S. and Sharma, N. 2004. Indian Phytopath. 57: 334.

Sonoda, R. M. 1973. Plant Dis. Reptr. 57: 638-39. 
Sonoda, R. M., Hayslip, N. C. and Stofella, P. J. 1982. Proc. Fla. State Hort. Soc. 94: 281-82. Soto, A. E. M., Pintode, T. A. and Cancino, E. L. 1973. Agricultra Tecnica 33: 176-82.

Souma, J., Tanka, F. and Tamura, O. 2002. Bull. Hokkaido. Prefectural Agric. Expt stations 82: $121-24$.

Spalding, D. H. 1982. Plant Dis. 66: 1185-86.

Spalding, D. H. and Reader W. F. 1979. Proc. Fla. St. Hort. Sci. 91: 186-87.

Spalding, D. H. and Reader W. F. 1986. Plant Dis. 70 : 1149-51.

Spiker, D. A., Schmitthnner, A. F. and Ellect, C. W. 1981. Phytopathology 71: 1027-29.

Spotts, R. A., Cervantes, L. A. and Mielke, 1990. Plant Dis. 83: 1051-54.

Spotts, R. A. and Tandon, R. N. 1969. Indian Phytopath. 22: 282-84.

Spotts, R. A. and Tandon, R. N. 1973. Indian Hort. 18: 10.

Sreekantaiah, K. R., Rao, N. K. S. and Rao, T. N. R. 1974. Indian Phytopath. 27: 114-15.

Sreemulanathan, H., Raja, K. C. M., Abraham, E. and Mathew, A. G. 1980. Proceedings. Seminar on Post-harvest Technology of Cassava. AFST (India). Thiruvananthapuram, Kerala.

Sreenarayanan, T. N. and Nariani, T. K. 1966. Indian Phytopath. 19: 189-93.

Sreenarayanan, V. V. and Rajeev, M. 1996. Malayal Manorama Daily, Oct. 2.

Sreenivasa Prasad, S. and Rao, K. 1993. Int. J. Pest Mngmt 39: 167-71.

Sreenivasan, K. V. 1953. Curr. Sci. 27: 20.

Sreenivasan, T. N. and Nariani, T. K. 1966. Indian Phytopath. 19: 189-93.

Sridhar, T. S. 1975. Curr. Sci. 44: 869.

Sridhar, T. S. and Sohi, H. S. 1974. Hindustan Antibiotics Bull. 17: 35-36.

Srinivas, C., Niranjana, S. R., Kumar, L. P., Nayaka, S. C. and Shetty, H. S. 2006. Indian Phytopath. 59: 62-67.

Srinivasan, R. and Shanmugam, V. 2006. Indian Phytopath. 59: 333-39.

Srivastava D. N., Echandi, E. and Walker, J. C. 1959. Phytopathology 49: 145.

Srivastava, H. C. 1967. The Mango. ICAR. New Delhi.

Srivastava, M. P. 1986. Z. Pflkrankh pflschutz. 75: 674-82.

Srivastava, M. P. and Tandon, R. N. 1966. Experientia 22: 789.

Srivastava, M. P. and Tandon, R. N. 1968. Indian Phytopath. 21: 194-97.

Srivastava, M. P. and Tandon, R. N. 1969. Plant Dis. Reptr. 53: 206-08.

Srivastava, M. P. and Tandon, R. N. 1969 a. Indian Phytopath. 22: 268-69.

Srivastava, M. P. and Tandon, R. N. 1969b. Indian Phytopath. 22: 124.

Srivastava, M. P. and Tandon, R. N. 1971. PNAS 17: 51-54.

Srivastava, M. P. and Tandon, R. N. 1971a. Indian Phytopath. 24: 115-118, 72.

Srivastava, M. P., Chandra, S. and Tandon, R. N. 1964. Proc. Natl. Acad. Sci. 34 B: 339-40.

Srivastava, M. P., Mehta, N., Sangwan, M. S. and Rakesh Kumar. 2002. Indian Phytopath. 55: 399.

Srivastava, M. P., Shanmugam, V., Kamalakannan, A. and Surendran, M. 2002. Acta Phytopathologic et Entomologica 37 : 119-35.

Srivastava, M. P., Tandon, R. N., Bilgrami, K. S. and Ghosh, A. K. 1964. Phytopath Z. 50: 250-61.

Srivastava, P. K., Gupta, R. P. and Sharma, R. C. 2001. Indian Phytopath. 54 : 501.

Srivastava, O. P. 1968. J. Indian Bot. Soc. 47: 328-29.

Srivastava, S. N. 2004. Indian Phytopath. 57: 358.

Srivastava, S. N. Bilgrami, K. S. and Ghosh, A. K. 1964. Phytopath. Z. 50: 250-61.

Srivastava, S. N. and Misra, S. R. 1972. Indian Phytopath. 25: 154-55.

Srivastava, S. N. D. N. and Rao, Y. P. 1963. Indian Phytopath. 16: 63. 
Srivastava, V., Singh, S. D. and Sharma, P. 2002. Plant Dis. Res. 17: 114-18.

Srivastava, V. P. 1984. Pesticides 18: 63-64.

Staglellini, M. E., Rasmussen, S. L. and Barta, D. J. 1990. Plant Dis. 1: 74-81.

Stevens, J. A. and Mc Colloch, L. P. 1947. Plant Dis. Reptr 31: 147.

Stinson, E. E., Dsman, S. F., Heisler, E. G., Siciliano, J. and Bills, D. D. 1981 J. Agric. Food Chemistry 29: 790-92.

Stover. 1972. Banana, Plantain and Abaca Diseases. Common Wealth Agricultural Bureaux. Farnham. Royal.

Stover. 1975. Trans. Brit. Mycol. Soc. 65: 328-30.

Stover, R. H. and Simmonds, N. W. 1987. Bananas, pp. 468. Third Edn, Longman Scientific and Technical Essex.

Strider, D. L. and Winstead, N. N. 1960. Phytopathology 50 : 583-87.

Sturgess, O. W. 1957. Queensland J. Agric. Sciences 14: 241-51.

Su, M. T. 1934. Rept Dept Agric., Burma, pp. 25-33.

Subramanium, L. S. 1919. Madras Agric. J. 6.

Subramanian. T. M., Sadasivan, R., Raman, N. V. and Bettai-Gowder, R. 1973. Madras Agric. J. 60: $90-92$.

Subramanian, T. M., Sadasivan, R., Raman, N. V. and Bettai-Gowder, R. 1973a. Indian Hort. 18: 10.

Subramanyam, P. and Sarma, Y. R. 1974. Indian Phytopath. 27: 389-90.

Subrahmanyan, H. and Mathur, P. B. 1956. Bull. CFTRI, Mysore 5 (5): 110-11.

Subrahmanyan, H., Chandiramani, S. V., Rajagoplan, R., Bhatia, D. S. and Swaminathan, M. 1958. Food Sci. 7: 14.

Sugha, S. K. 2000. Indian Phytopath. 53: 363.

Sugha, S. K., Kaushal, N. and Kumar, S. 2002. Indian Phytopath. 55: 26-29.

Sugiki, T., Fujika, K. and Matsunaka, K. 1984. Bulletin. Field Crops and Horticultural Experiment Station, Aomori, Japan 5: 1-7.

Suhag, L. L. and Duhan, J. C. 1979. Indian Phytopath. 32: 642.

Suharban, M. 1977. M. Sc. (Ag. ) Thesis, Kerala Agricultural University, Vellayani.

Suharban, M., Geetha, D. and Nair, H. K. 2000. Disease of guava fruits, College of Agriculture, Vellayani, Kerala (Personal communication).

Sujatha Bai, E., Seethraman, K. and Sivaprakasom, K. 1993. Indian Phytopath. 46: 338.

Sumbali, G. and Mehrotra, R. S. 1980. Indian Phytopath. 33: 517.

Sumbali, G. and Mehrotra, R. S. 1983. Indian Phytopath. 36: 270-73.

Summanwar, A., Marathe, T. S. and Dhale, M. G. 1994. Indian Phytopath. 47: 345.

Sundaram, N. V. 1951. Madras Agric. J. 38: 225-26.

Sundaram, N. V. 1955. Madras Agric. J. 42: 541-44.

Sundaresan, S., Lila Babu and Bala, N. 1990. ISRC Nat. Symposium Special. In: Recent Advances in the Production and Utilization of Tropical Tuber Crops, pp. 265-69. (Ed.) N. G. Nair.

Sunilkumar, Vijaypal, Indu Jalali and Singh, J. V. 2002. Proceedings National Symposium on Arid Legumes for Food, Nutrition and Promotion of Trade, pp. 426-31. Hisar, India.

Suntharalingam, S. 1996. Tropic. Sci. 36: 14-17.

Suryanarayana, D. 1978. Seed Pathology, pp. 111. Vikas Publishing House pvt. Ltd, New Delhi. Suryawanishi, A. V. and Deokar, C. D. 2000. Madras Agric. J. 87: 330.

Suslow, T. V. and Schroth, M. N. 1982. Phytopathology 72: 199-06.

Sutton, A. L. and Sutton, J. B. 1994. Plant Dis. 78: 668-73. 
Swain, M. R., Sarangi, B. and Ray, R. C. 2006. In: Root and Tubercrops. (Eds) Naskar, S. A., Nedunchezhiyan, M., Rajasekhara Rao, K., Sivakumar, P. S., Ray, R. C. Misra, R. S. and Mukherjee, A. CTCRI. Bhubaneshwar, Odisha.

Swaminathan, J., Mc Lean, K. L. and Stewart, A. 2002. New Zealand Plant Protection Society 122-25

Swarta, E. and Holz, G. 1991. Phytophylactia 23: 217-22.

Swarup, J., Nagarkoti, M. S. and Saksena, H. S. K. 1973. Indian J. Mycol. Plant Pathol. 3 : 187-89.

Tahvonen, R. 1981. J. Scientific Agric. Society, Finaland 53: 211-27.

Tahvonen, R. and Avikainen, H. 1987. J. Scientific Agric. Society, Finaland 59: 199-200.

Tak, S. K., Verma, O. P. and Pathak, V. N. 1985. Indian Pytopath. 38: 471-74.

Takeuchi, H. 1929. Bull. Sci. Fakutato Terkultura Kursa Imperica 3: 333-49.

Tanaka, H. 1968. Bull. Hort. Res. Sta., Japan B 8: 99-110.

Tandon, I. N. 1961. Hort. Adv. 5: 77-82.

Tandon, R. N. 1967. Final Technical Report. PL-480 Scheme. Allahabad University, Allahabad, Uttar Pradesh.

Tandon, R. N. 1968. Mucorales in India. ICAR. New Delhi.

Tandon, R. N. 1976. Indian Phytopath. 29: 464-65.

Tandon, R. N. and Bhargava, S. N. 1962. Curr. Sci. 31: 344-45.

Tandon, R. N. and Kakkar, R. K. 1970. In: Plant Disease Problems, pp. 301-07. Indian Phytopathological Society, New Delhi.

Tandon, R. N. and Mishra, A. N. 1969. Indian Phytopath. 22: 334-41.

Tandon, R. N. and Singh, B. B. 1968. Indian Phytopath. 21: 331-36.

Tandon, R. N. and Singh, B. B. 1969. Indian Phytopath. 22: 322-26.

Tandon, R. N. and Singh,, M. P. 1963. Curr. Sci. 32: 426-27.

Tandon, M. P. and Srivastava, G. 1974. Curr. Sci. 43: 795-96.

Tandon, and Verma, A. 1964. Curr Sci. 33 : 625-27.

Tandon, M. P., Bhargava, V. and Jamaluddin. 1975a. Indian Phytopath. 44: 708.

Tandon, M. P., Jamaluddin. and Bhargava, V. 1975. Curr. Sci. 44: 478.

Tandon, M. P., Jamaluddin and Bhargava, V. 1975. Indian Phytopath. 28: 571-72.

Tandon, M. P., Jamaluddin. and Bhargava, V. 1976. Proc. Natl. Acad. Sci. (India) 46 B: 456-58.

Tandon, R. N., Tandon, M. P. and Jamaluddin. 1974. In: Current Trends in Plant Pathology, pp. 209-20. (Eds)Raychaudhury, S. P. and Verma. J. P.

Taniguchi, Kishi, T., Tadashi, Tohyama, Akira. and Tsuda, M. 1994. Mycosci. 35 : 421-24.

Tsai, W. H. 1969. Taiwan Agric. Res. J. 18: 51-57.

Tasca, G. and Trandaf, F. 1984. Industrializarea Legumelor si Fructelor 15: 89-93.

Tate, G. and Cheah, L. H. 2003. Grower 58: 55-56.

Tauchen Haus, J. J. and Ezekiel, W. W. 1934. Annual Report. Texas Agric. Expt. Sta. 46 : 88.

Teco, C. 1980. Annual Report. Research branch. Dept Agric. Sarawak.

Teixido, N., Usall, J., Palou, L., Asensio, A., Nunes, C. and Vinas, I. 2001. European J. Plant Pathology 107: 685-94.

Tewari, A. K. and Mukhopadhyay, A. N. 2001. Indian Phytopath. 54: 67-71.

Tewari, A. K. and Mukhopadhyay, A. N. 2003. Indian Phytopath. 56: 39-42.

Tewari, D. K., Srivastava, R. C., Katiyar, N. and Lal, B. 1988. Indian Phytopath. 41: 491-92. Thakur, D. P. 1972. Indian Phytopath. 25: 354-58.

Thakur, D. P. and Chenulu, V. V. 1970. In: Plant Diseases Problems, pp. 301-08. (Eds) Raychaudhuri, S. P. et al. Indian Phytopathological Soceity, New Delhi. 
Thakur, D. P. and Chenulu, V. V. 1970a. Indian Phytopath. 23: 58-61.

Thakur, D. P. and Chenulu, V. V. 1972. Indian Phytopath. 25: 354-58.

Thakur, D. P. and Yadav, H. C. 1971. Indian Phytopath. 24: 583-84.

Thakur, D. P., Chenulu, V. V, Kanwar, Z. S. and Kherata, R. B. S. 1974. Indian Phytopath. 27: 375-78; 532-36.

Thakur, D. P., Singh, B. and Lal, S. B. 1962. Sci. \& Cult. 28: 177-78.

Thanassaoulopoulos, C. C. and Giapanoglou. 1994. Plant Dis. 78: 924.

Thankamma, L. 1983. Indian Phytopath. 36: 17-23.

Thankappan, M. 1994. Tuber crops. In: Advances in Horticulture. Vol. 8. (Eds) Chadha, K. L. and Nayar, G. G. Malhotra Publishing House, New Delhi.

Thapa, C. D. and Sharma, S. L. 1976. Indian J. Mycol. Plant Pathol. 6: 83-89

Theron, D. J. and Holz, G. 1989. Phytophylactica 37: 402.

Thind, B. S. and Jindal, K. K. 1988. In: Advances in Research on Plant Pathogenic Bacteria. (Eds) Gnanamancikam, S. S and Mahadeva, A. Todays and Tomorrows Printers and Publishers, New Delhi.

Thind, T. S. and Jhooty, J. S. 1982. Indian Phytopath. 35: 696-97.

Thind, T. S. and Jhooty, J. S. 1984. Indian Phytopath. 37: 402.

Thind, T. S. and Kumar, K. 1985. Indian Phytopath. 38: 601.

Thind, T. S. and Saksena, S. B. 1990. Indian Phytopath. 43: 53-56.

Thind, T. S., Saksena, S. B. and Agarwal, S. C. 1977. Indian Phytopath. 30: 536-37.

Thippeswamy, B., Krishnappa, M. and Chakravarthy, C. N. 2004. Indian Phytopath. 57: 379.

Thippeswamy, B., Krishnappa, M. and Chakravarthy, C. N. 2005. Indian Phytopath. 58: 410-13.

Thippeswamy, B., Krishnappa, M. and Chakravarthy, C. N., Sathisha. A. M., Jyothis, S. U. and Vasantha Kumar, K. 2006. Indian Phytopath. 59: 475-81.

Thirumalachar, M. J. 1955. Phytopathology 45: 91-93.

Thirumalachar, M. J. and Misra, J. N. 1953. FAO, Plant Prot. Bull. 2: 11.

Thiruvadainambi, S., Meena, B., Kantaswamy, V., Sreenivasan, K. and Veera Raghavathatham, D. 2004. South Indian Hort. 52: 368-70.

Thomas, G., Penny, P. S. P. and Mal Nab, A. A. 1981. Phytopathology 71: 260

Thomas, H. R. 1944. Phytopathology 34: 341-43.

Thomas, P. and Dalal, V. B. 1968. Sci. \& Cult. 34: 311.

Thomposon, A. K., Been, B. O. and Perkins, C. 1977. Trop. Agric. (Trinidad) 54: 179-83.

Throat, V. T., Patil, M. A., Suryawanshi, A. P. and Shete, R. D. 2005. Indian Phytopath. 58: 358.

Tiffany, L. H. 1951. Iowa State Coll. J. Sci. 25: 371-72.

Timmer, L. W. 1973. Plant Dis. Reptr 57: 899-901.

Timmer, Roberts, P. O., Darhower, H. M., Bshong, P. M., Peever, T. L. and Ibanez, A. M. 2000. Plant Dis. 84: 1294-98.

Ting, Z., Chuchun Lung., Liu, W. T. and Schaneider, K. E. 2001. Canadian J. Plant Path. 23: 246-52.

Tivoli, B. and Jouan, B. 1981. Agronomica 1: 787-93.

Tivoli, B., Razzaq, K. A., Jouan, B. and Cemerchand, E. 1986. Potato Research 29: 13-32.

Tiwari, A. and Nema, S. 1994. Indian Phytopath. 47: 336.

Tiwari, V. N. and Yadav, A. S. 1969. Indian Phytopath. 22: 258-60.

Toit, L. J. du. and Derie, M. L. 2002. Plant Dis. 86: 1178.

Toit, L. J. du., Inglis, D. A. and Pelter, G. Q. 2003. Plant Dis. 87: 750.

Tomikawa, A. and Kobyashi, I. 1990. Annals Phytopathological Society, Japan 56: 265-68. 
Torres, A., Chulz, S., Varsavsky, L. and Rodriguez. 1993. Mycopatholgia 121: 17-20.

Trindade, D. R. and Politronieri, L. S. 2002. Fitopatologe Brasileira 27: 422.

Tripathi, N., Austuma, A. and Dixit, S. N. 1984. Phytopath Z. 110: 328-35.

Tripathi, N. N. and Grover, R. K. 1977. Indian Phytopath. 30: 222-28.

Tripathi, P. and Dubey, N. K. 2003. Indian Phytopath. 56: 481-83.

Trivedi, B. M. and Patel, P. N. 1972. Bacterial diseases of plants in India. In: Plant Bacteriology,

Vol. I (Ed.) Patel, P. N., Summer Institute of Plant Bacteriology, IARI, New Delhi.

Tronsmo, A. and Dennis, C. 1977. Neth. J. Plant Pathol. 83 (Suppl. ) 1: 449-55.

Tronsmo, A. and Ystaas, J. 1980. Plant Dis. 64: 1009.

Trujillo, E. E. 1963. Phytopathology 53: 1370-71.

Tsai, W. H. 1969. Taiwan. Agric. Res. J. 18: 51-57.

Tsror, L. and Petretz, I. A. 2002. American J. Potato Research 79: 33-37.

Turner, G. J. and Tribe, H. T. 1976. Trans. Brit. Mycol. Soc. 66: 97-105.

Tyagi, R. N. S. and Sharma, N. D. 1977. Sci. \& Cult. 43: 508.

Ullasa, B. A. 1984. FAO. Plant Protection Bull. $32: 145$.

Ullasa, B. A. 1990. Indian Phytopath. 43: 291.

Ullasa, B. A. and Rawal, R. D. 1989. Acta Horticulturae 231: 540-43.

Ullasa, B. A., Mohalay, M. N. and Sohi, H. S. 1976. Curr. Sci. 45: 601-02.

Ullasa, B. A., Rawal, R. D., Sohi, H. S., Singh, D. P. and Joshi, M. C. 1981. Plant Dis. 65: 600-01.

Uma, N. U. 1981. Plant Dis. 65: 915-16.

Uma Devi, G. 2008. J. Mycol. Plant Pathol. 38: 307-10.

Uma Devi, G., Mahendra Pal and Mitter, N. 1997. Indian Phytopath. 50: 222-28.

Umamaheswari, C. and Ramakrishnan, G. 2000. In: Proceedings of Indian Phytopathological Society. IARI, New Delhi (1997).

Upadhyay, J. P. and Mukhopadhyay, A. N. 1986. Trop. Pest Management 32: 215-20.

Uppal, B. N. 1940. Rep. Dep. Agric., Bombay.

Uppal, B. N., Patel, M. K. and Kamat, M. N. 1953. The Fungi of Bombay 8: 1-56.

Upasana, R. and Verma, K. S. 2002. Plant Dis. Res. 17: 93-96.

Usha, C., Paramita, De and Bishwanath, C. 2008. J. Mycol. Plant Pathol. 38: 216-20.

Usha, R. and Saksena, S. B. 1979. Indian Phytopath. 32: 551-53.

Ushamalini, Rajapan, K. and Kousalya, G. 1997. Indian Phytopath. 50: 504-07.

Ushamalini, Rajapan, K. and Kousalya, G. 1998. Indian Phytopath. 51: 258-60.

Usharani, P. and Rama Rao. 1981. Indian Phytopath. 34: 381.

Ushiyama, K. 1979. Kangawa. Hortic. Exp. Stn. Bull. 26: 1-6.

Utikar, P. G., Lande, P. S. and More, B. B. 1976. Indian Phytopath. 29: 189.

Utikar, P. G., Sherkar, B. V., More B. B. and Shinde, P. A. 1980. Indian Phytopath. 33: 343-44.

Utkhede, R. and Mathur, S. 2003. Plant Dis. 87: 100.

Vaheeduddin, S., Rao, C. B., Reddy, G. S. and Rao, A. P. 1959. Proceedings. Seminar on Diseases

of Horticultural Plants, held at Shimla, pp. 94-99.

Vail, M. E. and Marois, J. J. 1991. Phytopathology 80: 188-91.

Valdebenito, S. R. M. 1973. Agricultra Tec. 33: 183-87.

Vanan, T. and Khirbat, S. K. 2002. Indian Phytopath. 55: 403.

Vanitha, S. and Suresh, M. 2001. The Hindu, Sci. \& Tech. Nov. 22.

Varma, C. S. 1994. Indian Phytopath. 47: 320.

Varma, P. K., Singh, S. and Gandhi, S. K. 2007. Indian Phytopath. 60: 180-86. 
Varma, S. P., Kanauija, R. S. and Upadhyay, R. R. 1988. Indian J. Plant Pathol. 16: 62-63.

Varshney, V. 2001. Indian Phytopath. $54: 88-90$.

Vashisth, K. S. 1977. Indian Phytopath. 30: 155-56.

Vasudeva, R. S. 1960. The Fungi of India (Revised), New Delhi.

Venkatanarayanan, S. V. and Delvi, M. H. 1951. Curr. Sci. 20 : 243-44.

Venkataratanam, L. 1968. Grape India, pp. 67-69. A. P. Grower Association, Hyderabad, Andhra Pradesh.

Venkatsubbaiah, P., Sutton, T. B. and Chilton, W. S. 1991. Phytopathology 81: 243-47.

Verma, B. R. and Sharma, S. L. 1984. Indian Phytopath. 37: 580: 81.

Verma, G. S. and Kamat, M. 1951. Curr. Sci. 20: 68-69.

Verma, G. S. and Kamat, M. 2004. Indian Phytopath. 57: 267-71.

Verma, J. S., Ramesh, C., Lakhan Pal, K. D., Sharma, S. G. and Chand, R. 1994. Himachal J. Agric. Res. 20: 44-48.

Verma, L. R. and Sharma, R. C. 1999. Diseases of Horticultural Crops, Vegetables, Oranmentals and Mushroom. Indus Publishing House, New Delhi.

Verma, M. L. 1973. Indian Phytopath. 26: 28-31.

Verma, S. and Dohroo, N. P. 2005. Indian J. Plant Pathol. 2: 131-34

Verma, V. 2008. Indian Phytopath. 61: 317-22.

Verma, V. S. and Tikoo, M. L. 2003. Plant Prot. Sci. 11: 79-82.

Verma, V. S. and Tikoo, M. L. 2004. Indian Phytopath. 57: 267-71.

Vero, S., Mondino, P., Burgueno, J., Soubes, M. and Wisniewski, M. 2002. Post-harvest Biology and Technology 26: 98.

Vidhyasekaran, P. and Durairaj, P. 1971. Indian Phytopath. 24: 781.

Vidhyasekaran, P. and Muthamilan, M. 1995. Plant Dis. 79: 780-82.

Vidhyasekaran, P. and Valluvaparidasan, V. 1982. Proceedings. National Seminar on Seed Pathology, TNAU, Coimbatore, Tamil Nadu.

Vidhyasekaran, P., Ramdoss, N., Ranganathan, K. and Krishnswamy. V. 1973. Indian Phytopath. 26: 736-38.

Vidhyasekaran, P., Thulasidas, G. and Kandaswamy, T. K. 1980. Indian Phytopath. 33: 259-61. Vigneautt, Jerry, A. B. and Steven, A. S. 2000. Plant Dis. 84: 1314-18.

Vijayakumar, A. 2001. Madras Agric. J. 88: 388-94.

Vijayalakshmi and Rao, U. 2003. J. Mycol. Plant Pathol. 33: 451-52.

Villarroel, D. A., Barid, R. E., Trevathan, L. E., Watson, C. E. and Scruggs, M. L. 2004. Mycopathologia 157: 207-15.

Vir, S. and Grewal, J. S. 1974. Indian Phytopath. 27: 355-60.

Vir, D., Raychaudhuri, S. P. and Prasad, S. S. 1975. Pesticides 9: 28-29.

Visconti, A., Sibillia, A. and Sabia, C. 1992. Mycotoxin Research 8: 9-16.

Vishwakarma, S. N. and Sitaramaiah, K. 1985. UGC National Seminar on Recent Advances in Plant Pathological Research, B. H. U. (Abst). 21.

Volin, R. B. and Pohronezny. 1989. Plant Dis. 73: 1018.

Vorob'eva, S. V. and Vorob'eva, V. T. 2000. Zashchita Kar antim Rasteni.

Votika, D. 2003. Zashichita Rasteni. 27 : 64-68.

Vozenilkova, B. and Zvara, J. 1990. Fytotechnika Rada 7 : 49-60.

Vozenilkova, B. and Skorepa, I. 1992. Fytotechnika Rada 9 : 93-105.

Vyas, K. M., Chaurasia, S. C. and Neeraj, S. 1978. Indian Phytopath. 31: 363

Vyas, N. L. and Panwar, K. S. 1976. Indian Phytopath. 29: 94-95. 
Vyas, N. S. 1984. Indian J. Mycol. Plant Pathol. 14: 287-88.

Vyas, R. K., Patil, R. K., Sharma, P. and Pathak, V. N. 1993. Indian Phytopath. 46: 189-90.

Vyas, S. C. 1994. Indian Phytopath. 47: 341.

Wade, N. L. and Morris, S. C. 1982. Plant Dis. 66: 549-52.

Wadia, K. D. R., Manoharachary, C. and Janaki, K. 1984. Indian Phytopath. 37: 565-66.

Wagan, K. H., Pathan, M. A., Jiskani, M. M., Langer, A. G. and Mugheri, S. A. 2001. Pakistan J. Phytopathology 13: 135-39.

Wahab, S. and Sharma, B. B. 1974. Hindustan Antibiotic Bull. 16: 193-96.

Wahab, S. and Sharma, B. B. 1976. Indian Phytopath. 29: 437-39.

Walker, J. C. 1975. Plant Pathology, pp. 819. Mc Graw-Hill Inc. New Delhi.

Walker, J. C. and Williams, P. H. 1965. Plant Dis. Reptr. 49: 198-01.

Wall, M. M. and Biles, C. 1993. Phytopathology 83: 627.

Wallace, G. B. and Wallace, M. M. 1948. East African Agric. J. 13: 240-44.

Wang, C. C. and Chien, H. S. 1975. Taiwan Agric. Quart. 11: 109-16.

Wangikar, P. D., Raut, J. C. and Gopalkrishnan, N. 1969. Indian Phytopath. 22: 403-04.

Ward, C. M. 1976. Annals applied Biol. 83 : 149.

Ward, H. S. Jr and Diner, U. L. 1961. Phytopathology 51: 244-50.

Wardlaw, C. W. 1972. Banana Diseases including Plantain and Abaca, pp. 877. Longman, London.

Warner, J., Cerkauskas, R., Zhang, T., Hao, X., Zhang, T. Q. and Hao, X. M. 2003. Hort Technology 13: 190-95.

Weber, R. W. S. and Tribe, H. T. 2004. Mycologist 18: 6-10.

Welch, A. W., Jenkins, S. F. and Averre, C. W. 1975. Plant Dis. Reptr. 59: 255-57.

Wellman, F. L. 1932. J. Agric. Res. 45: 461-69.

Wells, H. D., Bell, D. K. and Jaworski, C. A. 1972. Phytopathology 62: 442-47.

Westercamp, P. and Blargues, M. E. 2002. Arboriculture Fruittiere 564: 46-47.

Whiteside, J. O. 1979. Proceedings. Fla St. Hort. Soc. 92: 34-37.

Wiant, J. S. 1937. Tech. Bull. USDA No. 573, pp. 47.

Wicks, T., Lomman, G. and Rogers, I. A. 1987. Austra. J. Exptal. Agric. 27: 597-600.

Wilcox, B. F and Balogh, E. 1999. Wolwo University, Ile-Ife. Nigeria.

Wilkinson, E. H. 1954. Ann. appl. Biol. 41: 354-58.

Williams, P. H. and Walker, J. C. 1966. Phytopathology 56: 367-68.

Williamson, D. 1975. Disease of guava, pp. 341. In: Advances in Mycology and Pathology. (Eds) Raychaudhuri, S. P. et al. Prof. R. N. Tandon's Birthday Celebration Committee, New Delhi.

Williamson, D. and Tandon. R. N. 1966. Mycopath. Mycol. appl. 29: 245-53.

Wallace, G. B. and Wallace, M. M. 1948. East African. Agric. J. 13: 240-44.

Wills, R. B. H. and Scott, K. J. 1982. Hort. Science 17: 964-65.

Wills, R. B. H., Brown, B. I. and Scott, K. J. 1982. Aust. J. Exp. Agric. \& Anim. Hus.

Wilkie, J. P., Dye, D. W. and Watson, D. R. W. 1973. New Zealand J. Agric. Res. 16: 315-23.

Wilson, C. L., Franklin, J. D. and Pusey, L. 1987. Phytopathology77: 303-05.

Wilson, K. I. and Balagopalan, C. 1971. Indian Phytopath. 24: 385-86.

Wilson, K. I. and Jose, P. C. 1968. Indian Phytopath. 21: 130-31.

Windels, C. E. 1981. Phytopathology 71: 929-33.

Wolf, F. A. 1917. J. Agric. Res. 8 : 319-27. 
Wollen Weber, H. W. and Hochapfel, H. 1936. Z. Pflkrankh. 46: 534-44.

Workman, M. and Holm, D. G. 1984. Amer. Potato J. 61: 723-33.

Wright, W. R., Smith, M. A. and Beraha, L. 1964. Plant Dis. Reptr. 48: 437-38

Wu, W. S. and Lu, J. H. 1984. Seed Sci. Technol. 12: 851-62.

Xiao, C. L., Rogers, J. D. and Bral, R. J. 2004. Plant Dis. 88: 223.

Xu, J. Y., Zhau, Z. Q., Yan, Z. H. and Ward, C. M. 1992. J. Fruit Science 9: 43-46.

Yadav, R. K., Jat, R. C. and Yadav, S. C. 2007. J. Mycol. Pl. Pathol. 37: 525-26.

Yamada, S., Kuramoto, T. and Tanaka, H. 1992. Fruit Hortic Res. Stn. Ser. Bull (Okitsu) 12: 207-28.

Yamamoto, Yoshitani, K. and Maeda, M. 1955. Sci Rep. Hyogo Univ. Argic. 2: 69-79.

Yamashita, F., Benassi, M. T. and Kieckbusch, T. G. 1997. Trop. Sci. 37: 249-55.

Yanar, Sahin, F. and Miller, S. A. 1996. Plant Dis. 80: 342.

Yanar, Y. and Miller, S. A. 2003. Plant Dis. 87: 303-07.

Yang, Z., Cramer, C. I. and Lacy, G. H. 1989. Phytopathology 79: 1150.

Yaraguntaiah, R. C. and Nariani, T. K. 1963. Indian J. Microbiol. 3: 147-50.

Yeoung young Rog. and Kimhakki, J. 1996. Korean J. Hort. Sci. 37: 285-91.

Yoder, O. C. and Whalen, M. L. 1985. Can. J. Botany 53: 691-99.

Yu, S. H., Park, J. S., Oh, I. S., Wu, I. S. and Mathur, S. B. 1987. Korean J. Mycol. 15: 183-86.

Zahida, P. and Masud, S. Z. 2002. Pakistan J. Scientific and Industrial Research 45: 246-49.

Zaidi, S. B., Khan, M. I. and Saxena, S. K. 1991. Indian Phytopath. 44: 394-95.

Zaldivar, H. 1977. Ciencias de la Agricultura 1: 70-78.

Zaubermann, G. and Barkai Golan, R. 1975. Phytopathology 65: 216-17.

Zeitter, T. A. and Wien, H. C. 1984. Plant Dis. 68: 628.

Zhang, L., Zhang, U., Cao, Hui and Yang, X, 2010. Transaction of the Chinese society of Agricultural Engineering 26 (2): 365.

Zhu, S. J., Zuoling, A. H. and Yumting, W. 2004. Scientia Agricultura sinica 37: 406-09. 


\section{Subject Index}

Acacia nilotica 36

Alternaria blight 195

Alternaria leaf-spot 149

Alternaria spp. 7

Alternaria-rot 86, 96, 127, 136, 180, 230

Alternaria-rot/core-rot/black-rot 34

Alternate technologies 57

ammonia-releasing fumigants 245

Anamorph 3, 179, 214

Ananas comosus 98

Angular leaf-spot of beans 205

antagonistic microflora 233

Anthracnose 18, 35, 59, 73, 83, 107, $118,123,126,132,137,138,142$, 194, 198, 202

Anthracnose (Bird's eye-rot) 55

Anthracnose/ripe-rot/fruit-rot 152

Antibiotic substances 299

antibiotics, use of 81

Apple (Malus domestica) 1

Apple-scab 3

Apple-scald 12

Apricot 17

Aroids and yams 291

Artocarpus heterophyllus 67

Ascochyta pod-spot 204

Ascochyta-rot 86

Ash-grey spots 221

Aspergillus 37, 89

Aspergillus fruit-rot 106

Aspergillus niger 10

Aspergillus niger, metabolites of 243

Aspergillus-rot 64, 96, 101, 113, 129, 184, 272, 298

Aspire 50

Aubergine 143

Bacillus subtilis 168

Bacterial black-spot 77

Bacterial blight 196

Bacterial blight/fuscous blight 209
Bacterial diseases $17,28,40,77,90$, 108, 150, 173, 196, 201, 209, 215, 222, 223, 229, 239, 252, 270, 282

Bacterial epiphytes 251

Bacterial fruit-rot 189

bacterial leaf-spot 164

Bacterial soft-rot $150,173,188,240$, 252, 282

Bacterial stalk-rot 253

Bacterial wilt 270

Bacterial-blight 212, 239

Bacterial-rot 78

Bacterial-rotting 163

Bacterial-spot 189, 223, 230

Banana (Musa spp.) 18

Banana black-rot 27

banana fruit-rot 22

Bark extract 36

Basal-rot 98, 99

Bean mosaic virus 210

Beet root/sugarbeet 232

Benzyl alcohol, use of 57

Beta vulgaris 232

Biochemical changes 152

Biocontrol 73

biocontrol agent 168, 194

biocontrol antagonists 155

Biocontrol with antagonistic fungi 75 bio-ingredients 154

Biological control 5, 34, 35, 43, 50, 52, $53,66,84,86,112,145,262,295$, 299

Biological control in field 155

Biological control measures 237

Biological control methods 103

Bittergourd 131

Bitter-pit 13

Bitter-rot 6, 54, 96

Black curd-rot 217

Black curd-rot/dark leaf-spot/ Alternaria-rot 224

Black grain-rot 107 
Black mould-rot $10,25,75,109,126$, 207, 212, 242, 288

Black soft-rot 76

Black-blotch 76

Black-leg 173, 221, 236

Black-mould 50

Black-rot 54, 64, 68, 77, 206, 215, 222 , 239, 269, 286, 293

Black-rot/bacterial-rot 229

Black-spot 23, 108

blight 245

Blossom-end-rot 132

Blue mould-rot 50, 94, 95

Botryodiplodia fruit-rot 87

Botryodiplodia- rot 24

Botryodiplodia theobromae 21

Botryodiplodia-rot 27, 53, 60, 83, 95, 124, 139, 159

Botrytis cinerea 26

Botrytis end-rot 26

Botrytis-rot 187

Botrytis-rot/soft-rot 172

Bottlegourd 138

Brinjal 143

Brown discolouration 52

Brown dry-rot/wet-rot 297, 298

Brown pedicel-end-rot 109

Brown soft-rot 289

Brown spongy-rot 149

Brown-head 220

Brown-rot 5, 24, 47, 53, 68, 92, 96, $105,121,160,203$

Brown-rot/bacterial-wilt/ring disease 175

Brown-rot/Phytophthora-rot 38

Buck eye-rot 177

Bulb crops 242

Bulb-decay 254

Bulb-rot 251

bunch-rot of grapes 55

CA storage 58

Cabbage 217

Calyx-blotch and stem-end-rot 113

Candida oleophila 21

Carica papaya 83
Carrot 236

Cauliflower 224

celluloytic enzymes 174

Ceratocystis paradoxa 21, 160

Cercospora leaf-spot 235

Chaetosphaeropsis truncata 28

Chalmydospores 98

Charcoal-rot $125,128,137,141,171$, 246, 287

Chayote/Chow-chow 131

Chemical control 74

Chemical methods 181

Chemical protection 81, 299

Chemicals, use of 33,42

Chilli 151

Chilling disorder 104

chlorine dip 227

Choanephora-rot $120,124,127,159$, 227

Cigar-end rot 22

citral 164

Citrinin 4

citronellal 164

Citrus 32

Citrus canker 40

Citrus greasy-spot 39

Cladosporium fruit-rot 107

Cladosporium-rot 128, 161, 186, 227

Cladosporium-rot (Green ball-rot) 53

Cladosporium-rot/gummosis/scab 121

Clusterbean 211

coconut soap 9

Cold storage 15,278

Cole crops 217

Coleophoma fruit-spot 107

Collar-rot 193, 216

Colletotrichum 83

Colletotrichum fruit-rot 74, 261

Colletotrichum gloeosporioides 45

Colletotrichum musae 21

Colocasia 291

Common Beans /Rajmash/Frenchbean 202

Common scab 176

Conidial stage 222

controlled atmosphere 30 
Controlled atmosphere storage 16

Cool chamber technology 176

Cool chambers 29

Cool-chamber technology 190

Core-rot 7

Corky lesion. 258

Corm-rot 291

Corynespora fruit-rot 89,133

Cottony white-rot $125,133,193,234$, 237

Cottony-leak 124, 138, 140, 148, 182, 199,259

Cottony-leak/fruit-rot 117

Cottony-leak/Pythium-rot 131

Cowpea 197

Cowpea mild mottle virus 202

Cowpea mosaic virus 201

Creepy white rhizome-rot 268

Creepy white-rot/Sclerotium-wilt 171

Creepy-rot 141

Crown-rot 20

cucumber mosaic virus 201

Cucurbita pepo 123

cultivars for resistance 243

cultivars, resistant 271

cultivars, rhizome-rot resistant 271

Cunninghamella fruit-rot 124

Curd-rot 218

Curd-smudge 227

Curing, artificial 247

Curvularia fruit-rot 28, 147

Curvularia lunata 28, 161, 200

Curvularia-rot 53, 142

Cylindrocarpon-rot 97

Cylindrocladium-rot 185

Damping-off 160, 182, 206, 225

Damping-off and seedling diseases 234 depressed spots 179

Diaporthe pod-blight 207

Didymella black fruit-rot 134

Dioscorea/Greater Yam 296

Diplodia stem-end-rot 71

Diplodia-rot 149

Dirty grey-rot 140 disease syndrome 218

Diseases and their causal organisms $11,94,113,123,130,139,141,150$, $162,173,188,196,199,222,240$

Diseases management 56

Distal-end rot 258

Dolichos-bean 214

Dothiorella-rot 27

Downy mildew 195, 228, 250

Drechslera fruit-rot 108

Drumstick/Moringa Fruit 258

Dry fruit-rot 101, 159, 161, 198

Dry root-rot/Rhizoctonia root-rot 233

Dry surface-rot 45

Dry-rot $165,259,265,269,281,287$, 293

Dry-rot/Brown-rot 111

early-maturing varieties 196

Elephant-foot Yam 294

Embellisia allii 256

Endomyces reessii 240

Endo-polygalacturonase 33

Etiological studies 266

eugenol 164

Evaporative cool chamber 44

Eye-end rot 172

faresol 164

finger-rot 24

Fly- speck and sooty-blotch 9

Foliar-blight 257

Foxtail-bean 213

Fragaria chilensis 111

Fruit canker 61

Fruit- rot 107

Fruitlet core-rot 100

Fruit-rot $28,39,45,47,63,70,88$, $140,142,144,147,158,161$

Fruit-rot/cottony-leak 130

fruit-rot, management of 154

Fruit-rot/cottony-leak 127, 132

Fruit-rots and causal organisms 78

Fruit-spot 108, 186

fruit-wrapper 33

Fumigation 57 
Fungal Diseases 3, 17, 18, 32, 45, 48, Grey blight-rot 259

$59,67,69,71,83,92,95,105,109$, Grey mould-rot 48, 111, 219

$111,117,123,126,130,131,132$, Grey mould-rot/dry-eye rot/Botrytis-

$135,138,140,142,143,152,165, \quad \operatorname{rot} 11$

$177,192,198,202,211,214,215$, Grey white-rot 133

$224,230,232,236,239,240,242$, grey-mould 5

$257,264,271,280,284,291,294 \quad$ grey-mould species 246

Fungi associated with rotting 56

Fungi on Yam Chips 296

Fungicide impregnated paper-liners 190

fungicides application, preharvest 56

fungicides, seed treatment with 262

fungicides, systemic 42

Fungicides, systemic, use of 33

fungicides, use of $35,81,86$

Fusarium dry-rot 166

Fusarium moniliforme 146

Fusarium oxysporum 146

Fusarium spp. 38

Fusarium tip-rot 23

Fusarium-blight 260

Grey-mould/neck-rot 246

Grey-rot 270

Guava 59

Halo-blight 209

Head-rot 220

Helminthosporium fruit-rot 26

homeopathic drugs, use of 43

host range 266

Hot-water rinsing and brushing 190

Hot-water treatment 19, 80, 218

hot-water, use of $33,41,62$

Hydro-cooling 190

Indian Bean 214

insect repellent 254

Fusarium-rot 87, 129, 130, 131, 135 , 146, 178, 203, 214, 241, 286

Fusarium-rot /cottony-rot 138

Fuscous-blight 215

Fuzzy yellowish-rot 133

Internal bulb-rot 255

Internal dry-rot 269

Internal soft-rot 292

Irregular target-spot 186

Isatin 105

Ivory-gourd 142

Gangerine 170

Garden-pea 192

Jackfruit 67

Garlic 254

Garlic-bulb canker 256

Geotrichum candidum 37

Geotrichum-rot 270

Ginger 264

Ginger-yellows 268

Girdling of stem 221

Gliocladium virens 145

Gloeodes pomigena 9

Glomerella cingulata 6, 35

Goa-bean 213

Java black-rot 285

Johnston-spot 22

Jonathan-spot 15

Knol-khol/Kohl-rabi 230

Koval 142

Lady's finger 259

Late-blight 167, 169

Leaf extracts 251

Leaf-blight 257

Gooseberry/Aonla 45

Grape 48

Greater yam 296

Leaf-spot 204, 217, 241

Lenticel spots 15

Light leaf-spot 228

Green mould-rot 25, 64, 109, 171, 288

Greenaria fuligena 54

linseed oil 4

Litchi 69 
Litchi chinensis 69

Low-temperature storage 29

Macrophoma allahabadensis 63

Macrophoma-rot 142

Macrophomina root-rot 235

Macrophomina-rot 211

Malus pimula 3, 17

Mangifera indica 71

Mango 71

mango bacterial canker 77

Manilkara zapota 109

Marssonina coronariae 10

Marssonina-blotch 10

Melting decay of grapes 56

microflora, sequence of occurrence of 283

Microthyriella rubi 9

Minor diseases and their causal organisms 39,65

modified atmospheric packaging 21

molecular variabilities 180

Monilinia fructigena 5, 105

Mouldy brown-rot 46

Mucor-rot 95, 159, 260

Muskmelon 130

mycotoxins 4

Myrothecium-rot $128,134,185,198$, 208

necrosis 245

neem-based biopesticide 194

Nepeta hindostana 291

nerol 164

nest rot 48

Neurospora crassa 88

Nigrospora-rot 228

Non-parasitic storage disorders 12

Onion 242

Onion, curing of 244

Onion-smudge 248

organoleptic qualities 279

organomercurials 193

packing houses 41
Papaya 83

para amino benzoic acid 59

patulin 4, 135

Pea mosaic 197

Peach 92

Pear 95

pelleting 154

Pelleting with fungicides 234

Penicillium expansum 4, 95

Penicillium fruit-rot 106

Penicillium spp. 32

Penicillium-rot 32, 101, 251

Periconia-rot 161

Peronospora pisi 195

Pestalotia-rot 61

Phoma leaf-spot 236

Phoma-rot 160, 179, 207, 214

Phomopsis fruit-rot 54, 88, 106, 145

Phomopsis-blight 143

Phomopsis-rot 129, 172

Phyllanthus emblica 45

Phymatotrichum root-rot 289

Phytophthora finger-rot 27

Phytophthora fruit-rot 6, 63, 67, 110, 136

Phytophthora infestans 167

Phytophthora nicotianae var. parasitica 27

Phytophthora spp. 6

Phytophthora-rot 84, 120, 126, 127 , 131

Pimple-rot 54, 110

Pineapple 98

Pink disease 102

Pink mould-rot 26, 187

Pink-rot 88, 168, 216

Pitting disease 22

plant extract, use of 43

Plant products, use of 156

plastic-film packing 81

Plum 105

Plum-rot 105

Pod-blemish 207

Pod-rot 199, 214

Pod-rot/white-rot 194

Pod-spot 261 
polyethylene-lined CFB boxes 44 polymeric films 91

polythene packing 42

Pomegranate 106

Post-harvest curing 33

Post-harvest diseases management 28 ,

41, 70, 79, 90, 94, 190, 252

Post-harvest management $17,57,104$, $110,113,299$

post-harvest pathogens 273

post-harvest rotting 273

Post-harvest treatments 52

post-infection treatments 245

Potato 165

Powdery-mildew 94, 222, 228

Pre-harvest application of fungicides 52,56

Pre-harvest protection 19

Pre-harvest treatment 40, 41, 49, 218, 221

Prokaryotes and bacterial diseases 290 promelain 98

protoplasmic poison 243

Prunus armeniaca 17

Prunus domestica 105

Prunus persica 92

Pseudomonas syringae 5

Psidium guajava 59

Pumpkin 123

Punica granatum 106

Purple-blotch 245

pycnidial encrustations 36

pycnidial spots 143

pycniospores 144

Pyrus communis 95

Pythium aphanidermatum 225

Pythium fruit-rot 136

Pythium-rot/damping-off 220

radiation, use of 33,75

Radish 240

Red-rot 265, 269

rhizobacterial formulation 251

Rhizoctonia disease/collar-rot 204

Rhizoctonia fruit-rot 183

Rhizoctonia root-rot 238
Rhizoctonia solani 68

Rhizoctonia-rot 227

Rhizopus arrhizus 8

Rhizopus fruit-rot 85,235

Rhizopus soft-rot 181

Rhizopus stolonifer 25, 51

Rhizopus-rot 17, 25, 67, 93, 95, 102, $107,112,127,135,252,280,284$, 298

Rhizopus-rot/shrivelled bulb-rot 255

Rhizopus-rot/soft-rot 147

Ridge-gourd 140

Ring-rot 149,185

Ring-spot 219,228

Ripe fruit-rot 112

Root and corm-rot 292

Root crops 232

root extracts, use of 156

Root-scab 239

Rust 236

Sapota 109

Scanty cottony white-rot /Fusarium-rot

122

Sclerotinia fruit-rot 11, 26, 139

Sclerotinia sclerotiorum 11, 139

Sclerotinia stalk-rot/white-rot 226

Sclerotinia-rot 122

Sclerotium rolfsii 141

Sclerotium root-rot/creepy white-rot 232

Sclerotium-rot 185,272

Scurf 288

Sechium edule 131

Seed microflora 123, 189, 210

Seed mycoflora $135,151,164,197$,

$213,215,228,236,241,254$

seed-borne 192

Seed-borne infection 147

seed-borne inoculum 193

seed-borne pathogens 149

Seed-borne viral diseases 210

Seed-crop production 226

Seedling-blight 138, 232, 241

Seed-potatoes 176

Seed-rot 160, 208, 261 
Seed-rot/damping-off 211

seeds, pelleting of 154

Set-rot 281

Shiny black-rot 289

skin-spot 170

Slimy brown-patch 289

Slow pedicel end-rot 69

Smut 248, 256

Snakegourd and pointed-gourd 135

Soft corm-rot 294

Soft curd-rot 225

Soft watery-rot 132

Soft-rot $47,51,76,102,119,120,140$, $157,168,194,207,230,264,265$, 270

soft-rot management 268

soft-rot of stored onions 249

Soft-rot/ Mucor-rot 182

Soft-rot/ stalk-rot 223

Soft-rot/Rhizopus-rot, 64

Soft-rot/Sclerotium fruit-rot 125

Soft-rot/wet-rot/Rhizopus-rot 159

Soft-rots 110

Soft-scald 13

Soil solarization 226

soil sterilization by steam 190

Soil-rot 120,183

Solanum melongena 143

Sooty mould 27

Sooty-mould 77

sorbitol 105

Sour-rot 37, 130, 137, 141, 183, 238

Speckle/ black- spot/ black-tip 22

Sponge-gourd 141

Spongy-rot/soil-rot 125

Sporotrichum aureum 37

Sporotrichum-rot 37

Squirter disease 23

Stalk end-rot 60

Stem-and fruit-rot 161

Stem-end-rot 36, 99

Stemphylium-blight 251

sterilization of seed-tubers 175

Storage diseases and causal organisms 290

Storage studies of red chillies 163
Storage-rot $77,251,272$

Strawberry 111

Stylar-end rot 62

Sulphur dioxide fumigation 49

Sunken brown-spot 289

sunken spots 143

Sweet-potato 283

Sword-bean 215

systemic fungicides 42

Tapioca/cassava 277

Target-rot/early blight 169

Target-spot 217

Teliomorph 143, 172

Thanatephorus cucumeris 120

Thielaviopsis paradoxa 27

Tomato 176

toxic secondary metabolites 7

Trichoderma harzianum 11

Trichoderma viride 39

Trichoderma, effects of 267

Trichoderma-rot 39

Trichothecium roseum 8

Tropical Root/Tuber Crops 277

tuber chips, drying system for 280

Tuber-rot 173, 297

Tuber-rot/internal black-rot 173

Tuber-rots 282

Turmeric 271

Use of biphenyl impregnated fruitwrapper 33

Use of chemicals 33

Use of fungicides and chemicals 19

Use of systemic fungicides 33

Use of wrappers, wax-coating 15

Vacuum packing 30,44

Vapour, application of 57

Varietal resistance 144

varieties, resistant 266

Venturia inaequalis 3

Violet root-rot 289

Virus Diseases 197, 201, 210

Vitis vinifera 48

water soaked lesions 186 
Water-core 14

water-soaked areas 179

water-soaked lesions 147,148

Watery soft-rot 26, 118, 221, 236, 292

Watery wound-rot/leak 169

watery-rot/soft-rot 85

Wax coating 74

wax emulsion 82

Wax-coating 29, 42

Waxy-rot 240, 289

Web-blight 214

Wet-rot 148

Whiskers-rot/soft-rot 8

White mould /Sclerotinia-rot/soft-rot 205
White soft-rot/basal-rot 244

White-rot 249, 256

White-rust 241

Winged-bean 213

wrapper, use of 81

Wrinkled-rot 46

Xanthomonas campestris 40

yams 291

Yeast-rotting 56

Yeasty-rots 103

Zonations 192 



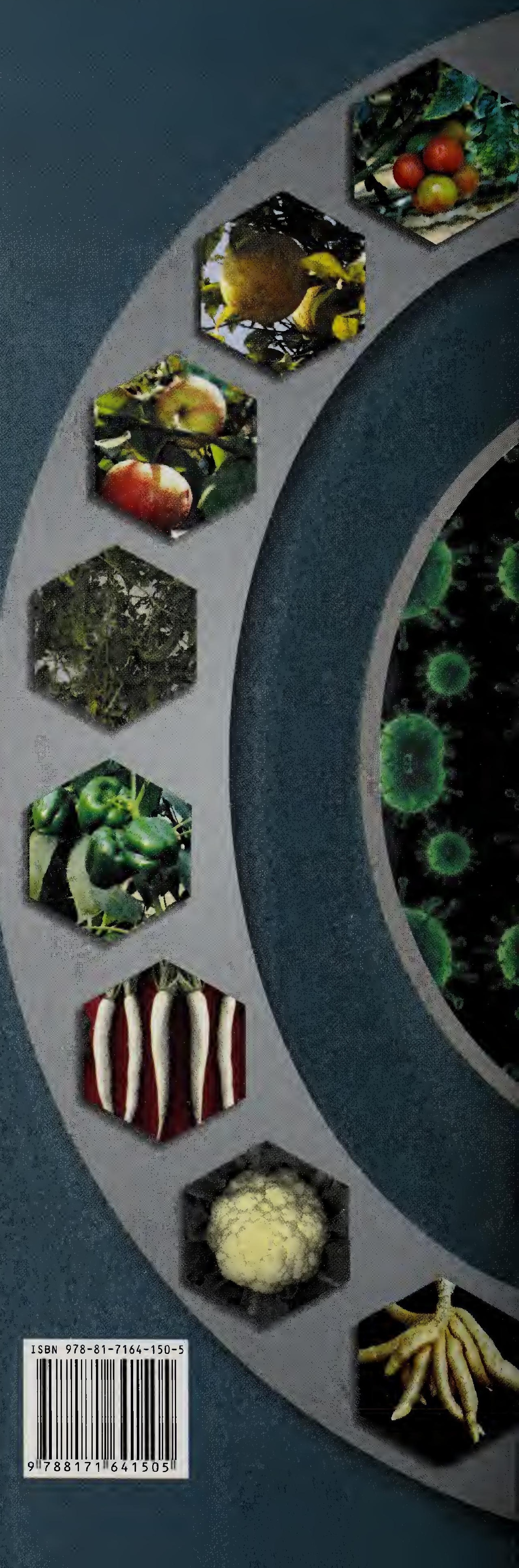

